\title{
The Influence of Fluorine, Chlorine and Water on the Rheology and Structure of $\mathrm{Na}_{2} \mathrm{O}-\mathrm{CaO}-\mathrm{Al}_{2} \mathrm{O}_{3}-\mathrm{SiO}_{2}$ Melts
}

\author{
Dissertation \\ zur Erlangung des mathematisch-naturwissenschaftlichen Doktorgrades \\ "Doctor rerum naturalium" \\ der Georg-August-Universität Göttingen \\ im Promotionsprogramm Geowissenschaften \\ der Georg-August School of Science (GAUSS) \\ vorgelegt von \\ Amrei Baasner \\ aus Dortmund
}

Göttingen, 2013 


\section{Betreuungsausschuss}

Prof. Dr. Sharon L. Webb

Abteilung experimentelle und angewandte Petrologie

Geowissenschaftliches Zentrum der Georg-August-Universität Göttingen

Dr. Burkhard C. Schmidt

Abteilung experimentelle und angewandte Petrologie

Geowissenschaftliches Zentrum der Georg-August-Universität Göttingen

\section{Prüfungskommission}

\section{$\underline{\text { Referent } 1}$}

Prof. Dr. Sharon L. Webb

Abteilung experimentelle und angewandte Petrologie

Geowissenschaftliches Zentrum der Georg-August-Universität Göttingen

\section{Referent 2}

Prof. Dr. Ray Dupree

Department of Physics

University of Warwick

\section{$\underline{\text { Referent } 3}$}

Dr. Burkhard C. Schmidt

Abteilung experimentelle und angewandte Petrologie

Geowissenschaftliches Zentrum der Georg-August-Universität Göttingen

\section{Weitere Mitglieder der Prüfungskommission}

Prof. Dr. Gerhard Wörner

Abteilung Geochemie

Geowissenschaftliches Zentrum der Georg-August-Universität Göttingen

Prof. Dr. Andreas Pack

Abteilung Isotopengeologie

Geowissenschaftliches Zentrum der Georg-August-Universität Göttingen

Prof. Dr. Harald Behrens

Institut für Mineralogie

Leibniz Universität Hannover

\section{Tag der mündlichen Prüfung}

\subsection{0 .2013}




\section{Preface}

The original idea for this project came from Sharon L. Webb and Burkhard C. Schmidt. This project was funded and supported by the German Science Foundation (DFG) (WE 1810/9-1), University of Warwick (UK), University of Hannover (GER), the US National Science Foundation (DMR-0084173) and the State of Florida. The UK $850 \mathrm{MHz}$ solid-state NMR Facility used in this research was funded by EPSRC and BBSRC, as well as the University of Warwick including via part funding through Birmingham Science City Advanced Materials Projects 1 and 2 supported by Advantage West Midlands (AWM) and the European Regional Development Fund (ERDF). This is the revised version of the thesis, which was first submitted in August 2013. This thesis comprises following publications in the versions that existed in August 2013 with corrections concerning typographic erros in the text, tables and figures:

Baasner, A., Schmidt, B.C., Webb, S.L., 2013a. Compositional dependence of the rheology of halogen $(\mathrm{F}, \mathrm{Cl})$ bearing aluminosilicate melts. Chem. Geol. 346, 172-183.

Baasner, A., Schmidt, B.C., Webb, S.L., 2013b. The effect of chlorine, fluorine and water on the viscosity of aluminosilicate melts. Chem. Geol. 357, 134-149. (Status August 2013: accepted, waiting for proofs).

Baasner, A., Schmidt, B.C., Dupree, R., Webb, S.L.,2014a. Fluorine speciation as a function of composition in peralkaline and peraluminous $\mathrm{Na}_{2} \mathrm{O}-\mathrm{CaO}-\mathrm{Al}_{2} \mathrm{O}_{3}-\mathrm{SiO}_{2}$ glasses: $\mathrm{A}$ multinuclear NMR study. Geochim. Cosmochim. Acta 132, 151-169. (Status August 2013: accepted, requires revision).

Baasner, A., Hung, I., Kemp, T.F., Dupree, R., Schmidt, B.C., Webb, S.L., 2014b. Constranints on the incorporation mechanism of chlorine in peralkaline and peraluminous $\mathrm{Na}_{2} \mathrm{O}-\mathrm{CaO}-\mathrm{Al}_{2} \mathrm{O}_{3}-\mathrm{SiO}_{2}$ glasses. Am. Mineral. http://dx.doi.org/10.2138/am.2014.4717. (Status August 2013: In preparation for American Mineralogist, initial title "The incorporation mechanism of chlorine in peralkaline and peraluminous $\mathrm{Na}_{2} \mathrm{O}-\mathrm{CaO}-\mathrm{Al}_{2} \mathrm{O}_{3}-\mathrm{SiO}_{2}$ glasses").

Because the last two publications did not exist in their final version before this thesis was first submitted in August 2013, there might be differences in the content between the published versions of these papers and the versions in this thesis. The versions of the publications from August 2013 were not simply replaced by the final published versions to preserve the initial state of the thesis based on that it was evaluated. 


\section{Zusammenfassung}

In dieser Studie wurde der alleinige und gemeinsame Einfluss von 1.6 bis 14.5 mol\% Wasser, 1.1 bis 18.3 mol\% Fluor $(\mathrm{F})$ und 0.5 bis 1.4 mol\% Chlor $(\mathrm{Cl})$ auf die Struktur und Viskosität von peralkalinen und peraluminösen $\mathrm{Na}_{2} \mathrm{O}-\mathrm{CaO}-\mathrm{Al}_{2} \mathrm{O}_{3}-\mathrm{SiO}_{2}$ Gläsern und Schmelzen mit $\sim 66 \mathrm{~mol} \% \mathrm{SiO}_{2}$ (auf volatilfreier Basis) untersucht. Die Zusammensetzung der peralkalinen Proben entspricht einem Modellsystem für Phonolithschmelzen. Die wasserfreien Proben wurden in $1 \mathrm{~atm}$ Öfen aus Oxid- und Karbonatverbindungen sowie Halogeniden hergestellt. Die wasserhaltigen peralkalinen Proben wurden in einer innenbeheizten Gasdruckanlage und die wasserhaltigen peraluminösen Proben in einer Stempelzylinderpresse hergestellt. Die Viskosität der Proben wurde mit der Mikropenetrationstechnik $\left(10^{8.5}-10^{13} \mathrm{Pas}\right)$ und der „parallel plate" Methode ( $\left.10^{5.5} \mathrm{~Pa} \mathrm{~s}-10^{9} \mathrm{~Pa} \mathrm{~s}\right)$ gemessen. Die Struktur der Gläser wurde mittels „magic angle spinning" (MAS) Kernspinresonanzspektroskopie (NMR) anhand der Nuklide ${ }^{19} \mathrm{~F},{ }^{23} \mathrm{Na},{ }^{27} \mathrm{Al}$, ${ }^{29} \mathrm{Si}$ and ${ }^{35} \mathrm{Cl}$ analysiert.

Fluor und Wasser allein oder in Kombination verringern die Viskosität der Schmelzen, wobei der Effekt von Wasser stärker ist als der von F. Beide Volatile verringern die Viskosität von peraluminösen Schmelzen stärker als in den peralkalinen Schmelzen. Für die peralkalinen Schmelzen wurde eine Verringerung der Viskosität durch $\mathrm{F}$ bis zu einer Konzentration von 1.9 mol\% $\mathrm{F}$ festgestellt, jedoch für eine Konzentration von $6.2 \mathrm{~mol} \% \mathrm{~F}$ wurde keine weitere Verringerung der Viskosität festgestellt. In den peraluminösen Schmelzen hingegen wurde bis zu einer Konzentration von $18.3 \mathrm{~mol} \% \mathrm{~F}$ ein stetiger Abfall der Viskosität mit zunehmendem Fluorgehalt beobachtet. Der gemeinsame Einfluss von $F$ und Wasser ist auf Grund ihrer jeweiligen Einzeleffekte geringer als angenommen, was zeigt, dass die Effekte von $\mathrm{F}$ und Wasser auf die Viskosität nicht unabhängig voneinander sind.

Der zusammensetzungs- und konzentrationsabhängige Effekt von $\mathrm{F}$ auf die Viskosität der Schmelzen stimmt mit Unterschieden im Einbaumechanismus von $F$ überein. ${ }^{19} \mathrm{~F}$-MAS-NMR-Spektren zeigen, dass in den peralkalinen Gläsern $F$ sowohl in „salzartigen“ $\mathrm{F}-\mathrm{Ca}(\mathrm{n})$ und $\mathrm{F}-\mathrm{Na}(\mathrm{n})$ als auch in nicht brückenbildenden Si-F-Na(n), Al-F-Ca(n), Al-F-Na(n) und brückenbildenden Al-F-Al Umgebungen vorkommt (,n“ bedeutet, dass die Anzahl der Atome unklar oder variabel ist). $\mathrm{F}-\mathrm{Ca}(\mathrm{n})$ ist die am häufigsten vorkommende Umgebung, obwohl $\mathrm{Ca}$ das am wenigsten häufige Kation in den Proben ist. In den peraluminösen Gläsern existiert $\mathrm{F}$ nur in Si-F und Al-F Umgebungen, wobei Al-F-Na(n) die am häufigsten vorkommende Umgebung ist. Die Bildung von salzartigen $\mathrm{F}-\mathrm{Ca}(\mathrm{n})$ und $\mathrm{F}-\mathrm{Na}(\mathrm{n})$ Umgebungen sollte zu einem Anstieg der Viskosität durch eine Verringerung der netzwerkmodifizierenden Kationen führen. Die Bildung von Si-F und Al-F Umgebungen sollte die Viskosität entweder auf Grund einer Reduzierung von brückenbildenden Sauerstoffen durch nicht brückenbildende $F$ oder durch einen Austausch von brückenbildenden Sauerstoffen durch brückenbildende F, welche eine niedrigere Bindungsstärke haben, verringern. Daraus lässt sich schließen, dass $F$ die Viskosität in 
peralkalinen Schmelzen weniger stark verringert als in peraluminösen Schmelzen, weil $\mathrm{F}$ in den peralkalinen Schmelzen in Umgebungen existiert, welche die Viskosität erhöhen oder erniedrigen können, während $F$ in den peraluminösen Schmelzen nur in Umgebungen existiert, welche die Viskosität verringern.

Der konzentrationsabhängige Einfluss von $\mathrm{F}$ auf die Viskosität in den peralkalinen Schmelzen scheint in Zusammenhang mit einer Änderung in der Fluorspeziation zu stehen: Der relative Anteil von $\mathrm{F}-\mathrm{Ca}(\mathrm{n})$ Umgebungen, von denen anzunehmen ist, dass sie die Viskosität erhöhen, steigt von 42 auf $53 \%$ bei einem Anstieg im F Gehalt von 1.2 auf 6.2 mol\% F. Veränderungen in der Fluorspeziation scheinen ebenfalls verantwortlich dafür zu sein, dass der Effekt von $\mathrm{F}$ und Wasser in Kombination geringer ist als erwartet. ${ }^{19} \mathrm{~F}$-MAS-NMR-Spektren von fluor- und wasserhaltigen Proben zeigen, dass der relative Anteil von Al-F Umgebungen, von denen anzunehmen ist, dass sie die Viskosität verringern, mit zunehmendem Wassergehalt abnimmt und dass im Gegenzug der relative Anteil von F-Ca(n) Umgebungen zunimmt. Mit IR-Spektroskopie wurde in den peralkalinen Proben kein Unterschied im $\mathrm{OH} / \mathrm{H}_{2} \mathrm{O}-$ Verhältnis bei gleichem Gesamtwassergehalt durch die Präsenz von F beobachtet. Im Gegensatz dazu gibt es starke Hinweise darauf, dass $\mathrm{F}$ in den peraluminösen Proben das $\mathrm{OH} / \mathrm{H}_{2} \mathrm{O}-\mathrm{Verhältnis} \mathrm{bei}$ gleichem Gesamtwassergehalt verringert, was erklären würde, weshalb $F$ und Wasser in Kombination die Viskosität weniger verringern als von ihren Einzeleffekten zu erwarten wäre.

Der Einfluss von $\mathrm{Cl}$ auf die Viskosität und Struktur der Schmelzen und Gläser ist sehr unterschiedlich verglichen mit $\mathrm{F}$. Cl erhöht die Viskosität in den peralkalinen Schmelzen und verringert die Viskosität in den peraluminösen Schmelzen. Viskositätsmessungen von wasserhaltigen, chlorfreien und chlorhaltigen peralkalinen Schmelzen zeigen, dass der Effekt von $\mathrm{Cl}$ auf die Viskosität nicht durch die Präsenz von Wasser beeinflusst wird. Das beobachtete ${ }^{35} \mathrm{Cl}-\mathrm{NMR}$-Signal zeigt, dass sowohl in den peralkalinen als auch in den peraluminösen Gläsern $\mathrm{Cl}$ in $\mathrm{Na}-\mathrm{Ca}-\mathrm{Cl}$ Umgebungen mit einem hohen $\mathrm{Na}$ Anteil existiert, was auf Grund des $\mathrm{Ca} / \mathrm{Na}$ Verhältnisses von 1/5 zu erwarten war. Die $\mathrm{Cl}$ Umgebung in den peralkalinen und peraluminösen Gläsern ist ähnlich, jedoch beinhaltet die $\mathrm{Cl}$ Umgebung in den peraluminösen Gläsern mehr Ca. In den ${ }^{35} \mathrm{Cl}$-MAS-NMR-Spektren wurde im Vergleich zu einem Natriumsilikatglas nur ein Teil des ${ }^{35} \mathrm{Cl}-\mathrm{NMR}$-Signals der peralkalinen und der peraluminösen Proben beobachtet. Das fehlende Signal deutet darauf hin, dass ein Teil der $\mathrm{Cl}$ Atome in verzerrten oder ungeordneten Umgebungen existiert, welche eine Signalbreite haben, die zu groß ist, um mit den verwendeten NMR-Spektroskopie-Methoden gemessen werden zu können. Der Anstieg der Viskosität durch $\mathrm{Cl}$ in den peralkalinen Schmelzen kann dadurch erklärt werden, dass $\mathrm{Cl}$ die Anzahl der netzwerkmodifizierenden Kationen reduziert, während mehrere Möglichkeiten zur Diskussion stehen, weshalb $\mathrm{Cl}$ die Viskosität in peraluminösen Schmelzen verringert.

Die Effekte von $\mathrm{F}$ und $\mathrm{Cl}$ auf die Viskosität sind unabhängig voneinander und summieren sich auf. Es wurde mit NMR-Spektroskopie kein Hinweis dafür gefunden, dass F einen Einfluss auf den Einbaumechanismus von $\mathrm{Cl}$ hat. 
Abstract

This study investigates the influence of 1.6 to $14.5 \mathrm{~mol} \%$ water, 1.1 to $18.3 \mathrm{~mol} \%$ fluorine $(\mathrm{F})$ and 0.5 to $1.4 \mathrm{~mol} \%$ chlorine $(\mathrm{Cl})$, alone and combined, on the structure and viscosity of peralkaline and peraluminous $\mathrm{Na}_{2} \mathrm{O}-\mathrm{CaO}-\mathrm{Al}_{2} \mathrm{O}_{3}-\mathrm{SiO}_{2}$ glasses and melts with $\sim 66 \mathrm{~mol} \% \mathrm{SiO}_{2}$ (on a volatile free basis). The composition of the peralkaline samples is intended as a model system for phonolitic melts. The anhydrous samples were produced in $1 \mathrm{~atm}$ furnaces using oxide, carbonate and halide compounds. The hydrous peralkaline samples were synthesised in an internally heated pressure vessel and the hydrous peraluminous samples in a piston cylinder. The viscosity of the melts was measured with the micropenetration technique $\left(10^{8.5}-10^{13} \mathrm{~Pa} \mathrm{~s}\right)$ and the parallel plate method $\left(10^{5.5} \mathrm{~Pa} \mathrm{~s}-10^{9} \mathrm{~Pa} \mathrm{~s}\right)$. The structure of the glasses was analysed with magic angle spinning (MAS) nuclear magnetic resonance spectroscopy (NMR) of the nuclides ${ }^{19} \mathrm{~F}$, ${ }^{23} \mathrm{Na},{ }^{27} \mathrm{Al},{ }^{29} \mathrm{Si}$ and ${ }^{35} \mathrm{Cl}$.

Fluorine and water, alone and combined, decrease melt viscosity, with the effect of water on the viscosity being stronger than that of $F$. Both volatiles decrease viscosity more strongly in the peraluminous melts than in the peralkaline melts. In peralkaline melts $\mathrm{F}$ decreases viscosity up to a concentration of $1.9 \mathrm{~mol} \% \mathrm{~F}$, but for a concentration of $6.2 \mathrm{~mol} \% \mathrm{~F}$ no further decrease was observed. In peraluminous melts, up to a concentration of $18.3 \mathrm{~mol} \% \mathrm{~F}$, further addition of $\mathrm{F}$ leads to further decrease in viscosity. The combined effect of water and fluorine on viscosity is less than could be expected from the sum of their single effects, indicating that their effects on viscosity are not independent from each other.

The composition- and concentration-dependent effect of $F$ on melt viscosity is consistent with differences in the incorporation mechanism of $F$ in the glasses. ${ }^{19} \mathrm{~F}$ MAS NMR spectra showed that in the peralkaline glasses $\mathrm{F}$ exists in "salt-like" $\mathrm{F}-\mathrm{Ca}(\mathrm{n})$ and $\mathrm{F}-\mathrm{Na}(\mathrm{n})$ as well as non-bridging Si-F-Na(n), Al-F-Ca(n), Al-F-Na(n) and bridging Al-F-Al environments (" $n$ " indicates that the number of atoms is variable or unclear). $\mathrm{F}-\mathrm{Ca}(\mathrm{n})$ is the most abundant environment, although $\mathrm{Ca}$ is the least common cation. In the peraluminous glasses $\mathrm{F}$ only exists in the Si-F and Al-F environments described above, with $\mathrm{Al}-\mathrm{F}-\mathrm{Na}(\mathrm{n})$ being the most abundant environment. The formation of salt-like $\mathrm{F}-\mathrm{Ca}(\mathrm{n})$ and $\mathrm{F}-\mathrm{Na}(\mathrm{n})$ environments should increase viscosity by reducing the amount of network-modifying cations. The formation of Si-F and Al-F environments should decrease viscosity by either reducing the number of bridging oxygens, in the case of the non-bridging $\mathrm{F}$ environments, or due to the replacement of bridging oxygens by bridging fluorines, which are assumed to have lower bond strength. It can be concluded that the decrease in viscosity due to $\mathrm{F}$ is less in the peralkaline melts than in the peraluminous melts, because in the peralkaline melts $\mathrm{F}$ exists in environments that could increase and decrease viscosity, while in the peraluminous melts $\mathrm{F}$ exists only in environments that decrease viscosity.

The concentration dependent effect of $F$ on viscosity in the peralkaline samples seems to be related to a change in $\mathrm{F}$ speciation: The relative fraction of the $\mathrm{F}-\mathrm{Ca}(\mathrm{n})$ environments, which are 
assumed to cause an increase in viscosity, increases from 42 to $53 \%$ for an increase in $F$ concentration from 1.2 to $6.2 \mathrm{~mol} \%$. Changes in $\mathrm{F}$ speciation also appear to be responsible for the fact that $\mathrm{F}$ and water combined reduce viscosity less than expected. ${ }^{19} \mathrm{~F}$ MAS NMR spectra of hydrous F-bearing peralkaline samples showed that the relative fraction of Al-F environments, which should decrease viscosity, is reduced with increasing water content and that instead the relative fraction of $\mathrm{F}-\mathrm{Ca}(\mathrm{n})$ increases. No difference in the $\mathrm{OH} / \mathrm{H}_{2} \mathrm{O}$ ratio for the same total water contents due to the presence of $F$ was observed with IR spectroscopy. In contrast, there is evidence that in the peraluminous samples $\mathrm{F}$ reduces the $\mathrm{OH} / \mathrm{H}_{2} \mathrm{O}$ ratio for the same total water contents, which would explain why in the peraluminous melts $\mathrm{F}$ and water combined reduce viscosity less than expected from their single effects.

The influence of $\mathrm{Cl}$ on viscosity and structure of the melts and glasses is different to that of $\mathrm{F}$. Chlorine increases the viscosity in peralkaline melts and decreases viscosity in peraluminous melts. Viscosity measurements of hydrous $\mathrm{Cl}$-free and $\mathrm{Cl}$-bearing peralkaline melts showed that the effect of $\mathrm{Cl}$ on viscosity is not affected by the presence of water. The observed ${ }^{35} \mathrm{Cl} \mathrm{NMR}$ signal shows, that $\mathrm{Cl}$ exist in $\mathrm{Na}-\mathrm{Ca}-\mathrm{Cl}$ environments dominated by $\mathrm{Na}$, as expected from the $\mathrm{Ca} / \mathrm{Na}$ ratio of $1 / 5$. The $\mathrm{Cl}$ environment is similar in the peralkaline and peraluminous glasses, though there is more $\mathrm{Ca}$ incorporated in the $\mathrm{Cl}$ environment in the peraluminous glasses. In the ${ }^{35} \mathrm{CI}$ MAS NMR spectra only a part of the ${ }^{35} \mathrm{Cl}$ NMR signal of the peralkaline and peraluminous samples were observed compared to a sodium silicate glass. The missing signal indicates that a part of the $\mathrm{Cl}$ anions exists in asymmetric or disordered environments with a line width which is too broad to be detected with the applied NMR methods. The increase in viscosity due to $\mathrm{Cl}$ in the peralkaline melts can be explained by $\mathrm{Cl}$ reducing the amount of network-modifying cations, while several possibilities remain to be dicussed, how $\mathrm{Cl}$ reduces viscosity in the peraluminous melts.

The effects of $\mathrm{F}$ and $\mathrm{Cl}$ on viscosity are independent of each other and add together. No evidence was found from NMR spectroscopy that the presence of $F$ has an influence on the incorporation mechanism of $\mathrm{Cl}$. 


\section{Contents}

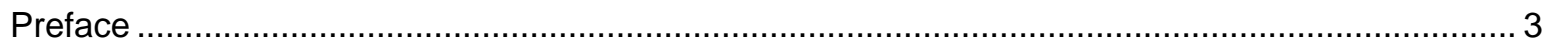

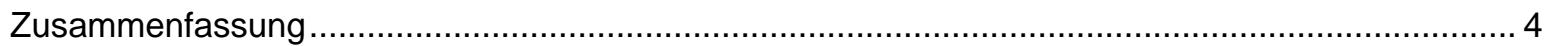

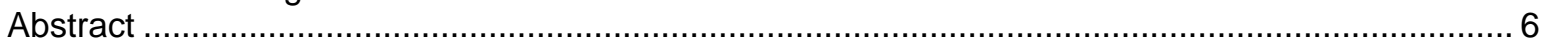

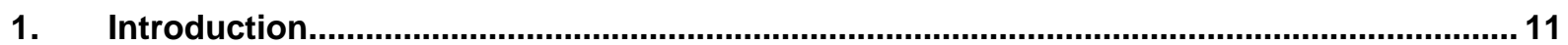

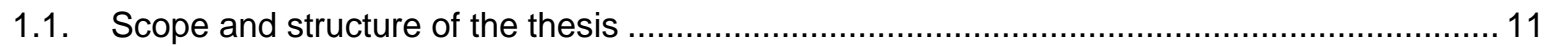

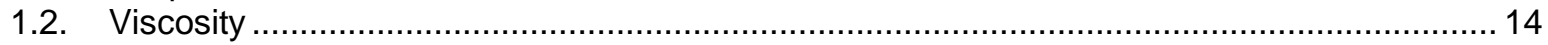

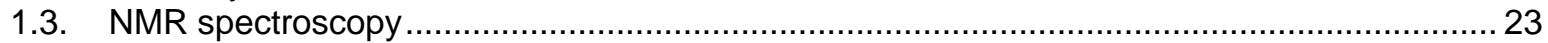

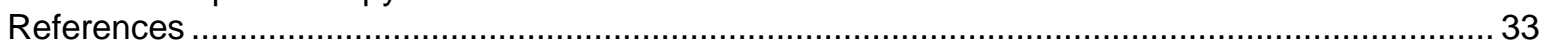

2. Compositional dependence of the rheology of halogen $(\mathrm{F}, \mathrm{Cl})$ bearing aluminosilicate

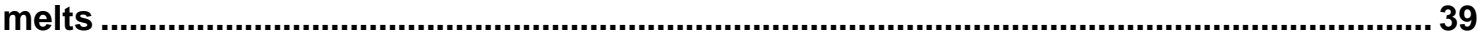

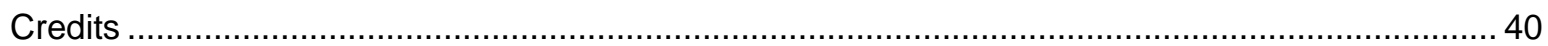

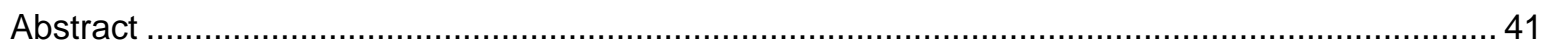

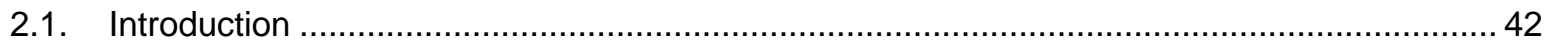

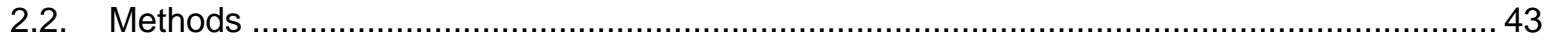

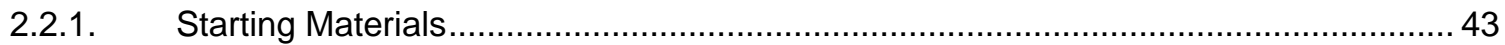

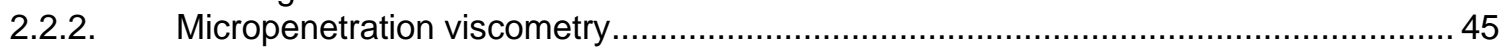

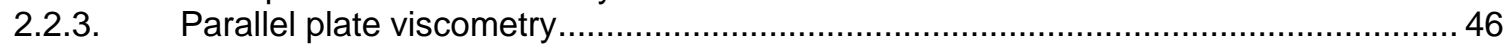

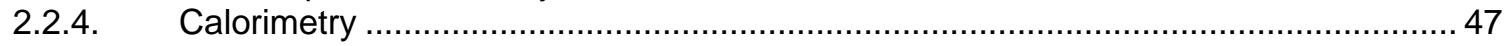

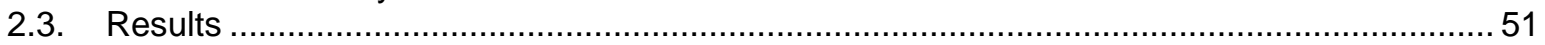

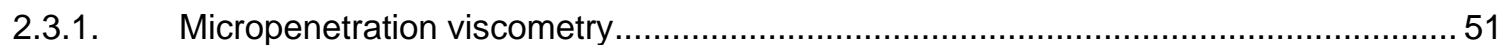

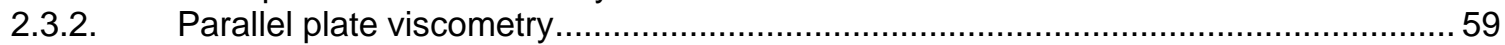

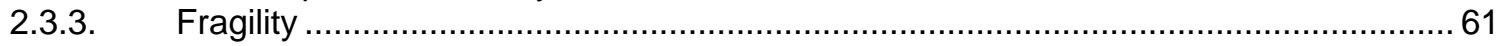

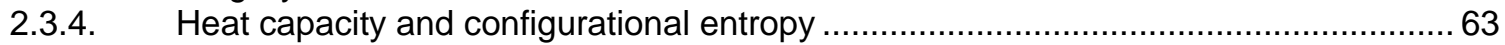

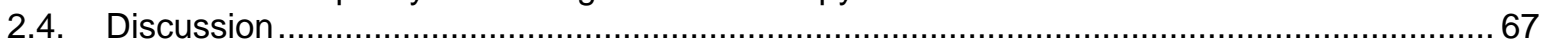

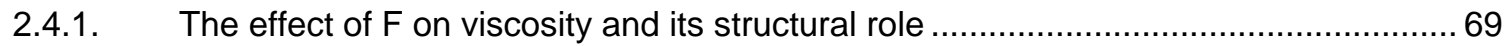

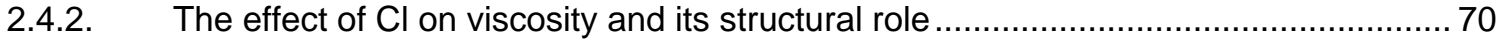

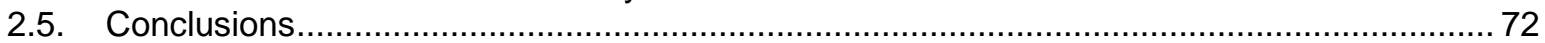

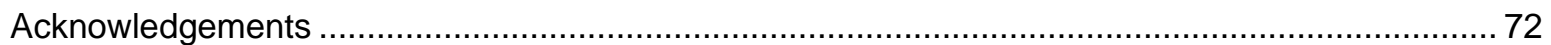

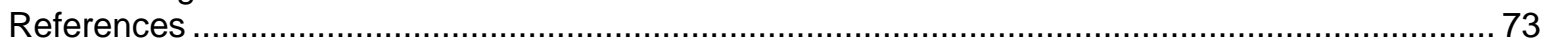

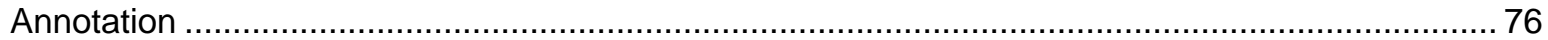

3. The effect of chlorine, fluorine and water on the viscosity of aluminosilicate melts ........77

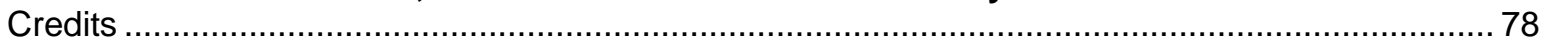

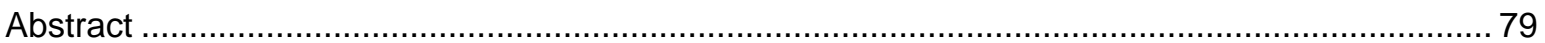

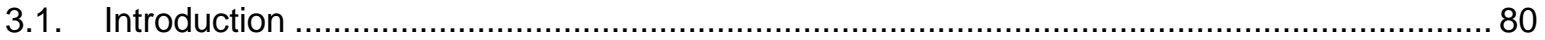

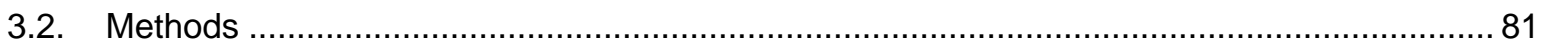

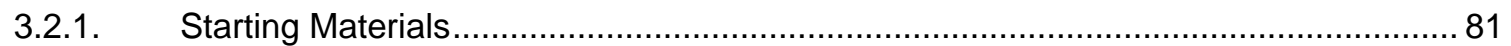

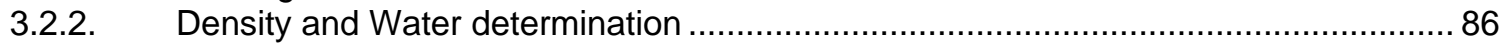

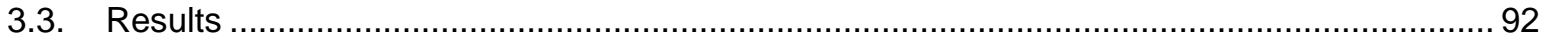

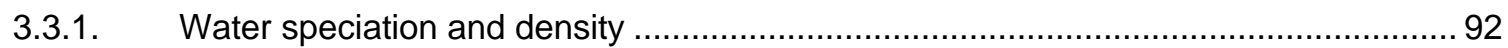

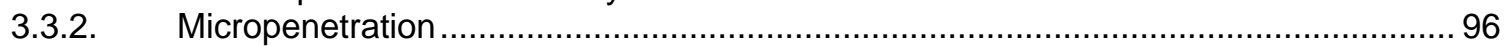

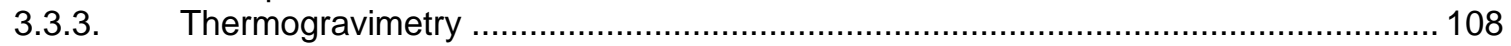

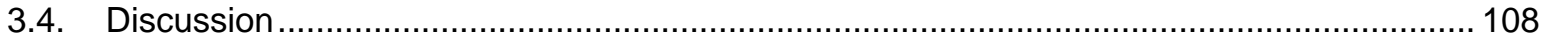

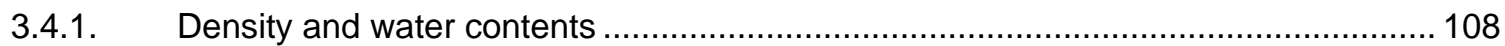

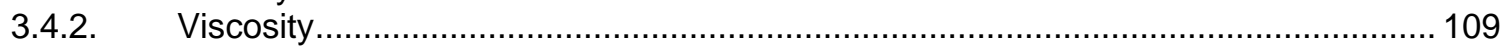

3.4.3. Influence of structure on viscosity of fluorine-bearings melts................................ 111

3.4.4. Incorporation of halogens and water and the influence on melt viscosity ................. 113

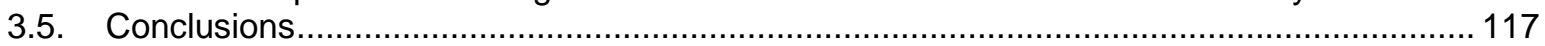

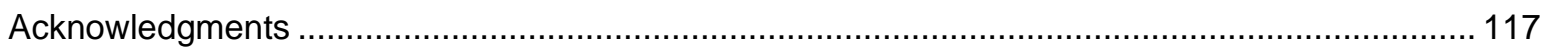

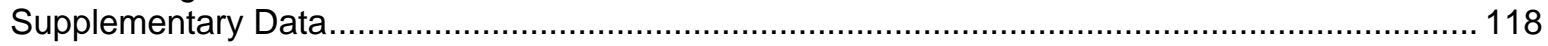

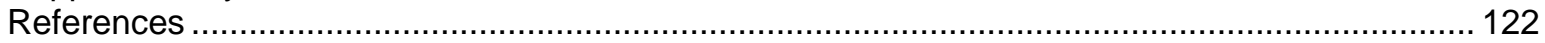


4. Fluorine speciation as a function of composition in peralkaline and peraluminous $\mathrm{Na}_{2} \mathrm{O}-\mathrm{CaO}-\mathrm{Al}_{2} \mathrm{O}_{3}-\mathrm{SiO}_{2}$ glasses: A multinuclear NMR study. ............................................ 129

Credits

Abstract .....

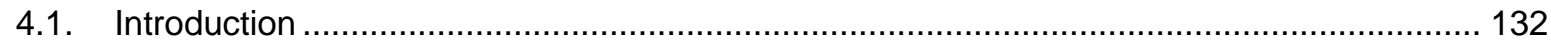

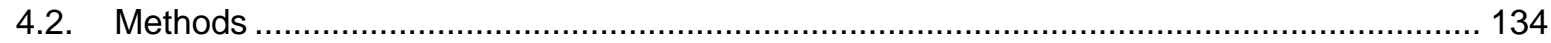

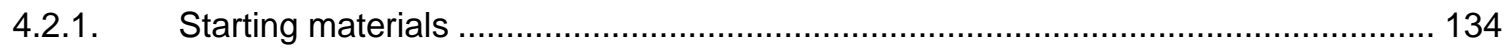

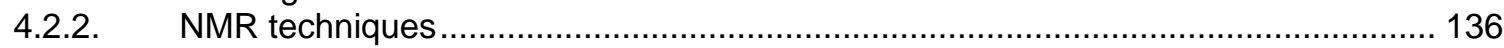

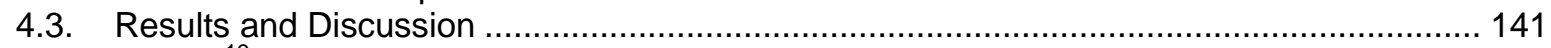

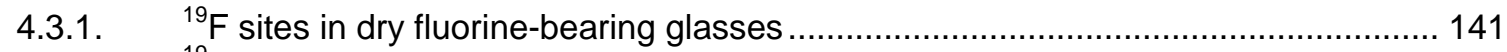

4.3.2. $\quad{ }^{19} \mathrm{~F}$ speciation of dry fluorine-bearing glasses ................................................. 149

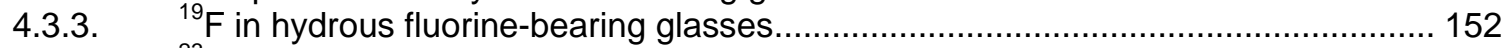

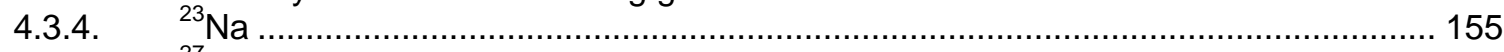

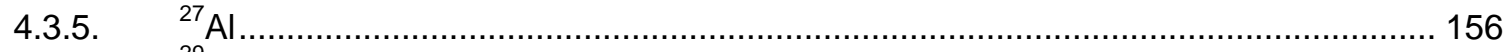

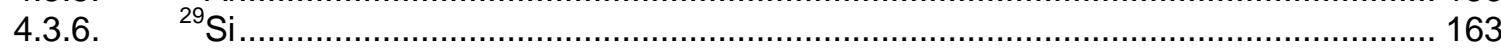

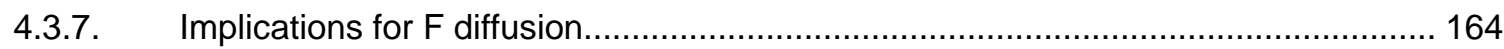

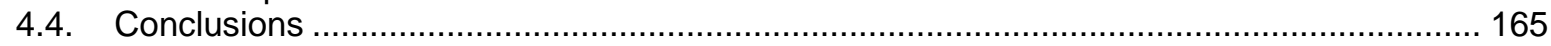

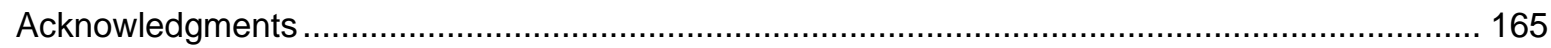

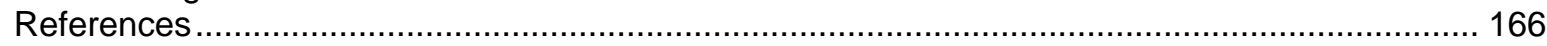

5. The incorporation mechanism of chlorine in peralkaline and peraluminous

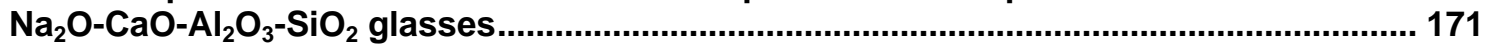

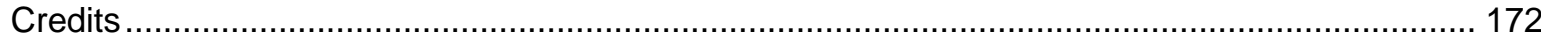

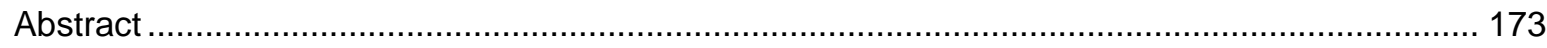

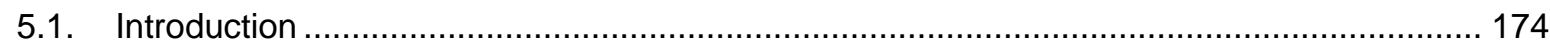

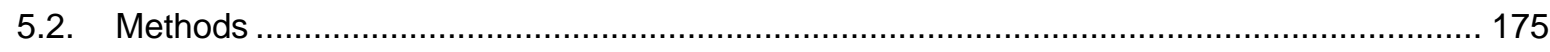

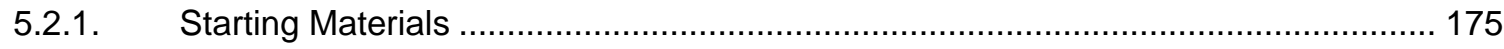

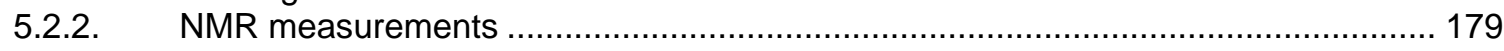

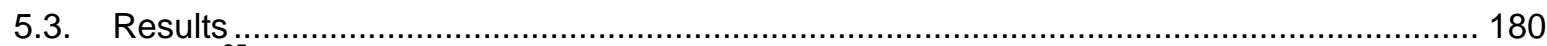

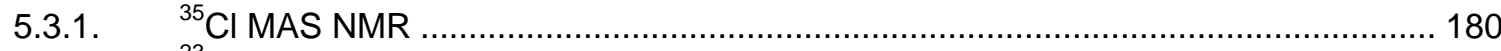

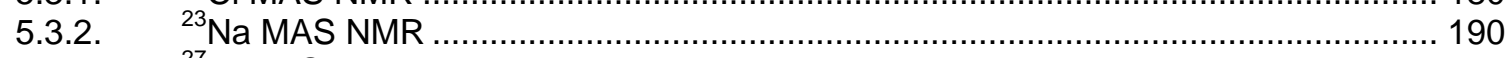

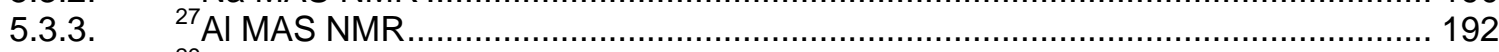

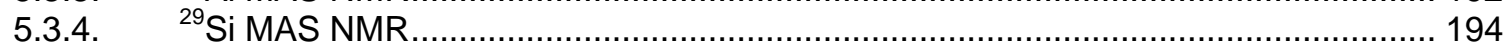

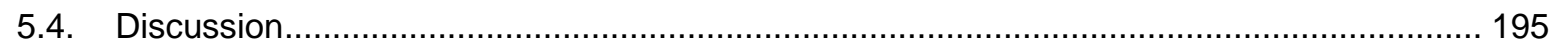

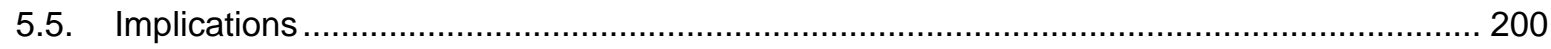

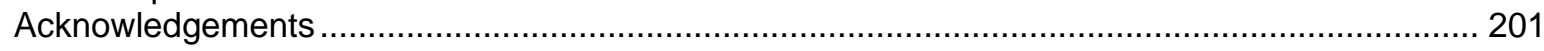

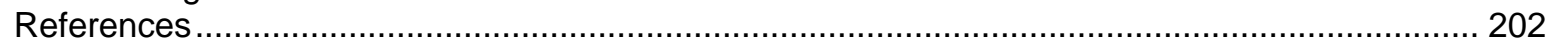

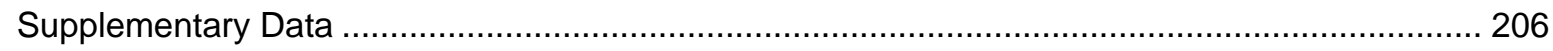

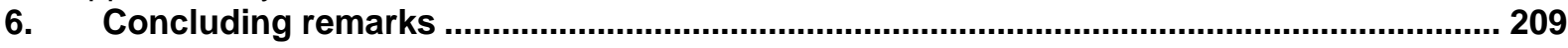

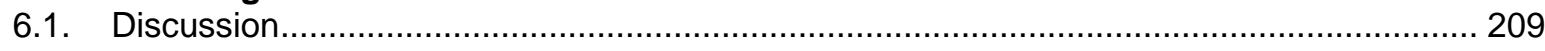

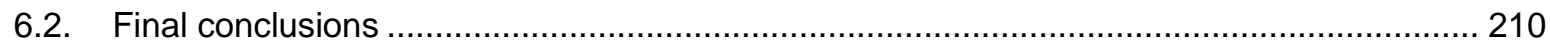

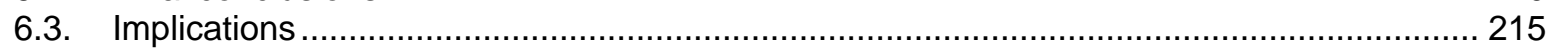

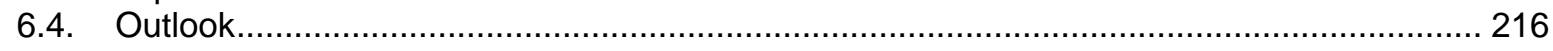

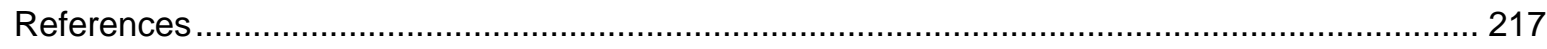

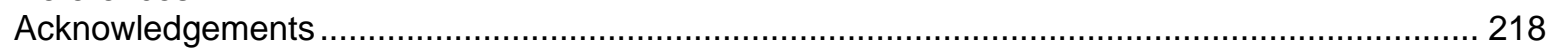

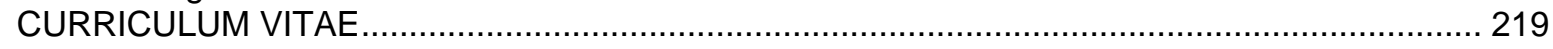




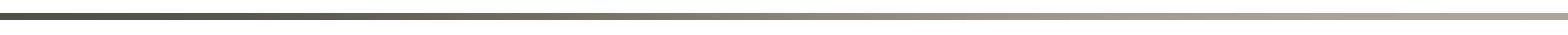




\section{Introduction}

\subsection{Scope and structure of the thesis}

The aim of this project is to study the influence of the volatiles fluorine, chlorine and water on the rheology and structure of peralkaline and peraluminous $\mathrm{Na}_{2} \mathrm{O}-\mathrm{CaO}-\mathrm{Al}_{2} \mathrm{O}_{3}-\mathrm{SiO}_{2}$ glasses and melts. The studied melt compositions can be used as simplified model systems for highly evolved $\mathrm{SiO}_{2}$-undersaturated magmatic melts like phonolitic melts. This is the first project about halogen- and water-bearing magmatic melts that was specially intended to focus on the relation between rheology and structure by combining viscosity measurements with nuclear magnetic resonance (NMR) and Infrared (IR) spectroscopy.

Phonolitic magmas can have pre-eruptive volatile concentrations of $1.2 \mathrm{wt} \%$ chlorine, $1.3 \mathrm{wt} \%$ fluorine (Aiuppa et al., 2009) and $4 \mathrm{wt} \%$ water (Harms and Schmincke, 2000). Although phonolites are not as common as rhyolites or basalts, the associated volcanoes can have explosive eruptions whose volcanic deposits can cover whole regions as prominent examples like Vesuvius (e.g. Sigurdsson et al., 1982; Rolandi et al., 1993) and Laacher See volcano (e.g. Bogaard and Schmincke, 1985) showed in the past.

The volatile content of a magma has significant influence on its viscosity (e.g. Shaw, 1963; Dingwell et al., 1985; Dingwell and Hess, 1998), which is an important parameter for processes like magma ascent (e.g. Rubin, 1995; Vigneresse and Clemens, 2000), bubble growth (e.g. Proussevitch et al., 1993; Sparks et al., 2004; Gonnermann and Manga, 2013), bubble migration (e.g. Batchelor, 1967; Gonnermann and Manga, 2013) and magma fragmentation (e.g. Papale, 1999) processes that control the eruption style of a volcano.

The key to understand viscous flow in magmatic melts lies in the melt structure. Combined data on the influence of halogens and water on structure and rheology of magmatic melts was up to now only available for the granitic system (e.g. Schaller et al., 1992; Baker and Vaillancourt, 1995; Giordano et al., 2004; Bartels et al., 2013) and more simple composition. Except the composition studied by Baker and Vaillancourt (1995) all other compositions were Ca-free. However, most magmatic 
melts contain, at least as a minor component, divalent cations like e.g. $\mathrm{Ca}^{2+}$ and previous NMR spectroscopic studies on more simple compositions showed that $\mathrm{Ca}^{2+}$ plays an important role in the incorporation mechanism of fluorine in silicate melts (Stebbins and Zeng, 2000).

Three issues are especially addressed by this project:

o The compositional dependence of the incorporation mechanism and influence on the melt viscosity of fluorine and chlorine

o The relation between the incorporation mechanism of fluorine and chlorine and their effect on viscosity

o The contrast between the influence of a single volatile on melt viscosity and that of fluorine, chlorine and water combined.

This is a cumulative thesis based on four publications, which contain all major data, results and conclusions from this project. Every publication has its own introduction and its own description of the used experimental methods. To avoid repetition, a detailed chapter about experimental methods and parameters is omitted and instead a more fundamental introduction to rheology and NMR spectroscopy is presented in chapter 1. Especially NMR spectroscopy is not a widespread method in geoscience and the publications are written in a way that some knowledge about NMR spectroscopy might be useful in the preface.

The following chapters 2 - 5 include the publications about the influence of fluorine and chlorine on the viscosity of dry and hydrous peralkaline and peraluminous $\mathrm{Na}_{2} \mathrm{O}-\mathrm{CaO}-\mathrm{Al}_{2} \mathrm{O}_{3}-\mathrm{SiO}_{2}$ melts and the NMR spectroscopic studies about their incorporation mechanism. Every publication is introduced by an overview about my participation in the publications and that of my co-authors.

The order of the publications in this thesis is not equivalent to the order they were written and submitted. The first and third publication (chapter 2 and 4) were written and submitted at a point where not all data were acquired or not evaluated and the conclusions were made based on the information that was accessible from literature. Therefore, some conclusions derived from our data in the first place turned out later on to be uncertain or unlikely and are inconsistent with conclusion in the following papers. However, these problems will be addressed in the discussion and the 
conclusions that represent the final state of this work are presented in the concluding remarks (chapter 6).

This study is a fundamental and experimental research study. It is not intended to explain a certain volcano. However, deep understanding of processes like magmatism can be only achieved by going from the simple to the complex and this study is a step in-between. 


\subsection{Viscosity}

Viscosity $\eta[\mathrm{Pa} \mathrm{s}]$ is a characteristic in rheology that describes the resistance of a material - like a silicate melt - against flow or permanent deformation/strain $\varepsilon$, respectively. It is defined as the ratio between stress $\sigma[\mathrm{Pa}]$ and strain rate $\dot{\varepsilon}\left[\mathrm{s}^{-1}\right]$ (e.g. Webb and Dingwell, 1995)

$$
\eta=\frac{\sigma}{\dot{\varepsilon}}
$$

with stress $\sigma$ being the force per area $\sigma=\mathrm{F} / \mathrm{A}\left[\mathrm{N} / \mathrm{m}^{2}=\mathrm{Pa}\right]$ and the strain rate $\dot{\varepsilon}$ being the relative change in length $/$ per time $t \dot{\varepsilon}=\Delta / /(I t)\left[\mathrm{s}^{-1}\right]$.

If a step function of stress is applied to a material there are three ways it can deform depending on applied stress and time (Fig. 1): Instantaneous recoverable elastic strain, time-dependent recoverable strain and time-dependent non-recoverable strain - the viscous flow (e g. Webb and Dingwell, 1995). If in the long timescale regime of viscous flow the strain rate increases linearly with increasing stress the viscosity is referred to as Newtonian, which is the case for silicate melts (e.g. Dingwell and Webb, 1989) The entire deformation process described above is referred to as viscoelastic behaviour (e g. Webb and Dingwell, 1995).

The temporal sequence of the deformation behaviour is controlled by the relaxation time $T$ of the material, which is the time the structure needs to rearrange and equilibrate to the applied stress (e g. Webb and Dingwell, 1995). The relaxation time $\tau[\mathrm{s}]$ and the Newtonian viscosity $\eta_{0}[\mathrm{~Pa}]$ are connected via the elastic modulus $G_{\infty}[\mathrm{Pa}]$ by the following relationship (Maxwell, 1867).

$$
T=\frac{\eta_{0}}{G_{\infty}}
$$

If the applied stress or the observation time are shorter than the time the material needs for structural relaxation one observes unrelaxed elastic behaviour, but if the applied stress and the observation time are longer than the structural relaxation time one will observe relaxed viscous behaviour (Fig. 1) (e.g. Webb and Dingwell, 1995). However, Dingwell and Webb (1989) found that in silicate melts full relaxation takes 
two orders of magnitude longer and the onset of non-Newtonian behaviour occurs two orders of magnitude earlier than expected from the relaxation time calculated with the Maxwell equation (Eq. 2).
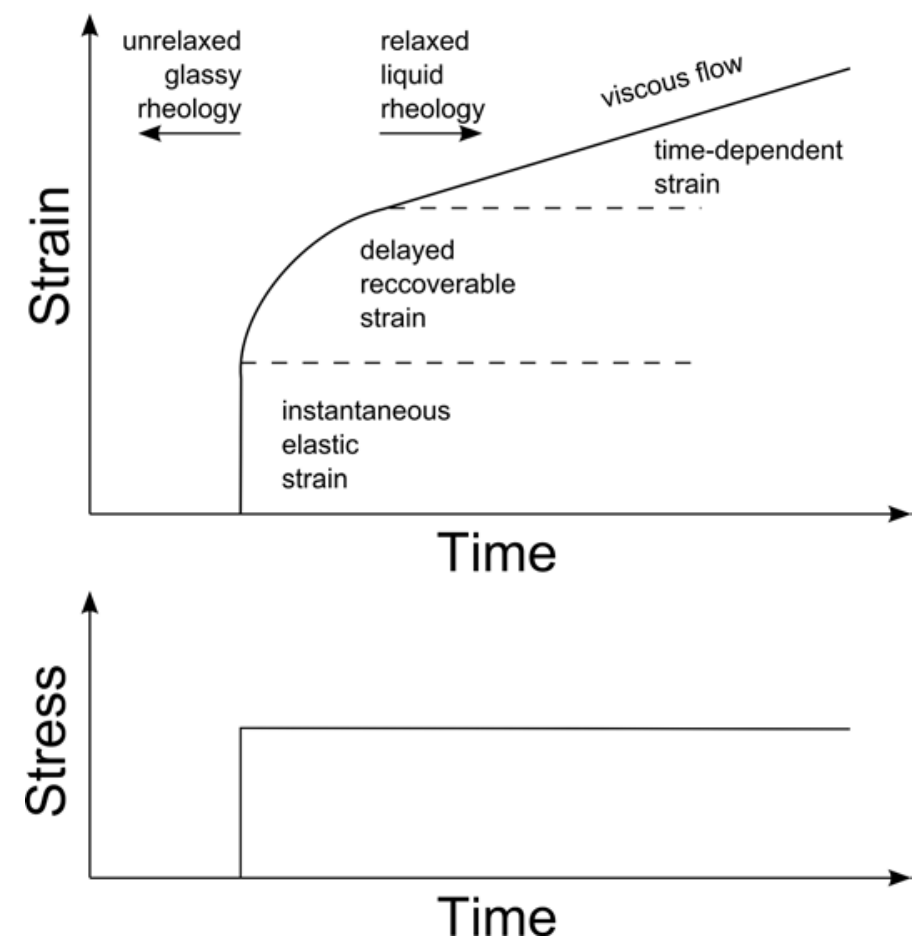

Fig. 1. Sketch of the deformation behaviour of a silicate melt depending on time upon the application of a step-function of stress (redrawn after Webb and Dingwell, 1995).

NMR spectroscopy of ${ }^{29} \mathrm{Si}$ showed that at an atomic level the viscous flow in a silicate melt depends on the life time of the Si-O bonds between Si-tetrahedra (Si tetrahedrally coordinated by oxygen) (Liu et al., 1988; Farnan and Stebbins, 1994). The presence of cations and anions like $\mathrm{Na}^{+}, \mathrm{Al}^{3+}$ or $\mathrm{F}^{-}$in a silicate melt has significant influence on the Si-O lifetime and therefore on the melt viscosity (e.g. Dingwell et al., 1985; Toplis et al., 1997).

In this study the viscosity of the melts was measured with two different methods in the same Netzsch TMA 420 dilatometer: The micropenetration method was used for the viscosity range between $10^{8.5}$ and $10^{13} \mathrm{~Pa} \mathrm{~s}$ and the continuous parallel-plate method for the viscosity range between $10^{5.5}$ and $10^{9} \mathrm{~Pa} \mathrm{~s}$. The principle of micropenetration (Fig. 2A) is to measure the indent depth $I[\mathrm{~m}]$ of a single-crystal corundum sphere with known radius $r$ [m] in the melt sample over time $t$ [s] under a certain force $F[\mathrm{~N}]$. The measurements are performed at constant temperature. The viscosity $\eta$ [Pa s] is calculated after Pocklington (1940): 


$$
\eta=\frac{0.1875 F t}{\sqrt{r} \sqrt{I^{3}}}
$$

The principle of parallel-plate (Fig. 2B) is to measure the height of a cylindrical sample $h[\mathrm{~m}]$ with a known volume $V\left[\mathrm{~m}^{3}\right]$ over time $\mathrm{t}[\mathrm{s}]$ that is compressed with a certain force $F[\mathrm{~N}]$ between two corundum cylinders that are covered with platinum. In this study the temperature was increased with a constant heating rate during the parallel-plate measurements to obtain the viscosity as a function of temperature. However, the parallel plate method is also used to measure viscosities above $10^{8} \mathrm{~Pa} \mathrm{~s}$ at constant temperature. The viscosity is calculated with the "non-slip" equation, which takes into account that the sample is deformed from cylindrical to barrel-shaped during measurement (Dienes and Klemm, 1946; Gent, 1960):

$$
\eta=\frac{2 \pi F h^{5}}{3 V \frac{\partial h}{\partial t}\left(2 \pi h^{3}+V\right)}
$$

The indent depth of the sphere or the height of the cylinder, respectively, is detected by the movement of the rod with a linear variable differential transformer (LVDT). The force is applied by weights that are placed on the top end of the rod on a pedestal.

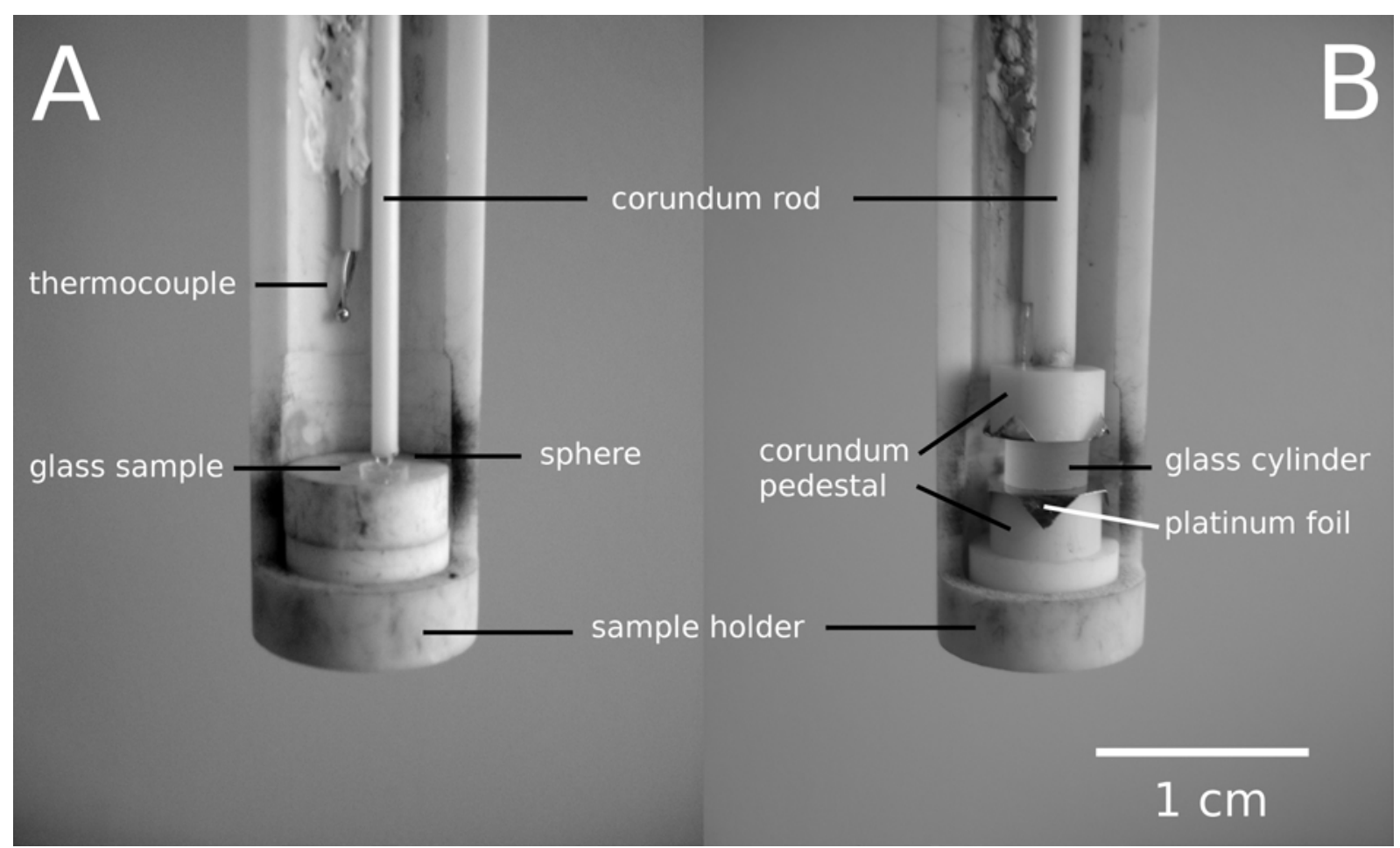

Fig. 2. Sample holder and general experimental setup of a micropenetration measurement (A) and a parallel-plate measurement (B). 
The same force applies a higher stress on the sample during a micropenetration measurement than during a measurement with the parallel-plate method. During micropenetration measurements the force of the load is concentrated on the small contact area between the spheres with 1 - $2 \mathrm{~mm}$ diameter and the sample, while during parallel-plate measurements the force is distributed on the whole area of the cylindrical sample with $6 \mathrm{~mm}$ diameter. Therefore, it is possible to measure lower viscosities with the parallel-plate method than with the micropenetration method, taking into account that the smallest weight that can be practically handled is $10 \mathrm{~g}$ $(0.098 \mathrm{~N})$. Usually in geoscience, viscosities of melts are measured below $10^{5} \mathrm{~Pa} \mathrm{~s}$ with the concentric cylinder and falling sphere method and above $10^{8} \mathrm{~Pa} \mathrm{~s}$ with micropenetration or parallel-plate method at constant temperature (e.g. Baker and Vaillancourt, 1995; Whittington et al., 2009; Bartels et al., 2013). The viscosity range in-between was only rarely measured, because the parallel-plate method at constant heating rate used here was assumed to be not working in this range, although it was used in material research for this purpose (Wilson and Poole, 1990). However, with our experimental setup, the method requires highly symmetrical glass cylinders with a diameter of at least $6 \mathrm{~mm}$ and a height of at least $4 \mathrm{~mm}$, which could only be produced from the anhydrous samples in this study that were produced in platinum crucibles in $1 \mathrm{~atm}$ furnaces and not from the hydrous glass samples that were synthesised under pressure in noble metal capsules with 3.6-4.7 mm diameter. In addition, the water-bearing samples in this study all degassed around a viscosity of $10^{8} \mathrm{~Pa} \mathrm{~s}$.

Figure 3 shows as an example the logarithmic viscosity $\eta$ of a dry and a hydrous peralkaline $\mathrm{Na}_{2} \mathrm{O}-\mathrm{CaO}$ aluminosilicate melt with $1.1 \mathrm{~mol} \% \mathrm{Cl}$ (NACS 1.1Cl) as a function of inverse temperature $T$. The viscosity decreases with increasing temperature and with the addition of water. Over a short temperature range $(\sim 100 \mathrm{~K})$ the viscosity-temperature behaviour can be described with an exponential Arrhenian equation (e.g. Reynolds, 1886):

$$
\eta=\eta_{0} \exp \frac{E_{a}}{R T}
$$

with the viscosity $\eta[\mathrm{Pas}]$, the activation energy $E_{a}\left[\mathrm{~J} \mathrm{~mol}^{-1}\right]$, the universal gas constant $R\left[\sim 8.314 \mathrm{~J} \mathrm{~mol}^{-1} \mathrm{~K}^{-1}\right]$ (e.g. Weast, 1972) and the temperature $T[\mathrm{~K}]$. The 
equation can be rewritten as a linear equation with the parameters $A_{A r r}$ and $B_{A r r}$, if one takes the logarithm of the viscosity

$$
\log _{10} \eta=A_{A r r}+\frac{B_{A r r}}{T}
$$

However, for a larger temperature range a non-Arrhenian viscosity-temperature behaviour can be observed by a curvature of the data (Fig. 3), that can be described with the Vogel-Fulcher-Tamman equation with the parameters $A_{V F T}, B_{V F T}$ and $C_{V F T}$ (Vogel, 1921; Fulcher, 1925; Tamman and Hesse, 1926):

$$
\log _{10} \eta=A_{V F T}+\frac{B_{V F T}}{T-C_{V F T}}
$$

$A_{V F T}$ is the logarithm of the viscosity at infinite temperature and is supposed to be the high temperature limit of viscosity. The viscosity at high temperatures is assumed to be limited by the timescale of the vibration of the liquid quasi-lattice vibration (Dingwell and Webb, 1989; Angell, 1991). Dingwell and Webb (1989) showed that the relaxation times of silicate melts tend to a common point for infinite temperature at $10^{-14} \mathrm{~s}$. Consistent with that Angell (1991) observed that most viscosity data for silicate melts and even polymers tend to a common point for infinite temperature at $10^{-4} \mathrm{~s}$. Assuming $\mathrm{G}_{\infty}=10^{10} \mathrm{~Pa}$, which was found to be a good approximation for most silicate melts (Dingwell and Webb, 1989), one can calculate the high temperature viscosity limit with the Maxwell equation (Eq. 2) to be $10^{-4} \mathrm{~Pa} \mathrm{~s}$. This value is consistent with the viscosity of gasses being $10^{-3.5}$ to $10^{-4.5} \mathrm{~Pa} s$ at all temperatures (Weast, 1973 and citations inside). Therefore, in this study in agreement with other studies (Giordano et al., 2008) $A_{V F T}$ was set to -4.5.

Besides the empirical equations discussed above there is also a thermodynamic approach to describe dependence of viscosity $\eta$ on the temperature $T$ (Richet, 1984; Richet and Bottinga, 1995):

$$
\log \eta=A_{e}+\frac{B_{e}}{T S_{c o n f}}
$$

with $A_{e}, B_{e}$ being parameters and $S_{\text {conf }}\left[\mathrm{J} \mathrm{mol}^{-1} \mathrm{~K}\right]$ the configurational entropy. The basic idea behind the approach is that the transport of matter in a liquid due to viscous flow needs structural rearrangement, which positively depends on the 
available configuration in the system (Adam and Gibbs, 1965; Richet and Bottinga, 1995). The measure for the amount of configurations is the configurational entropy $S_{\text {conf, }}$ which can be calculated as a function of the temperature $T$ for a liquid from the configurational entropy $S_{\text {conf }}\left(T_{f}\right)$ at the fictive temperature $T_{f}$ and the configurational heat capacity $C_{p}{ }^{\text {conf }}\left[\mathrm{J} \mathrm{mol}^{-1} \mathrm{~K}\right]$ (Richet, 1984; Richet and Bottinga, 1995):

$$
S_{\text {conf }}(T)=S_{\text {conf }}\left(T_{f}\right)+\int_{T_{f}}^{T} \frac{C_{p}^{\text {conf }}}{T} d T,
$$

with $C_{p}$ conf being the heat capacity of the liquid $C_{p l}$ minus the heat capacity of the glass $C_{p g}$, which can be obtained from calorimetry. The fictive temperature $T_{f}$ of glass is the temperature at which the melt structure is frozen. Because $T_{f}$ depends on the cooling rate, today, researchers use $T_{g}^{12}$ instead of $T_{f} . T_{g}^{12}$ is the temperature at which the viscosity of a melt is $10^{12 \mathrm{~Pa} \mathrm{~s}}$. Combining Eq. 1.8 with Eq. 1.9 the following equation is obtained (Richet, 1984; Richet and Bottinga, 1995),

$$
\log _{10} \eta=A_{e}+\frac{B_{e}}{\ln 10\left[S_{\text {conf }}\left(T_{g}^{12}\right)+\int_{T_{g}^{12}}^{T} \frac{C_{p}^{c o n f}}{T} d T\right] T}
$$

which can be used to calculate $S_{\text {conf }}\left(T_{g}{ }^{12}\right)$ of a melt from $C_{p}{ }^{\text {conf }}$ and the viscosity-temperature data.

Because of the non-Arrhenian viscosity-temperature behaviour, extrapolation to higher or lower temperatures based on Arrhenian equations fitted to the data causes a systematic error, which can be more than 1 log unit (Fig. 3). The combined data from micropenetration and parallel plate for NACS $1.1 \mathrm{Cl}$ is better described with a Vogel-Fulcher-Tamman (VFT) equation (Eq. 7). If no data from parallel-plate or other low viscosity methods are available, like in the case of NACS $1.1 \mathrm{Cl} 14.5 \mathrm{H}$, one can fit VFT equations also based only on micropenetration data to extrapolate the data. The present example in Fig. 3 shows that the difference between the VFT equation fitted to the micropenetration data of NACS $1.1 \mathrm{Cl}$ and the viscosities measured with the parallel plate technique is less than $0.4 \log$ units up to a viscosity of $10^{5.5} \mathrm{~Pa}$, which is far better than the extrapolation done with the Arrhenian equation. However, extrapolation of data always has an uncertainty. Therefore, in case samples have very different temperature-viscosity behaviours like in the example in Fig. 3 , it is more 
precise to compare the samples at a constant viscosity than at a constant temperature to show compositional trends. This is the reason why in some figures in the publications in this thesis instead of viscosity as a function of composition we present $T_{g}{ }^{12}$ as function of composition. $T_{g}{ }^{12}$ is the temperature at which the melts have a viscosity of $10^{12} \mathrm{Pas}$. The value $T_{g}{ }^{12}$ was only chosen for conventional reasons.

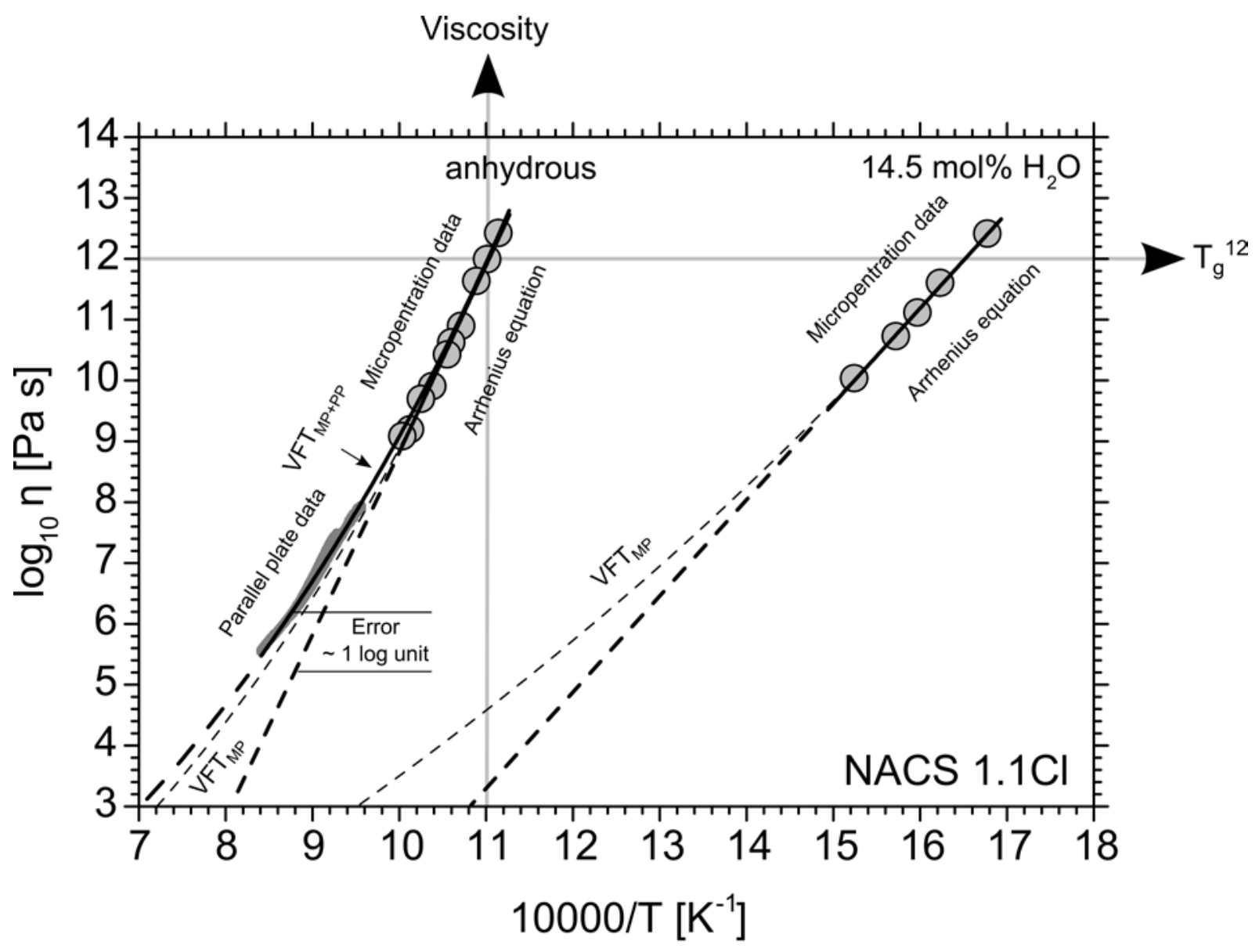

Fig. 3. Viscosity $\eta$ vs. inverse temperature $T$ for the peralkaline anhydrous sample NACS $1.1 \mathrm{Cl}$ (Baasner et al., 2013a) and the hydrous sample NACS 1.1Cl 14.5H (Baasner et al., 2013b). Arrhenian equations (Eq. 6) were fitted to the micropenetration data for both samples (solid straight lines). A Vogel-Fulcher-Tamman equation (Eq. 7) (VFT) was fitted to the micropenetration and parallel plate data of the sample NACS $1.1 \mathrm{Cl}\left(\mathrm{VFT}_{\mathrm{MP}+\mathrm{PP}}\right.$, solid curved line). Another set of Vogel-Fulcher-Tamman equations was only fitted to the micropenetration data for both samples (VFT $\mathrm{MP}_{\mathrm{PP}}$, thin dashed lines). The other thick dashed lines represent the extrapolation of the data to higher temperatures based on the different equations. The solid grey lines are the lines of projection for "viscosity" at a constant

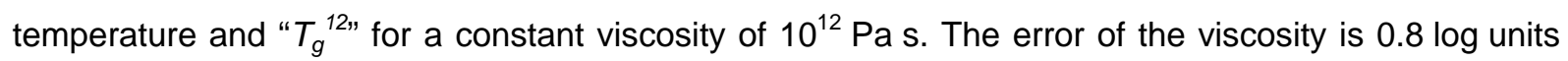
for the micropenetration data and 0.6 log units for the parallel plate data (Baasner et al, 2013a). 
The peralkaline melts $\left(\left[\mathrm{Na}_{2} \mathrm{O}+\mathrm{CaO}\right]>\mathrm{Al}_{2} \mathrm{O}_{3}\right.$, ratio on a molar basis $)$ and glasses in this study where designed as a rough model for phonolitic melts. The aim was to find a composition that has the most important compositional characteristics of a phonolitic melt $\left(\mathrm{SiO}_{2}\right.$-undersaturated, alkali-rich and more monovalent than divalent cations) and has a similar viscosity-temperature behaviour as a natural phonolitic melt, while it is still simple enough to make structural interpretations based on NMR spectroscopy. As iron causes a severe broadening of peaks in NMR spectra, the composition also has to be iron-free (see section 1.3). Therefore, the composition of pumice of the Vesuvius 79 AD eruption (Signorelli and Caroll, 2000; Carroll, 2005) was simplified by counting all tetravalent cations as $\mathrm{SiO}_{2}$, all trivalent cations as $\mathrm{Al}_{2} \mathrm{O}_{3}$, all divalent cations as $\mathrm{CaO}$ and all monovalent cations as $\mathrm{Na}_{2} \mathrm{O}$. The peraluminous composition $\left(\left[\mathrm{Na}_{2} \mathrm{O}+\mathrm{CaO}\right]<\mathrm{Al}_{2} \mathrm{O}_{3}\right.$ ) was chosen with the intention to investigate the influence of halogens and water as a function of the $\left[\mathrm{Na}_{2} \mathrm{O}+\mathrm{CaO}\right] / \mathrm{Al}_{2} \mathrm{O}_{3}$ ratio. In nature, there are no phonolites that are peraluminous as the peraluminous melts and glasses studied here. However, to better observe and understand trends in rheology and structure an "extreme" composition is required. Figure 4 shows the viscosity of highly evolved melts with natural and synthetic compositions for typical pre-eruptive temperatures of phonolites (Moussallam et al., 2013). The viscosity of the present peraluminous melt (ANCS) is, like that of the haplogranitic melt, orders of magnitude higher compared to that of the other melts, while the viscosity of the peralkaline melt (NACS) is similar to that of the phonolitic melts with natural compositions. 


\section{$\mathrm{T}[\mathrm{K}]$}

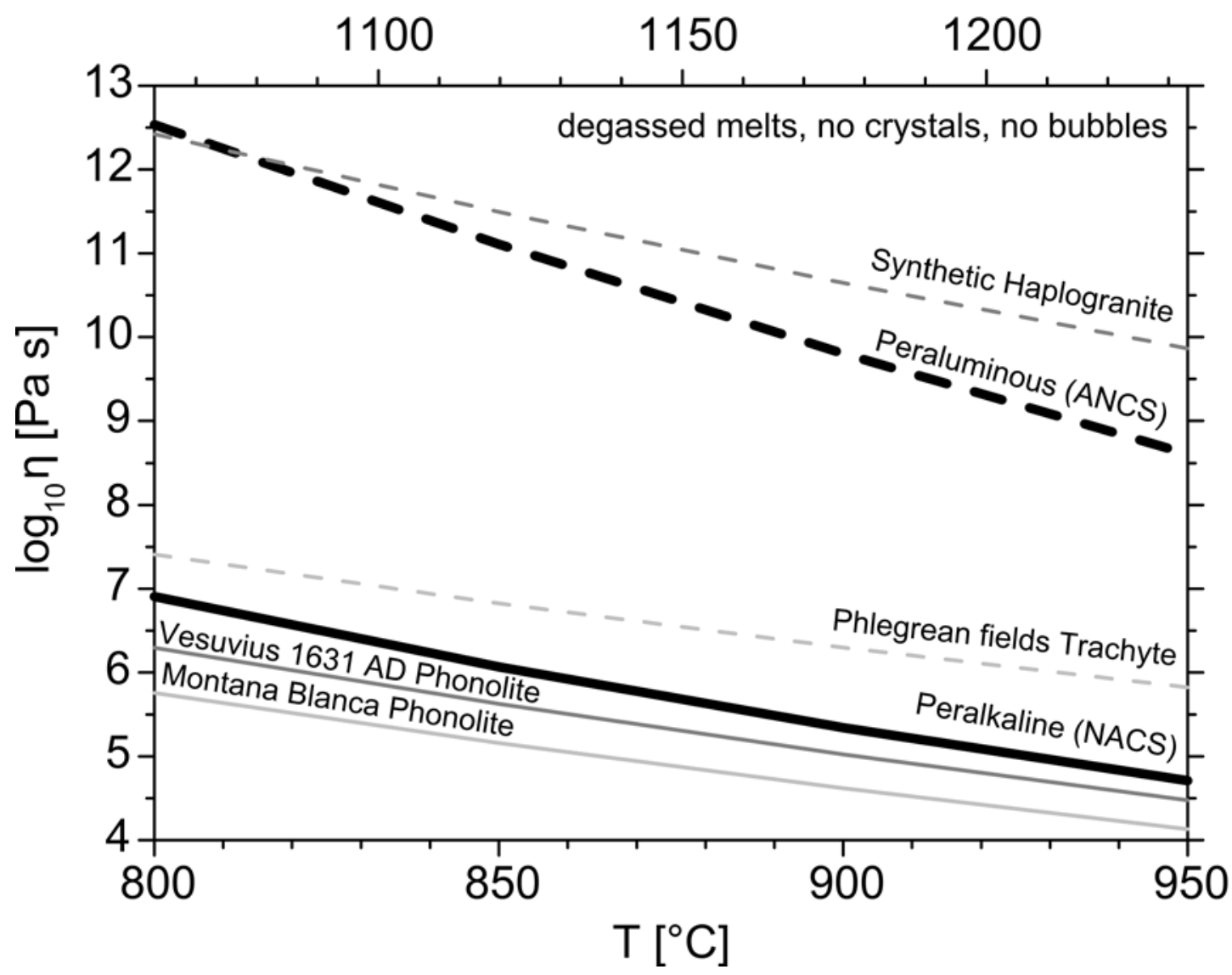

Fig. 4. Viscosity $\eta$ as a function of temperature $T$ for different volatile-, bubble- and crystal-free, highly evolved melts with synthetic and natural compositions and the peralkaline (NACS) and peraluminous (ANCS) $\mathrm{Na}_{2} \mathrm{O}-\mathrm{CaO}-\mathrm{Al}_{2} \mathrm{O}-\mathrm{SiO}_{2}$ base melts from Baasner et al. (2013a) over a range typical for the pre-eruptive storage conditions of phonolitic magmas (Moussallam et al., 2013). For the samples NACS and ANCS the curves were calculated from Arrhenian/Vogel-Fulcher-Tamman (VFT) equations (Eq. 6+7) fitted to the viscosity data from parallel plate and/or micropenetration, which cover the viscosity range presented here. For all other melts the curves were calculated from VFT equations that interpolate high and low viscosity data, but in the viscosity range presented here, viscosity was not measured, except in case of the haplogranite. Synthetic haplogranite (Dingwell et al., 1993; Hess et al., 1995), Phlegrean fields Trachyte and Vesuvius 1631 AD Phonolite (Romano et al., 2003), Montana Blanca Phonolite (Giordano et al., 2000). 


\subsection{NMR spectroscopy}

Nuclear magnetic resonance (NMR) spectroscopy is a method to investigate the environment of a distinct kind of nuclei in a material based on the interaction between their magnetic moment and an outer magnetic field, which is called Zeeman effect (Zeeman, 1896). Nuclides that have an even number of protons and an even number of neutrons such as ${ }^{12} \mathrm{C}{ }^{16} \mathrm{O}$ or ${ }^{28} \mathrm{Si}$ have in the ground state a nuclear spin $I=0$ and no magnetic moment, because the protons and neutrons can build pairs with anti-parallel spins that cancel each other (e.g. Bethe and Bacher, 1936). Due to their stable configuration these nuclides have a higher relative abundance than the other nuclides of the element, but, unfortunately, can not be used for NMR spectroscopy (e.g. Stebbins, 1995). All other nuclides with an odd number of protons or neutrons like ${ }^{1} \mathrm{H}(I=1 / 2),{ }^{2} \mathrm{H}(I=1),{ }^{27} \mathrm{Al}(I=5 / 2)$ and ${ }^{29} \mathrm{Si}(I=1 / 2)$ have a nuclear spin $I>0$ and, therefore, have a magnetic moment. A nucleus with $I>0$ has in the presence of an outer magnetic field energy $2 /+1$ energy levels $m$. Without an outer magnetic field the energy levels are degenerated, which means they have the same energy (Kirkpatrick, 1988). For example a nucleus with $I=1 / 2$ (like ${ }^{19} \mathrm{~F}$ and ${ }^{29} \mathrm{Si}$ in this study) has two degenerated energy levels that split into pairs of respective energy levels $m=-1 / 2$ and $m=+1 / 2$, if the nucleus is opposed to an outer magnetic field. At the higher energy level $(+1 / 2)$ the magnetic moment of the nucleus is oriented in the opposite direction to the outer magnetic field, while at the lower energy level $(-1 / 2)$ its magnetic moment is oriented with the outer magnetic field (e.g. Stebbins, 1995) (Fig. 5).

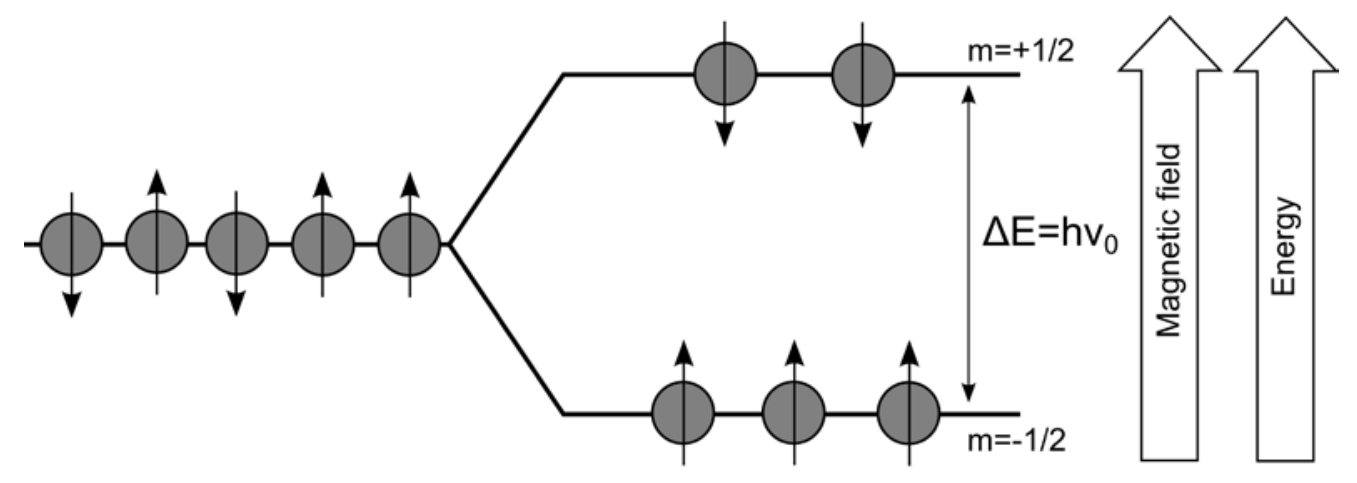

Without magnetic field

With magnetic field

Fig. 5. Zeeman effect for nuclei with $I=1 / 2$ The energy difference $\Delta E$ between the energy levels $m$ $+1 / 2$ and $-1 / 2$ equals the Larmor frequency $v_{0}$ times the Planck constant $h$ (redrawn and modified after Kirkpatrick, 1988). 
The energy required for a nuclear spin transition $\Delta E[\mathrm{~J}]$ between the upper and lower energy level is proportional to the resonant Larmor frequency $\boldsymbol{v}_{\mathbf{0}}[\mathrm{Hz}]$ and the outer magnetic field $B_{0}[T]$ multiplied with the Planck constant $\mathrm{h}\left[\sim 6.62910^{-34} \mathrm{~J} \mathrm{~s}\right]$ (e.g. Weast, 1972) and the the gyro magnetic ratio $y\left[\mathrm{~s}^{-1} \mathrm{~T}^{-1}\right]$, which is a constant for a given nucleus (e.g. Fechtelkord, 2004) (Fig. 5).

$$
\Delta E=h v_{0}=h \gamma B_{0}
$$

A nuclear spin transition is, in the normal case, only possible if the distance between the energy levels $\Delta m=1$, like in the case of the described $-1 / 2$ to $+1 / 2$ transition. The amount of nuclear spins in the higher energy level $N_{b}$ compared to the amount of nuclear spins in the lower energy level $N_{a}$ increases with increasing magnetic field $B$ and gyromagnetic ratio $\gamma$, but decreases with increasing temperature $T$, where $k$ [1.381 $\left.10^{-23} \mathrm{~J} \mathrm{~K}^{-1}\right]$ (e.g. Weast, 1972) is the Boltzmann constant (e.g. Engelhardt and Michel, 1987; Stebbins, 1995).

$$
\frac{N_{b}-N_{a}}{N_{b}+N_{a}} \approx \frac{y h B}{2 k T}
$$

The Larmor frequency has the same order of magnitude as radio frequencies. In a modern one-pulse NMR experiment (e.g. Duer, 2004) the sample is placed in the constant magnetic field of the NMR spectrometer (Fig. 8), then the nuclear spin transition is excited by energy due to a rectangular radio frequency pulse. After the radio frequency pulse the nuclear spin distribution returns to its equilibrium state and the re-emission of the signal, the free induction decay (FID), depending on time is observed. The time dependent signal is then transformed into a frequency dependent signal with a Fourier transformation.

NMR spectrometers are often classified as a XY MHz spectrometers instead of being named after the magnetic field in Tesla. The $X Y$ frequency is the proton Larmor frequency corresponding to the magnetic field. Protons have the highest gyro magnetic ratio of all naturally occuring nuclei and, therefore, the highest Larmor frequency for a given magnetic field.

On a "macroscopic" scale the magnetisation of the sample during a one-pulse NMR experiment can be simply described with classic mechanics by the motion of a single magnetic moment $\mu$ as follows (after Engelhardt and Michel, 1987): When the sample 
is placed into the magnet of the NMR spectrometer (Fig. 8), $\mu$ precesses around the direction of the outer magnetic field $B_{0}$ (z-axis in the laboratory frame) with the Larmor frequency $\omega_{0}=2 \pi v_{0}$ (Fig. 6A). The magnetic field is produced with a superconducting electromagnet made from a coil of superconducting wire. In order to observe a NMR signal one has to "kick" $\mu$ away from the direction of $B_{0}$. This is achieved by a rectangular radio frequency pulse emitted by another coil, which generates a second magnetic field $B_{1}$ (in the xy-plane in the laboratory frame) perpendicular to $B_{0}$ and which rotates around the $z$ axis with $\omega_{0}$.
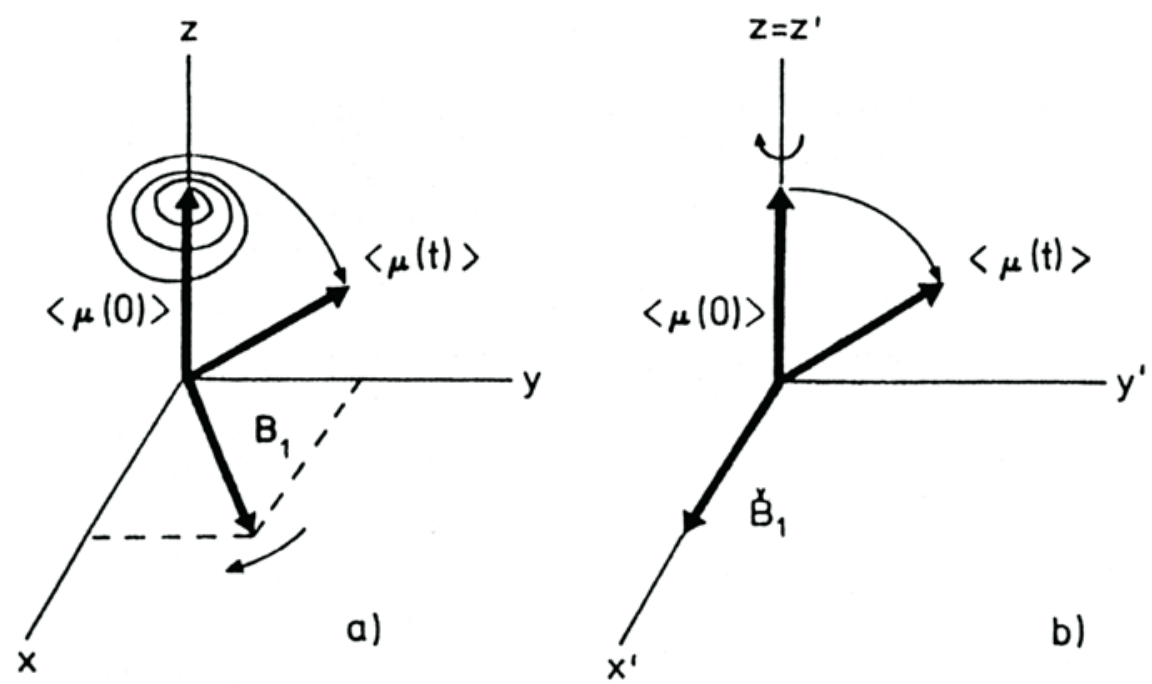

Fig. 6. (A) Motion of a magnetic moment $\mu$ in the laboratory frame as superposition of the precession around the outer magnetic field $B_{0}$ in (z-axis) and the rotating magnetic field $B_{1}$ (xy-plane) applied with an radio frequency pulse. (B) Motion of a magnetic moment $\mu$ in the rotating frame, where the coordinate system rotates around the direction of $B_{0}$ (z-axis) (Engelhardt and Michel, 1987).
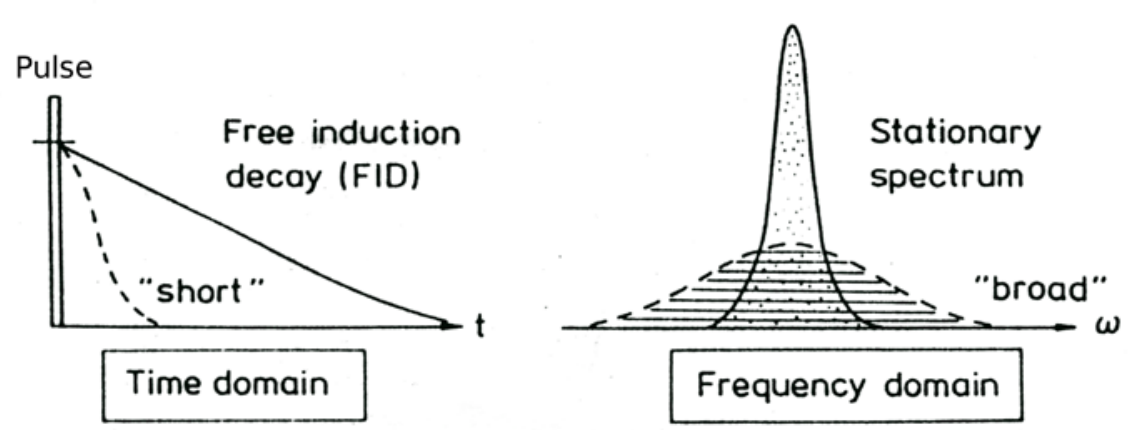

Fig. 7. The NMR signal, the free induction decay (FID), in the time $t$ domain and after Fourier transformation in the frequency $\omega$ domain in a stationary (static) spectrum. A short FID results in a broad peak in the frequency spectrum and vice versa (modified after Engelhardt and Michel, 1987). 
The motion of $\mu$ is now a superposition of the precession around $B_{0}$ with $\mu_{0}$ and the precession with $\omega_{1}$ around the instantaneous direction of $B_{1}$. It is comparable to the movement of a spinner top (Fig. 6A). Instead of $B_{1}$ one can, for a better description, let the coordinate system rotate with $\omega_{0}$ (the rotating frame with $x^{\prime}, y^{\prime}, z^{\prime}$ and a static $\breve{B}_{1}$ ) like in Fig. $6 \mathrm{~B}$. A $90^{\circ}$ pulse means for example that after the pulse the direction of $\mu$ points in a direction in the xy-plane perpendicular to the outer magnetic field $B_{0}$ of the NMR spectrometer. The angle of the pulse depends on the pulse length. After the pulse, the observation (acquisition) of the NMR signal starts and over time $\mu$ returns to the initial state, which is called relaxation or demagnetisation. The relaxation in the xy-plane, which is called the spin-spin relaxation or free induction decay (FID), is faster than or equal to the relaxation in the z-direction, the spin-lattice relaxation. The time-dependent FID is the actual signal of interest, which is then Fourier transformed into a frequency domain, whereby the length of the FID is inversely proportional to the width of the peak in the frequency domain (Fig. 7). To obtain the full signal intensity with the next pulse, one has to wait until all nuclei have fully relaxed. The time between two pulses is called recycle delay, which includes the pulse length, the acquisition time and the relaxation time. The spin-lattice relaxation time is the main factor controlling the pulse rate. However, as the spin-lattice relaxation takes longer than the signal acquisition, it can be useful to accelerate the spin-lattice relaxation for example by doping the sample with CoO. This acceleration is caused by a dipole-dipole interaction between the spins of the unpaired electrons of the Co atoms and the spins of the investigated nuclei. Unpaired electrons have a 1000 times higher gyro magnetic ratio than ${ }^{1} \mathrm{H}$, which has the highest of all nuclides (Stebbins, 1995). Therefore, if the concentration of unpaired electrons is too high, e.g. due to an iron concentration larger than $1 \mathrm{wt} \%$, the signal intensity could be strongly reduced and the line width broadened (Stebbins, 1995).

The observed resonance frequency of a nucleus is not necessarily the Larmor frequency and does not only depend on the gyro magnetic ratio and the outer magnetic field, but also on the exact local environment of the nucleus (e.g. Duer, 2004); otherwise it would be useless for structural interpretations. The frequency, the width and the line shape of the peak of the NMR signal are influenced by several effects, of which only those are discussed that are important for this study - the chemical shift and the quadrupole interaction. These effects can be very different 
depending on the site/environment of a nucleus in a molecule, crystal lattice or glass-network.

The chemical shift is caused by the shielding or deshielding of a nucleus from the outer magnetic field due to the surrounding electrons. The configuration of the electrons is influenced by the surrounding atoms in the local environments (e.g. Duer, 2004). The chemical shift $\delta$ and most other frequency values in NMR spectroscopy

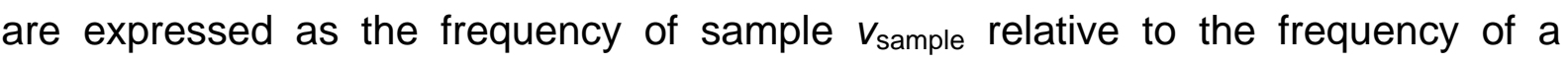
reference material $v_{\text {reference }}$ in ppm (e.g. Duer, 2004; Stebbins, 1995).

$$
\delta=10^{6} \frac{v_{\text {sample }}-v_{\text {reference }}}{v_{\text {reference }}}
$$

The atoms that could influence the chemical shift of a nucleus are the "nearest neighbours" and the "next-nearest neighbours". For a ${ }^{29} \mathrm{Si}$ nucleus in a fully polymerised aluminosilicate glass, where Si and Al are four-coordinated by oxygens connected to other Si and Al atoms, the nearest neighbour would be an oxygen and the next-nearest neighbour could be either a Si (Si-O-Si) or an Al (Si-O-Al), which could make a difference in chemical shift of $\sim 5$ ppm (Engelhardt and Michel, 1987).

Even if a nucleus only exists in one specific environment in a material, due to minor differences in the local environment one observes not a single chemical shift but a chemical shift distribution (CSD) in the NMR signal (e.g. Stebbins, 1995; Duer, 2004). The CSD influences, among other effects, the peak width of the NMR signal (width due to CSD $=W_{c s d}$ ) and is independent of the magnetic field, when expressed as ppm (e.g. Stebbins, 1995). The CSD is usually larger for a nucleus in a glass than in a crystalline material, because the glass network is more disordered.

If the chemical shift is independent from orientation it is called the isotropic chemical shift $\boldsymbol{\delta}_{\text {iso, }}$, which is, if expressed in ppm relative to a reference material (Eq.13), independent of the outer magnetic field and the spectrometer (e.g. Duer, 2004; Stebbins, 1995). For a symmetric Gaussian/Lorentzian peak $\delta_{\text {iso }}$ corresponds to the peak maximum and the centre of gravity $\boldsymbol{\delta}_{c g}$, which can be defined for our case as 


$$
\delta_{c g}=\frac{\int_{0}^{\infty} v f(v) d v}{\int_{0}^{\infty} f(v) d v}
$$

with $f(v)$ the peak function and $v$ the frequency. However, unless the environment of a nucleus is isotropic like a perfect sphere, cube, tetrahedron or octahedron, the chemical shift depends on the orientation of the surrounding electrons relative to the outer magnetic field, which is called chemical shift anisotropy (CSA) (e.g. Stebbins, 1995). The CSA can be described with an ellipsoid like the indicatrix in optical microscopy (Stebbins, 1995). Although the CSA is bearing information about the structure of a material, in case of a powdered or amorphous material (e.g. glass) a random distribution of all orientations is observed (the powder pattern), which causes a severe broadening of the signal (e.g. Duer, 2004). In low-viscous liquids the CSA is normally not observed, because due to the movement of the molecules the reorientation of structural units happens faster than the frequency range of the NMR spectrum - which is called motional averaging (e.g. Stebbins, 1995).

The idea of motional averaging in liquids can be also applied to NMR spectroscopy on solid materials by magic angle spinning (MAS). Technically this is realized by spinning the sample in a rotor (Fig. 9) by an air stream at an angle of $54.7^{\circ}$ to the direction of the outer magnetic field. To average out orientation dependent effects like the CSA the spinning frequency must be higher (in $\mathrm{Hz}$ ) than the peak width in a static spectrum. The angle $54.7^{\circ}$ results from the multiplier $\left(3 \cos ^{2} \theta-1\right)$, which appears in the equations that describe the orientation dependency of the NMR signal e.g. due to the CSA and the first-order quadrupople interaction (see discussion below) (e.g. Stebbins, 1995; Duer, 2004). $\theta$ is the polar angle between the largest component describing the anisotropy and the outer magnetic field $B_{0}$ (z-axis). For $\theta=54.7^{\circ}$ $3 \cos ^{2} \theta-1$ becomes zero. A spectrum collected without MAS is called static spectrum. In the case of a nucleus with $I=1 / 2$ the peak maximum of the NMR resonance corresponds under MAS conditions to the isotropic chemical shift $\delta_{\text {iso }}$. 


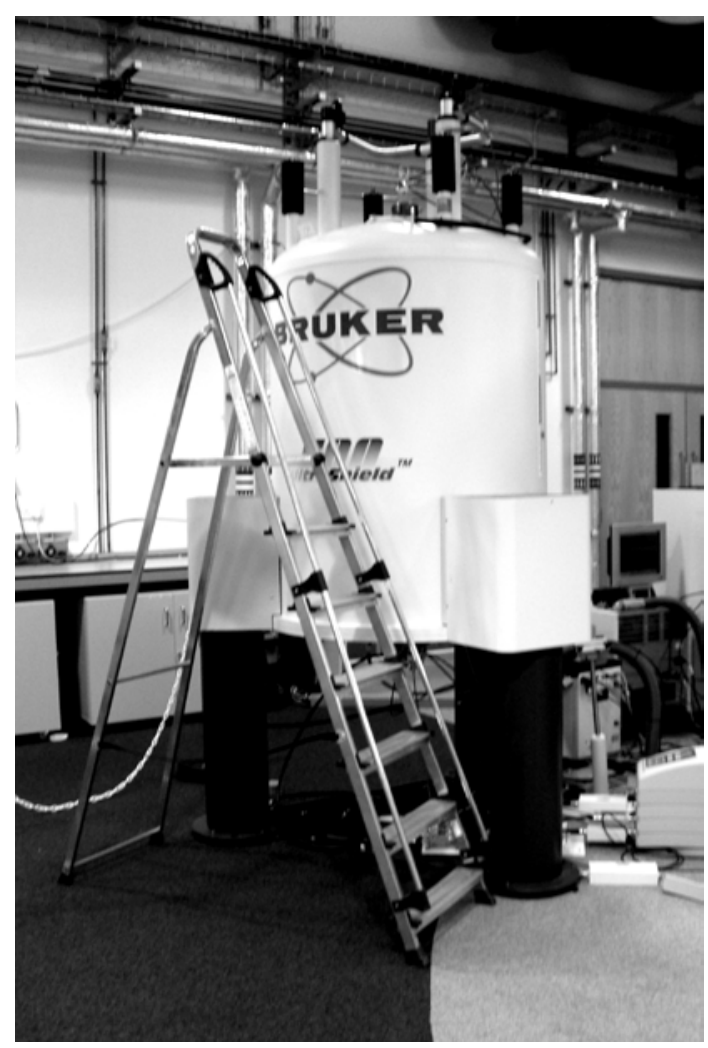

Fig. 8. $500 \mathrm{MHz}(11.7 \mathrm{~T})$ spectrometer at University of Warwick.

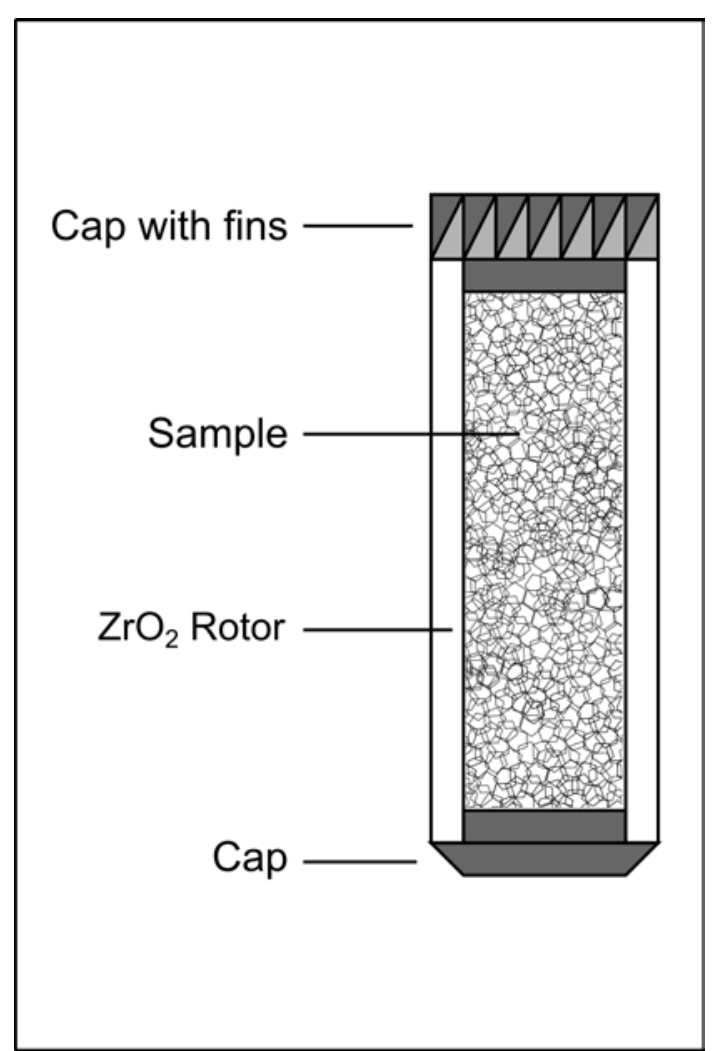

Fig. 9. Typical design of a NMR rotor. The diameter of a rotor ranges between a few to several millimetres.

An artefact of MAS are the spinning sidebands, which carry a part of the signal, if the CSA is not completely averaged to zero (e.g. Duer, 2004). They appear on the left and right hand of the NMR resonance in the exact distance of the spinning frequency. As the absolute $W_{c s d}$ and the CSA in $\mathrm{Hz}$ increase with the increasing magnetic field the spinning frequency that is required to move the spinning sidebands sufficiently away from the peak of the NMR signal also increases. However, the maximum spinning speed of the rotor is limited and decreases with increasing rotor diameter $\left(33 \mathrm{kHz}\right.$ for a $2.5 \mathrm{~mm}$ rotor $\sim 259 \mathrm{~m} \mathrm{~s}^{-1}$ ). Therefore, if $W_{\text {csd }}$ and CSA are large it can be an advantage to measure at a lower magnetic field, although then the signal intensity becomes less (e.g., Duer 2004).

In the present study mostly one-pulse MAS NMR experiments were used. However, in some cases it was necessary to divide the signal of the sample from interference signals produced by the spectrometer itself by using an echo pulse sequence. For a simple Hahn echo first a $90^{\circ}$ pulse and then during the free induction decay a second $180^{\circ}$ pulse is applied, which refocuses the magnetisation in the $x y$-plane and thus, the signal (e.g. Duer, 2004). In the time domain, due to the echo the signal of the 
sample does not appear simultaneously with the interference signal, but later. The general peak position and shape of the signal in the frequency domain are usually not affected by this procedure.

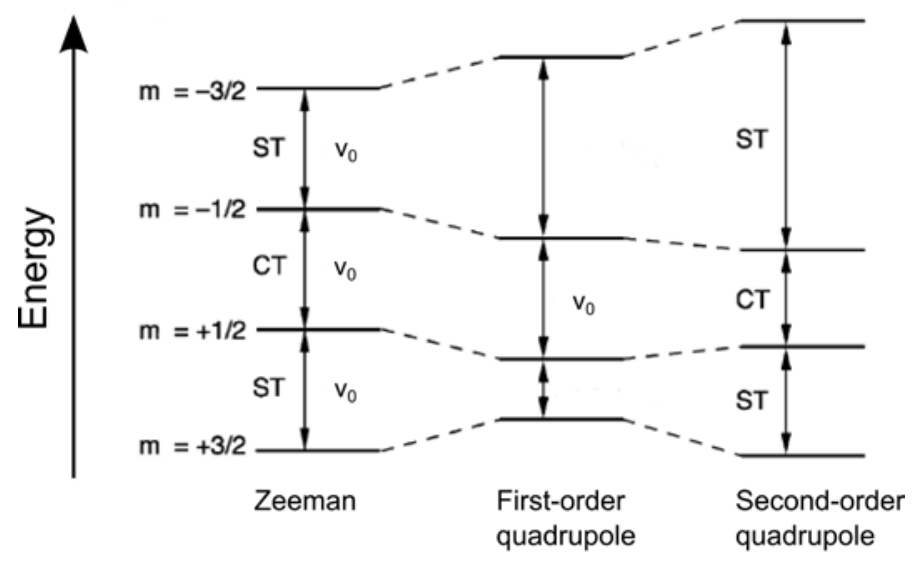

Fig. 10. Influence of the Zeeman, first-order and second-order quadrupole interaction on the nuclear spin energy levels $m$ and the transitions between them for a nucleus with $I=3 / 2$. Under the Zeeman interaction all nuclear spin transitions have the same energy $\Delta E$ corresponding to the Larmor frequency $v_{0}$. The $-1 / 2$ to $+1 / 2$ transition is the central transition (CT) and the other transitions (e.g. $-3 / 2$ to $+3 / 2$ ) are the satellite transitions (ST). Due to the first-order quadrupole interaction, which only affects the satellite transitions, the nuclear spin transitions are no longer equivalent. The second-order quadrupole interaction perturbs the central as well as the satellite transitions (redrawn and modified after Ashbrook, 2009).

Quadrupole nuclides have a $I>1 / 2$, like e.g. ${ }^{23} \mathrm{Na}$ and ${ }^{35} \mathrm{Cl}$ with $I=3 / 2$ or ${ }^{27} \mathrm{Al}$ with $I=5 / 2$, and a quadrupole moment $e Q$, with $e$ the charge of a proton and $Q$ a constant for a given nucleus (e.g. Duer, 2004). Around $75 \%$ of all NMR active nuclides are quadrupole nuclides (Ashbrook, 2009). Quadrupole nuclides opposed to an outer magnetic field can have according to the $2 /+1$ law more than two energy level $m$ between which a nuclear spin transition with $\Delta m=1$ can happen (Fig. 10) (e.g. Kirkpatrick, 1988; Ashbrook, 2009). However, the nuclear spin transitions between the energy levels are only energetically non-equivalent and therefore distinguishable, if the nucleus is placed in an asymmetric environment with a symmetry less than that of a perfect sphere or octahedron etc., where the quadrupole moment of the nucleus can interact with an electric field gradient (EFG) $\boldsymbol{V}>\mathbf{0}$ (e.g. Fechtelkord, 2004) 


$$
V=\left[\begin{array}{ccc}
V_{x x} & 0 & 0 \\
0 & V_{y y} & 0 \\
0 & 0 & V_{z z}
\end{array}\right], \quad V_{z z} \geq V_{y y} \geq V_{x x}
$$

which is correlated with the asymmetry parameter $\boldsymbol{\eta}$ (e.g. Fechtelkord, 2004)

$$
\eta=\frac{V_{y y}-V_{x x}}{V_{z z}}, \quad 0 \leq \eta \leq 1
$$

The effect of the first-order quadrupole interaction on the energy $E[\mathrm{~J}]$ of an energy level $m$ depends on the electric field gradient $\left(V_{z z}=e q\right)$ and is usually described in terms of the quadrupole coupling constant $C_{q}[\mathrm{~Hz}]$, the quadrupole frequency $v_{q}[\mathrm{~Hz}]$, the nuclear spin I and the asymmetry parameter $\eta$ (e.g. Engelhardt and Michel, 1987; Fechtelkord, 2004; Duer, 2004)

$$
\begin{gathered}
C_{q}=\frac{e^{2} q Q}{h}, \text { eq }=V_{z z} \\
v_{q}=\frac{C_{q}}{4 I(2 I-1)} \\
E_{m}=v_{q} h\left(3 m^{2}-(I+(I+1)) \frac{1}{2}\left[\left(3 \cos ^{2} \theta-1\right)+\eta \cos 2 \varphi \sin ^{2} \theta\right],\right.
\end{gathered}
$$

with $\theta$ and $\varphi$ being polar angles that describe the orientation of a molecule relative to the applied field $B_{0}$. The quadrupole coupling constant and the asymmetry parameter increase with increasing asymmetry of the environment around the nuclei. Because of the multiplier ( $\left.3 \cos ^{2} \theta-1\right)$ in Eq. 19 it is possible to avoid the first-order quadrupole interaction by MAS. In addition, the first-order quadrupole interaction does not affect the energy difference of the central $-1 / 2$ to $+1 / 2$ transition, only that of the satellite transitions, which are normally not observed with the applied NMR spectroscopic methods in the present studies (e.g. Kirkpatrick, 1988). However, there is also a second-order quadrupole interaction, which can not be completely suppressed by MAS and affects the position of the central transition (e.g. Kirkpatrick, 1988; Stebbins, 1995; Duer, 2004).

A consequence of the second-order quadrupole interaction is that the frequency distribution observed in the NMR spectrum is no longer Gaussian or Gaussian-Lorentzian, but has a tail on the lower frequency flank, which is called 
quadrupole tail (Fig. 11). Therefore, the centre of gravity $\delta_{c g}$ of a peak for a certain environment of a quadrupole nucleus in the NMR spectrum is no longer equivalent to the isotropic chemical shift $\delta_{i s o}$ and is shifted to lower frequencies. The position of $\delta_{c g}$ depends on the quadrupole coupling constant $C_{q}$, the nuclear spin $I$, the asymmetry parameter $\eta$ and the Larmor frequency $v_{0}$ (Freude and Haase, 1993).

$$
\delta_{c g}=\delta_{\text {iso }}-\frac{10^{6}}{40} \cdot \frac{C_{q}^{2} \cdot\left(3+\eta^{2}\right)}{v_{0}^{2} \cdot I^{2} \cdot(2 I-1)^{2}} \cdot(I(I+1)-3 / 4)
$$

The Larmor frequency $v_{0}$ increases with increasing magnetic field and therefore, the difference between $\delta_{c g}$ and $\delta_{\text {iso }}$ and the additional width due to second-order quadrupole interaction $\boldsymbol{W}_{\boldsymbol{q}}$ become less with increasing magnetic field (Fig. 11).

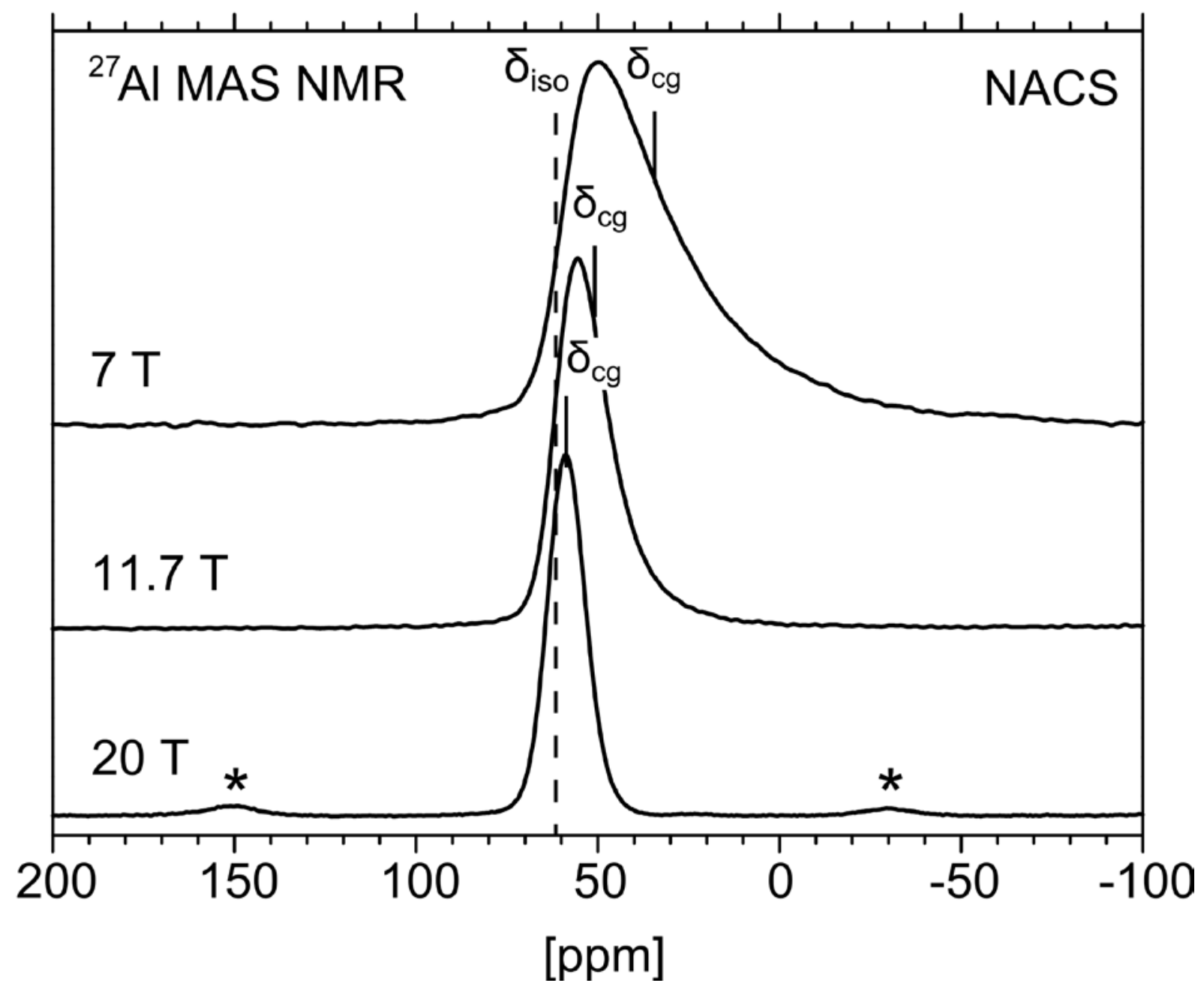

Fig. 11. ${ }^{27} \mathrm{Al}$ MAS NMR spectra of the peralkaline glass NACS at different magnetic fields (values in Tesla T). The dashed line indicates the isotropic chemical shift $\delta_{\text {iso }}$ and solid lines indicate the centres of gravity $\delta_{c g}$. The spinning sidebands are marked with an asterisk (data from Baasner et al. 2014a). 


\section{References}

Adam, G., Gibbs, J.H., 1965. On the temperature dependence of cooperative relaxation properties in glass-forming liquids. J. Chem. Phys. 43, 139-146.

Aiuppa, A., Baker, D.R., Webster, J.D., 2009. Halogens in volcanic systems. Chem. Geol. 263, 1-18.

Angell, C.A., 1991. Relaxation in liquids, polymers and plastic crystals - strong/fragile patterns and problems. J. Non-Cryst. Solids 131-133, 13-31.

Ashbrook, S.E., 2009. Recent advances in solid-state NMR spectroscopy of quadrupolar nuclei. Phys. Chem. Chem. Phys. 11, 6892-6905.

Baasner, A., Schmidt, B.C., Webb, S.L., 2013a. Compositional dependence of the rheology of halogen $(\mathrm{F}, \mathrm{Cl})$ bearing aluminosilicate melts. Chem. Geol. 346, 172-183.

Baasner, A., Schmidt, B.C., Webb, S.L., 2013b. The effect of chlorine, fluorine and water on the viscosity of aluminosilicate melts. Chem. Geol. 357, 134-149.

Baasner, A., Schmidt, B.C., Dupree, R., Webb, S.L., 2014a. Fluorine speciation as a function of composition in peralkaline and peraluminous $\mathrm{Na}_{2} \mathrm{O}-\mathrm{CaO}-\mathrm{Al}_{2} \mathrm{O}_{3}-\mathrm{SiO}_{2}$ glasses: $A$ multinuclear NMR study. Geochim. Cosmochim. Acta.

Baasner, A., Hung, I., Kemp, T.F., Dupree, R., Schmidt, B.C., Webb, S.L., 2014b. The incorporation mechanism of chlorine in peralkaline and peraluminous $\mathrm{Na}_{2} \mathrm{O}-\mathrm{CaO}-\mathrm{Al}_{2} \mathrm{O}_{3}-\mathrm{SiO}_{2}$ glasses. (in review).

Baker, D.R., Vaillancourt, J., 1995. The low viscosities of $\mathrm{F}+\mathrm{H}_{2} \mathrm{O}$-bearing granitic melts and implications for melt extraction and transport. Earth Planet. Sci. Lett. 132, 199-211.

Bartels, A., Behrens, H., Holtz, F., Schmidt, B.C., Fechtelkord, M., Knipping, J., Crede, L., Baasner, A., Pukallus, N., 2013. The effect of fluorine, boron and phosphorus on the viscosity of pegmatite forming melts. Chem. Geol. 346, 184-198.

Batchelor, G. K., 1967. An introduction to fluid dynamics. Cambridge University Press, Cambridge.

Bethe, H.A., Bacher, R.F., 1936. Nuclear Physics A. Stationary States of Nuclei. Rev. Mod. Phys. 8, 82-229.

Bogaard v.d., P., Schmincke, H.-U., 1985. Laacher See tephra: A widespread isochronous late Quaternary tephra layer in central and northern Europe. Geol. Soc. Am. Bull. 96, 1554-1571. 
Carroll, M.R., 2005. Chlorine solubility in evolved alkaline magmas. Ann. Geophys. 48, 619-631.

Dienes, G.J., Klemm, H.F., 1946. Theory and application of the parallel plate plastometer. J. Appl. Phys. 17, 458-471.

Dingwell, D.B., Hess, K.-U., 1998. Melt viscosities in the system Na-Fe-Si-O-Cl: Contrasting effects of $\mathrm{F}$ and $\mathrm{Cl}$ in alkaline melts. Am. Min. 83, 1016-1021.

Dingwell, D.B, Webb, S.L., 1989. Structural relaxation in silicate melts and non-Newtonian melt rheologie in geological processes. Phys. Chem. Minerals 16, 508-516.

Dingwell, D.B., Knoche, R., Webb, S.L, 1993. The effect of $\mathrm{P}_{2} \mathrm{O}_{5}$ on the viscosity of haplogranitic liquid. Eur. J. Mineral. 5, 133-140.

Dingwell, D.B., Scarfe, C.M., Cronin D.J., 1985. The effect of F on viscosities in the system $\mathrm{Na}_{2} \mathrm{O}-\mathrm{Al}_{2} \mathrm{O}_{3}-\mathrm{SiO}_{2}$ implications for phonolites, trachytes and rhyolites. Am. Mineral. 70, 80-87.

Duer, M.J., 2004. Introduction to solid-state NMR spectroscopy. Blackwell Publishing, Oxford.

Engelhardt, G., Michel, D., 1987. High-resolution solid-state NMR of silicates and zeolites. John Wiley \& Sons, Chichester.

Farnan, I., Stebbins, J.F., 1994. The nature of the glass transition in a silica-rich oxide melt. Science 265, 1206-1209.

Fechtelkord, M., 2004. Solid state NMR spectroscopy as supporting method in Rietveld structure refinements of rock-forming minerals: New developments and examples, in: Beran, A., Libowitzky, E. (Eds.), Spectroscopic methods in Mineralogy, EMU Notes in Mineralogy 6. Eötvös University Press, Budapest, pp. 421-463.

Freude, D., Haase, J., 1993. Quadrupole effects in solid state nuclear magnetic resonance, in: Diehl, P., Flunck, E., Günther, H., Kosfeld, R., Seelig, J. (Eds.), NMR basic principles and progress, Vol. 29. Springer, New York, pp. 1-90.

Fulcher, G.S., 1925. Analysis of recent measurements of the viscosity of glasses. J. Am. Ceram. Soc. 8, 339-355.

Gent, A.N., 1960. Theory of the parallel plate viscometer. Br. J. Appl. Phys. 11, 85-87.

Giordano, D., Dingwell, D.B., Romano, C., 2000. Viscosity of a Teide phonolite in the welding interval. J. Volcanol. Geotherm. Res. 103, 239-245.

Giordano, D., Romano, C., Dingwell, D.B., Poe, B., Behrens, H., 2004. The combined effects of water and fluorine on the viscosity of silicic magmas. Geochim. Cosmochim. Acta 68, 5159-5168. 
Giordano, D., Russell, J.K., Dingwell, D.B., 2008. Viscosity of magmatic liquids: A model. Earth Planet. Sci. Lett. 271, 123-134.

Gonnermann, H.G., Manga, M., 2013. Dynamics of magma ascent in the volcanic conduit, in: Fangents, S.A., Gregg, T.K.P., Lopes, R.M.C. (Eds.), Modelling volcanic processes: the physics and mathematics of volcanism. Cambridge University Press, Cambridge, pp. 55-85.

Harms, E., Schmincke, H.-U., 2000. Volatile composition of the phonolitic Laacher See magma (12,900 yr BP): implications for syn-eruptive degassing of $\mathrm{S}, \mathrm{F}, \mathrm{Cl}$ and $\mathrm{H}_{2} \mathrm{O}$. Contrib. Mineral. Petrol. 138, 84-98.

Hess, K.-U., Dingwell, D.B., Webb, S.L., 1995. The influence of excess alkalis on the viscosity of a haplogranitic melt. Am. Mineral. 80, 297-304.

Kirkpatrick, R.J., 1988. MAS NMR spectroscopy of minerals and glasses, in: Hawthorne, F.C. (Ed.), Spectroscopic methods in mineralogy and geology, Reviews in Mineralogy 18. Mineralogical Society of America, Washington D.C., pp. 341-429.

Liu, S.-B., Stebbins, J.F., Schneider, E., Pines, A., 1988. Diffusive motion in alkali-silicate melts: An NMR study at high temperature. Geochim. Cosmochim. Acta 52, 527-538.

Maxwell, J.C., 1867. On the dynamical theory of gases. Phil. Trans. R. Soc. 157, 49-88.

Moussallam, Y., Oppenheimer, C., Scaillet, B., Kyle, P.R., 2013. Experimental phase-equilibrium constraints on the phonolite magmatic system of Erebus volcano, Antartica. J. Petrol. 54, 1285-1307.

Papale, P., 1999. Strain-induced magma fragmentation in explosive eruptions. Nature 397, 425-428.

Pocklington, H.C., 1940. Rough measurements of high viscosities. Proc. Cambridge Phil. Soc. 36, 507-508.

Proussevitch, A. A., Sahagian, D.L., Anderson, A.T., 1993. Dynamics of diffusive bubble growth in magmas: Isothermal case. J. Geophys. Res. 98, 22283-22307.

Reynolds, O., 1886. On the theory of lubrication and its application to Mr. Beauchamp Tower's experiments, including an experimental determination of the viscosity of olive oil. Phil. Trans. R. Soc. 177, 157-234.

Richet, P., 1984. Viscosity and configurational entropy of silicate melts. Geochim. Cosmochim. Acta 48, 471-483.

Richet, P., Bottinga, Y., 1995. Rheology and configurational entropy of silicate melts, in: Stebbins, 
J.F., McMillan, P.F., Dingwell, D.B. (Eds.), Structure, dynamics and properties of silicate melts. Reviews in Mineralogy 32, Mineralogical Society of America, pp. 67-93.

Rolandi, G., Mastrolorenzo, G., Barrella, A.M., Borrelli, A., 1993. The Avellino plinian eruption of Somma-Vesuvius (3760 y. B.P.): the progressive evolution from magmatic to hydromagmatic style. J. Volcanol. Geoth. Res. 58, 67-88.

Romano, C., Giordano, D., Papale, P., Mincione, V., Dingwell, D.B., Rosi, M., 2003. The dry and hydrous viscosities of alkaline melts from Vesuvius and Phlegrean fields. Chem. Geol. 202, 23-38.

Rubin, A.,1995. Propagation of magma-filled cracks. Annu. Rev. Earth Planet. Sci. 23, 287-336.

Schaller T., Dingwell, D.B., Keppler, H., Knöller, W., Merwin, L., Sebald, A., 1992. Fluorine in silicate glasses: A multinuclear magnetic resonance study. Geochim. Cosmochim. Acta $56,701-707$

Shaw, H.R., 1963. Obsidian- $\mathrm{H}_{2} \mathrm{O}$ viscosities at 1000 and 2000 bars in the temperature range $700^{\circ}$ to $900^{\circ} \mathrm{C}$. J. Geophys. Res. $68,6337-6343$.

Signorelli, S., Carroll, M.R., 2000. Solubility and fluid-melt partitioning of $\mathrm{Cl}$ in hydrous phonolitic melts. Geochim. Cosmochim. Acta, 64, 2851-2862.

Sigurdsson, H., Cashdollar, S., Sparks, S.R.J., 1982. The eruption of Vesuvius in A.D. 79: Reconstruction from historical and volcanological evidence. Am. J. of Archaeol. 86, 39-51.

Sparks, R.S.J., Barclay, J., Jaupart, C., Mader, H.M., Phillips, J.C., 1994. Physical aspects of magmatic degassing I. Experimental and theoretical constraints on vesiculation, in: Carroll, M.R., Holloway, J.R. (Eds.), Volatiles in Magmas, Reviews in Mineralogy 30. Mineralogical Society of America, Washington D.C., pp. 413-445.

Stebbins, J.F., 1995. Dynamics and structure of silicate and oxide melts: nuclear magnetic resonance studies, in: Stebbins, J.F., McMillan, P.F., Dingwell, D.B. (Eds.), Structure, dynamics and properties of silicate melts, Reviews in Mineralogy 32. Mineralogical Society of America, Washington D.C., pp. 191-246.

Stebbins, J.F., Zeng, Q., 2000. Cation ordering at fluoride sites in silicate glasses: a high-resolution ${ }^{19}$ F NMR study. J. Non-Cryst. Solids 262, 1-5.

Tamman, G., Hesse, W., 1926. Die Abhängigkeit der Viscosität von der Temperatur bei unterkühlten Flüssigkeiten. ZAAC 156, 245-257.

Toplis, M.J., Dingwell, D.B., Lenci, T., 1997. Peraluminous viscosity maxima in $\mathrm{Na}_{2} \mathrm{O}-\mathrm{Al}_{2} \mathrm{O}_{3}-\mathrm{SiO}_{2}$ liquids: The role of triclusters in tectosilicate melts. Geochim. Cosmochim. Acta 61, 2605-2612. 
Vigneresse, J.L., Clemens, J.D., 2000. Granitic magma ascent and emplacement: neither diapirism nor neutral buoyancy. Geological Society, London, Special Publications 174, 1-19.

Vogel, H., 1921. Temperaturabhängigkeitsgesetz der Viskosität von Flüssigkeiten. Phys. Z. 22, 645-646.

Weast, R.C., 1972. Handbook of physics and chemistry. CRC Press, Cleveland.

Webb, S.L., Dingwell, D.B., 1995. Viscoelasticity, in: Stebbins, J.F., McMillan, P.F., Dingwell, D.B. (Eds.), Structure, dynamics and properties of silicate melts, Reviews in Mineralogy 32. The Mineralogical Society of America, Washington D.C., pp. 95-119.

Whittington, A.G., Hellwig, B.M., Behrens, H., Joachim, B., Stechern, A., Vetere, F., 2009. The viscosity of hydrous dacitic liquids: implications for the rheology of evolving silicic magmas. Bull. Vocanol. 71, 185-199.

Wilson, S.J., Poole, D., 1990. Glass viscosity measurement by parallel plate rheometry. Mat. Res. Bull. 25, 113-118.

Zeeman, P., 1896. Ueber einen Einfluss der Magnetisierung auf die Natur des von einer Substanz emittirten Lichtes. Verhandlungen der Physikalischen Gesellschaft zu Berlin 7, 127-130. 


\section{Compositional dependence of the rheology of halogen $(\mathrm{F}, \mathrm{Cl})$ bearing aluminosilicate melts}

Amrei Baasner, Burkhard C. Schmidt \& Sharon L. Webb

Published in 2013 in Chemical Geology 346, 172-183

\section{Graphical abstract}

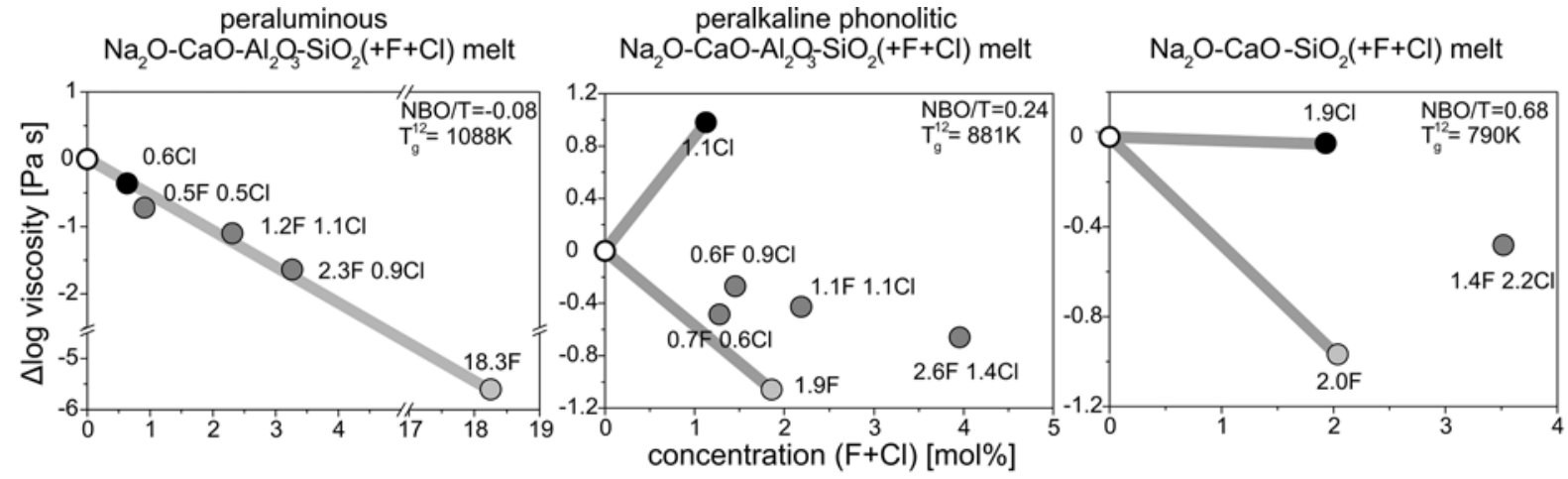

The change in viscosity by addition of fluorine and chlorine to different silicate melts. Viscosity measurements were done with micropenetration and parallel plate technique. The numbers ( $\mathrm{X} \mathrm{F} \mathrm{Y} \mathrm{Cl)} \mathrm{near} \mathrm{to} \mathrm{the} \mathrm{data} \mathrm{points} \mathrm{show} \mathrm{the}$ concentration of fluorine and chlorine in $\mathrm{mol} \%$. 


\section{Credits}

The scientific work and the writing for the publication

Baasner, A., Schmidt, B.C., Webb, S.L., 2013a. Compositional dependence of the rheology of halogen $(\mathrm{F}, \mathrm{Cl})$ bearing aluminosilicate melts. Chem. Geol. 346, 172-183.

\section{was conducted by}

\section{Amrei Baasner}

o Synthesis of the glasses containing both, $\mathrm{F}$ and $\mathrm{Cl}$, at 1 atm

- Electron microprobe analysis

o Density measurements

o IR spectroscopy

o Viscosity measurements with the micropenetration technique of the samples that contain both, $\mathrm{F}$ and $\mathrm{Cl}$.

o Development of the viscosity measurements with the parallel plate technique

o The evaluation of the above mentioned data

o Figures (except Fig. 2), tables and most of the text

- A significant part of the ideas presented in the discussion and conclusion section

Burkhard C. Schmidt

- General laboratory trouble shooting and support

o Some of the ideas presented in the discussion and conclusion section

o Correction and improvement of the figures, tables and text

Sharon L. Webb

0 Synthesis of the glasses containing either $\mathrm{F}$ or $\mathrm{Cl}$ at 1 atm and all $\mathrm{Na}_{2} \mathrm{O}-\mathrm{CaO}-\mathrm{SiO}_{2}$ glasses

- Viscosity measurements with the micropenetration technique of the samples mentioned above

o Heat capacity measurements

o The evaluation of the above mentioned data

- Figure 2 and some parts of the text concerning heat capacity

- A significant part of the ideas presented in the discussion and conclusion section

o Correction and improvement of the figures, tables and text 


\section{Abstract}

The rheology of three melt compositions containing different amounts of fluorine (F) and chlorine (Cl) or both was investigated with micropenetration and parallel-plate techniques. The heat capacity and configurational entropy of the melts were also determined. The observed viscosity range is between $10^{5.5}$ and $10^{13} \mathrm{Pas}$. The melts were produced in a $1 \mathrm{~atm}$ furnace at temperatures between 1523 and $1923 \mathrm{~K}$ using oxide and carbonate compounds. The halogens were incorporated using halides and halogen-bearing ammonium compounds. The first composition is a peraluminous $\mathrm{Na}_{2} \mathrm{O}-\mathrm{CaO}-\mathrm{Al}_{2} \mathrm{O}_{3}-\mathrm{SiO}_{2}$ melt (ANCS) with an apparent NBO/T of $\sim-0.08$, the second composition is a peralkaline $\mathrm{Na}_{2} \mathrm{O}-\mathrm{CaO}-\mathrm{Al}_{2} \mathrm{O}_{3}-\mathrm{SiO}_{2}$ melt (NACS) $(\mathrm{NBO} / \mathrm{T}=\sim 0.24)$, which is an analogue for phonolites, and the third is an aluminium-free $\mathrm{Na}_{2} \mathrm{O}-\mathrm{CaO}-\mathrm{SiO}_{2}$ melt (NCS) (NBO/T of $\sim 0.68$ ). Five halogen-bearing ANCS melts with up to $1.10 \mathrm{~mol} \% \mathrm{Cl}$ and $18.25 \mathrm{~mol} \% \mathrm{~F}, 6$ halogen-bearing NACS melts with up to $1.38 \mathrm{~mol} \% \mathrm{Cl}$ and $2.58 \mathrm{~mol} \% \mathrm{~F}$ and 3 halogen-bearing NCS melts with up to $2.15 \mathrm{~mol} \% \mathrm{Cl}$ and $2.04 \mathrm{~mol} \% \mathrm{~F}$ were investigated in this study.

Fluorine was found to decrease the viscosity for all compositions, but not with equal strength. Interpolated to $1 \mathrm{~mol} \%, \mathrm{~F}$ decreases the viscosity by $0.31 \pm 0.08$ log units in the peraluminous melt (ANCS), $0.57 \pm 0.11 \log$ units in the peralkaline melt (NACS) and $0.47 \pm 0.14$ log units in the NCS melt.

The effect of $\mathrm{Cl}$ on rheology depends on the melt composition. Interpolated to $1 \mathrm{~mol} \%, \mathrm{Cl}$ decreases the viscosity by $0.57 \pm 0.13$ log units in the peraluminous melt, but increases viscosity by $0.87 \pm 0.10 \log$ units in the peralkaline melt. There is no measurable effect on viscosity due to the addition of chlorine to the aluminium-free melt.

In the peraluminous melts the effects of $\mathrm{F}$ and $\mathrm{Cl}$ add almost linearly to decrease viscosity. In the peralkaline melts, $\mathrm{Cl}$ increases the viscosity while $\mathrm{F}$ decreases it, if both are present, the effects appear to balance each other; resulting in no change in viscosity for the addition of equal amounts (in mol\%) of fluorine and chlorine. The results were obtained from samples with higher and more varied halogen contents than in the most previous studies, therefore they hold true for a wide range of concentrations of both elements and should be taken into account for modelling magmatic processes. 


\subsection{Introduction}

Phonolites are highly evolved alkaline, $\mathrm{SiO}_{2}$-undersaturated effusive rocks that are sometimes related to explosive sub-plinian and plinian volcanic eruptions - as in the case of Montana Blanca and Las Canadas (Tenerife) (e.g. Ablay et al. 1995; Bryan, 2006) or Vesuvius (Italy) (e.g. Sigurdsson et al. 1982; Rolandi, 1993). In general, phonolites are halogen-rich magmas that can contain up to $1.3 \mathrm{wt} \% \mathrm{~F}$ and up to $1.2 \mathrm{wt} \% \mathrm{Cl}$. The maximum $\mathrm{F}$ content is less than in evolved rhyolites ( $7 \mathrm{wt} \%)$, but the maximum $\mathrm{Cl}$ content is more than in any other magmatic rock (Aiuppa et al., 2009).

Several studies on the influence of $F$ on the viscosity of different silicate melt compositions show, that $\mathrm{F}$ alone and in combination with water decreases the melt viscosity (e.g. Dingwell et al., 1985; Dingwell and Hess, 1998; Giordano et al., 2004). There are, however, few studies of the effect of $\mathrm{Cl}$ alone and combined with $\mathrm{F}$, on the rheology of silicate melts with relevance to magmatic systems. Dingwell and Hess (1998) found that in Na-Fe-Si-O melts $\mathrm{Cl}$ decreases the viscosity slightly in the high viscosity range and increases the viscosity slightly in the low viscosity range $\left(<10^{3} \mathrm{~Pa} \mathrm{~s}\right)$. Zimova and Webb (2006) found, that the influence of $\mathrm{Cl}$ in the $\mathrm{Na}_{2} \mathrm{O}-\mathrm{Fe}_{2} \mathrm{O}_{3}-\mathrm{Al}_{2} \mathrm{O}_{3}-\mathrm{SiO}_{2}$ system depends on composition: with $\mathrm{Cl}$ decreasing the viscosity of the peraluminous melts (with up to $0.12 \mathrm{~mol} \% \mathrm{Cl}$ ) and increasing the viscosity of peralkaline melts (up to 1.08 mol\% Cl). Zimova and Webb (2007) found in the same melts, that $\mathrm{F}$ and $\mathrm{Cl}$ combined causes viscosity to decrease in the peralkaline melts (up to $0.55 \mathrm{~mol} \% \mathrm{Cl}$ and $1.32 \mathrm{~mol} \% \mathrm{~F}$ ) and increases slightly in the peraluminous melts (up to $0.13 \mathrm{~mol} \% \mathrm{Cl}$ and $1.2 \mathrm{~mol} \% \mathrm{~F}$ ).

In this study we focus on the effect of $\mathrm{Cl}$ and $\mathrm{F}$ and their combination on the rheology of peralkaline $\mathrm{Na}_{2} \mathrm{O}-\mathrm{CaO}-\mathrm{Al}_{2} \mathrm{O}_{3}-\mathrm{SiO}_{2}$, melts as an analogue system for phonolites as well as peraluminous $\mathrm{Na}_{2} \mathrm{O}-\mathrm{CaO}-\mathrm{Al}_{2} \mathrm{O}_{3}-\mathrm{SiO}_{2}$ melts and simple $\mathrm{Na}_{2} \mathrm{O}-\mathrm{CaO}-\mathrm{SiO}_{2}$ melts. The peralkaline $\mathrm{Na}_{2} \mathrm{O}-\mathrm{CaO}-\mathrm{Al}_{2} \mathrm{O}_{3}-\mathrm{SiO}_{2}$ melts were created as a simple analogue to the composition of the 79 AD eruption of Vesuvius (Signorelli and Caroll, 2000). We replaced in the composition all divalent cations by calcium and all monovalent cations by sodium. This simplification was done to minimise factors that could create additional effects on rheology overlapping with those of fluorine and chlorine, for 
example oxidation state and the coordination of iron. As it is expected from the literature cited above that the effect of fluorine and chlorine depends on the ratio of network-modifying cations (e.g. sodium and calcium) to aluminium, we also investigated a peraluminous counterpart to the Vesuvius analogue and a simple aluminium-free sample series for comparison. The peraluminous melts have up to 10 times and the peralkaline melts have up to 2 times the $\mathrm{Cl}$ content of the Zimova and Webb (2007) study.

\subsection{Methods}

\subsubsection{Starting Materials}

Halogen-free peralkaline (NACS) and peraluminous (ANCS) $\mathrm{Na}_{2} \mathrm{O}-\mathrm{CaO}-\mathrm{Al}_{2} \mathrm{O}_{3}-\mathrm{SiO}_{2}$ and aluminium-free $\mathrm{Na}_{2} \mathrm{O}-\mathrm{CaO}-\mathrm{SiO}_{2}$ (NCS) glasses were made from oxide and carbonate powders in a 1 atm $\mathrm{MoSi}_{2}$ furnace in $\mathrm{Pt}_{90} \mathrm{Rh}_{10}$ crucibles at temperatures between 1523 and $1923 \mathrm{~K}$ for $1-7 \mathrm{~h}$. The powder mixtures had been previously decarbonated at $1173 \mathrm{~K}$ for $12 \mathrm{hrs}$. The peraluminous melts had with approximately $1873 \mathrm{~K}$ the highest liquidus temperature while the NACS and NCS melts were already molten around $1473 \mathrm{~K}$. We wanted to produce bubble-free glasses. The loss of bubbles increases with increasing temperature due to lower melt viscosity and a longer resident time in the furnace gave the bubbles more time to move out. However, too high temperatures or too long time in the furnace favoured the depletion of elements like halogens and sodium. Therefore, a time-temperature combination was chosen individually for each composition, depending on its assumed viscosity-temperature behaviour. Because with Pt-crucibles we were limited to a maximum temperature of $1923 \mathrm{~K}$, the peraluminous ANCS melts stayed, in general, longer in the furnace than the other compositions.

For the NACS and NCS melts the halogens were added by mixing crushed halogen-free glass and the ammonium compounds $\mathrm{NH}_{4} \mathrm{~F}$ and $\mathrm{NH}_{4} \mathrm{Cl}$. We used 3 times more $\mathrm{NH}_{4} \mathrm{Cl}$ and 2 times more $\mathrm{NH}_{4} \mathrm{~F}$ than the aspired amount of chlorine and fluorine, because a major part of the chemicals decomposed and degassed during heating of the crushed glass and chemicals. We found that in peraluminous melts the use of ammonium compounds is even less effective, presumably due to the higher liquidus temperatures of the melts. Therefore the halogen-bearing ANCS glasses 
were produced by mixing together oxide, carbonate and halide compounds $(\mathrm{NaCl}$, $\mathrm{NaF}, \mathrm{CaF}_{2}$ and $\mathrm{CaCl}_{2}$ ). All glasses were crushed and remelted several times in order to produce a homogeneous final product.

The composition of the glasses (see Table 1a and 1b) was analysed on 8 - 10 spots per sample with a JEOL JXA-8900RL electron microprobe (EMP) using a $30 \mu \mathrm{m}$ beam at $15 \mathrm{kv}$ and $15 \mathrm{nA}$. The halogen-free samples have NBO/T values of -0.08 (ANCS), 0.24 (NACS) and 0.68 (NCS). NBO/T is the number of non-bridging oxygens per tetrahedron. NBO/T can be calculated from the amount of oxygens $(\mathrm{O})$ in atom\% (Table $1 \mathrm{~b}$ ) and the number of tetrahedrally coordinated atoms like Si and $\mathrm{Al}(\mathrm{T})$ with the following equation based on a description of Mysen (1987): NBO/T = (2O - 4T)/T. Normally NBO/T ranges from 4 in an ideal fully depolymerised melt to 0 in an ideal fully polymerised melt, where each corner of a tetrahedron is connected to another tetrahedron. In peraluminous melts, that are assumed to be completely polymerised, NBO/T would be zero, but because of the excess of aluminium compared to charge-balancing cations like sodium and calcium the equation gives a negative value for NBO/T. We additionally provide in Table $1 \mathrm{a}$ the ratio $Y=\left(\mathrm{Na}_{2} \mathrm{O}+\mathrm{CaO}\right) /\left(\mathrm{Na}_{2} \mathrm{O}+\mathrm{CaO}+\mathrm{Al}_{2} \mathrm{O}_{3}\right)$ in mole fraction, which is also indicator for the degree of polymerisation of the melt by taking into account the number of sodium and calcium that is either used for charge-balancing aluminium or creating non-bridging oxygens in the melt (e.g. Toplis et al., 1997a; Webb et al., 2007). The peraluminous melts (ANCS) have a $\left(\mathrm{Na}_{2} \mathrm{O}+\mathrm{CaO}\right) /\left(\mathrm{Na}_{2} \mathrm{O}+\mathrm{CaO}+\mathrm{Al}_{2} \mathrm{O}_{3}\right)$ ratio $\gamma$ of $0.41 \pm 0.03$ and the peralkaline melts (NACS) have a $\gamma$ of $0.65 \pm 0.01$. Although up to $80 \%$ of the $\mathrm{F}$ and $\mathrm{Cl}$ added to the glasses was lost during the melting process, the final products contained up to $1.4 \mathrm{~mol} \% \mathrm{Cl}$ and $2.6 \mathrm{~mol} \% \mathrm{~F}$ in the NACS melt, $1.1 \mathrm{~mol} \% \mathrm{Cl}$ and $18.3 \mathrm{~mol} \% \mathrm{~F}$ in the ANCS melt and $2.2 \mathrm{~mol} \% \mathrm{Cl}$ and $2.0 \mathrm{~mol} \% \mathrm{~F}$ in the NCS melt. We were not able to detect any nitrogen remaining from the use of ammonium compounds with the EMP (detection limit $\sim 0.3 \mathrm{~mol} \%$ ) in the NACS melts.

The bubble content of the glasses ( 0 - 3 vol\%) was estimated by optical microscopy. Sample NACS $1.1 \mathrm{~F} 1.1 \mathrm{Cl}$ was the only sample with a bubble content of $3 \mathrm{vol} \%$. The other samples contained less or no bubbles. The size of most bubbles ranged between 0.1 and $1 \mathrm{~mm}$ in diameter. Water content of the nominally dry glasses was determined by FTIR, with a Perkin Elmer FTIR 2000, using the Paterson method (Paterson, 1982) and the method by Stolper (1982) with a molar absorptivity of 
$67 \mathrm{I} \mathrm{mol}^{-1} \mathrm{~cm}^{-1}$ on the fundamental $\mathrm{OH}$ stretching vibration $\left(3550 \mathrm{~cm}^{-1}\right)$ in MIR-spectra. For both methods the thickness of the polished samples $(\sim 0.8-1.1 \mathrm{~mm})$ was measured with a digital micrometer $( \pm 0.003 \mathrm{~mm}$ precision). To calculate the water content in ppm the densities of the samples (Table 2) are required, which were determined with the Archimedean method in ethanol. A general trend was observed, that with increasing halogen content density decreases. In Table 2 the water content of the NACS and ANCS samples for both methods is given. The water contents of the samples lay between 24 and 444 ppm (wt) or 27 and 415 ppm (wt) using the method of Paterson (1982) or Stolper, (1982), respectively. The difference between the water contents from the two methods is always within the error. NACS melts show a water increase with increasing halogen content from (190 - 444 ppm).

\subsubsection{Micropenetration viscometry}

The micropenetration method was used to determine viscosities over the range $10^{8.5}-10^{13} \mathrm{~Pa} \mathrm{~s}$. The principle is to push a single crystal sapphire sphere with known diameter into the sample at a fixed temperature and applied force. The micropenetration measurements were performed in a Netzsch TMA 420 dilatometer. Either 1 or $2 \mathrm{~mm}$ diameter $\mathrm{Al}_{2} \mathrm{O}_{3}$ spheres were used - depending upon the size of the melt sample. The applied force was between 0.1 and $10 \mathrm{~N}$. The measuring time lasts from 30 min to several hours. The samples were cored out glass cylinders with a diameter 6 - $8 \mathrm{~mm}$ that were sawed and polished to a thickness between 0.8 and $3 \mathrm{~mm}$.

From the dependence of the indent distance $/[\mathrm{m}]$ on time $t$ [s] for an applied force $F$ $\left[\mathrm{kg} \mathrm{m} \mathrm{s}^{-2}\right]$ and a sphere of radius $r[\mathrm{~m}]$ the viscosity $\eta$ [Pa s] was calculated after Pocklington (1940):

$$
\eta=\frac{0.1875 F t}{\sqrt{r} \sqrt{I^{3}}}
$$

The viscosity data are given in Table 3 . To determine the accuracy of the viscosity measurements, the standard glass DGG-1 was measured (see Table 3 and Fig. 1) 
and the results were compared with the standard viscosity values (Meerlender, 1974). The standard deviation of the residuals of the measurements was \pm 0.08 log units.

\subsubsection{Parallel plate viscometry}

The parallel plate method was used to determine viscosities between $10^{5.5} \mathrm{~Pa}$ s and $10^{9} \mathrm{~Pa} \mathrm{~s}$. The principle of the parallel plate method is to compress a cylinder between two parallel ceramic plates under an applied force. This can be done at a constant temperature or while heating at a constant rate (e.g. Wilson and Poole, 1990). Here the constant heating rate method was used.

Glass cylinders of $4-6 \mathrm{~mm}$ height and $6 \mathrm{~mm}$ diameter were cored out, sawed and then carefully polished, such that the flat surfaces were parallel to better than $\pm 0.015 \mathrm{~mm}$. The diameter and height of the cylinders were measured with $\mathrm{a}$ micrometer $( \pm 0.003 \mathrm{~mm}$ precision). A glass cylinder was placed between two polished $\mathrm{Al}_{2} \mathrm{O}_{3}$ plates (8 $\mathrm{mm}$ diameter and $5 \mathrm{~mm}$ high) with $50 \mu \mathrm{m}$ Pt foil between the glass sample and each plate. This sandwich was placed under the alumina push-rod in the Netzsch TMA 420 dilatometer and heated to a viscosity of $10^{12}-10^{10} \mathrm{~Pa}$ at $10 \mathrm{~K} \mathrm{~min}^{-1}$. Once the minimum temperature of interest was reached, the heating rate was reduced to $2.5 \mathrm{~K} \mathrm{~min}^{-1}$, and a force of $0.2-0.5 \mathrm{~N}$ was applied. A maximum compression length of $2500 \mu \mathrm{m}$ was used. Every second one data point was acquired. The measuring time was $\sim 1 \mathrm{~h}$. The data obtained is the change in height $h$ [m] of the cylinder as a function of time $t[\mathrm{~s}]$ and temperature $T[\mathrm{~K}]$ for the applied force $F\left[\mathrm{~kg} \mathrm{~m} \mathrm{~s}^{-2}\right]$ and the volume of the cylinder $V\left[\mathrm{~m}^{3}\right]$. For the calculation of viscosity, the extra weight of the ceramic push-rod $(6.1 \mathrm{~g})$ and the upper corundum plate $(1 \mathrm{~g})$ were taken into account. The viscosity $\eta$ was calculated with the "non-slip" equation (Dienes and Klemm, 1946; Gent, 1960):

$$
\eta=\frac{2 \pi F h^{5}}{3 V \frac{\partial h}{\partial t}\left(2 \pi h^{3}+V\right)}
$$

In principle there are two possible deformation modes during parallel plate deformation, requiring different data processing (e.g. Gent, 1960; Varshneya et al., 1990): "perfect slip" means the cylinder remains in its cylindrical shape and the radius and height change; while "non-slip" means friction between glass surface and the 
plates causes deformation of the cylinder to a barrel shape. It depends on the experimental assembly and the temperature range whether perfect slip, or non-slip conditions prevail. In the present experiments, every sample showed after measurement a barrel shape. Furthermore, parallel plate measurements of the standard glass DGG-1 (Fig. 1) processed with the "non-slip" equation agree with the standard values (Meerlender, 1974), with the standard deviation of the residuals of the measurements being \pm 0.06 log units.

\subsubsection{Calorimetry}

The measurements of the heat capacity of the glasses $C_{p g}$ and melts $C_{p l}$ as a function of temperature (for an example see Fig. 2) were done on polished glass cylinders that were $6 \mathrm{~mm}$ in diameter and $\sim 1.6 \mathrm{~mm}$ high in a Netzsch DSC 464C scanning calorimeter. The calorimeter was calibrated from the measurements of the heat capacity of a single crystal of $\mathrm{Al}_{2} \mathrm{O}_{3}$ and the data of Robie et al. (1978). The glass samples were heated at a rate of $20 \mathrm{~K} \mathrm{~min}^{-1}$ through the glass transition and into the temperature range of relaxed heat capacity-which occurs at a temperature equivalent to a viscosity of $\sim 10^{9} \mathrm{~Pa} \mathrm{~s}$. The configurational heat capacity $C_{p}{ }^{\text {conf }}$ was calculated from the difference between the relaxed liquid heat capacity and the glass heat capacity extrapolated to the same temperature as the relaxed liquid heat capacity. The glass heat capacity data at temperature above the glass transition were obtained by fitting the Maier-Kelley equation (Maier and Kelley, 1932) from $473 \mathrm{~K}$ to the beginning of the glass transition peak:

$$
C_{p g}=a+b T+c T^{-2}
$$

and then extrapolating with $T$ in $\mathrm{K}$ this equation to the required temperature. 


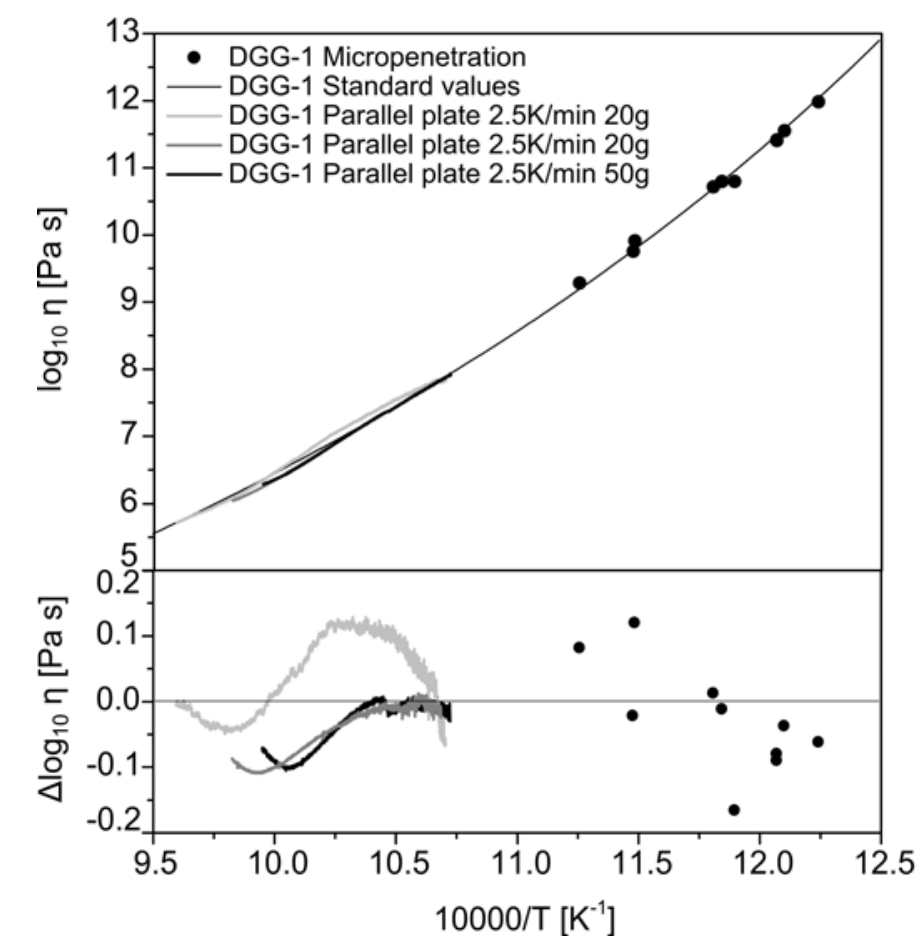

Fig. 1. Viscosity data for DGG-1 from micropenetration and parallel plate as function of inverse temperature (top) and their residuals (bottom) to the standard values.

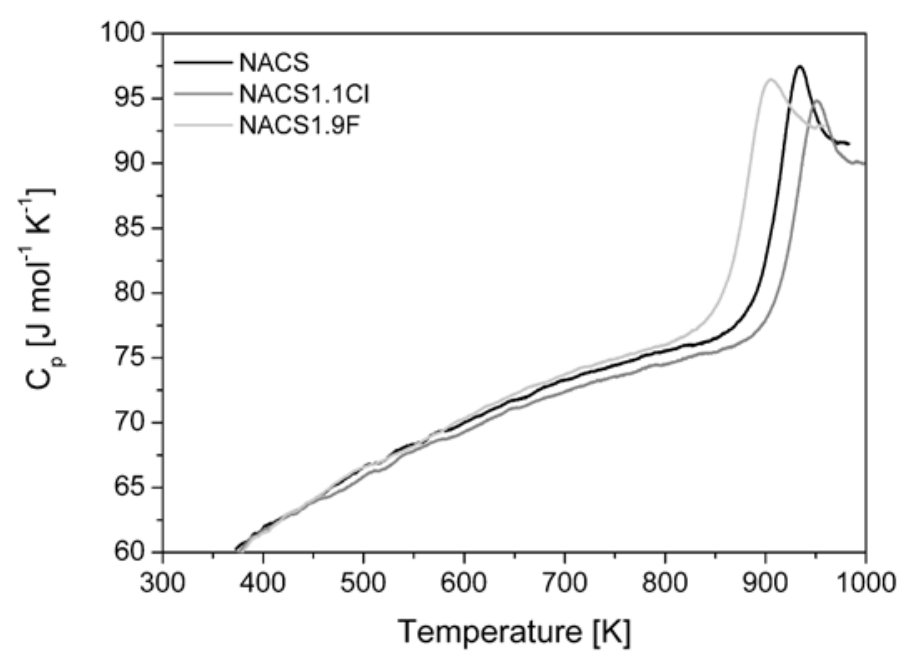

Fig. 2. Configurational heat capacity $C_{p}{ }^{\text {conf }}$ measurements as function of temperature for the peralkaline $\mathrm{Na}_{2} \mathrm{O}-\mathrm{CaO}-\mathrm{Al}_{2} \mathrm{O}_{3}-\mathrm{SiO}_{2}$ samples NACS, NACS 1.1 Cl and NACS 1.9F. 
Table 1a. Electron microprobe (EMP) analysis of the glass samples together with the standard deviation ( $\sigma)$ normalised to 100 mol\% ${ }^{a}$.

\begin{tabular}{|c|c|c|c|c|c|c|c|c|c|c|c|c|c|}
\hline & $\begin{array}{c}\mathrm{SiO}_{2} \\
\mathrm{~mol} \% \\
\end{array}$ & $\begin{array}{c}\sigma \\
\mathrm{mol} \% \\
\end{array}$ & $\begin{array}{l}\mathrm{Al}_{2} \mathrm{O}_{3} \\
\mathrm{~mol} \% \\
\end{array}$ & $\begin{array}{c}\Sigma \\
\mathrm{mol} \%\end{array}$ & $\begin{array}{c}\mathrm{CaO} \\
\mathrm{mol} \% \\
\end{array}$ & $\begin{array}{c}\Sigma \\
\mathrm{mol} \%\end{array}$ & $\begin{array}{l}\mathrm{Na}_{2} \mathrm{O} \\
\mathrm{mol} \% \\
\end{array}$ & $\begin{array}{c}\Sigma \\
\mathrm{mol} \%\end{array}$ & $\begin{array}{c}\mathrm{F}^{-} \\
\mathrm{mol} \% \\
\end{array}$ & $\begin{array}{c}\sigma \\
\mathrm{mol} \% \\
\end{array}$ & $\begin{array}{c}\mathrm{Cl}^{-} \\
\mathrm{mol} \% \\
\end{array}$ & $\begin{array}{c}\sigma \\
\mathrm{mol} \% \\
\end{array}$ & $\gamma^{b}$ \\
\hline NACS & 66.62 & 0.26 & 11.28 & 0.17 & 5.23 & 0.06 & 16.87 & 0.11 & - & - & - & - & 0.66 \\
\hline NACS $0.6 \mathrm{~F} 0.9 \mathrm{Cl}$ & 65.61 & 0.18 & 11.32 & 0.07 & 5.67 & 0.06 & 15.96 & 0.09 & 0.56 & 0.12 & 0.89 & 0.03 & 0.66 \\
\hline NACS $0.7 \mathrm{~F} 0.6 \mathrm{Cl}$ & 64.06 & 0.72 & 12.28 & 0.56 & 5.39 & 0.48 & 16.98 & 0.25 & 0.71 & 0.13 & 0.57 & 0.07 & 0.65 \\
\hline NACS $1.1 \mathrm{~F} 1.1 \mathrm{Cl}$ & 64.75 & 0.32 & 11.83 & 0.13 & 5.34 & 0.13 & 15.89 & 0.19 & 1.06 & 0.13 & 1.13 & 0.08 & 0.64 \\
\hline NACS $2.6 \mathrm{~F} 1.4 \mathrm{Cl}$ & 64.50 & 0.25 & 11.60 & 0.07 & 5.33 & 0.10 & 14.61 & 0.08 & 2.58 & 0.22 & 1.38 & 0.05 & 0.63 \\
\hline VNACS $1.1 \mathrm{Cl}$ & 65.96 & 0.20 & 11.73 & 0.10 & 5.61 & 0.09 & 15.57 & 0.13 & - & - & 1.13 & 0.01 & 0.64 \\
\hline NACS $1.9 F$ & 64.73 & 0.14 & 11.41 & 0.07 & 5.50 & 0.08 & 16.50 & 0.09 & 1.86 & 0.09 & - & - & 0.66 \\
\hline ANCS & 65.94 & 0.81 & 19.20 & 0.54 & 4.19 & 0.19 & 10.67 & 0.12 & - & - & - & - & 0.44 \\
\hline ANCS $0.5 \mathrm{~F} 0.5 \mathrm{Cl}$ & 66.40 & 0.82 & 19.06 & 0.60 & 3.81 & 0.20 & 9.82 & 0.07 & 0.46 & 0.12 & 0.45 & 0.07 & 0.42 \\
\hline ANCS $1.2 \mathrm{~F} 1.1 \mathrm{Cl}$ & 64.56 & 0.92 & 20.58 & 0.61 & 3.85 & 0.07 & 8.69 & 0.14 & 1.21 & 0.11 & 1.10 & 0.08 & 0.38 \\
\hline ANCS $2.3 \mathrm{~F} 0.9 \mathrm{Cl}$ & 62.84 & 0.68 & 21.25 & 0.57 & 4.06 & 0.13 & 8.58 & 0.06 & 2.34 & 0.12 & 0.92 & 0.04 & 0.37 \\
\hline ANCS $0.6 \mathrm{Cl}$ & 65.89 & 0.27 & 20.32 & 0.15 & 3.73 & 0.06 & 9.43 & 0.25 & - & - & 0.63 & 0.02 & 0.39 \\
\hline ANCS 18.3F & 53.12 & 0.27 & 16.26 & 0.09 & 3.11 & 0.09 & 9.27 & 0.07 & 18.25 & 0.21 & - & - & 0.43 \\
\hline NCS & 74.59 & 0.10 & - & - & 6.42 & 0.05 & 18.98 & 0.14 & - & - & - & - & - \\
\hline $\mathrm{NCS} 1.4 \mathrm{~F} 2.2 \mathrm{Cl}$ & 72.87 & 0.27 & - & - & 6.37 & 0.08 & 17.24 & 0.17 & 1.37 & 0.07 & 2.15 & 0.05 & - \\
\hline NCS $1.9 \mathrm{Cl}$ & 74.00 & 0.12 & - & - & 6.36 & 0.07 & 17.71 & 0.07 & - & - & 1.93 & 0.10 & - \\
\hline NCS 2.0F & 73.43 & 0.19 & - & - & 6.22 & 0.03 & 18.31 & 0.26 & 2.04 & 0.15 & - & - & - \\
\hline
\end{tabular}

a - Standards were: Wollastonite = Si, Ca; Anorthite = Al; Albite = Na, Topaz = F; Halite = Cl.; Sanidine = K. 8-10 spots on one sample per composition were

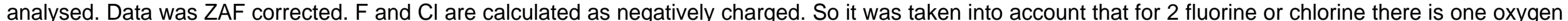

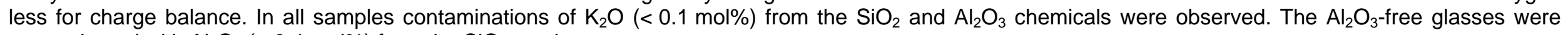
contaminated with $\mathrm{Al}_{2} \mathrm{O}_{3}(<0.4 \mathrm{~mol} \%)$ from the $\mathrm{SiO}_{2}$ used.

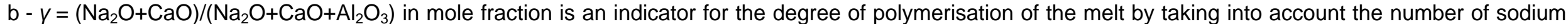
and calcium that is either used for charge balancing aluminium or creating non-bridging oxygens in the melt (e.g. Toplis et al., 1997a, Webb et al., 2007). 
Table 1b. Electron microprobe (EMP) analysis of the glass samples together with the standard deviation $(\sigma)$ normalised to 100 atom\% ${ }^{\mathrm{a}}$.

\begin{tabular}{|c|c|c|c|c|c|c|c|c|c|c|c|c|c|}
\hline & $\begin{array}{c}\mathrm{Si} \\
\text { at\% }\end{array}$ & $\begin{array}{c}\sigma \\
\text { at } \%\end{array}$ & $\begin{array}{c}\mathrm{Al} \\
\text { at\% }\end{array}$ & $\begin{array}{c}\sigma \\
\text { at\% }\end{array}$ & $\begin{array}{c}\mathrm{Ca} \\
\mathrm{at} \%\end{array}$ & $\begin{array}{c}\Sigma \\
\text { at } \%\end{array}$ & $\begin{array}{l}\mathrm{Na} \\
\mathrm{at} \%\end{array}$ & $\begin{array}{c}\Sigma \\
\text { at } \%\end{array}$ & $\begin{array}{c}\mathrm{F} \\
\text { at } \% \\
\end{array}$ & $\begin{array}{c}\sigma \\
\text { at } \% \\
\end{array}$ & $\begin{array}{c}\mathrm{Cl} \\
\text { at\% } \\
\end{array}$ & $\begin{array}{c}\sigma \\
\text { at } \% \\
\end{array}$ & $\begin{array}{l}\mathrm{O}^{\mathrm{b}} \\
\mathrm{at} \%\end{array}$ \\
\hline NACS & 20.99 & 0.08 & 7.11 & 0.11 & 1.65 & 0.02 & 10.63 & 0.07 & - & - & - & - & 59.62 \\
\hline NACS $0.6 \mathrm{~F} 0.9 \mathrm{Cl}$ & 20.94 & 0.06 & 7.22 & 0.05 & 1.81 & 0.02 & 10.19 & 0.06 & 0.18 & 0.04 & 0.28 & 0.01 & 59.38 \\
\hline NACS $0.7 \mathrm{~F} 0.6 \mathrm{Cl}$ & 20.27 & 0.23 & 7.78 & 0.36 & 1.71 & 0.15 & 10.75 & 0.16 & 0.23 & 0.04 & 0.18 & 0.02 & 59.09 \\
\hline NACS $1.1 \mathrm{~F} 1.1 \mathrm{Cl}$ & 20.70 & 0.10 & 7.56 & 0.08 & 1.71 & 0.04 & 10.16 & 0.12 & 0.34 & 0.04 & 0.36 & 0.02 & 59.18 \\
\hline NACS $2.6 \mathrm{~F} 1.4 \mathrm{Cl}$ & 20.94 & 0.08 & 7.53 & 0.05 & 1.73 & 0.03 & 9.49 & 0.05 & 0.84 & 0.07 & 0.45 & 0.02 & 59.02 \\
\hline NACS $1.1 \mathrm{Cl}$ & 20.94 & 0.06 & 7.45 & 0.06 & 1.78 & 0.03 & 9.88 & 0.08 & - & - & 0.36 & 0.00 & 59.59 \\
\hline NACS 1.9F & 20.70 & 0.04 & 7.30 & 0.05 & 1.76 & 0.02 & 10.56 & 0.06 & 0.60 & 0.03 & - & - & 59.09 \\
\hline ANCS & 19.73 & 0.24 & 11.49 & 0.32 & 1.25 & 0.06 & 6.38 & 0.07 & - & - & - & - & 61.14 \\
\hline ANCS $0.5 \mathrm{~F} 0.5 \mathrm{Cl}$ & 20.00 & 0.25 & 11.48 & 0.36 & 1.15 & 0.06 & 5.91 & 0.04 & 0.14 & 0.04 & 0.13 & 0.02 & 61.19 \\
\hline ANCS $1.2 \mathrm{~F} 1.1 \mathrm{Cl}$ & 19.47 & 0.28 & 12.42 & 0.36 & 1.16 & 0.02 & 5.25 & 0.09 & 0.37 & 0.03 & 0.33 & 0.02 & 61.01 \\
\hline ANCS $2.3 \mathrm{~F} 0.9 \mathrm{Cl}$ & 19.03 & 0.21 & 12.87 & 0.34 & 1.23 & 0.04 & 5.20 & 0.04 & 0.71 & 0.04 & 0.28 & 0.01 & 60.69 \\
\hline ANCS $0.6 \mathrm{Cl}$ & 19.65 & 0.08 & 12.12 & 0.09 & 1.11 & 0.02 & 5.62 & 0.15 & - & - & 0.19 & 0.01 & 61.31 \\
\hline ANCS 18.3F & 18.72 & 0.09 & 11.46 & 0.07 & 1.09 & 0.03 & 6.53 & 0.05 & 6.43 & 0.07 & - & - & 55.77 \\
\hline NCS & 25.41 & 0.04 & - & - & 2.19 & 0.02 & 12.93 & 0.09 & - & - & - & - & 59.47 \\
\hline $\mathrm{NCS} 1.4 \mathrm{~F} 2.2 \mathrm{Cl}$ & 25.58 & 0.09 & - & - & 2.24 & 0.03 & 12.11 & 0.12 & 0.48 & 0.02 & 0.75 & 0.02 & 58.84 \\
\hline $\mathrm{NCS} 1.9 \mathrm{Cl}$ & 25.62 & 0.04 & - & - & 2.20 & 0.02 & 12.27 & 0.05 & - & - & 0.67 & 0.04 & 59.24 \\
\hline NCS 2.0F & 25.44 & 0.07 & - & - & 2.15 & 0.01 & 12.69 & 0.18 & 0.71 & 0.05 & - & - & 59.02 \\
\hline
\end{tabular}

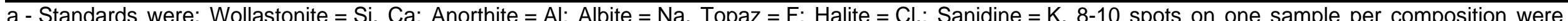

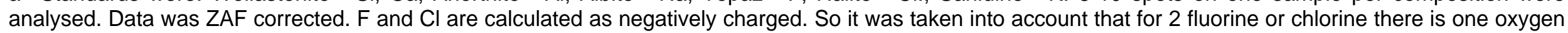

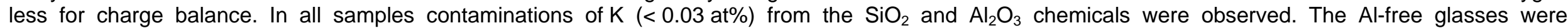
contaminated with $\mathrm{Al}(<0.3 \mathrm{at} \%)$ from the $\mathrm{SiO}_{2}$ used.

$\mathrm{b}$ - The number of oxygens was calculated from stoichiometry. 
Table 2. Density $\rho$ and water content $c\left(\mathrm{H}_{2} \mathrm{O}\right)$ of the glass samples.

\begin{tabular}{|c|c|c|c|c|c|c|}
\hline & $\begin{array}{c}\rho^{\mathrm{a}} \\
\mathrm{g} \mathrm{cm}^{-3}\end{array}$ & $\begin{array}{c}2 \sigma \\
\mathrm{g} \mathrm{cm}^{-3}\end{array}$ & $\begin{array}{c}\mathrm{C}\left(\mathrm{H}_{2} \mathrm{O}\right)^{\mathrm{b}} \\
\text { Paterson (1982) } \\
\text { ppm }^{\mathrm{c}}\end{array}$ & $\begin{array}{c} \pm \\
\mathrm{Ppm}\end{array}$ & $\begin{array}{c}c\left(\mathrm{H}_{2} \mathrm{O}\right)^{b} \\
\text { Stolper }(1982) \\
\text { ppm }\end{array}$ & $\begin{array}{c} \pm \\
\mathrm{ppm}\end{array}$ \\
\hline NACS & 2.472 & 0.001 & 190 & 20 & 180 & 19 \\
\hline NACS $0.6 \mathrm{~F} 0.9 \mathrm{Cl}$ & 2.467 & 0.007 & 261 & 29 & 246 & 25 \\
\hline NACS $0.7 \mathrm{~F} 0.6 \mathrm{Cl}$ & 2.467 & 0.007 & 254 & 27 & 237 & 33 \\
\hline NACS $1.1 \mathrm{~F} 1.1 \mathrm{Cl}$ & 2.455 & 0.004 & 342 & 35 & 320 & 33 \\
\hline NACS $2.6 \mathrm{~F} 1.4 \mathrm{Cl}$ & 2.454 & 0.002 & 444 & 45 & 415 & 44 \\
\hline NACS $1.1 \mathrm{Cl}$ & 2.463 & 0.004 & 168 & 20 & 165 & 17 \\
\hline NACS $1.9 F$ & 2.479 & 0.002 & 271 & 18 & 256 & 30 \\
\hline ANCS & 2.460 & 0.006 & 90 & 9 & 86 & 9 \\
\hline ANCS $0.5 \mathrm{~F} 0.5 \mathrm{Cl}$ & 2.458 & 0.013 & 113 & 11 & 107 & 11 \\
\hline ANCS $1.2 \mathrm{~F} 1.1 \mathrm{Cl}$ & 2.451 & 0.016 & 24 & 3 & 27 & 3 \\
\hline ANCS $2.3 \mathrm{~F} 0.9 \mathrm{Cl}$ & 2.446 & 0.011 & 68 & 7 & 65 & 7 \\
\hline ANCS $0.6 \mathrm{Cl}$ & 2.454 & 0.004 & 100 & 26 & 92 & 120 \\
\hline ANCS $18.3 \mathrm{~F}$ & 2.440 & 0.001 & 81 & 10 & 76 & 19 \\
\hline NCS & 2.461 & 0.004 & n.d $d^{d}$ & n.d & n.d & n.d \\
\hline $\mathrm{NCS} 1.4 \mathrm{~F} 2.2 \mathrm{Cl}$ & 2.440 & 0.006 & n.d & n.d & n.d & n.d \\
\hline $\mathrm{NCS} 1.9 \mathrm{Cl}$ & 2.443 & 0.004 & n.d & n.d & n.d & n.d \\
\hline NCS 2.0F & 2.459 & 0.002 & n.d & n.d & n.d & n.d \\
\hline & & $\begin{array}{l}\text { At leas } \\
3 \text { spec } \\
\text { ppm by } \\
\text { n.d. }=\end{array}$ & $\begin{array}{l}\text { asurements } \\
\text { compositio } \\
\text { ht } \\
\text { termined }\end{array}$ & sample & & \\
\hline
\end{tabular}

\subsection{Results}

\subsubsection{Micropenetration viscometry}

The micropenetration data are in Table 3. Figure 3A-D shows the micropenetration viscosity data as function of inverse temperature. Figure 3A presents an overview of the viscosity-temperature data of the halogen-free glasses for each composition. Figure 3B-D presents the viscosity-temperature data for the halogen-free and halogen-bearing melts of the peraluminous (ANCS) (Fig. 3B) and peralkaline (NACS) $\mathrm{Na}_{2} \mathrm{O}-\mathrm{CaO}-\mathrm{Al}_{2} \mathrm{O}_{3}-\mathrm{SiO}_{2}$ melts (Fig. 3C) and the $\mathrm{Na}_{2} \mathrm{O}-\mathrm{CaO}-\mathrm{SiO}_{2}$ (NCS) melts (Fig. 3D). The dependence of viscosity $\eta[\mathrm{Pas}]$ on temperature $T[\mathrm{~K}]$ for the micropenetration data was described with an Arrhenian equation with the fit parameters $A_{A r r}$ and $B_{A r r}$ (see Table 4):

$$
\log _{10} \eta=A_{A r r}+\frac{B_{A r r}}{T}
$$


Table 3. Micropenetration viscosity data $\eta$ for the peralkaline (NACS) and peraluminous (ANCS) $\mathrm{Na}_{2} \mathrm{O}-\mathrm{CaO}-\mathrm{Al}_{2} \mathrm{O}_{3}-\mathrm{SiO}_{2}$ melts, as well as the aluminium-free melts (NCS) and the standard melt DGG-1 at different temperatures $T$.

\begin{tabular}{|c|c|c|c|c|c|}
\hline $\begin{array}{l}T \\
\mathrm{~K}\end{array}$ & $\begin{array}{c}\log _{10} \eta \\
\mathrm{Pas}\end{array}$ & $\begin{array}{l}T \\
\mathrm{~K}\end{array}$ & $\begin{array}{c}\log _{10} \eta \\
\text { Pas }\end{array}$ & $\begin{array}{l}T \\
\mathrm{~K}\end{array}$ & $\begin{array}{c}\log _{10} \eta \\
\mathrm{Pas}\end{array}$ \\
\hline \multicolumn{2}{|c|}{ NACS } & \multicolumn{2}{|c|}{ NACS $0.6 \mathrm{~F} 0.9 \mathrm{Cl}$} & \multicolumn{2}{|c|}{ NACS $0.7 \mathrm{~F} 0.6 \mathrm{Cl}$} \\
\hline 873 & 12.27 & 865 & 12.26 & 863 & 12.09 \\
\hline 887 & 11.85 & 891 & 11.35 & 873 & 11.77 \\
\hline 911 & 10.84 & 917 & 10.66 & 882 & 11.40 \\
\hline 927 & 10.17 & 943 & 9.67 & 892 & 11.24 \\
\hline 935 & 10.03 & 969 & 9.00 & 897 & 11.08 \\
\hline \multirow[t]{4}{*}{959} & 9.25 & & & 906 & 10.63 \\
\hline & & & & 916 & 10.27 \\
\hline & & & & 944 & 9.59 \\
\hline & & & & 973 & 8.62 \\
\hline \multicolumn{2}{|c|}{ NACS $1.1 \mathrm{~F} 1.1 \mathrm{Cl}$} & \multicolumn{2}{|c|}{ NACS $2.6 \mathrm{~F} 1.4 \mathrm{Cl}$} & \multicolumn{2}{|c|}{ NACS $1.1 \mathrm{Cl}$} \\
\hline 860 & 12.28 & 865 & 12.38 & 897 & 12.42 \\
\hline 870 & 11.97 & 891 & 11.58 & 908 & 11.99 \\
\hline 886 & 11.36 & 917 & 10.58 & 918 & 11.63 \\
\hline 901 & 10.95 & 943 & 9.89 & 933 & 10.89 \\
\hline 938 & 9.74 & 969 & 9.31 & 943 & 10.62 \\
\hline 938 & 9.75 & & & 947 & 10.42 \\
\hline 963 & 9.18 & & & 963 & 9.90 \\
\hline \multirow[t]{3}{*}{964} & 9.22 & & & 975 & 9.69 \\
\hline & & & & 987 & 9.19 \\
\hline & & & & 996 & 9.08 \\
\hline \multicolumn{2}{|c|}{ NACS $1.9 \mathrm{~F}$} & \multicolumn{2}{|c|}{ ANCS } & \multicolumn{2}{|c|}{ ANCS $0.5 \mathrm{~F} 0.5 \mathrm{Cl}$} \\
\hline 841 & 12.58 & 1083 & 12.16 & 1054 & 12.25 \\
\hline 853 & 12.06 & 1121 & 11.16 & 1078 & 11.56 \\
\hline 866 & 11.36 & 1123 & 10.91 & 1102 & 10.87 \\
\hline 877 & 10.98 & 1140 & 10.57 & 1124 & 10.27 \\
\hline 882 & 10.87 & 1159 & 9.91 & 1126 & 10.27 \\
\hline 892 & 10.51 & 1178 & 9.55 & 1150 & 9.63 \\
\hline 898 & 10.23 & 1197 & 9.18 & 1169 & 9.28 \\
\hline 913 & 9.76 & & & & \\
\hline 923 & 9.56 & & & & \\
\hline 938 & 9.04 & & & & \\
\hline 952 & 8.78 & & & & \\
\hline
\end{tabular}


Table 3 (Continued). Micropenetration viscosity data $\eta$ for the peralkaline (NACS) and peraluminous (ANCS) $\mathrm{Na}_{2} \mathrm{O}-\mathrm{CaO}-\mathrm{Al}_{2} \mathrm{O}_{3}-\mathrm{SiO}_{2}$ melts, as well as the aluminium-free melts (NCS) and the standard melt DGG-1 at different temperatures $T$.

\begin{tabular}{|c|c|c|c|c|c|}
\hline $\begin{array}{l}T \\
\mathrm{~K}\end{array}$ & $\begin{array}{c}\log _{10} \eta \\
\mathrm{PaS}\end{array}$ & $\begin{array}{l}T \\
\mathrm{~K}\end{array}$ & $\begin{array}{c}\log _{10} \eta \\
\text { Pas }\end{array}$ & $\begin{array}{l}T \\
\mathrm{~K}\end{array}$ & $\begin{array}{c}\log _{10} \eta \\
\text { Pa s }\end{array}$ \\
\hline \multicolumn{2}{|c|}{ ANCS $1.2 \mathrm{~F} 1.1 \mathrm{Cl}$} & \multicolumn{2}{|c|}{ ANCS $2.3 \mathrm{~F} 0.9 \mathrm{Cl}$} & \multicolumn{2}{|c|}{ ANCS $0.6 \mathrm{Cl}$} \\
\hline 1040 & 12.25 & 1026 & 11.97 & 1068 & 12.35 \\
\hline 1059 & 11.74 & 1045 & 11.37 & 1093 & 11.46 \\
\hline 1078 & 11.22 & 1064 & 10.89 & 1128 & 10.38 \\
\hline 1116 & 10.08 & 1083 & 10.36 & 1149 & 10.03 \\
\hline 1135 & 9.68 & 1102 & 9.97 & 1153 & 9.77 \\
\hline 1135 & 9.66 & 1121 & 9.69 & 1174 & 9.53 \\
\hline \multirow[t]{2}{*}{1159} & 8.96 & 1121 & 9.67 & 1174 & 9.48 \\
\hline & & 1140 & 9.22 & 1194 & 9.09 \\
\hline \multicolumn{2}{|c|}{ ANCS 18.3F } & \multicolumn{2}{|c|}{ NCS } & \multicolumn{2}{|c|}{$\mathrm{NCS} 1.4 \mathrm{~F} 2.2 \mathrm{Cl}$} \\
\hline 824 & 12.30 & 772 & 12.97 & 757 & 13.01 \\
\hline 846 & 11.64 & 776 & 12.76 & 770 & 12.46 \\
\hline 849 & 11.65 & 788 & 12.11 & 778 & 12.07 \\
\hline 887 & 10.50 & 799 & 11.41 & 785 & 11.71 \\
\hline 907 & 10.18 & 813 & 10.85 & 797 & 11.08 \\
\hline \multirow[t]{7}{*}{928} & 9.52 & 824 & 10.40 & 810 & 10.55 \\
\hline & & 825 & 9.99 & 824 & 10.17 \\
\hline & & 840 & 9.82 & 836 & 9.67 \\
\hline & & 851 & 9.51 & 850 & 9.16 \\
\hline & & 856 & 9.32 & 863 & 8.81 \\
\hline & & 865 & 8.94 & & \\
\hline & & 882 & 8.59 & & \\
\hline \multicolumn{2}{|c|}{$\mathrm{NCS} 1.9 \mathrm{Cl}$} & \multicolumn{2}{|c|}{ NCS 2.0F } & \multicolumn{2}{|c|}{ DGG-1 } \\
\hline 780 & 12.57 & 754 & 12.68 & 817 & 11.98 \\
\hline 790 & 12.07 & 767 & 12.14 & 826 & 11.55 \\
\hline 794 & 11.57 & 780 & 11.43 & 829 & 11.40 \\
\hline 805 & 11.32 & 792 & 10.72 & 829 & 11.41 \\
\hline 805 & 11.20 & 793 & 10.99 & 841 & 10.79 \\
\hline 820 & 10.71 & 803 & 10.42 & 844 & 10.79 \\
\hline 825 & 10.60 & 816 & 9.92 & 847 & 10.71 \\
\hline 830 & 10.16 & 828 & 9.36 & 871 & 9.91 \\
\hline 847 & 9.72 & 842 & 8.96 & 871 & 9.75 \\
\hline 856 & 9.29 & 852 & 8.65 & 888 & 9.28 \\
\hline 868 & 9.04 & 855 & 8.74 & & \\
\hline 882 & 8.68 & & & & \\
\hline
\end{tabular}



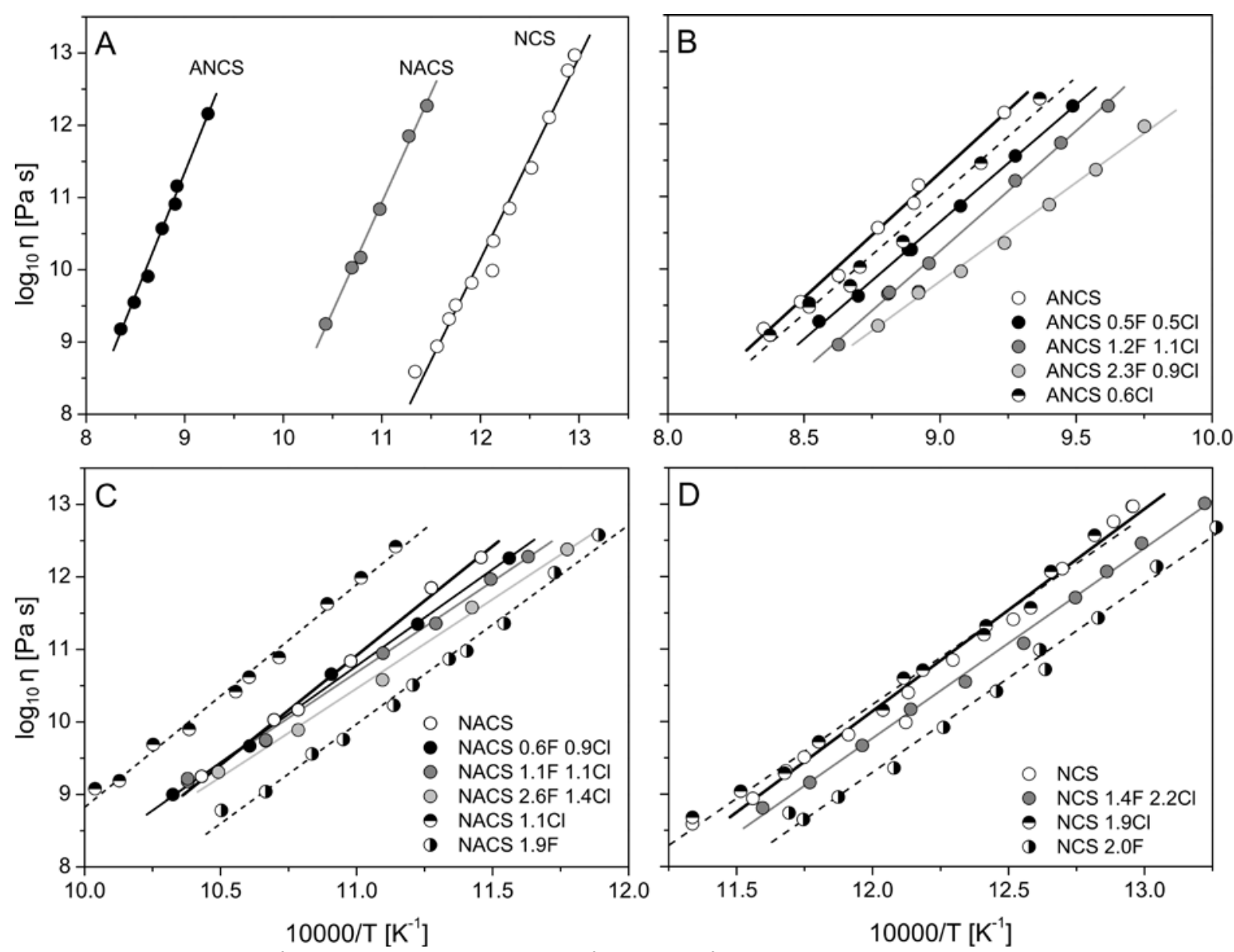

Fig. 3. Viscosity data from micropenetration as function of inverse temperature. The lines through the data are Arrhenian fits. The error of the temperature is $\pm 1 \mathrm{~K}$ and of the viscosity is \pm 0.08 log units. Fig. 3A provides an overview over the data of the halogen-free peraluminous (ANCS) and peralkaline (NACS) $\mathrm{Na}_{2} \mathrm{O}-\mathrm{CaO}-\mathrm{Al}_{2} \mathrm{O}_{3}-\mathrm{SiO}_{2}$ melts and the $\mathrm{Na}_{2} \mathrm{O}-\mathrm{CaO}-\mathrm{SiO}_{2}$ (NCS) melts. Fig. 3B-D show the data of the halogen-free and halogen-bearing $(+\mathrm{F} /+\mathrm{Cl}$ and $\mathrm{F}+\mathrm{Cl})$ samples for each composition (ANCS, NACS and NCS) separately. The data of the samples ANCS $18.3 \mathrm{~F}$ and NACS $0.7 \mathrm{~F} 0.6 \mathrm{Cl}$ where omitted for reasons of equal scaling and clarity. 
Figure 4 shows for each composition the change in viscosity as function of the sum of $\mathrm{F}$ and $\mathrm{Cl}$ relative to the viscosity of the halogen-free melt at its glass transition temperature $T_{g}{ }^{12}$ - the temperature at $\eta=10^{12 \mathrm{Pas}}$.

The viscosities of the halogen-bearing melts were calculated with the Eq. 4 for a constant temperature, $T_{g}{ }^{12}$ of the halogen-free melt, and then the viscosity difference to the halogen-free melt was determined.

$\mathrm{F}$ decreases the viscosity for all compositions. Interpolated to $1 \mathrm{~mol} \%, \mathrm{~F}$ decreases the viscosity by $\sim 0.31 \log$ units in the peraluminous melt (ANCS), $\sim 0.57$ log units in the peralkaline melt (NACS) and $\sim 0.47$ log units in the NCS melt. The effect of $\mathrm{Cl}$ on viscosity depends on the composition of the melt. Interpolated to $1 \mathrm{~mol} \%, \mathrm{Cl}$ decreases the viscosity by $\sim 0.57$ log units in ANCS, but increases viscosity by $\sim 0.87$ log units in NACS, while in NCS there is no measurable effect within error.

The addition of $\mathrm{F}+\mathrm{Cl}$ to the peraluminous ANCS melts causes an almost linear decrease in $\log _{10}$ viscosity as a function of $\mathrm{F}+\mathrm{Cl}$ (mol\%). The $\mathrm{F}+\mathrm{Cl}$ bearing peralkaline NACS melts also all have lower viscosities than the halogen-free melt, but their viscosities are not a simple function of the sum of the halogens. Even if the amount of total $\mathrm{F}+\mathrm{Cl}$ are very different in these melts, the change in viscosity is little: between the sample that contains the smallest amount of both halogens ( $1 \mathrm{~mol} \%$ - NACS 0.7F 0.6Cl) and that, which contains most ( 4 mol\% - NACS 2.6F $1.4 \mathrm{Cl}$ ), the viscosity difference is just $0.39 \pm 0.10 \mathrm{log}$ units. The sample NACS $2.6 \mathrm{~F} 1.4$ $\mathrm{Cl}$ has a $0.40 \pm 0.10 \mathrm{log}$ units higher viscosity than the F-bearing one NACS 1.9F despite the higher amount of fluorine and nearly double the amount of $\mathrm{F}+\mathrm{Cl}$. It seems that the viscosity-increasing effect of $\mathrm{Cl}$ and the viscosity-decreasing effect of $\mathrm{F}$ are balancing each other in these melts on a per mol basis.

The F+Cl-bearing NCS $1.4 \mathrm{~F} 2.2 \mathrm{Cl}$ melt has a lower viscosity than the halogen-free melt NCS. The decrease in viscosity $0.48 \pm 0.09$ log units is as high as it could be expected based on the viscosity decrease due to just fluorine. If the $\log _{10}$ viscosity changes of the samples NCS, NCS $1.42 .2 \mathrm{Cl}$ and NCS 2.0F would be plotted just as function of the F content, the samples would lie on one line (see also Fig. 4). The viscosity of the NCS melts is influenced by fluorine but not by chlorine.

Figure 5A-C shows $T_{g}{ }^{12}$ - the temperature at $\eta=10^{12}$ Pas - calculated from the Arrhenian equation as a function of the halogen content (Table 4 ). $T_{g}{ }^{12}$ on the $y$-axis 
has the advantage that the viscosity data are not extrapolated to temperatures, where no measurements were done - as in Fig. 3. On the other hand the viscosity information is not directly presented. To give an optimum presentation of the observed rheology trends, each composition is presented with a different $\mathrm{x}$-axis unit.

Figure 5A shows $T_{g}{ }^{12}$ for the ANCS melts as a function of the sum of $\mathrm{F}$ and $\mathrm{Cl}$. The fact that $T_{g}{ }^{12}$ almost linearly decreases as function of the sum of $\mathrm{F}$ and $\mathrm{Cl}$, shows not only that both, $\mathrm{F}$ and $\mathrm{Cl}$, cause a decrease in viscosity but also that their effects are equally strong. Because the effect of $\mathrm{F}$ and $\mathrm{Cl}$ on rheology goes in the opposite direction for the NACS melts and the ratio of $\mathrm{F}$ to $\mathrm{Cl}$ is important, a diagram with the sum of $\mathrm{F}+\mathrm{Cl}$ on the $\mathrm{x}$-axis as in Fig. 3 does not provide the best presentations as it does not take this ratio into account.

In Fig. 5B shows $T_{g}^{12}$ of the NACS melts against the concentration of $\mathrm{F}$ minus $\mathrm{Cl}$. The diagram is split into a $\mathrm{F}$ rich (right) and $\mathrm{Cl}$ rich (left) side with the halogen-free melts and melts that contain equal amounts of $\mathrm{F}$ and $\mathrm{Cl}$ plotting at zero. In Fig. 5B, it can be seen that $T_{g}{ }^{12}$ increases with increasing $\mathrm{Cl}$ content and decreases with increasing $\mathrm{F}$ content, but the trend between the $\mathrm{Cl}$ end-member NACS and the $\mathrm{F}$ end-member is not linear and the halogen-free melt (NACS) does not lie on the trend. The diagram also shows that the melts containing both $\mathrm{F}$ and $\mathrm{Cl}$ have, despite the different amounts of total halogens, nearly the same $T_{g}^{12}$ within $\pm 7 \mathrm{~K}$. Only a small decrease of $T_{g}{ }^{12}$ with increasing $\mathrm{F}$ to $\mathrm{Cl}$ ratio is noticeable.

In Fig. 5C, $T_{g}{ }^{12}$ of the aluminium-free NCS melts is plotted as function of $\mathrm{F}-$ because $\mathrm{Cl}$ seems to have no significant effect. In this diagram it can be seen that, no matter if chlorine is present or not, $\mathrm{F}$ causes at least in this compositional range an almost linear decrease in $T_{g}{ }^{12}$. 

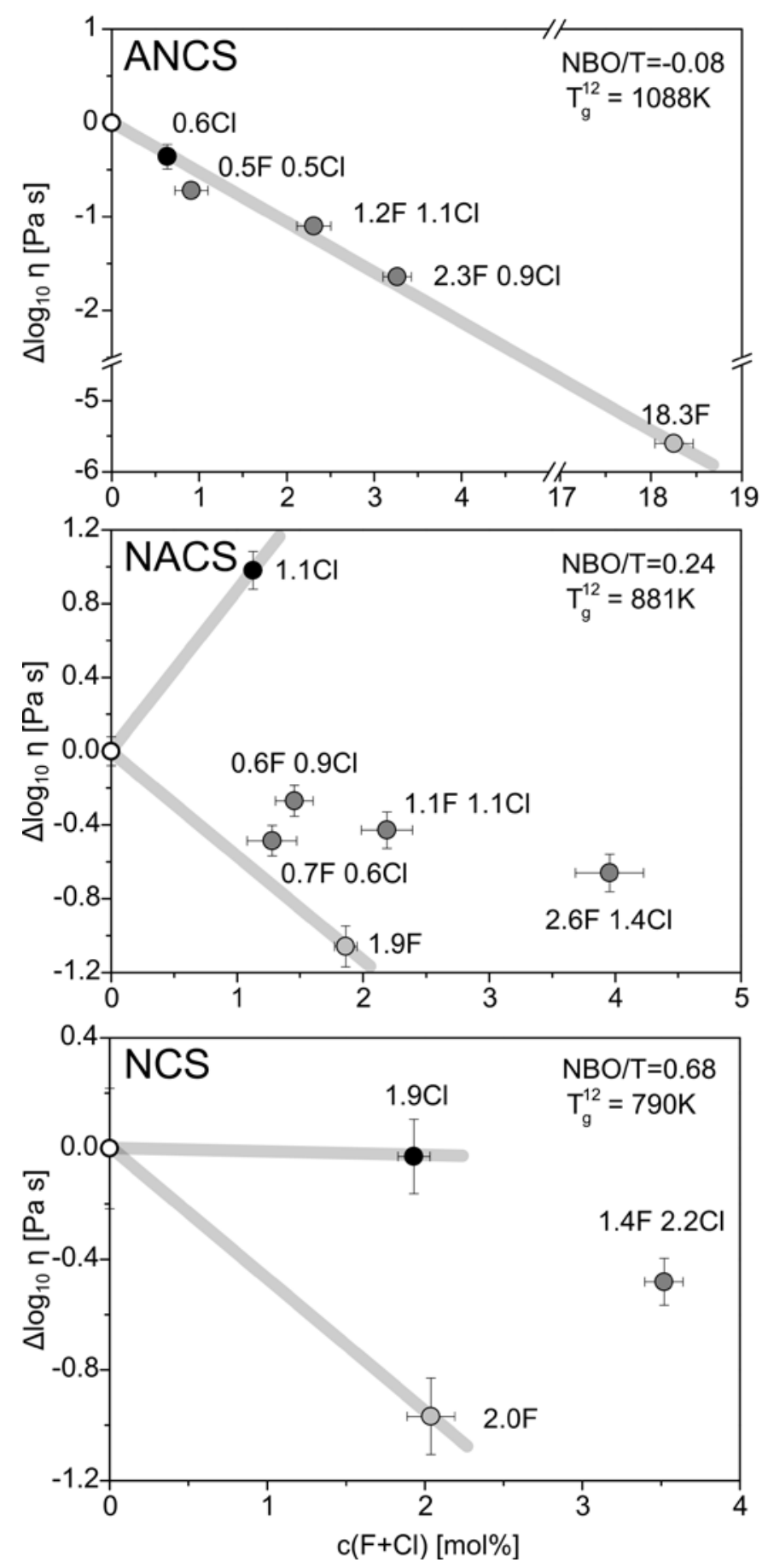

Fig. 4. The change in viscosity as function of the sum of fluorine and chlorine $c(\mathrm{~F}+\mathrm{Cl})$ compared to the viscosity of the halogen-free glass for each composition at the glass transition temperature $T_{g}{ }^{12}$ of the halogen-free melt. ANCS = peraluminous; $\mathrm{NACS}=$ peralkaline $\mathrm{Na}_{2} \mathrm{O}-\mathrm{CaO}-\mathrm{Al}_{2} \mathrm{O}_{3}-\mathrm{SiO}_{2}(+\mathrm{F} /+\mathrm{Cl}$ and $\mathrm{F}+\mathrm{Cl})$ and $\mathrm{NCS}=\mathrm{Na}_{2} \mathrm{O}-\mathrm{CaO}-\mathrm{SiO}_{2}(+\mathrm{F} /+\mathrm{Cl}$ and $\mathrm{F}+\mathrm{Cl}) . \mathrm{NBO} / \mathrm{T}=$ non bridging oxygens per tetrahedron . The grey lines serve as a guide to the eye. 

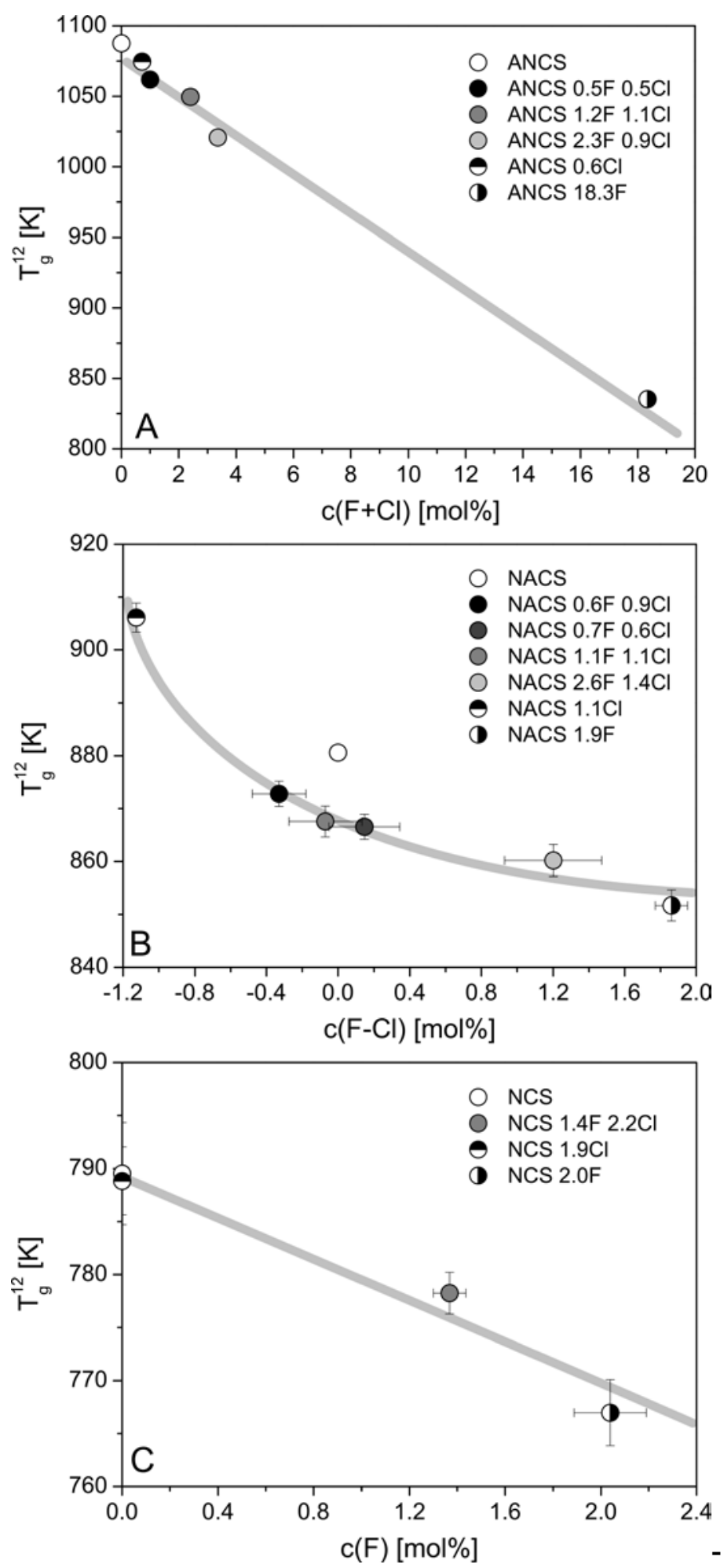

Fig. 5. The glass transition temperature $T_{g}^{12}$ as function of halogen content. Fig. $5 a T_{g}{ }^{12}$ of the peraluminous ANCS melts as function of the sum of $\mathrm{F}$ and $\mathrm{Cl} c(\mathrm{~F}+\mathrm{Cl})$. Fig. $5 \mathrm{~b} T_{g}^{12}$ of the peralkaline NACS melts as function of the concentration of $\mathrm{F}$ minus $\mathrm{Cl} c(\mathrm{~F}-\mathrm{Cl})$. Fig. $5 \mathrm{c} T_{g}{ }^{12}$ of the aluminium-free NCS melts as function of the $F$ concentration $c(F)$. The grey lines serve as a guide to the eye. 
Table 4. Parameters for Arrhenian fits (Eq. 4) to the viscosity data [Pa s] from micropenetration. $\left(0.999<\mathrm{R}^{2}<0.982\right)$.

\begin{tabular}{|c|c|c|c|c|c|c|c|}
\hline & $A_{\text {Arr }}$ & $\bar{\sigma}^{\mathrm{a}}$ & $\begin{array}{c}B_{\text {Arr }} \\
\mathrm{K} 10^{4}\end{array}$ & $\begin{array}{c}\bar{\sigma}^{a} \\
\mathrm{~K} 10^{4}\end{array}$ & $v^{2 b}$ & $N^{\mathrm{c}}$ & $S E_{y}{ }^{d}$ \\
\hline NACS & -22.30 & 1.01 & 3.02 & 0.09 & 0.02 & 6 & 0.08 \\
\hline NACS 0.6F 0.9Cl & -18.38 & 0.93 & 2.65 & 0.09 & 0.02 & 5 & 0.08 \\
\hline NACS 0.7F $0.6 \mathrm{Cl}$ & -18.39 & 0.78 & 2.63 & 0.07 & 0.05 & 9 & 0.08 \\
\hline NACS $1.1 \mathrm{~F} 1.1 \mathrm{Cl}$ & -16.88 & 0.67 & 2.51 & 0.06 & 0.04 & 6 & 0.10 \\
\hline NACS $2.6 \mathrm{~F} 1.4 \mathrm{Cl}$ & -16.47 & 1.11 & 2.45 & 0.10 & 0.03 & 5 & 0.10 \\
\hline NACS $1.1 \mathrm{Cl}$ & -21.88 & 0.97 & 3.07 & 0.09 & 0.09 & 10 & 0.10 \\
\hline NACS $1.9 \mathrm{~F}$ & -20.23 & 0.90 & 2.74 & 0.08 & 0.11 & 11 & 0.11 \\
\hline ANCS & -19.67 & 1.14 & 3.44 & 0.13 & 0.04 & 7 & 0.09 \\
\hline ANCS $0.5 \mathrm{~F} 0.5 \mathrm{Cl}$ & -18.48 & 0.49 & 3.24 & 0.06 & 0.01 & 7 & 0.04 \\
\hline ANCS $1.2 \mathrm{~F} 1.1 \mathrm{Cl}$ & -19.52 & 0.52 & 3.31 & 0.06 & 0.01 & 6 & 0.06 \\
\hline ANCS $2.3 \mathrm{~F} 0.9 \mathrm{Cl}$ & -14.69 & 0.79 & 2.72 & 0.09 & 0.04 & 7 & 0.09 \\
\hline ANCS $0.6 \mathrm{Cl}$ & -18.26 & 1.31 & 3.25 & 0.15 & 0.09 & 7 & 0.13 \\
\hline ANCS 18.3F & -12.16 & 0.74 & 2.02 & 0.06 & 0.02 & 6 & 0.08 \\
\hline NCS & -23.39 & 1.32 & 2.79 & 0.11 & 0.47 & 12 & 0.22 \\
\hline $\mathrm{NCS} 1.4 \mathrm{~F} 2.2 \mathrm{Cl}$ & -21.69 & 0.65 & 2.62 & 0.05 & 0.06 & 10 & 0.09 \\
\hline $\mathrm{NCS} 1.9 \mathrm{Cl}$ & -20.93 & 1.04 & 2.60 & 0.09 & 0.18 & 12 & 0.13 \\
\hline NCS 2.0F & -21.88 & 1.03 & 2.60 & 0.08 & 0.17 & 11 & 0.14 \\
\hline \multicolumn{8}{|c|}{$\begin{array}{l}\text { a }-\bar{\sigma}=\text { standard error } \\
b-v^{2}=\text { residual sum of squares } \\
c-N=\text { number of data points }\end{array}$} \\
\hline
\end{tabular}

\subsubsection{Parallel plate viscometry}

Figure 6 shows the combined micropenetration and parallel plate data for the peralkaline NACS melts across the viscosity range $10^{5.5}$ to $10^{13} \mathrm{~Pa}$ as function of inverse temperature. The combined viscosity data from micropenetration and parallel plate were fitted with the Vogel-Fulcher-Tamman equation (VFT) (Vogel, 1921; Fulcher, 1925; Tamman and Hesse, 1926) to describe the dependence of viscosity $\eta$ $\left[\mathrm{Pa}\right.$ s] on temperature $T[\mathrm{~K}]$ with the fitting parameters $A_{V F T}, B_{V F T}, C_{V F T}$ :

$$
\log _{10} \eta=A_{V F T}+\frac{B_{V F T}}{T-C_{V F T}}
$$

The fit parameters are shown in Table 6. Despite the range of viscosity data, it was not possible to obtain unique stable fits with all three parameters set free, that deliver values in a physically reasonable range: The term $A_{V F T}$ is assumed to be the $\log _{10}$ of 

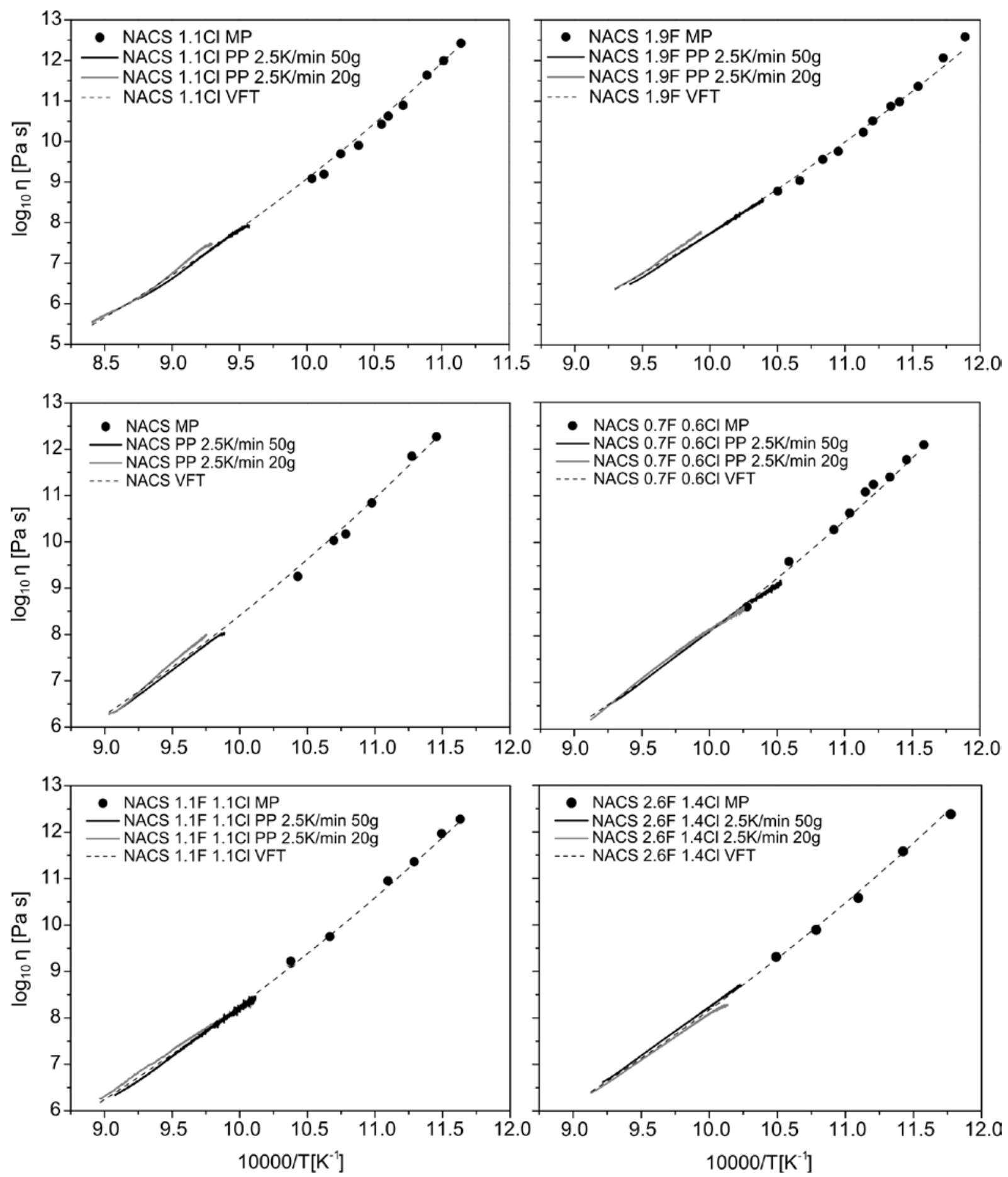

Fig. 6. Viscosity data from micropenetration (MP) and parallel plate (PP) for the peralkaline $\mathrm{Na}_{2} \mathrm{O}-\mathrm{CaO}-\mathrm{Al}_{2} \mathrm{O}_{3}-\mathrm{SiO}_{2}(+\mathrm{F} /+\mathrm{Cl}$ and $\mathrm{F}+\mathrm{Cl})$ melts (NACS) as function of inverse temperature. Vogel-Fulcher-Tamman equations (VFT) were fitted to the data (dashed lines).

a constant with a value between $10^{-3.5} \mathrm{~Pa}$ s and $10^{5.5} \mathrm{~Pa} \mathrm{~s}$ (e.g. Angell, 1991; Toplis 1998; Giordano et al., 2008). In our regressions, $A_{V F T}$ was fixed to $\log _{10}$ of $10^{-4.5} \mathrm{~Pa}$ s. In the case of the DGG-1 melt, $A_{V F T}$ was fixed to $\log _{10}$ of $10^{-2.5835} \mathrm{~Pa}$ s as this is the value given in the standard data sheet for this melt (Meerlender, 1974). The VFT fit to 
our DGG-1 micropenetration and parallel plate data is in good agreement with the standard values (see Fig. 1 and Table 6).

Figure 7 shows the VFT fits for the peralkaline NACS melts. These curves confirm the trends expected from the micropenetration viscosity data and show that the effects of chlorine and fluorine are still noticeable below a viscosity of $10^{8} \mathrm{~Pa} \mathrm{~s}$

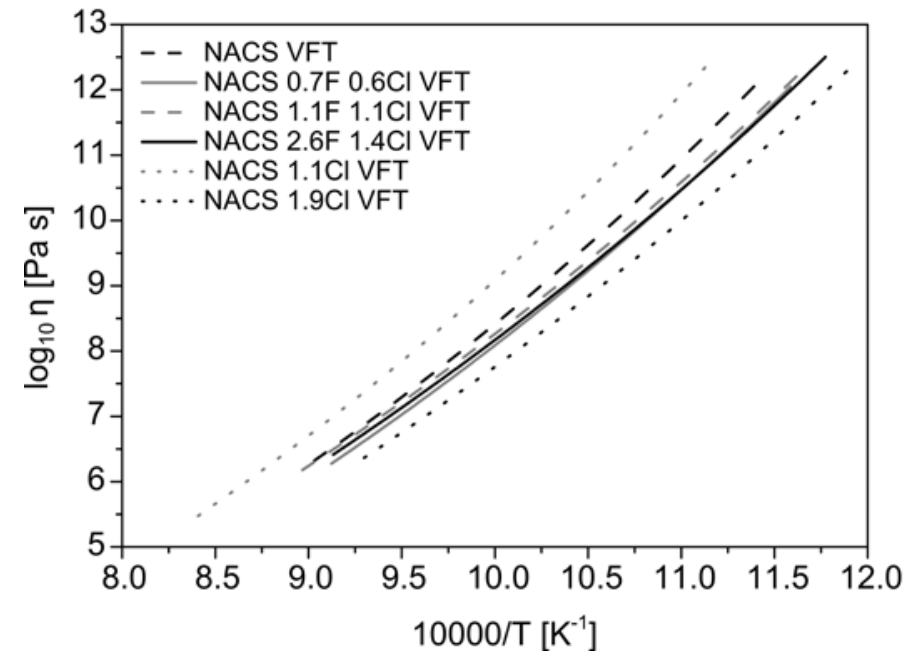

Fig. 7. Vogel-Fulcher-Tamman (VFT) fits to the viscosity data of the $\mathrm{Na}_{2} \mathrm{O}-\mathrm{CaO}-\mathrm{Al}_{2} \mathrm{O}_{3}-\mathrm{SiO}_{2}(\mathrm{~F}+\mathrm{Cl})$ melts (NACS) from micropenetration and parallel plate measurements as function of inverse temperature.

\subsubsection{Fragility}

The fragility $m$ concept distinguishes melts as "strong" and "fragile". The logarithmic viscosity vs. inverse temperature dependence of an ideal strong melt is almost linear and its fragility is low, while the logarithmic viscosity vs. inverse temperature dependence of a fragile melt is curved (Angell, 1991). Strong melts have a wider glass transition range than fragile melts. The fragility $m_{\text {Arr }}$ (Table 5 ) was calculated as function of $B_{A r r}$ and $T_{g}^{12}$ (Böhmer and Angell, 1992) from the Arrhenian fits:

$$
m_{\text {Arr }}=\frac{B_{A r r}}{T_{g}^{12}}
$$

The fragility $m_{V F T}$ (Table 5) was calculated from the fitting parameters of the VFT $B_{V F T}$ and $C_{V F T}$ and $T_{g}{ }^{12}$ (Platzek and Ngai, 1991): 


$$
m_{V F T}=\left.\frac{\partial\left(\log _{10} \eta\right)}{\partial\left(T_{g}^{12} / T\right)}\right|_{T=T g}=\frac{B_{V F T}}{T_{g}^{12}\left(1-C_{V F T} / T_{g}^{12}\right)^{2}} .
$$

The fragilities from Arrhenian and VFT fits to micropenetration and parallel plate data show the same trends. For all 3 melt types (NACS, ANCS and NCS) there is a smooth trend that the addition of halogens decreases the fragility - with the exceptions NACS $1.1 \mathrm{Cl}$ and ANCS $1.2 \mathrm{~F} 1.1 \mathrm{Cl}$.

Table 5. Comparison of $T_{g}{ }^{12}$ and fragility $m$ for the Arrhenian and VFT fits.

\begin{tabular}{lcccccc}
\hline & $T_{g}^{12}{ }_{\text {Arr }}$ & \pm & $m_{\text {Arr }}$ & $T_{g}^{12}$ VFT & \pm & $m_{\text {VFT }}$ \\
& \multicolumn{1}{c}{$\mathrm{K}^{2}$} & $\mathrm{~K}$ & & $\mathrm{~K}$ & $\mathrm{~K}$ & \\
\hline NACS & 881 & 2 & 34 & 879 & 2 & 33 \\
NACS 0.6F 0.9Cl & 873 & 2 & 30 & - & - & - \\
NACS 0.7F 0.6Cl & 867 & 2 & 30 & 864 & 1 & 33 \\
NACS 1.1F 1.1Cl & 868 & 3 & 29 & 866 & 2 & 31 \\
NACS 2.6F 1.4Cl & 860 & 3 & 28 & 863 & 2 & 31 \\
NACS 1.1Cl & 906 & 3 & 34 & - & - & - \\
NACS 1.9F & 852 & 3 & 32 & - & - & - \\
& & & & & & \\
ANCS & 1088 & 3 & 32 & - & - & - \\
ANCS 0.5F 0.5Cl & 1062 & 2 & 30 & - & - & - \\
ANCS 1.2F 1.1Cl & 1050 & 2 & 32 & - & - & - \\
ANCS 2.3F 0.9Cl & 1021 & 3 & 27 & - & - & - \\
ANCS 0.6Cl & 1075 & 5 & 30 & - & - & - \\
ANCS 18.3F & 835 & 3 & 24 & - & - & - \\
& & & & & & - \\
NCS & 790 & 5 & 35 & - & - & - \\
NCS 1.4F 2.2Cl & 778 & 2 & 34 & - & - & - \\
NCS 1.9Cl & 789 & 3 & 33 & - & - & - \\
NCS 2.0F & 767 & 3 & 34 & - & - & - \\
\hline
\end{tabular}


Table 6. Parameters for the VFT fit (Eq. 5) to the viscosity data $[\mathrm{Pa} \mathrm{s}]$ from micropenetration and parallel plate. $\left(0.990<R^{2}<0.975\right)$.

\begin{tabular}{|c|c|c|c|c|c|c|c|c|}
\hline & $A_{V F T}{ }^{a}$ & $\begin{array}{c}B_{V F T} \\
\mathrm{~K}\end{array}$ & $\begin{array}{l}\bar{\sigma}^{\mathrm{c}} \\
\mathrm{K}\end{array}$ & $\begin{array}{c}C_{V F T} \\
K\end{array}$ & $\begin{array}{l}\bar{\sigma} \\
\mathrm{K}\end{array}$ & $v^{2 d}$ & $N^{\mathrm{e}}$ & $S E_{y}{ }^{\dagger}$ \\
\hline NACS & -4.5 & 7166 & 15 & 445.0 & 1.3 & 40.95 & 6004 & 0.08 \\
\hline NACS $0.7 F 0.6 \mathrm{Cl}$ & -4.5 & 7200 & 6 & 428.0 & 0.5 & 17.30 & 6033 & 0.05 \\
\hline NACS 1.1F 1.1Cl & -4.5 & 7530 & 7 & 410.0 & 0.6 & 53.37 & 11403 & 0.07 \\
\hline NACS $2.6 F 1.4 \mathrm{Cl}$ & -4.5 & 7486 & 10 & 409.1 & 0.8 & 19.06 & 5167 & 0.06 \\
\hline DGG-1 & -2.5835 & 4321 & 6 & 521.3 & 0.6 & 20.82 & 5465 & 0.06 \\
\hline $\begin{array}{l}\text { DGG-1 standard } \\
\text { Values }\end{array}$ & -2.5835 & 4331.63 & - & 520.79 & - & - & - & - \\
\hline $\begin{array}{l}\text { a -fixed (see text) } \\
\mathrm{b}-\text { DGG-1 informati } \\
\mathrm{c}-\bar{\sigma}=\text { standard er } \\
\mathrm{d}-\mathrm{v}^{2}=\text { residual sur } \\
\mathrm{e}-N=\text { number of } \mathrm{d} \\
\mathrm{f}-S E_{y}=\sqrt{\frac{\sum_{i=2}^{n} v^{2}}{n-2}}\end{array}$ & $\begin{array}{l}\text { sheet of } \\
\text { f squares } \\
\text { points }\end{array}$ & Deu & & sch & & & & \\
\hline
\end{tabular}

\subsubsection{Heat capacity and configurational entropy}

The fictive temperature $T_{f}^{20}$, the heat capacity of the melts $C_{p l}$ and the configurational heat capacity $C_{p}{ }^{\text {conf }}$ are given in Table $7 . C_{p}{ }^{\text {conf }}$ is the difference of the heat capacity of the melt $C_{p l}$ and the heat capacity of the glass $C_{p g}$. $T_{f}^{20}$ values were obtained from heat capacity curves measured with $20 \mathrm{~K} \mathrm{~min}^{-1}$ heating rate using the method described by Moynihan et al. (1976) by integrating under the heat capacity curve. The samples had previously been cooled at a rate of $20 \mathrm{~K} \mathrm{~min}^{-1}$. The $T_{f}^{20}$ values in Table 7 and the glass transition temperatures from the viscosity measurements $T_{g}{ }^{12}$ (Table 5) show that the numbers are not identical, but reveal the same trends except for samples ANCS and ANCS $0.6 \mathrm{Cl}$. The heat capacity data illustrates that, as pointed out by Angell (1991), the value of $C_{p i} / C_{p g}$ for the present melts increases with increasing fragility. In Fig. 8A-C, the configurational heat capacity $C_{p}{ }^{\text {conf }}$ of the samples of the 3 compositions is plotted as a function of the concentration $\mathrm{F}$ minus $\mathrm{Cl}$. The advantage of this $\mathrm{x}$-axis is already explained in Section 3.1. The configurational heat capacity $C_{p}{ }^{\text {conf }}$ is the energy that is required to move the structure from the glassy to the liquid state. The halogen-free ANCS melt has the lowest $C_{p}^{\text {conf }}\left(\right.$ Fig. 8A), and the halogen-free NCS melt (Fig. 8C) has the highest $C_{p}^{\text {conf }}$, and the NACS melt (Fig. 8B) lies in between. The only clear observable trend was found for the NCS melts (Fig. $8 \mathrm{C}$ ). There $C_{p}{ }^{\text {conf }}$ decreases with increasing $\mathrm{Cl}$ and $\mathrm{F}$ 
content, but $\mathrm{F}$ has just a small effect. Two mol\% $\mathrm{Cl}$ decreases $C_{p}{ }^{\text {conf }}$ by $1.40 \pm 0.12 \mathrm{~J} \mathrm{~mol}^{-1} \mathrm{~K}^{-1}$, while $2 \mathrm{~mol} \% \mathrm{~F}$ decreases $C_{p}{ }^{\text {conf }}$ by $0.43 \pm 0.18 \mathrm{~J} \mathrm{~mol}^{-1} \mathrm{~K}^{-1}$. The NACS melts (Fig. 8B) also show a decrease with the addition of $\mathrm{Cl}$ alone and no effect with $\mathrm{F}$ alone. The NACS melts bearing both halogens, however, show the opposite trend with an increase in $C_{p}{ }^{\text {conf }}$ with increasing $\mathrm{F}$ to $\mathrm{Cl}$ ratio. On the other hand in the ANCS melts (Fig. 8A) $\mathrm{Cl}$ alone increases $C_{p}{ }^{\text {conf }}$ while $\mathrm{F}$ alone decreases $C_{p}{ }^{\text {conf }}$. The ANCS melts containing both halogens have higher $C_{p}{ }^{\text {conf }}$ values than the halogen-free and the only fluorine-bearing sample, but there is no clear trend apparent.

The configurational $S_{\text {conf }}$ entropy is a measure of the amount of disorder in the melt structure. $S_{\text {conf }}\left(T_{g}\right)\left[\mathrm{J} \mathrm{mol}^{-1} \mathrm{~K}^{-1}\right]$ (Table 7$)$ of the melts at $T_{g}{ }^{12}[\mathrm{~K}]$ was calculated after Richet (1984) using the viscosity $\eta[\mathrm{Pa} \mathrm{s}]$ from micropenetration, $C_{p}{ }^{\text {conf }}$ from calorimetry and the constant $A_{e}=\log _{10} 10^{-4.5}$ Pa s:

$$
\log _{10} \eta=A_{e}+\frac{B_{e}}{\ln 10\left[S_{\text {conf }}\left(T_{g}^{12}\right)+\int_{T_{g}^{12}}^{T} \frac{C_{p}^{\text {conf }}}{T} d T\right] T}
$$

In Fig. 9A-B, a weak trend of increasing configuration entropy $S_{\text {conf }}$ of the ANCS and NACS samples is observed with increasing $\mathrm{F}+\mathrm{Cl}$ concentration, while in the NCS samples (Fig. 9C) there is no change within the error. 

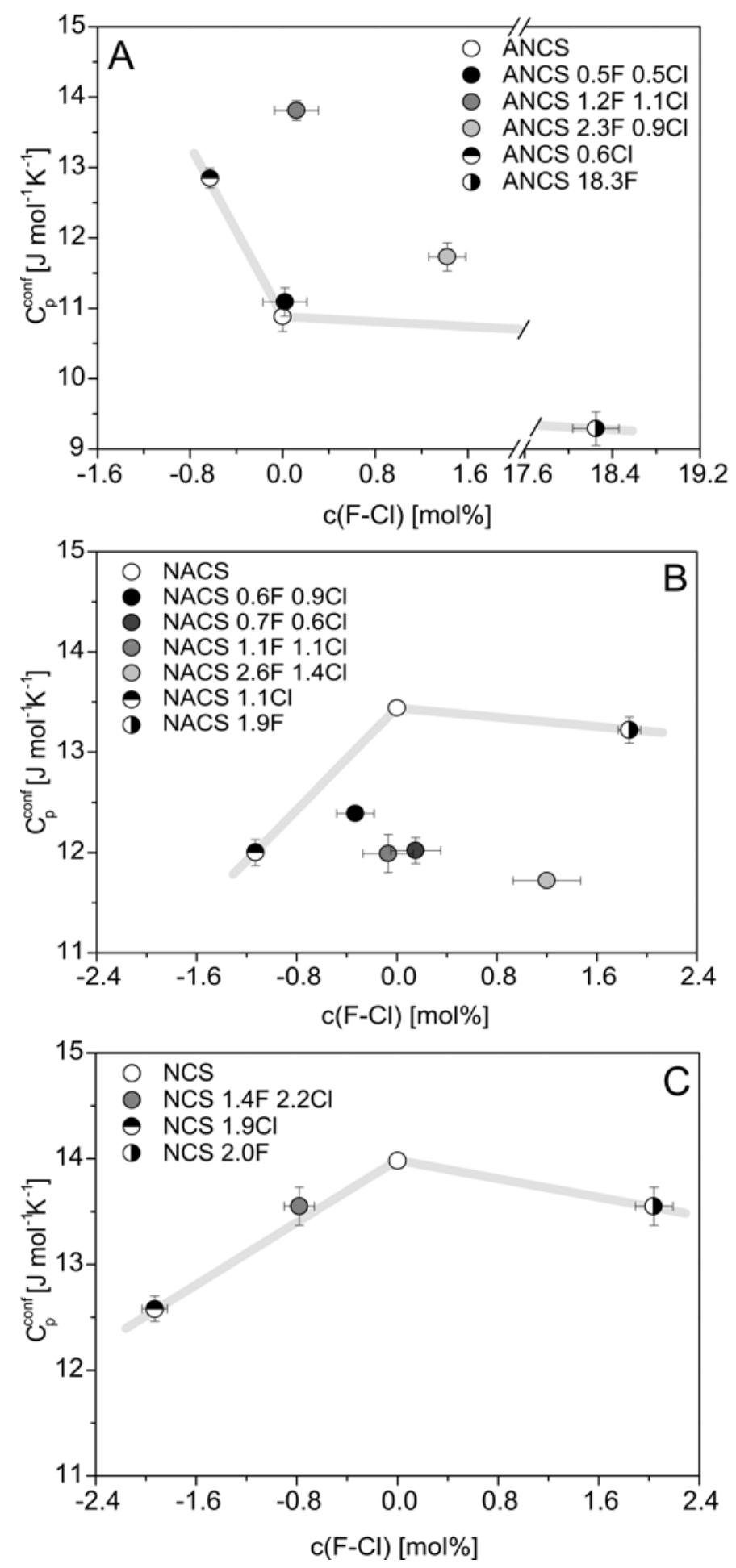

Fig. 8. Configurational heat capacity $\mathrm{C}_{p}{ }^{\text {conf }}$ as function of the concentration of $\mathrm{F}$ minus $\mathrm{Cl} c(\mathrm{~F}-\mathrm{Cl})$ for the peraluminous (ANCS) $(\mathrm{A})$ and peralkaline (NACS) $\mathrm{Na}_{2} \mathrm{O}-\mathrm{CaO}-\mathrm{Al}_{2} \mathrm{O}_{3}-\mathrm{SiO}_{2}(+\mathrm{F} /+\mathrm{Cl}$ and $\mathrm{F}+\mathrm{Cl}$ ) melts $(\mathrm{B})$ and the $\mathrm{Na}_{2} \mathrm{O}-\mathrm{CaO}-\mathrm{SiO}_{2}(+\mathrm{F} /+\mathrm{Cl}$ and $\mathrm{F}+\mathrm{Cl})$ melts $(\mathrm{NCS})(\mathrm{C})$. The grey lines serve as a guide to the eye. 

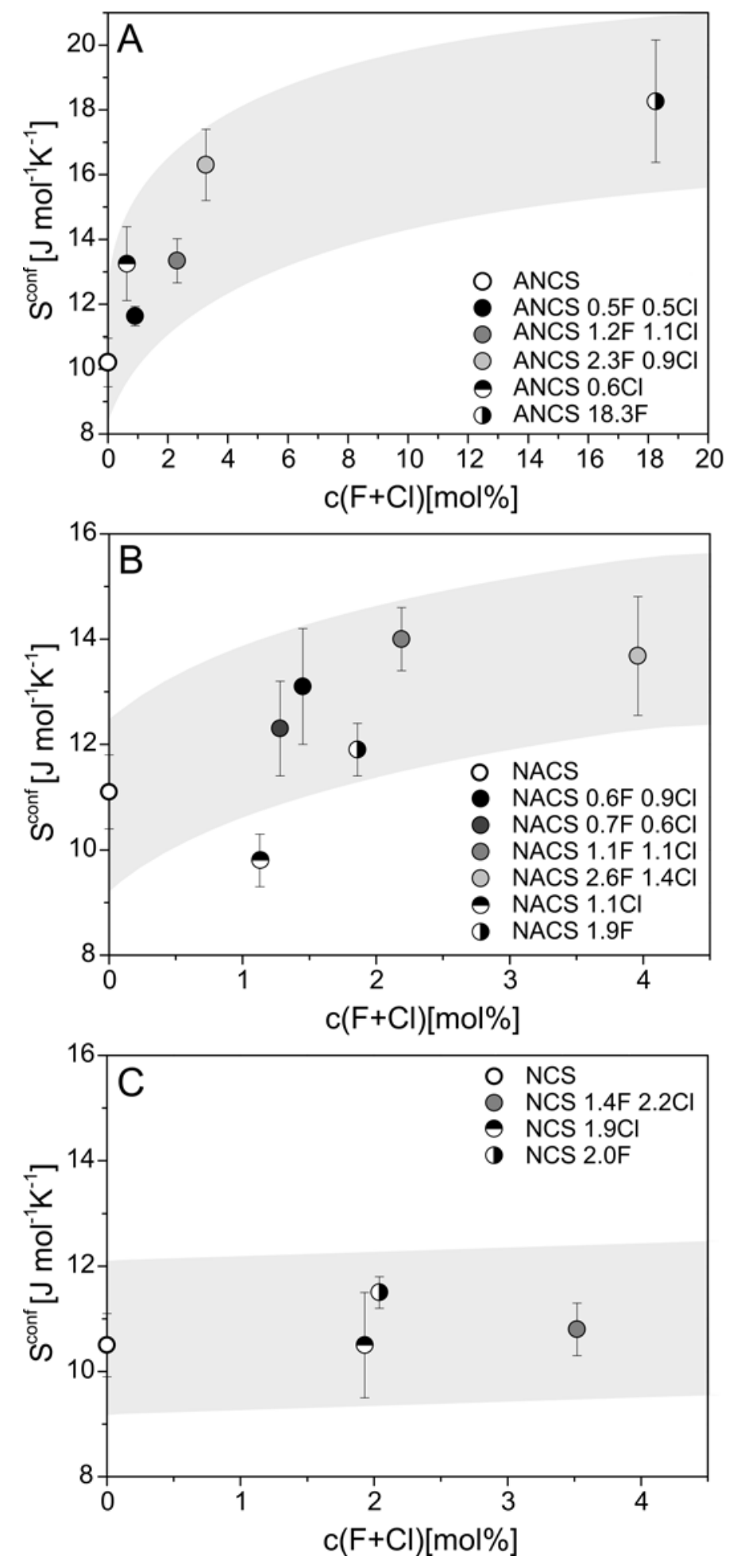

Fig. 9. Configurational entropy $S^{\text {conf }}$ as function of the sum of $\mathrm{F}$ and $\mathrm{Cl} c(\mathrm{~F}+\mathrm{Cl})$ for the peraluminous (ANCS) (A) and peralkaline (NACS) $\mathrm{Na}_{2} \mathrm{O}-\mathrm{CaO}-\mathrm{Al}_{2} \mathrm{O}_{3}-\mathrm{SiO}_{2}(+\mathrm{F} /+\mathrm{Cl}$ and $\mathrm{F}+\mathrm{Cl})$ melts $(\mathrm{B})$ and the $\mathrm{Na}_{2} \mathrm{O}-\mathrm{CaO}-\mathrm{SiO}_{2}(+\mathrm{F} /+\mathrm{Cl}$ and $\mathrm{F}+\mathrm{Cl})$ melts $(\mathrm{NCS})(\mathrm{C})$. The grey areas serve as a guide to the eye. 
Table 7. Fictive temperature $T_{f}^{20}$, together with relaxed liquid heat capacity $C_{p}$, configurational heat capacity $C_{p}{ }^{\text {conf }}$ and fit parameters $S_{\text {conf }}\left(T_{g}\right)$ and $B_{e}$ from Eq. 8.

\begin{tabular}{lccccccccc}
\hline & $\begin{array}{c}T_{f}^{20} \\
\mathrm{~K}\end{array}$ & \multicolumn{2}{c}{$\mathrm{J} \mathrm{mol}^{-1} \mathrm{~K}^{-1}$} & \multicolumn{2}{c}{$\mathrm{C}_{p}^{\text {conf }}$} & \multicolumn{2}{c}{$\mathrm{S}_{\text {conf }}\left(T_{g}\right)$} & & $B_{e}$ \\
& 886 & 94.45 & \pm 0.20 & 13.44 & \pm 0.07 & 11.10 & \pm 0.70 & 370 & \pm 21 \\
\hline NACS & $873 \mathrm{Kol}^{-1}$ & $\mathrm{~J} \mathrm{~mol}^{-1} \mathrm{~K}^{-1}$ & \\
NACS 0.6F 0.9Cl & 873 & 92.26 & \pm 0.19 & 12.39 & \pm 0.10 & 13.10 & \pm 1.10 & 434 & \pm 35 \\
NACS 0.7F 0.6Cl & 859 & 92.49 & \pm 0.13 & 12.02 & \pm 0.13 & 12.30 & \pm 0.90 & 406 & \pm 27 \\
NACS 1.1F 1.1Cl & 871 & 92.89 & \pm 0.19 & 11.99 & \pm 0.19 & 14.00 & \pm 0.60 & 462 & \pm 20 \\
NACS 2.6F 1.4Cl & 860 & 91.19 & \pm 0.19 & 11.72 & \pm 0.06 & 13.68 & \pm 1.13 & 462 & \pm 36 \\
NACS 1.1Cl & 906 & 90.30 & \pm 0.20 & 12.00 & \pm 0.13 & 9.80 & \pm 0.50 & 339 & \pm 15 \\
NACS 1.9F & 858 & 93.42 & \pm 0.19 & 13.22 & \pm 0.13 & 11.90 & \pm 0.50 & 384 & \pm 16 \\
& & & & & & & & & \\
ANCS & 1067 & 94.04 & \pm 0.07 & 10.88 & \pm 0.21 & 10.20 & \pm 0.75 & 422 & \pm 30 \\
ANCS 0.5F 0.5Cl & 1053 & 97.34 & \pm 0.07 & 11.09 & \pm 0.20 & 11.63 & \pm 0.30 & 469 & \pm 12 \\
ANCS 1.2F 1.1Cl & 1043 & 100.06 & \pm 0.20 & 13.81 & \pm 0.14 & 13.34 & \pm 0.68 & 532 & \pm 26 \\
ANCS 2.3F 0.9Cl & 1038 & 96.93 & \pm 0.14 & 11.73 & \pm 0.20 & 16.30 & \pm 1.10 & 635 & \pm 42 \\
ANCS 0.6Cl & 1074 & 99.28 & \pm 0.21 & 12.85 & \pm 0.14 & 13.25 & \pm 1.14 & 642 & \pm 44 \\
ANCS 18.3F & 816 & 83.65 & \pm 0.23 & 9.25 & \pm 0.24 & 18.27 & \pm 1.89 & 580 & \pm 58 \\
& & & & & & & & & \\
NCS & 800 & 87.75 & \pm 0.18 & 13.98 & \pm 0.06 & 10.50 & \pm 0.60 & 316 & \pm 17 \\
NCS 1.4F 2.2Cl & 780 & 85.51 & \pm 0.18 & 13.55 & \pm 0.18 & 11.50 & \pm 0.30 & 339 & \pm 10 \\
NCS 1.9Cl & 801 & 87.10 & \pm 0.18 & 12.58 & \pm 0.12 & 10.50 & \pm 1.00 & 309 & \pm 28 \\
NCS 2.0F & 782 & 85.01 & \pm 0.18 & 13.55 & \pm 0.18 & 10.80 & \pm 0.50 & 317 & \pm 15 \\
\hline
\end{tabular}

\subsection{Discussion}

Melt viscosity is sensitive to factors like alkali, bubble and water content. The influence of these elements on our results is discussed in the following on the basis of the samples that were affected most.

The electron microprobe measurements of the composition in Table $1 \mathrm{a}$ and $1 \mathrm{~b}$ show a depletion of sodium in some halogen-bearing samples compared to the halogen-free samples. This leads to a decrease of the ratio $V=\left(\mathrm{Na}_{2} \mathrm{O}+\mathrm{CaO}\right) /\left(\mathrm{Na}_{2} \mathrm{O}+\mathrm{CaO}+\mathrm{Al}_{2} \mathrm{O}_{3}\right)$ by up to 0.07 for the peraluminous sample ANCS $2.3 \mathrm{~F} 0.9 \mathrm{Cl}$ and up to 0.03 in the peralkaline sample NACS $2.6 \mathrm{~F} 1.4 \mathrm{Cl}$. We tried to model the influence of sodium depletion with the model of Hui and Zhang (2007) and Giordano and Dingwell (2003). However we were not even able to model the viscosity of the halogen free melts within an error of 1 log unit with both models. Therefore we decided to look at real data to estimate the error due to sodium depletion. According to the data of Webb et al. (2007) a decrease in $\gamma$ has no effect on the measured viscosities of the peraluminous samples with a $\gamma \sim 0.45$, as the dependence of viscosity on this ratio is in the range of the error of the viscosity measurements them self. We estimated based on Webb et al. (2007) for the 
peralkaline sample NACS $2.6 \mathrm{~F} 1.4 \mathrm{Cl}$, which has the highest depletion of sodium compared to the halogen-free sample, that in the worst case the sodium depletion leads to a possible increase in viscosity of $0.45 \mathrm{log}$ units equal to a decrease of $13 \mathrm{~K}$ in $T_{g}{ }^{12}$. In the case of the $\mathrm{Na}_{2} \mathrm{O}-\mathrm{CaO}-\mathrm{SiO}_{2}$ melts (NCS) the sample $\mathrm{NCS} 1.4 \mathrm{~F} 2.2 \mathrm{Cl}$ shows with $1 \mathrm{~mol} \%$ the highest depletion of sodium compared with the halogen-free glass. From data in Bansal and Doremus (1986) for viscosities in the $\mathrm{Na}_{2} \mathrm{O}-\mathrm{CaO}-\mathrm{SiO}_{2}$ system in a temperature range between 1400 and $500^{\circ} \mathrm{C}$ we can estimate that a depletion of 1 mol\% sodium decreases $T_{g}{ }^{12}$ by about $4 \mathrm{~K}$, which equals to a viscosity increase of 0.2 log units.

The bubble content of 0 - 3 vol\% did not affect the micropenetration data, because it was possible to measure around the bubbles. Bubbles could affect the viscosity measurements with the parallel plate method, but this plays a role only for the sample NACS $1.1 \mathrm{~F} 1.1 \mathrm{Cl}$, that had the highest bubble content of 3 vol\%. According to Bagdassarov and Dingwell (1992) 3 vol\% bubbles decrease the viscosity in rhyolites by about 0.25 log units at a temperature of around $1123 \mathrm{~K}$. Lejeune et al. (1999) found for calcium aluminosilicate melts in a viscosity range from $10^{9}$ to $10^{13} \mathrm{Pas}(1220-1100 \mathrm{~K})$ that 6 vol\% bubbles could cause a relative viscosity change of \pm 0.1 log units.

The observed enrichment of small amounts of water in the peralkaline NACS melts with increasing halogen content causes a decrease in viscosity resulting in $\sim 1 \mathrm{~K}$ decrease in $T_{g}{ }^{12}$ per 50 ppm $\mathrm{H}_{2} \mathrm{O}$ (based on the viscosity data of the water-bearing phonolite investigated by Whittington et al. (2001)). In the worst case for the sample NACS $2.6 \mathrm{~F} 1.4 \mathrm{Cl}$, which contains $\sim 444$ ppm water, this leads to a $9 \mathrm{~K}$ decrease in $T_{g}{ }^{12}$ or a decrease of 0.3 log units expressed in terms of viscosity. Over all, the possible sources for error reported here do not affect the general results and conclusions even in the worst case.

The observed crossovers of the viscosity-temperature lines in Fig. 3D of the samples NCS and NCS $1.9 \mathrm{Cl}$ and the curves in Fig. 7 belonging to the samples NACS 0.7F $0.6 \mathrm{Cl}$ and NACS $2.6 \mathrm{~F} 1.4 \mathrm{Cl}$ are with respect to the error of the viscosity measurements of \pm 0.08 log units not significant.

The values of $T_{f}^{20}$ (Table 7) and $T_{g}{ }^{12}$ (Table 5) show the same trends but are not identical, but this is not expected: The $T_{f}^{20}$ depends on cooling and heating rate and it 
does not necessarily coincide with viscosity of $10^{12} \mathrm{~Pa} \mathrm{~s}$, where $T_{g}{ }^{12}$ is calculated (Webb, 2011). In $C_{p}{ }^{\text {conf }}$ and $S_{\text {conf. }}$ there are no clear trends seen for the ANCS (Fig. 8A, 9A) and NACS melts (Fig. 8B, 9B), but the effect on $C_{p}{ }^{\text {conf }}$ due to the addition of halogens goes in different directions, while $S_{\text {conf }}$ of both melts increases with increasing halogen content.

\subsubsection{The effect of $F$ on viscosity and its structural role}

Nuclear magnetic resonance (NMR) studies show that in $\mathrm{Na}_{2} \mathrm{O}-\mathrm{CaO}-\mathrm{Al}_{2} \mathrm{O}_{3}-\mathrm{SiO}_{2}$ melts $\mathrm{F}$ favours Al-F-(Na,Ca) environments, with minor amounts of Si-F-Na and (Na,Ca)-F environments (Kohn et al., 1991; Zeng and Stebbins, 2000; Mysen et al., 2004). Thus, the addition of $F$ to the peralkaline and peraluminous melts results in the formation of non-bridging Al-F bonds (e.g. Zeng and Stebbins, 2000) in which the polymerisation of the melts is decreased. Based on this information we suggest two important mechanisms to explain the decrease in viscosity in the $\mathrm{Na}_{2} \mathrm{O}-\mathrm{CaO}-\mathrm{Al}_{2} \mathrm{O}_{3}-\mathrm{SiO}_{2}$ melts here studied due to $\mathrm{F}$ (Fig. 3 and Fig. 4):

$$
\mathrm{Q}^{4}{ }_{\mathrm{Al}}+\mathrm{Na}_{\mathrm{cb}}^{+}+\mathrm{F}^{-} \Leftrightarrow \mathrm{AlO}_{1.5} \mathrm{~F}+\mathrm{Na}_{\mathrm{cb}}^{+}+0.5 \uparrow \mathrm{O}^{2-}
$$

or

$$
\mathrm{Q}^{4}{ }_{\mathrm{Al}}+0.5 \mathrm{Ca}^{2+}{ }_{\mathrm{cb}}+\mathrm{F}^{-} \Leftrightarrow \mathrm{AlO}_{1.5} \mathrm{~F}+0.5 \mathrm{Ca}^{2+}{ }_{\mathrm{cb}}+0.5 \uparrow \mathrm{O}^{2-}
$$

with $\mathrm{Q}^{4}{ }_{\mathrm{Al}}$ being an $\mathrm{Al}$ atom tetrahedrally coordinated by 4 bridging oxygens (BO). $\mathrm{Na}$ and $\mathrm{Ca}$ cations charge balance the tetrahedrally coordinated Al, which is marked by an indice "cb". $\mathrm{AlO}_{1.5} \mathrm{~F}$ is a tetrahedrally coordinated $\mathrm{Al}$ surrounded by $3 \mathrm{O}$ and $1 \mathrm{~F}$ atom, with half of the $\mathrm{O}$ atoms belonging to other atoms. $\uparrow \mathrm{O}^{2-}$ is a free oxygen that is removed from the melt structure (indicated by an arrow) to ensure charge balance for $2 \mathrm{~F}^{-}$. It is an alternative to write $\mathrm{F}_{2} \mathrm{O}_{-1}$, which is sometimes used in the literature (see for example Dingwell, 1989). Equations 9 and 10 also apply for Al atoms that are tetrahedrally coordinated by $3 \mathrm{BO}$ and 1 non-bridging oxygen (NBO) $\left(\mathrm{Q}^{3} \mathrm{Al}\right)$ or $2 \mathrm{BO}$ and $2 \mathrm{NBO}\left(\mathrm{Q}^{2} \mathrm{Al}\right)$. Then according to the number of $\mathrm{NBO}, \mathrm{Na}$ and $\mathrm{Ca}$ atoms have to be added as network-modifying cations to the equation.

Stebbins and Zeng (2000) found in aluminium-free $\mathrm{Na}_{2} \mathrm{O}-\mathrm{CaO}-\mathrm{SiO}_{2}$ melts the major amount of $\mathrm{F}$ sits on Na-F and $\mathrm{Ca}-\mathrm{F}$ sites with a minor amount present in a Si-F-Na 
environment. They also observed in glasses containing $\mathrm{Ca}$ and $\mathrm{Na}$ that $\mathrm{F}$ seems to favour Ca-F environments more than $\mathrm{Na}-\mathrm{F}$ and in general higher field strength network-modifying cations. The existence of $\mathrm{Na}-\mathrm{F}$ and $\mathrm{Ca}-\mathrm{F}$ sites should increase the melt polymerisation by taking network modifiers out of the network (Stebbins and Zeng, 2000; Mysen et al., 2004). Stebbins and Zeng (2000) suggest the presence of Si-F-Na environments in $\mathrm{Na}_{2} \mathrm{O}-\mathrm{SiO}_{2}$ melts as well as that fluorine could trigger local network-breaking events by substitution for oxygen (suggested before by Dingwell, 1989) be responsible for the reduction of viscosity in aluminium-free soda-lime silicate melts. A significant amount of Si-F sites either in aluminium-free or aluminium-containing soda-lime silicate melts has never been verified.

Considering the points discussed above, the observed decrease of viscosity in our $\mathrm{Na}_{2} \mathrm{O}-\mathrm{CaO}-\mathrm{SiO}_{2}$ melts (Fig. 3 and Fig. 4) upon the addition of $\mathrm{F}$ is to be expected, but not fully explainable in terms of structure.

\subsubsection{The effect of $\mathrm{Cl}$ on viscosity and its structural role}

$F$ has various possible structural environments in silicate melts including network-building aluminium as well as network-modifying cations with a preference of that with the higher field strength. On the other hand $\mathrm{Cl}$ occurs in silicate melts in salt-like cation-Cl environments as was inferred from NMR investigations (Stebbins and Du, 2002; Sandland et al., 2004) and X-ray absorption near edge structure (XANES) spectroscopy (Evans et al., 2008). Sandland et al. (2004) found that in mixed $\left(\mathrm{CaO}, \mathrm{Na}_{2} \mathrm{O}\right)-\mathrm{SiO}_{2}$ glasses, $\mathrm{Cl}$ shows no preferences for $\mathrm{Na}^{+}$or $\mathrm{Ca}^{2+}$. In contrast, Evans et al. (2008) showed with XANES that $\mathrm{Cl}$ in multi component aluminosilicate glasses favours divalent cations like $\mathrm{Ca}^{2+}$ and $\mathrm{Mg}^{2+}$ more than $\mathrm{Na}^{+}$ and $\mathrm{K}^{+}$.

According to this information the increase in viscosity due to $\mathrm{Cl}$ in the peralkaline melts (NACS) (Figs. 4 and 5B) could be explained by $\mathrm{Cl}$ bonding to network-modifying cations $\left(\mathrm{Na}^{+}{ }_{\mathrm{nm}} \mathrm{Ca}^{2+}{ }_{\mathrm{nm}}\right)$, and thus decreasing the number of non-bridging oxygens (NBO) and increasing the number of bridging oxygens (BO):

$$
\mathrm{Q}^{3}+\mathrm{Na}^{+}{ }_{\mathrm{nm}}+\mathrm{Cl}^{-} \Leftrightarrow \mathrm{Q}^{4}+\text { "NaCl-unit" }+0.5 \uparrow \mathrm{O}^{2-}
$$




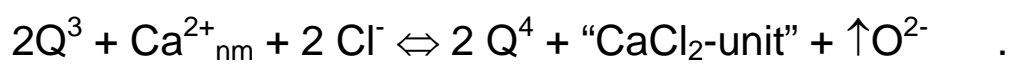

with $\mathrm{Q}^{3}$ species being $\mathrm{Al}$ or Si atoms tetrahedrally coordinated by 3 BO and 1 NBO and $\mathrm{Q}^{4}$ species being $\mathrm{Al}$ or $\mathrm{Si}$ atoms tetrahedrally coordinated by $4 \mathrm{BO}$ (for $\mathrm{Al}$ addition of charge balancers to the equations is needed). In this processes two $\mathrm{Q}^{3}$ with two NBO are transformed to two $\mathrm{Q}^{4}$, one $\mathrm{BO}$ and one free oxygen $\left(\uparrow \mathrm{O}^{2-}\right)$, that is removed from the structure to ensure charge-balancing for the two $\mathrm{Cl}^{-}$. However, $\mathrm{Cl}$ is not directly substituting for oxygen located at a tetrahedron, but is taking the network-modifying cations. The "NaCl-, $\mathrm{CaCl}_{2}$-units" are not isolated $\mathrm{NaCl}$ or $\mathrm{CaCl}_{2}$ molecules, but higher coordinated salt-like structures. Equation 11 and 12 also work with $\mathrm{Q}^{2}$ species on the left side and $\mathrm{Q}^{3}$ species on the right side of the equation, but then the number of $\mathrm{Na}^{+}{ }_{\mathrm{nm}}$ and $\mathrm{Ca}^{2+}{ }_{\mathrm{nm}}$, has to be increased.

In the peraluminous melts (ANCS) (Fig. 4 and 5A), $\mathrm{Cl}$ also bonds to $\mathrm{Na}$ and $\mathrm{Ca}$, but with different structural consequences, as these cations are all supposed to charge-balancing the tetrahedrally coordinated aluminium and there are no network-modifying cations:

$$
4 \mathrm{Q}^{4}{ }_{\mathrm{Al}}+4 \mathrm{Na}_{\mathrm{Cb}}^{+}+4 \mathrm{Cl}^{-} \Leftrightarrow 3 \mathrm{Q}^{4}{ }_{\mathrm{Al}}+\mathrm{Al}^{3+} \text {-unit }+4 " \mathrm{NaCl} \text {-units" + } 2 \uparrow \mathrm{O}^{2-}
$$

Here, because the number of charge balancers $\left(\mathrm{Na}^{+} \mathrm{cb}\right)$ is decreased due to the addition of $\mathrm{Cl}^{-}$one fully connected Al-tetrahedron $\left(\mathrm{Q}^{4}{ }_{\mathrm{Al}}\right)$ is transformed in $\mathrm{Al}^{3+}$-unit, that charge balances 3 other $\mathrm{Q}^{4}{ }_{\mathrm{Al}}$. In this scenario because one $\mathrm{Q}^{4}{ }_{\mathrm{Al}}$ with $2 \mathrm{BO}$ is transformed the number of BO is reduced from 8 to 6 and this explains the observed viscosity decrease (Figs. 3 and 4 ). It is not necessary to form an $\mathrm{Al}^{3+}$-unit, also a tricluster (e.g. Toplis et al., 1997a) is possible:

$$
2 \mathrm{Q}^{4}{ }_{\mathrm{Si}}+\mathrm{Q}^{4}{ }_{\mathrm{Al}}+\mathrm{Na}_{\mathrm{Cb}}^{+}+\mathrm{Cl}^{-} \Leftrightarrow \text { tricluster }+ \text { "NaCl-unit" }+0.5 \mathrm{O}^{2-}
$$

with the tricluster being for example $\mathrm{AlSi}_{2} \mathrm{O}_{5.5}$ having $5.5 \mathrm{BO}$. The $2 \mathrm{Q}^{4} \mathrm{Si}+\mathrm{Q}^{4}{ }_{\mathrm{Al}}$ have together $6 \mathrm{BO}$. So, the number of $\mathrm{BO}$ is reduced by 0.5 . A mechanism similar to those in Eqs. 13 and 14 would also work with $\mathrm{Ca}^{2+}$.

In the case of the aluminium-free melts (NCS) (Fig. 4 and 5C) one would expect based on the data for the peralkaline melts (NACS) - a viscosity increase due to the addition of $\mathrm{Cl}$. Instead, no significant change was observed in viscosity or in $T_{g}{ }^{12}$. Dingwell and Hess (1998) also observed no significant change in viscosity due to the presence of $\mathrm{Cl}$ in their strongly peralkaline melts (NBO/T >0.65). The NCS melts 
have an NBO/T of $\sim 0.68$, while the NACS have an NBO/T of $\sim 0.24$. It is probable that the $\mathrm{Cl}$ in the NCS melts does increase the polymerisation as in Eqs. 11-12, but because of the high degree of depolymerisation, the effect is not measurable as a change in viscosity. The observation, that compositional changes in strongly depolymerised silicate melts have less influence on viscosity, has already made for $\mathrm{Na}^{+}$(Toplis et al., 1997b), $\mathrm{H}_{2} \mathrm{O}$ (e.g. Mysen and Richet, 2005) and F (Dingwell et al., 1985).

\subsection{Conclusions}

While fluorine occurs in various structural sites as a function of melt composition (Kohn et al., 1991; Zeng and Stebbins, 2000; Stebbins and Zeng, 2000; Mysen et al., 2004 ) its presence always results in a decrease in viscosity. The effect of chlorine on the rheology of a silicate melts, however, has been found to be dependent upon the melt chemistry. Although $\mathrm{Cl}$ seems to bond in silicate melts always to the network-modifying cations (Stebbins and Du, 2002; Sandland et al., 2004; Evans et al., 2008), the effects on rheology highly depend on composition. The different effects of $\mathrm{Cl}$ depending on melt composition must be considered in models for the prediction of magma viscosity.

\section{Acknowledgements}

We wish to thank: Andreas Kronz for trouble shooting at the electron microprobe, Ursula Köhler, who helped with the viscosity measurements and Fred Neumeyer, who polished wonderful glass samples. Also we want to thank the Editor and the reviewers for their constructive discussions. This project was partially funded by the DFG grant WE 1810/9-1. 


\section{References}

Ablay, G.J., Ernst, G.G.J., Marti, J., Sparks, R.S.J., 1995. The $\sim 2$ ka subplinian eruption of Montana Blanca, Tenerife. Bull. Volcanol. 57, 337-355.

Aiuppa, A., Baker, D.R., Webster, J.D., 2009. Halogens in volcanic systems. Chem. Geol. 263, 1-18.

Angell, C.A., 1991. Relaxation in liquids, polymers and plastic crystals - strong/fragile patterns and problems. J. Non-Cryst. Solids 131-133, 13-31.

Bagdassarov, N.Sh., Dingwell, D.B., 1992. A rheological investigation of vesicular rhyolite. J. Volcanol. Geoth. Res. 50, 307-332.

Bansal, N.P., Doremus, R.H., 1986. Handbook of glass properties. Academic Press, New York.

Böhmer, R., Angell, C.A., 1992. Correlations of the nonexponentiality and state dependence of mechanical relaxations with bond connectivity in Ge-As-Se supercooled liquids. Phys. Rev. B 45, 10091- 10094.

Bryan, S.E., 2006. Petrology and geochemistry of the Quaternary caldera-forming, phonolitic Granadilla eruption, Tenerife (Canary Islands). J. Petrol. 47, 1557-1589.

Dienes, G.J., Klemm, H.F., 1946. Theory and application of the parallel plate plastometer. J. Appl. Phys. 17, 458-471.

Dingwell, D.B., 1989. Effect of fluorine on the viscosity of diopside liquid. Am. Mineral., 74, 333-338.

Dingwell, D.B., Hess, K.-U., 1998. Melt viscosities in the system Na-Fe-Si-O-Cl: Contrasting effects of $\mathrm{F}$ and $\mathrm{Cl}$ in alkaline melts. Am. Mineral. 83, 1016-1021.

Dingwell, D.B., Scarfe, C.M., Cronin D.J., 1985. The effect of F on viscosities in the system $\mathrm{Na}_{2} \mathrm{O}-\mathrm{Al}_{2} \mathrm{O}_{3}-\mathrm{SiO}_{2}$ implications for phonolites, trachytes and rhyolites. Am. Mineral. 70 , 80-87.

Evans, K.A., Mavrogenes, J.A., O`Neill, H.S., Keller, N.S., Jang, L.-Y., 2008. A preliminary investigation of chlorine XANES in silicate glasses. Geochem. Geophy. Geosyst. 9, No. 10, 1-15.

Fulcher, G.S., 1925. Analysis of recent measurements of the viscosity of glasses. J. Am. Ceram. Soc. 8, 339-355.

Gent, A.N., 1960. Theory of the parallel plate viscometer. Br. J. Appl. Phys. 11, 85-87. 
Giordano, D., Dingwell, D.B., 2003. Non-Arrhenian multicomponent melt viscosity: a model. Earth Planet. Sci. Lett. 208, 337-349.

Giordano, D., Romano, C., Dingwell, D. B., Poe, B., Behrens, H., 2004. The combined effects of water and fluorine on the viscosity of silicic magmas. Geochim. Cosmochim. Acta 68, 5159-5168.

Giordano, D., Russell, J.K., Dingwell, D.B., 2008. Viscosity of magmatic liquids: A model. Earth Planet. Sci. Lett. 271, 123-134.

Hui, H., Zhang, Y., 2007. Toward a general viscosity equation for natural anhydrous and hydrous silicate melts. Geochim. Cosmochim. Acta 71, 403-416.

Kohn S.C., Dupree, R., Mortuza, M.G., Henderson, C.M.B., 1991. NMR evidence for five- and six-coordinated aluminium fluoride complexes in F-bearing aluminosilicate glasses. Am. Mineral. 76, 309-312.

Lejeune, A., Bottinga, Y., Trull, T.W., Richet, P., 1999. Rheology of bubble-bearing magmas. Earth Planet. Sci. Lett. 166, 71-84.

Maier, C.G., Kelley, K.K., 1932. An equation for the representation of high temperature heat content data. J. Am. Chem. Soc. 54, 3242-3246.

Meerlender, G., 1974. Viskositäts-Temperaturverhalten des Standardglases I der DGG. Glastechn. Ber., 47, 1-3.

Moynihan, C.T., Easteal, A.J., DeBolt, M.A., Tucker, J., 1976. Dependence of the fictive temperature of glass on cooling rate. J. Am. Ceram. Soc. 59, 12-16.

Mysen, B.O., 1987. Magmatic silicate melts: Relations between bulk composition, structure and properties, in: Mysen, B. O. (Eds.), Magmatic processes: Physicochemical principles, Special Publication No. 1. The Geochemical Society, University Park, Pennsylvania, pp. 375-399.

Mysen B.O., Cody G.D., Smith A., 2004. Solubility mechanisms of fluorine in peralkaline and meta-aluminous silicate glasses and in melts to magmatic temperatures. Geochim. Cosmochim. Acta 68, 2745-2769.

Mysen, B., Richet, P., 2005. Silicate glasses and melts, Dev. Geochem. 10, Amsterdam.

Platzek, D.J., Ngai, K.L., 1991. Correlation of polymer segmental chain dynamics with temperature-dependent time-scale shifts. Macromolecules 24, 1222-1224.

Paterson, M.S., 1982. The determination of hydroxyl by infrared absorption in quartz, silicate glasses and similar materials. Bull. Mineral. 105, 20-29. 
Pocklington, H.C., 1940. Rough measurements of high viscosities. Proc. Cambridge Phil. Soc. 36, 507-508.

Richet, P., 1984.Viscosity and configurational entropy of silicate melts. Geochim. Cosmochim. Acta 48, 471-483.

Robie, R.A., Hemingway, B.S., Fischer, J.R., 1978. Thermodynamic properties of minerals and related substances at $298.15 \mathrm{~K}$ and 1 bar $\left(10^{5}\right.$ pascals) pressure and at higher temperatures. USGS Bull., 1452.

Rolandi, G., Mastrolorenzo, G., Barrella, A.M., Borrelli, A, 1993. The Avellino plinian eruption of Somma-Vesuvius ( 3760 y.B.P. ): the progressive evolution from magmatic to hydromagmatic style. J. Volcanol. Geoth. Res. 58, 67-88.

Sandland, T.O., Du, L.-S., Stebbins, J.F., Webster, J.D., 2004. Structure of Cl-containing silicate and aluminosilicate glasses: $\mathrm{A}{ }^{35} \mathrm{Cl}$ MAS-NMR study. Geochim. Cosmochim. Acta 68, 5059-5069.

Signorelli, S., Caroll, M.R., 2000. Solubility and fluid-melt partitioning of $\mathrm{Cl}$ in hydrous phonolitic melts. Geochim. Cosmochim. Acta 64, 2851-2862.

Sigurdsson, H., Cashdollar, S., Sparks, S.R.J., 1982. The eruption of Vesuvius in A. D. 79: Reconstruction from historical and volcanological evidence. Am. J. of Archaeol. 86, 39-51.

Stebbins, J.F., Du, L.-S., 2002. Chloride ion sites in silicate and aluminosilicate glasses: A preliminary study by ${ }^{35} \mathrm{Cl}$ solid-state NMR. Am. Mineral. 87, 359-363.

Stebbins, J.F., Zeng, Q., 2000. Cation ordering at fluoride sites in silicate glasses: a high-resolution ${ }^{19}$ F NMR study. J. of Non-Cryst. Solids 262, 1-5.

Stolper, E., 1982. Water in silicate glasses: An infrared spectroscopic study. Contrib. Mineral. Petrol., 81, 1-17.

Tamman, G., Hesse, W., 1926. Die Abhängigkeit der Viscosität von der Temperatur bei unterkühlten Flüssigkeiten. ZAAC 156, 245-257.

Toplis, M.J., 1998. Energy barriers to viscous flow and the prediction of glass transition temperatures of molten silicates. Am. Mineral. 83, 480-490.

Toplis, M.J., Dingwell, D.B., Lenci, T., 1997a. Peraluminous viscosity maxima in $\mathrm{Na}_{2} \mathrm{O}-\mathrm{Al}_{2} \mathrm{O}_{3}-\mathrm{SiO}_{2}$ liquids: The role of triclusters in tectosilicate melts. Geochim. Cosmochim. Acta 61, 2605-2612.

Toplis, M.J., Dingwell, D.B., Hess, K.-U., Lenci, T., 1997b. Viscosity, fragility, and configurational entropy of melts along the join $\mathrm{SiO}_{2}-\mathrm{NaAlSiO}_{4}$. Am. Mineral. 82, 979-990. 
Varshneya A.K., Burlingname, N.H., Schultze, W.H., 1990. Parallel plate viscometry to study deformation-induced viscosity changes in glass. Glastechn. Ber. 63K, 447-459.

Vogel, H., 1921. Temperaturabhängigkeitsgesetz der Viskosität von Flüssigkeiten. Phys. Z. 22, 645-646.

Webb, S.L., 2011. Configurational heat capacity of (Mg, Ca, Sr, Ba)O- $-\mathrm{Al}_{2} \mathrm{O}_{3}-\mathrm{SiO}_{2}$ melts. Eur. J. Mineral. 23, 457-497.

Webb, S.L., Banaszak, M., Köhler, U., Rausch S., Raschke, G., 2007. The viscosity of $\mathrm{Na}_{2} \mathrm{O}-\mathrm{CaO}-\mathrm{Al}_{2} \mathrm{O}_{3}-\mathrm{SiO}_{2}$ melts. Eur. J. Mineral. 19, 681-692.

Wilson, S.J., Poole, D., 1990. Glass viscosity measurement by parallel plate rheometry. Mat. Res. Bull. 25, 113-118.

Whittington, A., Richet, P., Linnard, Y., Holtz, F., 2001. The viscosity of hydrous phonolites and trachytes. Chem. Geol. 174, 209-223.

Zeng, Q., Stebbins, J.F., 2000. Fluoride sites in aluminosilicate glasses: High-resolution ${ }^{19}$ F NMR results. Am. Mineral. 85, 863-867.

Zimova, M., Webb, S.L., 2006. The effect of chlorine on the viscosity of $\mathrm{Na}_{2} \mathrm{O}-\mathrm{Fe}_{2} \mathrm{O}_{3}-\mathrm{Al}_{2} \mathrm{O}_{3}-\mathrm{SiO}_{2}$ melts. Am. Mineral. 91, 344-352.

Zimova, M., Webb, S.L., 2007. The combined effects of chlorine and fluorine on the viscosity of aluminosilicate melts. Geochim. Cosmochim. Acta 71, 1553-1562.

\section{Annotation}

In the original version of this paper the parameters obtained from the VFT fits for the samples NACS $1.1 \mathrm{Cl}$ and NACS $1.9 \mathrm{Cl}$ are missing. The values are:

In Table 5

\begin{tabular}{lcccccc}
\hline & $T_{g}^{12}{ }^{12}$ & \pm & $m_{\text {Arr }}$ & $T_{g}^{12}$ VFT & \pm & \multicolumn{2}{c}{$m_{\text {VFT }}$} \\
& $\mathrm{K}$ & $\mathrm{K}$ & & $\mathrm{K}$ & $\mathrm{K}$ & \\
\hline NACS 1.1Cl & 906 & 3 & 34 & 907 & 2 & 35 \\
NACS 1.9F & 852 & 3 & 32 & 849 & 2 & 32 \\
\hline
\end{tabular}

In Table 6

\begin{tabular}{lcccccccc}
\hline & $A_{V F T}{ }^{\mathrm{a}}$ & $B_{V F T}$ & $\bar{\sigma}^{\mathrm{c}}$ & $C_{V F T}$ & $\bar{\sigma}$ & $V^{2 \mathrm{~d}}$ & $N^{\mathrm{e}}$ & $S{ }^{\mathrm{f}}$ \\
& & $\mathrm{K}$ & $\mathrm{K}$ & $\mathrm{K}$ & $\mathrm{K}$ & & & \\
\hline NACS 1.1Cl & -4.5 & 7111 & 7 & 476.5 & 0.6 & 45.20 & 10128 & 0.07 \\
NACS 1.9 F & -4.5 & 7217 & 8 & 411.3 & 0.7 & 31.77 & 8056 & 0.06 \\
\hline
\end{tabular}


3. The effect of chlorine, fluorine and water on the viscosity of aluminosilicate melts

Amrei Baasner, Burkhard C. Schmidt \& Sharon L. Webb

Revised version submitted to Chemical Geology on $28^{\text {th }}$ July 2013

Status August 2013: accepted, waiting for proofs 


\section{Credits}

The scientific work and the writing for the publication

Baasner, A., Schmidt, B.C., Webb, S.L., 2013b. The effect of chlorine, fluorine and water on the viscosity of aluminosilicate melts. Chem. Geol. 357, 134-149. (Status August 2013: accepted, waiting for proofs).

\section{was conducted by}

\section{Amrei Baasner}

o Synthesis of the glasses containing both, $\mathrm{F}$ and $\mathrm{Cl}$, at 1 atm

o Synthesis of the fluorine-bearing glasses doped with $\mathrm{CoO}$ at $1 \mathrm{~atm}$

o Synthesis of the hydrous samples made under pressure in the internally heated pressure vessel and the piston cylinder apparatus

o Density measurements

- IR spectroscopy

o Karl-Fischer-Titration

o Thermogravimetry

o Viscosity measurements with the micropenetration technique of the above mentioned samples (some of the viscosity measurements on the fluorine-bearing samples doped with $\mathrm{CoO}$ were performed by Christina Norwig during her internship)

o The evaluation of the above mentioned data

o Figures, tables and most of the text

o Most of the ideas presented in the discussion and conclusion section

Burkhard C. Schmidt

o General laboratory trouble shooting and support

o Some of the ideas presented in the discussion and conclusion section

o Correction and improvement of the figures, tables and text

Sharon L. Webb

o Synthesis of the glasses containing either $\mathrm{F}$ or $\mathrm{Cl}$ at $1 \mathrm{~atm}$

o Viscosity measurements with the micropenetration technique of the samples that contain either $\mathrm{F}$ or $\mathrm{Cl}$.

o The evaluation of the above mentioned data

o Some of the ideas presented in the discussion and conclusion section

o Correction and improvement of the figures, tables and text 


\section{Abstract}

The influence of 1.6 to $14.5 \mathrm{~mol} \%$ water, 1.1 to $18.3 \mathrm{~mol} \%$ fluorine $(F)$ and 0.5 to $1.4 \mathrm{~mol} \%$ chlorine $(\mathrm{Cl})$ on the viscosity of peralkaline and peraluminous $\mathrm{Na}_{2} \mathrm{O}-\mathrm{CaO}-\mathrm{Al}_{2} \mathrm{O}_{3}-\mathrm{SiO}_{2}$ melts as a model system for phonolites was studied with the micropenetration method within the range of $10^{9}$ to $10^{13} \mathrm{Pas}$. Water and $\mathrm{F}$ alone and combined decrease viscosity non-linearly. With increasing $\mathrm{F}$ and water concentration the further addition of $\mathrm{F}$ and water becomes less effective in decreasing viscosity. Water decreases the viscosity of peraluminous melts more strongly than that of peralkaline melts. In the halogen-free peraluminous sample 5 mol\% water decreases $T_{g}{ }^{12}$ (the temperature where the viscosity $=10^{12} \mathrm{Pas}$ ) by $259 \pm 5 \mathrm{~K}$, while in the halogen-free peralkaline sample $5 \mathrm{~mol} \%$ water decreases $T_{g}^{12}$ by $189 \pm 5 \mathrm{~K}$. Fluorine (on a mol\% basis) decreases the viscosity of $\mathrm{Na}_{2} \mathrm{O}-\mathrm{CaO}-\mathrm{Al}_{2} \mathrm{O}_{3}-\mathrm{SiO}_{2}$ melts less than water. In the peraluminous melts the addition of 5 mol\% $\mathrm{F}$ decreases $T_{g}{ }^{12}$ by $\sim 95 \mathrm{~K}$. In the peralkaline melt $5 \mathrm{~mol} \% \mathrm{~F}$ decreases $T_{g}{ }^{12}$ by $\sim 30 \mathrm{~K}$. However, a significant decrease in $T_{g}{ }^{12}$ was only observed up to a $\mathrm{F}$ concentration of $1.9 \mathrm{~mol} \% \mathrm{~F}$, another sample with $6.2 \mathrm{~mol} \% \mathrm{~F}$ showed no further decrease of $T_{g}{ }^{12}$. In all hydrous peraluminous and peralkaline samples that contain $\mathrm{F}$ alone or combined with $\mathrm{Cl}$, the decrease of viscosity due to the addition of water is smaller than in the halogen-free samples. In a peraluminous melt with $18.3 \mathrm{~mol} \% \mathrm{~F}$ the addition of $5 \mathrm{~mol} \%$ water decreases $T_{g}{ }^{12}$ by about $152 \pm 5 \mathrm{~K}$ compared to the dry melt. In a peralkaline melt with $1.9 \mathrm{~mol} \% \mathrm{~F}$ the addition of $5 \mathrm{~mol} \%$ water decreases $T_{g}{ }^{12}$ by about $146 \pm 5 \mathrm{~K}$ compared to the dry melt. In both cases this is significant less than for the halogen-free samples. In peralkaline melts $\mathrm{Cl}$ has no influence on the decrease of viscosity upon the addition of water. The effects of water and $\mathrm{Cl}$ on viscosity are independent of each other and add together. The effects of water and F on viscosity are not independent, which could be, in the case of the peralkaline samples related to changes in F speciation due to the presence of water. 


\subsection{Introduction}

In nature felsic and intermediate magmas can contain several wt\% of volatiles like water $\left(\mathrm{H}_{2} \mathrm{O} / \mathrm{OH}\right)$, fluorine $(\mathrm{F})$ and chlorine $(\mathrm{Cl})$ at magmatic pressures. The influence of volatiles on viscosity is a matter of interest, as viscosity is an important parameter for magma ascent, magma degassing, and magma fragmentation (e.g. Sparks et al., 1994; Scaillet et al., 1998; Papale, 1999; Gottsmann et al., 2009). Water is the most abundant volatile in felsic and intermediate magmas, in which melt inclusions reveal pre-eruptive $\mathrm{H}_{2} \mathrm{O}$ contents up to $6-10 \mathrm{wt} \%$ (e.g. Di Muro et al., 2006). Detailed research has investigated the influence of water on the viscosity of silicate melts across a wide range of compositions (e.g. Shaw, 1963; Dingwell et al., 1996; Romano et al., 2001; Whittington et al., 2001). In all investigated silicate melts water reduces the viscosity. This effect is stronger in polymerised melts like rhyolites than in depolymerised melts like basalts (e.g. Mysen and Richet, 2005). The general abundance of $\mathrm{F}$ in intermediate and felsic magmas is very variable depending on the geological setting. Tin-granites and topaz-rhyolites can contain up to $7 \mathrm{wt} \% \mathrm{~F}$ (e.g. Aiuppa et al., 2009). There are several studies, which show that $F$ decreases the viscosity of silicate melts (Dingwell et al., 1985; Dingwell, 1989; Dingwell et al., 1993a; Dingwell and Hess, 1998; Zimova and Webb, 2007; Baasner et al. 2013; Bartels et al., 2013). Evolved peralkaline magmas can contain up to $\sim 1 \mathrm{wt} \%$, Cl like for example phonolites (Cioni et al., 1998; Aiuppa et al., 2009) and pantellerites (Lowenstern, 1994), while other felsic and intermediate magmas usually contain lower concentrations (Aiuppa et al., 2009). There are just a few studies investigating the influence of $\mathrm{Cl}$ alone (Dingwell and Hess, 1998; Zimova and Webb, 2006) and combined with F (Zimova and Webb, 2007; Baasner et al., 2013) on the viscosity of silicate melts. A comparison of these studies shows that the influence of $\mathrm{Cl}$, whether it decreases or increases viscosity, depends on the melt composition and temperature. Baasner et al. (2013) found in $\mathrm{Na}_{2} \mathrm{O}-\mathrm{CaO}-\mathrm{Al}_{2} \mathrm{O}_{3}-\mathrm{SiO}_{2}$ melts that $\mathrm{Cl}$ decreases viscosity in peraluminous melts $\left(\mathrm{Al}_{2} \mathrm{O}_{3}>\left[\mathrm{Na}_{2} \mathrm{O}+\mathrm{CaO}\right]\right)$ and increases viscosity in peralkaline melts $\left(\mathrm{Al}_{2} \mathrm{O}_{3}<\left[\mathrm{Na}_{2} \mathrm{O}+\mathrm{CaO}\right]\right)$. $\mathrm{F}$ decreases the viscosity in both types of melts. The effects of $\mathrm{F}$ and $\mathrm{Cl}$ on viscosity are independent of each other, i.e. the single effects are additive if both halogens are present in the melt. Up to now there have been only three studies about the combined influence of $F$ and water on 
the viscosity of silicate melts (Baker and Vaillancourt, 1995; Giordano et al., 2004; Bartels et al., 2013) and none on the combined effect of $\mathrm{Cl}, \mathrm{F}$ and water on viscosity. Giordano et al. (2004) found that at volatile contents of more than $10 \mathrm{~mol} \%$ $\left(\mathrm{H}_{2} \mathrm{O}+\mathrm{F}_{2} \mathrm{O}_{-1}\right)$ the combined effect of water and $\mathrm{F}$ on the viscosity of haplogranitic melts is undistinguishable. Bartels et al. (2013) found that in pegmatite forming melts the addition of water and fluorine decreases the viscosity less than the addition of the same amount of pure water, but with increasing water and F content the differences become less.

In this study we have investigated with the micropenetration technique within the range of $10^{9}$ to $10^{13} \mathrm{~Pa} s$ the combined effect of $\mathrm{Cl}(0.5-1.4 \mathrm{~mol} \% / 0.2-0.8 \mathrm{wt} \%), \mathrm{F}$ (1.1 - $18.3 \mathrm{~mol} \% / 0.1-6 \mathrm{wt} \%)$ and water (1.6- $14.5 \mathrm{~mol} \% / 0.1-4.5 \mathrm{wt} \%)$ on the viscosity-temperature behavior of peraluminous and peralkaline $\mathrm{Na}_{2} \mathrm{O}-\mathrm{CaO}-\mathrm{Al}_{2} \mathrm{O}_{3}-\mathrm{SiO}_{2}$ melts as a simple approach to natural evolved magmas like phonolites. We also look at the effect of these volatiles on density. With this study we want to answer the question, whether the effects of $\mathrm{Cl}, \mathrm{F}$ and water on viscosity of $\mathrm{Na}_{2} \mathrm{O}-\mathrm{CaO}-\mathrm{Al}_{2} \mathrm{O}_{3}-\mathrm{SiO}_{2}$ melts are independent of each other or not.

\subsection{Methods}

\subsubsection{Starting Materials}

The anhydrous peraluminous (ANCS) and peralkaline (NACS) $\mathrm{Na} 2 \mathrm{O}-\mathrm{CaO}-\mathrm{Al}_{2} \mathrm{O}_{3}-\mathrm{SiO}_{2}$ starting glasses from Baasner et al. (2013a) and Baasner et al. (2014), were melted in a $1 \mathrm{~atm}$ furnace at 1523 and $1923 \mathrm{~K}$ for $1-7 \mathrm{~h}$ from oxides and carbonates compounds, which were decarbonated at $1173 \mathrm{~K}$ for $12 \mathrm{~h}$. The halogen-bearing peralkaline glasses were produced by adding $\mathrm{NH}_{4} \mathrm{Cl}$ and $\mathrm{NH}_{4} \mathrm{~F}$ to the halogen-free base glass, while the halogen-bearing peraluminous melts were produced from mixtures of $\mathrm{NaCl}, \mathrm{NaF}, \mathrm{CaCl}_{2}, \mathrm{CaF}_{2}$ with oxide and carbonate compounds in the correct proportion to maintain a constant base composition. The peraluminous glasses required melting temperatures above $1873 \mathrm{~K}$, due to of their high liquidus temperatures, while the peralkaline melts were already molten around $1473 \mathrm{~K}$, but were produced at temperatures above $1523 \mathrm{~K}$ to reduce the amount of bubbles. Table 1a-b shows the composition of the glasses in mol\% and at $\%$. The composition of the glasses with $\mathrm{a} \mathrm{SiO}_{2}$ concentration of $\sim 66$ mol\% was chosen as a model 
system for phonolites. The composition was analysed on 8 - 14 spots per sample with a JEOL JXA-8900RL electron microprobe using a $15 \mathrm{kV}, 15 \mathrm{nA}$ beam defocused to $30 \mu \mathrm{m}$ (effective $21 \mu \mathrm{m}$ ). The composition of NACS 6.2F we measured the composition before and after the viscosity measurements with minimum repolishing, however, no significant difference in composition was found. We also provide in Table $1 \mathrm{a}$ the ratio $\mathrm{y}=\left(\mathrm{Na}_{2} \mathrm{O}+\mathrm{CaO}\right) /\left(\mathrm{Na}_{2} \mathrm{O}+\mathrm{CaO}+\mathrm{Al}_{2} \mathrm{O}_{3}\right)$ in mole fraction, which is an indicator for the degree of polymerisation of the melt. This ratio takes into account the number of $\mathrm{Na}$ and $\mathrm{Ca}$ atoms that could either charge-balance $\mathrm{Al}$ or create non-bridging oxygens (NBO) in the melt (e.g. Toplis et al., 1997; Webb et al., 2007). Peraluminous melts, where not enough cations are available to charge-balance all Al tetrahedra (Al tetrahedrally coordinated by 4 oxygen) and most $\mathrm{O}$ exist as bridging oxygens (BO) (e.g. Thompson and Stebbins, 2011), have a $y$ ratio $<0.5$. Peralkaline melts, which contain enough cations $(\mathrm{Na}, \mathrm{Ca})$ to charge balance all of the $\mathrm{Al}$ tetrahedra and to create non-bridging oxygens (NBO), have a $y$ ratio $>0.5$. For the present peraluminous melts $\gamma$ is $0.41 \pm 0.03$ and for the present peralkaline melts $\gamma$ is $0.65 \pm 0.01$. Another indicator for the degree of polymerisation is the number of non-bridging oxygens per tetrahedron (NBO/T), which is zero for fully polymerised and four for fully depolymerised melts (Mysen, 1987). The calculated NBO/T ratio can become negative, if there is more Al than charge-balancing cations. The dry halogen-free peraluminous melt have a NBO/T $=-0.08$ and the dry halogen-free peralkaline melt has a NBO/T = 0.24 (Baasner et al., 2013).

Hydrous samples were produced from the nominally dry glasses under pressure. For the hydrous peralkaline samples $200-300 \mathrm{mg}$ glass powder of the dry starting glasses together with 0.5, 1.0, 2.5 and 4.0 wt $\% \mathrm{H}_{2} \mathrm{O}$ were welded into $\mathrm{Au}_{75} \mathrm{Pd}_{25}$ or $\mathrm{Pt}$ capsules of $25 \mathrm{~mm}$ length, $4 \mathrm{~mm}$ outer and $3.6 \mathrm{~mm}$ inner diameter. The samples were hydrated in an internally heated pressure vessel (IHPV) at $1473-1523 \mathrm{~K}$ and 150 - $250 \mathrm{MPa}$ for 2 - 3 days. At the end of the experiment the melts were rapidly quenched to glasses $\sim 100-150 \mathrm{~K} \mathrm{~s}^{-1}$ with a device similar to that described by Roux and Lefèvre (1992). Under the same conditions nominally dry samples of the halogen-bearing glasses were produced for comparison with those synthesized at $1 \mathrm{~atm}$. Because of their high liquidus temperatures $(>1773 \mathrm{~K})$, the hydrous peraluminous samples were produced in a piston cylinder apparatus at $1723-1923 \mathrm{~K}$ and $5 \mathrm{kbar}$ for $3 \mathrm{~h}$. The quench rate was approximately $30-50 \mathrm{~K} \mathrm{~s}^{-1}$. For the piston cylinder experiments $150 \mathrm{mg}$ glass powder of the dry starting glasses 
together with 2, 3 and 4 wt $\% \mathrm{H}_{2} \mathrm{O}$ were welded in $\mathrm{Pt}_{90} \mathrm{Rh}_{10}$ capsules with the design developed by Audetat and Bali (2010). The capsules consist of a tube (10 mm length, $5 \mathrm{~mm}$ outer and $4.3 \mathrm{~mm}$ inner diameter), a top and a bottom lid and a $1 \mathrm{~mm}$ thick $\mathrm{Pt}$ plate. The $1 \mathrm{~mm}$ thick plate was pressed on top of the glass powder in the capsule and then the whole capsule was crimped at the position of the plate to prevent water loss during welding of the top lid (Audetat and Bali, 2010). The plate also helped to compress the glass powder and gave the capsule more stability. The assemblies had a length of $35 \mathrm{~mm}$ and a diameter of $12.7 \mathrm{~mm}$. They consisted from outside to inside of a $\mathrm{NaCl}$ sleeve, a $\mathrm{MgO}$ sleeve, a stepped graphite furnace with a thicker part at the position of the capsule, a MgO tube around the capsule, a MgO bottom and a MgO top plug above the capsule and a $\mathrm{MgO}$ thermocouple tube with a $\mathrm{Pt}_{90} \mathrm{Rh}_{10} / \mathrm{Pt}$ thermocouple. The stepped graphite furnace was used to reduce the temperature gradient at high temperature (Watson et al., 2002). With the MgO thermocouple tube, the S-type thermocouple survived $\sim 5$ min at $1923 \mathrm{~K}$, whereas thermocouples with in a sintered $\mathrm{Al}_{2} \mathrm{O}_{3}$ tube broke before reaching the final temperature of $1923 \mathrm{~K}$. Before every IHPV and piston cylinder experiment the capsules spent 1 day in the drying oven to distribute the water across the capsule and check for water loss. After the IHPV experiments the weight of the capsules was checked again. In the case of the piston cylinder experiments this was not possible as too much assembly material stuck to the capsules.

After the experiments the samples were then sawn into $1.5 \mathrm{~mm}$ discs and were polished to a thickness of $0.8-1 \mathrm{~mm}$. In the IHPV experiments material for $5-10$ discs was produced, whereas the material from the piston cylinder experiments provided only two discs. The thickness of the samples was determined with a digital micrometer ( $\pm 0.003 \mathrm{~mm}$ precision). The glasses from the piston cylinder experiments had some cracks, especially at the top of the capsule. To hold these samples together the platinum around the peraluminous glass samples was not removed and the whole capsule was cut into slices. After polishing, the glass samples were checked with optical microscopy for bubbles and crystals. In hydrous peralkaline samples made in IHPV experiments a few bubbles were usually observed. However, the bubble content in the samples did not exceed 1 vol\% and contained no crystals. The piston cylinder samples were in most cases bubble-free. 
Table 1a. Electron microprobe (EMP) analysis as oxide components of the glass samples with the $2 \sigma$ standard deviation normalised to 100 mol\% ${ }^{\mathrm{a}}$.

\begin{tabular}{|c|c|c|c|c|c|c|c|c|c|c|c|c|c|}
\hline & $\begin{array}{c}\mathrm{SiO}_{2} \\
{[\mathrm{~mol} \%]}\end{array}$ & $\begin{array}{c}2 \sigma \\
{[\mathrm{mol} \%]}\end{array}$ & $\begin{array}{c}\mathrm{Al}_{2} \mathrm{O}_{3} \\
{[\mathrm{~mol} \%]}\end{array}$ & $\begin{array}{c}2 \sigma \\
{[\mathrm{mol} \%]}\end{array}$ & $\begin{array}{c}\mathrm{CaO} \\
{[\mathrm{mol} \%]}\end{array}$ & $\begin{array}{c}2 \sigma \\
{[\mathrm{mol} \%]}\end{array}$ & $\begin{array}{c}\mathrm{Na}_{2} \mathrm{O} \\
{[\mathrm{mol} \%]}\end{array}$ & $\begin{array}{c}2 \sigma \\
{[\mathrm{mol} \%]}\end{array}$ & $\begin{array}{c}\mathrm{F} \\
{[\mathrm{mol} \%]}\end{array}$ & $\begin{array}{c}2 \sigma \\
{[\mathrm{mol} \%]}\end{array}$ & $\begin{array}{c}\mathrm{Cl} \\
{[\mathrm{mol} \%]}\end{array}$ & $\begin{array}{c}2 \sigma \\
{[\mathrm{mol} \%]}\end{array}$ & $\gamma^{c}$ \\
\hline \multicolumn{14}{|l|}{ Peralkaline } \\
\hline $\mathrm{NACS}^{d}$ & 66.62 & 0.52 & 11.28 & 0.34 & 5.23 & 0.12 & 16.87 & 0.22 & - & - & - & - & 0.66 \\
\hline NACS $0.7 F \quad 0.6 \mathrm{Cl}^{\mathrm{d}}$ & 64.06 & 1.44 & 12.28 & 1.12 & 5.39 & 0.96 & 16.98 & 0.50 & 0.71 & 0.26 & 0.57 & 0.14 & 0.65 \\
\hline NACS $1.1 \mathrm{~F} 1.1 \mathrm{Cl}^{\mathrm{d}}$ & 64.75 & 0.64 & 11.83 & 0.26 & 5.34 & 0.26 & 15.89 & 0.38 & 1.06 & 0.26 & 1.13 & 0.16 & 0.64 \\
\hline NACS $2.6 \mathrm{~F} 1.4 \mathrm{Cl}^{\mathrm{d}}$ & 64.50 & 0.50 & 11.60 & 0.14 & 5.33 & 0.20 & 14.61 & 0.16 & 2.58 & 0.44 & 1.38 & 0.10 & 0.63 \\
\hline $\operatorname{NACS} 1.1 \mathrm{Cl}^{\mathrm{d}}$ & 65.96 & 0.40 & 11.73 & 0.20 & 5.61 & 0.18 & 15.57 & 0.26 & - & - & 1.13 & 0.02 & 0.64 \\
\hline NACS $1.9 F^{d}$ & 64.73 & 0.28 & 11.41 & 0.14 & 5.50 & 0.16 & 16.50 & 0.18 & 1.86 & 0.18 & - & - & 0.66 \\
\hline NACS $6.2 F^{\text {be }}$ & 63.30 & 0.68 & 11.22 & 0.16 & 5.36 & 0.12 & 13.92 & 0.21 & 6.20 & 0.71 & - & - & 0.63 \\
\hline NACS $6.2 F^{b f}$ & 63.49 & 0.52 & 11.18 & 0.10 & 5.48 & 0.13 & 13.73 & 0.22 & 6.13 & 0.60 & - & - & 0.63 \\
\hline \multicolumn{14}{|l|}{ Peraluminous } \\
\hline ANCS $^{d}$ & 65.94 & 1.62 & 19.2 & 1.08 & 4.19 & 0.38 & 10.67 & 0.24 & - & - & - & - & 0.44 \\
\hline ANCS $0.5 F \quad 0.5 \mathrm{Cl}^{\mathrm{d}}$ & 66.40 & 1.64 & 19.06 & 1.20 & 3.81 & 0.40 & 9.82 & 0.14 & 0.46 & 0.24 & 0.45 & 0.14 & 0.42 \\
\hline ANCS $1.2 \mathrm{~F} 1.1 \mathrm{Cl}^{\mathrm{d}}$ & 64.56 & 1.84 & 20.58 & 1.22 & 3.85 & 0.14 & 8.69 & 0.28 & 1.21 & 0.22 & 1.10 & 0.16 & 0.38 \\
\hline ANCS $2.3 F{ }^{0.9} \mathrm{Cl}^{\mathrm{d}}$ & 62.84 & 1.36 & 21.25 & 1.14 & 4.06 & 0.26 & 8.58 & 0.12 & 2.34 & 0.24 & 0.92 & 0.08 & 0.37 \\
\hline ANCS $0.6 \mathrm{Cl}^{\mathrm{d}}$ & 65.89 & 0.54 & 20.32 & 0.30 & 3.73 & 0.12 & 9.43 & 0.50 & - & - & 0.63 & 0.04 & 0.39 \\
\hline ANCS $1.1 F^{\text {be }}$ & 64.38 & 0.22 & 19.36 & 0.20 & 3.65 & 0.10 & 11.52 & 0.13 & 1.09 & 0.24 & - & - & 0.44 \\
\hline ANCS $3.5 F^{\text {be }}$ & 63.51 & 1.36 & 18.43 & 0.76 & 3.53 & 0.25 & 11.05 & 0.67 & 3.48 & 0.26 & - & - & 0.44 \\
\hline ANCS 9.7F & 59.14 & 0.71 & 18.00 & 0.34 & 3.65 & 0.08 & 9.48 & 0.91 & 9.73 & 0.48 & - & - & 0.42 \\
\hline ANCS $18.3 F^{d}$ & 53.12 & 0.54 & 16.26 & 0.18 & 3.11 & 0.18 & 9.27 & 0.14 & 18.25 & 0.42 & - & - & 0.43 \\
\hline
\end{tabular}

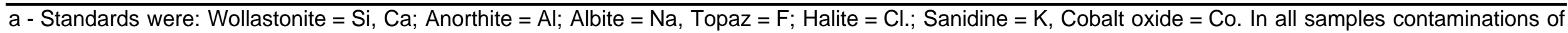
$\mathrm{K}_{2} \mathrm{O}(<0.1 \mathrm{~mol} \%)$ from the $\mathrm{SiO}_{2}$ and $\mathrm{Al}_{2} \mathrm{O}_{3}$ chemicals were observed.

b - Doped with $<0.12 \mathrm{~mol} \% \mathrm{CoO}$, because samples were used also for NMR spectroscopy.

$\mathrm{c}-\mathrm{V}=\left(\mathrm{Na}_{2} \mathrm{O}+\mathrm{CaO}\right) /\left(\mathrm{Na}_{2} \mathrm{O}+\mathrm{CaO}+\mathrm{Al}_{2} \mathrm{O}_{3}\right)$ in mole fraction is an indicator for the degree of polymerisation of the melt by taking into account the number of sodium

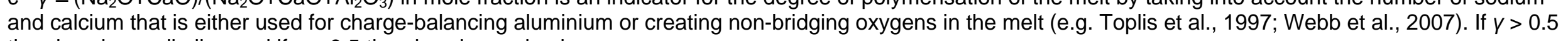
the glass is peralkaline and if $y<0.5$ the glass is peraluminous.

d - Published in Baasner et al. (2013a)

e - Published in Baasner et al. (2013b)

$\mathrm{f}$ - Control analysis after viscosity measurements. Analysis was not used for further evaluation. 
Table $1 \mathrm{~b}$. Electron microprobe (EMP) analysis of the glass samples together with the $2 \sigma$ standard deviation normalised to 100 atom $\%{ }^{\mathrm{a}}$.

\begin{tabular}{|c|c|c|c|c|c|c|c|c|c|c|c|c|c|}
\hline & $\begin{array}{c}\mathrm{Si} \\
\text { at\% }\end{array}$ & $\begin{array}{c}2 \sigma \\
\text { at } \%\end{array}$ & $\begin{array}{c}\mathrm{Al} \\
\text { at } \% \\
\end{array}$ & $\begin{array}{c}2 \sigma \\
\text { at } \%\end{array}$ & $\begin{array}{l}\mathrm{Ca} \\
\mathrm{at} \%\end{array}$ & $\begin{array}{c}2 \sigma \\
\text { at } \%\end{array}$ & $\begin{array}{l}\mathrm{Na} \\
\text { at } \%\end{array}$ & $\begin{array}{c}2 \sigma \\
\text { at } \%\end{array}$ & $\begin{array}{c}\mathrm{F} \\
\text { at\% }\end{array}$ & $\begin{array}{c}2 \sigma \\
\text { at } \%\end{array}$ & $\begin{array}{c}\mathrm{Cl} \\
\text { at\% } \\
\end{array}$ & $\begin{array}{c}2 \sigma \\
\text { at } \%\end{array}$ & $\begin{array}{c}\mathrm{O}^{\mathrm{c}} \\
\mathrm{at} \% \\
\end{array}$ \\
\hline \multicolumn{14}{|l|}{ Peralkaline } \\
\hline $\operatorname{NACS}^{d}$ & 20.99 & 0.16 & 7.11 & 0.22 & 1.65 & 0.04 & 10.63 & 0.14 & - & - & - & - & 59.62 \\
\hline NACS $0.7 \mathrm{~F} 0.6 \mathrm{Cl}^{\mathrm{d}}$ & 20.27 & 0.46 & 7.78 & 0.72 & 1.71 & 0.30 & 10.75 & 0.32 & 0.23 & 0.08 & 0.18 & 0.04 & 59.09 \\
\hline NACS $1.1 \mathrm{~F} 1.1 \mathrm{Cl}^{\mathrm{d}}$ & 20.70 & 0.20 & 7.56 & 0.16 & 1.71 & 0.08 & 10.16 & 0.24 & 0.34 & 0.08 & 0.36 & 0.04 & 59.18 \\
\hline NACS $2.6 \mathrm{~F} 1.4 \mathrm{Cl}^{\mathrm{d}}$ & 20.94 & 0.16 & 7.53 & 0.10 & 1.73 & 0.06 & 9.49 & 0.10 & 0.84 & 0.14 & 0.45 & 0.04 & 59.02 \\
\hline $\operatorname{NACS} 1.1 \mathrm{Cl}^{\mathrm{d}}$ & 20.94 & 0.12 & 7.45 & 0.12 & 1.78 & 0.06 & 9.88 & 0.16 & - & - & 0.36 & 0.01 & 59.59 \\
\hline NACS $1.9 F^{d}$ & 20.70 & 0.08 & 7.30 & 0.10 & 1.76 & 0.04 & 10.56 & 0.12 & 0.60 & 0.06 & - & - & 59.09 \\
\hline NACS $6.2 F^{\text {be }}$ & 20.99 & 0.23 & 7.44 & 0.11 & 1.78 & 0.04 & 9.23 & 0.14 & 2.05 & 0.23 & - & - & 58.51 \\
\hline NACS $6.2 F^{b f}$ & 21.05 & 0.17 & 7.41 & 0.07 & 1.82 & 0.04 & 9.10 & 0.15 & 2.03 & 0.20 & - & - & 58.58 \\
\hline \multicolumn{14}{|l|}{ Peraluminous } \\
\hline ANCS $^{d}$ & 19.73 & 0.48 & 11.49 & 0.64 & 1.25 & 0.12 & 6.38 & 0.14 & - & - & - & - & 61.14 \\
\hline ANCS $0.5 \mathrm{~F} 0.5 \mathrm{Cl}^{\mathrm{d}}$ & 20.00 & 0.50 & 11.48 & 0.72 & 1.15 & 0.12 & 5.91 & 0.08 & 0.14 & 0.08 & 0.13 & 0.04 & 61.19 \\
\hline ANCS $1.2 \mathrm{~F} 1.1 \mathrm{Cl}^{\mathrm{d}}$ & 19.47 & 0.56 & 12.42 & 0.72 & 1.16 & 0.04 & 5.25 & 0.18 & 0.37 & 0.06 & 0.33 & 0.04 & 61.01 \\
\hline ANCS $2.3 F=0.9 \mathrm{Cl}^{\mathrm{d}}$ & 19.03 & 0.42 & 12.87 & 0.68 & 1.23 & 0.08 & 5.20 & 0.08 & 0.71 & 0.08 & 0.28 & 0.02 & 60.69 \\
\hline ANCS $0.6 \mathrm{Cl}^{d}$ & 19.65 & 0.16 & 12.12 & 0.18 & 1.11 & 0.04 & 5.62 & 0.30 & - & - & 0.19 & 0.02 & 61.31 \\
\hline ANCS $1.1 \mathrm{~F}^{\mathrm{be}}$ & 19.37 & 0.07 & 11.65 & 0.12 & 1.10 & 0.03 & 6.93 & 0.08 & 0.33 & 0.07 & - & - & 60.62 \\
\hline ANCS $3.5 \mathrm{~F}^{\text {be }}$ & 19.56 & 0.42 & 11.36 & 0.47 & 1.09 & 0.08 & 6.81 & 0.41 & 1.07 & 0.08 & - & - & 60.12 \\
\hline ANCS $9.7 \mathrm{~F}^{\text {be }}$ & 19.20 & 0.23 & 11.69 & 0.22 & 1.19 & 0.03 & 6.15 & 0.59 & 3.16 & 0.16 & - & - & 58.62 \\
\hline ANCS $18.3 \mathrm{~F}^{\mathrm{d}}$ & 18.72 & 0.18 & 11.46 & 0.14 & 1.09 & 0.06 & 6.53 & 0.10 & 6.43 & 0.14 & - & - & 55.77 \\
\hline
\end{tabular}

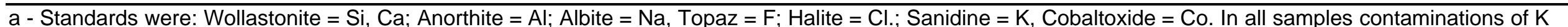
$\left(<0.03\right.$ at\%) from the $\mathrm{SiO}_{2}$ and $\mathrm{Al}_{2} \mathrm{O}_{3}$ chemicals were observed.

b - Doped with $<0.12 \mathrm{~mol} \% \mathrm{CoO}$, because samples were used also for NMR spectroscopy.

c - Calculated from stochiometry taking into account for two $\mathrm{F}^{-}$there is one less $\mathrm{O}^{2-}$ in the glass.

d - Published in Baasner et al. (2013a)

e - Published in Baasner et al. (2013b)

$\mathrm{f}$ - Control analysis after viscosity measurements. Analysis was not used for further evaluation. 


\subsubsection{Density and Water determination}

Glass densities were determined with the buoyancy method by weighing glass blocks 5 - 16 times in air and ethanol on a Mettler Toledo Excellence XS laboratory balance equipped with a density determination kit. The densities of the samples $\rho_{\text {sample }}$ $\left[\mathrm{g} \mathrm{cm}^{-3}\right]$ were calculated using the following equation (e.g. Mettler Toledo, 2008)

$$
\rho_{\text {sample }}=\frac{w_{\text {air }}}{w_{\text {air }}-w_{\text {ethanol }}}\left(\rho_{\text {ethanol }}-\rho_{\text {air }}\right)+\rho_{\text {air }}
$$

where $\rho_{\text {ethanol }}\left[\mathrm{g} \mathrm{cm}^{-3}\right]$ is the density of ethanol at a given temperature (Lindsay, 1957), $\rho_{\text {air }}\left[0.0012 \mathrm{~g} \mathrm{~cm}^{-3}\right.$ at $\left.293 \mathrm{~K}\right]$ is the density of air (Weast, 1972), $w_{\text {air }}[\mathrm{g}]$ is the weight of the sample in air and $w_{\text {ethanol }}[g]$ is the weight of the sample in ethanol.

The water contents of the glasses were determined with infrared spectroscopy using a Perkin Elmer FTIR 2000 spectrometer. Doubly polished glass sections with $\sim 1 \mathrm{~mm}$ thickness (depending on water content) were glued to apertures of 1 - $3 \mathrm{~mm}$ diameter. The thickness of the glass sections was measured with a digital Mitutoyo micrometre with an accuracy of $\pm 3 \mu \mathrm{m}$. Absorption spectra were measured in the sample chamber of the spectrometer.

The water content of the nominally dry samples was determined from mid infrared (MIR) spectra. One to three spectra were collected in 36 - 108 scans from each glass using a Globar light source, a KBr beamsplitter and a TGS detector. We used the Paterson method (Paterson, 1982) and the method by Stolper (1982) (linear molar extinction coefficient $=67 \mathrm{I} \mathrm{mol}^{-1} \mathrm{~cm}^{-1}$ ) to calculate water concentrations from the fundamental hydroxyl $\left(\mathrm{OH}^{-}\right)$stretching vibration $\left(3550 \mathrm{~cm}^{-1}\right)$. Within error both methods delivered the same values (see discussion in Baasner et al. 2013). For further evaluation we then used the values calculated with the Stolper (1982) method.

The water contents of the hydrous samples were determined from near infrared (NIR) spectra using a tungsten light source, a quartz beamsplitter and a TGS detector. One to three spectra of top and bottom pieces were acquired in 36 - 108 scans. Water contents were determined from the peak heights of the combination modes of hydroxyl groups $\left(\mathrm{OH}^{-}\right)$at $4500 \mathrm{~cm}^{-1}$ and molecular water $\left(\mathrm{H}_{2} \mathrm{O}\right)$ at $5200 \mathrm{~cm}^{-1}$ (e.g. Bartholomew et al., 1980; Stolper, 1982; Behrens et al., 1996). Peak heights were 
determined after subtracting a linear baseline that was defined by two anchor points at $\sim 4750 \mathrm{~cm}^{-1}$ and $\sim 5400 \mathrm{~cm}^{-1}$ and was extrapolated to $4000 \mathrm{~cm}^{-1}$ (underneath the $4500 \mathrm{~cm}^{-1}$ band). The water content of the hydrous samples used for viscosity measurements was determined from 3 NIR spectra collected from top and bottom pieces. Within error the water was homogeneously distributed in all samples.

The determination of water concentrations from NIR spectra requires the extinction coefficients for the 4500 and $5200 \mathrm{~cm}^{-1}$ bands. These were determined for the halogen free NACS and ANCS glasses by independent calibrations. For the peralkaline NACS series, hydrous glasses with 1, 2, 3, 4, 6 wt $\% \mathrm{H}_{2} \mathrm{O}$ were synthesized in the IHPV and were prepared as described before (NACS IR). For the peraluminous glasses we used the samples with 2, 3 and $4 \mathrm{wt} \% \mathrm{H}_{2} \mathrm{O}$ that were produced for the viscosity measurements, and synthesized two additional glasses with 5 and $6 \mathrm{wt} \% \mathrm{H}_{2} \mathrm{O}$ in a piston cylinder apparatus as described before. For the NIR calibration the water contents of the samples were determined by independent methods. The water content of the peralkaline samples was determined with Karl-Fischer-Titration (KFT) at the University of Hannover (a detailed description of the device and procedure is given in Behrens et al., 1996) and that of the peraluminous samples plus NACS IR $15.0 \mathrm{H}$ was determined with thermogravimetry (TG) on a Setaram 92-16.18 TG analyzer with a heating rate of $10 \mathrm{~K} \mathrm{~min}^{-1}$ (a detailed description of the procedure is given in Schmidt and Behrens, 2008). As a correction for unextracted water, we added $0.1 \mathrm{wt} \% \mathrm{H}_{2} \mathrm{O}$ to the KFT measurements (e.g. Behrens et al., 1996). This value was found to be a good approximation for rhyolitic glasses (e.g. Leschik et al., 2004), but for other glass compositions the amount of unextracted water may be less because of a higher water diffusivity. From the thermogravimetric measurements we also obtained the temperature at which the water loss occurred. For each glass two measurements were performed with either KFT or TG to determine the water content. For the samples NACS IR $4.5 \mathrm{H}$ and NACS IR $15.0 \mathrm{H}$ water contents were determined with KFT as well as thermogravimetry and were found to be in good agreement with each other (Table 2). The extinction coefficients $\varepsilon$ were then determined following the procedures described in detail in Behrens et al. (1996) and in the electronic Annex of Schmidt et al. (2013). For the peralkaline samples $\varepsilon_{4500}=0.983 \pm 0.048 \mathrm{~L} \mathrm{~mol}^{-1} \mathrm{~cm}^{-1}$ and $\varepsilon_{5200}=0.956 \pm 0.021 \mathrm{~L} \mathrm{~mol}^{-1} \mathrm{~cm}^{-1}$ and for the peraluminous samples $\varepsilon_{4500}=1.119 \pm 0.124 \mathrm{~L} \mathrm{~mol}^{-1} \mathrm{~cm}^{-1}$ and $\varepsilon_{5200}=1.126 \pm 0.064 \mathrm{~L} \mathrm{~mol}^{-1} \mathrm{~cm}^{-1}$. 
The extinction coefficients for the halogen free glass series were also applied for the halogen bearing samples. In order to test if this procedure yield reliable results, the hydrous sample series NACS 2.6F 1.4Cl, NACS 1.1Cl, ANCS 2.3F 0.9Cl and ANCS 18.3F were also analysed for their water contents with KFT (1 - 2 analyses per sample). In the case of the hydrous peraluminous samples of ANCS $2.3 \mathrm{~F} 0.9 \mathrm{Cl}$ and ANCS 18.3F KFT measurements were also done after the viscosity measurements. The comparison of water contents obtained from NIR spectroscopy and measured with KFT (Table 2) showed a significant and systematical offset of $\sim+15 \%$ for the hydrous glasses of NACS $2.6 \mathrm{~F} 1.4 \mathrm{Cl}$, and $\sim-14 \%$ for the peraluminous hydrous glasses of ANCS 2.3F $0.9 \mathrm{Cl}$ ("+" means more water detected with NIR than with KFT, relative errors for both methods less than 10\%). The peralkaline hydrous glasses of NACS $1.1 \mathrm{Cl}$ showed significant differences in water content between measurements with IR spectroscopy and KFT of -6 to $+16 \%$, but no systematic offset. As the KFT device had some technical problems directly after the measurements of NACS $1.1 \mathrm{Cl}$, we cannot exclude that the water determinations of NACS $1.1 \mathrm{Cl}$ were also affected and are therefore erroneous. In the case of the sample series ANCS 18.3F no significant or systematic differences between the water content determined from NIR spectroscopy and KFT were observed. This indicates that high concentrations of $F$ do not affect the IR extinction coefficients for this series. We cannot exclude that the presence of $\mathrm{Cl}$ affects the IR extinction coefficients, however the possible relative error of the water contents measured with IR spectroscopy due to the presence of $\sim 1 \mathrm{~mol} \% \mathrm{Cl}$ is at most $\pm 15 \%$. We found that this error does not affect the general conclusions about the influence of water on density and viscosity in this study. For the further evaluation of samples, where water concentrations from KFT or TG are available, we used these data instead of water concentrations from IR spectroscopy (except for NACS 1.1Cl). A complete overview of the data from IR spectroscopy for $\mathrm{OH}$ and $\mathrm{H}_{2} \mathrm{O}$ can be found in the supplementary data. 
Table 2. Density $\rho$ and water contents of the nominally dry and hydrous peralkaline (NACS) and peraluminous (ANCS) $\mathrm{Na}_{2} \mathrm{O}-\mathrm{CaO}-\mathrm{Al}_{2} \mathrm{O}_{3}-\mathrm{SiO}_{2}$ glasses.

\begin{tabular}{|c|c|c|c|c|c|c|c|c|c|}
\hline Sample & $\begin{array}{c}\rho \\
{\left[\mathrm{g} \mathrm{cm}^{-3}\right]}\end{array}$ & $\begin{array}{c}2 \sigma \\
{\left[\mathrm{g} \mathrm{cm}^{-3}\right]}\end{array}$ & $\begin{array}{c}c\left(\mathrm{H}_{2} \mathrm{O}\right) \\
{[\mathrm{wt} \%]}\end{array}$ & $\begin{array}{c}\Delta\left(\mathrm{H}_{2} \mathrm{O}\right)^{\mathrm{a}} \\
{[\mathrm{wt} \%]}\end{array}$ & $\begin{array}{c}c_{\text {total }}\left(\mathrm{H}_{2} \mathrm{O}\right) \\
{[\mathrm{mol} \%]}\end{array}$ & $\begin{array}{c}\Delta c_{\text {total }}\left(\mathrm{H}_{2} \mathrm{O}\right) \\
{[\mathrm{mol} \%]}\end{array}$ & $\begin{array}{c}c(\mathrm{OH}) \\
{[\mathrm{mol} \%]}\end{array}$ & $\begin{array}{l}\Delta c(\mathrm{OH})^{\mathrm{b}} \\
{[\mathrm{mol} \%]}\end{array}$ & method $^{\mathrm{C}}$ \\
\hline \multicolumn{10}{|l|}{ Peralkaline } \\
\hline NACS IR $4.5 \mathrm{H}$ & 2.482 & 0.002 & 1.29 & 0.05 & 4.51 & 0.19 & 3.24 & 0.22 & NIR \\
\hline NACS IR $6.4 \mathrm{H}$ & 2.472 & 0.005 & 1.81 & 0.07 & 6.24 & 0.25 & 3.87 & 0.26 & NIR \\
\hline NACS IR 9.8H & 2.458 & 0.005 & 3.01 & 0.12 & 10.07 & 0.40 & 4.54 & 0.32 & NIR \\
\hline NACS IR $15.0 \mathrm{H}$ & 2.429 & 0.005 & 4.71 & 0.15 & 15.12 & 0.49 & 5.11 & 0.35 & NIR \\
\hline NACS IR $15.3 \mathrm{H}$ & 2.424 & 0.007 & 4.77 & 0.15 & 15.29 & 0.49 & 5.05 & 0.35 & NIR \\
\hline NACS IR 19.3H & 2.395 & 0.010 & 6.15 & 0.19 & 19.10 & 0.59 & 5.04 & 0.33 & NIR \\
\hline NACS IR 4.5H & 2.482 & 0.002 & 1.29 & 0.07 & 4.50 & 0.26 & & & KFT \\
\hline NACS IR $6.4 \mathrm{H}$ & 2.472 & 0.005 & 1.86 & 0.07 & 6.39 & 0.24 & & & KFT \\
\hline NACS IR 9.8H & 2.458 & 0.005 & 2.94 & 0.11 & 9.83 & 0.36 & & & KFT \\
\hline NACS IR $15.0 \mathrm{H}$ & 2.429 & 0.005 & 4.68 & 0.14 & 15.03 & 0.45 & & & KFT \\
\hline NACS IR $15.3 \mathrm{H}$ & 2.424 & 0.007 & 4.78 & 0.19 & 15.31 & 0.60 & & & KFT \\
\hline NACS IR $19.3 \mathrm{H}$ & 2.395 & 0.010 & 6.22 & 0.26 & 19.29 & 0.79 & & & KFT \\
\hline NACS IR $4.5 \mathrm{H}$ & 2.482 & 0.002 & 1.26 & 0.04 & 4.38 & 0.15 & & & TG \\
\hline NACS IR $15.0 \mathrm{H}$ & 2.429 & 0.005 & 4.68 & 0.51 & 15.03 & 1.64 & & & TG \\
\hline$N A C S^{d}$ & 2.482 & 0.005 & 0.0179 & 0.0019 & 0.0648 & 0.0067 & & & MIR \\
\hline NACS $1.6 \mathrm{H}$ & 2.484 & 0.002 & 0.44 & 0.02 & 1.55 & 0.09 & 1.55 & 0.09 & NIR \\
\hline NACS $3.8 \mathrm{H}$ & 2.477 & 0.004 & 1.09 & 0.06 & 3.81 & 0.21 & 2.93 & 0.18 & NIR \\
\hline NACS $8.4 \mathrm{H}$ & 2.455 & 0.010 & 2.48 & 0.14 & 8.39 & 0.46 & 4.55 & 0.28 & NIR \\
\hline NACS $12.6 \mathrm{H}$ & 2.435 & 0.004 & 3.84 & 0.13 & 12.58 & 0.42 & 4.98 & 0.24 & NIR \\
\hline NACS $0.7 F 0.6 \mathrm{Cl}^{d}$ & 2.467 & 0.007 & 0.0237 & 0.0033 & 0.0854 & 0.0118 & & & MIR \\
\hline NACS $0.7 F \quad 0.6 \mathrm{Cl}$ (IHPV) & - & - & 0.0581 & 0.0159 & 0.2090 & 0.0573 & & & MIR \\
\hline NACS $0.7 \mathrm{~F} 0.6 \mathrm{Cl} 2.4 \mathrm{H}$ & 2.475 & 0.003 & 0.69 & 0.04 & 2.43 & 0.15 & 2.11 & 0.11 & NIR \\
\hline NACS $0.7 \mathrm{~F} 0.6 \mathrm{Cl} 4.5 \mathrm{H}$ & 2.471 & 0.003 & 1.29 & 0.07 & 4.48 & 0.23 & 3.35 & 0.18 & NIR \\
\hline NACS $0.7 F \quad 0.6 \mathrm{Cl} 8.4 \mathrm{H}$ & 2.453 & 0.002 & 2.46 & 0.10 & 8.33 & 0.33 & 4.57 & 0.24 & NIR \\
\hline NACS $0.7 F \quad 0.6 \mathrm{Cl} 13.1 \mathrm{H}$ & 2.425 & 0.008 & 4.00 & 0.27 & 13.05 & 0.89 & 5.13 & 0.49 & NIR \\
\hline NACS $1.1 \mathrm{~F} 1.1 \mathrm{Cl}^{\mathrm{d}}$ & 2.455 & 0.004 & 0.0320 & 0.0033 & 0.1144 & 0.0119 & & & MIR \\
\hline NACS 1.1F 1.1Cl (IHPV) & - & - & 0.0778 & 0.0078 & 0.2778 & 0.0280 & & & MIR \\
\hline NACS $1.1 \mathrm{~F} 1.1 \mathrm{Cl} 2.2 \mathrm{H}$ & 2.469 & 0.002 & 0.63 & 0.06 & 2.23 & 0.21 & 1.97 & 0.16 & NIR \\
\hline NACS $1.1 \mathrm{~F} 1.1 \mathrm{Cl} 5.0 \mathrm{H}$ & 2.461 & 0.004 & 1.45 & 0.07 & 4.99 & 0.24 & 3.58 & 0.19 & NIR \\
\hline NACS $1.1 \mathrm{~F} 1.1 \mathrm{Cl} 7.9 \mathrm{H}$ & 2.450 & 0.008 & 2.32 & 0.09 & 7.84 & 0.31 & 4.02 & 0.22 & NIR \\
\hline NACS $1.1 \mathrm{~F} 1.1 \mathrm{Cl} 13.5 \mathrm{H}$ & 2.428 & 0.002 & 4.16 & 0.14 & 13.44 & 0.47 & 5.22 & 0.28 & NIR \\
\hline NACS 2.6F $1.4 \mathrm{Cl}^{\mathrm{d}}$ & 2.454 & 0.002 & 0.0415 & 0.0044 & 0.1463 & 0.0155 & & & MIR \\
\hline NACS 2.6F $1.4 \mathrm{Cl}$ (IHPV) & - & - & 0.1345 & 0.0139 & 0.4733 & 0.0491 & & & MIR \\
\hline NACS $2.6 \mathrm{~F} 1.4 \mathrm{Cl} 2.8 \mathrm{H}$ & 2.463 & 0.006 & 0.79 & 0.06 & 2.74 & 0.22 & & & KFT \\
\hline NACS $2.6 \mathrm{~F} 1.4 \mathrm{Cl} 3.8 \mathrm{H}$ & 2.457 & 0.006 & 1.09 & 0.07 & 3.75 & 0.23 & & & KFT \\
\hline NACS $2.6 \mathrm{~F} 1.4 \mathrm{Cl} 9.6 \mathrm{H}$ & 2.432 & 0.002 & 2.88 & 0.07 & 9.49 & 0.23 & & & KFT \\
\hline NACS $2.6 \mathrm{~F} 1.4 \mathrm{Cl} 13.3 \mathrm{H}$ & 2.414 & 0.002 & 4.11 & 0.06 & 13.14 & 0.18 & & & KFT \\
\hline NACS $2.6 \mathrm{~F} 1.4 \mathrm{Cl} 2.8 \mathrm{H}$ & 2.463 & 0.006 & 0.96 & 0.052 & 3.32 & 0.18 & 2.77 & 0.15 & NIR \\
\hline NACS $2.6 \mathrm{~F} 1.4 \mathrm{Cl} 3.8 \mathrm{H}$ & 2.457 & 0.006 & 1.29 & 0.061 & 4.41 & 0.21 & 3.37 & 0.17 & NIR \\
\hline NACS $2.6 \mathrm{~F} 1.4 \mathrm{Cl} 9.6 \mathrm{H}$ & 2.432 & 0.002 & 3.31 & 0.12 & 10.79 & 0.39 & 5.13 & 0.26 & NIR \\
\hline NACS $2.6 \mathrm{~F} 1.4 \mathrm{Cl} 13.3 \mathrm{H}$ & 2.414 & 0.002 & 4.72 & 0.16 & 14.89 & 0.52 & 5.49 & 0.29 & NIR \\
\hline NACS $1.1 \mathrm{Cl}^{\mathrm{d}}$ & 2.463 & 0.004 & 0.0165 & 0.0017 & 0.0594 & 0.0063 & & & MIR \\
\hline $\mathrm{NACS} 1.1 \mathrm{Cl} 2.2 \mathrm{H}$ & 2.465 & 0.007 & 0.64 & 0.12 & 2.28 & 0.42 & & & KFT \\
\hline NACS $1.1 \mathrm{Cl} 3.7 \mathrm{H}$ & 2.466 & 0.005 & 0.89 & 0.05 & 3.11 & 0.16 & & & KFT \\
\hline NACS $1.1 \mathrm{Cl} 7.5 \mathrm{H}$ & 2.450 & 0.008 & 1.90 & 0.12 & 6.50 & 0.42 & & & KFT \\
\hline NACS $1.1 \mathrm{Cl} 14.5 \mathrm{H}^{\mathrm{d}}$ & 2.381 & 0.008 & 3.94 & 0.36 & 12.86 & 1.19 & & & $\mathrm{KFT}$ \\
\hline $\mathrm{NACS} 1.1 \mathrm{Cl} 2.2 \mathrm{H}$ & 2.465 & 0.007 & 0.61 & 0.06 & 2.16 & 0.20 & 1.82 & 0.11 & NIR \\
\hline $\mathrm{NACS} 1.1 \mathrm{Cl} 3.7 \mathrm{H}$ & 2.466 & 0.005 & 1.05 & 0.05 & 3.69 & 0.16 & 2.92 & 0.14 & NIR \\
\hline $\mathrm{NACS} 1.1 \mathrm{Cl} 7.5 \mathrm{H}$ & 2.450 & 0.008 & 2.20 & 0.08 & 7.47 & 0.29 & 4.46 & 0.22 & NIR \\
\hline $\mathrm{NACS} 1.1 \mathrm{Cl} 14.5 \mathrm{H}^{\mathrm{e}}$ & 2.381 & 0.008 & 4.58 & 0.15 & 14.47 & 0.47 & 5.57 & 0.27 & NIR \\
\hline NACS $1.9 F^{d}$ & 2.475 & 0.003 & 0.0257 & 0.0030 & 0.0913 & 0.0108 & & & MIR \\
\hline NACS $1.9 F 2.8 \mathrm{H}$ & 2.480 & 0.004 & 0.78 & 0.04 & 2.73 & 0.14 & 2.24 & 0.12 & NIR \\
\hline NACS $1.9 F 5.8 \mathrm{H}$ & 2.471 & 0.005 & 1.69 & 0.07 & 5.76 & 0.23 & 3.81 & 0.19 & NIR \\
\hline NACS 1.9F 13.2H & 2.457 & 0.007 & 2.61 & 0.10 & 8.73 & 0.33 & 4.63 & 0.23 & NIR \\
\hline NACS $1.9 \mathrm{~F} 13.1 \mathrm{H}$ & 2.432 & 0.010 & 4.06 & 0.13 & 13.10 & 0.43 & 4.94 & 0.24 & NIR \\
\hline NACS $6.2 \mathrm{~F}$ & 2.461 & 0.008 & 0.0070 & 0.0011 & 0.0243 & 0.0039 & & & MIR \\
\hline
\end{tabular}


Table 2 (continued). Density $\rho$ and water contents of the nominally dry and hydrous peralkaline (NACS) and peraluminous (ANCS) $\mathrm{Na}_{2} \mathrm{O}-\mathrm{CaO}-\mathrm{Al}_{2} \mathrm{O}_{3}-\mathrm{SiO}_{2}$ glasses.

\begin{tabular}{|c|c|c|c|c|c|c|c|c|c|}
\hline Sample & $\begin{array}{c}\rho \\
{\left[\mathrm{g} \mathrm{cm}^{-3}\right]}\end{array}$ & $\begin{array}{c}2 \sigma \\
{\left[\mathrm{g} \mathrm{cm}^{-3}\right]}\end{array}$ & $\begin{array}{c}c\left(\mathrm{H}_{2} \mathrm{O}\right) \\
{[\mathrm{wt} \%]}\end{array}$ & $\begin{array}{c}\Delta\left(\mathrm{H}_{2} \mathrm{O}\right)^{\mathrm{a}} \\
{[\mathrm{wt} \%]}\end{array}$ & $\begin{array}{c}c_{\text {total }}\left(\mathrm{H}_{2} \mathrm{O}\right) \\
{[\mathrm{mol} \%]}\end{array}$ & $\begin{array}{c}\Delta c_{\text {total }}\left(\mathrm{H}_{2} \mathrm{O}\right) \\
{[\mathrm{mol} \%]}\end{array}$ & $\begin{array}{c}c(\mathrm{OH}) \\
{[\mathrm{mol} \%]}\end{array}$ & $\begin{array}{c}\Delta c(\mathrm{OH})^{\mathrm{b}} \\
{[\mathrm{mol} \%]}\end{array}$ & method $^{c}$ \\
\hline \multicolumn{10}{|l|}{ Peraluminous } \\
\hline ANCS $^{d}$ & 2.460 & 0.006 & 0.0086 & 0.0009 & 0.0326 & 0.0033 & & & MIR \\
\hline ANCS $6.8 \mathrm{H}$ & 2.430 & 0.010 & 1.91 & 0.35 & 6.87 & 1.24 & 5.61 & 1.04 & NIR \\
\hline ANCS $10.0 \mathrm{H}$ & 2.406 & 0.013 & 2.73 & 0.26 & 9.61 & 0.90 & 6.28 & 0.70 & NIR \\
\hline ANCS $13.2 \mathrm{H}$ & 2.397 & 0.016 & 3.91 & 0.34 & 13.33 & 1.15 & 6.78 & 0.76 & NIR \\
\hline ANCS $14.3 \mathrm{H}$ & 2.390 & 0.008 & 4.22 & 0.36 & 14.29 & 1.21 & 6.91 & 0.77 & NIR \\
\hline ANCS $18.2 \mathrm{H}$ & 2.369 & 0.020 & 5.95 & 0.47 & 19.31 & 1.51 & 6.62 & 0.74 & NIR \\
\hline ANCS $6.8 \mathrm{H}$ & 2.430 & 0.010 & 1.89 & 0.06 & 6.79 & 0.20 & & & TG \\
\hline ANCS $10.0 \mathrm{H}$ & 2.406 & 0.013 & 2.84 & 0.23 & 9.95 & 0.79 & & & TG \\
\hline ANCS $13.2 \mathrm{H}$ & 2.397 & 0.016 & 3.88 & 0.04 & 13.23 & 0.14 & & & TG \\
\hline ANCS $14.3 \mathrm{H}$ & 2.390 & 0.008 & 4.22 & 0.16 & 14.27 & 0.53 & & & TG \\
\hline ANCS $18.2 \mathrm{H}$ & 2.369 & 0.020 & 5.54 & 0.06 & 18.15 & 0.19 & & & TG \\
\hline ANCS $0.5 \mathrm{~F}^{0.5 \mathrm{Cl}^{d}}$ & 2.458 & 0.013 & 0.0107 & 0.0011 & 0.0403 & 0.0040 & & & MIR \\
\hline ANCS $0.5 \mathrm{~F} 0.5 \mathrm{Cl} 0.8 \mathrm{H}$ & 2.476 & 0.018 & 0.22 & 0.03 & 0.81 & 0.10 & 0.74 & 0.09 & NIR \\
\hline ANCS $0.5 \mathrm{~F} 0.5 \mathrm{Cl} 5.1 \mathrm{H}$ & 2.445 & 0.008 & 1.40 & 0.27 & 5.06 & 0.99 & 4.21 & 0.52 & NIR \\
\hline ANCS $0.5 \mathrm{~F} 0.5 \mathrm{Cl} 8.8 \mathrm{H}$ & 2.421 & 0.008 & 2.48 & 0.23 & 8.74 & 0.83 & 5.84 & 0.65 & NIR \\
\hline ANCS $0.5 \mathrm{~F} 0.5 \mathrm{Cl} 13.0 \mathrm{H}$ & 2.404 & 0.010 & 3.79 & 0.33 & 12.91 & 1.12 & 6.95 & 0.77 & NIR \\
\hline ANCS $1.2 \mathrm{~F} 1.1 \mathrm{Cl}^{\mathrm{d}}$ & 2.451 & 0.016 & 0.0028 & 0.0003 & 0.0106 & 0.0012 & & & MIR \\
\hline ANCS $1.2 \mathrm{~F} 1.1 \mathrm{Cl} 6.2 \mathrm{H}$ & 2.476 & 0.014 & 1.69 & 0.18 & 6.11 & 0.64 & 5.17 & 0.58 & NIR \\
\hline ANCS $1.2 \mathrm{~F} 1.1 \mathrm{Cl} 9.8 \mathrm{H}$ & 2.417 & 0.007 & 2.79 & 0.29 & 9.75 & 1.01 & 6.54 & 0.74 & NIR \\
\hline ANCS $1.2 \mathrm{~F} 1.1 \mathrm{Cl} 12.0 \mathrm{H}$ & 2.400 & 0.010 & 3.45 & 0.31 & 11.88 & 1.05 & 6.67 & 0.75 & NIR \\
\hline ANCS $2.3 F 0.9 \mathrm{Cl}^{\mathrm{d}}$ & 2.446 & 0.011 & 0.0065 & 0.0007 & 0.0246 & 0.0026 & & & MIR \\
\hline ANCS $2.3 \mathrm{~F} 0.9 \mathrm{Cl} 7.0 \mathrm{H}$ & 2.425 & 0.014 & 1.95 & 0.07 & 6.96 & 0.25 & & & KFT \\
\hline ANCS $2.3 \mathrm{~F} 0.9 \mathrm{Cl} 9.4 \mathrm{H}$ & 2.403 & 0.011 & 2.64 & 0.07 & 9.24 & 0.25 & & & KFT \\
\hline ANCS $2.3 \mathrm{~F} 0.9 \mathrm{Cl} 13.1 \mathrm{H}$ & 2.381 & 0.008 & 3.80 & 0.08 & 12.95 & 0.26 & & & KFT \\
\hline ANCS $2.3 \mathrm{~F} 0.9 \mathrm{Cl} 7.0 \mathrm{H}$ & 2.425 & 0.014 & 1.68 & 0.17 & 6.03 & 0.61 & 4.66 & 0.52 & NIR \\
\hline ANCS $2.3 \mathrm{~F} 0.9 \mathrm{Cl} 9.4 \mathrm{H}$ & 2.403 & 0.011 & 2.32 & 0.22 & 8.22 & 0.79 & 5.63 & 0.64 & NIR \\
\hline ANCS $2.3 \mathrm{~F} 0.9 \mathrm{Cl} 13.1 \mathrm{H}$ & 2.381 & 0.008 & 3.37 & 0.30 & 11.59 & 1.02 & 6.61 & 0.73 & NIR \\
\hline ANCS $0.6 \mathrm{Cl}^{d}$ & 2.454 & 0.004 & 0.0092 & 0.0120 & 0.0350 & 0.0456 & & & MIR \\
\hline ANCS 1.1F & 2.445 & 0.004 & 0.0077 & 0.0018 & 0.0288 & 0.0067 & & & MIR \\
\hline ANCS 3.5F & 2.453 & 0.003 & 0.0069 & 0.0008 & 0.0255 & 0.0029 & & & MIR \\
\hline ANCS 9.7F & 2.439 & 0.006 & 0.0050 & 0.0008 & 0.0177 & 0.0028 & & & MIR \\
\hline ANCS $18.3 F^{d}$ & 2.440 & 0.001 & 0.0076 & 0.0019 & 0.0300 & 0.0070 & & & MIR \\
\hline ANCS $18.3 \mathrm{~F} 5.3 \mathrm{H}$ & 2.450 & 0.035 & 1.57 & 0.14 & 5.12 & 0.49 & 3.31 & 0.38 & NIR \\
\hline ANCS $18.3 F$ 8.9H & 2.413 & 0.021 & 2.67 & 0.25 & 8.88 & 0.78 & 4.78 & 0.54 & NIR \\
\hline ANCS 18.3F 12.19H & 2.407 & 0.024 & 3.77 & 0.14 & 11.47 & 0.93 & 4.78 & 0.53 & NIR \\
\hline ANCS $18.3 \mathrm{~F} 5.3 \mathrm{H}$ & 2.450 & 0.035 & 1.50 & 0.14 & 5.34 & 0.48 & & & KFT \\
\hline ANCS $18.3 \mathrm{~F} 8.9 \mathrm{H}$ & 2.413 & 0.021 & 2.68 & 0.24 & 8.85 & 0.83 & & & KFT \\
\hline ANCS $18.3 F 12.19 \mathrm{H}$ & 2.407 & 0.024 & 3.53 & 0.24 & 12.19 & 0.44 & & & $\mathrm{KFT}$ \\
\hline
\end{tabular}

a - $2 \sigma$ standard deviation (KFT, TG), Gaussian error propagation (MIR, NIR, KFT of NACS 2.6F 1.4Cl and ANCS 2.3F 0.9Cl)

$\mathrm{b}$ - Water in mol\% dissolved as $\mathrm{OH}$

c - NIR = nearinfrared spectroscopy after Bartholomew (1980), MIR = mid infrared spectroscopy after Stolper (1982), KFT = Karl-Fischer-Titration (Behrens et al., 1996), TG = thermogravimetry.

d - Density and water concentration already published in (Baasner et al., 2013), density of NACS and NACS $1.9 F$ re-measured for this study

$\mathrm{e}$ - Density was corrected to $2.429 \mathrm{~g} \mathrm{~cm}^{-3}$ for calculation of the water content with the linear equation in table 3 because of bubbles that lowered the measured density. 


\subsection{Micropenetration}

The viscosity of the $\mathrm{Na}_{2} \mathrm{O}-\mathrm{CaO}-\mathrm{Al}_{2} \mathrm{O}_{3}-\mathrm{SiO}_{2}$ melts (Table 3 ) was determined over a range between $10^{8.5}$ and $10^{13} \mathrm{~Pa} \mathrm{~s}$ with the micropenetration method, by pushing with a corundum rod a single crystal sapphire sphere with known diameter into the sample at fixed temperature and applied force. The viscosity $\eta[\mathrm{Pa}$ s] was calculated from indent distance $/[\mathrm{m}]$ over time $t[\mathrm{~s}]$, applied force $F\left[\mathrm{~kg} \mathrm{~m} \mathrm{~s}^{-2}\right]$ and the radius of the sphere $r[\mathrm{~m}]$ after Pocklington (1940):

$$
\eta=\frac{0.1875 F t}{\sqrt{r} \sqrt{I^{3}}}
$$

The micropenetration measurements of all dry and hydrous samples were performed in a Netzsch TMA 420 dilatometer. The viscosity measurements of the dry samples are described in detail in Baasner et al. (2013), but the technique is in general not different from that used for the hydrous samples in this study. The accuracy of the measurements was determined to be \pm 0.08 log units by measuring the standard glass DDG-1 (Baasner et al. 2013). The relative error of the $\mathrm{Pt} / \mathrm{Pt}_{90} \mathrm{Rh}_{10}$ thermocouple is $0.25 \%$ of the temperature. The viscosity measurements of the hydrous samples were performed using a $1 \mathrm{~mm} \varnothing$ hollow corundum rod and $1 \mathrm{~mm} \varnothing$ single crystal sapphire spheres. The samples were heated with $10 \mathrm{~K} \mathrm{~min}^{-1}$ and for the last $50 \mathrm{~K}$ with $5 \mathrm{~K} \mathrm{~min}^{-1}$, then held for $10 \mathrm{~min}$ at the desired temperature before the measurements started in order to achieve a constant temperature and structural relaxation. The measuring time did not exceed $30 \mathrm{~min}$. Including combined heating and cooling periods the samples were not exposed to temperatures above the temperature $T_{g}{ }^{12}$ (where the viscosity $\eta=10^{12} \mathrm{Pas}$ ) for longer than $1.5 \mathrm{~h}$ in one measurement. To detect possible water loss during measurements, viscosity measurements were performed on different glass pieces and the order of temperatures was chosen randomly, so no false slope could be created by a slow water loss over several measurements. The measurements were performed only up to temperatures (and viscosities) where no alteration such as cracks on the surface or massive growth of pre-existing bubbles appeared. 


\subsection{Results}

\subsubsection{Water speciation and density}

Table 2 shows the densities and water contents of the nominally dry and hydrous $\mathrm{Na}_{2} \mathrm{O}-\mathrm{CaO}-\mathrm{Al}_{2} \mathrm{O}_{3}-\mathrm{SiO}_{2}$ glasses that were used for further study (some data on the dry glasses were already published in Baasner et al. (2013)).

Figure 1 shows the concentration of water dissolved as hydroxyl groups $(\mathrm{OH})$ as a function of the total water content for some of the peralkaline (NACS) and peraluminous (ANCS) halogen-free and halogen-bearing glasses. The water speciation for all samples is given in the supplementary data. The dependence of $\mathrm{OH}$ on total water content is the same for all peralkaline samples. Between 0 and $10 \mathrm{~mol} \%$ water, the concentration of $\mathrm{OH}$ increases with increasing water content and levels off at $\sim 5 \mathrm{~mol} \% \mathrm{OH}$ for total water concentrations higher than $10 \mathrm{~mol} \%$. The hydrous samples of the peraluminous glass ANCS 18.3F with 18.3 mol\% F follow the same trend as the peralkaline glasses. On the other hand, for the peraluminous glasses with no or smaller halogen concentrations, the concentration of $\mathrm{OH}$ increases with increasing water content between 0 and 10 mol\% water and levels off at $\sim 6.5 \mathrm{~mol} \% \mathrm{OH}$ for total water concentrations higher than $10 \mathrm{~mol} \%$.

Figures $2 A-C$ show the densities of some of the halogen-free and halogen-bearing, peralkaline and peraluminous $\mathrm{Na}_{2} \mathrm{O}-\mathrm{CaO}-\mathrm{Al}_{2} \mathrm{O}_{3}-\mathrm{SiO}_{2}$ glasses as a function of fluorine and water content (Table 2). The density linearly decreases with increasing water and $F$ concentration. Linear equations with the parameters $A$ and $B$ (Table 3 ) that were fitted to the data of the hydrous samples describe the dependence of the density $\rho\left[\mathrm{g} \mathrm{cm}^{-3}\right]$ on the water content $c\left(\mathrm{H}_{2} \mathrm{O}\right)[\mathrm{mol} \%]$.

$$
\rho=A-B \cdot c\left(H_{2} \mathrm{O}\right)
$$

Parameter B represents the decrease in density per mol\% of water, while $A$ is the expected density at a water content of zero.

If one compares peralkaline and peraluminous samples with similar $\mathrm{Cl}, \mathrm{F}$ and water content, the peraluminous samples have in general lower densities. This behaviour is 
consistent with data from Falenty and Webb (2010) for $\mathrm{Na}_{2} \mathrm{O}-\mathrm{Al}_{2} \mathrm{O}_{3}-\mathrm{SiO}_{2}$ and $\mathrm{Na}_{2} \mathrm{O}-\mathrm{Fe}_{2} \mathrm{O}_{3}-\mathrm{Al}_{2} \mathrm{O}_{3}-\mathrm{SiO}_{2}$ glasses.

In the peralkaline melts $\mathrm{Cl}$ alone decreases density by $\sim 0.017 \mathrm{~g} \mathrm{~cm}^{-3}$ per $\mathrm{mol} \% \mathrm{Cl}$ and $F$ alone decreases it by $0.003 \mathrm{~g} \mathrm{~cm}^{-3}$ per mol\% $F$ (Fig. 2A+B). In the peraluminous samples the $\mathrm{Cl}$-bearing sample ANCS $0.6 \mathrm{Cl}$ has within error the same density as the halogen-free sample (Table 2), which might be related to the low $\mathrm{Cl}$ concentration of $0.6 \mathrm{~mol} \% \mathrm{Cl}$. $\mathrm{F}$ alone decreases the density of the peraluminous glass series by $0.001 \mathrm{~g} \mathrm{~cm}^{-3}$ per mol\% $\mathrm{F}$ and that of the peralkaline series by $0.003 \mathrm{~g} \mathrm{~cm}^{-3}$ (Fig. 2A-C). The effect of $\mathrm{F}$ on density is stronger in the peralkaline than in the peraluminous glasses.

In the peralkaline samples water linearly decreases density by $0.0050 \pm 0.0003 \mathrm{~g} \mathrm{~cm}^{-3}$ per mol\% $\mathrm{H}_{2} \mathrm{O}$ (Fig. 2B). Its effect is weaker than that of $\mathrm{Cl}$ but stronger than that of $\mathrm{F}$. The nominally dry samples made at $1 \mathrm{~atm}$ and slow cooling rates have up to $0.014 \mathrm{~g} \mathrm{~cm}^{-3}$ lower densities than hydrous samples with low water contents $(<4 \mathrm{~mol} \%$ $\mathrm{H}_{2} \mathrm{O}$ ) produced at high pressures and fast quench rates. In the peraluminous samples water linearly decreases the density with $0.0050 \pm 0.0002 \mathrm{~g} \mathrm{~cm}^{-3}$ per mol\% $\mathrm{H}_{2} \mathrm{O}$ (Fig. 2C). The effect is stronger than that of $\mathrm{F}$. The effect of water on density is within error the same in the halogen-free peraluminous halogen-free and peralkaline glass. In the peralkaline and peraluminous glasses the presence of $\mathrm{Cl}$ and $\mathrm{F}$ has within error no influence on the decreasing effect of water on density.

In Fig. $3 \mathrm{~A}$ and $\mathrm{B}$ we show the partial molar volume for $\mathrm{F}_{2} \mathrm{O}_{-1}\left(V_{F 2 O-1}\right)$ and water $\left(V_{H 2 O}\right)$ at room temperature for some of the peralkaline and peraluminous samples $\left(\mathrm{F}_{2} \mathrm{O}_{-1}\right.$ takes into account that there is $1 \mathrm{O}^{2-}$ less for $2 \mathrm{~F}^{1-}$ ). The partial molar volumes of water and $\mathrm{F}_{2} \mathrm{O}_{-1}$ are given in Table 3. The partial molar volume of $\mathrm{F}_{2} \mathrm{O}_{-1}$ (Fig. 3A) at room temperature is higher in the peralkaline glasses with $18.7 \pm 1.4 \mathrm{~cm}^{3} \mathrm{~mol}^{-1}$ than in the peraluminous glasses with $11.8 \pm 1.6 \mathrm{~cm}^{3} \mathrm{~mol}^{-1}$. For comparison, we also calculated the partial molar volume of $\mathrm{F}_{2} \mathrm{O}_{-1}$ at room temperature in haplogranitic glasses (Dingwell et al., 1993b), which is with $11.3 \pm 1.3 \mathrm{~cm}^{3} \mathrm{~mol}^{-1}$ within error the same as in the present peraluminous glasses. The partial molar volume of water (Fig. 3B) in the halogen-free peralkaline glasses (NACS $+\mathrm{H}_{2} \mathrm{O}$ ) is with $11.5 \pm 0.4 \mathrm{~cm}^{3} \mathrm{~mol}^{-1}$ similar to that in the halogen-free peraluminous glasses (ANCS $+\mathrm{H}_{2} \mathrm{O}$ ) with $12.4 \pm 0.3 \mathrm{~cm}^{3} \mathrm{~mol}^{-1}$. This is consistent with the observation of Richet et al. (2000) that the partial molar volume of $\mathrm{H}_{2} \mathrm{O}$ in glasses at room 
temperature is in most cases $12.0 \pm 0.5 \mathrm{~cm}^{3} \mathrm{~mol}^{-1}$. With respect to the different synthesis conditions for the hydrous samples, no significant difference in the partial molar volume of water between the halogen-free and the halogen-bearing peralkaline and peraluminous glasses was observed. It appears that in the halogen-bearing glasses the partial molar volume of water is slightly reduced, however, this might be still within error. The relative difference in the partial molar volumes calculated for $\mathrm{F}_{2} \mathrm{O}_{-1}$ is larger than that observed for water, and might indicate a different incorporation mechanism of $\mathrm{F}$ in peralkaline and peraluminous melts.

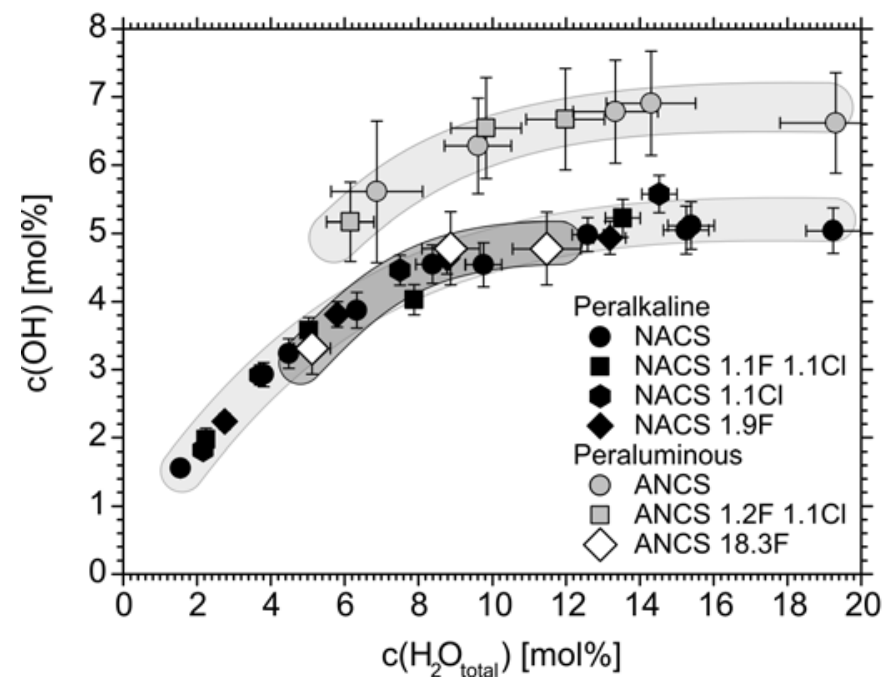

Fig. 1. Concentration of hydroxyl groups $c(\mathrm{OH})$ determined with NIR spectroscopy as a function of the total water content $c\left(\mathrm{H}_{2} \mathrm{O}\right)$ for peralkaline (NACS) and peraluminous (ANCS) $\mathrm{Na}_{2} \mathrm{O}-\mathrm{CaO}-\mathrm{Al}_{2} \mathrm{O}_{3}-\mathrm{SiO}_{2}$ glasses.

Table 3. Parameters of the linear equations (Eq. 3) fit to the density data as a function of water and fluorine content and partial molar volume of water and $\mathrm{F}_{2} \mathrm{O}_{-1} V_{\mathrm{H} 2 \mathrm{O}} V_{\mathrm{F} 2 \mathrm{O}-1}$ at room temperature.

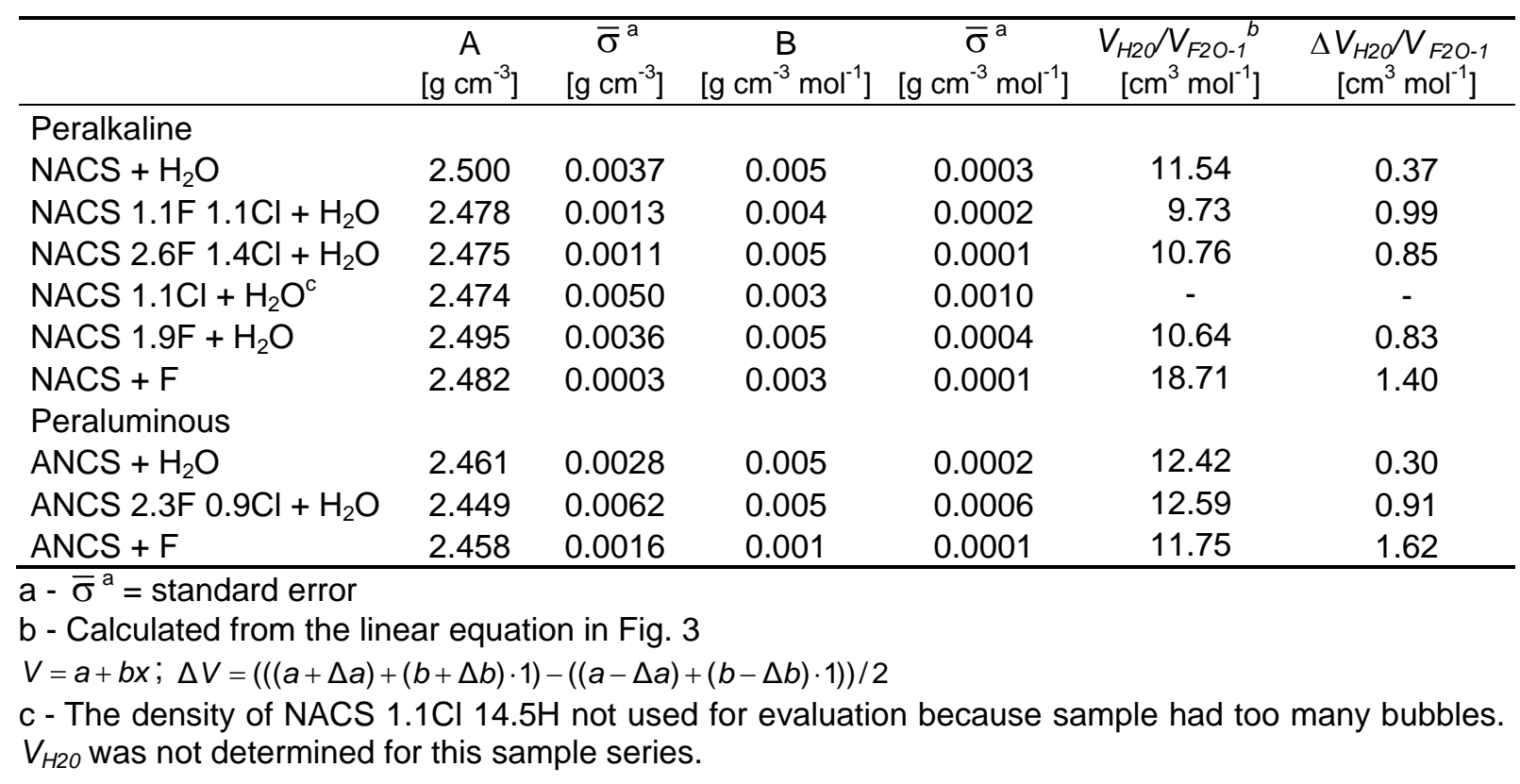



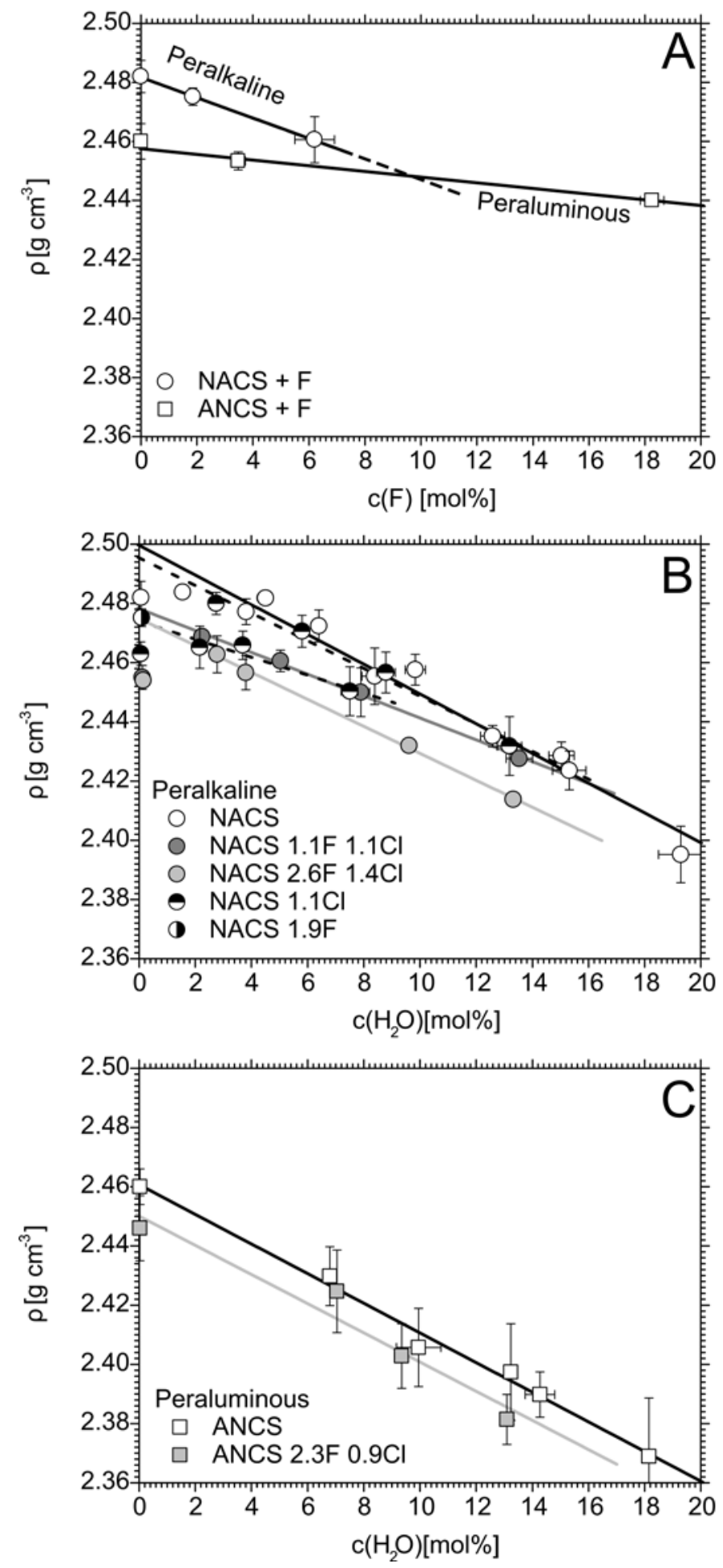

Fig. 2. Density $\rho$ vs. fluorine concentration $c(F)$ of some fluorine-free and fluorine-bearing peralkaline (NACS) and peraluminous (ANCS) glasses (A). Density $\rho$ vs. water concentration of some halogen-free and halogen-bearing peralkaline (NACS) and peraluminous (ANCS) $\mathrm{Na}_{2} \mathrm{O}-\mathrm{CaO}-\mathrm{Al}_{2} \mathrm{O}_{3}-\mathrm{SiO}_{2}$ glasses vs. water concentration $c\left(\mathrm{H}_{2} \mathrm{O}\right)(\mathrm{B}+\mathrm{C})$. 

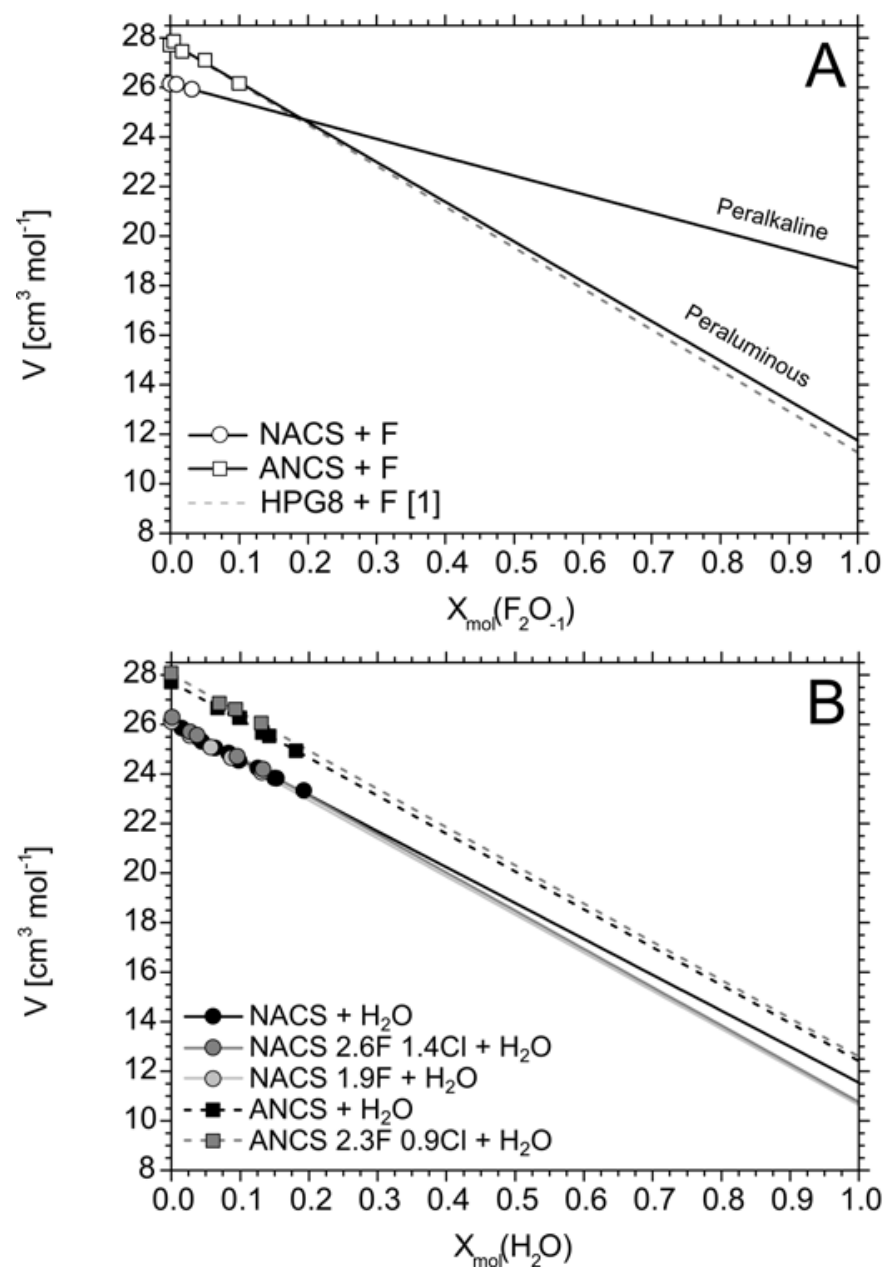

Fig. 3. Molar Volume $V$ vs. mole fraction $X_{m o l}$ of $\mathrm{F}_{2} \mathrm{O}_{-1}(\mathrm{~A})$ and water $(\mathrm{B})$ for the halogen-free and halogen-bearing peralkaline (NACS) and peraluminous (ANCS) glasses as well as fluorine-bearing haplogranitic melts (HPG8, [1] Dingwell et al., 1993b). The intercepts for $X_{m o l}=1$ give the partial molar Volume of $\mathrm{F}_{2} \mathrm{O}_{-1}$ and water.

\subsubsection{Micropenetration}

The viscosity vs. temperature data for nominally dry and hydrous peralkaline (NACS) and peraluminous (ANCS) $\mathrm{Na}_{2} \mathrm{O}-\mathrm{CaO}-\mathrm{Al}_{2} \mathrm{O}_{3}-\mathrm{SiO}_{2}$ melts are given in Table 4 (viscosity data of some dry samples were already published in Baasner et al. (2013)). Some viscosity data as a function of inverse temperature are shown exemplarily in Figs. 4 and 5. Arrhenian equations were fitted to the viscosity data to describe the dependence of viscosity $\eta[\mathrm{Pa}$ s] on temperature $T[\mathrm{~K}]$.

$$
\log \eta=\log A+\frac{10000 B}{T}
$$


The parameters $A$ and $B$ for all samples are given in Table 5. The parameters were used to calculate the temperature $T_{g}^{12}$ (Table 5 ), where the viscosity $\eta=10^{12} \mathrm{~Pa} \mathrm{~s}$. The fragility $m$ (Table 5 ) of the melts was calculated after Böhmer and Angell (1992):

$$
m=\frac{B}{T_{g}^{12}}
$$

The fragility describes how viscosity-temperature behaviour changes with temperature. The logarithmic viscosity vs. inverse temperature dependence of "fragile" melts is curved, while that of "strong" melts is almost linear and their fragility is low (Angell, 1991). We observed that the halogen-free melts have higher fragilities than the halogen-bearing melts and that the dry melts have higher fragilities than the hydrous melts.

Fig. 4 shows the viscosity of the dry fluorine-free and fluorine-bearing peraluminous (ANCS) and peralkaline (NACS) melts. The viscosity decreases with increasing temperature. The fluorine-free peraluminous melt has $a \sim 5$ orders of magnitude higher viscosity than the peralkaline fluorine-free melt. In the peraluminous glasses $F$ decreases the viscosity by $\sim 1$ log unit per mol\% for $F$ concentration lower than $1.1 \mathrm{~mol} \%$ and about $\sim 0.4 \log$ unit per mol\% for $\mathrm{F}$ concentration higher than that (Fig. 4). In the peralkaline melts 1.9 mol\% $\mathrm{F}$ decreases the viscosity by about 0.6 log units per mol\% (Fig. 4). The decreasing effect of fluorine on viscosity is stronger in the peraluminous melts than in the peralkaline melts. The Arrhenian equation fitted to the data for NACS 6.2F with $6.2 \mathrm{~mol} \% \mathrm{~F}$ intersects at viscosities around $10^{12.5} \mathrm{Pas}$ with that of the sample NACS $1.9 \mathrm{~F}$ with $1.9 \mathrm{~mol} \% \mathrm{~F}$, while at viscosities around $10^{10} \mathrm{~Pa}$ s the data intersects with that of the halogen-free sample NACS. The higher viscosities of NACS 6.2F compared to NACS 1.9F clearly suggest that for higher $F$ concentrations viscosity starts to increase. Below viscosities of $10^{10} \mathrm{Pas}$ the addition of $6.2 \mathrm{~mol} \% \mathrm{~F}$ to the peralkaline melts even leads to an increase in viscosity with respect to that of the peralkaline halogen-free melt.

Figure 5 shows the viscosity of halogen-free dry and hydrous peraluminous (ANCS) and peralkaline (NACS) melts. The viscosity of the melts decreases with increasing water content, with the effect of additional water becoming smaller at higher total water contents. In the peraluminous as well as in the peralkaline melts the addition of 
water decreases viscosity more strongly than the addition of fluorine (on a mol\% basis).

In Fig. 6 the temperature $T_{g}{ }^{12}$ of peralkaline (NACS) (A) and peraluminous (ANCS) (B) melts is shown as a function of $F$ concentration. The use of $T_{g}^{12}$ instead of logarithmic viscosity on the $y$-axis has the advantage that the data are not extrapolated to temperatures where no measurements were performed. The peralkaline sample NACS $1.9 \mathrm{~F}$ has $29 \mathrm{~K}$ lower $T_{g}^{12}$ than the halogen-free sample NACS, corresponding to a decrease of $15 \mathrm{~K}$ per mol\% $\mathrm{F}$. The sample NACS $6.2 \mathrm{~F}$ has within error the same $T_{g}{ }^{12}$ as the sample NACS $1.9 \mathrm{~F}$. In the peraluminous melts the first $1.1 \mathrm{~mol} \% \mathrm{~F}$ cause a decrease of $T_{g}{ }^{12}$ by $38 \mathrm{~K}$ per mol\% $\mathrm{F}$, between 1.1 and 9.7 mol\% $\mathrm{F} \mathrm{T}_{g}{ }^{12}$ decreases by $\sim 19 \mathrm{~K}$ per mol\% $\mathrm{F}$ and between 9.7 and $18.3 \mathrm{~mol} \% \mathrm{~F}$ $T_{g}{ }^{12}$ decreases by $\sim 5 \mathrm{~K}$ per mol\% $\mathrm{F}$ (values were calculated from data points in Fig. 6 not from a regression). The decreasing effect of $F$ on $T_{g}{ }^{12} /$ viscosity in peralkaline melts is not only weaker than in peraluminous melts, but also the concentration of $F$ up to which a decreasing effect can be observed is lower.

Figure 7 shows the temperature $T_{g}{ }^{12}$ as a function of the water concentration for halogen-free and halogen-bearing peralkaline (NACS) (A) and peraluminous melts (ANCS) (B) and an overview of data from this study in comparison with fluorine-free (HPG8) and fluorine-bearing (HPG83F) dry and hydrous haplogranitic melts (Dingwell et al., 1993a; Hess et al., 1995; Dingwell et al., 1996; Giordano et al., 2004) (C). The following empirical equation was found fit best the decrease in $T_{g}{ }^{12}$ due to the addition of water $\mathrm{c}\left(\mathrm{H}_{2} \mathrm{O}\right)[\mathrm{mol} \%]$.

$$
T_{g}^{12}=A-B \cdot \ln \left(c\left(H_{2} \mathrm{O}\right)+C\right)
$$

The parameters $A, B$ and $C$ are given in Table 6 . Water decreases $T_{g}{ }^{12}$ for all melts studied here. The decrease of $T_{g}{ }^{12}$ due to the addition of water is stronger in peraluminous than in the peralkaline melts. The increasing effect of chlorine on $T_{g}{ }^{12} /$ viscosity of the peralkaline melts that was found for dry melts by Baasner et al. (2013) is still present in the hydrous samples (Fig. 7A). The $T_{g}{ }^{12}$ vs. $c\left(\mathrm{H}_{2} \mathrm{O}\right)$ curve of NACS $1.1 \mathrm{Cl}$ runs parallel to that of the halogen-free sample NACS. This is not the case for the samples that contain F alone or combined with $\mathrm{Cl}$. Baasner et al. (2013) found for the dry peralkaline melts that $F$ alone decreases $T_{g}{ }^{12} /$ viscosity and in melts containing both halogens the effects of $\mathrm{F}$ and $\mathrm{Cl}$ compensate each other. The 
hydrous fluorine-bearing peralkaline glasses studied here have either the same or higher $T_{g}^{12}$ than the halogen-free sample NACS. For the dry peraluminous melts it was found by Baasner et al. (2013) that F as well as $\mathrm{Cl}$ decrease viscosity. The present hydrous halogen-bearing peraluminous samples have lower $T_{g}^{12}$ than the halogen-free sample ANCS (Fig. 7B). However, with increasing water content the differences in viscosity between the halogen-bearing melts and halogen-free melt become less. Similar effects were observed for the haplogranitic melts (Dingwell et al., 1993a; Hess et al., 1995; Dingwell et al., 1996; Giordano et al., 2004) (Fig. 7C).

Figure 8 shows the change in $T_{g}{ }^{12}$ of the hydrous melts compared to that of the dry melts $\left(\Delta T_{g}{ }^{12}\right)$ as a function of the water concentration for samples with different halogen concentrations. These plots have the advantage that all data are normalised to the same starting point for $0 \mathrm{~mol} \%$ water. In the peralkaline halogen-free melt NACS and the chlorine-bearing melt NACS $1.1 \mathrm{Cl}, 5$ mol\% water decreases $T_{g}^{12}$ by $186 \pm 5 \mathrm{~K}$ (Fig. 8A). In the peralkaline melts that contain only $\mathrm{F}$ or both $\mathrm{F}$ and $\mathrm{Cl}$ combined, $5 \mathrm{~mol} \%$ water decreases $T_{g}{ }^{12}$ by $\sim 146$ to $166 \mathrm{~K}$. In the halogen-free peraluminous melts $5 \mathrm{~mol} \%$ water decreases $T_{g}^{12}$ by $259 \pm 5 \mathrm{~K}$ (Fig. 8A). With increasing $F$ concentration in the halogen-bearing peraluminous samples the decrease of viscosity due to the addition of water becomes less. 5 mol\% water leads to a decrease of $203 \pm 5 \mathrm{~K}$ in the case of ANCS $2.3 \mathrm{~F} 0.9 \mathrm{Cl}$ and $152 \pm 5 \mathrm{~K}$ in the case of ANCS 18.3F (Fig. 8B). The reduction in the decreasing effect of water on viscosity is stronger in the fluorine-bearing peraluminous melts than in the fluorine-bearing peralkaline melts (Fig. 8C). The decrease of $T_{g}^{12}$ due to water is strongest in the haplogranitic melt HPG8 (Dingwell et al., 1993a; Hess et al., 1995; Dingwell et al., 1996). The reduction of the decreasing effect of water on viscosity is stronger in the haplogranitic melt with 9.7 mol\% F HPG83F (Dingwell et al., 1993a; Giordano et al., 2004) than in the present peraluminous melt with 18.3 mol\% F ANCS 18.3F (Fig. 8C). The decreasing effect of water on $T_{g}{ }^{12}$ is only slightly greater in the peraluminous melt with 18.3 mol\% $\mathrm{F}$ than in the haplogranite melt with $9.7 \mathrm{~mol} \% \mathrm{~F}$, indicating that in the haplogranitic melts the reduction of the decreasing effect of water on viscosity due to $\mathrm{F}$ is stronger than in the present peraluminous melts.

In summary, in the peralkaline chlorine-bearing melt NACS $1.1 \mathrm{Cl}$ the increase in $T_{g}{ }^{12} /$ viscosity due to $\mathrm{Cl}$ adds to the decrease in $T_{g}{ }^{12} /$ viscosity due to water. However in all peraluminous, peralkaline and haplogranitic (Dingwell et al., 1993a; Hess et al., 
1995; Dingwell et al., 1996; Giordano et al., 2004) melts that contain $\mathrm{F}$ alone or combined with $\mathrm{Cl}$ the decrease in viscosity $/ T_{g}{ }^{12}$ due to water seems to be less than in the halogen-free melts. The combined effects of $F$ and water on viscosity are less than the sum of their single effects.

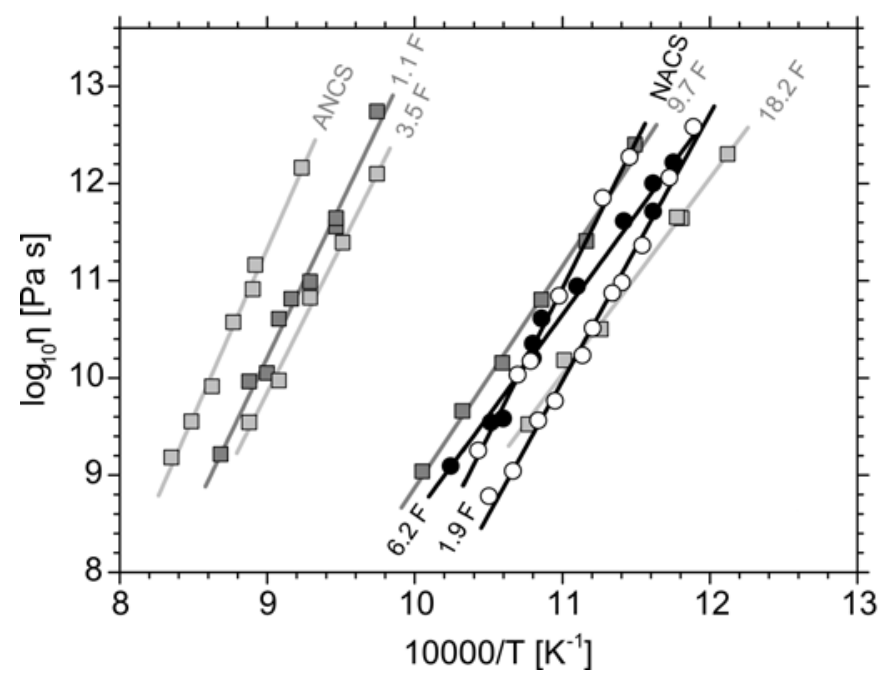

Fig. 4. Viscosity $\eta$ vs. inverse temperature $T$ of the halogen-free dry and fluorine-bearing peralkaline (NACS, circles) and peraluminous (ANCS, squares) melts. Errors are smaller than the symbols.

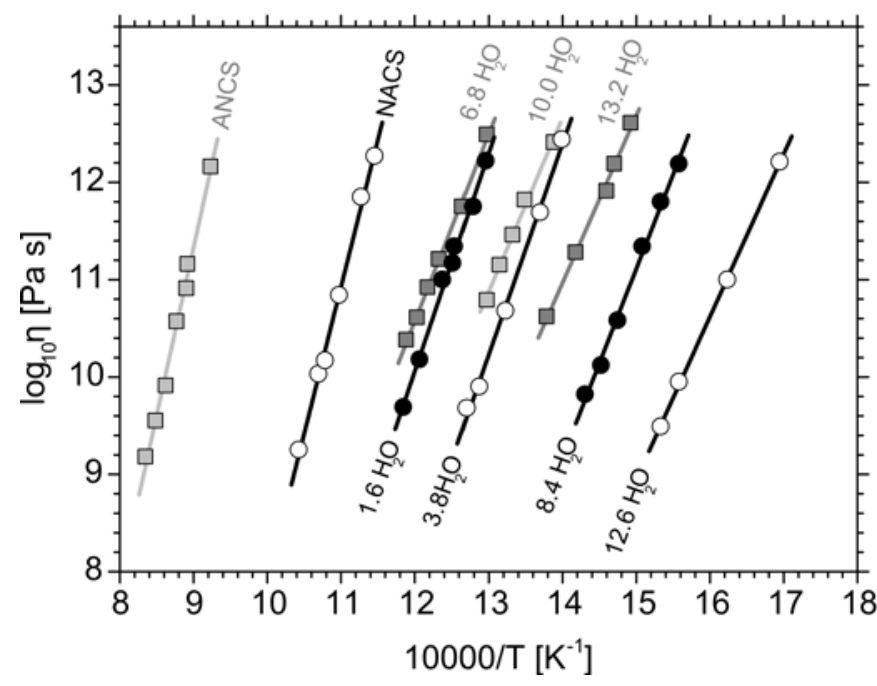

Fig. 5. Viscosity $\eta$ vs. inverse temperature $T$ of the halogen-free dry and hydrous peralkaline (NACS, circles) and peraluminous (ANCS, squares) melts. Errors are smaller than the symbols. 
Table 4. Micropenetration viscosity data $\eta( \pm 0.08 \log$ unit) for the peralkaline (NACS) and peraluminous (ANCS) $\mathrm{Na}_{2} \mathrm{O}-\mathrm{CaO}-\mathrm{Al}_{2} \mathrm{O}_{3}-\mathrm{SiO}_{2}$ melts at different temperatures $T( \pm 1 \mathrm{~K}$ ).

\begin{tabular}{|c|c|c|c|c|c|c|c|c|c|c|c|}
\hline$T$ & $\log _{10} \eta$ & $T$ & $\log _{10} \eta$ & $T$ & $\log _{10} \eta$ & $T$ & $\log _{10} \eta$ & $T$ & $\log _{10} \eta$ & $T$ & $\log _{10} \eta$ \\
\hline K & (Pa s) & $\mathrm{K}$ & (Pa s) & K & (Pa s) & K & (Pa s) & K & (Pa s) & K & (Pa s) \\
\hline \multicolumn{2}{|c|}{$\mathrm{NACS}^{\mathrm{a}}$} & \multicolumn{2}{|c|}{ NACS $0.7 F \quad 0.6 \mathrm{Cl}^{a}$} & \multicolumn{2}{|c|}{ NACS $1.1 \mathrm{~F} 1.1 \mathrm{Cl}^{\mathrm{a}}$} & \multicolumn{2}{|c|}{$\mathrm{NACS} 2.6 \mathrm{~F} 1.4 \mathrm{Cl}^{\mathrm{a}}$} & \multicolumn{2}{|c|}{ NACS $1.1 \mathrm{Cl}^{\mathrm{a}}$} & \multicolumn{2}{|c|}{ NACS $1.9 F^{a}$} \\
\hline 873 & 12.27 & 863 & 12.09 & 860 & 12.28 & 865 & 12.38 & 897 & 12.42 & 841 & 12.58 \\
\hline 887 & 11.85 & 873 & 11.77 & 870 & 11.97 & 891 & 11.58 & 908 & 11.99 & 853 & 12.06 \\
\hline 911 & 10.84 & 882 & 11.40 & 886 & 11.36 & 917 & 10.58 & 918 & 11.63 & 866 & 11.36 \\
\hline 927 & 10.17 & 892 & 11.24 & 901 & 10.95 & 943 & 9.89 & 933 & 10.89 & 877 & 10.98 \\
\hline 935 & 10.03 & 897 & 11.08 & 938 & 9.74 & 969 & 9.31 & 943 & 10.62 & 882 & 10.87 \\
\hline \multirow[t]{6}{*}{959} & 9.25 & 906 & 10.63 & 938 & 9.75 & & & 947 & 10.42 & 892 & 10.51 \\
\hline & & 916 & 10.27 & 963 & 9.18 & & & 963 & 9.90 & 898 & 10.23 \\
\hline & & 944 & 9.59 & 964 & 9.22 & & & 975 & 9.69 & 913 & 9.76 \\
\hline & & 973 & 8.62 & & & & & 987 & 9.19 & 923 & 9.56 \\
\hline & & & & & & & & 996 & 9.08 & 938 & 9.04 \\
\hline & & & & & & & & & & 952 & 8.78 \\
\hline \multicolumn{2}{|c|}{ NACS $6.2 \mathrm{~F}$} & \multicolumn{2}{|c|}{$\begin{array}{c}\text { NACS 0.7F 0.6Cl } \\
(\mathrm{IHPV})\end{array}$} & \multicolumn{2}{|c|}{$\begin{array}{c}\text { NACS 1.1F 1.1Cl } \\
\text { (IHPV) }\end{array}$} & \multicolumn{2}{|c|}{$\begin{array}{c}\text { NACS 2.6F 1.4Cl } \\
\text { (IHPV) }\end{array}$} & \multicolumn{2}{|c|}{ NACS $1.6 \mathrm{H}$} & \multicolumn{2}{|c|}{$\begin{array}{c}\text { NACS 0.7F 0.6Cl } \\
2.4 \mathrm{H} \\
\end{array}$} \\
\hline 851 & 12.22 & 844 & 12.56 & 839 & 12.32 & 829 & 12.46 & 771 & 12.22 & 744 & 12.63 \\
\hline 861 & 12.00 & 854 & 12.26 & 844 & 12.16 & 844 & 11.84 & 782 & 11.75 & 756 & 12.20 \\
\hline 861 & 11.71 & 863 & 11.79 & 865 & 11.35 & 855 & 11.50 & 798 & 11.34 & 777 & 11.16 \\
\hline 876 & 11.61 & 873 & 11.45 & 870 & 11.05 & 870 & 10.87 & 799 & 11.17 & 797 & 10.52 \\
\hline 901 & 10.94 & 882 & 11.20 & & & & & 808 & 11.00 & 818 & 9.99 \\
\hline 921 & 10.61 & & & & & & & 829 & 10.18 & 829 & 9.65 \\
\hline 926 & 10.20 & & & & & & & 844 & 9.69 & & \\
\hline 926 & 10.35 & & & & & & & & & & \\
\hline 944 & 9.58 & & & & & & & & & & \\
\hline 951 & 9.54 & & & & & & & & & & \\
\hline 976 & 9.09 & & & & & & & & & & \\
\hline \multicolumn{2}{|c|}{$\begin{array}{c}\text { NACS } 1.1 \mathrm{~F} 1.1 \mathrm{Cl} \\
2.2 \mathrm{H}\end{array}$} & \multicolumn{2}{|c|}{$\begin{array}{c}\text { NACS } 2.6 \mathrm{~F} 1.4 \mathrm{Cl} \\
2.8 \mathrm{H} \\
\end{array}$} & \multicolumn{2}{|c|}{ NACS $1.1 \mathrm{Cl} 2.2 \mathrm{H}$} & \multicolumn{2}{|c|}{ NACS $1.9 \mathrm{~F} 2.8 \mathrm{H}$} & \multicolumn{2}{|c|}{ NACS $3.8 \mathrm{H}$} & \multicolumn{2}{|c|}{$\begin{array}{c}\text { NACS } 0.7 \mathrm{~F} 0.6 \mathrm{Cl} \\
4.5 \mathrm{H} \\
\end{array}$} \\
\hline 766 & 12.27 & 746 & 12.10 & 781 & 12.44 & 746 & 12.49 & 715 & 12.44 & 704 & 12.45 \\
\hline 786 & 11.49 & 746 & 12.06 & 786 & 12.32 & 756 & 12.13 & 730 & 11.69 & 715 & 11.97 \\
\hline 812 & 10.50 & 757 & 11.52 & 791 & 12.17 & 776 & 11.46 & 756 & 10.68 & 735 & 11.04 \\
\hline \multirow[t]{6}{*}{833} & 9.82 & 787 & 10.65 & 801 & 11.70 & 796 & 10.83 & 777 & 9.90 & 756 & 10.36 \\
\hline & & 811 & 10.06 & 821 & 11.04 & 816 & 10.25 & 787 & 9.68 & 777 & 9.76 \\
\hline & & 821 & 9.81 & 841 & 10.40 & 836 & 9.79 & & & & \\
\hline & & & & 861 & 9.84 & 846 & 9.60 & & & & \\
\hline & & & & 882 & 9.45 & & & & & & \\
\hline & & & & 892 & 9.17 & & & & & & \\
\hline \multicolumn{2}{|c|}{$\begin{array}{c}\text { NACS 1.1F 1.1Cl } \\
5.0 \mathrm{H} \\
\end{array}$} & \multicolumn{2}{|c|}{$\begin{array}{c}\text { NACS 2.6F 1.4Cl } \\
3.8 \mathrm{H} \\
\end{array}$} & NACS & $\mathrm{Cl} 3.7 \mathrm{H}$ & NACS & $\mathrm{F} 5.8 \mathrm{H}$ & NA & $8.4 \mathrm{H}$ & NACS & $\begin{array}{l}\mathrm{F} 0.6 \mathrm{Cl} \\
\mathrm{H}\end{array}$ \\
\hline 704 & 12.27 & 720 & 12.27 & 746 & 12.55 & 676 & 12.50 & 642 & 12.19 & 642 & 12.36 \\
\hline 724 & 11.36 & 730 & 11.77 & 766 & 11.69 & 686 & 12.08 & 652 & 11.80 & 647 & 12.16 \\
\hline 745 & 10.49 & 756 & 10.96 & 786 & 10.92 & 706 & 11.25 & 663 & 11.34 & 652 & 11.79 \\
\hline 766 & 10.00 & 771 & 10.51 & 806 & 10.41 & 726 & 10.72 & 678 & 10.58 & 683 & 10.48 \\
\hline & & 776 & 10.34 & 826 & 9.83 & 766 & 9.36 & 689 & 10.12 & 694 & 10.17 \\
\hline & & 781 & 10.19 & 836 & 9.56 & 746 & 9.82 & 699 & 9.82 & 704 & 9.86 \\
\hline
\end{tabular}


Table 4 (continued). Micropenetration viscosity data $\eta( \pm 0.08$ log unit) for the peralkaline (NACS) and peraluminous (ANCS) $\mathrm{Na}_{2} \mathrm{O}-\mathrm{CaO}-\mathrm{Al}_{2} \mathrm{O}_{3}-\mathrm{SiO}_{2}$ melts at different temperatures $T( \pm 1 \mathrm{~K})$.

\begin{tabular}{|c|c|c|c|c|c|c|c|c|c|c|c|}
\hline $\begin{array}{l}T \\
\mathrm{~K}\end{array}$ & $\begin{array}{l}\log _{10} \eta \\
\text { (Pa s) }\end{array}$ & $\begin{array}{l}T \\
\mathrm{~K}\end{array}$ & $\begin{array}{l}\log _{10} \eta \\
(\mathrm{Pa} \mathrm{s})\end{array}$ & $\begin{array}{l}T \\
\mathrm{~K}\end{array}$ & $\begin{array}{l}\log _{10} \eta \\
\text { (Pa s) }\end{array}$ & $\begin{array}{l}T \\
\mathrm{~K}\end{array}$ & $\begin{array}{l}\log _{10} \eta \\
(\mathrm{Pa} \mathrm{s})\end{array}$ & $\begin{array}{l}T \\
\mathrm{~K}\end{array}$ & $\begin{array}{r}\log _{10} \eta \\
(\mathrm{Pa} \mathrm{s})\end{array}$ & $\begin{array}{l}T \\
\mathrm{~K}\end{array}$ & $\begin{array}{r}\log _{10} \eta \\
\text { (Pa s) }\end{array}$ \\
\hline \multicolumn{2}{|c|}{$\begin{array}{c}\text { NACS } 1.1 \mathrm{~F} 1.1 \mathrm{Cl} \\
7.9 \mathrm{H}\end{array}$} & \multicolumn{2}{|c|}{$\begin{array}{c}\text { NACS } 2.6 \mathrm{~F} 1.4 \mathrm{Cl} \\
9.6 \mathrm{H} \\
\end{array}$} & \multicolumn{2}{|c|}{ NACS $1.1 \mathrm{Cl} 7.5 \mathrm{H}$} & \multicolumn{2}{|c|}{ NACS $1.9 F$ 13.2H } & \multicolumn{2}{|c|}{ NACS $12.6 \mathrm{H}$} & \multicolumn{2}{|c|}{$\begin{array}{c}\text { NACS 0.7F 0.6Cl } \\
13.1 \mathrm{H} \\
\end{array}$} \\
\hline 650 & 12.70 & 630 & 12.36 & 676 & 12.29 & 636 & 12.45 & 590 & 12.21 & 590 & 12.41 \\
\hline 660 & 12.27 & 645 & 11.65 & 686 & 11.95 & 656 & 11.56 & 616 & 11.00 & 590 & 12.33 \\
\hline 670 & 11.89 & 655 & 11.19 & 696 & 11.49 & 676 & 10.70 & 642 & 9.95 & 605 & 11.42 \\
\hline 690 & 10.90 & 670 & 10.76 & 716 & 10.66 & 696 & 10.06 & 652 & 9.49 & 611 & 11.28 \\
\hline 700 & 10.62 & 680 & 10.41 & 736 & 10.13 & 716 & 9.45 & & & 631 & 10.27 \\
\hline \multirow[t]{2}{*}{710} & 10.29 & 690 & 9.92 & 756 & 9.60 & & & & & 642 & 9.82 \\
\hline & & & & & & & & & & 652 & 9.61 \\
\hline \multicolumn{2}{|c|}{$\begin{array}{c}\text { NACS } 1.1 \mathrm{~F} 1.1 \mathrm{Cl} \\
13.5 \mathrm{H} \\
\end{array}$} & \multicolumn{2}{|c|}{$\begin{array}{c}\text { NACS } 2.6 \mathrm{~F} 1.4 \mathrm{Cl} \\
13.3 \mathrm{H} \\
\end{array}$} & \multicolumn{2}{|c|}{ NACS $1.1 \mathrm{Cl} 14.5 \mathrm{H}$} & \multicolumn{2}{|c|}{ NACS $1.9 \mathrm{~F} 13.10 \mathrm{H}$} & \multicolumn{2}{|c|}{$\mathrm{ANCS}^{\mathrm{a}}$} & \multicolumn{2}{|c|}{ ANCS $0.5 \mathrm{~F} 0.5 \mathrm{Cl}^{\mathrm{a}}$} \\
\hline 595 & 12.24 & 574 & 12.88 & 596 & 12.41 & 586 & 12.27 & 1083 & 12.16 & 1054 & 12.25 \\
\hline 606 & 11.75 & 589 & 12.15 & 616 & 11.60 & 596 & 11.90 & 1121 & 11.16 & 1078 & 11.56 \\
\hline 631 & 10.61 & 599 & 11.57 & 626 & 11.11 & 616 & 10.96 & 1140 & 10.57 & 1102 & 10.87 \\
\hline \multirow[t]{4}{*}{657} & 9.65 & 609 & 11.15 & 636 & 10.72 & 636 & 10.41 & 1159 & 9.91 & 1126 & 10.27 \\
\hline & & 630 & 10.42 & 656 & 10.03 & 666 & 9.26 & 1178 & 9.55 & 1150 & 9.63 \\
\hline & & 650 & 9.76 & & & & & 1197 & 9.18 & 1169 & 9.28 \\
\hline & & & & & & & & 1123 & 10.91 & 1124 & 10.27 \\
\hline \multicolumn{2}{|c|}{ ANCS $1.2 \mathrm{~F} 1.1 \mathrm{Cl}^{\mathrm{a}}$} & \multicolumn{2}{|c|}{ ANCS $2.3 \mathrm{~F} 0.9 \mathrm{Cl}^{\mathrm{a}}$} & \multicolumn{2}{|c|}{ ANCS $1.1 F^{a}$} & \multicolumn{2}{|c|}{ ANCS $3.5 \mathrm{~F}^{\mathrm{a}}$} & \multicolumn{2}{|c|}{ ANCS $9.7 F^{a}$} & \multicolumn{2}{|c|}{ ANCS $18.3 F^{a}$} \\
\hline 1040 & 12.25 & 1026 & 11.97 & 1026 & 12.74 & 1026 & 12.10 & 870 & 12.40 & 825 & 12.30 \\
\hline 1059 & 11.74 & 1045 & 11.37 & 1056 & 11.64 & 1051 & 11.39 & 896 & 11.41 & 847 & 11.64 \\
\hline 1078 & 11.22 & 1064 & 10.89 & 1056 & 11.56 & 1076 & 10.82 & 921 & 10.80 & 849 & 11.65 \\
\hline 1116 & 10.08 & 1083 & 10.36 & 1076 & 10.99 & 1101 & 9.97 & 944 & 10.15 & 888 & 10.50 \\
\hline 1135 & 9.68 & 1102 & 9.97 & 1091 & 10.81 & 1126 & 9.54 & 969 & 9.66 & 908 & 10.18 \\
\hline 1135 & 9.66 & 1121 & 9.69 & 1101 & 10.61 & & & 995 & 9.04 & 929 & 9.52 \\
\hline \multirow[t]{3}{*}{1159} & 8.96 & 1121 & 9.67 & 1111 & 10.05 & & & & & & \\
\hline & & 1140 & 9.22 & 1126 & 9.96 & & & & & & \\
\hline & & & & 1151 & 9.21 & & & & & & \\
\hline \multicolumn{2}{|c|}{$\begin{array}{c}\text { ANCS } 0.5 \mathrm{~F} 0.5 \mathrm{Cl} \\
0.8 \mathrm{H}\end{array}$} & ANC & $6.8 \mathrm{H}$ & $\begin{array}{r}\text { ANCS } \\
5 \\
\end{array}$ & $\mathrm{~F} 0.5 \mathrm{Cl}$ & $\begin{array}{r}\text { ANCS } \\
6\end{array}$ & $\mathrm{~F} \mathrm{1.1Cl}$ & ANCS & $\mathrm{F} 0.9 \mathrm{Cl}$ & ANCS & $=5.3 \mathrm{H}$ \\
\hline 972 & 12.30 & 771 & 12.49 & 821 & 12.40 & 781 & 12.18 & 771 & 12.06 & 676 & 12.01 \\
\hline 992 & 11.74 & 791 & 11.75 & 841 & 11.77 & 786 & 11.87 & 781 & 11.74 & 681 & 11.78 \\
\hline 1013 & 11.17 & 811 & 11.21 & 851 & 11.44 & 791 & 11.70 & 791 & 11.22 & 686 & 11.73 \\
\hline 1033 & 10.66 & 821 & 10.92 & 861 & 11.14 & 801 & 11.43 & 801 & 10.88 & 696 & 11.33 \\
\hline & & 831 & 10.61 & 871 & 10.79 & 811 & 11.09 & & & 701 & 11.02 \\
\hline & & 841 & 10.38 & & & 821 & 10.87 & & & 711 & 10.70 \\
\hline & & & & & & & & & & 726 & 10.21 \\
\hline ANC & $0.0 \mathrm{H}$ & ANCS & $\mathrm{F} 0.5 \mathrm{Cl}$ & $\begin{array}{r}\text { ANCS } \\
9\end{array}$ & $\mathrm{~F} 1.1 \mathrm{Cl}$ & $\begin{array}{r}\mathrm{ANCS} \\
9\end{array}$ & $\mathrm{~F} 0.9 \mathrm{Cl}$ & ANCS & $3 F 8.9 H$ & ANC & $3.2 \mathrm{H}$ \\
\hline 720 & 12.41 & 720 & 12.66 & 720 & 12.06 & 730 & 12.23 & 636 & 12.15 & 670 & 12.61 \\
\hline 741 & 11.82 & 740 & 11.94 & 730 & 11.64 & 741 & 11.83 & 636 & 12.24 & 680 & 12.19 \\
\hline 751 & 11.46 & 751 & 11.58 & 741 & 11.33 & 761 & 11.23 & 656 & 11.55 & 685 & 11.91 \\
\hline 761 & 11.15 & 761 & 11.25 & 751 & 11.11 & 771 & 10.88 & 666 & 11.02 & 705 & 11.28 \\
\hline 771 & 10.79 & 771 & 10.85 & 761 & 10.73 & & & 676 & 10.86 & 725 & 10.62 \\
\hline & & & & & & & & 686 & 10.42 & & \\
\hline
\end{tabular}


Table 4 (continued). Micropenetration viscosity data $\eta$ ( \pm 0.08 log unit) for the peralkaline (NACS) and peraluminous (ANCS) $\mathrm{Na}_{2} \mathrm{O}-\mathrm{CaO}-\mathrm{Al}_{2} \mathrm{O}_{3}-\mathrm{SiO}_{2}$ melts at different temperatures $T( \pm 1 \mathrm{~K}$ ).

\begin{tabular}{|c|c|c|c|c|c|c|c|c|c|c|c|}
\hline $\begin{array}{l}T \\
\mathrm{~K}\end{array}$ & $\begin{array}{r}\log _{10} \eta \\
\text { (Pa s) }\end{array}$ & $\begin{array}{l}T \\
\mathrm{~K}\end{array}$ & $\begin{array}{r}\log _{10} \eta \\
\text { (Pa s) }\end{array}$ & $\begin{array}{l}T \\
\mathrm{~K}\end{array}$ & $\begin{array}{l}\log _{10} \eta \\
(\mathrm{Pa} \mathrm{s})\end{array}$ & $\begin{array}{l}T \\
\mathrm{~K}\end{array}$ & $\begin{array}{r}\log _{10} \eta \\
\text { (Pa s) }\end{array}$ & $\begin{array}{l}T \\
\mathrm{~K}\end{array}$ & $\begin{array}{r}\log _{10} \eta \\
(\mathrm{Pa} \mathrm{s})\end{array}$ & $\begin{array}{l}T \\
\mathrm{~K}\end{array}$ & $\begin{array}{r}\log _{10} \eta \\
(\mathrm{Pa} \mathrm{s})\end{array}$ \\
\hline \multicolumn{2}{|c|}{$\begin{array}{c}\text { ANCS } 0.5 \mathrm{~F} 0.5 \mathrm{Cl} \\
13.0 \mathrm{H}\end{array}$} & \multicolumn{2}{|c|}{$\begin{array}{c}\text { ANCS } 1.2 \mathrm{~F} 1.1 \mathrm{Cl} \\
12.0 \mathrm{H}\end{array}$} & \multicolumn{2}{|c|}{$\begin{array}{c}\text { ANCS 2.3F } 0.9 \mathrm{Cl} \\
13.1 \mathrm{H}\end{array}$} & \multicolumn{2}{|c|}{$\begin{array}{c}\text { ANCS 18.3F } \\
12.19 \mathrm{H}\end{array}$} & & & & \\
\hline 650 & 13.23 & 680 & 12.35 & 670 & 12.55 & 596 & 12.45 & & & & \\
\hline 670 & 12.69 & 700 & 11.65 & 680 & 12.23 & 606 & 12.14 & & & & \\
\hline 690 & 12.06 & 700 & 11.83 & 690 & 11.75 & 616 & 11.76 & & & & \\
\hline 710 & 11.10 & 710 & 11.43 & 700 & 11.35 & 626 & 11.43 & & & & \\
\hline \multirow[t]{3}{*}{720} & 10.79 & 720 & 11.13 & 710 & 10.76 & 636 & 10.74 & & & & \\
\hline & & 720 & 10.99 & & & 646 & 10.59 & & & & \\
\hline & & 730 & 10.61 & & & 666 & 10.04 & & & & \\
\hline
\end{tabular}

a - Published in Baasner et al. (2013a)

Table 5. Parameters $(A, B)$ of Arrhenian fits to the viscosity data $\left(\log _{10} \eta\right.$ in Pa s) (Eq. 4), $T_{g}^{12}$ (temperature at $\eta=10^{12} \mathrm{Pas}$ ) and the fragility $m$.

\begin{tabular}{|c|c|c|c|c|c|c|c|c|c|c|c|}
\hline & $\bar{A}$ & $\overline{\bar{\sigma}^{a}}$ & $\begin{array}{c}B \\
{\left[\begin{array}{ll}K & 10^{4}\end{array}\right]}\end{array}$ & $\begin{array}{c}\bar{\sigma}^{\mathrm{a}} \\
{\left[\begin{array}{ll}\mathrm{K} & 10^{4}\end{array}\right]}\end{array}$ & $v^{2 b}$ & $N^{c}$ & $S E_{y}{ }^{d}$ & $\begin{array}{l}T_{g}^{12} \\
{[\mathrm{~K}]}\end{array}$ & $\begin{array}{c} \pm \\
{[\mathrm{K}]}\end{array}$ & $m^{f}$ & \pm \\
\hline \multicolumn{12}{|l|}{ Peraluminous } \\
\hline $\mathrm{ANCS}^{\mathrm{e}}$ & -19.67 & 1.14 & 3.44 & 0.13 & 0.04 & 7 & 0.09 & 1088 & 3 & 32 & 1.2 \\
\hline ANCS $6.8 \mathrm{H}$ & -12.56 & 0.56 & 1.93 & 0.05 & 0.01 & 6 & 0.04 & 785 & 1 & 25 & 0.6 \\
\hline ANCS $10.0 \mathrm{H}$ & -12.35 & 1.04 & 1.79 & 0.08 & 0.01 & 5 & 0.05 & 734 & 2 & 24 & 1.1 \\
\hline ANCS $13.2 \mathrm{H}$ & -13.09 & 0.92 & 1.72 & 0.06 & 0.01 & 5 & 0.06 & 685 & 2 & 25 & 0.9 \\
\hline ANCS $0.5 \mathrm{~F} 0.5 \mathrm{Cl}^{\mathrm{e}}$ & -18.48 & 0.49 & 3.24 & 0.06 & 0.01 & 7 & 0.04 & 1062 & 2 & 30 & 0.5 \\
\hline ANCS $0.5 \mathrm{~F} 0.5 \mathrm{Cl} 0.8 \mathrm{H}$ & -15.82 & 0.25 & 2.73 & 0.03 & 0.00 & 4 & 0.01 & 983 & 0 & 28 & 0.3 \\
\hline ANCS $0.5 \mathrm{~F} 0.5 \mathrm{Cl} 5.1 \mathrm{H}$ & -14.94 & 0.62 & 2.25 & 0.05 & 0.00 & 5 & 0.03 & 833 & 1 & 27 & 0.6 \\
\hline ANCS $0.5 \mathrm{~F} 0.5 \mathrm{Cl} 8.8 \mathrm{H}$ & -14.73 & 0.53 & 1.97 & 0.04 & 0.00 & 5 & 0.03 & 739 & 1 & 27 & 0.5 \\
\hline ANCS $0.5 \mathrm{~F} 0.5 \mathrm{Cl} 13.0 \mathrm{H}$ & -12.20 & 1.87 & 1.66 & 0.13 & 0.08 & 5 & 0.16 & 686 & 4 & 24 & 1.9 \\
\hline ANCS $1.2 \mathrm{~F} 1.1 \mathrm{Cl}^{\mathrm{e}}$ & -19.52 & 0.52 & 3.31 & 0.06 & 0.01 & 7 & 0.05 & 1050 & 2 & 32 & 0.5 \\
\hline ANCS $1.2 \mathrm{~F} 1.1 \mathrm{Cl} 6.2 \mathrm{H}$ & -13.67 & 1.57 & 2.01 & 0.13 & 0.02 & 6 & 0.07 & 783 & 2 & 26 & 1.6 \\
\hline ANCS $1.2 \mathrm{~F} 1.1 \mathrm{Cl} 9.8 \mathrm{H}$ & -12.07 & 1.26 & 1.74 & 0.09 & 0.01 & 5 & 0.05 & 721 & 2 & 24 & 1.3 \\
\hline ANCS $1.2 \mathrm{~F} 1.1 \mathrm{Cl} 12.0 \mathrm{H}$ & -12.31 & 1.68 & 1.68 & 0.12 & 0.05 & 7 & 0.10 & 692 & 3 & 24 & 1.7 \\
\hline ANCS $2.3 \mathrm{~F} 0.9 \mathrm{Cl}^{\mathrm{e}}$ & -14.69 & 0.79 & 2.72 & 0.09 & 0.04 & 8 & 0.08 & 1021 & 3 & 27 & 0.8 \\
\hline ANCS $2.3 \mathrm{~F} 0.9 \mathrm{Cl} 7.0 \mathrm{H}$ & -20.17 & 2.16 & 2.49 & 0.17 & 0.01 & 4 & 0.06 & 773 & 1 & 32 & 2.2 \\
\hline ANCS $2.3 \mathrm{~F} 0.9 \mathrm{Cl} 9.4 \mathrm{H}$ & -13.03 & 0.80 & 1.84 & 0.06 & 0.00 & 4 & 0.03 & 737 & 1 & 25 & 0.8 \\
\hline ANCS $2.3 \mathrm{~F} 0.9 \mathrm{Cl} 13.1 \mathrm{H}$ & -18.75 & 2.00 & 2.10 & 0.14 & 0.03 & 5 & 0.09 & 684 & 2 & 31 & 2.0 \\
\hline ANCS 1.1F & -18.28 & 1.40 & 3.17 & 0.15 & 0.14 & 9 & 0.14 & 1045 & 5 & 30 & 1.4 \\
\hline ANCS 3.5F & -17.30 & 1.27 & 3.02 & 0.14 & 0.03 & 5 & 0.09 & 1030 & 3 & 29 & 1.4 \\
\hline ANCS 9.7F & -13.93 & 0.88 & 2.28 & 0.08 & 0.04 & 6 & 0.10 & 879 & 3 & 26 & 1.3 \\
\hline ANCS $18.3 \mathrm{~F}^{\mathrm{e}}$ & -12.16 & 0.74 & 2.02 & 0.06 & 0.02 & 6 & 0.08 & 835 & 3 & 24 & 0.9 \\
\hline ANCS 18.3F 5.3H & -14.47 & 1.01 & 1.79 & 0.07 & 0.02 & 7 & 0.06 & 676 & 2 & 26 & 0.8 \\
\hline ANCS $18.3 F$ 8.9H & -11.81 & 1.19 & 1.53 & 0.08 & 0.03 & 6 & 0.08 & 641 & 2 & 24 & 1.0 \\
\hline ANCS $18.3 \mathrm{~F} 12.19 \mathrm{H}$ & -11.60 & 1.34 & 1.43 & 0.08 & 0.08 & 7 & 0.13 & 608 & 3 & 24 & 1.2 \\
\hline
\end{tabular}


Table 5 (continued). Parameters $(A, B)$ of Arrhenian fits to the viscosity data $\left(\log _{10} \eta\right.$ in Pa s) (Eq. 4), $T_{g}^{12}$ (temperature at $\eta=10^{12} \mathrm{~Pa} \mathrm{~s}$ ) and the fragility $m$.

\begin{tabular}{|c|c|c|c|c|c|c|c|c|c|c|c|}
\hline & $A$ & $\bar{\sigma}^{a}$ & $\begin{array}{c}B \\
{\left[\mathrm{~K} 10^{4}\right]}\end{array}$ & $\begin{array}{c}\bar{\sigma}^{a} \\
{\left[K \quad 10^{4}\right]}\end{array}$ & $v^{2 b}$ & $N^{c}$ & $S E_{y}^{d}$ & $\begin{array}{l}T_{g}^{12} \\
{[\mathrm{~K}]}\end{array}$ & $\begin{array}{c} \pm \\
{[\mathrm{K}]}\end{array}$ & $m^{f}$ & \pm \\
\hline \multicolumn{12}{|l|}{ Peralkaline } \\
\hline $\mathrm{NACS}^{\mathrm{e}}$ & -22.30 & 1.01 & 3.02 & 0.09 & 0.02 & 6 & 0.08 & 881 & 2 & 34 & 1.0 \\
\hline NACS $1.6 \mathrm{H}$ & -16.86 & 0.90 & 2.24 & 0.07 & 0.02 & 7 & 0.07 & 777 & 2 & 29 & 0.9 \\
\hline NACS $3.8 \mathrm{H}$ & -17.92 & 0.97 & 2.17 & 0.07 & 0.02 & 5 & 0.08 & 724 & 2 & 30 & 1.0 \\
\hline NACS $8.4 \mathrm{H}$ & -17.98 & 0.89 & 1.94 & 0.06 & 0.02 & 6 & 0.07 & 647 & 1 & 30 & 0.9 \\
\hline NACS $12.6 \mathrm{H}$ & -16.13 & 0.36 & 1.67 & 0.02 & 0.00 & 4 & 0.03 & 594 & 1 & 28 & 0.4 \\
\hline NACS $0.7 F \quad 0.6 \mathrm{Cl}^{\mathrm{e}}$ & -18.39 & 0.78 & 2.63 & 0.07 & 0.05 & 9 & 0.08 & 867 & 2 & 30 & 0.8 \\
\hline NACS 0.7F 0.6Cl (IHPV) & -19.96 & 1.70 & 2.74 & 0.15 & 0.01 & 5 & 0.06 & 859 & 2 & 32 & 1.7 \\
\hline NACS $0.7 \mathrm{~F} 0.6 \mathrm{Cl} 2.4 \mathrm{H}$ & -17.03 & 0.89 & 2.21 & 0.07 & 0.02 & 6 & 0.07 & 760 & 2 & 29 & 0.9 \\
\hline NACS $0.7 \mathrm{~F} 0.6 \mathrm{Cl} 4.5 \mathrm{H}$ & -16.52 & 1.21 & 2.03 & 0.09 & 0.01 & 5 & 0.06 & 714 & 1 & 29 & 1.2 \\
\hline NACS $0.7 \mathrm{~F} 0.6 \mathrm{Cl} 8.4 \mathrm{H}$ & -16.39 & 0.92 & 1.84 & 0.06 & 0.03 & 6 & 0.08 & 649 & 2 & 28 & 1.0 \\
\hline NACS $0.7 \mathrm{~F} 0.6 \mathrm{Cl} 13.1 \mathrm{H}$ & -17.53 & 1.14 & 1.76 & 0.07 & 0.06 & 7 & 0.11 & 596 & 2 & 30 & 1.2 \\
\hline NACS $1.1 \mathrm{~F} 1.1 \mathrm{Cl}^{\mathrm{e}}$ & -16.88 & 0.67 & 2.51 & 0.06 & 0.04 & 8 & 0.08 & 868 & 2 & 29 & 0.7 \\
\hline NACS 1.1F 1.1Cl (IHPV) & -22.53 & 1.76 & 2.93 & 0.15 & 0.01 & 4 & 0.05 & 847 & 1 & 35 & 1.8 \\
\hline NACS $1.1 \mathrm{~F} 1.1 \mathrm{Cl} 2.2 \mathrm{H}$ & -18.01 & 1.24 & 2.32 & 0.10 & 0.02 & 4 & 0.10 & 772 & 3 & 30 & 1.3 \\
\hline NACS $1.1 \mathrm{~F} 1.1 \mathrm{Cl} 5.0 \mathrm{H}$ & -16.30 & 2.01 & 2.01 & 0.15 & 0.03 & 4 & 0.13 & 709 & 3 & 28 & 2.1 \\
\hline NACS $1.1 \mathrm{~F} 1.1 \mathrm{Cl} 7.9 \mathrm{H}$ & -16.32 & 0.87 & 1.89 & 0.06 & 0.02 & 6 & 0.07 & 666 & 2 & 28 & 0.9 \\
\hline NACS $1.1 \mathrm{~F} 1.1 \mathrm{Cl} 13.5 \mathrm{H}$ & -15.30 & 0.42 & 1.64 & 0.03 & 0.00 & 4 & 0.03 & 600 & 1 & 27 & 0.4 \\
\hline NACS $2.6 \mathrm{~F} 1.4 \mathrm{Cl}^{\mathrm{e}}$ & -16.47 & 1.11 & 2.45 & 0.10 & 0.03 & 5 & 0.10 & 860 & 3 & 28 & 1.2 \\
\hline NACS 2.6F 1.4Cl (IHPV) & -20.55 & 0.90 & 2.74 & 0.08 & 0.00 & 4 & 0.03 & 840 & 1 & 33 & 0.9 \\
\hline NACS $2.6 \mathrm{~F} 1.4 \mathrm{Cl} 2.8 \mathrm{H}$ & -12.48 & 0.95 & 1.83 & 0.07 & 0.03 & 6 & 0.09 & 746 & 3 & 24 & 1.0 \\
\hline NACS $2.6 \mathrm{~F} 1.4 \mathrm{Cl} 3.8 \mathrm{H}$ & -13.93 & 0.68 & 1.88 & 0.05 & 0.01 & 6 & 0.05 & 726 & 1 & 26 & 0.7 \\
\hline NACS $2.6 \mathrm{~F} 1.4 \mathrm{Cl} 9.6 \mathrm{H}$ & -14.36 & 1.01 & 1.68 & 0.07 & 0.02 & 6 & 0.08 & 637 & 2 & 26 & 1.1 \\
\hline NACS $2.6 \mathrm{~F} 1.4 \mathrm{Cl} 13.3 \mathrm{H}$ & -14.04 & 0.93 & 1.54 & 0.06 & 0.03 & 6 & 0.09 & 592 & 2 & 26 & 1.0 \\
\hline $\operatorname{NACS} 1.1 \mathrm{Cl}^{\mathrm{e}}$ & -21.88 & 0.97 & 3.07 & 0.09 & 0.09 & 10 & 0.10 & 906 & 3 & 34 & 1.0 \\
\hline NACS $1.1 \mathrm{Cl} 2.2 \mathrm{H}$ & -14.36 & 0.58 & 2.09 & 0.05 & 0.05 & 9 & 0.08 & 794 & 3 & 26 & 0.6 \\
\hline NACS $1.1 \mathrm{Cl} 3.7 \mathrm{H}$ & -14.82 & 0.94 & 2.03 & 0.07 & 0.05 & 6 & 0.11 & 758 & 3 & 27 & 1.0 \\
\hline NACS $1.1 \mathrm{Cl} 7.5 \mathrm{H}$ & -13.64 & 1.00 & 1.75 & 0.07 & 0.04 & 6 & 0.10 & 682 & 3 & 26 & 1.0 \\
\hline NACS $1.1 \mathrm{Cl} 14.5 \mathrm{H}$ & -13.90 & 0.61 & 1.57 & 0.04 & 0.01 & 5 & 0.04 & 605 & 1 & 26 & 0.6 \\
\hline NACS $1.9 F^{\mathrm{e}}$ & -20.23 & 0.90 & 2.74 & 0.08 & 0.11 & 11 & 0.11 & 852 & 3 & 32 & 0.9 \\
\hline NACS $1.9 \mathrm{~F} 2.8 \mathrm{H}$ & -12.24 & 0.50 & 1.84 & 0.04 & 0.02 & 7 & 0.06 & 759 & 2 & 24 & 0.5 \\
\hline NACS $1.9 \mathrm{~F} 5.8 \mathrm{H}$ & -14.49 & 0.87 & 1.82 & 0.06 & 0.04 & 6 & 0.09 & 688 & 2 & 26 & 0.9 \\
\hline NACS $1.9 F$ 13.2H & -14.48 & 0.82 & 1.71 & 0.06 & 0.02 & 5 & 0.08 & 645 & 2 & 26 & 0.9 \\
\hline NACS $1.9 F$ & -12.50 & 0.82 & 1.45 & 0.05 & 0.02 & 5 & 0.08 & 592 & 2 & 25 & 0.9 \\
\hline NACS $6.2 \mathrm{~F}$ & -12.13 & 0.85 & 2.07 & 0.08 & 0.09 & 11 & 0.10 & 858 & 4 & 24 & 0.9 \\
\hline \multicolumn{12}{|c|}{$\begin{array}{l}a-\bar{\sigma}=\text { Standard error } \\
b-v^{2}=\text { Residual sum of squares } \\
c-N=\text { Number of data points }\end{array}$} \\
\hline
\end{tabular}




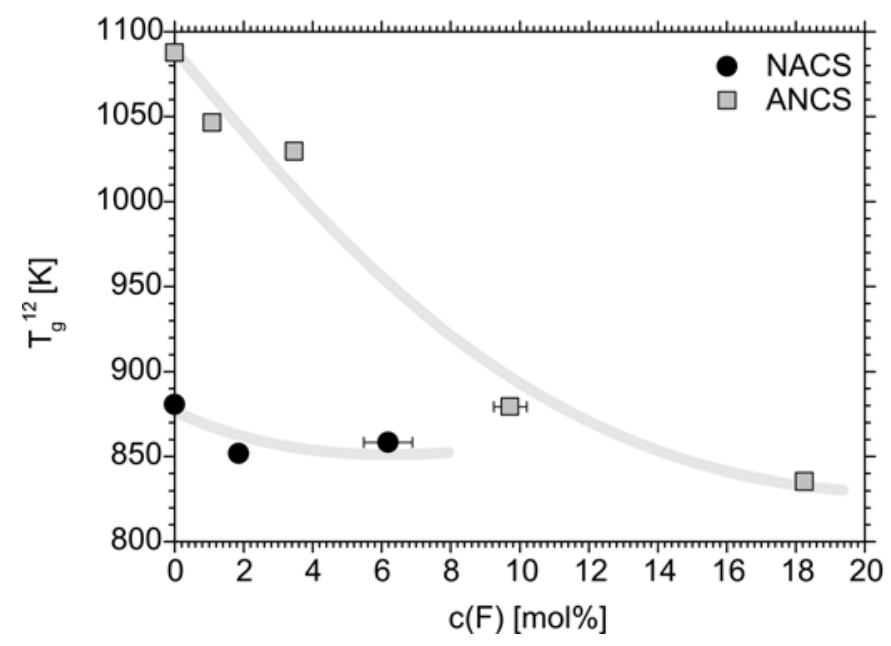

Fig. 6. $T_{g}{ }^{12}$ (temperature at $\eta=10^{12} \mathrm{Pas}$ ) as a function of fluorine concentration $c(\mathrm{~F})$ of the fluorine-free and fluorine-bearing peralkaline (NACS) and peraluminous (ANCS) melts. The grey lines were not fit, but only a guide to the eye. Y-errors are smaller than the symbols.

Table 6. Parameters $(A, B, C)$ of Eq. 6 fitted to the $T_{g}^{12}$ data .

\begin{tabular}{|c|c|c|c|c|c|c|c|c|c|}
\hline & $\begin{array}{c}A \\
{[\mathrm{~K}]}\end{array}$ & $\begin{array}{l}\bar{\sigma}^{\mathrm{a}} \\
{[\mathrm{K}]}\end{array}$ & $\begin{array}{c}B \\
{[\mathrm{~K}]}\end{array}$ & $\begin{array}{l}\bar{\sigma}^{\mathrm{a}} \\
{[\mathrm{K}]}\end{array}$ & C & $\bar{\sigma}^{a}$ & $\begin{array}{l}v^{2 b} \\
{[K]}\end{array}$ & $N^{c}$ & $\begin{array}{c}S E_{y}{ }^{d} \\
{[K]}\end{array}$ \\
\hline \multicolumn{10}{|l|}{ Peralkaline } \\
\hline $\mathrm{NACS}+\mathrm{H}_{2} \mathrm{O}$ & 897 & 39 & 113 & 16 & 1.1 & 0.4 & 196 & 5 & 10 \\
\hline NACS $0.7 \mathrm{~F} 0.6 \mathrm{Cl}+\mathrm{H}_{2} \mathrm{O}$ & 962 & 14 & 135 & 5 & 1.9 & 0.2 & 15 & 6 & 2 \\
\hline $\mathrm{NACS} 1.1 \mathrm{~F} 1.1 \mathrm{Cl}+\mathrm{H}_{2} \mathrm{O}$ & 975 & 36 & 135 & 13 & 2.2 & 0.5 & 82 & 6 & 5 \\
\hline NACS $2.6 \mathrm{~F} 1.4 \mathrm{Cl}+\mathrm{H}_{2} \mathrm{O}$ & 949 & 26 & 130 & 9 & 1.8 & 0.3 & 61 & 6 & 4 \\
\hline NACS $1.1 \mathrm{Cl}+\mathrm{H}_{2} \mathrm{O}$ & 977 & 24 & 133 & 9 & 1.6 & 0.3 & 49 & 5 & 5 \\
\hline $\mathrm{NACS} 1.9 \mathrm{~F}+\mathrm{H}_{2} \mathrm{O}$ & 1066 & 28 & 168 & 9 & 3.5 & 0.4 & 2 & 5 & 1 \\
\hline \multicolumn{10}{|l|}{ Peraluminous } \\
\hline ANCS $+\mathrm{H}_{2} \mathrm{O}$ & 1147 & 41 & 172 & 15 & 1.4 & 0.3 & 18 & 4 & 3 \\
\hline ANCS $0.5 \mathrm{~F} 0.5 \mathrm{Cl}+\mathrm{H}_{2} \mathrm{O}$ & 1156 & 90 & 175 & 33 & 1.7 & 0.8 & 337 & 5 & 11 \\
\hline ANCS $1.2 \mathrm{~F} 1.1 \mathrm{Cl}+\mathrm{H}_{2} \mathrm{O}$ & 1109 & 9 & 161 & 3 & 1.4 & 0.1 & 1 & 4 & 1 \\
\hline ANCS $2.3 \mathrm{~F} 0.9 \mathrm{Cl}+\mathrm{H}_{2} \mathrm{O}$ & 1179 & 35 & 181 & 12 & 2.4 & 0.3 & 6 & 4 & 2 \\
\hline ANCS 18.3F $+\mathrm{H}_{2} \mathrm{O}$ & 858 & 36 & 95 & 14 & 1.2 & 0.4 & 22 & 4 & 3 \\
\hline \multicolumn{10}{|l|}{ Haplogranitic } \\
\hline $\mathrm{HPG} 8+\mathrm{H}_{2} \mathrm{O}$ & 1036 & 30 & 155 & 14 & 0.6 & 0.2 & 455 & 7 & 10 \\
\hline $\mathrm{HPG} 83 \mathrm{~F}+\mathrm{H}_{2} \mathrm{O}$ & 794 & 18 & 65 & 9 & 0.4 & 0.2 & 153 & 6 & 6 \\
\hline & $\begin{array}{l}a-\bar{c} \\
b-v \\
c-N\end{array}$ & $\begin{array}{l}=\text { Stan } \\
=\text { Resi } \\
=\text { Numb } \\
\sum_{i=1}^{n}\end{array}$ & $\begin{array}{l}\text { ard er } \\
\text { al sur } \\
\frac{r}{v^{2}} \text { of } d a\end{array}$ & $\begin{array}{l}\text { of squa } \\
\text { points }\end{array}$ & & & & & \\
\hline
\end{tabular}



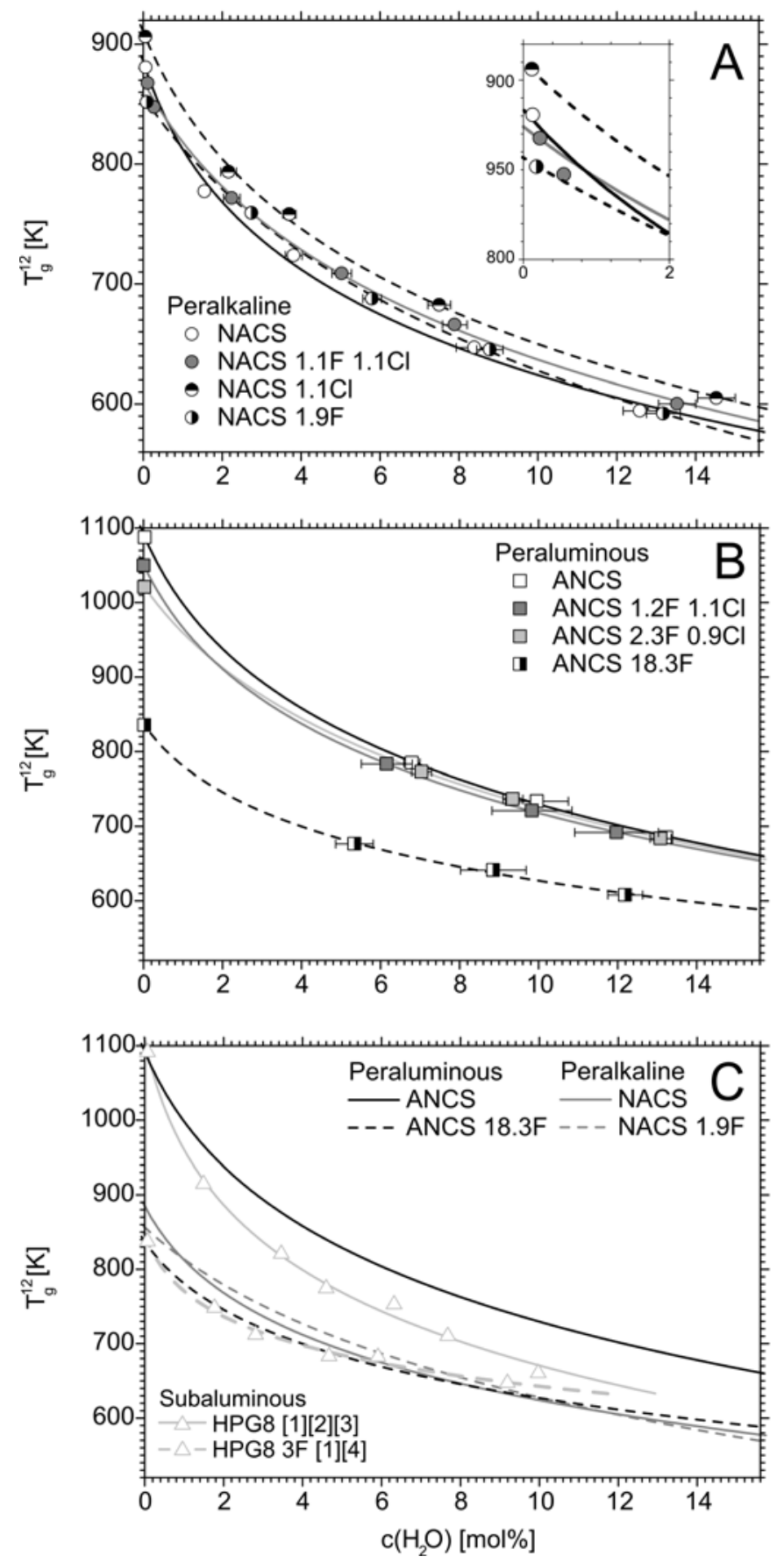

Fig. 7. $T_{g}^{12}$ (temperature at $\eta=10^{12} \mathrm{Pas}$ ) as a function of water concentration $c\left(\mathrm{H}_{2} \mathrm{O}\right)$ of the halogen-free and halogen-bearing peralkaline (NACS) and peraluminous (ANCS) melts. (C) Comparison of data from this study with data of fluorine-free (HPG8) and fluorine-bearing (HPG83F with 9.7 mol\% F) haplogranitic melts ([1] Dingwell et al., 1993a; [2] Hess et al., 1995, [3] Dingwell et al., 1996; [4] Giordano et al., 2004). Y-errors are smaller than the symbols. 

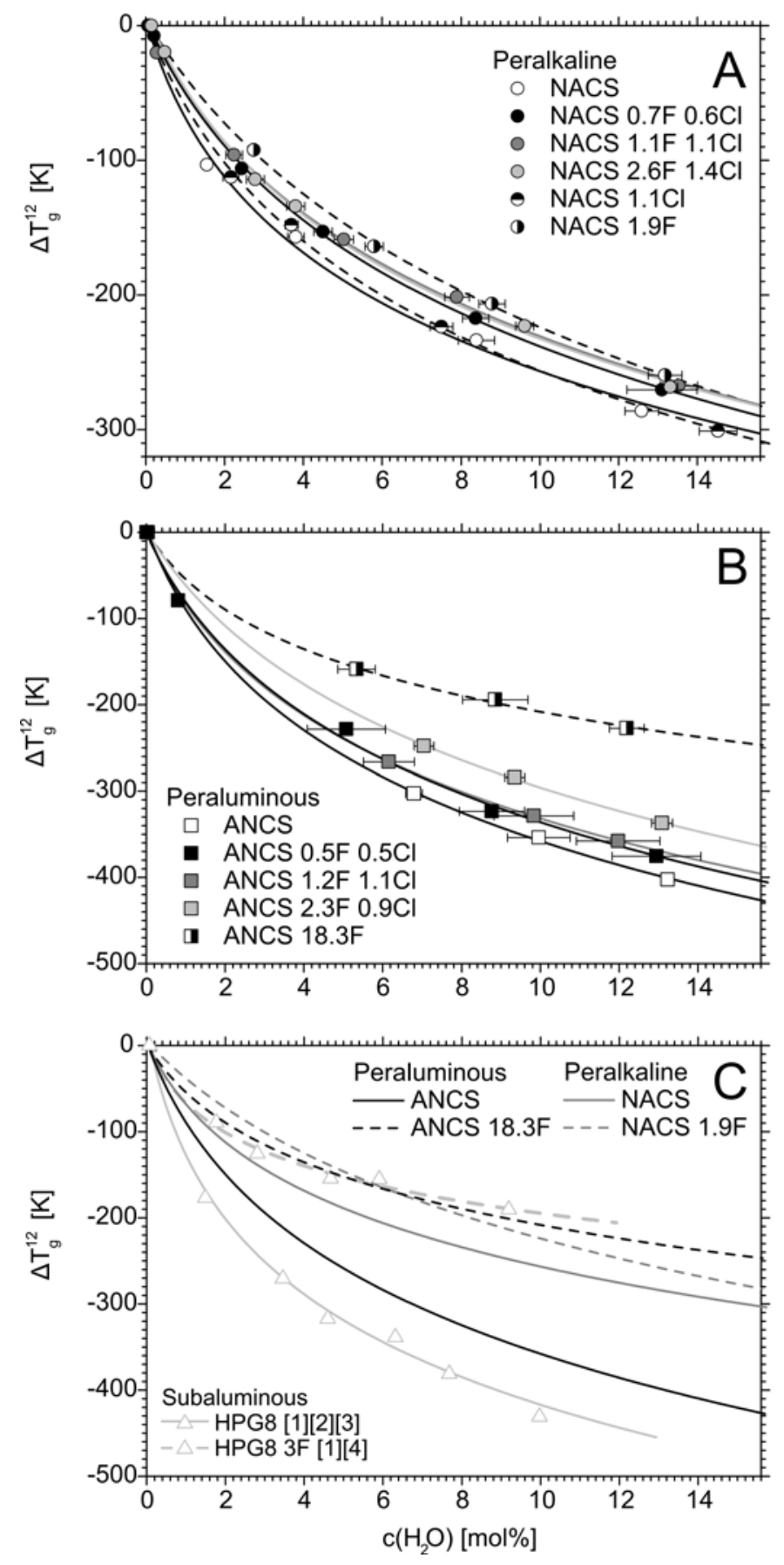

Fig. 8. The change in $T_{g}{ }^{12}$ ( temperature at $\left.\eta=10^{12} \mathrm{~Pa} \mathrm{~s}\right) \Delta T_{g}^{12}$ as a function of water concentration $c\left(\mathrm{H}_{2} \mathrm{O}\right)$ of the halogen-free and halogen-bearing peralkaline (NACS) (A) and peraluminous (ANCS) (B) melts. (C) Comparison data from this study with data of fluorine-free (HPG8) and fluorine-bearing (HPG83F with 9.7 mol\% F) haplogranitic melts ([1] Dingwell et al., 1993a; [2] Hess et al., 1995, [3] Dingwell et al., 1996; [4] Giordano et al., 2004). Y-errors are smaller than the symbols. 


\subsubsection{Thermogravimetry}

The thermogravimetry measurements of the peraluminous samples showed that the water loss in the fluorine-free peraluminous samples $\left(\mathrm{ANCS}+\mathrm{H}_{2} \mathrm{O}\right)$ with 6.8 - $14.3 \mathrm{~mol} \%$ (1.9-4.2 wt\%) $\mathrm{H}_{2} \mathrm{O}$ starts between $805-938 \mathrm{~K}$ and in the peralkaline samples NACS IR $4.5 \mathrm{H}$, NACS IR $15.0 \mathrm{H}$, NACS $12.6 \mathrm{H}$ with 4.5 - 15.0 mol\% (1.3- $4.7 \mathrm{wt} \%) \quad \mathrm{H}_{2} \mathrm{O}$ between $697-865 \mathrm{~K}$ (Table 7). These temperatures all correspond independently of composition and water concentration to a viscosity of $\sim 10^{8} \mathrm{~Pa} \mathrm{~s}$, which can be calculated from the Arrhenian equations given in Table 5.

Table 7. Water content $c\left(\mathrm{H}_{2} \mathrm{O}\right)$, temperature of water loss $T_{\text {water loss }}$ during thermogravimetry measurement and viscosity $\eta$ at this temperature.

\begin{tabular}{lcccccc}
\hline & $\begin{array}{c}c\left(\mathrm{H}_{2} \mathrm{O}\right) \\
{[\mathrm{wt} \%]}\end{array}$ & $\begin{array}{c}2 \sigma^{\mathrm{a}} \\
{[\mathrm{wt} \%]}\end{array}$ & $\begin{array}{c}T_{\text {water loss }} \\
{[\mathrm{K}]}\end{array}$ & $\begin{array}{c}2 \sigma^{\mathrm{a}} \\
{[\mathrm{K}]}\end{array}$ & $\begin{array}{c}\log _{10} \eta \\
{[\mathrm{Pa} \mathrm{s}]}\end{array}$ & $\begin{array}{c} \pm \\
{[\mathrm{Pa} \text { s }]}\end{array}$ \\
\hline ANCS 6.8H & 1.89 & 0.06 & 938 & 12 & 8.0 & 0.5 \\
ANCS 10.0H & 2.84 & 0.23 & 868 & 30 & 8.2 & 1.4 \\
ANCS 13.2H & 3.88 & 0.04 & 805 & 7 & 8.2 & 0.3 \\
ANCS 14.3H & 4.22 & 0.16 & 791 & 39 & - & - \\
ANCS 18.2H & 5.54 & 0.06 & 745 & 9 & - & - \\
NACS IR 4.5H & 1.26 & 0.04 & 865 & 42 & 7.2 & 2.4 \\
NACS IR 15.0H & 4.68 & 0.51 & 697 & 9 & 7.9 & 0.6 \\
NACS 12.6H & 3.62 & - & 704 & - & 7.6 & - \\
\hline
\end{tabular}

a - $2 \sigma$ standard deviation

b - calculated with the Arrhenian equation of NACS $3.8 \mathrm{H}$

$\mathrm{c}$ - calculated with the Arrhenian equation of NACS $12.6 \mathrm{H}$

$\mathrm{d}$ - only one measurement because of small sample quantity

\subsection{Discussion}

\subsubsection{Density and water contents}

The density data for the hydrous peraluminous samples have a significant higher standard deviation than that of the peralkaline samples (Fig. $2 B+C$ ), because of cracks, contamination with small platinum pieces, lower mass of the samples in general and alteration during the viscosity measurements. These problems occur especially for the series ANCS $0.5 \mathrm{~F} 0.5 \mathrm{Cl}$ and ANCS $1.2 \mathrm{~F} 1.1 \mathrm{Cl}$ and ANCS 18.3F. The samples NACS 1.1Cl 14.5H, ANCS 1.1F and ANCS 9.7F contained some large bubbles. These samples were not used for discussions about density effects. 
The hydrous peralkaline glasses with low water contents ( $<4$ mol\%), which were produced under pressure, have a up to $0.014 \mathrm{~g} \mathrm{~cm}^{-3}$ higher density than the nominally dry samples made in a 1 atm furnace (Fig. 2B). A similar effect was also reported by Behrens et al. (1996) and Richet et al. (2000). The nominally dry peralkaline glasses produced in the IHPV had too many bubbles to compare them with the dry glasses produced at $1 \mathrm{~atm}$. The peraluminous glass series do not show a density anomaly (Fig. 2C). The density of these glasses, however, was determined after the viscosity measurements, in which they were heated above the glass transition temperature several times and therefore are structurally relaxed. This suggests that the density anomaly is due to pressure densification. The change in density $\rho\left[\mathrm{g} \mathrm{cm}^{-3}\right]$ with pressure $P[\mathrm{~Pa}]$ depends on the bulk modulus $\mathrm{K}[\mathrm{Pa}]$

$$
\Delta \rho=\rho \frac{\Delta P}{K}
$$

Rivers and Carmichael (1987) found for mixed albite-anorthite melts an adiabatic K of $17.610^{9} \mathrm{~Pa}$. According to Eq. 7 for a melt with the density of $2.475 \mathrm{~g} \mathrm{~cm}^{-3}$ an increase in pressure by about $200 \mathrm{MPa}$ causes an increase in density of $0.0281 \mathrm{~g} \mathrm{~cm}^{-3}$. Therefore, the up to $0.014 \mathrm{~g} \mathrm{~cm}^{-3}$ higher density of the hydrous peralkaline samples made under pressure compared to the dry samples made at 1 atm can be explained just due to densification by pressure.

\subsubsection{Viscosity}

In comparing the viscosity data of the samples presented here, one has to be aware that viscosity measurements are sensitive to variations in alkali and water content as well as bubbles or crystals in the melt samples. There are small deviations from the ideal compositions in the alkali content within the peraluminous and peralkaline series of some samples (e.g. NACS 2.6F 1.4Cl, NACS 6.2F, ANCS 1.2F 1.1Cl, ANCS 2.3F $0.9 \mathrm{Cl}$, Table 1 ), which reflects in a variation of the $\gamma$ parameter $\left(=\left(\mathrm{Na}_{2} \mathrm{O}+\mathrm{CaO}\right) /\left(\mathrm{Na}_{2} \mathrm{O}+\mathrm{CaO}+\mathrm{Al}_{2} \mathrm{O}_{3}\right)\right)$ of about 0.03 . Baasner et al. (2013) found for dry $\mathrm{Na}_{2} \mathrm{O}-\mathrm{CaO}-\mathrm{Al}_{2} \mathrm{O}_{3}-\mathrm{SiO}_{2}$ melts with the same or similar composition as the present glasses, that these differences play practically no role for the peraluminous samples. In the peralkaline samples a decrease of 0.03 in the $y$ ratio causes in the worst case an increase of $0.45 \mathrm{log}$ units in viscosity corresponding to an increase in $T_{g}{ }^{12}$ of 
- $13 \mathrm{~K}$ (Baasner et al., 2013). A significant influence on the slope of the viscosity-temperature curve or the fragility due to a change of 0.03 in the $y$ ratio is not expected, as even between the peraluminous samples ANCS $(\gamma=0.45)$ and the peralkaline sample NACS $(\gamma=0.66)$ the differences in slope and fragility are less than 15\% (Figs. 4 and 5). As mentioned before, our glasses were crystal-free but most of them contained few bubbles (less than 1 vol\%). Bagdassarov and Dingwell (1992) found for rhyolites that a bubble content of 3 vol\% causes a decrease in viscosity of $\sim 0.25 \mathrm{log}$ units at a temperature of $\sim 1123 \mathrm{~K}$. In calcium aluminosilicate melts in a viscosity range from $10^{9}$ to $10^{13} \mathrm{~Pa} \mathrm{~s}(1220$ - 1100K) 6 vol\% bubbles could cause a relative viscosity change of \pm 0.1 log units (Lejeune et al., 1999). Therefore, the small bubble content in our samples did not influence the general conclusions from viscosity data.

In particular, the unusual appearing viscosity-temperature behavior of the sample NACS 6.2F (Fig. 4), which intersects with the samples NACS and NACS 1.9F, cannot be related to bubbles, crystals or to differences in composition but must rather be related to the fluorine dissolution mechanism.

The thermogravimetry measurements showed that water loss in the hydrous samples happens independently of water content at a viscosity of around $10^{8} \mathrm{~Pa} \mathrm{~s}$. This indicates that at higher viscosities bubble aggregation and migration are not taking place sufficiently to allow the loss of large quantities of water. However, on some samples surface cracks developed during viscosity measurements of the hydrous samples at high temperatures in the viscosity range between $10^{9}$ and $10^{10} \mathrm{~Pa} \mathrm{~s}$, which might indicate some minor earlier water loss (these altered samples and their data were not used for further evaluation). Although, water loss due to diffusion during viscosity measurements in the range of the present viscosities does certainly happen, it can be ignored, because the width of the diffusion zone is much shorter than the average indent depth during viscosity measurements of $\sim 50 \mu \mathrm{m}$; and the viscosity measurements were performed on several samples. As an extreme example one can estimate from diffusion data for Laacher See phonolite by Schmidt et al. (2013) that a water molecule in the peralkaline melt NACS $12.6 \mathrm{H}$ could diffuse less than $14 \mu \mathrm{m}(x \sim \sqrt{D t}$, with the distance $x$, the diffusion coefficient $D$ and time $t)$ during an 80 min long viscosity measurement with 40 min of heating and 40 min at $650 \mathrm{~K}\left(=\sim 10^{9.5} \mathrm{~Pa} \mathrm{~s}\right)$. We also want to remark that a potential loss of $\mathrm{F}$ or $\mathrm{Cl}$ due to 
diffusion during viscosity measurements will be even less than that of water, as the diffusivities of $\mathrm{F}$ and $\mathrm{Cl}$ in phonolites are one, respectively two, orders of magnitude lower than that of water (Böhm and Schmidt, 2013).

A significant water loss during viscosity measurements can be excluded, as no water loss for the hydrous peraluminous samples of ANCS $18.3 \mathrm{~F}$ and ANCS $2.3 \mathrm{~F} 0.9 \mathrm{Cl}$ from the KFT measurements after the viscosity measurements was detected compared to the NIR measurements done before the viscosity measurements. The electron microprobe analysis of the sample NACS $6.2 \mathrm{~F}$ before and after the viscosity measurements showed no significant difference in fluorine content (Table $1 A+B)$. In addition, as we measured viscosity on different sample pieces and chose temperatures for viscosity measurements randomly, a significant loss of water or $F$ would cause an increase in viscosity resulting in data points that would not fit on an Arrhenian line with the other data. Therefore, the unusual viscosity temperature behaviour of the sample NACS 6.2F cannot be explained by a significant loss of $F$ or any other element.

\subsubsection{Influence of structure on viscosity of fluorine-bearings melts}

Fluorine on mol\% basis decreases the viscosity more strongly in the peraluminous melts than in the peralkaline melts (Figs. 4 and 6). The different trends are related to the different incorporation mechanisms of $F$ in these melts. Baasner et al. (2014) conducted a nuclear magnetic resonance (NMR) spectroscopic study on the same fluorine-bearing peralkaline and peraluminous glasses studied here. It was found that in peraluminous glasses all $\mathrm{F}$ is associated with $\mathrm{Al}$ and $\mathrm{Si}$ in the glass network. The major fraction are non-bridging $\mathrm{F}$ attached to $\mathrm{Al}$ and $\mathrm{Si}$, while a minor amount are bridging $\mathrm{F}$ between two Al. The non-bridging $\mathrm{F}$ sites are assumed to depolymerise the glass/melt network and thus decrease viscosity. In peralkaline glasses the largest fraction of $\mathrm{F}$ exists in salt-like F-Ca environments. Smaller fractions of $\mathrm{F}$ exist as non-bridging $\mathrm{F}$ attached to $\mathrm{Si}$ and $\mathrm{Al}$, as bridging $\mathrm{F}$ between two $\mathrm{Al}$ or in salt-like $\mathrm{F}-\mathrm{Na}$ environments (Baasner et al., 2014). The salt-like F-Ca and F-Na environments consist of F surrounded by 4 or fewer Ca cations and F surrounded by $\sim 6 \mathrm{Na}$ cations, respectively. In peralkaline melts the $\mathrm{F}$ speciation depends on the $\mathrm{F}$ concentration. With increasing F content the F-Ca sites increase from $42 \%$ in a sample with 
$1.2 \mathrm{~mol} \%$ to up to $53 \%$ in a sample with $6.2 \mathrm{~mol} \% \mathrm{~F}$. Baasner et al. (2014) found that the F-Ca and F-Na sites exclusively exist in peralkaline melts, with these sites only being formed if network-modifying cations are present. This means that the formation of F-Ca and F-Na sites in peralkaline glasses reduces the number of network-modifying cations and, therefore, polymerizes the aluminosilicate network and increases viscosity, in contrast to the non-bridging $F$ sites. This explains the strong decrease in viscosity due to the addition of $F$ in peraluminous melts compared to peralkaline melts, because in the peraluminous melts $\mathrm{F}$ predominantly exists as non-bridging $\mathrm{F}$. The increase in $\mathrm{F}-\mathrm{Ca}$ sites with increasing $\mathrm{F}$ concentration might explain, why in the peralkaline melts at first viscosity decreases due to the addition of $1.9 \mathrm{~mol} \% \mathrm{~F}$ and then at a $\mathrm{F}$ content of $6.2 \mathrm{~mol} \%$ stagnates or increases (Fig. 4 and Fig. 6). However, we want to remark that the viscosity of a melt does not only depend on the connectivity of the network, but also on the different bond energies. Therefore, the structural information from NMR spectroscopy only allows certain qualitative considerations but not a quantification.

Dingwell et al. (1985) found in the system $\mathrm{Na}_{2} \mathrm{O}-\mathrm{Al}_{2} \mathrm{O}_{3}-\mathrm{SiO}_{2}$ a smaller difference between peraluminous and peralkaline melts in the decrease in viscosity due to the addition of $F$ than was observed here (Fig. 4 and Fig. 6). This observation does not stand in contradiction to our results, as the melts studied by Dingwell et al. (1985) contained only $\mathrm{Na}$ and no $\mathrm{Ca}$. In silicate glasses $\mathrm{F}$ has a strong preference towards Ca compared to $\mathrm{Na}$ (Stebbins and Zeng, 2000; Baasner et al., 2014). Zeng and Stebbins (2000) showed that F-Na sites exist in albitic glasses only if they have an excess in $\mathrm{Na}$ (peralkaline), but not in pure albite glass and albitic glasses with an excess in $\mathrm{Al}$ (peraluminous). These authors also showed that in the peralkaline albitic glasses F-Na environments are only a minor species. The major species in all their albitic glasses are non-bridging $\mathrm{F}$ bonded to $\mathrm{Al}$ and $\mathrm{Si}$. The albitic glasses studied by Zeng and Stebbins are comparable to those of Dingwell et al. (1985). It appears that the minor differences in the effect of $F$ on viscosity in peralkaline and peraluminous $\mathrm{Na}_{2} \mathrm{O}-\mathrm{Al}_{2} \mathrm{O}_{3}-\mathrm{SiO}_{2}$ observed by Dingwell et al. (1985) are related to the minor differences in the incorporation mechanism of $F$. 


\subsubsection{Incorporation of halogens and water and the influence on melt viscosity}

Water dissolves in silicate melts as hydroxyl groups $(\mathrm{OH})$ and undissociated molecular water $\left(\mathrm{H}_{2} \mathrm{O}\right)$ (Scholze, 1960). As observed here, the fraction of $\mathrm{OH}$ compared to $\mathrm{H}_{2} \mathrm{O}$ decreases with increasing water content (Bartholomew et al., 1980; Stolper, 1982; Behrens et al., 1996). There is evidence from NMR spectroscopy that some of the $\mathrm{OH}$ groups form $\mathrm{Al}-\mathrm{OH}$ and $\mathrm{Si}-\mathrm{OH}$ units in aluminosilicate melts (e.g. Zeng et al., 2000; Schmidt et al., 2001; Malfait and Xue, 2010). The formation of these units has been discussed in the literature to be responsible for the decrease in viscosity due to the addition of water as bridging-oxygen bonds are broken. Other proposed dissolution mechanisms like protons replacing network-modifying or charge-balancing alkali and alkaline-earth cations, which then bond to hydroxyl groups, may happen, but do not completely explain the massive decrease in viscosity in silicate melts due to the addition of water (e.g. Kohn et al., 1989; Zeng et al., 2000; Whittington et al., 2001). However, it is commonly agreed that the decrease in viscosity and the amount of hydroxyl groups are related. The 1.2-1.7 mol\% (0.3 - 0.4 wt\%) higher concentration of water dissolved as $\mathrm{OH}$ in the peraluminous samples (except ANCS 18.3F) compared to the peralkaline samples (Fig. 1) might explains the stronger decrease in viscosity due to the addition of water in the peraluminous melts (Fig. $7 \mathrm{C}$ and Fig. 8C). The higher $\mathrm{OH} / \mathrm{H}_{2} \mathrm{O}$ ratio in the peraluminous glasses than in the peralkaline samples, at the same total water content, is likely to be caused by the higher fictive temperature $T_{f}$ of the peraluminous glasses, because in silicate glasses the $\mathrm{OH} / \mathrm{H}_{2} \mathrm{O}$ ratio increases with increasing fictive temperature $T_{f}$ (e.g. Dingwell and Webb, 1990; Behrens and Nowak, 2003). $T_{f}$ is the temperature at which the frozen structure of the melt would be in thermodynamic equilibrium. $T_{f}$ increases with increasing quench rate (e.g. DeBolt et al., 1976; Behrens and Nowak, 2003). As the $T_{f}$ depends not only on the structure of a melt but also on quench rate, one might assume that the differences in $\mathrm{OH}$ between the sample series can be caused by different quench rates, which were $\sim 150-100 \mathrm{~K} \mathrm{~s}^{-1}$ for the peralkaline samples and $50-30 \mathrm{~K} \mathrm{~s}^{-1}$ for the peraluminous samples. However, this is unlikely as Behrens and Nowak (2003) showed that one order of magnitude difference in quench rate causes at most $0.15 \mathrm{wt} \%$ difference in $\mathrm{OH}$ content. In addition, the higher quench rate of the peralkaline samples and the 
lower quench rate of the peraluminous samples would only result in the differences in $\mathrm{OH}$ concentration becoming less between the sample series. Therefore, the higher $\mathrm{OH}$ concentration in the peraluminous samples (except ANCS 18.3F) compared to the peralkaline samples cannot be caused by different quench rates.

A lower $T_{f}$ due to the presence of $\mathrm{F}$ can explain the lower $\mathrm{OH} / \mathrm{H}_{2} \mathrm{O}$ ratio of the samples ANCS 18.3F $+\mathrm{H}_{2} \mathrm{O}$ (Fig. 1) and thus the smaller decrease in viscosity due to the addition of water compared to the halogen-free samples ANCS $+\mathrm{H}_{2} \mathrm{O}$ (Fig. 7B and Fig. 8B). All the hydrous peraluminous samples were quenched in the same piston cylinder apparatus; therefore, the quench rate of these samples is nearly the same. The difference in $T_{f}$ for different samples quenched at the same rate can be estimated from the difference in $T_{g}{ }^{12}$ as it has been shown by a number of authors that these two values follow the same trends (e.g. Yue et al., 2004; Webb, 2011). Figure 7B shows that the ANCS $18.3 \mathrm{~F}+\mathrm{H}_{2} \mathrm{O}$ samples have a more than $100 \mathrm{~K}$ lower $T_{g}{ }^{12}$ than the ANCS $+\mathrm{H}_{2} \mathrm{O}$ samples and, thus, an approximately more than $100 \mathrm{~K}$ lower $T_{f}$. Behrens and Nowak (2003) showed for haplogranitic melts that $\mathrm{a} \sim 80 \mathrm{~K}$ lower $T_{f}$ leads to $\mathrm{a} \sim 0.2 \mathrm{wt} \%$ lower $\mathrm{OH}$ concentration for same water content. This is consistent with a difference in water dissolved as $\mathrm{OH}$ of $0.3-0.4 \mathrm{wt} \%$ for a difference of more than $100 \mathrm{~K}$ in $T_{f}$ between the hydrous peraluminous samples with low halogen concentrations and the hydrous samples of ANCS 18.3F. However, a decrease of the $\mathrm{OH} / \mathrm{H}_{2} \mathrm{O}$ ratio due to the addition of $\mathrm{F}$ (Fig. 1) was within error only observed in the case of ANCS 18.3F, which has the highest F concentration of all samples studied here. Therefore, it remains unclear, if the smaller decrease in viscosity due to water in the samples with lower $F$ concentration can be simply explained by $\mathrm{F}$ decreasing the fraction of water dissolved as $\mathrm{OH}$ We have to point out that the IR spectroscopy measured $\mathrm{OH}$ concentration in the glasses only partly reflect the in situ $\mathrm{OH}$ concentration at the temperatures of viscosity measurements, because the IR measurements were done before the viscosity measurements directly after the quench of the synthesis experiments.

In addition to the process, where $\mathrm{F}$ decreases the $\mathrm{OH} / \mathrm{H}_{2} \mathrm{O}$ ratio and ,therefore, reduces the decrease in viscosity due to water, also the opposite process, where water changes the $F$ speciation and, therefore, reduces the decreasing effect of $F$ on viscosity, has to be considered. Baasner et al. (2014) found for hydrous fluorine-bearing peralkaline $\mathrm{Na} 2 \mathrm{O}-\mathrm{CaO}-\mathrm{Al}_{2} \mathrm{O}_{3}-\mathrm{SiO}_{2}$ glasses with the same base 
composition as the glasses studied here, that with increasing water content the fraction of non-bridging $\mathrm{F}$ connected to Al decreases, while the fraction of F-Ca sites increases. These authors suggest that this happens because water competes against $\mathrm{F}$ for certain $\mathrm{Al}$ sites. The increase of the fraction of $\mathrm{F}-\mathrm{Ca}$ sites, which decreases the number of network-modifying cations forming NBO`s, together with the decrease in the fraction of non-bridging $F$ sites, which depolymerises the melt network, would reduce the decreasing effect of F on viscosity. It appears that in the fluorine-bearing peralkaline melts the smaller decrease in viscosity due to water (Fig. 7A and Fig. 8A) results rather from water changing $F$ speciation than from $F$ changing water speciation. Whether water also decreases the fraction of non-bridging $\mathrm{F}$ sites and would lead to the creation of F-Ca sites in the peraluminous samples remains unclear as the hydrous peraluminous glasses were not studied by Baasner et al. (2014). Baasner et al. (2014) showed with NMR spectroscopy that F does not form salt-like $\mathrm{F}-\mathrm{Ca}$ or $\mathrm{F}-\mathrm{Na}$ sites in dry peraluminous $\mathrm{Na}{ }_{2} \mathrm{O}-\mathrm{CaO}-\mathrm{Al}_{2} \mathrm{O}_{3}-\mathrm{SiO}_{2}$ glasses. The process described for the peralkaline glasses would only apply to the peraluminous glasses if protons from the added water replace charge-balancing cations and produce some network-modifying cations, which then could form salt-like F-Ca and F-Na sites.

Viscosity measurements of haplogranitic melts (Dingwell et al., 1993a; Hess et al., 1995; Dingwell et al., 1996, Giordano et al., 2004) also show that the decrease in viscosity due to water is lower in fluorine-bearing than in fluorine-free glasses (Fig. 7C and Fig. 8C). Compared to the $\mathrm{Na}_{2} \mathrm{O}-\mathrm{CaO}-\mathrm{Al}_{2} \mathrm{O}_{3}-\mathrm{SiO}_{2}$ melts studied here, $\mathrm{F}$ in the haplogranitic melts reduces the decrease in viscosity due to water even more. The dry haplogranitic melt is subaluminous, which means it is completely polymerised like the dry halogen-free peraluminous sample studied here. Schaller et al. (1992) found from NMR spectroscopy that water has only a minor effect on the ${ }^{19} \mathrm{~F}$ environment in fluorine-bearing haplogranitic glasses. However, there is no study for haplogranitic melts that shows how the presence of $\mathrm{F}$ affects the $\mathrm{OH} / \mathrm{H}_{2} \mathrm{O}$ ratio. Therefore, in the case of the present fluorine-bearing peraluminous melts and fluorine-bearing haplogranitic melts (Dingwell et al., 1993a, Giordano et al., 2004, Schaller et al., 1992) one possible process for the reduction of the decrease in viscosity may be that $\mathrm{F}$ reduces the concentration of $\mathrm{OH}$ groups. 
That $\mathrm{Cl}$ has no influence on the decrease in viscosity due to the addition of water (Fig. 7A and Fig. 8A) was expected as Sandland et al. (2004) found from NMR spectroscopy that in $\mathrm{Na}_{2} \mathrm{O}-\mathrm{Al}_{2} \mathrm{O}_{3}-\mathrm{SiO}_{2}$ and $\mathrm{CaO}-\mathrm{Al}_{2} \mathrm{O}_{3}-\mathrm{SiO}_{2}$ glasses $\mathrm{Cl}$ forms salt-like environments with $\mathrm{Na}$ and $\mathrm{Ca}$ and that the $\mathrm{Cl}$ environment is similar or the same in the dry and hydrous samples. These salt-like environments decrease the number of network-modifying cations in peralkaline melts and thus increase the viscosity. 


\subsection{Conclusions}

The decreasing effects of $\mathrm{Cl}, \mathrm{F}$ and water on the density of $\mathrm{Na}{ }_{2} \mathrm{O}-\mathrm{CaO}-\mathrm{Al}_{2} \mathrm{O}_{3}-\mathrm{SiO}_{2}$ glasses are independent from each other and add up linearly. The decrease in density due to the presence of $F$ is stronger in peraluminous than in peralkaline melts. In the peralkaline melts $\sim 2$ mol\% $F$ leads to a decrease in viscosity, while the addition of further $4 \mathrm{~mol} \% \mathrm{~F}$ (altogether $\sim 6 \mathrm{~mol} \% \mathrm{~F}$ ) does not result in a further decrease in viscosity. In peralkaline melts the increase in viscosity due to the addition of $\mathrm{Cl}$ and the decrease in viscosity due to the addition of water are independent from each other and add linearly together. In the peralkaline as well as the peraluminous melts the decrease in viscosity due to water and $F$ is not independent from each other. The fluorine-bearing samples show smaller decrease in viscosity due to the addition of water than the fluorine-free samples. Results from NMR spectroscopy by Baasner et al. (2013b) and IR spectroscopy show in the case of fluorine-bearing peralkaline $\mathrm{Na}_{2} \mathrm{O}-\mathrm{CaO}-\mathrm{Al}_{2} \mathrm{O} 3-\mathrm{SiO}_{2}$ melts that the reason for the reduced decrease in viscosity due to water is that water decreases the fraction of $F$ sites in the glasses/melts that depolymerise the aluminosilicate network rather than that $F$ decreases the concentration of hydroxyl groups. For fluorine-bearing peraluminous $\mathrm{Na}_{2} \mathrm{O}-\mathrm{CaO}-\mathrm{Al}_{2} \mathrm{O}_{3}-\mathrm{SiO}_{2}$ melts a reduced fraction of water dissolved as $\mathrm{OH}$ groups due to the presence of $F$ remains a possible process to explain the reduced decrease in viscosity due to the addition of water.

\section{Acknowledgements}

We thank Christina Norwig and Frederik Neumeyer, who worked for the project during their internship. We thank Prof. Dr. Harald Behrens and the team at the University of Hannover for the use of the Karl-Fischer-Titration. We thank the reviewer for a constructive review. This project was funded by the DFG grant WE 1810/9-1. 


\section{Supplementary Data}

Table A. Density $\rho$, thickness $d$ and the near infrared (NIR) absorption at the $4500 \mathrm{~cm}^{-1}$ and $5300 \mathrm{~cm}^{-1}$ bands in spectra of the hydrous peralkaline and peraluminous glasses, which were used to calculate the concentration of water dissolved as $\mathrm{OH}$ and $\mathrm{H}_{2} \mathrm{O}$.

\begin{tabular}{|c|c|c|c|c|c|c|c|c|c|c|c|c|c|c|c|c|c|c|c|c|c|}
\hline \multirow[b]{3}{*}{ Peralkaline } & \multirow[b]{2}{*}{$\frac{\sqrt{0}}{\frac{0}{0}}$} & \multirow{2}{*}{\multicolumn{2}{|c|}{$\begin{array}{c}\rho^{\mathrm{b}} \quad 2 \sigma^{\mathrm{c}} \\
{\left[\mathrm{g} \mathrm{cm}^{-3}\right]}\end{array}$}} & \multirow{2}{*}{\multicolumn{2}{|c|}{$\begin{array}{c}d^{b} \quad 2 \sigma \\
{[\mu \mathrm{m}]}\end{array}$}} & \multicolumn{4}{|c|}{ Absorption $^{\mathrm{a}}$} & \multicolumn{6}{|c|}{ Concentration } & \multicolumn{6}{|c|}{ Concentration } \\
\hline & & & & & & $\begin{array}{l}\mathrm{OH} \\
\qquad-\mathrm{los}\end{array}$ & $\begin{array}{l}2 \sigma \\
g \text { transn }\end{array}$ & $\begin{array}{l}\mathrm{H}_{2} \mathrm{O} \\
\text { nission\% }\end{array}$ & $2 \sigma$ & $\mathrm{OH}$ & $\pm^{\mathrm{d}}$ & $\begin{array}{l}\mathrm{H}_{2} \mathrm{O} \\
\quad[w t \%\end{array}$ & \pm & $\begin{array}{c}\mathrm{H}_{2} \mathrm{O} \\
\text { total }\end{array}$ & \pm & $\mathrm{OH}$ & \pm & $\begin{array}{l}\mathrm{H}_{2} \mathrm{O} \\
\quad[\mathrm{mol}\end{array}$ & \pm & $\begin{array}{c}\mathrm{H}_{2} \mathrm{O} \\
\text { total }\end{array}$ & \pm \\
\hline & & & & & & & & & & & & & & & & & & & & & \\
\hline NACS IR 4.5H & 1 & 2.482 & 0.002 & 774 & 2 & 0.108 & - & 0.039 & - & 0.96 & 0.08 & 0.38 & 0.01 & 1.34 & 0.09 & 3.35 & 0.28 & 1.33 & 0.04 & 4.68 & 0.31 \\
\hline NACS IR $4.5 \mathrm{H}$ & 2 & 2.482 & 0.002 & 755 & 3 & 0.097 & - & 0.034 & - & 0.89 & 0.05 & 0.34 & 0.01 & 1.23 & 0.05 & 3.12 & 0.16 & 1.18 & 0.03 & 4.30 & 0.19 \\
\hline NACS IR 6.2H & 1 & 2.472 & 0.005 & 785 & 4 & 0.133 & - & 0.080 & - & 1.18 & 0.10 & 0.77 & 0.02 & 1.95 & 0.12 & 4.05 & 0.33 & 2.63 & 0.08 & 6.68 & 0.41 \\
\hline NACS IR 6.2H & 2 & 2.472 & 0.005 & 781 & 7 & 0.120 & - & 0.069 & - & 1.07 & 0.06 & 0.67 & 0.02 & 1.74 & 0.07 & 3.69 & 0.19 & 2.30 & 0.05 & 5.99 & 0.25 \\
\hline NACS IR $10.1 \mathrm{H}$ & 1 & 2.458 & 0.005 & 395 & 9 & 0.076 & - & 0.082 & - & 1.34 & 0.11 & 1.58 & 0.06 & 2.92 & 0.17 & 4.48 & 0.38 & 5.30 & .19 & 9.78 & 0.57 \\
\hline NACS IR $10.1 \mathrm{H}$ & 2 & 2.458 & 0.005 & 407 & 8 & 0.080 & - & 0.082 & - & 1.37 & 0.08 & 1.54 & 0.04 & 2.91 & 0.12 & 4.60 & 0.27 & 5.14 & 0.15 & 9.74 & 0.40 \\
\hline NACS IR $15.1 \mathrm{H}$ & 1 & 2.429 & 0.005 & 774 & 9 & 0.181 & - & 0.333 & - & 1.66 & 0.14 & 3.31 & 0.10 & 4.97 & 0.24 & 5.30 & 0.44 & 10.57 & .33 & 15.87 & 0.77 \\
\hline NACS IR 15.1H & 2 & 2.429 & 0.005 & 757 & 5 & 0.164 & - & 0.305 & - & 1.63 & 0.08 & 3.14 & 0.07 & 4.77 & 0.15 & 4.93 & 0.25 & 9.98 & 0.23 & 14.91 & 0.49 \\
\hline NACS IR 15.3H & 1 & 2.424 & 0.007 & 686 & 2 & 0.160 & - & 0.294 & - & 1.65 & 0.14 & 3.29 & 0.10 & 4.94 & 0.23 & 5.27 & 0.43 & 10.50 & 0.31 & 15.76 & 0.74 \\
\hline NACS IR 15.3H & 2 & 2.424 & 0.007 & 714 & 7 & 0.151 & - & 0.286 & - & 1.60 & 0.08 & 3.11 & 0.07 & 4.71 & 0.15 & 4.83 & 0.27 & 9.91 & 0.24 & 14.74 & 0.49 \\
\hline NACS IR $19.1 \mathrm{H}$ & 1 & 2.395 & 0.010 & 694 & 5 & 0.162 & - & 0.422 & - & 1.68 & 0.14 & 4.73 & 0.14 & 6.41 & 0.28 & 5.18 & 0.43 & 14.61 & 0.45 & 19.79 & 0.87 \\
\hline NACS IR $19.1 \mathrm{H}$ & 2 & 2.395 & 0.010 & 684 & 7 & 0.150 & - & 0.389 & - & 1.57 & 0.08 & 4.43 & 0.11 & 6.00 & 0.19 & 4.90 & 0.24 & 13.80 & 0.34 & 18.70 & 0.60 \\
\hline NACS IR $4.5 \mathrm{H}$ & 1 & 2.482 & 0.002 & 774 & 2 & 0.108 & - & 0.039 & - & 0.96 & 0.08 & 0.38 & 0.01 & 1.34 & 0.09 & 1.61 & 0.08 & 0.00 & 0.00 & 1.61 & 0.08 \\
\hline NACS IR $4.5 \mathrm{H}$ & 2 & 2.482 & 0.002 & 755 & 3 & 0.097 & - & 0.034 & - & 0.89 & 0.05 & 0.34 & 0.01 & 1.23 & 0.05 & 1.50 & 0.09 & 0.00 & 0.00 & 1.50 & 0.09 \\
\hline NACS $1.6 \mathrm{H}$ & 1 & 2.484 & 0.002 & 821 & 2 & 0.050 & 0.001 & 0.000 & 0.000 & 0.45 & 0.02 & 0.00 & 0.00 & 0.45 & 0.02 & 2.89 & 0.18 & 0.83 & 0.04 & 3.72 & 0.23 \\
\hline NACS $1.6 \mathrm{H}$ & 2 & 2.484 & 0.002 & 806 & 7 & 0.046 & 0.002 & 0.000 & 0.000 & 0.42 & 0.03 & 0.00 & 0.00 & 0.42 & 0.03 & 2.96 & 0.17 & 0.94 & 0.02 & 3.90 & 0.20 \\
\hline NACS $3.8 \mathrm{H}$ & 1 & 2.477 & 0.004 & 811 & 3 & 0.090 & 0.004 & 0.025 & 0.001 & 0.83 & 0.05 & 0.24 & 0.01 & 1.06 & 0.06 & 4.56 & 0.33 & 3.84 & 0.22 & 8.41 & 0.55 \\
\hline NACS $3.8 \mathrm{H}$ & 2 & 2.477 & 0.004 & 806 & 3 & 0.092 & 0.003 & 0.028 & 0.000 & 0.85 & 0.05 & 0.27 & 0.01 & 1.11 & 0.06 & 4.53 & 0.24 & 3.84 & 0.13 & 8.38 & 0.37 \\
\hline NACS 8.4H & 1 & 2.455 & 0.010 & 646 & 1 & 0.117 & 0.006 & 0.096 & 0.005 & 1.35 & 0.10 & 1.14 & 0.07 & 2.48 & 0.16 & 4.87 & 0.24 & 7.53 & 0.18 & 12.40 & 0.42 \\
\hline NACS $8.4 \mathrm{H}$ & 2 & 2.455 & 0.010 & 641 & 6 & 0.115 & 0.002 & 0.095 & 0.002 & 1.34 & 0.07 & 1.13 & 0.04 & 2.47 & 0.11 & 5.09 & 0.25 & 7.68 & 0.18 & 12.77 & 0.43 \\
\hline NACS $12.6 \mathrm{H}$ & 1 & 2.435 & 0.004 & 784 & 5 & 0.155 & 0.001 & 0.232 & 0.002 & 1.49 & 0.07 & 2.29 & 0.05 & 3.78 & 0.13 & 3.35 & 0.28 & 1.33 & 0.04 & 4.68 & 0.31 \\
\hline NACS $12.6 \mathrm{H}$ & 2 & 2.435 & 0.004 & 767 & 3 & 0.159 & 0.001 & 0.233 & 0.002 & 1.56 & 0.08 & 2.35 & 0.06 & 3.90 & 0.13 & 3.12 & 0.16 & 1.18 & 0.03 & 4.30 & 0.19 \\
\hline
\end{tabular}


Table A continued. Density $\rho$, thickness $d$ and the near infrared (NIR) absorption at the $4500 \mathrm{~cm}^{-1}$ and $5300 \mathrm{~cm}^{-1}$ bands in spectra of the hydrous peralkaline and peraluminous glasses, which were used to calculate the concentration of water dissolved as $\mathrm{OH}$ and $\mathrm{H}_{2} \mathrm{O}$.

\begin{tabular}{|c|c|c|c|c|c|c|c|c|c|c|c|c|c|c|c|c|c|c|c|c|c|}
\hline \multirow{3}{*}{ Peralkaline } & \multirow[b]{2}{*}{$\frac{\stackrel{\sigma}{0}}{\frac{0}{0}}$} & \multirow{2}{*}{\multicolumn{2}{|c|}{$\begin{array}{c}\rho^{\mathrm{b}} \quad 2 \sigma^{\mathrm{c}} \\
{\left[\mathrm{g} \mathrm{cm}^{-3}\right]}\end{array}$}} & \multirow{2}{*}{\multicolumn{2}{|c|}{$\begin{array}{l}d^{b} \quad 2 \sigma \\
{[\mu \mathrm{m}]}\end{array}$}} & \multicolumn{4}{|c|}{ Absorption $^{\mathrm{a}}$} & \multicolumn{6}{|c|}{ Concentration } & \multicolumn{6}{|c|}{ Concentration } \\
\hline & & & & & & $\begin{array}{l}\mathrm{OH} \\
\quad[-\mathrm{lo}\end{array}$ & $\begin{array}{l}2 \sigma \\
g \text { transr }\end{array}$ & $\begin{array}{l}\mathrm{H}_{2} \mathrm{O} \\
\text { mission }\end{array}$ & $\%]$ & $\mathrm{OH}$ & $\pm^{d}$ & $\begin{array}{r}\mathrm{H}_{2} \mathrm{O} \\
{[\mathrm{wt}}\end{array}$ & \pm & $\begin{array}{c}\mathrm{H}_{2} \mathrm{O} \\
\text { total }\end{array}$ & \pm & $\mathrm{OH}$ & \pm & $\begin{array}{l}\mathrm{H}_{2} \mathrm{O} \\
\quad[\mathrm{mo}\end{array}$ & \pm & $\begin{array}{r}\mathrm{H}_{2} \mathrm{O} \\
\text { total }\end{array}$ & \pm \\
\hline & & & & & & & & & & & & & & & & & & & & & \\
\hline NACS $0.7 \mathrm{~F} 0.6 \mathrm{Cl} 2.4 \mathrm{H}$ & 1 & 2.475 & .003 & 895 & 5 & 0.071 & .002 & 0.011 & 0.001 & 0.59 & .03 & 0.09 & 0.01 & 0.68 & 0.04 & 2.10 & 0.12 & 0.33 & 0.02 & 2.44 & 0.14 \\
\hline NACS $0.7 \mathrm{~F} 0.6 \mathrm{Cl} 2.4 \mathrm{H}$ & 2 & 2.475 & .003 & 903 & 6 & 0.073 & 0.001 & 0.011 & 0.001 & 0.60 & .03 & 0.09 & 0.01 & 0.69 & 0.04 & 2.13 & 0.11 & 0.32 & 0.04 & 2.45 & 0.15 \\
\hline NACS $0.7 \mathrm{~F} 0.6 \mathrm{Cl} 4.5 \mathrm{H}$ & 1 & 2.471 & 0.003 & 951 & 2 & 0.122 & 0.003 & 0.039 & 0.002 & 0.95 & .05 & 0.31 & 0.02 & 1.26 & 0.07 & 3.34 & 0.19 & 1.09 & 0.06 & 1.43 & 0.25 \\
\hline NACS $0.7 \mathrm{~F} 0.6 \mathrm{Cl} 4.5 \mathrm{H}$ & 2 & 2.471 & 0.003 & 984 & 1 & 0.127 & 0.001 & 0.045 & 0.002 & 0.96 & .05 & 0.35 & 0.02 & 1.31 & 0.06 & 3.36 & 0.17 & 1.22 & 0.05 & 4.57 & 0.22 \\
\hline NACS $0.7 \mathrm{~F} 0.6 \mathrm{Cl} 8.4 \mathrm{H}$ & 1 & 2.453 & 0.002 & 749 & 2 & 0.131 & 0.002 & 0.102 & 0.002 & 1.31 & 0.07 & 1.05 & 0.03 & 2.36 & 0.09 & 4.45 & 0.22 & 3.58 & 0.10 & 8.04 & \\
\hline NACS $0.7 F 0.6$ & 2 & 2.453 & 0.002 & 751 & 4 & 0.139 & 0.003 & 0.115 & 0.001 & 1.38 & .08 & 1.18 & 0.03 & 2. & 0.10 & 4.69 & 0.26 & 4.01 & 0.09 & 8.70 & 0.35 \\
\hline NACS $0.7 \mathrm{~F} 0.6 \mathrm{Cl} 13.1 \mathrm{H}$ & 1 & 2.425 & 0.008 & 960 & 5 & 0.202 & 0.026 & 0.297 & 0.023 & 1.59 & .22 & 2.41 & 0.19 & 4.00 & 0.41 & 5.22 & 0.72 & 7.89 & 0.63 & 13.11 & 1.35 \\
\hline NACS $0.7 \mathrm{~F} 0.6 \mathrm{Cl} 13.1 \mathrm{H}$ & 2 & 2.425 & 0.008 & 926 & 2 & 0.188 & 0.002 & 0.293 & 0.000 & 1.54 & 0.08 & 2.46 & 0.05 & 4.00 & 0.13 & 5.04 & 0.25 & 8.06 & 0.18 & 13.10 & 0.43 \\
\hline NACS $1.1 \mathrm{~F} 1.1 \mathrm{Cl} 2.2 \mathrm{H}$ & 1 & 2.469 & 0.002 & 839 & 3 & 0.064 & 0.004 & 0.008 & 0.001 & 0.56 & .05 & 0.08 & 0.01 & 0.64 & 0.06 & 2.00 & 0.16 & 0.27 & 0.04 & 2.27 & 0.21 \\
\hline NACS $1.1 \mathrm{~F} 1.1 \mathrm{Cl} 2.2 \mathrm{H}$ & 2 & 2.469 & 0.002 & 808 & 2 & 0.060 & 0.004 & 0.008 & 0.002 & 0.55 & 0.05 & 0.08 & 0.01 & 0.63 & 0.06 & 1.95 & 0.16 & 0.27 & 0.05 & 2.22 & 0.21 \\
\hline NACS $1.1 \mathrm{~F} 1.1 \mathrm{Cl} 5.0 \mathrm{H}$ & 1 & 2.461 & 0.004 & 817 & 3 & 0.116 & 0.002 & 0.045 & 0.002 & 1.06 & .05 & 0.42 & 0.02 & 1.48 & 0.08 & 3.67 & 0.19 & 1.46 & 0.08 & 5.13 & 0.26 \\
\hline NACS $1.1 \mathrm{~F} 1.1 \mathrm{Cl} 5.0 \mathrm{H}$ & 2 & 2.461 & 0.004 & 823 & 4 & 0.110 & 0.003 & 0.045 & 0.001 & 1.00 & 0.05 & 0.42 & 0.01 & 1.42 & 0.07 & 3.48 & 0.19 & 1.45 & 0.04 & 4.93 & 0.23 \\
\hline NACS $1.1 \mathrm{~F} 1.1 \mathrm{Cl} 7.9 \mathrm{H}$ & 1 & 2.450 & 0.008 & 1109 & 7 & 0.173 & 0.004 & 0.162 & 0.001 & 1.17 & .06 & 1.12 & 0.03 & 2.29 & 0.09 & 3.97 & 0.22 & 3.82 & 0.09 & 7.79 & 0.31 \\
\hline NACS $1.1 \mathrm{~F} 1.1 \mathrm{Cl} 7.9 \mathrm{H}$ & 2 & 2.450 & 0.008 & 1077 & 6 & 0.173 & 0.004 & 0.162 & 0.001 & 1.20 & .07 & 1.15 & 0.03 & 2.36 & 9 & 4.08 & 0.23 & 3.92 & 0.09 & 8.00 & 0.32 \\
\hline NACS $1.1 \mathrm{~F} 1.1 \mathrm{Cl} 13.5 \mathrm{H}$ & 1 & 2.428 & 0.002 & 995 & 4 & 0.207 & 0.003 & 0.324 & 0.002 & 1.57 & 0.08 & 2.53 & 0.06 & 4.11 & 0.14 & 5.13 & 0.26 & 8.24 & 0.19 & 13.37 & 0.45 \\
\hline NACS $1.1 \mathrm{~F} 1.1 \mathrm{Cl} 13.5 \mathrm{H}$ & 2 & 2.428 & 0.002 & 991 & 1 & 0.215 & 0.005 & 0.329 & 0.004 & 1.64 & & 2.58 & & 4. & & 5.31 & 0.29 & 8.38 & 0.21 & 13.69 & 0.50 \\
\hline NACS $2.6 \mathrm{~F} 1.4 \mathrm{Cl} 2.8 \mathrm{H}$ & 1 & 2.463 & 0.006 & 846 & 3 & 0.089 & 0.003 & 0.019 & 0.000 & 0.79 & 0.04 & 0.18 & 0.01 & 0.96 & 0.05 & 2.75 & 0.16 & 0.61 & 0.02 & 3.36 & 0.18 \\
\hline NACS $2.6 \mathrm{~F} 1.4 \mathrm{Cl} 2.8 \mathrm{H}$ & 2 & 2.463 & 0.006 & 857 & 3 & 0.092 & 0.001 & 0.019 & 0.001 & 0.80 & 0.04 & 0.17 & 0.01 & 0.97 & 0.05 & 2.78 & 0.14 & 0.59 & 0.04 & 3.37 & 0.18 \\
\hline NACS $2.6 \mathrm{~F} 1.4 \mathrm{Cl} 3.8 \mathrm{H}$ & 1 & 2.457 & 0.006 & 867 & 4 & 0.111 & 0.002 & 0.035 & 0.001 & 0.96 & 0.05 & 0.31 & 0.01 & 1.27 & 0.06 & 3.32 & 0.17 & 1.08 & 0.04 & 4.41 & 0.21 \\
\hline NACS $2.6 \mathrm{~F} 1.4 \mathrm{Cl} 3.8 \mathrm{H}$ & 2 & 2.457 & 0.006 & 845 & 8 & 0.112 & 0.000 & 0.036 & 0.001 & 0.99 & 0.05 & 0.32 & 0.01 & 1.31 & 0.06 & 3.42 & 0.17 & 1.12 & 0.04 & 4.55 & 0.21 \\
\hline NACS $2.6 \mathrm{~F} 1.4 \mathrm{Cl} 9.6 \mathrm{H}$ & 1 & 2.432 & 0.002 & 753 & 2 & 0.154 & 0.001 & 0.168 & 0.001 & 1.54 & 0.08 & 1.73 & 0.04 & 3.27 & 0.11 & 5.09 & 0.25 & 5.73 & 0.13 & 10.82 & 0.38 \\
\hline NACS $2.6 \mathrm{~F} 1.4 \mathrm{Cl} 9.6 \mathrm{H}$ & 2 & 2.432 & 0.002 & 765 & 8 & 0.159 & 0.003 & 0.176 & 0.001 & 1.57 & 0.08 & 1.78 & 0.04 & 3.35 & 0.13 & 5.17 & 0.27 & 5.88 & 0.14 & 11.05 & 0.42 \\
\hline NACS $2.6 \mathrm{~F} 1.4 \mathrm{Cl} 13.3 \mathrm{H}$ & 1 & 2.414 & 0.002 & 937 & 4 & 0.215 & 0.003 & 0.361 & 0.002 & 1.75 & 0.09 & 3.01 & 0.07 & 4.76 & 0.16 & 5.57 & 0.29 & 9.62 & 0.22 & 15.19 & 0.50 \\
\hline NACS $2.6 \mathrm{~F} 1.4 \mathrm{Cl} 13.3 \mathrm{H}$ & 2 & 2.414 & 0.002 & 961 & 12 & 0.214 & 0.005 & 0.368 & 0.002 & 1.69 & 0.09 & 2.99 & 0.08 & 4.68 & 0.17 & 5.41 & 0.30 & 9.56 & 0.25 & 14.96 & 0.54 \\
\hline
\end{tabular}


Table A continued. Density $\rho$, thickness $d$ and the near infrared (NIR) absorption at the $4500 \mathrm{~cm}^{-1}$ and $5300 \mathrm{~cm}^{-1}$ bands in spectra of the hydrous peralkaline and peraluminous glasses, which were used to calculate the concentration of water dissolved as $\mathrm{OH}$ and $\mathrm{H}_{2} \mathrm{O}$.

\begin{tabular}{|c|c|c|c|c|c|c|c|c|c|c|c|c|c|c|c|c|c|c|c|c|c|}
\hline \multirow[b]{3}{*}{ Peralkaline } & \multirow[b]{2}{*}{ 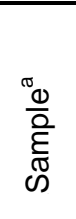 } & \multirow{2}{*}{\multicolumn{2}{|c|}{$\begin{array}{c}\rho^{\mathrm{b}} \quad 2 \sigma^{\mathrm{c}} \\
{\left[\mathrm{g} \mathrm{cm}^{-3}\right]}\end{array}$}} & \multirow{2}{*}{\multicolumn{2}{|c|}{$\begin{array}{l}d^{b} \quad 2 \sigma \\
{[\mu \mathrm{m}]}\end{array}$}} & \multicolumn{4}{|c|}{ Absorption $^{\mathrm{a}}$} & \multicolumn{6}{|c|}{ Concentration } & \multicolumn{6}{|c|}{ Concentration } \\
\hline & & & & & & $\begin{array}{l}\mathrm{OH} \\
{[-\mathrm{log}}\end{array}$ & $\begin{array}{l}2 \sigma \\
g \text { transr }\end{array}$ & $\begin{array}{l}\mathrm{H}_{2} \mathrm{O} \\
\text { nission\% }\end{array}$ & $\begin{array}{l}2 \sigma \\
\%]\end{array}$ & $\mathrm{OH}$ & $\pm^{d}$ & $\begin{array}{l}\mathrm{H}_{2} \mathrm{O} \\
{[\mathrm{wt}}\end{array}$ & \pm & $\begin{array}{r}\mathrm{H}_{2} \mathrm{O} \\
\text { total }\end{array}$ & \pm & $\mathrm{OH}$ & \pm & $\begin{array}{l}\mathrm{H}_{2} \mathrm{O} \\
\quad[\mathrm{mo}\end{array}$ & \pm & $\begin{array}{c}\mathrm{H}_{2} \mathrm{O} \\
\text { total }\end{array}$ & \pm \\
\hline & & & & & & & & & & & & & & & & & & & & & \\
\hline NACS $1.1 \mathrm{Cl} 2.2 \mathrm{H}$ & 1 & 2.465 & 0.007 & 1060 & 5 & 0.07 & 0.00 & 0.012 & 0.006 & 0.51 & 0.04 & 0.09 & 0.04 & 0.59 & 0.08 & 1.80 & 0.13 & 0.30 & 0.15 & 2.10 & 0.29 \\
\hline NACS $1.1 \mathrm{Cl} 2.2 \mathrm{H}$ & 2 & 2.465 & 0.007 & 1058 & 4 & 0.07 & 0.00 & 0.015 & 0.001 & 0.52 & 0.03 & 0.11 & 0.01 & 0.63 & 0.03 & 1.85 & 0.09 & 0.38 & 0.02 & 2.23 & 0.11 \\
\hline NACS $1.1 \mathrm{Cl} 3.7 \mathrm{H}$ & 1 & 2.466 & 0.005 & 822 & 5 & 0.09 & 0.00 & 0.026 & 0.000 & 0.85 & 0.04 & 0.24 & 0.01 & 1.09 & 0.05 & 2.99 & 0.15 & 0.86 & 0.02 & 3.84 & 0.17 \\
\hline NACS $1.1 \mathrm{Cl} 3.7 \mathrm{H}$ & 2 & 2.466 & 0.005 & 856 & 5 & 0.09 & 0.00 & 0.023 & 0.000 & 0.81 & 0.04 & 0.20 & 0.00 & 1.01 & 0.04 & 2.85 & 0.14 & 0.71 & 0.02 & 3.56 & 0.16 \\
\hline NACS $1.1 \mathrm{Cl} 7.5 \mathrm{H}$ & 1 & 2.450 & 0.008 & 949 & 5 & 0.17 & 0.00 & 0.110 & 0.001 & 1.33 & 0.07 & 0.89 & 0.02 & 2.22 & 0.09 & 4.54 & 0.22 & 3.04 & 0.07 & 7.58 & 0.29 \\
\hline NACS $1.1 \mathrm{Cl} 7.5 \mathrm{H}$ & 2 & 2.450 & 0.008 & 979 & 7 & 0.17 & 0.00 & 0.113 & 0.000 & 1.28 & 0.06 & 0.89 & 0.02 & 2.17 & 0.08 & 4.38 & 0.22 & 3.04 & 0.07 & 7.42 & 0.29 \\
\hline $\mathrm{NACS} 1.1 \mathrm{Cl} 14.5 \mathrm{H}^{\mathrm{e}}$ & 1 & 2.381 & 0.008 & 845 & 4 & 0.19 & 0.00 & 0.296 & 0.001 & 1.70 & 0.08 & 2.72 & 0.06 & 4.43 & 0.15 & 5.52 & 0.27 & 8.81 & 0.20 & 14.33 & 0.47 \\
\hline NACS $1.1 \mathrm{Cl} 14.5 \mathrm{H}^{\mathrm{e}}$ & 2 & 2.381 & 0.008 & 818 & 4 & 0.19 & 0.00 & 0.297 & 0.001 & 1.74 & 0.09 & 2.82 & 0.06 & 4.56 & 0.15 & 5.63 & 0.28 & 9.09 & 0.21 & 14.72 & 0.48 \\
\hline NACS $1.9 F 2.8 \mathrm{H}$ & 1 & 2.480 & 0.004 & 398 & 2 & 0.035 & 0.000 & 0.006 & 0.000 & 0.65 & 0.03 & 0.12 & 0.01 & 0.77 & 0.04 & 2.27 & 0.11 & 0.43 & 0.02 & 2.70 & 0.14 \\
\hline NACS $1.9 \mathrm{~F} 2.8 \mathrm{H}$ & 2 & 2.480 & 0.004 & 391 & 1 & 0.033 & 0.001 & 0.009 & 0.000 & 0.63 & 0.04 & 0.17 & 0.01 & 0.79 & 0.04 & 2.20 & 0.12 & 0.59 & 0.02 & 2.79 & 0.15 \\
\hline NACS $1.9 F 5.8 \mathrm{H}$ & 1 & 2.471 & 0.005 & 879 & 5 & 0.130 & 0.001 & 0.067 & 0.000 & 1.10 & 0.05 & 0.58 & 0.01 & 1.68 & 0.07 & 3.77 & 0.19 & 2.01 & 0.05 & 5.78 & 0.23 \\
\hline NACS 1.9F 5.8H & 2 & 2.471 & 0.005 & 900 & 4 & 0.136 & 0.000 & 0.068 & 0.000 & 1.12 & 0.05 & 0.57 & 0.01 & 1.69 & 0.07 & 3.85 & 0.19 & 1.97 & 0.05 & 5.82 & 0.23 \\
\hline NACS $1.9 \mathrm{~F} 13.2 \mathrm{H}$ & 1 & 2.457 & 0.007 & 889 & 7 & 0.163 & 0.001 & 0.141 & 0.001 & 1.37 & 0.07 & 1.21 & 0.03 & 2.58 & 0.10 & 4.60 & 0.23 & 4.08 & 0.10 & 8.68 & 0.32 \\
\hline NACS $1.9 F$ 13.2H & 2 & 2.457 & 0.007 & 878 & 10 & 0.164 & 0.000 & 0.143 & 0.000 & 1.39 & 0.07 & 1.25 & 0.03 & 2.65 & 0.10 & 4.67 & 0.23 & 4.21 & 0.10 & 8.88 & 0.34 \\
\hline NACS $1.9 \mathrm{~F} 13.1 \mathrm{H}$ & 1 & 2.432 & 0.010 & 985 & 3 & 0.201 & 0.000 & 0.328 & 0.000 & 1.53 & 0.07 & 2.58 & 0.06 & 4.12 & 0.13 & 4.98 & 0.24 & 8.38 & 0.19 & 13.36 & 0.43 \\
\hline NACS $1.9 \mathrm{~F} 13.1 \mathrm{H}$ & 2 & 2.432 & 0.010 & 983 & 3 & 0.196 & 0.001 & 0.316 & 0.002 & 1.51 & 0.07 & 2.49 & 0.06 & 4.00 & 0.13 & 4.89 & 0.24 & 8.11 & 0.19 & 13.00 & 0.43 \\
\hline Peraluminous & & & & & & & & & & & & & & & & & & & & & \\
\hline ANCS $6.8 \mathrm{H}^{*}$ & $1 a$ & 2.430 & 0.010 & 1260 & 186 & 0.313 & 0.004 & 0.069 & 0.001 & 1.65 & 0.31 & 0.36 & 0.06 & 2.01 & 0.36 & 5.91 & 1.09 & 1.29 & 0.20 & 7.20 & 1.30 \\
\hline ANCS $6.8 \mathrm{H}^{*}$ & $1 b$ & 2.430 & 0.010 & 1260 & 186 & 0.280 & 0.004 & 0.066 & 0.001 & 1.47 & 0.27 & 0.35 & 0.06 & 1.82 & 0.33 & 5.31 & 0.98 & 1.25 & 0.20 & 6.56 & 1.18 \\
\hline ANCS $10.0 \mathrm{H}$ & 1 & 2.406 & 0.013 & 1510 & 17 & 0.377 & 0.003 & 0.216 & 0.002 & 1.67 & 0.19 & 0.95 & 0.06 & 2.62 & 0.24 & 5.90 & 0.66 & 3.35 & 0.20 & 9.25 & 0.86 \\
\hline ANCS $10.0 \mathrm{H}$ & 2 & 2.406 & 0.013 & 1454 & 18 & 0.413 & 0.002 & 0.207 & 0.001 & 1.90 & 0.21 & 0.95 & 0.06 & 2.85 & 0.27 & 6.66 & 0.74 & 3.31 & 0.19 & 9.98 & 0.94 \\
\hline ANCS $13.2 \mathrm{H}$ & 1 & 2.397 & 0.016 & 1088 & 12 & 0.326 & 0.004 & 0.315 & 0.003 & 2.01 & 0.23 & 1.93 & 0.11 & 3.95 & 0.34 & 6.86 & 0.77 & 6.60 & 0.39 & 13.45 & 1.16 \\
\hline ANCS $13.2 \mathrm{H}$ & 2 & 2.397 & 0.016 & 1074 & 6 & 0.314 & 0.001 & 0.307 & 0.005 & 1.96 & 0.22 & 1.91 & 0.11 & 3.87 & 0.33 & 6.71 & 0.75 & 6.51 & 0.39 & 13.22 & 1.13 \\
\hline ANCS $14.3 \mathrm{H}$ & 1 & 2.390 & 0.008 & 1340 & 8 & 0.403 & 0.001 & 0.438 & 0.003 & 2.03 & 0.22 & 2.19 & 0.13 & 4.21 & 0.35 & 6.86 & 0.76 & 7.41 & 0.43 & 14.27 & 1.19 \\
\hline ANCS $14.3 \mathrm{H}$ & 2 & 2.390 & 0.008 & 1356 & 5 & 0.413 & 0.002 & 0.441 & 0.011 & 2.05 & 0.23 & 2.18 & 0.14 & 4.23 & 0.36 & 6.95 & 0.77 & 7.38 & 0.46 & 14.33 & 1.23 \\
\hline ANCS $18.2 \mathrm{H}$ & 1 & 2.369 & 0.020 & 1171 & 8 & 0.346 & 0.002 & 0.681 & 0.018 & 2.01 & 0.22 & 3.93 & 0.25 & 5.94 & 0.47 & 6.53 & 0.73 & 12.75 & 0.81 & 19.28 & 1.53 \\
\hline ANCS $18.2 \mathrm{H}$ & 2 & 2.369 & 0.020 & 711 & 8 & 0.216 & 0.002 & 0.410 & 0.003 & 2.07 & 0.23 & 3.90 & 0.23 & 5.96 & 0.46 & 6.71 & 0.75 & 12.64 & 0.74 & 19.35 & 1.49 \\
\hline
\end{tabular}


Table A continued. Density $\rho$, thickness $d$ and the near infrared (NIR) absorption at the $4500 \mathrm{~cm}^{-1}$ and $5300 \mathrm{~cm}^{-1}$ bands in spectra of the hydrous peralkaline and peraluminous glasses, which were used to calculate the concentration of water dissolved as $\mathrm{OH}$ and $\mathrm{H}_{2} \mathrm{O}$.

\begin{tabular}{|c|c|c|c|c|c|c|c|c|c|c|c|c|c|c|c|c|c|c|c|c|c|}
\hline \multirow[b]{3}{*}{ ANCS $0.5 \mathrm{~F} 0.5 \mathrm{Cl} 0.8 \mathrm{H}$} & \multirow{3}{*}{ 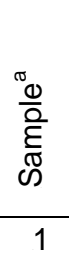 } & \multirow{2}{*}{\multicolumn{2}{|c|}{$\begin{array}{l}\rho^{\mathrm{b}} \quad 2 \sigma^{\mathrm{c}} \\
{\left[\mathrm{g} \mathrm{cm}^{-3}\right]}\end{array}$}} & \multirow{2}{*}{\multicolumn{2}{|c|}{$\begin{array}{l}d^{b} \quad 2 \sigma \\
{[\mu \mathrm{m}]}\end{array}$}} & \multicolumn{4}{|c|}{ Absorption $^{\mathrm{a}}$} & \multicolumn{6}{|c|}{ Concentration } & \multicolumn{6}{|c|}{ Concentration } \\
\hline & & & & & & \multicolumn{4}{|c|}{$\begin{array}{l}\mathrm{OH} \quad 2 \sigma \quad \mathrm{H}_{2} \mathrm{O} \quad 2 \sigma \\
\text { [-log transmission\%] }\end{array}$} & \multirow{2}{*}{$\begin{array}{r}\mathrm{OH} \\
0.19\end{array}$} & \multirow{2}{*}{$\begin{array}{l} \pm^{d} \\
0.02\end{array}$} & \multirow{2}{*}{$\begin{array}{l}\mathrm{H}_{2} \mathrm{O} \\
\quad[w t \% \\
0.02\end{array}$} & \multirow{2}{*}{$\begin{array}{c} \pm \\
0.00\end{array}$} & \multirow{2}{*}{$\begin{array}{c}\mathrm{H}_{2} \mathrm{O} \\
\text { total } \\
0.21\end{array}$} & \multirow{2}{*}{$\begin{array}{l} \pm \\
0.03\end{array}$} & \multirow{2}{*}{$\begin{array}{l}\mathrm{OH} \\
0.71\end{array}$} & \multirow{2}{*}{$\begin{array}{c} \pm \\
0.09\end{array}$} & \multirow{2}{*}{$\begin{array}{l}\mathrm{H}_{2} \mathrm{O} \\
{[\mathrm{mol}} \\
0.08\end{array}$} & \multirow{2}{*}{$\begin{array}{l} \pm \\
0.01\end{array}$} & \multirow{2}{*}{$\begin{array}{l}\mathrm{H}_{2} \mathrm{O} \\
\text { total }\end{array}$} & \multirow{2}{*}{$\begin{array}{l} \pm \\
0.09\end{array}$} \\
\hline & & 2.476 & 0.018 & 990 & 25 & 0.029 & 0.001 & 0.003 & 0.000 & & & & & & & & & & & & \\
\hline ANCS $0.5 \mathrm{~F} 0.5 \mathrm{Cl} 0.8 \mathrm{H}$ & 2 & 2.476 & 0.018 & 705 & 15 & 0.022 & 0.001 & 0.002 & 0.000 & 0.21 & 0.02 & 0.02 & 0.00 & 0.22 & 0.03 & 0.78 & 0.09 & 0.06 & 0.01 & 0.84 & 0.11 \\
\hline ANCS $0.5 \mathrm{~F} 0.5 \mathrm{Cl} 5.1 \mathrm{H}$ & 1 & 2.445 & 0.008 & 1334 & 2 & 0.221 & 0.001 & 0.047 & 0.001 & 1.09 & 0.12 & 0.23 & 0.01 & 1.32 & 0.13 & 3.97 & 0.44 & 0.83 & 0.05 & 4.80 & 0.49 \\
\hline ANCS $0.5 \mathrm{~F} 0.5 \mathrm{Cl} 5.1 \mathrm{H}$ & $2 a$ & 2.445 & 0.008 & 1306 & 4 & 0.235 & 0.023 & 0.048 & 0.017 & 1.18 & 0.18 & 0.24 & 0.09 & 1.42 & 0.26 & 4.30 & 0.64 & 0.87 & 0.32 & 5.17 & 0.96 \\
\hline ANCS $0.5 \mathrm{~F} 0.5 \mathrm{Cl} 5.1 \mathrm{H}$ & $2 b$ & 2.445 & 0.008 & 1306 & 4 & 0.238 & 0.000 & 0.050 & 0.000 & 1.20 & 0.13 & 0.25 & 0.01 & 1.45 & 0.15 & 4.36 & 0.48 & 0.91 & 0.05 & 5.27 & 0.54 \\
\hline ANCS $0.5 \mathrm{~F} 0.5 \mathrm{Cl} 8.8 \mathrm{H}$ & 1 & 2.421 & 0.008 & 1138 & 5 & 0.267 & 0.001 & 0.148 & 0.001 & 1.56 & 0.17 & 0.86 & 0.05 & 2.42 & 0.22 & 5.52 & 0.61 & 3.04 & 0.17 & 8.55 & 0.79 \\
\hline ANCS $0.5 \mathrm{~F} 0.5 \mathrm{Cl} 8.8 \mathrm{H}$ & 2 & 2.421 & 0.008 & 1117 & 27 & 0.293 & 0.001 & 0.135 & 0.001 & 1.75 & 0.20 & 0.80 & 0.05 & 2.55 & 0.25 & 6.16 & 0.70 & 2.82 & 0.17 & 8.98 & 0.87 \\
\hline ANCS $0.5 \mathrm{~F} 0.5 \mathrm{Cl} 13.0 \mathrm{H}$ & 1 & 2.404 & 0.010 & 1175 & 12 & 0.366 & 0.002 & 0.316 & 0.004 & 2.08 & 0.23 & 1.79 & 0.11 & 3.87 & 0.34 & 7.10 & 0.79 & 6.11 & 0.36 & 13.21 & 1.15 \\
\hline ANCS $0.5 \mathrm{~F} 0.5 \mathrm{Cl} 13.0 \mathrm{H}$ & 2 & 2.404 & 0.010 & 1267 & 14 & 0.376 & 0.002 & 0.327 & 0.002 & 1.99 & 0.22 & 1.72 & 0.10 & 3.70 & 0.32 & 6.80 & 0.76 & 5.89 & 0.34 & 12.68 & 1.10 \\
\hline ANCS $1.2 \mathrm{~F} 1.1 \mathrm{Cl} 6.2 \mathrm{H}$ & 1 & 2.476 & 0.014 & 1406 & 13 & 0.311 & 0.003 & 0.059 & 0.002 & 1.44 & 0.16 & 0.27 & 0.02 & 1.71 & 0.18 & 5.22 & 0.58 & 0.98 & 0.07 & 6.20 & 0.65 \\
\hline ANCS $1.2 \mathrm{~F} 1.1 \mathrm{Cl} 6.2 \mathrm{H}$ & 2 & 2.476 & 0.014 & 870 & 13 & 0.188 & 0.003 & 0.037 & 0.000 & 1.41 & 0.16 & 0.27 & 0.02 & 1.68 & 0.17 & 5.12 & 0.58 & 1.00 & 0.06 & 6.12 & 0.64 \\
\hline ANCS $1.2 \mathrm{~F} 1.1 \mathrm{Cl} 9.8 \mathrm{H}$ & 1 & 2.417 & 0.007 & 876 & 21 & 0.244 & 0.001 & 0.123 & 0.001 & 1.85 & 0.21 & 0.93 & 0.06 & 2.79 & 0.27 & 6.54 & 0.74 & 3.29 & 0.21 & 9.83 & 0.95 \\
\hline ANCS $1.2 \mathrm{~F} 1.1 \mathrm{Cl} 12.0 \mathrm{H}$ & 1 & 2.400 & 0.010 & 1154 & 16 & 0.334 & 0.004 & 0.259 & 0.001 & 1.94 & 0.22 & 1.50 & 0.09 & 3.44 & 0.31 & 6.74 & 0.76 & 5.20 & 0.30 & 11.94 & 1.06 \\
\hline ANCS $1.2 \mathrm{~F} 1.1 \mathrm{Cl} 12.0 \mathrm{H}$ & 2 & 2.400 & 0.010 & 1125 & 12 & 0.319 & 0.001 & 0.263 & 0.005 & 1.90 & 0.21 & 1.56 & 0.09 & 3.46 & 0.31 & 6.60 & 0.73 & 5.41 & 0.33 & 12.01 & 1.06 \\
\hline ANCS $2.3 \mathrm{~F} 0.9 \mathrm{Cl} 7.0 \mathrm{H}$ & 1 & 2.425 & 0.014 & 1350 & 10 & 0.275 & 0.002 & 0.082 & 0.004 & 1.35 & 0.15 & 0.40 & 0.03 & 1.75 & 0.18 & 4.91 & 0.55 & 1.45 & 0.11 & 6.35 & 0.65 \\
\hline ANCS $2.3 \mathrm{~F} 0.9 \mathrm{Cl} 7.0 \mathrm{H}$ & 2 & 2.425 & 0.014 & 1399 & 8 & 0.256 & 0.001 & 0.082 & 0.001 & 1.21 & 0.13 & 0.39 & 0.02 & 1.60 & 0.16 & 4.42 & 0.49 & 1.41 & 0.08 & 5.83 & 0.57 \\
\hline ANCS $2.3 \mathrm{~F} 0.9 \mathrm{Cl} 9.4 \mathrm{H}$ & 1 & 2.403 & 0.011 & 1367 & 13 & 0.319 & 0.001 & 0.142 & 0.001 & 1.57 & 0.17 & 0.69 & 0.04 & 2.26 & 0.21 & 5.60 & 0.62 & 2.48 & 0.14 & 8.08 & 0.77 \\
\hline ANCS $2.3 \mathrm{~F} 0.9 \mathrm{Cl} 9.4 \mathrm{H}$ & 2 & 2.403 & 0.011 & 1300 & 37 & 0.307 & 0.000 & 0.157 & 0.000 & 1.59 & 0.18 & 0.80 & 0.05 & 2.39 & 0.23 & 5.66 & 0.65 & 2.86 & 0.18 & 8.52 & 0.83 \\
\hline ANCS $2.3 \mathrm{~F} 0.9 \mathrm{Cl} 13.1 \mathrm{H}$ & 1 & 2.381 & 0.008 & 1256 & 6 & 0.354 & 0.001 & 0.276 & 0.001 & 1.91 & 0.21 & 1.48 & 0.08 & 3.38 & 0.30 & 6.62 & 0.73 & 5.13 & 0.29 & 11.75 & 1.03 \\
\hline ANCS $2.3 \mathrm{~F} 0.9 \mathrm{Cl} 13.1 \mathrm{H}$ & 2 & 2.381 & 0.008 & 1249 & 13 & 0.350 & 0.001 & 0.270 & 0.001 & 1.90 & 0.21 & 1.45 & 0.08 & 3.35 & 0.30 & 6.60 & 0.73 & 5.05 & 0.29 & 11.65 & 1.03 \\
\hline ANCS 18.3F 5.3H & 1 & 2.450 & 0.035 & 752 & 5 & 0.114 & 0.000 & 0.065 & 0.000 & 1.00 & 0.11 & 0.57 & 0.03 & 1.56 & 0.14 & 3.40 & 0.38 & 1.93 & 0.11 & 5.33 & 0.49 \\
\hline ANCS 18.3F 5.3H & 2 & 2.450 & 0.035 & 824 & 26 & 0.118 & 0.001 & 0.063 & 0.001 & 0.94 & 0.11 & 0.50 & 0.03 & 1.44 & 0.14 & 3.23 & 0.38 & 1.69 & 0.11 & 4.92 & 0.49 \\
\hline ANCS 18.3F 8.9H & 1 & 2.413 & 0.021 & 1149 & 21 & 0.248 & 0.001 & 0.211 & 0.001 & 1.44 & 0.16 & 1.22 & 0.07 & 2.66 & 0.24 & 4.78 & 0.54 & 4.04 & 0.24 & 8.82 & 0.78 \\
\hline ANCS 18.3F $8.9 \mathrm{H}$ & 2 & 2.413 & 0.021 & 987 & 9 & 0.213 & 0.000 & 0.187 & 0.001 & 1.44 & 0.16 & 1.25 & 0.07 & 2.70 & 0.23 & 4.78 & 0.53 & 4.16 & 0.24 & 8.94 & 0.77 \\
\hline ANCS $18.3 \mathrm{~F} 12.19 \mathrm{H}$ & 1 & 2.407 & 0.024 & 834 & 9 & 0.183 & 0.001 & 0.259 & 0.002 & 1.47 & 0.16 & 2.06 & 0.12 & 3.53 & 0.28 & 4.78 & 0.53 & 6.70 & 0.39 & 11.47 & 0.93 \\
\hline
\end{tabular}




\section{References}

Aiuppa, A., Baker, D.R., Webster, J.D., 2009. Halogens in volcanic systems. Chem. Geol. 263, 1-18.

Angell, C.A., 1991. Relaxation in liquids, polymers and plastic crystals - strong/fragile patterns and problems. J. Non-Cryst. Solids 131-133, 13-31.

Audetat, A., Bali, E., 2010. A new technique to seal volatile-rich samples into platinum capsules. Eur. J. Mineral. 22, 23-27.

Baasner, A., Schmidt, B.C., Webb, S.L., 2013. Compositional dependence of the rheology of halogen $(\mathrm{F}, \mathrm{Cl})$ bearing melts. Chem. Geol. 346, 172-183.

Baasner, A., Schmidt, B.C., Dupree, R., Webb, S.L.,2014a. Fluorine speciation as a function of composition in peralkaline and peraluminous $\mathrm{Na}_{2} \mathrm{O}-\mathrm{CaO}-\mathrm{Al}_{2} \mathrm{O}_{3}-\mathrm{SiO}_{2}$ glasses: $\mathrm{A}$ multinuclear NMR study. Geochim. Cosmochim. Acta 132, 151-169.

Bagdassarov, N.Sh., Dingwell, D.B., 1992. A rheological investigation of vesicular rhyolite. J. Volcanol. Geoth. Res. 50, 307-332.

Baker, D.R., Vaillancourt, J., 1995. The low viscosities of $\mathrm{F}+\mathrm{H}_{2} \mathrm{O}$-bearing granitic melts and implications for melt extraction and transport. Earth Planet. Sci. Lett. 132, 199-211.

Bartholomew, R.F., Butler, B.L., Hoover, H.L., Wu, C.K., 1980. Infrared spectra of a water-containing glass. J. Am. Ceram. Soc. 63, 481-485.

Bartels, A., Behrens, H., Holtz, F., Schmidt, B.C., Fechtelkord, M., Knipping, J., Crede, L., Baasner, A., Pukallus, N., 2013. The effect of fluorine, boron and phosphorus on the viscosity of pegmatite forming melts. Chem. Geol. 346, 184-198.

Behrens, $\mathrm{H}$., Nowak, M., 2003. Quantification of $\mathrm{H}_{2} \mathrm{O}$ speciation in silicate glasses and melts by IR spectroscopy - in situ versus quench techniques. Phase transit. 76, 45-61.

Behrens, H., Romano, C., Nowak, M., Holtz, F., Dingwell, D. B., 1996. Near-infrared spectroscopic determination of water species in glasses of the system $\mathrm{MAISi}_{3} \mathrm{O}_{8}(\mathrm{M}=\mathrm{Li}$, $\mathrm{Na}, \mathrm{K})$ : an interlaboratory study. Chem. Geol. 128, S. 41-63.

Böhm, A., Schmidt, B.C., 2013. Fluorine and chlorine diffusion in phonolitic melt. Chem. Geol. $346,162-171$. 
Böhmer, R., Angell, C.A., 1992. Correlations of the nonexponentiality and state dependence of mechanical relaxations with bond connectivity in Ge-As-Se supercooled liquids. Phys. Rev. B 45, 10091-10094.

Cioni, R., Marianelli, P., Santacroce, R., 1998. Thermal and compositional evolution of the shallow magma chamber of Vesuvius: Evidence from pyroxene phenocrysts and melt inclusions. J. Geophys. Res. 103, 18277-18294.

DeBolt, M.A., Easteal, A.J., Macedo, P.B., Moynihan, C.T., 1976. Analysis of structural relaxation in glass using rate heating data. J. Am. Ceram. Soc. 59, 16-21.

Di Muro, A., Villemant, B., Montagnac, G., Scaillet, B., Reynard, B., 2006. Quantification of water content and speciation in natural silicic glasses (phonolite, dacite, rhyolite) by confocal microRaman spectrometry. Geochim. Cosmochim. Acta 70, 2868-2884.

Dingwell, D.B., 1989. Effect of fluorine on the viscosity of diopside liquid. Am. Mineral. 74, 333-338.

Dingwell, D.B., Hess, K.-U., 1998. Melt viscosities in the system Na-Fe-Si-O-F-Cl: Contrasting effects of $\mathrm{F}$ and $\mathrm{Cl}$ in alkaline melts. Am. Mineral. 83, 1016-1021.

Dingwell, D.B., Webb, S.L. 1990. Relaxation in silicate melts. Eur. J. Mineral. 2, 427-449.

Dingwell, D.B., Knoche, R., Webb, S.L, 1993a. The effect of $\mathrm{P}_{2} \mathrm{O}_{5}$ on the viscosity of haplogranitic liquid. Eur. J. Mineral. 5, 133-140.

Dingwell, D.B., Knoche, R., Webb, S.L, 1993b. The effect of F on the density of haplogranite melt. Am. Mineral. 78, 325-330.

Dingwell, D.B., Romano, C., Hess, K.-U., 1996. The effect of water on the viscosity of a haplogranitic melt under P-T-X conditions relevant to silicic volcanism. Contrib. Mineral. Petrol. 124, 19-28.

Dingwell, D.B., Scarfe, C.M., Cronin, D.J., 1985. The effect of F on viscosities in the system $\mathrm{Na}_{2} \mathrm{O}-\mathrm{Al}_{2} \mathrm{O}_{3}-\mathrm{SiO}_{2}$ implications for phonolites, trachytes and rhyolites. Am. Mineral. 70 , 80-87. 
Falenty, K., Webb, S.L., 2010. Shear modulus, heat capacity, viscosity and structural relaxation time of $\mathrm{Na}_{2} \mathrm{O}-\mathrm{Al}_{2} \mathrm{O}_{3}-\mathrm{SiO}_{2}$ and $\mathrm{Na}_{2} \mathrm{O}-\mathrm{Fe}_{2} \mathrm{O}_{3}-\mathrm{Al}_{2} \mathrm{O}_{3}-\mathrm{SiO}_{2}$ melts. Phys. Chem. Minerals 37, 613-634.

Giordano, D., Romano, C., Dingwell, D.B., Poe, B., Behrens, H., 2004. The combined effects of water and fluorine on the viscosity of silicic magmas. Geochim. Cosmochim. Acta 68, $5159-5168$.

Gottsmann, J., Lavallee, Y., Marti, J., Aguirre-Diaz, G., 2009. Magma-tectonic interaction and the eruption of silicic batholiths. Earth Planet. Sci. Lett. 284, 426-434.

Hess, K.-U., Dingwell, D.B., Webb, S.L., 1995. The influence of excess alkalis on the viscosity of a haplogranitic melt. Am. Mineral. 80, 297-304.

Kohn, S.C., Dupree, R., Smith, M.E., 1989. A multinuclear magnetic resonance study of the structure of hydrous albite glasses. Geochim. Cosmochim. Acta 53, 2925-2935.

Lejeune, A.M., Bottinga, Y., Trull, T.W., Richet, P., 1999. Rheology of bubble-bearing magmas. Earth Planet. Sci. Lett. 166, 71-84.

Leschik, M., Heide, G., Frischat, G. H., Behrens, H., Wiedenbeck, M., Wagner, N., Heide, K., Geißler, H., Reinholz, U., 2004. Determination of $\mathrm{H}_{2} \mathrm{O}$ and $\mathrm{D}_{2} \mathrm{O}$ contents in rhyolitic glasses. Phys. Chem. Glasses 45, 238-251.

Lindsay, R., 1957. Density and Compressibility of Liquids, in: Gray, D.E. (Ed.), American Institute of Physics handbook. McGraw-Hill Book Company, New York, 136-164.

Lowenstern, J.B., 1994. Chlorine, fluid immiscibility, and degassing in peralkaline magmas from Pantelleria, Italy. Am. Mineral. 79. 353-369.

Malfait, W.J., Xue, X., 2010. The nature of hydroxyl groups in aluminosilicate glasses: Quantifying $\mathrm{Si}-\mathrm{OH}$ and $\mathrm{Al}-\mathrm{OH}$ abundances along the $\mathrm{SiO}_{2}-\mathrm{NaAlSiO}_{4}$ join by ${ }^{1} \mathrm{H},{ }^{27} \mathrm{Al}-{ }^{1} \mathrm{H}$ and ${ }^{29} \mathrm{Si}-{ }^{1} \mathrm{H}$ NMR spectroscopy. Geochim. Cosmochim. Acta 74, 719-737.

Mettler Toledo, 2008. Density determination kit for excellence XP/XS analytical balances.http://us.mt.com/us/en/home/supportive content/product documentation/operati

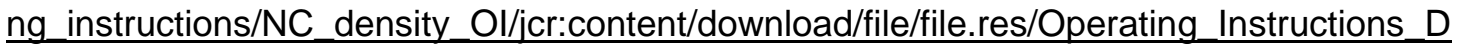
ensity\%20Kit (OP-EN).pdf 
Mysen, B.O., 1987. Magmatic silicate melts, in: Mysen, B. O. (Ed.), Magmatic processes: Physicochemical principles, Special Publication No. 1. The Geochemical Society, University Park, Pennsylvania, pp. 375-399.

Mysen, B., Richet, P., (2005). Silicate glasses and melts. Developments in Geochemistry, 10 . Amsterdam.

Papale, P., 1999. Strain-induced magma fragmentation in explosive eruptions. Nature 397, 425-428.

Paterson, M.S., 1982. The determination of hydroxyl by infrared absorption in quartz, silicate glasses and similar materials. Bull. Mineral. 105, 20-29.

Pocklington, H.C., 1940. Rough measurements of high viscosities. Proc. Cambridge Phil. Soc. 36, 507-508.

Richet, P., Whittington, A., Holtz, F., Behrens, H., Ohlhorst, S., Wilke, M., 2000. Water and the density of silicate glasses. Contrib. Mineral. Petrol. 138, 337-347.

Rivers, M.L., Carmichael, I.S.E., 1987. Ultrasonic studies of silicate melts. J. Geophys. Res. 92, 9247-9270.

Romano, C., Poe, B., Mincione, V., Hess, K.-U., Dingwell, D.B., 2001. The viscosities of dry and hydrous $\mathrm{XAISi}_{3} \mathrm{O}_{8}\left(\mathrm{X}=\mathrm{Li}, \mathrm{Na}, \mathrm{K}, \mathrm{Ca}_{0.5}, \mathrm{Mg}_{0.5}\right)$ melts. Chem. Geol. 174, 115-132.

Roux, J., Lefèvre, A., 1992. A fast-quench device for internally heated pressure vessels. Eur. J. Mineral. 4, 279-281.

Sandland, T.O., Du, L.-S., Stebbins, J.F., Webster, J.D., 2004. Structure of Cl-containing silicate and aluminosilicate glasses: $\mathrm{A}{ }^{35} \mathrm{Cl}$ MAS-NMR study. Geochim. Cosmochim. Acta 68, 5059-5069.

Scaillet, B., Holtz, F., Pichavant, M., 1998. Phase equilibrium constraints on the viscosity of silicic magmas: 1. Volcanic-plutonic comparison. J. Geophys. Res. 103, 27257-27266.

Schaller, T., Dingwell, D.B., Keppler, H., Knöller, W., Merwin, L., Sebald, A., 1992. Fluorine in silicate glasses: A multinuclear magnetic resonance study. Geochim. Cosmochim. Acta 56, 701-707.

Shaw, H.R., 1963. Obsidian- $\mathrm{H}_{2} \mathrm{O}$ viscosities at 1000 and 2000 bars in the temperature range $700^{\circ}$ to $900^{\circ} \mathrm{C}$. J. Geophys. Res. $68,6337-6343$. 
Schmidt, B.C., and Behrens, H., 2008. Water solubility in phonolite melts: Influence of melt composition and temperature. Chem. Geol. 256, 259-268.

Schmidt, B.C., Riemer, T., Kohn, S.C., Holtz, F., Dupree, R., 2001. Structural implications of water dissolution in haplogranitic glasses from NMR spectroscopy: Influence of total water content and mixed alkali effect. Geochim. Cosmochim. Acta 65, 2949-2964.

Schmidt, B.C., Blum-Oeste, N., Flagmeier, J., 2013. Water diffusion in phonolite melts. Geochim. Cosmochim. Acta 107, 220-230.

Sparks, R.S.J., Barclay, J., Jaupart, C., Mader, H.M., Phillips, J.C., 1994. Physical aspects of magmatic degassing I. Experimental and theoretical constraints on vesiculation, in: Carroll, M.R., Holloway, J.R. (Eds.), Volatiles in Magmas, Reviews in Mineralogy 30. The Mineralogical Society of America, Washington D.C., pp. 413-446.

Scholze, H., 1960. Zur Frage der Unterscheidung von $\mathrm{H}_{2} \mathrm{O}-$ Molekeln und $\mathrm{OH}-G r u p p e n$ in Gläsern und Mineralien. Naturwissenschaften 47, 226-227.

Stebbins, J.F., Zeng, Q., 2000. Cation ordering at fluoride sites in silicate glasses: a high-resolution ${ }^{19}$ F NMR study. J. Non-Cryst. Solids 262, 1-5.

Stolper, E., 1982. Water in silicate glasses: An infrared spectroscopic study. Contrib. Mineral. Petrol. 81, 1-17.

Thompson, L.M., Stebbins, J.F., 2011. Non-bridging oxygen and high-coordinated aluminum in metaluminous and peraluminous calcium and potassium aluminosilicate glasses: High-resolution ${ }^{17} \mathrm{O}$ and ${ }^{27} \mathrm{Al}$ MAS NMR results. Am. Mineral. 96, 841-853.

Toplis, M.J., Dingwell, D.B., Lenci, T., 1997. Peraluminous viscosity maxima in $\mathrm{Na}_{2} \mathrm{O}-\mathrm{Al}_{2} \mathrm{O}_{3}-\mathrm{SiO}_{2}$ liquids: The role of triclusters in tectosilicate melts. Geochim. Cosmochim. Acta 61, 2605-2612.

Watson, E.B., Wark, D.A., Price, J.D., Van Orman, J.A., 2002. Mapping the thermal structure of solid-media pressure assemblies. Contrib. Mineral. Petrol. 142, 640-652.

Weast, R.C., 1972. Handbook of physics and chemistry. CRC Press, Cleveland.

Webb, S.L., 2011. Configurational heat capacity and viscosity of $(\mathrm{Mg}, \mathrm{Ca}, \mathrm{Sr}, \mathrm{Ba}) \mathrm{O}-\mathrm{Al}_{2} \mathrm{O}_{3}-\mathrm{SiO}_{2}$ melts. Eur. J. Mineral. 23, 487-497.

Webb, S.L., Banaszak, M., Köhler, U., Rausch, S., Raschke, G., 2007. The viscosity of $\mathrm{Na}_{2} \mathrm{O}-$ $\mathrm{CaO}-\mathrm{Al}_{2} \mathrm{O}_{3}-\mathrm{SiO}_{2}$ melts. Eur. J. Mineral. 19, 681-692. 
Whittington, A., Richet, P., Linard, Y., Holtz, F., 2001. The viscosity of hydrous phonolites and trachytes. Chem. Geol. 174, 209-223.

Yue, Y., von der Ohe, R., Jensen, S. L., 2004. Fictive temperature, cooling rate, and viscosity of glasses. J. Chem. Phys. 120, 8053-8059.

Zeng, Q., Stebbins, J.F., 2000. Fluoride sites in aluminosilicate glasses: High-resolution ${ }^{19}$ F NMR results. Am. Mineral. 85, 863-867.

Zeng, Q., Nekvasil, H., Grey, C.P., 2000. In support of a depolymerization model for water in sodium aluminosilicate glasses: Information from NMR spectroscopy. Geochim. Cosmochim. Acta 64, 883-896.

Zimova, M., Webb, S.L., 2006. The effect of chlorine on the viscosity of $\mathrm{Na}_{2} \mathrm{O}-\mathrm{Fe}_{2} \mathrm{O}_{3}-\mathrm{Al}_{2} \mathrm{O}_{3}-\mathrm{SiO}_{2}$ melts. Am. Mineral. 91, 344-352.

Zimova, M., Webb, S.L., 2007. The combined effects of chlorine and fluorine on the viscosity of aluminosilicate melts. Geochim. Cosmochim. Acta 71, 1553-1562. 
4. Fluorine speciation as a function of composition in peralkaline and peraluminous $\mathrm{Na}_{2} \mathrm{O}-\mathrm{CaO}-\mathrm{Al}_{2} \mathrm{O}_{3}-\mathrm{SiO}_{2}$ glasses:

\section{A multinuclear NMR study.}

Amrei Baasner, Burkhard C. Schmidt, Ray Dupree \& Sharon L. Webb

Submitted to Geochimica Cosmochimica Acta on $27^{\text {th }}$ March 2013

Status August 2013: Accepted, requires revision*

* Some of the reviewers` and editor's comments regarding spelling and grammar mistakes were already included. 


\section{Credits}

The scientific work and the writing for the publication

Baasner, A., Schmidt, B.C., Dupree, R., Webb, S.L.,2014a. Fluorine speciation as a function of composition in peralkaline and peraluminous $\mathrm{Na}_{2} \mathrm{O}-\mathrm{CaO}-\mathrm{Al}_{2} \mathrm{O}_{3}-\mathrm{SiO}_{2}$ glasses: A multinuclear NMR study. Geochim. Cosmochim. Acta 132, 151-169. (Status August 2013: accepted, requires revision).

\section{was conducted by}

\section{Amrei Baasner}

o Synthesis of the glasses containing both, $\mathrm{F}$ and $\mathrm{Cl}$, and glasses doped with $\mathrm{CoO}$ at $1 \mathrm{~atm}$

o Synthesis of the glasses made under pressure in the internally heated pressure vessel

- Electron microprobe analysis

o IR spectroscopy

o Participation in the acquisition of most NMR MAS spectra except the ${ }^{19} \mathrm{~F}$ MAS NMR spectra of the hydrous fluorine-bearing samples at $2.3 \mathrm{~T}$ and the ${ }^{27} \mathrm{Al}$ MAS NMR spectra at $20 \mathrm{~T}$

- Evaluation of all MAS NMR spectra

- Figures, tables and most of the text

o most of the ideas presented in the discussion and conclusion section

Burkhard C. Schmidt

- General laboratory trouble shooting and support

o Supporting the acquisition of the MAS NMR spectra

o Some of the ideas presented in the discussion and conclusion section

o Correction and improvement of the figures, tables and text

Ray Dupree

o Supporting the acquisition of the MAS NMR spectra

o Acquisition of the ${ }^{19} \mathrm{~F}$ MAS NMR spectra of the hydrous fluorine-bearing samples at $2.3 \mathrm{~T}$ and the ${ }^{27} \mathrm{Al}$ MAS NMR spectra at $20 \mathrm{~T}$

o Some of the ideas presented in the discussion and conclusion section

o Correction and improvement of the figures, tables and text

Sharon L. Webb

o Synthesis of the glasses containing either $\mathrm{F}$ or $\mathrm{Cl}$ without $\mathrm{CoO}$ at $1 \mathrm{~atm}$

o Some of the ideas presented in the discussion and conclusion section

o Correction and improvement of the figures, tables and text 


\section{Abstract}

The incorporation mechanisms of fluorine $(F)$ into $\mathrm{Na}_{2} \mathrm{O}-\mathrm{CaO}$ aluminosilicate glasses with - $65 \mathrm{~mol} \% \mathrm{SiO}_{2}$ (model system for phonolites) and their influence on structure were investigated by magic angle spinning (MAS) nuclear magnetic resonance (NMR) spectroscopy. ${ }^{19} \mathrm{~F}$ MAS NMR spectra of fluorine-bearing peralkaline $\mathrm{Na}_{2} \mathrm{O}-\mathrm{CaO}-\mathrm{Al}_{2} \mathrm{O}_{3}-\mathrm{SiO}_{2}$ glasses with up to $6.2 \mathrm{~mol} \%$ fluorine (F) show five F sites: F-Ca(n) at $\sim-113$ ppm, Si-F-Na(n) or Al-F-Ca(n) at -146 ppm, Al-F-Al at $\sim-168 \mathrm{ppm}, \mathrm{Al}-\mathrm{F}-\mathrm{Na}(\mathrm{n})$ at $\sim-188 \mathrm{ppm}$ and $\mathrm{F}-\mathrm{Na}(\mathrm{n})$ at $\sim-225 \mathrm{ppm}$ ("n" indicates that the number of atoms is variable or unclear). $\mathrm{F}-\mathrm{Ca}(\mathrm{n})$ is the most abundant site which is remarkable as $\mathrm{Ca}$ is the least common cation in the glasses. The fraction of $\mathrm{F}-\mathrm{Ca}(\mathrm{n})$ sites increases from 42 to $53 \%$ with increasing $\mathrm{F}$ content from 1.2 to $6.2 \mathrm{~mol} \%$. Such a $\mathrm{F}$ speciation has not been reported before for any other aluminosilicate glasses. The addition of up to $16.5 \mathrm{~mol} \%$ (5.3 wt\%) water strongly affects $\mathrm{F}$ speciation in peralkaline glasses and results in a decrease in the fraction of F-Al sites compared to $\mathrm{F}-\mathrm{Ca}(\mathrm{n})$ sites. It seems that hydroxyl groups $(\mathrm{OH})$ and $\mathrm{F}$ prefer the same Al environments and that $\mathrm{F}$ cannot compete with $\mathrm{OH}$.

${ }^{19} \mathrm{~F}$ MAS NMR spectra of peraluminous $\mathrm{Na}_{2} \mathrm{O}-\mathrm{CaO}-\mathrm{Al}_{2} \mathrm{O}_{3}-\mathrm{SiO}_{2}$ glasses with up to $18.3 \mathrm{~mol} \% \mathrm{~F}$ show three F sites: Si-F-Na(n) or Al-F-Ca(n) at -149 ppm, Al-F-Al at -170 ppm and Al-F-Na(n) at $\sim-190 \mathrm{ppm}$. Al-F-Na(n) is the most abundant site with a fraction of 54 to $61 \%$. The $\mathrm{F}$ speciation also changes with the $\mathrm{F}$ concentration, with a minimum in Al-F-Na(n) sites between 3.5 and $9.7 \mathrm{~mol} \% \mathrm{~F}$

Fluorine has only a small effect on the ${ }^{23} \mathrm{Na}$ and ${ }^{29} \mathrm{Si}$ MAS NMR spectra. ${ }^{27} \mathrm{Al}$ MAS NMR spectra of the peralkaline glasses show only four-coordinated Al while in the peraluminous glasses $\sim 5 \%$ of the Al was found to be five-coordinated. The amount of five-coordinate Al does not change with increasing $\mathrm{F}$ content, but the environment becomes more symmetric.

F speciation in $\mathrm{Na}_{2} \mathrm{O}-\mathrm{CaO}-\mathrm{Al}_{2} \mathrm{O}_{3}-\mathrm{SiO}_{2}$ glasses is strongly affected by composition, water content and $\mathrm{F}$ concentration. 


\subsection{Introduction}

Depending on melt composition and geological setting, natural magmatic silicate melts can contain various amounts of fluorine $(F)$ reaching several wt\% in highly evolved magmas (e.g. phonolites up to $1.3 \mathrm{wt} \%$, tin and topaz granites up to $7 \mathrm{wt} \% \mathrm{~F}$, e.g. Aiuppa et al. 2009). Therefore, fluorine (F) can be considered as the second most important volatile in such melts after water. Fluorine significantly affects physical properties and phase relations of silicate melts and its presence decreases density and viscosity, (e.g Dingwell et al., 1993; Dingwell et al. 1985; Giordano et al. 2004; Baasner et al., 2013a; Bartels et al., 2013), lowers solidus and affects liquidus temperatures of granitic melts (e.g. Bailey, 1977; Manning, 1981) and increases their water solubility (e.g. Holtz et al., 1993).

Incorporation mechanisms of $F$ into (alumino)silicate melts and glasses have been investigated in several NMR spectroscopic studies (e.g. Kohn et al., 1991; Schaller et al., 1992; Stebbins and Zeng, 2000; Zeng and Stebbins, 2000; Kiczenski and Stebbins, 2002; Stebbins et al., 2000; Mysen et al., 2004; Stamboulis et al., 2005; Karpukhina et al., 2008; Brauer et al., 2009) with the result that many different F-environments have been found to exist, depending on the specific glass composition. Fluorine in a melt/glass replaces $\mathrm{O}$ via two main incorporation mechanisms: The bonding between $\mathrm{F}$ and network-forming cations ( $\mathrm{Si}, \mathrm{Al}$ ) and the bonding between $\mathrm{F}$ and network-modifying cations (e.g. $\mathrm{Na}, \mathrm{K}, \mathrm{Ca}$ ) by forming salt-like environments.

In binary alkali or alkaline earth silicate glasses $F$ bonds preferentially to the network-modifying cations by e.g. forming $\mathrm{F}-\mathrm{Na}(\mathrm{n})$ or $\mathrm{F}-\mathrm{Ca}(\mathrm{n})$ units and to a much lesser extent to Si by e.g. forming Si-F-Na(n) units (" $n$ " indicates that the number of atoms is variable or uncertain) (Zeng and Stebbins, 2000; Kiczenski and Stebbins, 2002; Brauer et al., 2009). In mixed binary alkali or alkaline earth silicate glasses, Stebbins and Zeng (2000) found that F preferentially bonds to the higher field strength network-modifying cation $(\mathrm{Ca}>\mathrm{Na}>\mathrm{K})$.

In sodium aluminosilicate glasses $\mathrm{F}$ predominantly bonds to Al forming Al-F-Na(n) sites with minor amounts of Si-F-Na(n) and F-Na(n) sites (Zeng and Stebbins, 2000; Mysen et al., 2004). F-Na(n) sites are only present when the glasses are peralkaline 
$\left(\mathrm{Na}_{2} \mathrm{O} /\left[\mathrm{Na}_{2} \mathrm{O}+\mathrm{Al}_{2} \mathrm{O}_{3}\right]>0.5\right)$ and their fraction increases with increasing $\mathrm{Na} / \mathrm{Al}$ ratio (Zeng and Stebbins, 2000; Mysen et al., 2004). This indicates that the existence of $\mathrm{F}-\mathrm{Na}(\mathrm{n})$ sites is related to network-modifying $\mathrm{Na}$ cations creating non-bridging oxygens mostly at Si tetrahedra (e.g. Lee, 2004; Lee and Stebbins, 2009) and not to $\mathrm{Na}$ cations charge-balancing $\mathrm{Al}$ tetrahedra (tetrahedra means here Si/Al in tetrahedral coordination with 4 oxygens) (Zeng and Stebbins, 2000; Mysen et al., 2004).

In calcium aluminosilicate glasses $\mathrm{F}$ exists mainly in $\mathrm{F}-\mathrm{Ca}(\mathrm{n})$ and $\mathrm{Al}-\mathrm{F}-\mathrm{Ca}(\mathrm{n})$ sites. $\mathrm{F}-\mathrm{Ca}(\mathrm{n})$ sites were observed in metaluminous (defined here as $\left.\mathrm{CaO} /\left[\mathrm{CaO}+\mathrm{Al}_{2} \mathrm{O}_{3}\right]>0.5\right)$ glasses as well as in anorthite glass $\left(\mathrm{CaAlSi}{ }_{2} \mathrm{O}_{8}\right)$, where almost all $\mathrm{Ca}$ is charge-balancing $\mathrm{Al}$ (Zeng and Stebbins, 2000; Kiczenski and Stebbins, 2002; Karpukhina et al., 2008). In metaluminous calcium aluminosilicate glasses the dominant site is F-Ca(n) (Karpukhina et al., 2008), while in anorthitic glasses the dominant site is F-Al-Ca(n) (Zeng and Stebbins, 2000; Kiczenski and Stebbins, 2002). Kiczenski and Stebbins (2002) found evidence for Si-F-Ca(n) sites in anorthitic glass as did Stamboulis et al. (2005) in phosphorous-bearing $\mathrm{Na}_{2} \mathrm{O}-\mathrm{CaO}-\mathrm{SrO}$ aluminosilicate glasses.

Karpukhina et al. (2008) reported that the fraction of Al-F-Ca(n) sites increases compared to the $\mathrm{F}-\mathrm{Ca}(\mathrm{n})$ sites with an increasing amount of $\mathrm{F}$ in metaluminous calcium aluminosilicate glasses with a fixed $\mathrm{CaO} /\left[\mathrm{CaO}+\mathrm{Al}_{2} \mathrm{O}_{3}\right]$ ratio. In contrast, Schaller et al. (1992) found no evidence that $F$ speciation depends on $F$ concentration in sodium aluminosilicate glasses. Schaller et al. (1992) also observed no speciation change of $F$ in haplogranitic glasses due to the dissolution of water.

In some sodium and calcium aluminosilicate glasses $F$ not only bonds to five- and six-coordinated $\mathrm{Al}\left(\mathrm{Al}^{\mathrm{V}}\right.$ and $\left.\mathrm{Al}^{\mathrm{VI}}\right)$ but also leads to the formation of higher coordinated Al (Kohn et al., 1991; Stebbins et al., 2000), even if the compositions are peralkaline and significant amounts of higher coordinated aluminium are not expected (at least at $1 \mathrm{~atm})$ (e.g. Lee et al., 2004; Neuville et al., 2006). Significant amounts of higher coordinated Al are usually only present in peraluminous aluminosilicate glasses (at $1 \mathrm{~atm}$ ), where not enough network-modifying cations (e.g. $\mathrm{Na}, \mathrm{Ca}$ ) are present to charge-balance all of the Al tetrahedra (e.g. $\left.\left[\mathrm{Na}_{2} \mathrm{O}+\mathrm{CaO}\right] /\left[\mathrm{Na}_{2} \mathrm{O}+\mathrm{CaO}+\mathrm{Al}_{2} \mathrm{O}_{3}\right]<0.5\right)$ (e.g. Schmücker et al., 1997; Thompson and Stebbins, 2011). 
Although the $\mathrm{F}$ speciation in some glass compositions have already been studied with NMR spectroscopy, there is no study up to now which investigates F speciation in peralkaline and peraluminous mixed sodium calcium aluminosilicate glasses with different $F$ concentrations. However these are important compositions as highly evolved natural aluminosilicate melts/glasses contain in addition to monovalent cations (e.g. $\mathrm{Na}^{+}$) also minor amounts of divalent cations (e.g. $\mathrm{Ca}^{2+}$ ).

Our work focuses on how F speciation depends on Al content, on the F amount and on the presence of water in peralkaline and peraluminous mixed $\mathrm{Na}_{2} \mathrm{O}-\mathrm{CaO}$ aluminosilicate glasses. We have also investigated how $\mathrm{F}$ influences the $\mathrm{Na}, \mathrm{Al}$ and Si environments in peraluminous and peralkaline glasses.

\subsection{Methods}

\subsubsection{Starting materials}

Anhydrous fluorine-free and fluorine-bearing peralkaline (NACS) and peraluminous (ANCS) $\mathrm{Na}_{2} \mathrm{O}-\mathrm{CaO}$ aluminosilicate glasses were synthesised from powdered oxides, carbonates, $\mathrm{CaF}_{2}, \mathrm{NaF}$ and $\mathrm{NH}_{4} \mathrm{~F}$. The powder mixtures were decarbonated for $12 \mathrm{~h}$ at $1173 \mathrm{~K}$ at $1 \mathrm{~atm}$. The decarbonated powders were melted at $1473-1923 \mathrm{~K}$ at 1 atm in Pt crucibles in an $1 \mathrm{~atm}$ furnace for several hours. Chemical homogenisation was achieved by crushing the glasses several times and remelting them. Using this method about half of the added $F$ was dissolved in the melt. Under these conditions we could dissolve up to $6.2 \mathrm{~mol} \% \mathrm{~F}$ in the peralkaline melts and $18.3 \mathrm{~mol} \% \mathrm{~F}$ in the peraluminous melts. Two of the nominally dry fluorine-bearing peralkaline glasses with 2.4 and 2.7 mol\% F (NACS 2.4F and NACS 2.7F) were synthesised in Pt capsules under pressure in an internally heated pressure vessel (IHPV) at $150 \mathrm{MPa}$ and 1473 - $1523 \mathrm{~K}$ for 2 - 3 days. This approach was necessary in order to produce the designated $\mathrm{F}$ content of the melts. Most of the glasses were doped with less than $0.1 \mathrm{wt} \% \mathrm{CoO}$ to enhance spin lattice relaxation during NMR measurements.

Synthesis experiments to dissolve 10 and $18 \mathrm{~mol} \% \mathrm{~F}$ in the peralkaline melts in the IHPV at $150 \mathrm{MPa}$ and 1473 - $1523 \mathrm{~K}$ with a runtime of 2 - 3 days and a rapid quench of $100-150 \mathrm{~K} \mathrm{~s}^{-1}$ (e.g. Roux and Lefèvre, 1992) were not successful. The glasses contained $\mathrm{CaF}_{2}$ crystals, which were detected with ${ }^{19} \mathrm{~F}$ NMR spectroscopy and X-Ray 
diffraction. The crystals are finely distributed and very small as they were not observed by optical microscopy or with the electron microprobe. These samples were not used for further evaluation.

Hydrous samples of the peralkaline glass NACS 2.4F with $1.5 \pm 0.2$ and $5.3 \pm 0.6 \mathrm{wt} \%$ water were produced in an IHPV in Pt capsules at 150 - $250 \mathrm{MPa}$ and 1473 - $1523 \mathrm{~K}$ with a runtime of 2 - 3 days and a rapid quench at the end. We did not measure NMR spectra of hydrous peraluminous glasses, as their liquidus temperatures are with $>1823 \mathrm{~K}$ too high for synthesis in an IHPV.

The compositions of the dry glass samples were determined using a JEOL JXA-8900RL electron microprobe. Eight to ten measurements per sample were obtained using a $15 \mathrm{kV}$ and $15 \mathrm{nA}$ beam defocused to $30 \mu \mathrm{m}$. Tables $1 \mathrm{a}-\mathrm{b}$ show the compositions of the glasses in mol\% oxides, and also in atom\% (at\%). The notation in at\% takes into account that, because of charge balance, there is one $\mathrm{O}^{2-}$ less in the glass for two $\mathrm{F}^{-}$. Table $1 \mathrm{a}$ also contains the $\left(\mathrm{Na}_{2} \mathrm{O}+\mathrm{CaO}\right) /\left(\mathrm{Na}_{2} \mathrm{O}+\mathrm{CaO}+\mathrm{Al}_{2} \mathrm{O}_{3}\right)$ ratio, which is referred as $R$ value (e.g. Thompson and Stebbins, 2011) or the gamma value (e.g. Toplis et al., 1997; Webb et al., 2007) in the literature. If $R>0.5$ the glasses are peralkaline and if $R<0.5$ the glasses are peraluminous. The fluorine-free peralkaline glass (NACS) has a non-bridging oxygen per tetrahedron value (NBO/T) of 0.24 and the fluorine-free peraluminous glass (ANCS) has a NBO/T value of -0.08 . NBO/T is calculated after Mysen (1987) from the number of oxygens (O) and the number of network-building cations $(T=S i, A I): N B O / T=(2 O-4 T) / T$. $\mathrm{NBO} / \mathrm{T}=4$ means the glass/melt is completely depolymerised and all $\mathrm{O}$ are non-bridging oxygens (NBO). $\mathrm{NBO} / \mathrm{T}=0$ means the glass/melt is completely polymerised and all $\mathrm{O}$ are bridging oxygens (BO). Peraluminous glasses have negative NBO/T values, because there are not enough network-modifying cations to charge-balance Al.

The water contents in the hydrous samples were measured with near infrared (NIR) spectroscopy using the combined stretching and bending vibrations of hydroxyl groups $(\mathrm{X}-\mathrm{OH})$ at $4500 \mathrm{~cm}^{-1}$ and molecular water $\left(\mathrm{H}_{2} \mathrm{O}\right)$ at $5200 \mathrm{~cm}^{-1}$ as described by Bartholomew et al. (1980) (data is not presented in this study). The extinction coefficients for the peralkaline melts $\varepsilon_{5200}=0.956 \pm 0.021 \mathrm{~L} \mathrm{~mol}^{-1} \mathrm{~cm}^{-1}$ and $\varepsilon_{4500}=0.983 \pm 0.048 \mathrm{~L} \mathrm{~mol}^{-1} \mathrm{~cm}^{-1}$ were determined by an IR-calibration on the fluorine-free peralkaline glass samples with 1 - 6 wt\% water (Baasner et al., 2013b). 
The water contents of the glasses for the IR-calibration were measured independently with Karl-Fischer-Titration (KFT) (University of Hannover) (detailed description of the device in Behrens et al., 1996).

\subsubsection{NMR techniques}

\section{${ }^{19} \mathrm{~F}$ MAS NMR}

${ }^{19} \mathrm{~F}$ magic angle spinning (MAS) spectra were collected at $94.146 \mathrm{MHz}$ on an $100 \mathrm{MHz}$ Chemagnetics Infinity (2.3 T) and at 282.241 MHz on a $300 \mathrm{MHz}$ Varian Infinity Plus (7T) spectrometer. As reference material we used $\mathrm{C}_{2} \mathrm{~F}_{4}$ polytetrafluoroethylene (PTFE) that was set to $-123.17 \mathrm{ppm}$ relative to trichloro-fluoro-methane $\mathrm{CFCl}_{3}$. The spectra on the $300 \mathrm{MHz}$ spectrometer, and the spectrum of the sample NACS $6.2 \mathrm{~F}$ on the $100 \mathrm{MHz}$ spectrometer were collected with a probe with very low $F$ background. A test with an empty rotor showed no significant background. The spectra on the $300 \mathrm{MHz}$ spectrometer were collected with a spinning speed of $26 \mathrm{kHz}$ in a $2.5 \mathrm{~mm}$ rotor, a pulse length of $1 \mu \mathrm{s}$ and 400 - 8480 acquisitions, depending on F content. Different recycle delays for each composition were tested carefully to avoid saturation of certain sites. The recycle delays ranged from $2.5-30 \mathrm{~s}$ and increased with decreasing $\mathrm{F}$ content. With a maximum spinning speed of $26 \mathrm{kHz}$ for the $300 \mathrm{MHz}$ spectrometer we were not able to move all spinning sidebands out of the region of the central bands. Therefore, $a$ spectrum of the sample NACS 6.2F was also collected on a $100 \mathrm{MHz}$ spectrometer with a spinning speed of $17.5 \mathrm{kHz}$, in a $2.5 \mathrm{~mm}$ rotor, a pulse length of $1 \mu \mathrm{s}$, a recycle delay of $5 \mathrm{~s}$ and 167560 acquisitions. Because of the lower magnetic field this spinning speed was sufficient to move all spinning sidebands out of the central band.

The spectra of the dry and hydrous samples of NACS $2.4 \mathrm{~F}$ were collected on the $100 \mathrm{MHz}$ spectrometer with a probe that had a significant $\mathrm{F}$ background (due to the failure of the probe with low $F$ background). An echo sequence was used in an effort to remove the small background. For the dry sample (NACS 2.4F) we used a first pulse length of $1 \mu \mathrm{s}$, with an echo delay of $60 \mu \mathrm{s}$ (NACS 2.4F) and a second pulse length of $2 \mu \mathrm{s}$. For the hydrous samples (NACS $2.4 \mathrm{~F}+\mathrm{H}_{2} \mathrm{O}$ ) we used a first pulse length of $0.75 \mu \mathrm{s}$, an echo delay of $70 \mu \mathrm{s}$ and a second pulse length of $1.5 \mu \mathrm{s}$. The spectra were collected with a spinning speed of $14.5 \mathrm{kHz}$ in a $3.2 \mathrm{~mm}$ rotor and 
34,350-100,000 acquisitions. This spinning speed was sufficient to move all sidebands out of the central bands. The spectrum of an empty rotor run showed that the background was not completely removed by the echo sequence and the remaining small background from the empty rotor spectrum was subtracted from the sample spectra.

\section{${ }^{23} \mathrm{Na}$ MAS NMR}

${ }^{23} \mathrm{Na}$ MAS spectra were collected at $132.286 \mathrm{MHz}$ on a $500 \mathrm{MHz}$ Bruker Avance III (11.7 T) spectrometer. Solid $\mathrm{NaCl}$ was used as the reference material that was set to $-7 \mathrm{ppm}$ relative to aqueous $\mathrm{NaCl}$ solution. The spectra were collected with a spinning speed of $26 \mathrm{kHz}$ in a $2.5 \mathrm{~mm}$ rotor, a pulse length of $1.5 \mu \mathrm{s}$, a recycle delay of $1 \mathrm{~s}$ and 60 - 660 acquisitions.

\section{${ }^{27}$ Al MAS NMR}

${ }^{27} \mathrm{Al}$ MAS spectra were collected at $78.197 \mathrm{MHz}$ on a $300 \mathrm{MHz}$ Varian Infinity Plus (7 T), at 130.301 MHz on a $500 \mathrm{MHz}$ Bruker Avance III (11.7 T) and at 221.550 MHz on an $850 \mathrm{MHz}$ Bruker Avance III (20 T) spectrometer. Yttrium aluminium garnet (YAG) was used as the reference material that was set to $0.7 \mathrm{ppm}$ relative to $1 \mathrm{M}$ aqueous $\mathrm{AlCl}_{3}$ solution. The spectra on the $300 \mathrm{MHz}$ spectrometer were collected with a spinning speed of $20-26 \mathrm{kHz}$ in $3.2 \mathrm{~mm}$ and $2.5 \mathrm{~mm}$ rotors, a pulse length of $1.5 \mu \mathrm{s}$, a recycle delay of $1 \mathrm{~s}$ and 1800 acquisitions. The spectra on the $500 \mathrm{MHz}$ spectrometer were collected with a spinning speed of $26 \mathrm{kHz}$ in a $2.5 \mathrm{~mm}$ rotor, a pulse length of $0.75 \mu \mathrm{s}$, a recycle delay of $1 \mathrm{~s}$ and $1600-16000$ acquisitions. The spectra on the $850 \mathrm{MHz}$ spectrometer were collected with a spinning speed of $20 \mathrm{kHz}$ in a $3.2 \mathrm{~mm}$ rotor, a pulse length of $0.8 \mu \mathrm{s}$, a recycle delay of $2 \mathrm{~s}$ and 84 acquisitions. 


\section{${ }^{29}$ Si MAS NMR}

${ }^{29} \mathrm{Si}$ MAS spectra were collected at $59.615 \mathrm{MHz}$ on a $300 \mathrm{MHz}$ Varian Infinity Plus (7 T) spectrometer. Kaolinite was used as reference material that was set to $-91.5 \mathrm{ppm}$ relative to tetramethylsilane $\left(\mathrm{TMS}, \mathrm{Si}\left(\mathrm{CH}_{3}\right)_{4}\right)$. The spectra were collected with a spinning speed of $4 \mathrm{kHz}$ in a $7 \mathrm{~mm}$ rotor, a pulse length of $3.5 \mu \mathrm{s}$, a recycle delay of 30 - 60 s and 172 - 2544 acquisitions. 
Table 1a. Electron microprobe (EMP) analysis as oxide components of the glass samples with the $2 \sigma$ standard deviation normalised to 100 mol\% ${ }^{\mathrm{a}}$.

\begin{tabular}{|c|c|c|c|c|c|c|c|c|c|c|c|c|}
\hline & $\begin{array}{c}\mathrm{SiO}_{2} \\
{[\mathrm{~mol} \%]}\end{array}$ & $\begin{array}{c}2 \sigma \\
{[\mathrm{mol} \%]}\end{array}$ & $\begin{array}{c}\mathrm{Al}_{2} \mathrm{O}_{3} \\
{[\mathrm{~mol} \%]}\end{array}$ & $\begin{array}{c}2 \sigma \\
{[\mathrm{mol} \%]}\end{array}$ & $\begin{array}{c}\mathrm{CaO} \\
{[\mathrm{mol} \%]}\end{array}$ & $\begin{array}{c}2 \sigma \\
{[\mathrm{mol} \%]}\end{array}$ & $\begin{array}{c}\mathrm{Na}_{2} \mathrm{O} \\
{[\mathrm{mol} \%]}\end{array}$ & $\begin{array}{c}2 \sigma \\
{[\mathrm{mol} \%]}\end{array}$ & $\begin{array}{c}\mathrm{F} \\
{[\mathrm{mol} \%]}\end{array}$ & $\begin{array}{c}2 \sigma \\
{[\mathrm{mol} \%]}\end{array}$ & $\begin{array}{c}\text { Sum } \\
{[\mathrm{mol} \%]}\end{array}$ & $\mathrm{R}^{\mathrm{c}}$ \\
\hline \multicolumn{13}{|l|}{ Peralkaline } \\
\hline $\mathrm{NACS}^{\mathrm{b}}$ & 65.52 & 1.42 & 11.94 & 1.02 & 5.53 & 0.36 & 17.02 & 0.57 & 0.00 & 0.01 & 100.00 & 0.65 \\
\hline NACS $1.2 F^{b}$ & 65.32 & 0.74 & 11.48 & 0.20 & 5.59 & 0.12 & 16.43 & 0.61 & 1.17 & 0.53 & 100.00 & 0.66 \\
\hline NACS $2.4 F^{b}$ & 65.43 & 0.27 & 11.45 & 0.12 & 5.52 & 0.14 & 15.17 & 0.28 & 2.43 & 0.24 & 100.00 & 0.64 \\
\hline NACS $2.7 F^{b}$ & 63.63 & 0.44 & 11.66 & 0.20 & 5.59 & 0.12 & 16.40 & 0.28 & 2.72 & 0.10 & 100.00 & 0.65 \\
\hline NACS $6.2 F^{b}$ & 63.30 & 0.68 & 11.22 & 0.16 & 5.36 & 0.12 & 13.92 & 0.21 & 6.20 & 0.71 & 100.00 & 0.63 \\
\hline \multicolumn{13}{|l|}{ Peraluminous } \\
\hline ANCS & 65.93 & 1.63 & 19.20 & 1.07 & 4.19 & 0.39 & 10.67 & 0.25 & 0.02 & 0.08 & 100.00 & 0.44 \\
\hline ANCS $1.1 F^{b}$ & 64.38 & 0.22 & 19.36 & 0.20 & 3.65 & 0.10 & 11.52 & 0.13 & 1.09 & 0.24 & 100.00 & 0.44 \\
\hline ANCS $3.5 F^{b}$ & 63.51 & 1.36 & 18.43 & 0.76 & 3.53 & 0.25 & 11.05 & 0.67 & 3.48 & 0.26 & 100.00 & 0.44 \\
\hline ANCS $9.7 F^{b}$ & 59.14 & 0.71 & 18.00 & 0.34 & 3.65 & 0.08 & 9.48 & 0.91 & 9.73 & 0.48 & 100.00 & 0.42 \\
\hline ANCS 18.3 & 53.12 & 0.54 & 16.26 & 0.19 & 3.11 & 0.19 & 9.27 & 0.13 & 18.25 & 0.42 & 100.00 & 0.43 \\
\hline \multicolumn{13}{|c|}{$\begin{array}{l}\text { a - Standards were: Wollastonite }=\mathrm{Si}, \mathrm{Ca} \text {; Anorthite }=\mathrm{Al} \text {; Albite }=\mathrm{Na} \text {, Topaz = F; Halite }=\mathrm{Cl} \text {; Sanidine = K, Cobalt oxide = Co. In all samples contaminations c } \\
\mathrm{K}_{2} \mathrm{O}(<0.1 \mathrm{~mol} \%) \text { from the } \mathrm{SiO}_{2} \text { and } \mathrm{Al}_{2} \mathrm{O}_{3} \text { chemicals were observed. } \\
\mathrm{b}-\mathrm{Doped} \text { with }<0.12 \mathrm{~mol} \% \mathrm{CoO} \text {. } \\
\mathrm{c}-\mathrm{R}=\left(\mathrm{Na}_{2} \mathrm{O}+\mathrm{CaO}\right) /\left(\mathrm{Na}_{2} \mathrm{O}+\mathrm{CaO}+\mathrm{Al}_{2} \mathrm{O}_{3}\right) \text { in mole fraction is an indicator for the degree of polymerisation of the melt by taking into account the number of sodium } \\
\text { and calcium that is either used for charge-balancing aluminium or creating non-bridging oxygens in the melt (e.g. Thompson and Stebbins, } 2011) \text {. If } \mathrm{R}>0.5 \text { the } \\
\text { glass is peralkaline and if } \mathrm{R}<0.5 \text { the glass is peraluminous. }\end{array}$} \\
\hline
\end{tabular}


Table 1b. Electron microprobe (EMP) analysis of the glass samples together with the $2 \sigma$ standard deviation normalised to 100 atom\% ${ }^{\mathrm{a}}$.

\begin{tabular}{|c|c|c|c|c|c|c|c|c|c|c|c|c|}
\hline & $\begin{array}{c}\mathrm{Si} \\
{[\mathrm{at} \%]}\end{array}$ & $\begin{array}{c}2 \sigma \\
{[\text { at\%] }}\end{array}$ & $\begin{array}{c}\mathrm{Al} \\
{[\mathrm{at} \%]}\end{array}$ & $\begin{array}{c}2 \sigma \\
{[\text { at\%] }}\end{array}$ & $\begin{array}{c}\mathrm{Ca} \\
{[\mathrm{at} \%]}\end{array}$ & $\begin{array}{c}2 \sigma \\
{[\mathrm{at} \%]}\end{array}$ & $\begin{array}{c}\mathrm{Na} \\
{[\mathrm{at} \%]}\end{array}$ & $\begin{array}{c}2 \sigma \\
{[\text { at\%] }}\end{array}$ & $\begin{array}{c}\mathrm{F} \\
{[\mathrm{at} \%]}\end{array}$ & $\begin{array}{c}2 \sigma \\
{[\text { at\%] }}\end{array}$ & $\begin{array}{c}\mathrm{O}^{\mathrm{c}} \\
{[\mathrm{at} \%]}\end{array}$ & $\begin{array}{l}\text { Sum } \\
\text { [at\%] }\end{array}$ \\
\hline \multicolumn{13}{|l|}{ Peralkaline } \\
\hline $\mathrm{NACS}^{\mathrm{b}}$ & 20.58 & 0.45 & 7.50 & 0.64 & 1.74 & 0.11 & 10.69 & 0.36 & 0.00 & 0.00 & 59.49 & 100.00 \\
\hline NACS $1.2 F^{b}$ & 20.77 & 0.24 & 7.30 & 0.13 & 1.78 & 0.04 & 10.45 & 0.39 & 0.37 & 0.17 & 59.32 & 100.00 \\
\hline NACS $2.4 F^{b}$ & 21.02 & 0.09 & 7.36 & 0.08 & 1.77 & 0.05 & 9.75 & 0.18 & 0.78 & 0.08 & 59.33 & 100.00 \\
\hline NACS $2.7 F^{b}$ & 20.46 & 0.14 & 7.50 & 0.13 & 1.80 & 0.04 & 10.55 & 0.18 & 0.87 & 0.03 & 58.81 & 100.00 \\
\hline NACS $6.2 F^{b}$ & 20.99 & 0.23 & 7.44 & 0.11 & 1.78 & 0.04 & 9.23 & 0.14 & 2.05 & 0.23 & 58.51 & 100.00 \\
\hline \multicolumn{13}{|l|}{ Peraluminous } \\
\hline ANCS & 19.73 & 0.49 & 11.49 & 0.64 & 1.25 & 0.12 & 6.38 & 0.15 & 0.01 & 0.02 & 61.14 & 100.00 \\
\hline ANCS $1.1 F^{b}$ & 19.37 & 0.07 & 11.65 & 0.12 & 1.10 & 0.03 & 6.93 & 0.08 & 0.33 & 0.07 & 60.62 & 100.00 \\
\hline ANCS $3.5 F^{b}$ & 19.56 & 0.42 & 11.36 & 0.47 & 1.09 & 0.08 & 6.81 & 0.41 & 1.07 & 0.08 & 60.12 & 100.00 \\
\hline ANCS $9.7 \mathrm{~F}^{\mathrm{b}}$ & 19.20 & 0.23 & 11.69 & 0.22 & 1.19 & 0.03 & 6.15 & 0.59 & 3.16 & 0.16 & 58.62 & 100.00 \\
\hline ANCS 18.3F & 18.72 & 0.19 & 11.46 & 0.13 & 1.09 & 0.07 & 6.53 & 0.09 & 6.43 & 0.15 & 55.77 & 100.00 \\
\hline
\end{tabular}

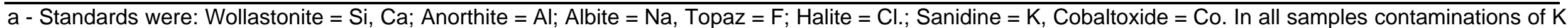
$\left(<0.03\right.$ at\%) from the $\mathrm{SiO}_{2}$ and $\mathrm{Al}_{2} \mathrm{O}_{3}$ chemicals were observed.

b - Doped with $<0.04$ at\% Co.

c - Calculated from stochiometry taking in account for two $\mathrm{F}^{-1}$ there is one less $\mathrm{O}^{-2}$ in the glass. 


\subsection{Results and Discussion}

\subsection{1. ${ }^{19} \mathrm{~F}$ sites in dry fluorine-bearing glasses}

Figure 1 shows the ${ }^{19} \mathrm{~F}$ MAS NMR spectra of the dry fluorine-bearing peralkaline and peraluminous glasses. The spectra peaks were deconvolved using the program DmFit (Massiot et al., 2002). The spectra were fitted based on the deconvolution of the spectra from the samples with the highest $F$ concentration. The isotropic chemical shift $\delta_{\text {iso }}$ and the line width FWHM (full width half maximum, related to the chemical shift distribution CSD) were held constant for peaks of the same F site. The peak parameters are given in Table 2. Where possible, the sidebands were also fitted using DmFit and their area added to that of the corresponding central band.

The spectra were found to be best fit with a line shape of $20 \%$ Lorentzian and $80 \%$ Gaussian and this was used throughout. However, using pure Gaussian peaks does not influence the general conclusions derived from the spectra. The number of spectrum peaks presented here is the minimum required to satisfactorily reproduce the spectra. It cannot be excluded that there are more than one site with similar shifts under the same envelope.

Five F sites were found in the peralkaline glasses (Fig. 1) at -109 to -117 ppm, -145 to -147 ppm, -168 ppm, -187 to -189 ppm and -222 to -228 ppm. In the peraluminous glasses three $F$ sites were found at -148 to -150 ppm, -169 to -171 ppm and -189 to $-190 \mathrm{ppm}$. The two peaks at -109 to $-117 \mathrm{ppm}$ and -222 to $-228 \mathrm{ppm}$ that are present in the peralkaline glasses are completely missing in the peraluminous glasses. A comparison of the parameters of the fitted peaks in Table 2 shows that the sites that are present in both glass types have similar $\delta_{\text {iso }}$ and CSD (line width), suggesting these $\mathrm{F}$ environments are very similar, regardless of whether the glass is peraluminous or peralkaline.

The spectrum of the sample NACS $6.2 \mathrm{~F}$ at $2.3 \mathrm{~T}$ is slightly different to the spectrum at $7 \mathrm{~T}$. In the spectrum at $2.3 \mathrm{~T}$ the peak maximum of the right peak lies at $-109 \mathrm{ppm}$, while in the spectrum at $7 \mathrm{~T}$ the maximum of this peak is at $-115 \mathrm{ppm}$ and seems to be slightly narrower. However, the resulting peak areas for the sample NACS 6.2F from the two spectra at 2.3 and $7 \mathrm{~T}$ are almost identical so that the general 
conclusions of structure based on these spectra are not influenced by the slightly different peak positions.

To assign the peaks, we used literature data for $\delta_{\text {iso }}$ of $F$ sites in crystalline phases and $a b$ initio calculations compiled in Table 3 as well as literature data for $\delta_{\text {iso }}$ of $F$ sites in glasses (Schaller et al., 1992; Stebbins and Zeng, 2000; Zeng and Stebbins, 2000; Kiczenski and Stebbins, 2002; Mysen et al., 2004; Stamboulis et al., 2005; Karpukhina et al., 2008; Brauer et al., 2009). Table 3 also provides an overview of the F sites found in this study with a short description of the possible structure.

\section{$\underline{\text { F sites at }-109 \text { to }-117 \mathrm{ppm}}$}

The peak at -109 to -117 ppm, which is only observed in our peralkaline glasses, has a broad line width of 51 to $54 \mathrm{ppm}$. It strongly overlaps with the position of four-coordinated $\mathrm{F}$ in $\mathrm{CaF}_{2}(\mathrm{~F}-\mathrm{Ca}(4))$ at $-108 \mathrm{ppm}$ (Miller, 1996), but in its high frequency tail extends also to the position of a F-Ca(n) site $(n \leq 4)$ that was found at around $-90 \mathrm{ppm}$ in calcium silicate, calcium sodium silicate, anorthitic, pure calcium aluminosilicate and phosphorous-bearing $\mathrm{Na}_{2} \mathrm{O}-\mathrm{CaO}-\mathrm{SrO}$ aluminosilicate glasses (Stebbins and Zeng, 2000; Zeng and Stebbins, 2000; Karpukhina et al., 2008; Stamboulis, 2005). However, the chemical shift of the peak at -109 to -117 ppm is too low to be only produced by a F-Ca(n) site. On the other hand, mixed four-coordinated $\mathrm{F}-\mathrm{Ca}(\mathrm{n}) / \mathrm{Na}(\mathrm{n})$ sites in glasses have a more negative chemical shift of $-142 \mathrm{ppm}$ (Stebbins and Zeng, 2000; Brauer et al., 2009). As our glasses contain Ca and $\mathrm{Na}$, it is possible that mixed $\mathrm{F}-\mathrm{Ca} / \mathrm{Na}(\mathrm{n})$ sites also contribute to the peak at -109 to $-117 \mathrm{ppm}$. Another possible $\mathrm{F}$ environment that may contribute to the peak at -109 to $-117 \mathrm{ppm}$ is a Si-F-Ca(n) site, which was observed at -123 to $-126 \mathrm{ppm}$ in phosphorous-bearing $\mathrm{Na}_{2} \mathrm{O}-\mathrm{CaO}-\mathrm{SrO}$ aluminosilicate glasses (Stamboulis et al., 2005) and in anorthitic glass (Kiczenski and Stebbins, 2002).

In sample NACS $6.2 \mathrm{~F}$ the $\mathrm{Ca} / \mathrm{F}$ ratio is $\sim 0.9$ and $\sim 50 \%$ of the $\mathrm{F}$ contributes to the peak at -109 to -117 ppm. Thus, there is not enough Ca to form $\mathrm{F}-\mathrm{Ca}(4)$ sites. This means that most of the $F$ that contributes to the site at -109 to -117 ppm must exist in sites that are either less than four-coordinated F-Ca(n), four or less coordinated mixed F-Ca(n)/Na(n) or Si-F-Ca(n) sites. The large line width of this peak, 51 to $54 \mathrm{ppm}$, means that the shift range is sufficient to cover all these possibilities. 
However, Stebbins and Zeng (2000) showed that in mixed calcium sodium silicate glasses $\mathrm{F}$ has a preference for $\mathrm{Ca}$. In addition, Si-F-Ca(n) sites have been observed only in minor amounts and are not resolved as a single peak in anorthitic and phosphorous-bearing $\mathrm{Na}_{2} \mathrm{O}-\mathrm{CaO}-\mathrm{SrO}$ aluminosilicate glasses (Kiczenski and Stebbins, 2002; Stamboulis et al., 2005). Therefore, it is probable that the peak at -109 to -117 ppm is mainly a F-Ca(n) site with minor amounts of $\mathrm{F}-\mathrm{Ca}(\mathrm{n}) / \mathrm{Na}(\mathrm{n})$ and Si-F-Ca(n) sites in the lower frequency flank.

\section{F sites at -145 to $-152 \mathrm{ppm}$}

The peak at -145 to -152 ppm has a chemical shift similar to Si-F-Na(n) sites found in the mineral malladrite $\left(\mathrm{Na}_{2} \mathrm{SiF}_{6}\right)$ as well as in sodium silicate and sodium aluminosilicate glasses at around -147 ppm (Stebbins and Zeng, 2000; Zeng and Stebbins, 2000; Liu and Nekvasil, 2002). In pure F doped silica glass F bonded to four-coordinated $\mathrm{Si}\left(\mathrm{Si}^{\mathrm{iV}}\right)$ has a chemical shift of -146 ppm (Youngmann and Sen, 2004). In addition, the resonances of $\mathrm{Al}-\mathrm{F}-\mathrm{Ca}(\mathrm{n})$ sites were found around -145 to $-154 \mathrm{ppm}$ in the mineral Jakobssonite $\left(\mathrm{CaAlF}_{5}\right)$ as well as in anorthitic, pure calcium aluminosilicate and phosphorous-bearing $\mathrm{Na}_{2} \mathrm{O}-\mathrm{CaO}-\mathrm{SrO}$ aluminosilicate glasses (Zeng and Stebbins, 2000; Kiczenski and Stebbins, 2002; Karpukhina et al. 2008; Stamboulis et al., 2005). The present glasses have a low $\mathrm{Ca} /[\mathrm{Ca}+\mathrm{Na}]$ ratio of 0.14 ; which may suggest that the peak at -145 to -152 ppm is mainly a Si-F-Na(n) environment. In contrast, Stebbins and Zeng (2000) showed that in silicate glasses F favours Ca more than $\mathrm{Na}$. Thus, none of these sites can be excluded.

Liu and Tossell (2003) calculated chemical shifts between -134 and -162 ppm for $\mathrm{Si}^{\mathrm{IV}}-\mathrm{F}-\mathrm{Al}^{\mathrm{IV}}$ sites, which also overlap with the peak at -145 to $-152 \mathrm{ppm}$ in our glasses. However, it was pointed out that $\mathrm{Al}$ in such a site would have a large quadrupole constant $C_{q}$ of $\sim 27 \mathrm{MHz}$. Our results from ${ }^{27} \mathrm{Al}$ NMR spectroscopy (see section 3.3.5) do not support large quantities of this site. Liu and Tossell (2003) found from ab initio calculations that in some configurations $\mathrm{F}$ bridging $\mathrm{Al}^{\vee}$ could have a chemical shift that would fit to the peak at -145 to -152 ppm. However, large amounts of these sites are not likely in our glasses, as in the peraluminous glasses only $5 \%$ of the $\mathrm{Al}$ is $\mathrm{Al}^{\mathrm{V}}$ (see section 3.3.5) and for the peralkaline glasses we found no evidence for higher coordinated Al. Therefore, in the peraluminous glasses only $1 \mathrm{~mol} \% \mathrm{~F}$ at most could 
be in these sites. This hardly explains the intensities for example in the peraluminous glass with 18.3 mol\% F (ANCS 18.3F), where the peak at -150 ppm accounts for $27 \%$ of the $\mathrm{F}$ spectrum. As we found no evidence for $\mathrm{Al}^{\mathrm{VI}}$ in our glasses, topaz-like sites (bridging $\mathrm{F}$ between $\mathrm{Al}^{\mathrm{Vl}}$ ), as suggested by Mysen et al. (2004), can be excluded for our glasses. We suggest, the peak at -145 to -152 ppm mainly consists of non-bridging $\mathrm{F}$ sites like Si-F-Na(n) and Al-F-Ca(n).

\section{$\underline{F \text { sites at }-168 \text { to }-171 \mathrm{ppm}}$}

The peak at -168 to -171 ppm has previously only been observed by Zeng and Stebbins (2000) and Mysen et al. (2004) in sodium aluminosilicate glasses as an unresolved shoulder at -165 to $-170 \mathrm{ppm}$. Zeng and Stebbins (2000) remarked that the chemical shift of this peak is similar to that of the $F$ site in crystalline chiolite at $-166 \mathrm{ppm}$, where $\mathrm{F}$ is bridging two $\mathrm{AlF}_{6}{ }^{3-}$ octahedra and two sodium atoms are near to $\mathrm{F}$; as well as that of crystalline $\mathrm{AlF}_{3}$ at $-174 \mathrm{ppm}$ (Miller, 1996), where $\mathrm{F}$ is bridging two $\mathrm{AlF}_{6}{ }^{3-}$ octahedra. Liu and Nekvasil (2002) calculated that $\mathrm{F}$ bridging two $\mathrm{Al}^{\mathrm{IV}}$, tetrahedrally coordinated by three $\mathrm{O}$ and one $\mathrm{F}$, will have a chemical shift of -170 ppm. Liu and Nekvasil (2001) remarked that $\mathrm{Al}^{\mathrm{IV}}$ in a site like this would have a $C_{q}$ of $16.8 \mathrm{MHz}$, which is unusually high for $\mathrm{Al}$ in glasses. Our ${ }^{27} \mathrm{Al}$ spectra of the peraluminous glasses (see section 3.3.5) do not show a significant amount of this site. Liu and Tossell (2003) found from ab initio calculations that in some configurations $\mathrm{F}$ bridging $\mathrm{Al}^{\vee}$ would have a chemical shift of $-169 \mathrm{ppm} .{ }^{19} \mathrm{~F}{ }^{27} \mathrm{Al}$ cross polarization MAS NMR by Kohn et al. (1991) showed for jadeite $+\mathrm{NaF}$ and jadeite + cryolite glasses that most ${ }^{19} \mathrm{~F}$ is bonded to five-coordinated and six-coordinated $\mathrm{Al}\left(\mathrm{Al}^{\mathrm{V}}\right.$ and $\left.\mathrm{Al}^{\mathrm{Vl}}\right)$, with a minor amount of $\mathrm{Al}^{\mathrm{IV}}$. As no evidence was found for $\mathrm{Al}^{\mathrm{VI}}$ in the ${ }^{27} \mathrm{Al}$ spectra of the present glasses (see section 3.3.5), it is most probable that the peak at -168 to $-171 \mathrm{ppm}$ is an Al-F-Al site, where $\mathrm{F}$ is linking two $\mathrm{Al}^{\mathrm{IV}}$ and/or $\mathrm{Al}^{\mathrm{IV}}-\mathrm{Al}^{\mathrm{V}}$.

\section{$\underline{F \text { sites at }-187 \text { to }-190 \mathrm{ppm}}$}

The relatively sharp peak at -187 to -190 ppm with a line width of 17 to 21 ppm has a chemical shift similar to a peak with a strong resonance observed in all sodium 
aluminosilicate glasses studied up to now $\sim-190 \mathrm{ppm}$, which was assigned as Al-F-Na(n) or cryolite-like site (Schaller et al., 1992; Zeng and Stebbins, 2000; Mysen et al., 2004). In the phosphorous-bearing $\mathrm{Na}_{2} \mathrm{O}-\mathrm{CaO}-\mathrm{SrO}$ aluminosilicate glasses of Stamboulis et al. (2005) with $\mathrm{Ca}>\mathrm{Na}$ a minor amount of an Al-F-Na(n) site was observed at -180 ppm. Stebbins et al. (2000) found that most F bonded to Al in albitic and anorthitic glasses belongs to $\mathrm{Al}^{\mathrm{V}}$ and $\mathrm{Al}^{\mathrm{VI}}$. In minerals that contain $\mathrm{Al}^{\mathrm{VI}}$ coordinated by six $\mathrm{F}\left(\mathrm{AlF}_{6}{ }^{3-}\right)$ with sodium atoms between the Al octahedra (like cryolite and chiolite), both $\mathrm{F}$ sites that are not corner-shared have resonances at around -182 to -190 ppm (Zeng and Stebbins, 2000).

Ab initio NMR calculations for non-bridging $\mathrm{F}$ in $\mathrm{AlF}_{5}{ }^{2-}$ and $\mathrm{AlF}_{3} \mathrm{O}_{2}{ }^{2-}$ clusters that are deshielded by nearby $\mathrm{Na}$ atoms yield ${ }^{19} \mathrm{~F}$ chemical shifts of -181 to -198 ppm (Liu and Nekvasil, 2002; Liu and Tossell, 2003), which match the chemical shift range observed here. It was also found by same authors that $\mathrm{F}$ bonded to $\mathrm{Al}^{\mathrm{IV}}$ could have resonances of -193 to $-206 \mathrm{ppm}$. No evidence for $\mathrm{Al}^{\mathrm{VI}}$ was found in any of the ${ }^{27} \mathrm{Al}$ spectra of the present glasses (see section 3.3.5). Hence, it is suggested that the peak observed at -187 to $-190 \mathrm{ppm}$ belongs to an $\mathrm{Al}-\mathrm{F}-\mathrm{Na}(\mathrm{n})$ site where a non-bridging $\mathrm{F}$ is bonded to $\mathrm{Al}^{\mathrm{IV}}$ and or $\mathrm{Al}^{\mathrm{V}}$ involving $\mathrm{Na}$ atoms.

\section{F site at -222 to $-228 \mathrm{ppm}$}

The peak at -222 to $-228 \mathrm{ppm}$ has a similar chemical shift to the six-coordinated $\mathrm{F}$ site in NaF at -225 ppm (Zeng and Stebbins, 2000) and the F-Na(n) site observed in sodium silicate and aluminosilicate glasses (Stebbins and Zeng, 2000; Zeng and Stebbins, 2000; Mysen et al., 2004) in a range of -220 to -224 ppm. Therefore, it is suggested that the peak at -222 to -228 ppm is a $\mathrm{F}-\mathrm{Na}(\mathrm{n})$ site where $\mathrm{F}$ is coordinated by about six $\mathrm{Na}$ cations. 
Table $2 .{ }^{19} \mathrm{~F}$ isotropic chemical shift $\delta_{\text {iso }}$, full width half maximum $F W H M$ and fraction of the area of the total spectrum for the fitted peaks of the different $\mathrm{F}$ sites in the ${ }^{19} \mathrm{~F}$ MAS spectra at 2.3 and $7 \mathrm{~T}$ of the dry peralkaline and peraluminous glasses ${ }^{\mathrm{a}}$.

\begin{tabular}{|c|c|c|c|c|c|c|c|c|c|c|c|c|c|c|c|}
\hline & \multicolumn{3}{|c|}{$\mathrm{F}-\mathrm{Ca}(\mathrm{n})$} & \multicolumn{3}{|c|}{ Si-F-Na(n)/Al-F-Ca(n) } & \multicolumn{3}{|c|}{ Al-F-Al } & \multicolumn{3}{|c|}{ Al-F-Na(n) } & \multicolumn{3}{|c|}{$\mathrm{F}-\mathrm{Na}(\mathrm{n})$} \\
\hline & $\begin{array}{c}\delta_{\text {iso }}{ }^{\mathrm{b}} \\
{[\mathrm{ppm}]}\end{array}$ & $\begin{array}{c}F W H M^{b} \\
{[p p m]}\end{array}$ & $\begin{array}{c}\text { area }^{c} \\
{[\%]}\end{array}$ & $\begin{array}{c}\delta_{\text {iso }} \\
{[\mathrm{ppm}]}\end{array}$ & $\begin{array}{c}\text { FWHM } \\
\text { [ppm] }\end{array}$ & $\begin{array}{c}\text { area } \\
{[\%]}\end{array}$ & $\begin{array}{c}\delta_{\text {iso }} \\
{[\mathrm{ppm}]}\end{array}$ & $\begin{array}{c}\text { FWHM } \\
\text { [ppm] }\end{array}$ & $\begin{array}{c}\text { area } \\
{[\%]}\end{array}$ & $\begin{array}{c}\delta_{\text {iso }} \\
{[\mathrm{ppm}]}\end{array}$ & $\begin{array}{c}\text { FWHM } \\
\text { [ppm] }\end{array}$ & $\begin{array}{c}\text { area } \\
{[\%]}\end{array}$ & $\begin{array}{c}\delta_{\text {iso }} \\
{[\mathrm{ppm}]}\end{array}$ & $\begin{array}{c}\text { FWHM } \\
\text { [ppm] }\end{array}$ & $\begin{array}{c}\text { area } \\
{[\%]}\end{array}$ \\
\hline \multicolumn{16}{|l|}{ Peralkaline } \\
\hline NACS 1.2 & -117 & 51 & 42 & -147 & 26 & 8 & -168 & 22 & 15 & -189 & 17 & 25 & -228 & 21 & 10 \\
\hline NACS 2.7 & -117 & 51 & 49 & -145 & 26 & 7 & -168 & 23 & 18 & -188 & 17 & 17 & -228 & 20 & 9 \\
\hline NACS 6.2 & -115 & 51 & 53 & -147 & 26 & 11 & -168 & 22 & 13 & -187 & 18 & 20 & -222 & 15 & 3 \\
\hline NACS 6.2 (2.3 T) & -109 & 54 & 54 & -145 & 25 & 8 & -168 & 23 & 9 & -189 & 21 & 24 & -228 & 25 & 5 \\
\hline Peraluminous & & & & & & & & & & & & & & - & - \\
\hline ANCS 1.1 & - & - & - & -149 & 26 & 30 & -171 & 20 & 9 & -190 & 20 & 61 & - & - & - \\
\hline ANCS 3.5 & - & - & - & -148 & 27 & 34 & -171 & 20 & 12 & -189 & 20 & 54 & - & - & - \\
\hline ANCS 9.7 & - & - & - & -149 & 27 & 35 & -171 & 20 & 10 & -190 & 20 & 55 & - & - & - \\
\hline ANCS 18.2 & - & - & - & -150 & 27 & 31 & -169 & 20 & 9 & -190 & 20 & 60 & - & - & - \\
\hline
\end{tabular}

a - Fitted to a $20 \%$ Lorentzian and $80 \%$ Gaussian line shape.

$\mathrm{b}$ - The estimated errors for all $\delta_{\text {iso }}$ and FWHM of all fitted peaks are around \pm 1 to 2 ppm.

c - The estimated errors for all areas are $\pm 3 \%$ except for the sample ANCS 1.1, where we assume an error of $\pm 5 \%$ because of the worse signal to noise ratio. The areas of the sidebands were added to the areas of the central bands when it was possible to fit or simulate the sidebands. 

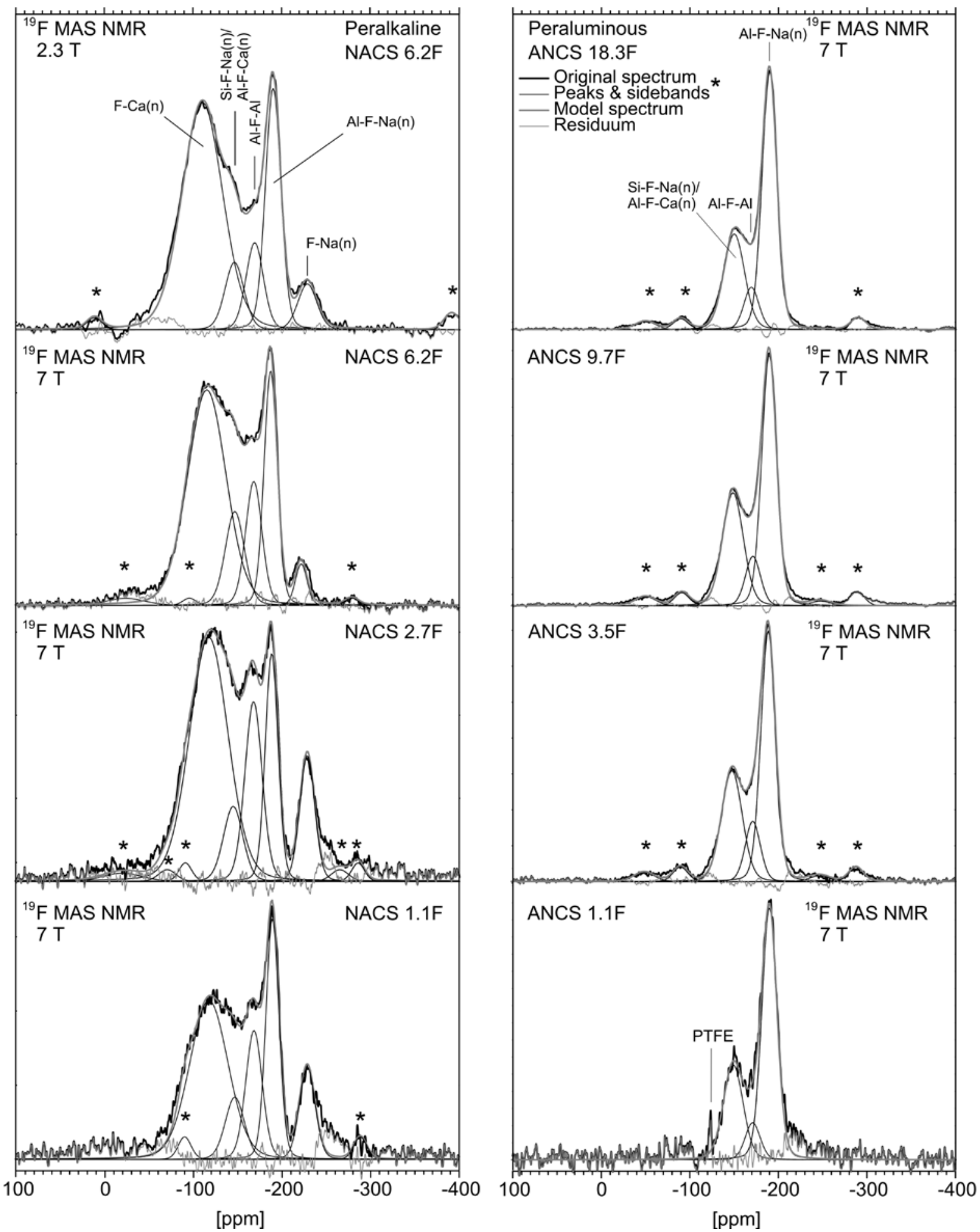

Fig. 1. ${ }^{19} \mathrm{~F}$ MAS NMR spectra of the dry fluorine-bearing peralkaline and peraluminous glasses at 2.3 and $7 \mathrm{~T}$. Spinning sidebands are marked with an asterisk. The spectra were normalised to the same peak height. 
Table 3. ${ }^{19} \mathrm{~F}$ NMR isotropic chemical shifts $\delta_{\text {iso }}$ chemical shifts (relative to $\mathrm{CFCl}_{3}$ ) of $\mathrm{F}$ sites in minerals, clusters in glasses (from ab initio calculations) and in the glasses studied here.

\begin{tabular}{|c|c|c|c|c|}
\hline Site & $\delta_{\text {iso }}$ in $\mathrm{ppm}$ & Mineral \& Phase & Structure & Ref. $^{a}$ \\
\hline \multicolumn{5}{|c|}{ Crystalline phases \& Minerals } \\
\hline $\mathrm{F}-\mathrm{Ca}(4)$ & $\begin{array}{l}-108 \\
-110\end{array}$ & $\mathrm{CaF}_{2,}$ Fluorite & F coordinated by $4 \mathrm{Ca}$ & $\begin{array}{l}{[1]} \\
{[2]}\end{array}$ \\
\hline Si-F-Ca(n) ${ }^{b}$ & $-123--135$ & $\mathrm{CaSiF}_{6}$ & $\mathrm{~F}$ in $\mathrm{SiF}_{6}{ }^{2-}$ bonded to $1 \mathrm{Ca}^{\mathrm{c}}$ & [3] \\
\hline $\mathrm{Si}-\mathrm{F}-\mathrm{Na}(2)$ & -152 & $\mathrm{Na}_{2} \mathrm{SiF}_{6}$, Malladrite & $\mathrm{F}$ in $\mathrm{SiF}_{6}^{2-}$ bonded to $2 \mathrm{Na}$ & [4] \\
\hline A-F-Al & -140 & $\mathrm{Al}_{2}(\mathrm{~F}, \mathrm{OH})_{2} \mathrm{SiO}_{4} \mathrm{Topaz}$ & $\begin{array}{l}\mathrm{F} \text { bridging } \mathrm{A}^{\mathrm{VI}} \text { bonded to } 4 \mathrm{O} \text { and } 2 \mathrm{~F} \\
\left(144.7^{\circ}\right)^{\mathrm{e}}\end{array}$ & [1] \\
\hline Al-F-Ca(2) & -146 & $\mathrm{CaAlF}_{5}$, Jakobssonite & $\mathrm{F}$ in $\mathrm{AlF}_{6}^{3-}$ bonded to 1 to $2 \mathrm{Ca}$ & [3] \\
\hline Al-F-Ca(1) & -154 & & & \\
\hline Al-F-Al $(+C a)^{d}$ & -164 & CaAlF $_{5}$, Jakobssonite & $\mathrm{F}$ bridging $2 \mathrm{AlF}_{6}^{3-}\left(157.5^{\circ}\right)$ & [3] \\
\hline $\mathrm{Al}-\mathrm{F}-\mathrm{Al}(+2 \mathrm{Na})$ & -166 & $\mathrm{Na}_{5} \mathrm{Al}_{3} \mathrm{~F}_{14}$, Chiolite & $\mathrm{F}$ bridging $2 \mathrm{AlF}_{6}{ }^{3-}\left(151.2^{\circ}\right)$ & [5] \\
\hline A-F-Al & -174 & $\mathrm{AlF}_{3}$ & $\mathrm{~F}$ bridging $2 \mathrm{AlF}_{6}{ }^{3-}\left(156.5^{\circ}\right)$ & [1] \\
\hline $\mathrm{A}-\mathrm{F}-\mathrm{Na}(4)$ & -182 & $\mathrm{Na}_{5} \mathrm{Al}_{3} \mathrm{~F}_{14}$, Chiolite & $\mathrm{F}$ in $\mathrm{AlF}_{6}{ }^{3-}$ bonded to 3 to $4 \mathrm{Na}$ & [5] \\
\hline $\mathrm{A}-\mathrm{F}-\mathrm{Na}(3)$ & -190 & & & \\
\hline Al-F-Na(3) & -191 & $\mathrm{Na}_{3} \mathrm{AlF}_{6}$, Cryolite & $\mathrm{F}$ in $\mathrm{AlF}_{6}{ }^{3-}$ bonded to $3 \mathrm{Na}$ & [5] \\
\hline $\mathrm{F}-\mathrm{Na}(6)$ & $\begin{array}{r}-221--224 \\
-225\end{array}$ & NaF, Villiaumite & dinated by $6 \mathrm{Na}$ & $\begin{array}{l}{[1]} \\
{[5]}\end{array}$ \\
\hline \multicolumn{5}{|c|}{ Cluster in glasses from ab initio calculations } \\
\hline Si-F-Na(n) & $\begin{array}{r}-138--150 \\
-147\end{array}$ & $\begin{array}{l}\mathrm{SiF}_{5}{ }^{-}+\mathrm{Na}(2) \text { cluster } \\
\mathrm{SiFO}_{3}+\mathrm{Na}(1) \text { cluster }^{\dagger}\end{array}$ & $\begin{array}{l}\mathrm{F}(\text { next to } 2 \mathrm{Na}) \text { in } \mathrm{SiF}_{5}^{-} \\
\mathrm{F}(\text { next to } 1 \mathrm{Na}) \text { bonded to } \mathrm{Si} \\
\text { coordinated by } 3 \mathrm{O} \text { and } 1 \mathrm{~F}\end{array}$ & $\begin{array}{l}{[6]} \\
{[6]}\end{array}$ \\
\hline $\mathrm{Al}-\mathrm{F}-\mathrm{Al}(+\mathrm{nNa})$ & $-124--177$ & $\mathrm{Al}^{\mathrm{V}}-\mathrm{F}-\mathrm{Al}^{\mathrm{V}}(+\mathrm{nNa})$ cluster & $\begin{array}{l}\mathrm{F} \text { (next to } \mathrm{n} \mathrm{Na} \text { ) bridging two } \mathrm{Al}^{\mathrm{V}} \\
\text { coordinated by different } 0 \text { to } 5 \mathrm{~F} \text { and } 0 \\
\text { to } 4 \mathrm{O}\end{array}$ & [7] \\
\hline Si-F-Al & $-134--162$ & $\mathrm{Si}^{\mathrm{iV}}$-F-Alv cluster & $\mathrm{F}$ bridging $\mathrm{Si}^{\mathrm{IV}}$ and $\mathrm{Al}^{\mathrm{IV}}$ & [7] \\
\hline \multirow[t]{2}{*}{ Al-F-Al(+Na) } & -163 & $\mathrm{Al}^{\mathrm{IV}}-\mathrm{F}-\mathrm{A}^{\mathrm{IV}}(+1 \mathrm{Na})$ cluster & $\mathrm{F}\left(\right.$ next to $1 / 0 \mathrm{Na}$ ) bridging two $\mathrm{Al}^{\mathrm{IV}}$ & [7] \\
\hline & -170 & $\mathrm{Al}^{\mathrm{IV}}-\mathrm{F}-\mathrm{A}^{\mathrm{IV}}$ cluster & $\mathrm{d}$ by $3 \mathrm{O}$ and $1 \mathrm{~F}$ & [6] \\
\hline \multirow[t]{2}{*}{$\mathrm{Al}-\mathrm{F}-\mathrm{Na}(\mathrm{n})$} & $-193--206$ & $\mathrm{AlF}_{\mathrm{x}} \mathrm{O}_{4-\mathrm{x}}{ }^{-}+\mathrm{Na}(\mathrm{n})$ cluster & $\begin{array}{l}\mathrm{F}(\text { next to } \mathrm{n} \mathrm{Na}) \text { bonded to } \mathrm{Al}^{\mathrm{IV}} \\
\text { coordinated by } 1 \text { to } 4 \mathrm{~F} \text { and } 0 \text { to } 4 \mathrm{O}\end{array}$ & [6][7] \\
\hline & $-181--198$ & $\begin{array}{l}\mathrm{AlF}_{3} \mathrm{O}_{2}{ }^{2-} / \mathrm{AlF}_{5}{ }^{2-}+\mathrm{Na}(2) \\
\text { cluster }\end{array}$ & $\begin{array}{l}\mathrm{F} \text { (next to } 2 \mathrm{Na} \text { ) bonded to } \mathrm{Al}^{\mathrm{V}} \\
\text { coordinated by } 3 \text { to } 5 \mathrm{~F} \text { and and } 0 \text { to } 2 \\
\mathrm{O}\end{array}$ & [6][7] \\
\hline \multicolumn{5}{|c|}{ Glasses in this study } \\
\hline $\mathrm{F}-\mathrm{Ca}(\mathrm{n})$ & $-109--117$ & Ca-Na-Al-Si peralkaline & $\begin{array}{l}\mathrm{F} \text { coordinated by } 4 \text { or fewer Ca with } \\
\text { minor amounts of } \mathrm{F}-\mathrm{Ca}(\mathrm{n}) / \mathrm{Na}(\mathrm{n}) \text { and } \\
\mathrm{Si}-\mathrm{F}-\mathrm{Ca}(\mathrm{n})\end{array}$ & [2] \\
\hline $\begin{array}{l}\text { Si-F-Na(n)/ } \\
\text { Al-F-Ca(n) }\end{array}$ & $-145--150$ & $\begin{array}{l}\text { Ca-Na-Al-Si peralkaline \& } \\
\text { peraluminous }\end{array}$ & $\begin{array}{l}\mathrm{F}(\text { next to } \mathrm{n} \mathrm{Na} \text { ) bonded to } \mathrm{Si} \text { and/or } \\
\mathrm{F}(\text { next to } \mathrm{n} \mathrm{Ca}) \text { bonded to } \mathrm{Al}, \mathrm{Al}=\mathrm{Al}^{\mathrm{IV}} \\
\text { or Al }\end{array}$ & [2] \\
\hline Al-F-Al & 171 & $\begin{array}{l}\text { Ca-Na-Al-Si peralkaline } \\
\& \text { peraluminous }\end{array}$ & $\mathrm{F}$ bridging two $\mathrm{Al}^{\mathrm{IV}}$ and/or $\mathrm{Al}^{\mathrm{V}}$ & [2] \\
\hline Al-F-Na(n) & $-187--190$ & $\begin{array}{l}\text { Ca-Na-Al-Si peralkaline \& } \\
\text { peraluminous }\end{array}$ & $\begin{array}{l}\mathrm{F}\left(\text { next to } \mathrm{n} \mathrm{Na} \text { ) bonded to } \mathrm{Al}, \mathrm{Al}=\mathrm{Al}^{\mathrm{IV}}\right. \\
\text { or } \mathrm{Al}^{\mathrm{V}}\end{array}$ & [2] \\
\hline $\mathrm{F}-\mathrm{Na}(\mathrm{n})$ & $-222--228$ & Ca-Na-Al-Si peralkaline & F coordinated by $\sim 6 \mathrm{Na}$ & [2] \\
\hline
\end{tabular}

a - References: [1] Miller (1996), [2] this study, [3] Kiczenski and Stebbins (2002), [4] Stebbins and Zeng (2000), [5] Zeng and Stebbins (2000), [6] Liu and Nekvasil (2002), [7] Liu and Tossell (2003) $\mathrm{b}-(\mathrm{n})$ indicates the number of atoms is variable or uncertain.

c - Kiczenski and Stebbins (2002) wrote that the structure of $\mathrm{CaSiF}_{6}$ is unclear, now there is structural data from XRD by Frisoni et al. (2011).

$d-(+X Y)$ indicates cations that are bonded to the bridging $F$.

e - Bond angle

$\mathrm{f}$ - All oxygens in the cluster models are shared between Al and Si: Al-O-Si. 


\subsection{2. ${ }^{19} \mathrm{~F}$ speciation of dry fluorine-bearing glasses}

In the ${ }^{19} \mathrm{~F}$ MAS NMR spectra in Fig. 1 the resonances of three groups of F sites were observed: 1.) Salt-like environments $\mathrm{F}-\mathrm{Ca}(\mathrm{n})$ and $\mathrm{F}-\mathrm{Na}(\mathrm{n})$, that are not connected to the glass network 2.) $\mathrm{F}$ bridging $\mathrm{Al}$ as part of the glass network (Al-F-Al) 3.) Non-bridging $\mathrm{F}$ bonded to $\mathrm{Si}$ and $\mathrm{Al}$ in the glass network with $\mathrm{Na}$ and $\mathrm{Ca}$ cations next to $\mathrm{F}(\mathrm{Si}-\mathrm{F}-\mathrm{Na}(\mathrm{n}), \mathrm{Al}-\mathrm{F}-\mathrm{Ca}(\mathrm{n}), \mathrm{Al}-\mathrm{F}-\mathrm{Na}(\mathrm{n})$. Fig. 2A-B show peak areas (Table 2) assigned to these $F$ sites as a function of the $F$ concentration in the peraluminous and peralkaline glasses. As single pulse NMR is quantitative, the peak areas reflect the relative amount of $F$ in these sites.

In the peralkaline glasses (Fig. 2A) the most abundant site is $\mathrm{F}-\mathrm{Ca}(\mathrm{n})$. The remaining $\mathrm{F}$ is located in sites with $\mathrm{Si}$ and $\mathrm{Al}$ and a minor amount are $\mathrm{F}-\mathrm{Na}(\mathrm{n})$ sites. This is remarkable as $\mathrm{Ca}$ is the least common cation in the glasses. There are more non-bridging $\mathrm{F}$ sites (Al-F-Na(n)) than bridging $\mathrm{F}$ sites (Al-F-Al). In the peralkaline glasses the $F$ speciation depends on the concentration of $F$. With increasing $F$ content, the fraction of F-Ca(n) sites increases by $\sim 11 \%$, while the sum of the sites where $\mathrm{F}$ is bonded to the glass network ( $\mathrm{Si}, \mathrm{Al})$ decreases by $\sim 4 \%$ and the fraction of $\mathrm{F}-\mathrm{Na}(\mathrm{n})$ sites decreases by $\sim 7 \%$.

In contrast, in the peraluminous glasses (Fig. 2B) all $\mathrm{F}$ exists in sites with $\mathrm{Al}$ and $\mathrm{Si}$ with the non-bridging $\mathrm{F}$ site Al-F-Na(n) being the most abundant. The sites F-Ca(n) and $\mathrm{F}-\mathrm{Na}(\mathrm{n})$ are completely missing. The ratio of the non-bridging $\mathrm{F}$ sites $(\mathrm{Al}-\mathrm{F}-\mathrm{Na}(\mathrm{n}))$ to the bridging $\mathrm{F}$ site (Al-F-Al) is higher than for the peralkaline glasses. In the peraluminous glasses the $F$ speciation also depends on the concentration of $F$. The fraction of $\mathrm{Al}-\mathrm{F}-\mathrm{Na}(\mathrm{n})$ sites decreases by $~ 7 \%$ as the amount of fluorine is increased from 1.1 to $3.5 \mathrm{~mol} \% \mathrm{~F}$; then stagnates between 3.5 and $10 \mathrm{~mol} \% \mathrm{~F}$; to increase again by $\sim 5 \%$ between 10 and 18 mol\% F. The Si-F-Na(n)/Al-F-Ca(n) site and the Al-F-Al site show an opposite trend.

The speciation of $\mathrm{F}$ in our peraluminous $\mathrm{Na}_{2} \mathrm{O}-\mathrm{CaO}$ aluminosilicate glasses is very similar to that observed for albitic glasses as well as albitic glasses with an excess in Al by Zeng and Stebbins (2000). However, a similar F speciation to that observed here in the peralkaline glasses has not been reported previously for any other aluminosilicate glasses. 

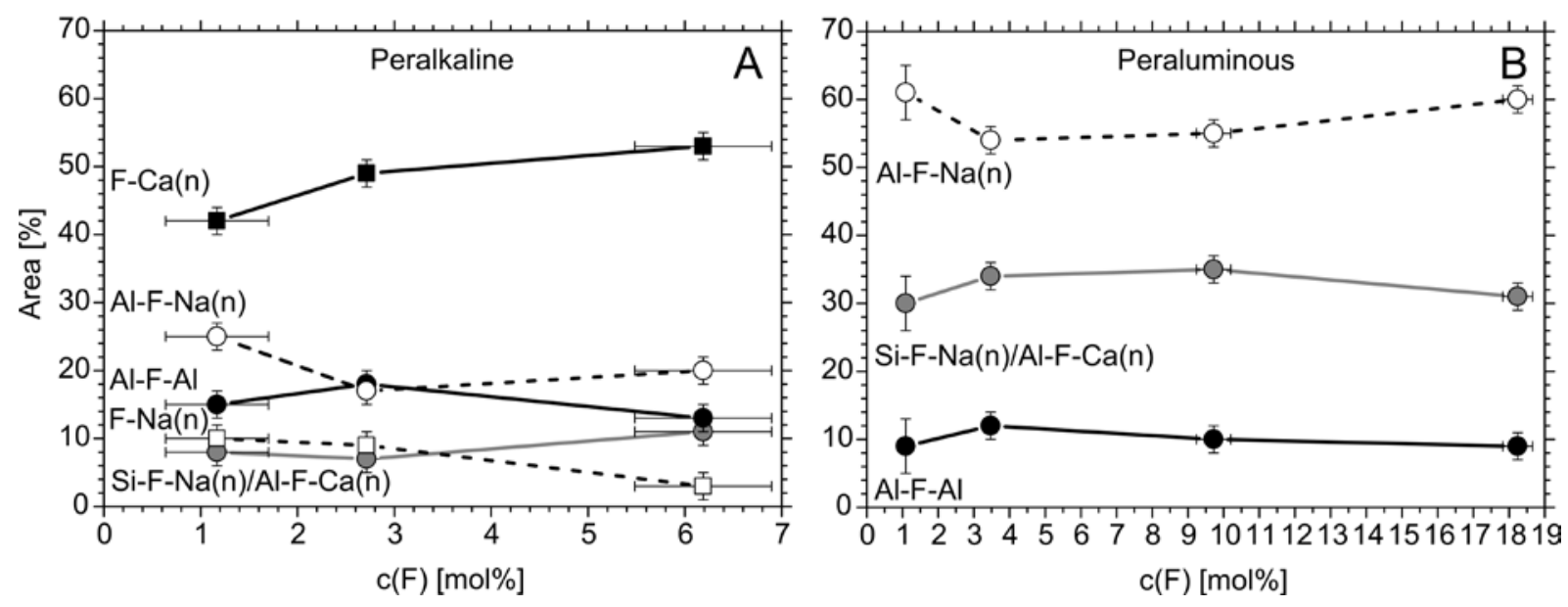

Fig. 2. Fluorine speciation in the peralkaline $(A)$ and peraluminous (B) glasses represented by the peak areas in the ${ }^{19} \mathrm{~F}$ MAS NMR spectra at $7 \mathrm{~T}$ as percentage of the total spectrum, as a function of the fluorine concentration $c(F)$ in $m o l \%$.

A preference of $\mathrm{F}$ for $\mathrm{Ca}$ instead of $\mathrm{Na}$ (as in the peralkaline glasses) was also observed by Stebbins and Zeng (2000) in $\mathrm{Na}_{2} \mathrm{O}-\mathrm{CaO}$ silicate glasses. They found that $\mathrm{F}$ prefers the smaller and higher-charged high field strength cations and that this explains the preference of $\mathrm{F}$ for $\mathrm{Al}$ in aluminosilicate glasses. The field strength $\left(\mathrm{z}^{2} / \mathrm{r}\right.$; $z=$ charge and $r=$ radius of a cation) trend of the cations in the present glasses is $\mathrm{Si}>\mathrm{Al}>\mathrm{Ca}>\mathrm{Na}$. However, in the present peralkaline aluminosilicate glasses $45-54 \%$ of the $\mathrm{F}$ is located in sites with $\mathrm{Ca}$ and $\sim 45 \%$ with $\mathrm{Al}$ (counting the entire area of the Si-F-Na(n)/Al-F-Ca(n) site for Al). Field strength can explain the preference of $\mathrm{Ca}$ compared to $\mathrm{Na}$, but not that of Ca compared to $\mathrm{Al}$ or $\mathrm{Si}$. A too low Al concentration can also not be the reason, as even in the peralkaline glass with $6.2 \mathrm{~mol} \% \mathrm{~F}$ (NACS 6.2F) the Al/F ratio is 3.6 and this is enough for every $\mathrm{F}$ to bond to one $\mathrm{Al}$, while the $\mathrm{Ca} / \mathrm{F}$ ratio is 0.9 and $\mathrm{Ca}$ is the least common cation.

In addition to cation field strength, the bond strength, the size of a site, the number of atoms involved and their concentration might play a role in the speciation of $F$ in aluminosilicate glasses. The fact that $\mathrm{F}$ tends to be coordinated by four or fewer $\mathrm{Ca}$ cations rather than $\sim 6 \mathrm{Na}$ cations might be because this requires less space. The Ca-NBO bond distance as well as the Ca-BO distance is in general longer than that of Al-O and Si-O bonds in Al-O-Si (Jiang, 2002; Jakse et al., 2012) and thus is assumed to be weaker. This should drive the $\mathrm{F}$ to take a $\mathrm{Ca}$ instead of breaking a stronger Al-O-Si bond to form a F-Al site. 
In the present study, $\mathrm{F}-\mathrm{Ca}(\mathrm{n})$ and $\mathrm{F}-\mathrm{Na}(\mathrm{n})$ were only observed in the peralkaline glasses, where a significant amount of $\mathrm{Ca}$ and $\mathrm{Na}$ exist as network-modifiers, that mostly create NBO bonded to Si tetrahedra (e.g. Allwardt et al., 2003; Lee, 2004; Lee and Stebbins, 2006; Lee and Stebbins, 2009). This observation is consistent with observations in pure $\mathrm{Na}_{2} \mathrm{O}$ or $\mathrm{CaO}$ aluminosilicate glasses of other authors (Zeng and Stebbins, 2000; Mysen et al., 2004). F-Ca(n) sites were not only found in metaluminous calcium aluminosilicate glasses (Karpukhina et al., 2008), but also in anorthitic glass (Zeng and Stebbins, 2000; Kiczenski and Stebbins, 2002), which has enough $\mathrm{Ca}$ to charge-balance Al but not enough to create a significant amount of NBO. Thus, anorthitic glass contains only minor amounts of $\mathrm{F}-\mathrm{Ca}(\mathrm{n})$ sites, while in the peralkaline calcium aluminosilicate glasses $\mathrm{F}-\mathrm{Ca}(\mathrm{n})$ are the dominant $\mathrm{F}$ species. Therefore, the existence of $\mathrm{F}-\mathrm{Ca}(\mathrm{n})$ sites seems to be also strongly related to the presence of $\mathrm{Ca}$ as network-modifying cation.

It may appear that in peraluminous glasses, where most of the $\mathrm{Ca}$ and $\mathrm{Na}$ atoms are charge-balancing $\mathrm{Al}$ and only a few NBO are present (Thompson and Stebbins, 2011), F is not able to compete with Al for $\mathrm{Ca}$ and $\mathrm{Na}$ and so exists in sites bonded to $\mathrm{Al}$ and $\mathrm{Si}$. Bond length differences can not be the reason for this, as a $\mathrm{Ca}$ or $\mathrm{Na}$ bonded to a NBO has a shorter bond length than a charge-balancing $\mathrm{Ca}$ or $\mathrm{Na}$ bonded to a BO (Uchino and Toshinobu, 1998; Jiang, 2002, Lee and Stebbins, 2003; Lee and Stebbins, 2006; Jakse et al., 2012) and one could argue is therefore stronger.

In pure sodium aluminosilicate glasses no significant speciation change depending on F concentration was observed by Schaller et al. (1992). However, Karpukhina et al. (2008) found in their metaluminous calcium aluminosilicate glasses that, with increasing $\mathrm{F}$ concentration, the number of $\mathrm{Al}-\mathrm{F}-\mathrm{Ca}(\mathrm{n})$ sites increases compared to $\mathrm{F}-\mathrm{Ca}(\mathrm{n})$, which is the opposite trend observed in the present $\mathrm{Na}_{2} \mathrm{O}-\mathrm{CaO}$ aluminosilicate glasses. In the present peralkaline $\mathrm{Na}_{2} \mathrm{O}-\mathrm{CaO}$ aluminosilicate glasses the relative fraction of $\mathrm{F}-\mathrm{Ca}(\mathrm{n})$ sites increases, while sites where $\mathrm{F}$ is bonded to $\mathrm{Si}$ and $\mathrm{Al}$ and $\mathrm{F}-\mathrm{Na}(\mathrm{n})$ sites decrease. Our results show that $\mathrm{F}$ has a strong preference for $\mathrm{Ca}$, but it cannot compete with $\mathrm{Al}$ for $\mathrm{Ca}$ that is charge-balancing Al. The increase of the fraction of $\mathrm{F}-\mathrm{Ca}(\mathrm{n})$ sites with increasing $\mathrm{F}$ concentration indicates that there is a mechanism due to the addition of $F$ itself that enhances the availability or accessibility of Ca for F. 
It is commonly agreed that glasses are charge-balanced and two $\mathrm{F}^{-}$should replace one $\mathrm{O}^{2-}$ in the glass structure. Thus, the incorporation of $\mathrm{F}$ in a glass/melt by bonding to Al cannot lead to the conversion of charge-balancing cations to network-modifying cations. However, it might happen that locally due to the replacement of two bridging oxygens at an Al tetrahedron $\left(\mathrm{AlO}_{2}^{-}\right)$by two bridging $\mathrm{F}$ (AlFO) the negative charge around the $\mathrm{Al}$ is reduced and its charge-balancing cation is transformed into a network-modifier. However, this cannot be described with a charge-balanced equation.

The following process is more likely to explain the relative decrease in $\mathrm{F}-\mathrm{Na}(\mathrm{n})$ sites and the relative increase in $\mathrm{F}-\mathrm{Ca}(\mathrm{n})$ sites with increasing $\mathrm{F}$ content. First $\mathrm{F}$ bonds to network-modifying Ca cations that are available in the melt and forms $\mathrm{F}-\mathrm{Ca}(\mathrm{n})$ sites. If these are consumed, network-modifying $\mathrm{Na}^{+}$cations $\left(\mathrm{Na}^{+}{ }_{\mathrm{nm}}\right)$ replace charge-balancing $\mathrm{Ca}^{2+}$ cations $\left(\mathrm{Ca}^{2+}{ }_{\mathrm{cb}}\right)$ at $\mathrm{Al}$ tetrahedra $\left(\mathrm{AlO}_{2}{ }^{-}\right)$, which then become network-modifying $\mathrm{Ca}^{2+}\left(\mathrm{Ca}^{2+}{ }_{\mathrm{nm}}\right)$ and are available for $\mathrm{F}$ to form $\mathrm{F}-\mathrm{Ca}(\mathrm{n})$ sites.

$$
1 \mathrm{Na}^{+}{ }_{\mathrm{nm}}+\left[\mathrm{AlO}_{2}^{-}+0.5 \mathrm{Ca}^{2+}{ }_{\mathrm{cb}}\right] \rightarrow\left[\mathrm{AlO}_{2}^{-}+\mathrm{Na}^{+}{ }_{\mathrm{cb}}\right]+0.5 \mathrm{Ca}^{2+}{ }_{\mathrm{nm}}
$$

A relative increase of charge-balancing $\mathrm{Na}$ compared to charge-balancing $\mathrm{Ca}$ in $\mathrm{Na}_{2} \mathrm{O}-\mathrm{CaO}$ aluminosilicate melts was discussed by Kohn et al. (1991) to explain results from Luth and Muncill (1989), who found that $F$ in the system albite-anorthite decreases the activity of anorthite by possibly forming Ca-F complexes. The metaluminous calcium aluminosilicate glasses from Karpukhina et al. (2008) do not contain any $\mathrm{Na}$ and this can explain why they observed a decrease of the fraction of $\mathrm{F}-\mathrm{Ca}(\mathrm{n})$ sites compared to Al-F-Ca(n) sites with increasing F concentration.

\subsection{3. ${ }^{19} \mathrm{~F}$ in hydrous fluorine-bearing glasses}

Figure 3 shows the ${ }^{19} \mathrm{~F}$ MAS NMR spectra for the dry and hydrous sample NACS 2.4F collected at $2.3 \mathrm{~T}$ with an echo sequence to reduce the small background present with the available probe. A small PTFE peak, contamination by the reference material, was subtracted from the spectra. The general shape of the ${ }^{19} \mathrm{~F}$ spectrum of dry NACS 2.4F appears to be similar to that of the dry NACS 2.7F glass (Fig. 1) as expected since both glasses have nearly the same F content. Although there are small differences (max. $7 \mathrm{ppm}$ ) in the apparent positions of the $5 \mathrm{~F}$ peaks between 
the echo and the single pulse spectra, the spectra of the dry and hydrous samples of NACS 2.4F were all acquired with an echo sequence on the same spectrometer and should therefore be comparable to each other. The spectra of the hydrous NACS 2.4F samples reveal a significantly different $F$ speciation from the dry sample. The fractions of all the sites between the $\mathrm{F}-\mathrm{Ca}(\mathrm{n})$ site and the F-Na(n) where F exists with $\mathrm{Al}$ and Si (Al-F-Na(n) and Al-F-Al), decrease with increasing water content while the fraction of F-Ca(n) sites increases significantly.

No additional signal which could be related to the presence of HF was observed in the spectra. Schaller et al. (1992) concluded that undissociated HF in hydrous fluorine-bearing sodium aluminosilicate glasses is unlikely. As undissociated HF should have a broad signal due to strong $\mathrm{H}-\mathrm{F}$ heteronuclear dipole coupling (Schaller et al., 1992), minor amounts cannot be completely excluded as the whole ${ }^{19} \mathrm{~F}$ resonance is very broad. Schaller et al. (1992) also found no evidence that water has a large influence on $\mathrm{F}$ speciation in their sodium aluminosilicate glasses. The large effect of water on $\mathrm{F}$ speciation observed for the present $\mathrm{Na}_{2} \mathrm{O}-\mathrm{CaO}$ aluminosilicate glasses might be related to the presence of $\mathrm{Ca}$ and the possibility for $\mathrm{F}$ to form $\mathrm{F}-\mathrm{Ca}(\mathrm{n})$ sites.

Water in silicate melts exists as hydroxyl groups $(\mathrm{X}-\mathrm{OH})$ and molecular water $\left(\mathrm{H}_{2} \mathrm{O}\right)$ (Scholze, 1960; Bartholomew et al., 1980). The speciation of water in silicate glasses depends mainly on the concentration of water itself and not the bulk composition (Stolper, 1982; Silver et al., 1990).

One explanation for the change in $\mathrm{F}$ speciation in the present $\mathrm{Na}_{2} \mathrm{O}-\mathrm{CaO}$ aluminosilicate glasses due to the dissolution of water could be that $\mathrm{Ca}$ becomes more accessible for $\mathrm{F}$, because protons $\left(\mathrm{H}^{+}\right)$replace charge-balancing cations ( $\mathrm{Na}$, $\mathrm{Ca})$ at Al tetrahedra (e.g. Zeng et al., 2000). $\mathrm{H}^{+}$may also replace network-modifying Ca cations that are bonded to a NBO at Si tetrahedra, but this process would not lead to an increase in network-modifying Ca cations.

Another explanation for the change in $F$ speciation observed here due to the presence of water could be the formation of Al-OH groups. Several studies have shown that hydroxyl groups in aluminosilicate glasses bond to Al and their number increases with increasing $\mathrm{Al} /(\mathrm{Al}+\mathrm{Si})$ ratio (e.g. Zeng et al., 2000; Schmidt et al., 2001; Malfait and Xue, 2010). The present peralkaline glasses have a $\mathrm{Al} /(\mathrm{Al}+\mathrm{Si})$ ratio of 
0.27. Therefore, according to Malfait and Xue (2010), 15 to $20 \%$ of the hydroxyl groups in the present hydrous glasses should be bonded to Al. The NIR spectra of the hydrous glasses show that in the glass with $1.5 \mathrm{wt} \%$ water $(5.2 \mathrm{~mol} \%) \sim 70 \%$ of the water is dissolved as $\mathrm{X}-\mathrm{OH}$. In the glass with $5.3 \mathrm{wt} \%$ water $(16.5 \mathrm{~mol} \%) \sim 30 \%$ of the water is dissolved as $\mathrm{X}-\mathrm{OH}$. This means that 3.6 and $5.0 \mathrm{~mol} \%$ of the water are dissolved in the glass as $\mathrm{X}-\mathrm{OH}$, of which $20 \%$ may form Al-OH groups. Therefore, the number of $\mathrm{Al}-\mathrm{OH}$ groups in the glasses may account for $0.7 \mathrm{~mol} \%$ and $1.0 \mathrm{~mol} \%$. In the dry fluorine-bearing peralkaline glasses, up to $45 \%$ of the $F$ is located in sites with $\mathrm{Al}$ (counting the whole area of the Si-F-Na(n)/Al-F-Ca(n) site for Al). Disregarding for one moment that water causes a change in $\mathrm{F}$ speciation, this would mean for the hydrous NACS 2.4F glass with 16.5 mol\% water, that 0.9 mol\% F are located in sites with Al. These sites could contain either one (Al-F-Ca(n), Al-F-Na(n)) or two Al (Al-F-Al). In summary, in this approach between 0.9 and $1.8 \mathrm{~mol} \% \mathrm{Al}$ would be located in sites with $\mathrm{F}$ and $1 \mathrm{~mol} \% \mathrm{Al}$ is bonded to $\mathrm{OH}$. The glass NACS 2.4F with $16.5 \mathrm{~mol} \%$ water and $9.9 \mathrm{~mol} \% \mathrm{Al}_{2} \mathrm{O}_{3}$ theoretically contains enough $\mathrm{Al}$ for both sites. Hence, a simple lack of Al cannot be the reason for the decrease in the number of the sites Al-F-Na(n) and Al-F-Al due to the addition of water. We suggest that $\mathrm{OH}$ and $\mathrm{F}$ prefer the same Al environments and that $\mathrm{F}$ can not compete with $\mathrm{OH}$.

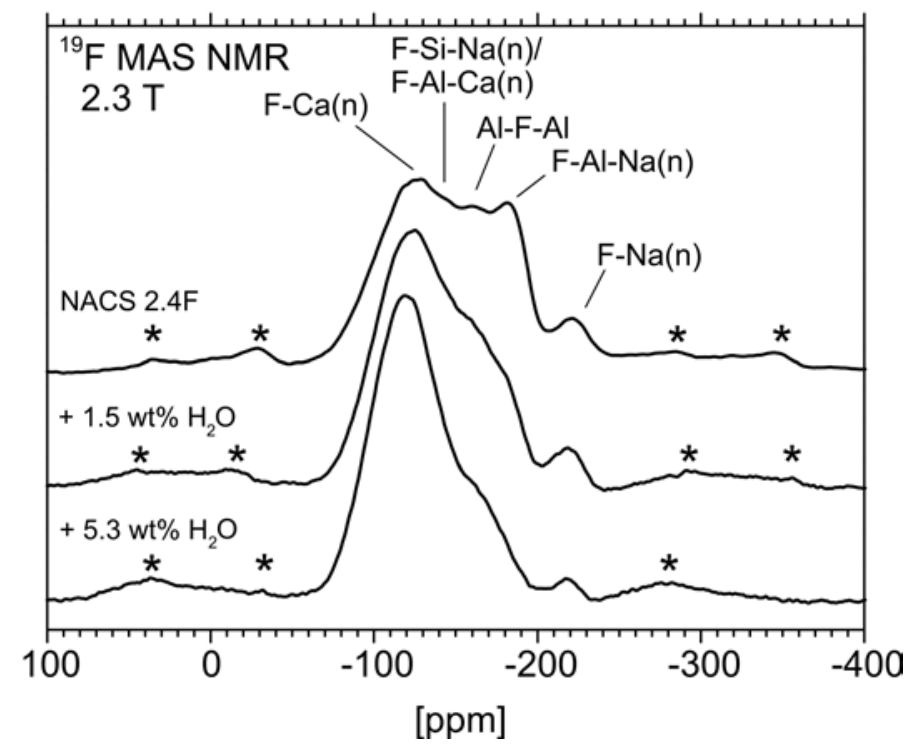

Fig. 3. ${ }^{19} \mathrm{~F}$ MAS NMR spectra at 2.3 T of the dry and hydrous samples of the peralkaline glass NACS 2.4F. Spinning sidebands are marked with an asterisk. The spectra were normalised to the same area. 


\subsection{4. ${ }^{23} \mathrm{Na}$}

Figure 4 shows ${ }^{23} \mathrm{Na}$ MAS NMR spectra of the fluorine-free and fluorine-bearing peralkaline and peraluminous glasses at $11.7 \mathrm{~T}$. Table 4 shows the position of the peak maxima, the centre of gravity and line width FWHM (full width half maximum). The peaks have a mixed Lorentzian-Gaussian shape. This shows that the peak shapes at this magnetic field are not strongly affected by second order quadrupole broadening. The positions of the peak maxima of the fluorine-free peralkaline glass are $5 \mathrm{ppm}$ higher and the FWHMs are $5 \mathrm{ppm}$ wider than those of the fluorine-free peraluminous glasses. The less negative shift of the signal of the peralkaline glasses compared to the peraluminous glasses could be related to network-modifying $\mathrm{Na}$ cations forming NBO (Lee and Stebbins, 2003). The centre of gravities of the fluorine-bearing glasses are shifted compared to the fluorine-free glasses by up to $-1.2 \mathrm{ppm}$ for the peraluminous glasses and up to $-3.2 \mathrm{ppm}$ for the peralkaline glasses. In the peralkaline glass NACS $6.2 \mathrm{~F}, 3 \%$ of the 6.2 mol\% F exist in $\mathrm{F}-\mathrm{Na}(\mathrm{n})$ sites. (see section 3.3.2). Assuming every $F$ is coordinated by six $\mathrm{Na}$ atoms $4.0 \%$ (NACS 6.2F) of all $\mathrm{Na}$ atoms exist in $\mathrm{F}-\mathrm{Na}(\mathrm{n})$ sites in this glass. Crystalline $\mathrm{NaF}$ has a ${ }^{23} \mathrm{Na}$ chemical shift of 5 to $7 \mathrm{ppm}$ (Zwanziger et al., 2006). If the $\mathrm{F}-\mathrm{Na}(\mathrm{n})$ environment in glasses has a similiar ${ }^{23} \mathrm{Na}$ chemical shift, its signal would lie in the high frequency flank of the ${ }^{23} \mathrm{Na}$ peak, where it would be difficult to observe, because of the small amount of $\mathrm{F}-\mathrm{Na}(\mathrm{n})$. The negative shift in centre of gravity of the fluorine-bearing glasses compared to the fluorine-free glasses might be partly related to the formation of Si-F-Na(n) and Al-F-Na(n) sites. However, this does not explain why the centre of gravity of the peralkaline glasses with $6.2 \mathrm{~mol} \% \mathrm{~F}$ (NACS 6.2F) is shifted more strongly to negative values than the peraluminous glass with 18.3 mol\% (ANCS 18.3F) as in the peraluminous glasses all $F$ exists in these sites and the glass contains more $\mathrm{F}$. It might be that a replacement mechanism of charge-balancing $\mathrm{Ca}$ by network-modifying $\mathrm{Na}$ cations due to the addition of $\mathrm{F}$ as discussed in equation 1 (see section 3.3.2) decreases the number of network-modifying $\mathrm{Na}$ cations and therefore causes a negative shift of the ${ }^{23} \mathrm{Na}$ signal. 


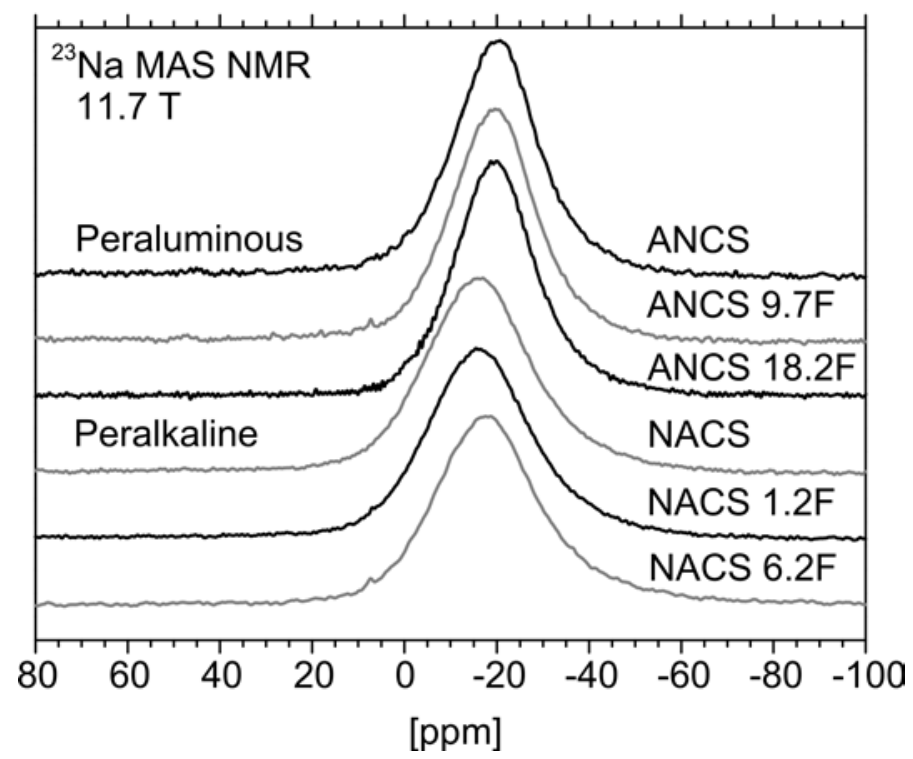

Fig. 4. ${ }^{23} \mathrm{Na}$ MAS NMR spectra at $11.7 \mathrm{~T}$ of fluorine-free and fluorine-bearing peraluminous and peralkaline glasses. The spectra were normalised to the same area. The small peak around $7 \mathrm{ppm}$ is a contamination due to the reference material $\mathrm{NaCl}$.

Table $4 .{ }^{23} \mathrm{Na}$ peak maximum, centre of gravity and full width half maximum FWHM of the ${ }^{23} \mathrm{Na}$ at $11.7 \mathrm{~T}^{\mathrm{a}}$.

\begin{tabular}{lccc}
\hline & $\begin{array}{c}\text { Peak maximum } \\
{[\mathrm{ppm}]}\end{array}$ & $\begin{array}{c}\text { Centre of gravity } \\
{[\mathrm{ppm}]}\end{array}$ & $\begin{array}{c}F W H M \\
{[\mathrm{ppm}]}\end{array}$ \\
\hline Peralkaline & & & \\
NACS & -17.0 & -16.9 & 25.7 \\
NACS 1.2F & -15.5 & -17.3 & 25.5 \\
NACS 6.2F & -18.7 & -20.1 & 25.0 \\
Peraluminous & & & \\
ANCS & -20.7 & -19.2 & 20.7 \\
ANCS 9.7F & -19.6 & -19.1 & 20.9 \\
ANCS 18.3F & -19.9 & -20.4 & 19.5 \\
\hline a - the errors of peak maximum, centre of gravity and FWHM are around $\pm 0.5 \mathrm{ppm}$.
\end{tabular}

\subsection{5. ${ }^{27} \mathrm{Al}$}

The NMR parameters (peak maximum, centre of gravity and line width $F W H M=$ full width half maximum) are given in Table 5 for the ${ }^{27} \mathrm{Al}$ MAS NMR spectra collected at $7 \mathrm{~T}, 11.7 \mathrm{~T}$ and $20 \mathrm{~T}$. Fig. 5 shows the ${ }^{27} \mathrm{Al}$ MAS NMR spectra at $11.7 \mathrm{~T}$ of the dry fluorine-free (NACS) and fluorine-bearing peralkaline glass with 6.2 mol\% F (NACS $6.2 \mathrm{~F}$ ). Only an $\mathrm{Al}^{\mathrm{IV}}$ peak is observable at 55 to $56 \mathrm{ppm}$. The peak maximum of the fluorine-bearing glass NACS $6.2 \mathrm{~F}$ is shifted about $-0.8 \mathrm{ppm}$ compared to the fluorine-free glass NACS. The general peak shape is identical. Figure 6 shows the centre of gravity $\delta_{c g}[\mathrm{ppm}]$ of the ${ }^{17} \mathrm{Al}$ MAS centrebands, measured at different magnetic fields as a function of the inverse squared Larmor frequency $v^{-2}\left[\mathrm{MHz}^{-2}\right]$ for 
the peralkaline glasses. The isotropic chemical shift $\delta_{\text {iso }}[\mathrm{ppm}]$ is calculated from the ordinate of the line fit to the data, and the quadrupole coupling constant $C_{q}[\mathrm{MHz}]$ from the slope of the line assuming an asymmetry parameter of $\eta=0.6$ in the equation described by Schmidt et al. (2000a, b):

$$
\delta_{c g}=\delta_{\text {iso }}-\left(3 C_{q}^{2} / 500 v_{0}^{2}\right)\left(1+\eta^{2} / 3\right)
$$

The calculated values for $\delta_{\text {iso }}$ and $C_{q}$ are given in Table 6 . The $\delta_{\text {iso }}$ of the peralkaline fluorine-bearing glasses is shifted up to $-3 \mathrm{ppm}$ and their $C_{q}$ decreases slightly ( $0.5 \mathrm{MHz})$ compared with the fluorine-free glass. To calculate the width due to the chemical shift distribution (CSD) $W_{c s d}[\mathrm{~Hz}]$ for the peralkaline glasses (Table 6) we used also a method described by Schmidt et al. (2000a, b) where $W_{c s d}[\mathrm{~Hz}]$ and the width due to the quadrupole effect $W_{q}[\mathrm{~Hz}]$ are calculated iteratively from the full width maxima $F W H M_{1}$ and $F W H M_{2}[\mathrm{~Hz}]$ of two spectra measured at two magnetic fields $B_{1}$ and $B_{2}[T]$.

$$
F W H M_{1}^{2}=W_{q}^{2}+W_{c s d}^{2}
$$

and

$$
F W H M_{2}^{2}=\left(B_{1} / B_{2}\right)^{2} W_{q}^{2}+\left(B_{2} / B_{1}\right)^{2} W_{c s d}^{2}
$$

${ }^{27} \mathrm{Al}$ data of peralkaline aluminosilicate glasses of other studies (Kohn et al., 1991; Stebbins et al., 2000) suggested that most $\mathrm{Al}$ in $\mathrm{Al}-\mathrm{F}$ sites is $\mathrm{Al}^{\mathrm{V}}$ and $\mathrm{Al}^{\mathrm{VI}}$. The peralkaline glass NACS $6.2 \mathrm{~F}$ studied here contains 6.2 mol\% $\mathrm{F}$, of which $33 \%$ exists in Al-F sites (Al-F-Al 13\%) and (Al-F-Na(n) 20\%) When in the peralkaline glass NACS 6.2F most $\mathrm{Al}$ in $\mathrm{Al}-\mathrm{F}-\mathrm{Al}$ and $\mathrm{Al}-\mathrm{F}-\mathrm{Na}(\mathrm{n})$ environments are $\mathrm{Al}^{\mathrm{V}}$ or $\mathrm{Al}^{\mathrm{VI}}$, their quantities are expected to be between 1.5\% (assuming $6 \mathrm{~F}$ per $\mathrm{Al}^{\mathrm{Vl}}$ ), 1.8\% (assuming $5 \mathrm{~F}$ per $\mathrm{Al}^{\mathrm{V}}$ ) and 9.1\% (assuming one $\mathrm{F}$ per $\mathrm{Al}^{\mathrm{V}}$ or $\mathrm{Al}^{\mathrm{Vl}}$ ) of the area of the $\mathrm{Al}$ spectrum. In ${ }^{27} \mathrm{Al}$ spectra at 8.45 T of fluorine-bearing peralkaline glasses of Kohn et al. (1991) amounts of $2.7 \% \mathrm{Al}^{\mathrm{V}}$ and $0.7 \% \mathrm{Al}^{\mathrm{VI}}$ were observable. Therefore, the presence of $\mathrm{a}$ significant amount of $\mathrm{Al}^{\mathrm{VI}}$ in our peralkaline glasses can be excluded. However, a small amount of $\mathrm{Al}^{\vee}$ less than in the glasses of Kohn et al. (1991) cannot be excluded. Stebbins et al. (2000) were able to resolve an amount of $1 \% \mathrm{Al}^{\mathrm{V}}$ in ${ }^{27} \mathrm{Al}$ spectra of their peralkaline albitic fluorine-bearing glasses, but only at a magnetic field of $14.1 \mathrm{~T}$ and higher. The negative shift of $\delta_{\text {iso }}$ and the peak maximum of the spectrum of the fluorine-bearing glass NACS $6.2 \mathrm{~F}$ compared to the fluorine-free glass NACS might 
be related to the presence of $\mathrm{Al}^{v}$. On the other hand this could be also caused by the effect of $\mathrm{F}$ on $\mathrm{Al}^{\mathrm{IV}}$ environment.

Figure 7A-B show the ${ }^{27} \mathrm{Al}$ MAS NMR spectra at $20 \mathrm{~T}$ for the peralkaline fluorine-free glass and the peraluminous fluorine-free and fluorine-bearing glasses. An $\mathrm{Al}^{\mathrm{IV}}$ peak at $55-59 \mathrm{ppm}$ and an $\mathrm{Al}^{\mathrm{V}}$ peak in its lower frequency flank at $\sim 30 \mathrm{ppm}$ in the spectra of the peraluminous glasses can be clearly distinguished. The peaks of $\mathrm{Al}^{\mathrm{lV}}$ and $\mathrm{Al}^{\mathrm{V}}$ at $20 \mathrm{~T}$ were deconvolved using the program DmFit (Massiot et al., 2002) to obtain the isotropic chemical shift $\delta_{\text {iso, }}$ the line width due to the chemical shift distribution $W_{c s d}$, the quadrupole coupling constant $C_{q}$ and the area of $\mathrm{Al}^{\mathrm{IV}}$ and $\mathrm{Al}^{\mathrm{V}}$ (Table 6). The parameters derived from DmFit and the two methods using spectra from different fields (Eq. 2-4) for the sample NACS, are in good agreement. Because of the significant presence of $\mathrm{Al}^{\mathrm{V}}$ in the peraluminous glasses the evaluation by Schmidt et al. $(2000 a, b)$ is not useful for the present peraluminous glasses, as the method is applied to the entire centre band and does not distinguish between $\mathrm{Al}^{\mathrm{VI}}$ and $\mathrm{Al}^{\mathrm{V}}$.

The $\mathrm{Al}^{\mathrm{IV}}$ peak in the peraluminous fluorine-free glass has a $\sim-0.8 \mathrm{ppm}$ lower $\delta_{\text {iso }}$ than the peralkaline fluorine-free glass. This shows that in both glasses $A I^{\mathrm{IV}}$ exists mainly as $\mathrm{Q}^{4}$ species, i.e. Al tetrahedrally coordinated by four $\mathrm{BO}$ connected to other $\mathrm{Si}$ or $\mathrm{Al}$ tetrahedra. In the peralkaline glass a large amount of $\mathrm{Al}^{3}$ species, where $\mathrm{Al}$ is coordinated by three $\mathrm{BO}$ and one $\mathrm{NBO}$, was not expected, as in aluminosilicate glasses most network-modifying cations create NBO at Si tetrahedra and not at $\mathrm{Al}$ tetrahedra (e.g. Allwardt et al., 2003; Lee et al., 2004; Lee and Stebbins, 2006; Lee and Stebbins, 2009). The higher $C_{q}$ of the peraluminous glasses indicates that the $\mathrm{Al}^{\mathrm{IV}}$ are more distorted than in the peralkaline glasses. It appears that the CSD of $\mathrm{Al}^{\mathrm{IV}}$ in the peraluminous ANCS 18.3F glass is smaller than in the fluorine-free glass (ANCS), which means the $\mathrm{Al}^{\mathrm{lV}}$ environment becomes more symmetric. Such behaviour was also observed in other studies (e.g. Kohn et al., 1991).

In the spectra of the peralkaline glass no $\mathrm{Al}^{\mathrm{V}}$ or $\mathrm{Al}^{\mathrm{Vl}}$ is observable, while in all peraluminous glasses, within error, around $5 \%$ of $\mathrm{Al}$ is $\mathrm{Al}^{\vee}$. This amount is consistent with data from fluorine-free potassium aluminosilicate glasses (Thompson and Stebbins, 2011). We observed that the amount of $\mathrm{Al}^{\mathrm{V}}$ does not increase nor is there a significant amount of $\mathrm{Al}^{\mathrm{VI}}$ present for the addition of up to $18.2 \mathrm{~mol} \% \mathrm{~F}$. However, while the $\mathrm{Al}^{\vee}$ peak in the peraluminous sample containing $9.7 \mathrm{~mol} \% \mathrm{~F}$ (ANCS 9.7F) is 
quite similar to that in the fluorine-free sample (ANCS), the $\mathrm{Al}^{\mathrm{V}}$ peak in the sample containing $18.3 \mathrm{~mol} \% \mathrm{~F}$ (ANCS 18.3F) is shifted by $-2.8 \mathrm{ppm}$ compared to the fluorine-free sample ANCS and the CSD and the $C_{q}$ are smaller. This suggests that $F$ is present in sites containing $\mathrm{Al}^{\mathrm{V}}$ in the fluorine-bearing peraluminous glasses and the $\mathrm{Al}^{\mathrm{V}}$ environment becomes more symmetric. The lowering of the chemical shift of $\mathrm{Al}^{\mathrm{V}}$ due to the presence of F was also observed by Kohn et al. (1991) and is predicted by Liu and Nekvasil (2001).

Several authors suggest that $F$ in aluminosilicate glasses is located in sites with higher coordinated Al (Kohn et al., 1991; Schaller et al., 1992; Stebbins et al., 2000). The following consideration should test if this is also plausible for the present peraluminous glasses. In the peraluminous glass with 18.3 mol\% F (ANCS 18.3F) $60 \%$ of the $\mathrm{F}$ is located in $\mathrm{Al}-\mathrm{F}-\mathrm{Na}(\mathrm{n})$ sites and $9 \%$ in Al-F-Al. As discussed in section 3.3.1., in both sites $\mathrm{Al}$ could be $\mathrm{Al}^{\mathrm{V}}$. Assuming that $\mathrm{Al}$ in these sites is only $\mathrm{Al}^{\mathrm{V}}$ this would mean that there are $12.6 \mathrm{~mol} \% \mathrm{~F}$ bonded to $1.6 \mathrm{~mol} \% \mathrm{Al}^{\vee}$ and the $\mathrm{F}^{\mathrm{Al}} \mathrm{I}^{\vee}$ ratio would be 7.9. This is not possible; as the maximum $\mathrm{F}^{\mathrm{A}} \mathrm{V}^{\vee}$ ratio is 5 (because of five-coordinated $\mathrm{Al}$ ). Thus, the $\mathrm{Al}$ in the sites Al-F-Al and Al-F-Na(n) cannot be only $\mathrm{Al}^{\mathrm{V}}$. Even if one assumes only the $\mathrm{Al}$ in the Al-F-Al site (which contains $9 \%$ of the $\mathrm{F}$ in glass ANCS 18.3F) is $\mathrm{Al}^{\mathrm{V}}$, there is not enough $\mathrm{Al}^{\mathrm{V}}$ because every $\mathrm{F}$ needs two $\mathrm{Al}^{\mathrm{V}}$ to form this site. However, as discussed before (see section 3.3.1), $\mathrm{Al}^{\mathrm{IV}}$ in an Al-F-Al site and an Al-F-Na(n) site could contribute to the two peaks at around $-168 \mathrm{ppm}$ and $-190 \mathrm{ppm}$ in the ${ }^{19} \mathrm{~F}$ spectra. The increase in symmetry of $\mathrm{Al}^{\vee}$ due to the addition of $\mathrm{F}$ indicates that $\mathrm{F}$ forms together with $\mathrm{Al}^{\mathrm{V}} \mathrm{AlF}_{5}{ }^{2-}$ or $\mathrm{AlF}_{3} \mathrm{O}_{2}{ }^{2-}$ clusters (Tossell, 1993). $\mathrm{F}$ located in such sites with some $\mathrm{Na}$ cations nearby would then contribute to the peak assigned as Al-F-Na(n) site at -190 ppm (Liu and Nekvasil, 2002; Liu and Tossell, 2003).

In summary, the presence of a significant amount of $\mathrm{Al}^{\mathrm{Vl}}$ can be excluded for the peralkaline and peraluminous glasses studied here. The effects of $F$ on the environment of $\mathrm{Al}^{\mathrm{V}}$ indicate that some $\mathrm{Al}^{\mathrm{V}}$ is present in $\mathrm{Al}-\mathrm{F}-\mathrm{Na}(\mathrm{n})$ sites that contribute to the peak at $\sim-190 \mathrm{ppm}$ in ${ }^{19} \mathrm{~F}$ spectra, but from mass balance it seems that $\mathrm{Al}^{\mathrm{IV}}$ in Al-F-Na(n) sites also contributes to this peak. 
Table $5 .{ }^{27} \mathrm{Al}$ peak maximum, centre of gravity and full width half maximum FWHM of the ${ }^{27} \mathrm{Al}$ spectra at different fields ${ }^{\text {ab }}$.

\begin{tabular}{lccccccccc}
\hline & \multicolumn{3}{c}{ Peak maximum } & \multicolumn{3}{c}{ Center of gravity } & \multicolumn{3}{c}{$\begin{array}{c}F W H M \\
{[\mathrm{ppm}]}\end{array}$} \\
& $7 \mathrm{~T}$ & $11.7 \mathrm{~T}$ & $20 \mathrm{~T}$ & $7 \mathrm{~T}$ & $11.7 \mathrm{~T}$ & $20 \mathrm{~T}$ & $7 \mathrm{~T}$ & $11.7 \mathrm{~T}$ & $20 \mathrm{~T}$ \\
\hline Peralkaline & & & & & & & & & \\
NACS & 49.8 & 55.5 & 58.8 & 33.8 & 51.2 & 58.6 & 34.2 & 16.9 & 12.1 \\
NACS 1.2F & 50.1 & 55.5 & - & 36.7 & 51.3 & - & 33.2 & 16.7 & - \\
NACS 6.2F & 49.8 & 54.8 & - & 35.9 & 50.9 & - & 34.5 & 17.4 & - \\
Peraluminous & & & & & & & & & \\
ANCS & 47.0 & 52.6 & 57.0 & 29.5 & 43.9 & 54.3 & 46.7 & 23.2 & 15.0 \\
ANCS 9.7F & 47.6 & 52.4 & 55.9 & 25.0 & 41.3 & 52.0 & 50.5 & 25.2 & 16.0 \\
ANCS 18.3F & 46.7 & 51.4 & 55.2 & 21.1 & 38.3 & 51.7 & 53.2 & 26.2 & 15.7 \\
\hline
\end{tabular}

$\mathrm{a}$ - The errors of peak maximum, centre of gravity and FWHM are around $\pm 0.5 \mathrm{ppm}$ for the $7 \mathrm{~T}$ spectra and $\pm 0.25 \mathrm{ppm}$ for the 11.7 and $20 \mathrm{~T}$ spectra.

b - Frequencies are $78.2 \mathrm{MHz}$ at $7 \mathrm{~T}, 130.3 \mathrm{MHz}$ at $11.7 \mathrm{~T}$ and $221.6 \mathrm{MHz}$ at $20 \mathrm{~T}$.

Table $6 .{ }^{27} \mathrm{Al}$ Isotropic chemical shift $\delta_{\text {iso }}$, width due to chemical shift distribution $W_{\text {csd }}$ and quadrupole coupling constant $C_{q}$ and area of total spectrum obtained from fitting spectra at $20 \mathrm{~T}$ with the program DMFit and evaluation of spectra at 7 and $11.7 \mathrm{~T}$ described by e.g. Schmidt et al. (2000a, b) (see section 3.3.5).

\begin{tabular}{lcccc}
\hline & \multicolumn{3}{c}{ DMFit } & \\
\hline & $\begin{array}{c}\delta_{\text {iso }}{ }^{a} \\
{[\mathrm{ppm}]}\end{array}$ & $\begin{array}{c}W_{\text {csd }}{ }^{\mathrm{a}} \\
{[\mathrm{ppm}]}\end{array}$ & $\begin{array}{c}C_{q}^{\mathrm{b}} \\
{[\mathrm{MHz}]}\end{array}$ & $\begin{array}{c}\text { area } \\
{[\%]}\end{array}$ \\
\hline Al $^{\mathrm{IV}}$ & 61.3 & 10.4 & 4.5 & 100.0 \\
NACS & 60.5 & 11.1 & 6.8 & 94.3 \\
ANCS & 60.5 & 11.1 & 6.8 & 94.3 \\
ANCS 9.7F & 60.0 & 10.7 & 6.8 & 95.6 \\
ANCS 18.3F & & & & \\
Al $^{\mathrm{V}}$ & 34.7 & 15.4 & 7.4 & 5.7 \\
ANCS & 34.5 & 16.3 & 7.1 & 5.7 \\
ANCS 9.7F & 31.9 & 12.5 & 6.7 & 4.5 \\
\hline ANCS 18.3F &
\end{tabular}

\begin{tabular}{lllll}
\hline \multicolumn{5}{c}{ Evaluation after Schmidt et al. (2000a, b) } \\
\hline Al $^{\text {IV }}$ & 62 & 12.4 & 5.1 & 100 \\
NACS & 60 & 12.4 & 4.6 & 100 \\
NACS 1.2F & 59 & 13.1 & 4.6 & 100 \\
NACS 6.2F & 59
\end{tabular}

a - The maximum errors for $\delta_{\text {iso, }} W_{\text {csd }}$ derived from fitting with DmFit are around $\pm 0.25 \mathrm{ppm}$ and those derived from the evaluation methods after Schmidt et al. (2000a, b) \pm 1 ppm.

$\mathrm{b}-C_{q}$ was calculated estimating asymmetry parameter $\eta=0.6$. The maximum error of $C_{q}$ is $\pm 0.4 \mathrm{MHz}$ taking in account that $\eta$ could range from 0 to 1. 


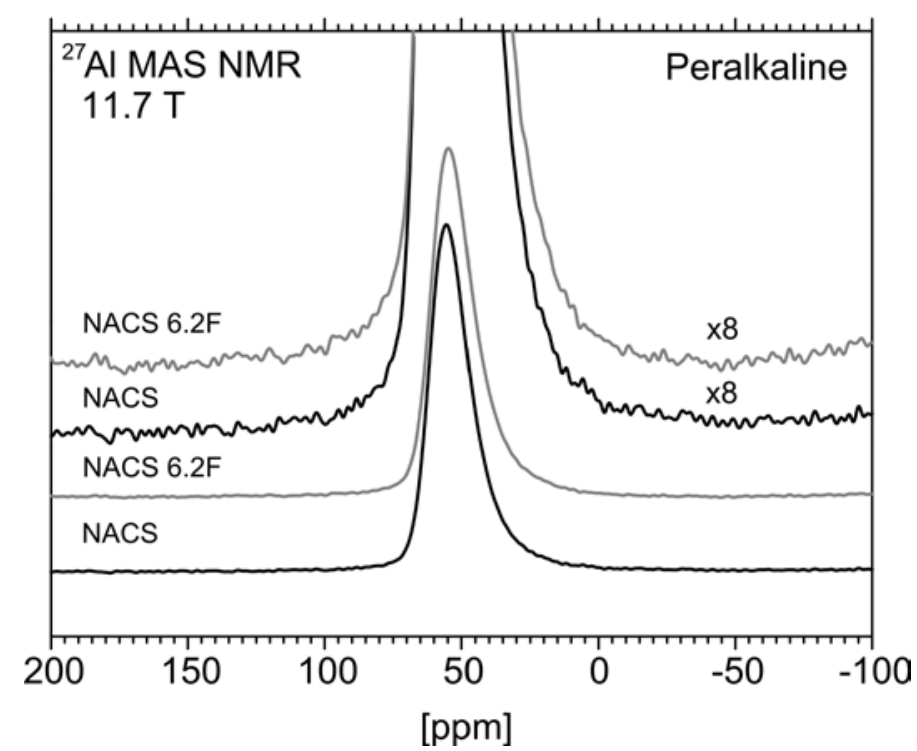

Fig. 5. ${ }^{27} \mathrm{Al}$ MAS NMR spectra at $11.7 \mathrm{~T}$ spectrometer of peralkaline fluorine-free (NACS) and the fluorine-bearing glass with $6.2 \mathrm{~mol} \% \mathrm{~F}$ (NACS 6.2F). The spectra were normalised to the same peak height.

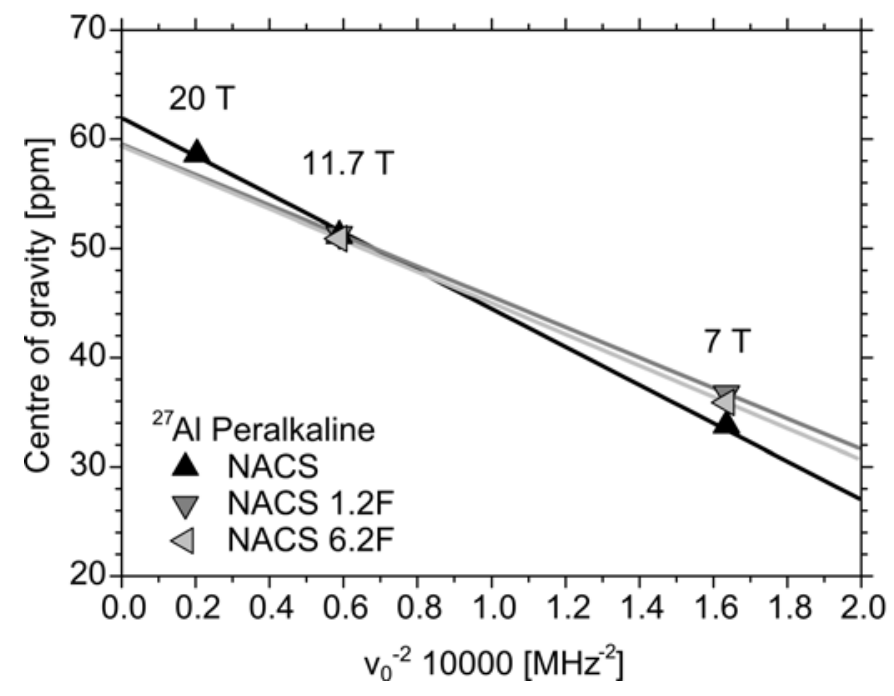

Fig. 6. Centre of gravity of ${ }^{27} \mathrm{Al}$ central bands of the fluorine-free and fluorine-bearing peralkaline glasses as a function of inverse squared Larmor frequency $v_{0}^{-2}$. The ordinate of the lines fitted to the data is the isotropic chemical shift $\delta_{i s o}$ and the quadrupole coupling $C_{q}$ constant was calculated from the slope (see section 3.3.5 and Table 6). The numbers over the data are the magnetic fields in Tesla. 

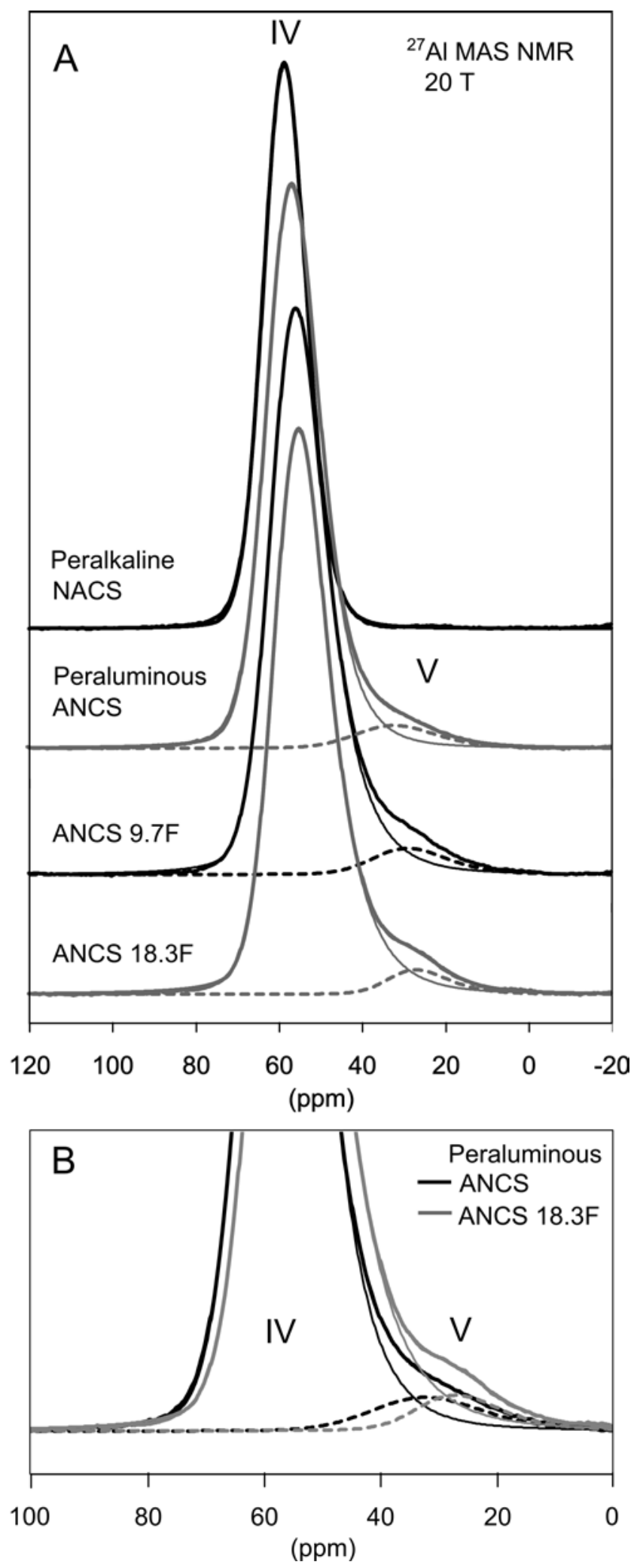

Fig. 7. (A) ${ }^{27} \mathrm{Al}$ MAS NMR spectra of fluorine-free and fluorine-bearing peralkaline and peraluminous glasses at $20 \mathrm{~T}$ and fitted peaks for four- $(\mathrm{VI})$ and five-coordinated $(\mathrm{V})$ (shown dashed) aluminium. Six-coordinated aluminium would be expected around $0 \mathrm{ppm}$, but is not observed here. The spectra were normalised to the same height of the central band. (B) Enlarged overlay of the fluorine-free and a fluorine-bearing peraluminous glass. 


\subsection{6. ${ }^{29} \mathrm{Si}$}

Figure 8 shows ${ }^{29}$ Si MAS NMR spectra of some dry fluorine-free and fluorine-bearing peralkaline and peraluminous glasses. Table 7 shows the isotropic chemical shift $\delta_{\text {iso, }}$ the centre of gravity and the line width FWHM (full width half maximum). The peak for the halogen-free peralkaline glass (NACS) at $-96.3 \mathrm{ppm}$ is shifted compared to the halogen-free peraluminous glass (ANCS) at $-100.4 \mathrm{ppm}$ by about $+4 \mathrm{ppm}$. In the peraluminous glass (NBO/T of -0.08) all $\mathrm{Si}$ are expected to be $\mathrm{Q}^{4}$ species ( $\mathrm{Si}$ coordinated by $4 \mathrm{BO}$ ), while in the peralkaline glasses (NBO/T of 0.24 ) $\sim 25 \%$ of the Si are expected to be $\mathrm{Q}^{3}$ species ( $\mathrm{Si}$ coordinated by three $\mathrm{BO}$ and one NBO) and $\sim 75 \% \mathrm{Q}^{4}$ species. The observed shift in $\delta_{\text {iso }}$ to higher ppm values between the fluorine-free peralkaline and peraluminous glass reflects the depolymerisation of the glass network (e.g. Engelhardt and Michel, 1987). In the peraluminous glass with 9.7 mol\% F (ANCS 9.7F) the peak is shifted by about +1 ppm compared to the fluorine-free peraluminous glass, indicating some depolymerisation of the glass network. We think this shift is related to the formation of non-bridging Si-F-Na(n) sites as we found no charge-balanced mechanism by which due to the incorporation of $F$ in the glass structure the number of NBO should be increased (see section 3.3.2). In the peralkaline glasses the addition of $1.2 \mathrm{~mol} \% \mathrm{~F}$ leads to no significant effect on the Si environment. It appears that there possibly is a slight shift of $0.5 \mathrm{ppm}$ to lower ppm values indicating some polymerisation. This is consistent with the observed formation of $\mathrm{F}-\mathrm{Na}(\mathrm{n})$ and $\mathrm{F}-\mathrm{Ca}(\mathrm{n})$ sites, which decreases the number of network-modifying cations and therefore the number of NBOs.

Table $7 .{ }^{29} \mathrm{Si}$ isotropic chemical shift $\delta_{\text {iso, }}$, centre of gravity and full width half maximum $(F W H M)$ of the ${ }^{29} \mathrm{Si}$ at $7 \mathrm{~T}^{\mathrm{a}}$.

\begin{tabular}{lccc}
\hline & $\begin{array}{c}\delta_{\text {iso }} \\
{[\mathrm{ppm}]}\end{array}$ & $\begin{array}{c}\text { Centre of gravity } \\
{[\mathrm{ppm}]}\end{array}$ & $\begin{array}{c}F W H M \\
{[\mathrm{ppm}]}\end{array}$ \\
\hline NACS & -96.3 & -96.2 & 17.1 \\
NACS 1.2F & -96.3 & -96.7 & 17.3 \\
ANCS & -100.4 & -100.4 & 17.9 \\
ANCS 9.7F & -99.6 & -99.4 & 17.4 \\
\hline a - the errors of $\delta_{\text {iso }}$, centre of gravity and $F W H M$ are around $\pm 0.4 \mathrm{ppm}$.
\end{tabular}




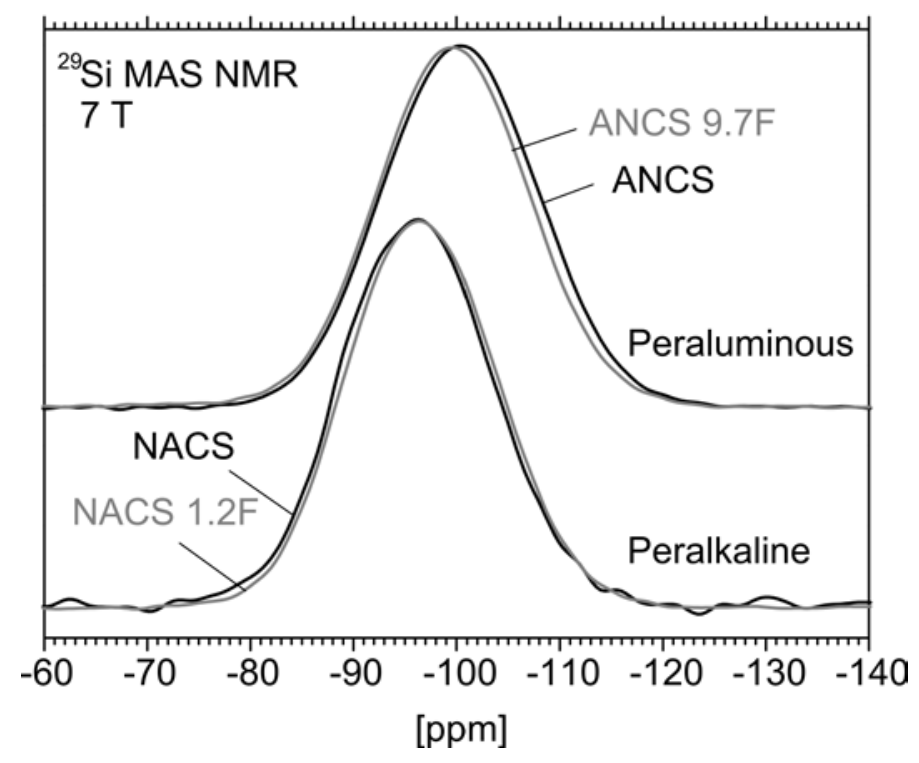

Fig. $8 .{ }^{29}$ Si MAS NMR spectra at $7 \mathrm{~T}$ of fluorine-free (black line) and fluorine-bearing (grey line) peralkaline and peraluminous glasses. The spectra were normalised to the same peak height.

\subsubsection{Implications for $F$ diffusion}

Böhm and Schmidt (2013) proposed that the higher diffusivity of F compared to oxygen in phonolites indicates that the diffusion of $F$ is decoupled from the aluminosilicate network and could be related to the formation of alkali- or alkalineearth-halogen species. We found in our peralkaline glasses, with a composition that is a model system for phonolites, a significant amount of such alkali- and alkalineearth-halogen species. Our results also show that the higher diffusivity of $F$ in hydrous silicate melts (e.g. Böhm and Schmidt, 2013) are not necessarily related to the formation of HF species, but can also be explained by an increase in the number of $\mathrm{F}-\mathrm{Ca}(\mathrm{n})$ and $\mathrm{F}-\mathrm{Na}(\mathrm{n})$ sites compared to sites where $\mathrm{F}$ is bonded to network-building $\mathrm{Al}$ and $\mathrm{Si}$. 


\subsection{Conclusions}

The speciation of $\mathrm{F}$ in $\mathrm{Na}_{2} \mathrm{O}-\mathrm{CaO}$ aluminosilicate glasses depends on the $\left[\mathrm{Na}_{2} \mathrm{O}+\mathrm{CaO}\right] / \mathrm{Al}_{2} \mathrm{O}_{3}$ ratio and on the $\mathrm{F}$ concentration itself. In the peraluminous glasses $\mathrm{F}$ only bonds to the network-building cations $\mathrm{Si}$ and $\mathrm{Al}$, while in peralkaline glasses $\mathrm{F}$ additionally bonds to the network-modifying cations $\mathrm{Ca}$ and $\mathrm{Na}$ by forming salt-like environments. In the peralkaline $\mathrm{Na}_{2} \mathrm{O}-\mathrm{CaO}$ aluminosilicate glasses $\mathrm{F}$ preferentially exists in salt-like environments with $\mathrm{Ca}$, although $\mathrm{Ca}$ is the least common cation. It appears $F$ can only form salt-like environments with network-modifying $\mathrm{Ca}$ and $\mathrm{Na}$ cations, but cannot compete with $\mathrm{Al}$ for charge-balancing cations. $\mathrm{F}$ incorporation in $\mathrm{Na}_{2} \mathrm{O}-\mathrm{CaO}$ aluminosilicate glasses does not lead to the formation of $\mathrm{Al}^{\mathrm{Vl}}$. Si-F bonding is likely in peralkaline and peraluminous $\mathrm{Na}_{2} \mathrm{O}-\mathrm{CaO}$ aluminosilicate glasses. In contrast to water speciation, $\mathrm{F}$ speciation depends more on composition than on concentration. Water in peralkaline $\mathrm{Na}_{2} \mathrm{O}-\mathrm{CaO}$ aluminosilicate glasses has a strong influence on the $\mathrm{F}$ speciation, leading to an increase in the number of $\mathrm{F}-\mathrm{Ca}(\mathrm{n})$ sites and a decrease in the number of Al-F-Al and Al-F-Na(n) sites. The dependence of F speciation on composition, the $F$ concentration and the presence of water can explain the different diffusivity of $F$ in silicate melts.

\section{Acknowledgements}

We thank Dr. T. Kemp from Warwick University for his assistance in collecting ${ }^{19} \mathrm{~F}$ NMR spectra on the $100 \mathrm{MHz}$ spectrometer. This project was funded by the DFG grant WE 1810/9-1. The UK $850 \mathrm{MHz}$ solid-state NMR Facility used in this research was funded by EPSRC and BBSRC, as well as the University of Warwick including via part funding through Birmingham Science City Advanced Materials Projects 1 and 2 supported by Advantage West Midlands (AWM) and the European Regional Development Fund (ERDF).We thank Prof. Dr. Harald Behrens and the team of the Mineralogy Department of the University of Hannover for the use of the Karl-Fischer-Titration. 


\section{References}

Aiuppa, A., Baker, D.R., Webster, J.D., 2009. Halogens in volcanic systems. Chem. Geol. 263, 1-18.

Allwardt, J.R., Lee, S.K., Stebbins, J.F., 2003. Bonding preferences of non-bridging O atoms: Evidence from ${ }^{17} \mathrm{O}$ MAS and 3QMAS NMR on calcium aluminate and low-silica Ca-aluminosilicate glasses. Am. Mineral. 88, 949-954.

Baasner, A., Schmidt, B.C., Webb, S.L., 2013a. Compositional dependence of the rheology of halogen $(\mathrm{F}, \mathrm{Cl})$ bearing melts. Chem. Geol. 346, 172-183.

Baasner, A., Schmidt, B.C., Webb, S.L., 2013b. The effect of chlorine, fluorine and water on the viscosity of aluminosilicate melts. Chem. Geol. 357, 134-149.

Bailey, J.C., 1977. Fluorine in granitic rocks and melts: A review. Chem. Geol. 19, 1-42.

Bartels, A., Behrens, H., Holtz, F., Schmidt, B.C., Fechtelkord, M., Knipping, J., Crede, L., Baasner, A., Pukallus, N., 2013. The effect of fluorine, boron and phosphorus on the viscosity of pegmatite forming melts. Chem. Geol. 346, 184-198.

Bartholomew, R.F., Butler, B.L., Hoover, H.L., Wu, C.K., 1980. Infrared spectra of a water-containing glass. J. Am. Ceram. Soc. 63, 481-485.

Behrens, H., Romano, C., Nowak, M., Holtz, F., Dingwell, D. B., 1996. Near-infrared spectroscopic determination of water species in glasses of the system $\mathrm{MAISi}_{3} \mathrm{O}_{8}(\mathrm{M}=\mathrm{Li}$, $\mathrm{Na}, \mathrm{K}$ ): an interlaboratory study. Chem. Geol. 128, 41-63.

Brauer, D.S., Karpukhina, N., Law, R. V., Hill, R.G., 2009. Structure of fluoride-containing bioactive glasses. J. Mater. Chem. 19, 5629-5636.

Böhm, A., Schmidt, B.C., 2013. Fluorine and chlorine diffusion in phonolitic melt. Chem. Geol. 346, 162-171.

Dingwell, D.B., Knoche, R., Webb, S.L., 1993. The effect of F on the density of haplogranite melt. Am. Mineral. 78, 325-330.

Dingwell, D.B., Scarfe, C.M., Cronin, D.J., 1985. The effect of F on viscosities in the system $\mathrm{Na}_{2} \mathrm{O}-\mathrm{Al}_{2} \mathrm{O}_{3}-\mathrm{SiO}_{2}$ implications for phonolites, trachytes and rhyolites. Am. Mineral. 70, 80-87.

Engelhardt, G., Michel, D., 1987. High-Resolution Solid-State NMR of Silicates and Zeolites. John Wiley \& Sons, Chichester. 
Frisoni, S., Brenna, S., Masciocchi, N., 2011. Structural characterization of anhydrous and bishydrated hexafluorosilicate by powder diffraction methods. Powder Diffr. 26, 308-312.

Giordano, D., Romano, C., Dingwell, D. B., Poe, B., Behrens, H., 2004. The combined effects of water and fluorine on the viscosity of silicic magmas. Geochim. Cosmochim. Acta 68, 5159-5168.

Holtz, F., Dingwell, D.B., Behrens, H., 1993. Effects of $F, B_{2} \mathrm{O}_{3}$, and $\mathrm{P}_{2} \mathrm{O}_{5}$ on the solubility of water in haplogranite melts compared to natural silicate melts. Contrib. Mineral. Petrol. $113,492-501$.

Jakse N., Bouhadja, M., Kozaily, J., Drewitt, J.W.E., Hennet, L., Neuville, D.R., Fischer, H.E., Cristiglio, V., Pasturel, A., 2012. Interplay between non-bridging oxygen, triclusters, and fivefold Al coordination in low silica content calcium aluminosilicate melts. Appl. Phys. Lett. 101, 201903.

Jiang, N., 2002. On detection of non-bridging oxygen in glasses by electron-energy-loss spectroscopy. Solid State Commun. 122, 7-10.

Karpukhina, N., Law, R.V., Hill, R.G., 2008. Solid state NMR study of calcium fluoroaluminosilicate glasses. Adv. Mat. Res. 39-40, 25-30.

Kiczenski, T.J., Stebbins, J.F., 2002. Fluorine sites in calcium and barium oxyfluorides: F-19 NMR on crystalline model compounds and glasses. J. Non-Cryst. Solids 306, 160-168.

Kohn, S.C., Dupree, R., Mortuza, M.G., Henderson, C.M.B., 1991. NMR evidence for five- and six-coordinated aluminium fluoride complexes in F-bearing aluminosilicate glasses. Am. Mineral. 76, 309-312.

Lee, S.K., Stebbins, J.F., 2003. The distribution of sodium ions in aluminosilicate glasses: A high-field Na-23 MAS and 3QMAS NMR study. Geochim. Cosmochim. Acta 67, 1699-1709.

Lee, S.K., 2004. Structure of silicate glasses and melts at high pressure: Quantum chemical calculations and solid-state NMR. J. Phys. Chem. B 108, 5889-5900.

Lee, S.K., Cody, G.D., Fei, Y., Mysen, B.O., 2004. Nature of polymerization and properties of silicate melts and glasses at high pressure. Geochim. Cosmochim. Acta 68, 4189-4200.

Lee, S.K., Stebbins J.F., 2006. Disorder and extent of polymerization in calcium silicate and aluminosilicate glasses: 0-17 NMR results and quantum chemical molecular orbital calculations. Geochim. Cosmochim. Acta 70, 4275-4286. 
Lee, S.K., Stebbins, J.F., 2009. Effects of the degree of polymerization on the structure of sodium silicate and aluminosilicate glasses and melts: An ${ }^{17} \mathrm{O}$ NMR study. Geochim. Cosmochim. Acta 73, 1109-1119.

Liu, Y., Nekvasil, H., 2001. Ab initio studies of possible fluorine-bearing four- and fivefold coordinated Al species in aluminosilicate glasses. Am. Mineral. 86, 491-497.

Liu, Y., Nekvasil, H., 2002. Si-F bonding in aluminosilicate glasses: Inferences from ab initio NMR calculations. Am. Mineral. 87, 339-346.

Liu, Y., Tossell, J., 2003. Possible Al-F bonding environment in fluorine-bearing sodium aluminosilicate glasses: From calculations of ${ }^{19} \mathrm{~F}$ NMR shifts. J. Phys. Chem. B 107, 11280 - 11289.

Luth, R.W., Muncill, G.E., 1989. Fluorine in aluminosilicate systems: Phase relations in the system $\mathrm{NaAlSi}_{3} \mathrm{O}_{8}-\mathrm{CaAl}_{2} \mathrm{Si}_{2} \mathrm{O}_{8}-\mathrm{F}_{2} \mathrm{O}_{-1}$. Geochim. Cosmochim. Acta 53, 1937-1942.

Malfait, W.J., Xue, X., 2010. The nature of hydroxyl groups in aluminosilicate glasses: Quantifying $\mathrm{Si}-\mathrm{OH}$ and $\mathrm{Al}-\mathrm{OH}$ abundances along the $\mathrm{SiO}_{2}-\mathrm{NaAlSiO}_{4}$ join by ${ }^{1} \mathrm{H},{ }^{27} \mathrm{Al}-{ }^{1} \mathrm{H}$ and ${ }^{29} \mathrm{Si}^{1}{ }^{1} \mathrm{H}$ NMR spectroscopy. Geochim. Cosmochim. Acta 74, 719-737.

Manning, D.A.C., 1981. The effect of fluorine on liquidus phase relationships in the system Qz-Ab-Or with excess water at 1kb. Contrib. Mineral. Petrol. 76, 206-215.

Massiot, D., Fayon, F., Capron, M., King, I., Le Calve, S., Alonso, B., Durand, J.-O., Bujoli, B., Gan, Z., Hoatson, G., 2002. Modelling one- and two-dimensional solid-state NMR spectra. Magn. Reson. Chem. 40, 70-76.

Miller, J.M., 1996. Fluorine-19 magic-angle spinning NMR. Prog. Nucl. Mag. Res. Sp. 28, 255-281.

Mysen, B.O., 1987. Magmatic silicate melts, in: Mysen, B.O. (Ed.), Magmatic Processes: Physicochemical Principles, Special Publication No. 1. The Geochemical Society, University Park, Pennsylvania, pp. 375-399.

Mysen, B.O., Cody, G.D., Smith, A., 2004. Solubility mechanisms of fluorine in peralkaline and meta-aluminous silicate glasses and in melts to magmatic temperatures. Geochim. Cosmochim. Acta 68, 2745-2769.

Neuville, D.R., Cormier, L., Massiot, D., 2006. Al coordination and speciation in calcium aluminosilicate glasses: Effects of composition determined by ${ }^{27} \mathrm{Al}$ MQ-MAS NMR and Raman spectroscopy. Chem. Geol. 229, 173-185.

Roux, J., Lefèvre, A., 1992. A fast-quench device for internally heated pressure vessels. Eur. J. Mineral. 4, 279-281. 
Schaller, T., Dingwell, D.B., Keppler, H., Knöller, W., Merwin, L., Sebald, A., 1992. Fluorine in silicate glasses: A multinuclear magnetic resonance study. Geochim. Cosmochim. Acta 56, 701-707.

Schmidt, B.C., Riemer, T., Kohn, S.C., Behrens, H., Dupree, R., 2000a. Different water solubility mechanisms in hydrous glasses along the Qz-Ab join: Evidence from NMR spectroscopy. Geochim. Cosmochim. Acta 64, 513-526.

Schmidt, B.C., Riemer, T., Kohn, S.C., Behrens, H., Dupree, R., 2000b. Erratum to "Different water solubility mechanisms in hydrous glasses along the Qz-Ab join: Evidence from NMR spectroscopy". Geochim. Cosmochim. Acta 64, 2895-2896.

Schmidt, B.C., Riemer, T., Kohn, S.C., Holtz, F., Dupree, R., 2001. Structural implications of water dissolution in haplogranitic glasses from NMR spectroscopy: Influence of total water content and mixed alkali effect. Geochim. Cosmochim. Acta 65, 2949-2964.

Schmücker, M., MacKenzie, K.J.D., Schneider, H., Meinhold, R., 1997. NMR studies on rapidly solidified $\mathrm{SiO}_{2}-\mathrm{Al}_{2} \mathrm{O}_{3}$ and $\mathrm{SiO}_{2}-\mathrm{Al}_{2} \mathrm{O}_{3}-\mathrm{Na}_{2} \mathrm{O}$-glasses. J. Non-Cryst. Solids 217, 99-105.

Scholze, H., 1960. Zur Frage der Unterscheidung von $\mathrm{H}_{2} \mathrm{O}$-Molekeln und $\mathrm{OH}$-Gruppen in Gläsern und Mineralien. Naturwissenschaften 47, 226-227.

Silver, L.A., Ihinger, P.D., Stolper, E., 1990. The influence of bulk composition on the speciation of water in silicate glasses. Contrib. Mineral. Petrol. 104, 142-162.

Stebbins, J.F., Kroeker, S., Lee, S.K., Kiczenski, T.J., 2000. Quantification of five- and six-coordinated aluminum ions in aluminosilicate and fluoride-containing glasses by high- field, high-resolution ${ }^{27}$ Al NMR. J. Non-Cryst. Solids 275, 1-6.

Stebbins, J.F., Zeng, Q., 2000. Cation ordering at fluoride sites in silicate glasses: a high-resolution ${ }^{19}$ F NMR study. J. Non-Cryst. Solids 262, 1-5.

Stamboulis, A., Hill, R.G., Law, R.V., 2005. Structural characterization of fluorine containing glasses by ${ }^{19} \mathrm{~F},{ }^{27} \mathrm{Al},{ }^{29} \mathrm{Si}$ and ${ }^{31} \mathrm{P}$ MAS-NMR spectroscopy. J. Non-Cryst. Solids 351 , 3289-3295.

Stolper, E., 1982. Water in silicate glasses: An infrared spectroscopic study. Contrib. Mineral. Petrol. 81, 1-17.

Thompson, L., Stebbins, J.F., 2011. Non-bridging oxygen and high-coordinated aluminum in metaluminous and peraluminous calcium and potassium aluminosilicate glasses: High-resolution ${ }^{17} \mathrm{O}$ and ${ }^{27} \mathrm{Al}$ MAS NMR results. Am. Mineral. 96, 841-853.

Toplis, M.J., Dingwell, D.B., Lenci, T., 1997. Peraluminous viscosity maxima in $\mathrm{Na}_{2} \mathrm{O}-\mathrm{Al}_{2} \mathrm{O}_{3}-\mathrm{SiO}_{2}$ liquids: The role of triclusters in tectosilicate melts. Geochim. Cosmochim. Acta 61, 
$2605-2612$.

Tossell, J.A., 1993. Theoretical studies of the speciation of Al in F-bearing aluminosilicate glasses. Am. Mineral. 78, 16-22.

Uchino, T., Toshinobu, Y., 1998. Structural and vibrational properties of sodium disilicate glass from ab initio molecular orbital calculations. J. Phys. Chem. B 102, 8372-8378.

Webb, S.L., Banaszak, M., Köhler, U., Rausch, S., Raschke, G., 2007. The viscosity of $\mathrm{Na}_{2} \mathrm{O}-$ $\mathrm{CaO}-\mathrm{Al}_{2} \mathrm{O}_{3}-\mathrm{SiO}_{2}$ melts. Eur. J. Mineral. 19, 681-692.

Youngmann, R.E., Sen, S., 2004. The nature of fluorine in amorphous silica. J. Non-Cryst. Solids 337, 182-186.

Zeng, Q., Stebbins, J.F., 2000. Fluoride sites in aluminosilicate glasses: High-resolution ${ }^{19} \mathrm{~F}$ NMR results. Am. Mineral. 85, 863-867.

Zeng, Q., Nekvasil, H., Grey, C.P., 2000. In support of a depolymerization model for water in sodium aluminosilicate glasses: Information from NMR spectroscopy. Geochim. Cosmochim. Acta 64, 883-896.

Zwanziger, J.W., Werner-Zwanziger, U., Zanotto, E.D., Rotari, E., Glebova, L.N., Glebov, L.B., Schneider, J.F., 2006. Residual iternal stress in partially crystallized photothermorefractive glass: Evaluation by nuclear magnetic resonance spectroscopy and first principle calculations. J. Appl. Phys. 99, 083511. 
5. The incorporation mechanism of chlorine in peralkaline and peraluminous $\mathrm{Na}_{2} \mathrm{O}-\mathrm{CaO}-\mathrm{Al}_{2} \mathrm{O}_{3}-\mathrm{SiO}_{2}$ glasses

Amrei Baasner, Ivan Hung, Thomas F. Kemp, Burkhard C. Schmidt, Ray

Dupree, Sharon L. Webb

Status August 2013: In preparation for American Mineralogist 


\section{Credits}

The scientific work and the writing for the publication

Baasner, A., Hung, I., Kemp, T.F., Dupree, R., Schmidt, B.C., Webb, S.L., 2014b. Constranints on the incorporation mechanism of chlorine in peralkaline and peraluminous $\mathrm{Na}_{2} \mathrm{O}-\mathrm{CaO}-\mathrm{Al}_{2} \mathrm{O}_{3}-\mathrm{SiO}_{2}$ glasses. Am. Mineral. http://dx.doi.org/10.2138/am.2014.4717 (Status August 2013: In preparation for American Mineralogist)

\section{was conducted by}

\section{Amrei Baasner}

o Synthesis of the glasses containing both, $\mathrm{F}$ and $\mathrm{Cl}$, and the glasses doped with $\mathrm{CoO}$ at $1 \mathrm{~atm}$

o Synthesis of the chlorine-bearing glasses made under pressure in the internally heated pressure vessel and the piston cylinder apparatus

o Electron microprobe analysis

o Participation in the acquisition of the MAS NMR spectra collected in Warwick except the ${ }^{27} \mathrm{Al}$ MAS NMR spectra at $20 \mathrm{~T}$ and the static ${ }^{35} \mathrm{Cl}$ NMR spectra.

o Most of the evaluation of the NMR spectra

o Figures, tables and most of the text

- A significant part of the ideas presented in the discussion and conclusion section Ivan Hung

o Acquisition of the ${ }^{35} \mathrm{Cl}$ MAS NMR spectra at $19.6 \mathrm{~T}$ collected in Tallahassee

o Correction and improvement of the figures, tables and text

Thomas Kemp

o Acqisition of the ${ }^{35} \mathrm{Cl}$ static NMR spectra

\section{Ray Dupree}

o Supporting the acquisition of all static and MAS NMR spectra collected in Warwick

o Acquisition of the ${ }^{27} \mathrm{Al}$ MAS NMR spectra at $20 \mathrm{~T}$

o Some parts of the evaluation of the NMR spectra

o A significant part of the ideas presented in the discussion and conclusion section

Burkhard C. Schmidt

o General laboratory trouble shooting and support

o Supporting the acquisition of the MAS NMR spectra collected in Warwick

o Some of the ideas presented in the discussion and conclusion section

o Correction and improvement of the figures, tables and text

Sharon L. Webb

o Synthesis of the glasses containing $\mathrm{Cl}$ without $\mathrm{CoO}$ at $1 \mathrm{~atm}$

o Some of the ideas presented in the discussion and conclusion section

o Correction and improvement of the figures, tables and text 


\section{Abstract}

The incorporation mechanism of $\mathrm{Cl}$ in peralkaline and peraluminous $\mathrm{Na}_{2} \mathrm{O}-\mathrm{CaO}-\mathrm{Al}_{2} \mathrm{O}_{3}-\mathrm{SiO}_{2}$ glasses as a model system for phonolitic melts was investigated using ${ }^{35} \mathrm{Cl},{ }^{23} \mathrm{Na},{ }^{27} \mathrm{Al}$ and ${ }^{29} \mathrm{Si}$ magic angle spinning (MAS) nuclear magnetic resonance (NMR) spectroscopy. The size and large distribution of electric field gradients for ${ }^{35} \mathrm{Cl}$ causes loss of signal in the MAS NMR experiment and this, in combination with the low concentration of $\mathrm{Cl}$ and the large chemical shift dispersion, means that even at the highest available fields we are at the limits of MAS NMR. Nevertheless clear differences in the $\mathrm{Cl}$ environment in peralkaline and peraluminous glasses can readily be seen. In both glass types most $\mathrm{Cl}$ exists in relatively symmetric Na-Ca-Cl environments with the ${ }^{35} \mathrm{Cl}$ chemical shift dominated by the presence of $\mathrm{Na}$ cations, consistent with the $\mathrm{Na} / \mathrm{Ca}$ ratio of $5 / 1$ in the glasses. The peraluminous glasses have a larger chemical shift distribution and a more positive isotropic chemical shift, $\sim-75 \mathrm{ppm}$, than the peralkaline glasses, $\sim-100 \mathrm{ppm}$. They also have a larger quadrupole coupling constant with a larger distribution, indicating greater disorder in the peraluminous glasses. It is likely that there are more $\mathrm{Ca}$ cations present in the $\mathrm{Cl}$ environments in the peraluminous glasses than in the peralkaline glasses despite their having the same $\mathrm{Na} / \mathrm{Ca}$ ratio. In the peralkaline glasses the formation of $\mathrm{Na}-\mathrm{Ca}-\mathrm{Cl}$ environments leads to a decrease in the number of network-modifying cations, which causes a polymerisation of the glass network. No effect on the glass polymerisation was observed in the peraluminous glasses. Some ${ }^{35} \mathrm{Cl}$ signal is also lost in the static spectra indicating that $\sim 20 \%$ of $\mathrm{Cl}$ for a peralkaline glass and $\sim 75 \%$ for a peraluminous glass must be in environments where there is a large enough electric field gradient to result in a very broad line. The $\mathrm{Cl}$ environment in the present mixed $\mathrm{Na}_{2} \mathrm{O}-\mathrm{CaO}$ aluminosilicate glasses appears to be more disordered than was to be expected from previous NMR spectroscopic studies on simpler glass compositions. 


\subsection{Introduction}

In natural highly evolved magmas chlorine $(\mathrm{Cl})$ concentration usually does not exceed $1 \mathrm{wt} \%$, although alkali-rich magmas like phonolites can contain up to $1.2 \mathrm{wt} \%$ $\mathrm{Cl}$ (Carroll, 2005; Aiuppa et al., 2009). Even though the abundance of $\mathrm{Cl}$ in natural magmatic systems is low compared to $\mathrm{H}_{2} \mathrm{O}$, the incorporation mechanism of $\mathrm{Cl}$ in silicate melts with compositions relevant to magmatic systems is important as the presence of $\mathrm{Cl}$ can lead to the formation of brines (e.g. Sourirajan and Kennedy, 1962; Anderko and Pitzer, 1993; Signorelli and Caroll, 2000) as well as ore deposits (e.g. Helgeson, 1969; Webster, 1997a; Candela, 1997) and it influences melt rheology (Dingwell and Hess, 1998; Zimova and Webb, 2006; Baasner et al., 2013a). Baasner et al. (2013a) showed that incorporation of $\mathrm{Cl}$ into the system $\mathrm{Na}_{2} \mathrm{O}-\mathrm{CaO}-\mathrm{Al}_{2} \mathrm{O}_{3}-\mathrm{SiO}_{2}$ results in contrasting behaviour with $1.1 \mathrm{~mol} \%$ (0.6 wt\%) increasing the viscosity in peralkaline melts by a factor of 10 , whereas $0.6 \mathrm{~mol} \%$ (0.3 wt\%) $\mathrm{Cl}$ in peraluminous melts decreases viscosity by a factor of 3 .

Although the incorporation mechanism of $\mathrm{Cl}$ in silicate melts is the key to understand the behaviour of $\mathrm{Cl}$ in magmatic systems, there are only a few studies about this topic. Stebbins and Du (2002) found from ${ }^{35} \mathrm{Cl}$ magic angle spinning (MAS) nuclear magnetic resonance (NMR) spectroscopy that in silicate and aluminosilicate glasses $\mathrm{Cl}$ is coordinated by mono- and divalent cations like $\mathrm{Na}$ or Ba rather than by $\mathrm{Al}$ and $\mathrm{Si}$. These authors observed that in general the $\mathrm{Cl}$ environment is very similar in salts and glasses. For example in sodium silicate and aluminosilicate glasses $\mathrm{Cl}$ is coordinated by less than six (as for halides) but more than $4 \mathrm{Na}$ cations (as in sodalite).

Sandland et al. (2004) concluded from ${ }^{35} \mathrm{Cl}$ MAS NMR spectroscopy that $\mathrm{Cl}$ in mixed $\mathrm{Na}_{2} \mathrm{O}-\mathrm{CaO}$ silicate glasses shows no strong preference for either $\mathrm{Na}$ or $\mathrm{Ca}$. These authors also found that the presence of $\mathrm{Al}$ or $\mathrm{H}_{2} \mathrm{O}$ does not significantly affect the $\mathrm{Cl}$ environment. Evans et al. (2008) investigated ${ }^{35} \mathrm{Cl}$ environment in aluminosilicate glasses containing monovalent $(\mathrm{Na}, \mathrm{K})$ as well as divalent $(\mathrm{Mg}, \mathrm{Ca})$ cations with $\mathrm{x}$-ray absorption near edge structure (XANES) spectroscopy. They found that the salt-like $\mathrm{Cl}$ environments in magmatic melts are dominated by $\mathrm{Ca}$ and $\mathrm{Mg}$ and that alkali content, redox conditions and water only play a subsidiary role. 
There are only two NMR studies of ${ }^{35} \mathrm{Cl}$ in silicate glasses, probably because ${ }^{35} \mathrm{Cl}$ is much more difficult to measure than other nuclei such as ${ }^{19} \mathrm{~F}$ or ${ }^{23} \mathrm{Na}$; the solubility in (alumino)silicate glasses is usually lower than $2 \mathrm{wt} \%$ for $0-200 \mathrm{MPa}$ (Webster, 1997b; Carroll, 2005; Tanimoto and Rehren, 2008) and, as ${ }^{35} \mathrm{Cl}$ is a quadrupole nucleus with a spin of $I=3 / 2$ a large quadrupole moment and a low Larmor frequency, its line shape, even at high magnetic fields under MAS conditions, is severely influenced by second order quadrupole broadening (e.g. Sandland et al. 2004). It also has a large (> 1000 ppm) chemical shift range (Johnson et al., 1969; Sandland et al., 2004) further broadening the line in disordered systems, thus the acquisition of ${ }^{35} \mathrm{Cl}$ spectra of glasses with an acceptable signal to noise ratio, even at magnetic fields of $14.1 \mathrm{~T}$ and higher, can take more than a day.

To date the $\mathrm{Cl}$ environment in mixed $\mathrm{Na}_{2} \mathrm{O}-\mathrm{CaO}$ aluminosilicate glasses as a function of the Al concentration has not been studied. In this work we investigate the incorporation mechanism of $0.6-1.9 \mathrm{~mol} \% \quad(0.3-1 \mathrm{wt} \%) \quad \mathrm{Cl}$ in peralkaline $\left(\left[\mathrm{Na}_{2} \mathrm{O}+\mathrm{CaO}\right]>\mathrm{Al}_{2} \mathrm{O}_{3}\right)$ and peraluminous $\left(\left[\mathrm{Na}_{2} \mathrm{O}+\mathrm{CaO}\right]<\mathrm{Al}_{2} \mathrm{O}_{3}\right) \quad \mathrm{Na}_{2} \mathrm{O}-\mathrm{CaO}$ aluminosilicate glasses with about $66 \mathrm{~mol} \% \mathrm{SiO}_{2}$, which are a first approximation for phonolitic melts, using ${ }^{35} \mathrm{Cl},{ }^{27} \mathrm{Al},{ }^{23} \mathrm{Na}$ and ${ }^{29} \mathrm{Si}$ MAS NMR spectroscopy. The general differences between halogen-free peralkaline and peraluminous spectra and their relation to structure have been discussed previously by Baasner et al. (2014). The focus of this paper will be on the incorporation mechanism of $\mathrm{Cl}$.

\subsection{Methods}

\subsubsection{Starting Materials}

Peralkaline (NACS) and peraluminous (ANCS) $\mathrm{Na}_{2} \mathrm{O}-\mathrm{CaO}$ aluminosilicate glasses containing $\mathrm{Cl}$ alone or combined with $\mathrm{F}$ were synthesised from powdered oxides, carbonates, halides and ammonium halides. In addition, one Cl-bearing sodium silicate glass (NS) was synthesised. The powder mixtures were decarbonated for $12 \mathrm{~h}$ at $1173 \mathrm{~K}$ at $1 \mathrm{~atm}$ and then melted at $1473-1923 \mathrm{~K}$ for several hours in a Pt crucible in an $1 \mathrm{~atm}$ furnace. The glasses were crushed and remelted several times to achieve chemical homogenisation. The sample ANCS $1.2 \mathrm{Cl}$ was synthesised in a piston cylinder apparatus at $1923 \mathrm{~K}$ and $500 \mathrm{MPa}$ for $3 \mathrm{~h}$ in a $\mathrm{Pt}_{90} \mathrm{Rh}_{10}$ capsule 
(detailed description in Baasner et al., 2013b). Some of the samples were doped with $<0.1 \mathrm{wt} \% \mathrm{CoO}$ to enhance the spin lattice relaxation.

The compositions of the glasses were determined using a JEOL JXA-8900RL electron microprobe with eight to ten measurements per sample using a $15 \mathrm{kV}$ and $15 \mathrm{nA}$ beam defocused to $30 \mu \mathrm{m}$. Table $1 \mathrm{a}, \mathrm{b}$ presents the compositions of the glasses in mol\% oxides and in atom\% (at\%). The notation in at\% takes into account that there is one $\mathrm{O}^{2-}$ less for two $\mathrm{Cl}^{-}$or $\mathrm{F}^{-}$. Table $1 \mathrm{a}$ also shows the $\left(\mathrm{Na}_{2} \mathrm{O}+\mathrm{CaO}\right) /\left(\mathrm{Na}_{2} \mathrm{O}+\mathrm{CaO}+\mathrm{Al}_{2} \mathrm{O}_{3}\right)$ ratio, which is referred as $\mathrm{R}$ value (e.g. Thompson and Stebbins, 2011) or the gamma value (e.g. Toplis et al., 1997; Webb et al., 2007). Peralkaline glasses have an $\mathrm{R}>0.5$ indicating that there are enough $\mathrm{Na}$ and $\mathrm{Ca}$ cations to charge balance Al-tetrahedra (Al coordinated by four oxygens) and that the remaining $\mathrm{Na}$ and $\mathrm{Ca}$ cations exist as network-modifiers, which create mostly non-bridging oxygens (NBO) at Si-tetrahedra (Si coordinated by four oxygens), which can be seen from NMR spectroscopy (e.g. Allwardt et al., 2003; Lee, 2004; Lee and Stebbins, 2009). Peraluminous glasses have an $\mathrm{R}<0.5$ indicating that there are not enough $\mathrm{Na}$ and $\mathrm{Ca}$ cations to charge-balance all Al-tetrahedra, which leads to the formation of higher-coordinated Al (Schmücker et al., 1997; Kohn et al., 1991) or triclusters (Toplis et al., 1997) and that there are (nearly) no network-modifying cations that create NBO`s (Thompson and Stebbins, 2011).

The $\mathrm{Ca} /[\mathrm{Ca}+\mathrm{Na}]$ ratio (Table $1 \mathrm{~b}$ ) in the peralkaline and the peraluminous samples is almost the same $(\sim 0.15$ and $\sim 0.17)$ although it is slightly higher for peraluminous glasses as they were produced in the $1 \mathrm{~atm}$ furnace at significantly higher temperatures than the peralkaline glasses, which caused some Na volatilisation and a relative enrichment in $\mathrm{Ca}$ of the melt. The $\mathrm{Cl}$ concentration of the samples $\mathrm{NS} 2.2 \mathrm{Cl}$ and NACS $1.1 \mathrm{Cl}$ was confirmed with laser-ablation inductive coupled plasma mass spectrometry (LA-ICPMS). 
Table 1a. Electron microprobe (EMP) analysis as oxide components of the glass samples. ${ }^{\text {a }}$

\begin{tabular}{|c|c|c|c|c|c|c|c|c|c|c|c|c|c|c|}
\hline & $\begin{array}{c}\mathrm{SiO}_{2} \\
{[\mathrm{~mol} \%]}\end{array}$ & $\begin{array}{c}2 \sigma \\
{[\mathrm{mol} \%]}\end{array}$ & $\begin{array}{c}\mathrm{Al}_{2} \mathrm{O}_{3} \\
{[\mathrm{~mol} \%]}\end{array}$ & $\begin{array}{c}2 \sigma \\
{[\mathrm{mol} \%]}\end{array}$ & $\begin{array}{c}\mathrm{CaO} \\
{[\mathrm{mol} \%]}\end{array}$ & $\begin{array}{c}2 \sigma \\
{[\mathrm{mol} \%]}\end{array}$ & $\begin{array}{c}\mathrm{Na}_{2} \mathrm{O} \\
{[\mathrm{mol} \%]}\end{array}$ & $\begin{array}{c}2 \sigma \\
{[\mathrm{mol} \%]}\end{array}$ & $\begin{array}{c}\mathrm{F} \\
{[\mathrm{mol} \%]}\end{array}$ & $\begin{array}{c}2 \sigma \\
{[\mathrm{mol} \%]}\end{array}$ & $\begin{array}{c}\mathrm{Cl} \\
{[\mathrm{mol} \%]}\end{array}$ & $\begin{array}{c}2 \sigma \\
{[\mathrm{mol} \%]}\end{array}$ & $\mathrm{R}^{\mathrm{c}}$ & $\mathrm{Ca} /[\mathrm{Ca}+\mathrm{Na}]$ \\
\hline \multicolumn{15}{|l|}{ Peralkaline } \\
\hline $\mathrm{NACS}^{b}$ & 65.52 & 1.42 & 11.94 & 1.02 & 5.53 & 0.36 & 17.02 & 0.57 & - & - & - & - & 0.65 & 0.14 \\
\hline NACS $1.0 \mathrm{~F} 1.0 \mathrm{Cl}^{\mathrm{b}}$ & 65.77 & 0.27 & 11.95 & 0.10 & 5.50 & 0.10 & 15.79 & 0.17 & 0.99 & 0.15 & 1.02 & 0.04 & 0.64 & 0.15 \\
\hline $\mathrm{NACS} 1.1 \mathrm{Cl}^{\mathrm{b}}$ & 66.86 & 0.42 & 11.82 & 0.13 & 5.75 & 0.16 & 15.57 & 0.37 & - & - & 1.10 & 0.06 & 0.64 & 0.16 \\
\hline NACS $1.9 \mathrm{Cl}^{\mathrm{b}}$ & 65.55 & 0.31 & 11.95 & 0.16 & 5.81 & 0.10 & 16.69 & 0.17 & - & - & 1.92 & 0.06 & 0.65 & 0.15 \\
\hline \multicolumn{15}{|l|}{ Peraluminous } \\
\hline ANCS $^{d}$ & 65.94 & 1.63 & 19.20 & 1.07 & 4.19 & 0.39 & 10.67 & 0.25 & - & - & - & - & 0.44 & 0.16 \\
\hline ANCS $1.0 \mathrm{~F} 0.9 \mathrm{Cl}^{\mathrm{b}}$ & 66.48 & 0.80 & 19.73 & 0.55 & 3.84 & 0.12 & 8.95 & 0.25 & 1.01 & 0.19 & 0.88 & 0.02 & 0.39 & 0.18 \\
\hline ANCS $0.6 \mathrm{Cl}^{\mathrm{d}}$ & 66.31 & 0.55 & 20.45 & 0.31 & 3.75 & 0.11 & 9.49 & 0.51 & - & - & 0.64 & 0.05 & 0.39 & 0.16 \\
\hline ANCS $1.2 \mathrm{Cl}^{\mathrm{b}}$ & 67.01 & 0.35 & 18.55 & 0.13 & 4.03 & 0.13 & 10.41 & 0.21 & - & - & 1.18 & 0.13 & 0.44 & 0.16 \\
\hline \multicolumn{15}{|l|}{ Sodium silicate } \\
\hline $\mathrm{NS} 2.2 \mathrm{Cl}^{\mathrm{b}}$ & 78.09 & 1.10 & 0.44 & 0.05 & 0.04 & 0.03 & 21.43 & 0.67 & - & - & 2.20 & 0.50 & - & - \\
\hline \multicolumn{15}{|c|}{ 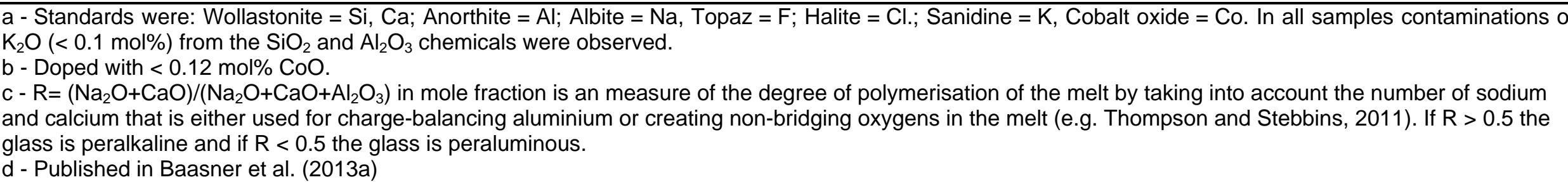 } \\
\hline
\end{tabular}


Table 1b. Electron microprobe (EMP) analysis of the glass samples. ${ }^{a}$

\begin{tabular}{|c|c|c|c|c|c|c|c|c|c|c|c|c|c|c|}
\hline & $\begin{array}{c}\mathrm{Si} \\
{[\mathrm{at} \%]}\end{array}$ & $\begin{array}{c}2 \sigma \\
{[a t \%]}\end{array}$ & $\begin{array}{c}\mathrm{Al} \\
{[\mathrm{at} \%]}\end{array}$ & $\begin{array}{c}2 \sigma \\
{[a t \%]}\end{array}$ & $\begin{array}{c}\mathrm{Ca} \\
{[\mathrm{at} \%]}\end{array}$ & $\begin{array}{c}2 \sigma \\
{[a t \%]}\end{array}$ & $\begin{array}{c}\mathrm{Na} \\
{[\mathrm{at} \%]}\end{array}$ & $\begin{array}{c}2 \sigma \\
{[a t \%]}\end{array}$ & $\begin{array}{c}F \\
{[a t \%]}\end{array}$ & $\begin{array}{c}2 \sigma \\
{[a t \%]}\end{array}$ & $\begin{array}{c}\mathrm{Cl} \\
{[\mathrm{at} \%]}\end{array}$ & $\begin{array}{c}2 \sigma \\
{[a t \%]}\end{array}$ & $\begin{array}{c}\mathrm{O}^{\mathrm{c}} \\
{[\mathrm{at} \%]}\end{array}$ & $\mathrm{Ca} /[\mathrm{Ca}+\mathrm{Na}]$ \\
\hline \multicolumn{15}{|l|}{ Peralkaline } \\
\hline $\mathrm{NACS}^{\mathrm{b}}$ & 20.58 & 0.45 & 7.50 & 0.64 & 1.74 & 0.11 & 10.69 & 0.36 & - & - & - & - & 59.49 & 0.14 \\
\hline NACS $1.0 \mathrm{~F} 1.0 \mathrm{Cl}^{\mathrm{b}}$ & 20.79 & 0.09 & 7.55 & 0.06 & 1.74 & 0.03 & 9.98 & 0.10 & 0.31 & 0.05 & 0.32 & 0.012 & 59.31 & 0.15 \\
\hline NACS $1.1 \mathrm{Cl}^{\mathrm{b}}$ & 21.00 & 0.13 & 7.42 & 0.08 & 1.81 & 0.05 & 9.78 & 0.23 & - & - & 0.34 & 0.019 & 59.65 & 0.16 \\
\hline NACS $1.9 \mathrm{Cl}^{\mathrm{b}}$ & 20.54 & 0.10 & 7.49 & 0.10 & 1.82 & 0.03 & 10.46 & 0.11 & - & - & 0.60 & 0.018 & 59.08 & 0.15 \\
\hline \multicolumn{15}{|l|}{ Peraluminous } \\
\hline ANCS $^{d}$ & 19.73 & 0.49 & 11.49 & 0.64 & 1.25 & 0.12 & 6.38 & 0.15 & - & - & - & - & 61.14 & 0.16 \\
\hline ANCS 1.0F $0.9 \mathrm{Cl}^{\mathrm{b}}$ & 19.93 & 0.24 & 11.83 & 0.33 & 1.15 & 0.04 & 5.37 & 0.15 & 0.30 & 0.06 & 0.26 & 0.006 & 61.16 & 0.18 \\
\hline ANCS $0.6 \mathrm{Cl}^{\mathrm{d}}$ & 19.65 & 0.16 & 12.12 & 0.18 & 1.11 & 0.03 & 5.62 & 0.30 & - & - & 0.19 & 0.014 & 61.31 & 0.16 \\
\hline ANCS $1.2 \mathrm{Cl}^{\mathrm{b}}$ & 20.08 & 0.10 & 11.12 & 0.08 & 1.21 & 0.04 & 6.24 & 0.13 & - & - & 0.36 & 0.040 & 60.99 & 0.16 \\
\hline \multicolumn{15}{|l|}{ Sodium silicate } \\
\hline $\mathrm{NS} 2.2 \mathrm{Cl}^{\mathrm{b}}$ & 25.86 & 0.37 & 0.29 & 0.04 & 0.01 & 0.01 & 14.20 & 0.44 & - & - & 0.73 & 0.165 & 58.91 & - \\
\hline
\end{tabular}

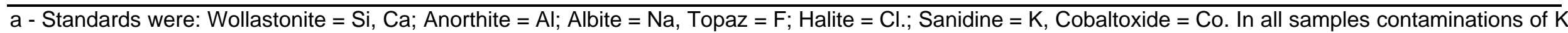
$\left(<0.03\right.$ at\%) from the $\mathrm{SiO}_{2}$ and $\mathrm{Al}_{2} \mathrm{O}_{3}$ chemicals were observed.

b - Doped with $<0.04$ at\% Co.

c - Calculated from stochiometry taking in account for two $\mathrm{F}^{-1}$ there is one less $\mathrm{O}^{-2}$ in the glass

d - Published in Baasner et al. (2013a) 


\subsubsection{NMR measurements}

All NMR measurements in this study were performed at University of Warwick except for the very high field ${ }^{35} \mathrm{Cl}$ MAS data, which were collected at $81.599 \mathrm{MHz}$ on an $830 \mathrm{MHz}$ Bruker DRX (19.6 T) spectrometer at the National High Magnetic Field Laboratory, Tallahassee. ${ }^{35} \mathrm{Cl}$ MAS spectra were also collected at $58.726 \mathrm{MHz}$ on a $600 \mathrm{MHz}$ Bruker Avance II+ (14.1 T) or at 59.010 MHz on a $600 \mathrm{MHz}$ Varian (14.1 T) spectrometer. At $14.1 \mathrm{~T}$ a $3.2 \mathrm{~mm}$ rotor with a spinning speed of $20 \mathrm{kHz}$ was used and the spectra were collected using an echo sequence with pulse lengths of 1.75 (a solids $90^{\circ}$ ) and $3.5 \mu \mathrm{s}$ (a solids $180^{\circ}$ ) an inter-pulse spacing of one rotor cycle (sample NACS $1.1 \mathrm{Cl}$ was also run with a 4 rotor cycle inter-pulse spacing for comparison), a recycle delay of $0.1 \mathrm{~s}$ and $36,000-2,300,000$ acquisitions. The inter-pulse spacing and the recycle delay were carefully tested to avoid saturation or any other distortion of the signal. In addition, static spectra of the samples $\mathrm{NS} 2.2 \mathrm{Cl}$, NACS $1.1 \mathrm{Cl}$, ANCS $1.0 \mathrm{~F} 0.9 \mathrm{Cl}$ were collected in a $10 \mathrm{~mm}$ static probe with an echo spacing of $200 \mu \mathrm{s}$, pulse lengths of 2 and $4 \mu \mathrm{s}$, a recycle delay of $0.1 \mathrm{~s}$ and $730,000-2,300,000$ acquisitions. The spectra at 19.6 T were collected in a $1.8 \mathrm{~mm}$ rotor with a spinning speed of $30 \mathrm{kHz}$. The spectra were measured using an echo sequence with pulse lengths of 1.85 (a solids $90^{\circ}$ ) and $3.7 \mu$ s (a solids $180^{\circ}$ ), an inter-pulse delay of 4 rotor cycles, a recycle delay of $0.1 \mathrm{~s}$ and $70,000-4,800,000$ acquisitions (total time 6 days). Solid $\mathrm{NaCl}$ was used as reference and was set to $-46 \mathrm{ppm}$ relative to $1 \mathrm{M}$ aqueous $\mathrm{NaCl}$ solution.

${ }^{23} \mathrm{Na}$ MAS spectra were collected at $132.286 \mathrm{MHz}$ on a $500 \mathrm{MHz}$ Bruker Avance III $(11.7 \mathrm{~T})$ spectrometer. The samples were measured in a $2.5 \mathrm{~mm}$ rotor with a spinning speed of $26 \mathrm{kHz}$, a pulse length of $1.5 \mu \mathrm{s}$, a recycle delay of $1 \mathrm{~s}$ and $60-660$ acquisitions. Solid $\mathrm{NaCl}$ was used as reference that was set to $-7 \mathrm{ppm}$ relative to $1 \mathrm{M}$ aqueous $\mathrm{NaCl}$ solution.

${ }^{27} \mathrm{Al}$ MAS spectra were collected at $130.301 \mathrm{MHz}$ on a $500 \mathrm{MHz}$ Bruker Avance III (11.7 T) and at 221.550 MHz on an $850 \mathrm{MHz}$ Bruker Avance III (20 T) spectrometer. The samples at $11.7 \mathrm{~T}$ were measured in a $2.5 \mathrm{~mm}$ rotor with a spinning speed of $26 \mathrm{kHz}$, a pulse length of $0.75 \mu \mathrm{s}$, a recycle delay of $1 \mathrm{~s}$ and 1,600-16,000 acquisitions. The samples at $20 \mathrm{~T}$ were measured in a $3.2 \mathrm{~mm}$ rotor with a spinning 
speed of $20 \mathrm{kHz}$, a pulse length of $0.8 \mu \mathrm{s}$, a recycle delay of $2 \mathrm{~s}$ and 84 acquisitions. The peak of six-coordinated Al in yttrium aluminium garnet (YAG) was used as reference and was set to $0.7 \mathrm{ppm}$ relative to $1 \mathrm{M}$ aqueous $\mathrm{AlCl}_{3}$ solution.

${ }^{29} \mathrm{Si}$ MAS spectra were collected at $59.615 \mathrm{MHz}$ on a $300 \mathrm{MHz}$ Varian Infinity Plus (7 T) spectrometer. The samples were measured in a $7 \mathrm{~mm}$ rotor with a spinning speed of $4 \mathrm{kHz}$, a pulse length of $3.5 \mu \mathrm{s}$, a recycle delay of $30-60 \mathrm{~s}$ and $172-2,544$ acquisitions (spectra for the samples ANCS $0.6 \mathrm{Cl}$ and ANCS $1.2 \mathrm{Cl}$ were not measured due to failure of the spectrometer). Kaolinite was used as reference and was set to $-91.5 \mathrm{ppm}$ relative to tetramethylsilane $\left(\mathrm{TMS}, \mathrm{Si}\left(\mathrm{CH}_{3}\right)_{4}\right)$.

\subsection{Results}

\subsection{1. ${ }^{35} \mathrm{CI}$ MAS NMR}

Figures 1 and 2 show the ${ }^{35} \mathrm{Cl}$ MAS NMR spectra of the Cl-bearing samples at 14.1 and 19.6 T. The spectrum of the $\mathrm{Na}_{2} \mathrm{O}-\mathrm{SiO}_{2}$ glass has a quadrupole tail on the right hand side. In contrast, the lines of the peralkaline and peraluminous glasses are broader and weaker, approximately Gaussian with only a small quadrupole tail visible on the right hand side for some samples. The signal to noise ratio of the ${ }^{35} \mathrm{Cl}$ spectra (Figs. 1 and 2) decreases from the sodium silicate glass to the peralkaline glasses to the peraluminous glasses, although the peraluminous samples were collected with the higher number of acquisitions. Compared to the sodium silicate glass and normalised to same amount of $\mathrm{Cl}$ atoms and number of acquisitions only $\sim 60 \%$ of the ${ }^{35} \mathrm{Cl}$ MAS NMR signal was observed for the peralkaline glasses and only $\sim 25 \%$ for the peraluminous glasses. (The effect of different sample densities and rotor packing on the signal intensities is less than 10\%.) However the line widths of the peralkaline and peraluminous glasses are much broader than those of the sodium silicate glass, $\sim 10 \mathrm{kHz}$ and $>\sim 15 \mathrm{kHz}$ respectively. This suggests that a significant amount of the $\mathrm{Cl}$ exists in environments with a large enough electric field gradient that the intensity of the central band is reduced because significant intensity appears in the sidebands and/or the line width is too large to be narrowed by the MAS experiment (Massiot et al., 1990). 


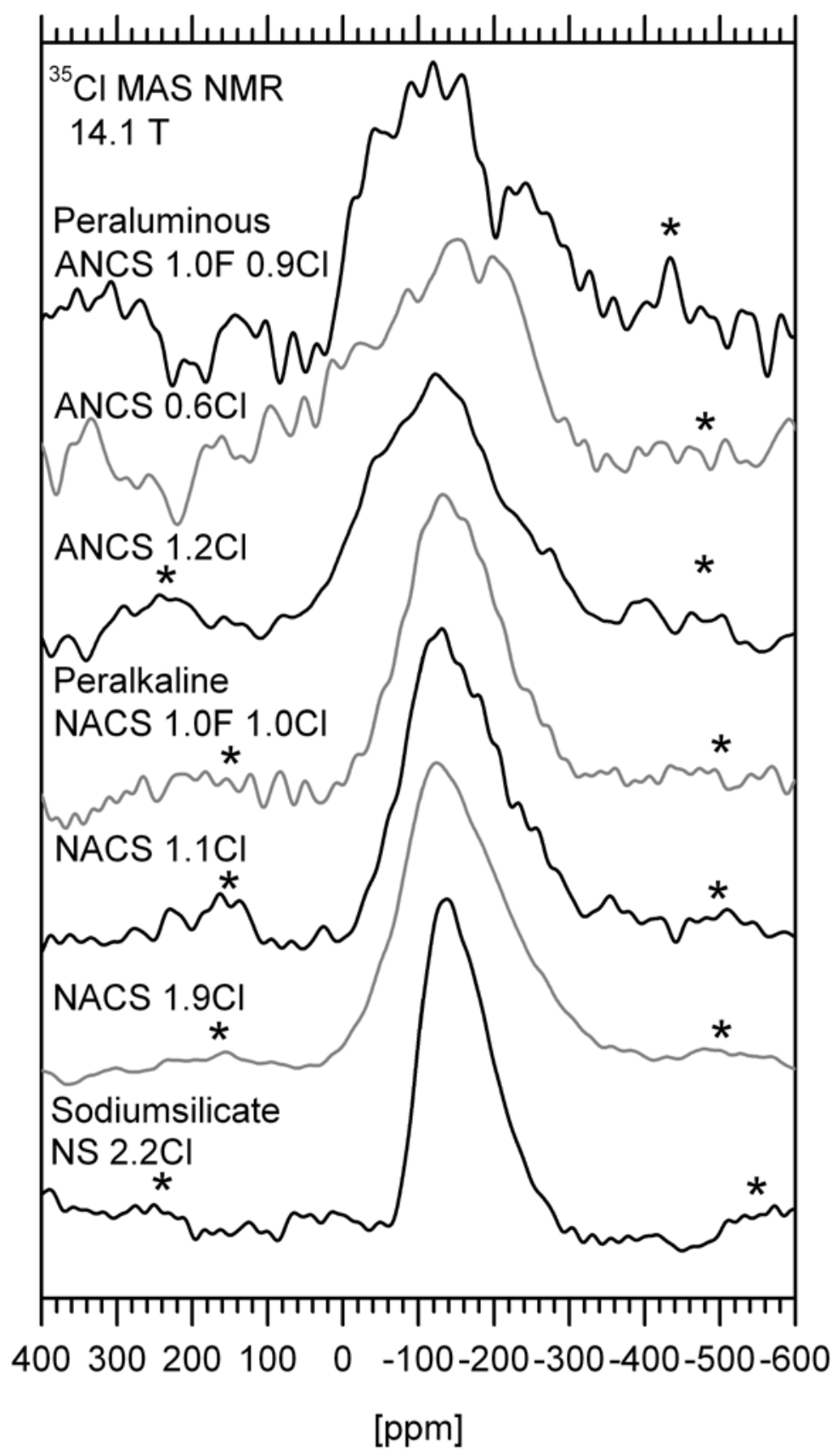

Fig. 1. ${ }^{35} \mathrm{Cl}$ MAS NMR spectra of the $\mathrm{Cl}$ - and F-bearing peraluminous, peralkaline and sodium silicate glasses at $14.1 \mathrm{~T}$. Spinning sidebands are marked with an asterisk. The spectra are normalised to the same peak height. 


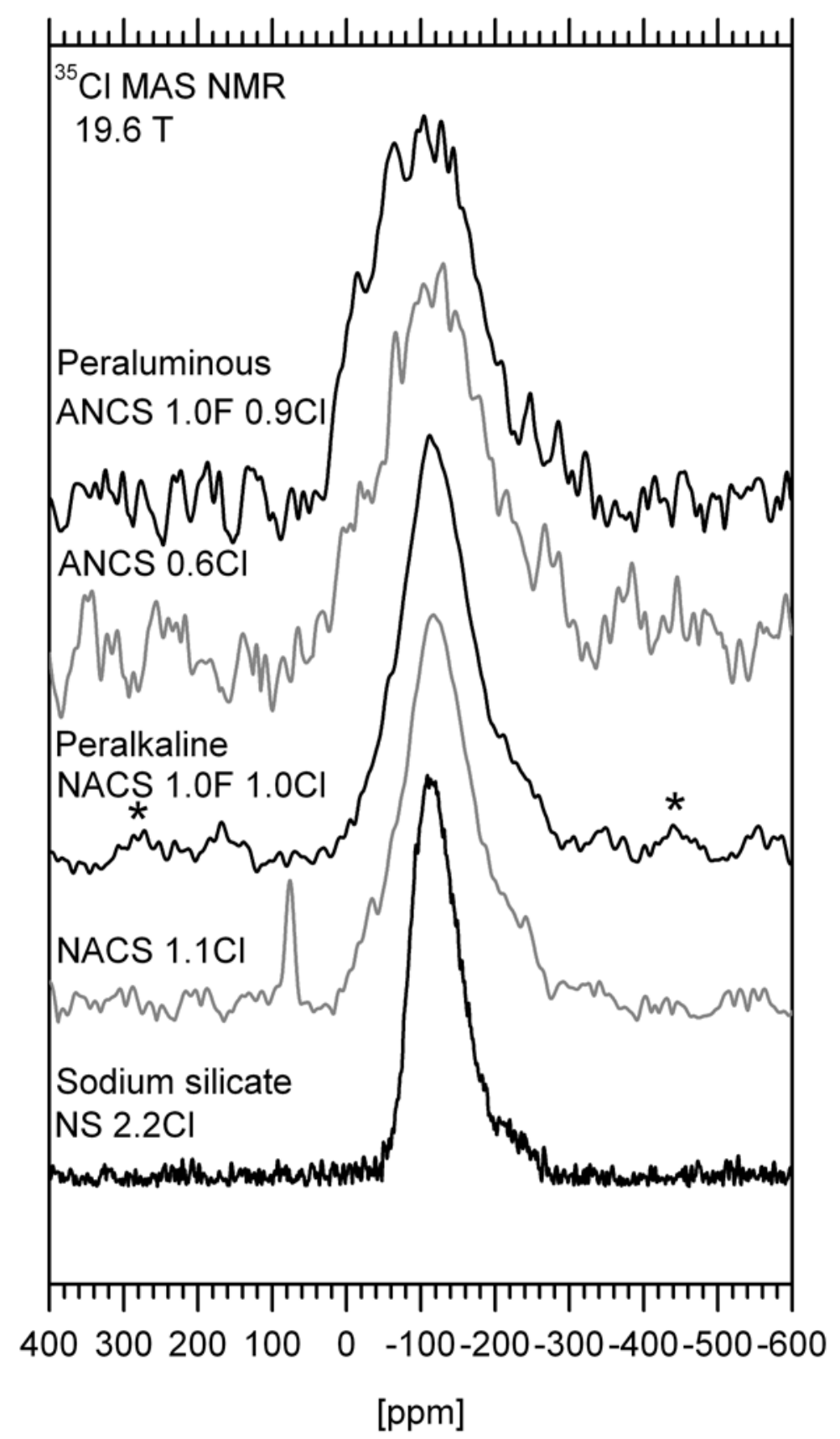

Fig. 2. ${ }^{35} \mathrm{Cl}$ MAS NMR spectra of the $\mathrm{Cl}$ - and F-bearing peraluminous, peralkaline and sodium silicate glasses at 19.6 T. Spinning sidebands are marked with an asterisk. The spectra are normalised to the same peak height. The small peak at $75 \mathrm{ppm}$ in the spectrum of NACS $1.1 \mathrm{Cl}$ is a contamination with an unknown material, which was not observed in the spectrum of NACS $1.1 \mathrm{Cl}$ at $14.1 \mathrm{~T}$. 
Figure 3 shows the spectra of the peralkaline glass $\mathrm{NACS} 1.9 \mathrm{Cl}$ and the peraluminous glass ANCS $1.2 \mathrm{Cl}$ at $14.1 \mathrm{~T}$ normalised to the same number of acquisitions and the same number of $\mathrm{Cl}$ atoms. For ANCS $1.2 \mathrm{Cl}$ compared to NACS $1.9 \mathrm{Cl}$ only about half of the ${ }^{35} \mathrm{Cl}$ signal was obtained. Fig. 3 also shows that there is a small broad, un-narrowed background underneath the ${ }^{35} \mathrm{Cl}$ peak, which is similar for both spectra. The static NMR spectrum of the peralkaline sample NACS $1.1 \mathrm{Cl}$ (Fig. 4) extents over $\sim 94 \mathrm{kHz}$ and $\sim 80 \%$ of the ${ }^{35} \mathrm{Cl}$ signal was detected compared with the sodium silicate glass (NS 2.2Cl). The static NMR spectrum of the peraluminous glass ANCS $1.0 \mathrm{~F} 0.9 \mathrm{Cl}$ shows an even broader ${ }^{35} \mathrm{Cl}$ peak that extends over $\sim 130 \mathrm{kHz}$ with $\sim 25 \%$ of the ${ }^{35} \mathrm{Cl}$ signal compared to the sodium silicate glass (Fig. A in the supplementary data). In general the static line shapes are consistent with the parameters obtained from MAS NMR spectroscopy in Tables 2 - 4. Thus the remaining $\mathrm{Cl}$ must be in environments where there is a large electric field gradient which results in an extremely broad line.

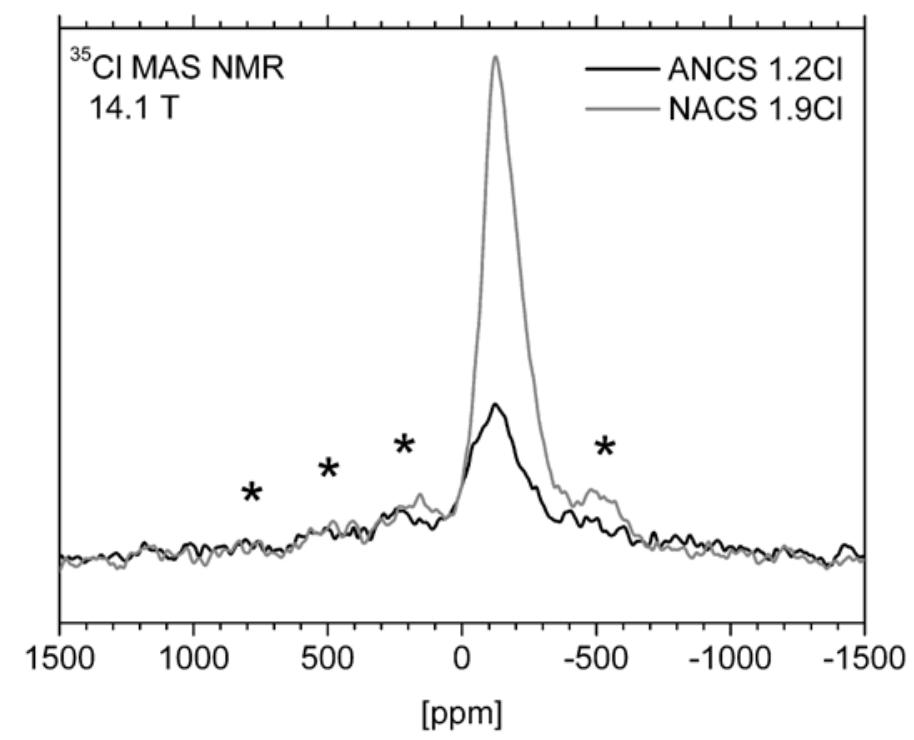

Fig. 3. ${ }^{35} \mathrm{Cl}$ MAS NMR spectra of the Cl-bearing peraluminous (ANCS) and peralkaline (NACS) glasses at 14.1 T. Spinning sidebands are marked with an asterisk. The spectra are normalised to the same number of acquisitions and same number of $\mathrm{Cl}$ atoms. 


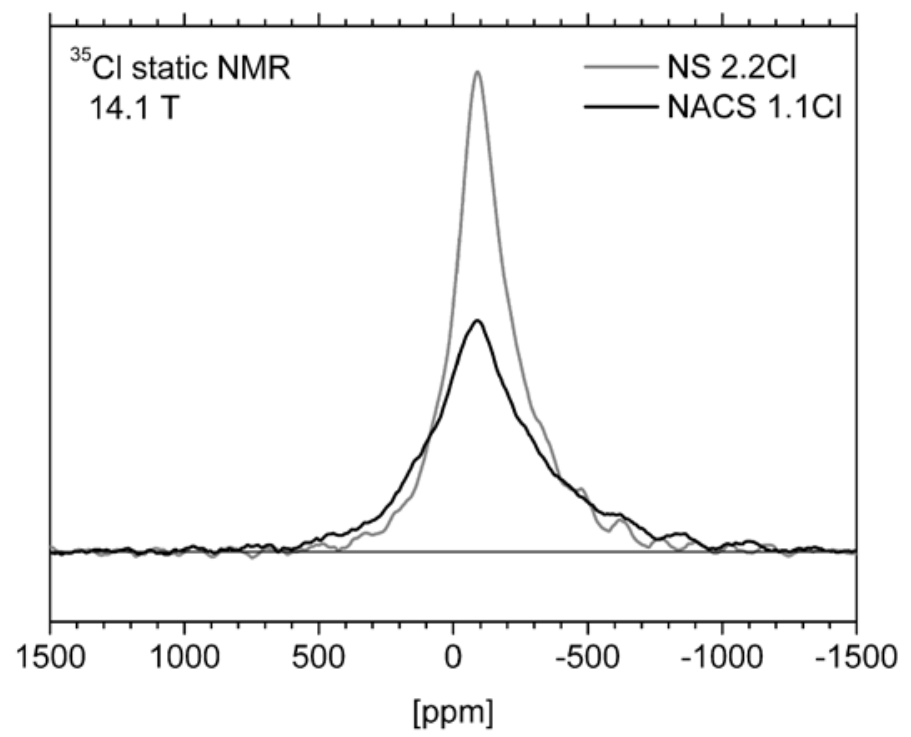

Fig. 4. Static ${ }^{35} \mathrm{CI}$ NMR spectra of the sodium silicate glass NS $2.2 \mathrm{Cl}$ and the peralkaline glass NACS $1.1 \mathrm{Cl}$ at $14.1 \mathrm{~T}$. The spectra are normalised to the same number of acquisitions and same number of $\mathrm{Cl}$ atoms (peak maxima for both samples $\sim 90 \mathrm{ppm}$ ).

Table $2 .{ }^{35} \mathrm{Cl}$ peak maximum, centre of gravity and full width half maximum $F W H M$ of the ${ }^{35} \mathrm{Cl}$ MAS NMR spectra at different fields ${ }^{a}$.

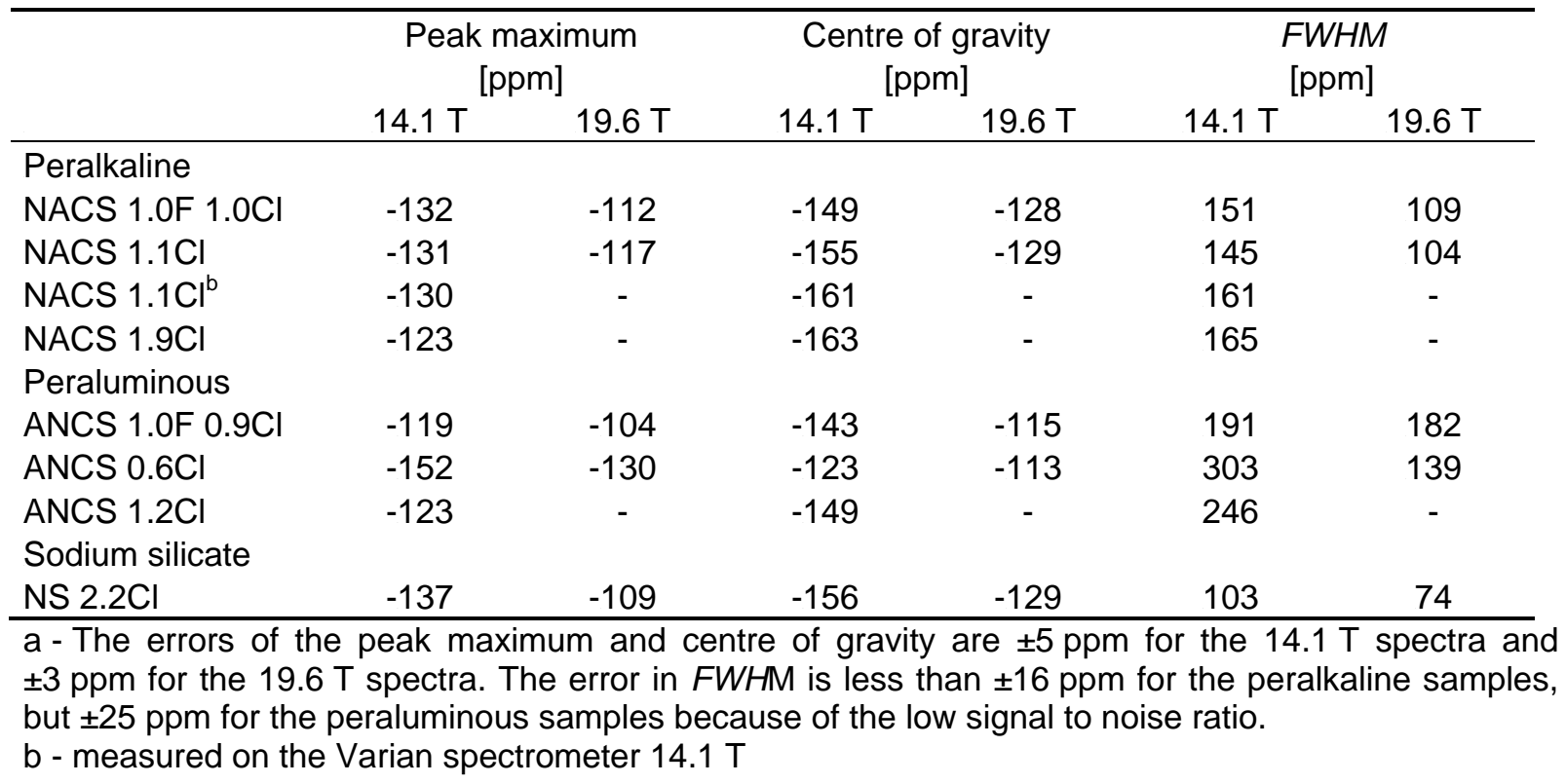

Table 2 gives the peak maxima, the centres of gravity and the full width half maxima FWHM of the ${ }^{35} \mathrm{Cl}$ MAS NMR spectra. The centres of gravity of the peralkaline glasses and the sodium silicate glass are similar with $\sim-155 \mathrm{ppm}$ at $14.1 \mathrm{~T}$ and $\sim-130 \mathrm{pm}$ at 19.6 T, while the centres of gravity of the peraluminous glasses are shifted to higher ppm values of $\sim-140 \mathrm{ppm}$ at $14.1 \mathrm{~T}$ and $\sim-115 \mathrm{ppm} 19.6 \mathrm{~T}$. In case of the spectra at $14.1 \mathrm{~T}$, the spinning sidebands are not completely separated from 
the central band, which contributes to an error of $\pm 5 \mathrm{ppm}$ for the centres of gravity. The FWHM increases by a factor two or more at both fields from sodium silicate to peraluminous glasses.

Figure 5 shows an overlay of the ${ }^{35} \mathrm{Cl}$ MAS NMR spectra of peralkaline and peraluminous glasses at $14.1 \mathrm{~T}$ and $19.6 \mathrm{~T}$ normalised to same peak height. The increased width together with a shift of the ${ }^{35} \mathrm{Cl}$ resonance to higher ppm values in the peraluminous glass compared to the peralkaline glass can be clearly seen from both overlays.

Figure 6 shows the centre of gravity $\delta_{c g}$ [ppm] as function of the inverse squared Larmor frequency $v_{0}^{-2}\left[\mathrm{MHz}^{-2}\right]$ for some of the Cl-bearing samples. Linear equations were fitted to the data. The ordinates of the linear equations give the isotropic chemical shift $\delta_{\text {iso }}$ [ppm] (Table 3). A mean quadrupole coupling constant $C_{q}[\mathrm{MHz}]$ (Table 3) can be calculated from the slope of Eq. 1 (after e.g. Freude and Haase, 1993; Schmidt et al., 2000a) using the asymmetry parameter $\eta=0.7$ (Stebbins and $\mathrm{Du}, 2002)$

$$
\delta_{c g}=\delta_{\text {iso }}-\frac{1}{40} \cdot \frac{C_{q}^{2} \cdot\left(1+\eta^{2} / 3\right)}{v_{0}^{2}}
$$

For the peralkaline glasses the spectra of the samples NACS $1.1 \mathrm{Cl}$ and NACS $1.9 \mathrm{Cl}$ were used for the plot in Fig. 6. For the peraluminous glasses the spectrum of ANCS $0.6 \mathrm{Cl}$ at $19.6 \mathrm{~T}$ and the spectrum of ANCS $1.2 \mathrm{Cl}$ at $14.1 \mathrm{~T}$ was used as the spectrum of ANCS $0.6 \mathrm{Cl}$ at $14.1 \mathrm{~T}$ had a very poor signal to noise ratio. The higher concentration of $\mathrm{Cl}$ in ANCS $1.2 \mathrm{Cl}$ compared to ANCS $0.6 \mathrm{Cl}$ is not expected to have a significant influence on the results (e.g. Stebbins and Du, 2002; Sandland et al., 2004) as the concentration of $\mathrm{Cl}$ is low. The centre of gravity vs. inverse squared Larmor frequency plots for the other samples containing both, $\mathrm{Cl}$ and $\mathrm{F}$, are given in Figs. $\mathrm{B}$ and $\mathrm{C}$ in the supplementary data.

An estimate of the width due to the quadrupole effect $W_{q}$ and the width due to the chemical shift distribution $W_{c s d}($ Table 3$)$ can be calculated after Schmidt et al. (2000a, b)

$$
F W H M_{1}^{2}=W_{q}^{2}+W_{c s d}^{2}
$$


and

$$
F W H M_{2}^{2}=\left(B_{1} / B_{2}\right)^{2} W_{q}^{2}+\left(B_{2} / B_{1}\right)^{2} W_{c s d}^{2}
$$

with $F W H M_{1}$ and $F W H M_{2}[\mathrm{~Hz}]$ being the full width half maxima of two spectra measured at a lower magnetic field $B_{1}[T]$ and a higher magnetic field $B_{2}[T]$. Because of the low signal to noise ratio $W_{q}$ and $W_{c S d}$ of the samples ANCS $0.6 \mathrm{Cl}$ and ANCS $1.0 \mathrm{~F} 0.9 \mathrm{Cl}$ are not presented.

The sodium silicate glass and the peralkaline glass have, within error ( $\pm 16 \mathrm{ppm})$, the same isotropic chemical shift of $\sim-100 \mathrm{ppm}$, while the peraluminous glasses have a higher chemical shift of $\sim-75 \mathrm{ppm}$. The mean $C_{q}$ s of the samples range from 2.3 - 3.1 MHz. The presence of $\mathrm{F}$ only has a minor influence, comparable with the error, on the chemical shift and $C_{q}$. The chemical shift dispersion, $W_{c s d}$, for the sodium silicate glass is $\sim 60 \mathrm{ppm}$, smaller than that of the peralkaline glasses, 80 - 90 ppm (Table 3). The values for $W_{q}$ are only 50\% larger than those of $W_{c s d}$ at 14.1 $\mathrm{T}$ for both glasses. At 19.6 T $W_{c s d}$ is the dominant contribution to the line width, even though second-order quadrupole broadening is still affecting the signal, which is consistent with the relatively small $C_{q}$ for ${ }^{35} \mathrm{Cl}$ observed here.

Table $3 .{ }^{35} \mathrm{Cl}$ isotropic chemical shift $\delta_{\text {iso, }}$, width due to quadrupole broadening $W_{q}$, width due to chemical shift distribution $W_{c s d}$ and quadrupole coupling constant $C_{q}$ obtained from spectra ${ }^{35} \mathrm{Cl}$ MAS spectra at 14.1 T and 19.6 T evaluated after Schmidt et al. (2000a, b).

\begin{tabular}{|c|c|c|c|c|}
\hline & $\begin{array}{c}\delta_{\text {iso }}{ }^{\mathrm{a}} \\
{[\mathrm{ppm}]}\end{array}$ & $\begin{array}{c}C_{q}{ }^{b} \\
{[\mathrm{MHz}]}\end{array}$ & $\begin{array}{c}W_{q}^{\mathrm{c}} \\
{[\mathrm{ppm}]} \\
14.1 \mathrm{~T}\end{array}$ & $\begin{array}{l}W_{c s d}{ }^{\mathrm{c}} \\
{[\mathrm{ppm}]} \\
14.1 \mathrm{~T}\end{array}$ \\
\hline \multicolumn{5}{|l|}{ Peralkaline } \\
\hline NACS $1.0 \mathrm{~F} 1.0 \mathrm{Cl}$ & -105 & 2.3 & 123 & 89 \\
\hline $\mathrm{NACS} 1.1 \mathrm{Cl}+\mathrm{NACS} 1.9 \mathrm{Cl}^{\mathrm{d}}$ & -95 & 2.8 & 131 & 79 \\
\hline \multicolumn{5}{|l|}{ Peraluminous } \\
\hline ANCS $1.0 \mathrm{~F} 0.9 \mathrm{Cl}^{f}$ & -74 & 3.1 & - & - \\
\hline ANCS $0.6 \mathrm{Cl}+$ ANCS $1.2 \mathrm{Cl}^{\mathrm{ef}}$ & -75 & 3.0 & - & - \\
\hline \multicolumn{5}{|l|}{ Sodium silicate } \\
\hline $\mathrm{NS} 2.2 \mathrm{Cl}$ & -101 & 2.6 & 84 & 60 \\
\hline
\end{tabular}

a - The maximum error in $\delta_{\text {iso }}$ is $\pm 16 \mathrm{ppm}$.

$\mathrm{b}-C_{q}$ was calculated estimating an asymmetry parameter $\eta=0.7$. The maximum error in $C_{q}$ is $\pm 0.3 \mathrm{MHz}$ taking into account that $\eta$ could range from 0 to 1 .

$c$ - The maximum error in $W_{q}$ and $W_{C S D}$ is less than $\pm 12.5 \%$ for a max. error of $16 \mathrm{ppm}$ in FWHM.

$\mathrm{d}$ - The evaluation was done based on the measurements of the sample $\mathrm{NACS} 1.1 \mathrm{Cl}$ at $14.1 \mathrm{~T}$ and 19.6 $\mathrm{T}$ and the sample NACS $1.9 \mathrm{Cl}$ at $14.1 \mathrm{~T}$.

$\mathrm{e}$ - The spectrum of ANCS $0.6 \mathrm{Cl}$ at $14.1 \mathrm{~T}$ was not included in the evaluation for $\delta_{\text {iso }}$ and $C_{q}$ because of its poor/low signal to noise ratio. The evaluation was done based on the measurement of ANCS $1.2 \mathrm{Cl}$ at $14.1 \mathrm{~T}$ and $\mathrm{ANCS} 0.6 \mathrm{Cl}$ at $19.6 \mathrm{~T}$.

$\mathrm{f}-W_{q}$ and $W_{C S D}$ are not presented for the peraluminous spectra because of their low signal to noise ratio. 


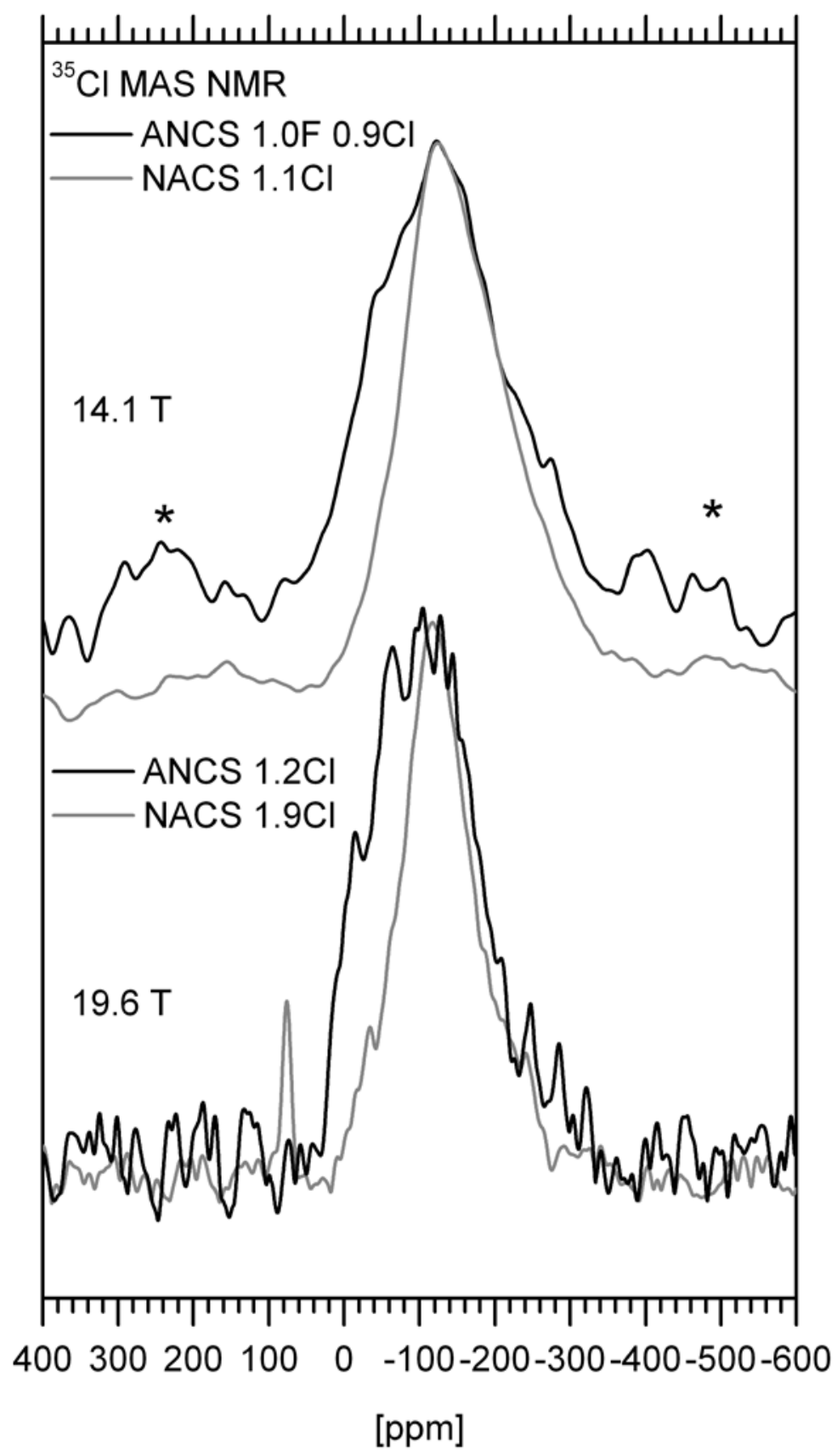

Fig. $5 .{ }^{35} \mathrm{Cl}$ MAS NMR spectra of the $\mathrm{Cl}$ - bearing peraluminous (ANCS) and peralkaline glasses (NACS) at $14.1 \mathrm{~T}$ and 19.6T. Spinning sidebands are marked with an asterisk. The spectra are normalised to the same peak height. The baseline is the same for all spectra. The spectrum of ANCS $1.2 \mathrm{Cl}$ only appears to have a higher baseline because of spinning sidebands. 


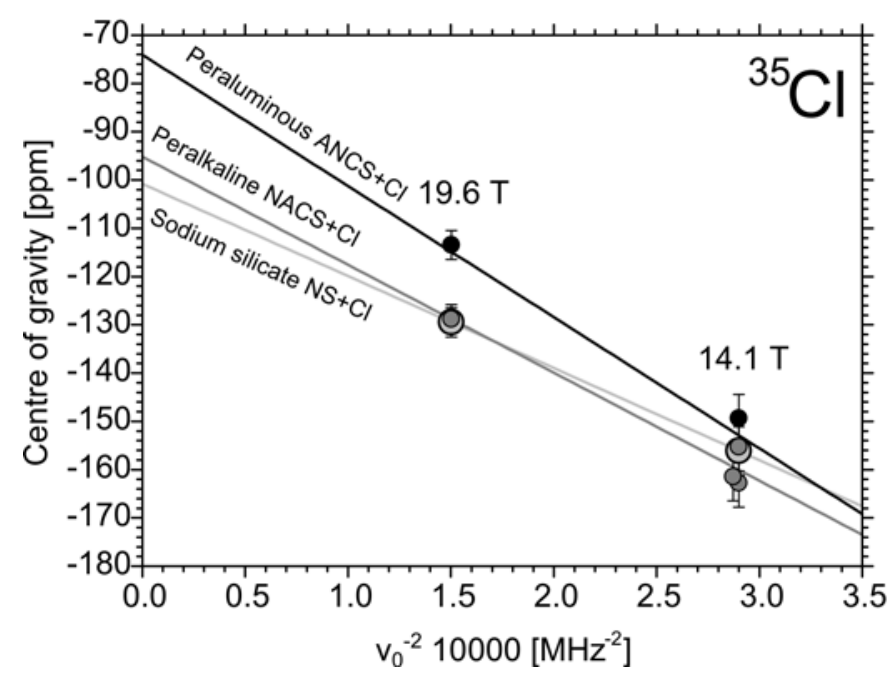

Fig. 6. Centre of gravity of ${ }^{35} \mathrm{Cl}$ MAS NMR central bands of the Cl-bearing peraluminous (ANCS $1.2 \mathrm{Cl}$ (14.1 T)+ANCS 0.6Cl (19.6 T)), peralkaline (NACS 1.9Cl (14.1 T)+NACS 1.1Cl (14.1 T, 19.6 T) and sodium silicate glass as a function of inverse squared Larmor frequency $v_{0}^{-2}$. The ordinate of the linear regressions gives the isotropic chemical shift $\delta_{i s o}$ and the quadrupole coupling $C_{q}$ constant is calculated from the slope. (see Table 3). The numbers over the data are the magnetic fields in Tesla.

An alternate way of describing the effect of significant distributions in the parameters, if data at more than one field are available, is to use programs such as Quadfit to simulate the spectra (Kemp et al., 2009). Quadfit not only uses the parameter $\delta_{\text {iso, }} a$ mean $\bar{C}_{q}, W_{c s d}$ and a mean $\bar{\eta}$ for simulation, but also allows a distribution of $C_{q}$ $\left(\Delta \bar{C}_{q}\right)$ and $\eta(\Delta \bar{\eta})$. Using Quadfit to fit the spectra with a single quadrupole line, worked well for the NS glass (Fig. D in the supplementary data) but was not entirely successful for the peraluminous and peralkaline glasses. Figure 7 shows, as an example, the spectrum of NACS $1.1 \mathrm{Cl}$ at $14.1 \mathrm{~T}$ and 19.6 T simulated with Quadfit. There is some additional intensity $(\sim 10-20 \%)$ on the high frequency flank of the peralkaline and peraluminous spectra that could not be simulated. This suggests that there might be more than one type of $\mathrm{Cl}$ environment, although this could be within the signal to noise ratio. The parameters obtained from peak fitting of all spectra except ANCS $0.6 \mathrm{Cl}$ at $14.1 \mathrm{~T}$ (because of too low signal to noise) are given in Table 4. The parameters suggest that for the sodium silicate, peralkaline and peraluminous glasses the mean chemical shifts, $\delta_{\text {iso }}$ are $-80 \mathrm{ppm},-74$ to $-79 \mathrm{ppm}$, and -30 to $-58 \mathrm{ppm}$ respectively, whilst the distribution in chemical shifts $W_{c s d}$ increases from $37 \mathrm{ppm}$ to $\sim 75 \mathrm{ppm}$ and to $\sim 125 \mathrm{ppm}$. The mean quadrupole 
coupling constant $\bar{C}_{q}$ also increases from $-3.5 \mathrm{MHz}$ in the sodium silicate and peralkaline glasses to $\sim 4.2 \mathrm{MHz}$ for the peraluminous glasses. For all glasses the distribution of the quadrupole coupling constant is large, $\Delta \bar{C}_{q} \geq 2.1-3.0 \mathrm{MHz}$, with the peraluminous samples having the highest values. The mean asymmetry parameter $\bar{\eta}$ ranges from 0.5 to 0.8 with a distribution $\Delta \bar{\eta} \geq 0.2$. In summary, the values for the isotropic chemical shifts simulated with Quadfit are $\sim 20$ To 30 ppm more positive and the quadrupole coupling constants $\sim 1 \mathrm{MHz}$ larger than those obtained using the method of Schmidt et al. (2000a, b), however both methods show the same trends: The peralkaline glasses have similar chemical shifts to the sodium silicate glass with the peraluminous glasses having a $\sim 25$ to $\sim 40$ ppm higher chemical shift. Both the chemical shift dispersion and the distribution in quadrupole coupling constants increase markedly from sodium silicate to peralkaline to peraluminous glass.

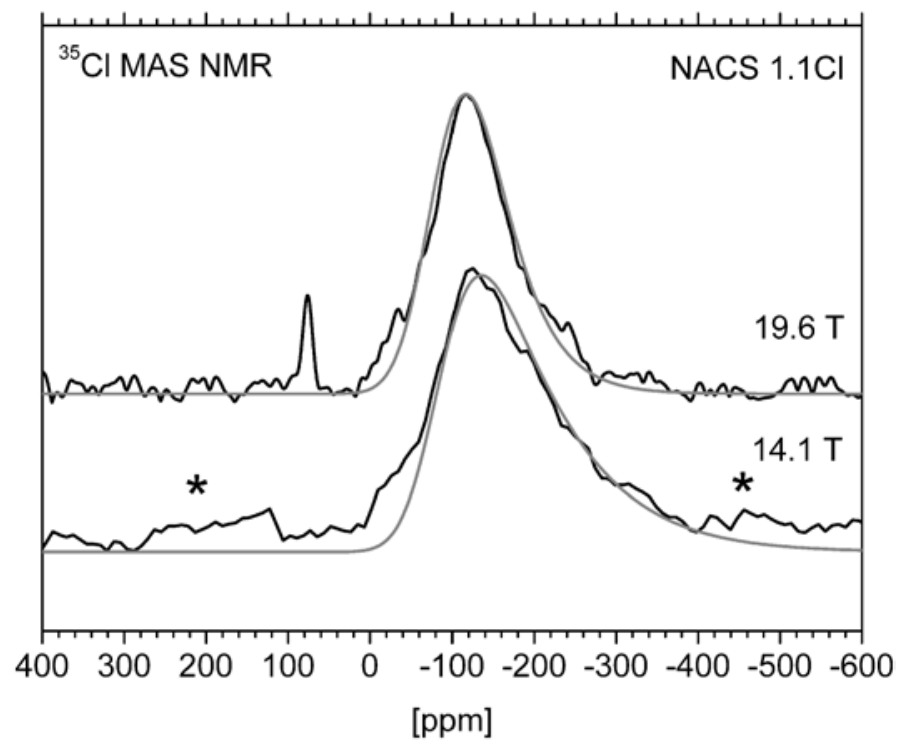

Fig. $7 .{ }^{35} \mathrm{Cl}$ MAS NMR spectra of the peralkaline glass NACS $1.1 \mathrm{Cl}$ at $14.1 \mathrm{~T}$ and $19.6 \mathrm{~T}$ (black lines) fitted with the program Quadfit (grey lines). Spinning sidebands are marked with an asterisk. The spectra are normalised to the same peak height. 
Table 4. ${ }^{35} \mathrm{Cl}$ chemical shift $\delta_{\text {iso, }}$ width due to chemical shift distribution $W_{c s d}$ and quadrupole coupling constant $\bar{C}_{q}$, the quadrupole distribution $\Delta \bar{C}_{q}$, the asymmetry parameter $\eta$ and the distribution of the asymmetry parameter $\Delta \eta$ of the curves fitted to the ${ }^{35} \mathrm{CI}$ MAS NMR spectra at different magnetic fields $B$ with the program Quadfit ${ }^{\mathrm{a}}$.

\begin{tabular}{lcccccc}
\hline & $\begin{array}{c}\delta_{\text {iso }} \\
{[\mathrm{ppm}]}\end{array}$ & $\begin{array}{c}W_{C S D} \\
{[\mathrm{ppm}]}\end{array}$ & $\begin{array}{c}\bar{C}_{q} \\
{[\mathrm{MHz}]}\end{array}$ & $\begin{array}{c}\Delta \bar{C}_{q} \\
{[\mathrm{MHz}]}\end{array}$ & $\bar{\eta}$ & $\Delta \bar{\eta}$. \\
\hline ANCS 1.0F 0.9Cl & -45 & 125 & 4.2 & 3.0 & 0.8 & 0.2 \\
ANCS 0.6Cl & -58 & 125 & 4.3 & 3.0 & 0.8 & 0.2 \\
ANCS 1.2Cl & -30 & 125 & 4.2 & 3.0 & 0.8 & 0.2 \\
NACS 1.0F 1.0Cl & -79 & 72 & 3.3 & 2.1 & 0.8 & 0.2 \\
NACS 1.1Cl & -77 & 82 & 3.7 & 2.7 & 0.5 & 0.2 \\
NACS 1.9Cl & -74 & 82 & 3.5 & 3.0 & 0.7 & 0.2 \\
NS 2.2Cl & -80 & 37 & 3.5 & 2.5 & 0.5 & 0.3 \\
\hline a- Various approach
\end{tabular}

a - Various approaches to fit the spectra suggest that the errors of the parameter are \pm 5 ppm for $\delta_{\text {iso }}$ $\pm 10 \mathrm{ppm}$ for $W_{c s d}, \pm 0.2$ for $\bar{\eta}, \pm 0.1$ for $\Delta \bar{\eta}$ and $\pm 0.2 \mathrm{MHz}$ for $\bar{C}_{q}$ and $\Delta \bar{C}_{q}$.

\subsection{2. ${ }^{23} \mathrm{Na}$ MAS NMR}

Figure 8 shows ${ }^{23} \mathrm{Na}$ MAS NMR spectra at $11.7 \mathrm{~T}$. The peak shape is nearly Gaussian. The peak maxima, centres of gravity and the FWHM are given in Table 5. The peak parameters and the spectra of the halogen-free samples NACS and ANCS were taken from Baasner et al. (2014). The peak maximum of the halogen-free peralkaline glass has a higher shift, -17.0 ppm, and the FWHM is broader, $25.7 \mathrm{ppm}$, than that of the halogen-free peraluminous glass, $-20.7 \mathrm{ppm}$ and $20.7 \mathrm{ppm}$ respectively. In the peralkaline as well as in the peraluminous glasses containing the highest $\mathrm{Cl}$ concentration the presence of $\mathrm{Cl}$ causes a small positive shift in the peak maxima of up to 2 ppm while the centres of gravity and the FWHM remain constant.

Table $5 .{ }^{23} \mathrm{Na}$ peak maximum, centre of gravity and full width half maximum FWHM of the ${ }^{23} \mathrm{Na}$ MAS NMR spectra at $11.7 \mathrm{~T}^{\mathrm{a}}$.

\begin{tabular}{lccc}
\hline & $\begin{array}{c}\text { Peak maximum } \\
{[\mathrm{ppm}]}\end{array}$ & $\begin{array}{c}\text { Centre of gravity } \\
{[\mathrm{ppm}]}\end{array}$ & $\begin{array}{c}F W H M \\
{[\mathrm{ppm}]}\end{array}$ \\
\hline NACS $^{\mathrm{b}}$ & -17.0 & -16.9 & 25.7 \\
NACS 1.0Cl 1.0F & -16.0 & -16.6 & 24.4 \\
NACS 1.1Cl & -16.3 & -16.8 & 24.7 \\
NACS 1.9Cl & -14.9 & -16.7 & 25.2 \\
ANCS $^{b}$ & -20.7 & -19.2 & 20.7 \\
ANCS 0.9Cl 1.0F $_{\text {ANCS 1.2Cl }}$ & -20.6 & -20.8 & 20.9 \\
\hline
\end{tabular}

a - The errors of peak maximum, centre of gravity and $F W H M$ are $\sim \pm 0.5 \mathrm{ppm}$.

b - from Baasner et al. (2014) 


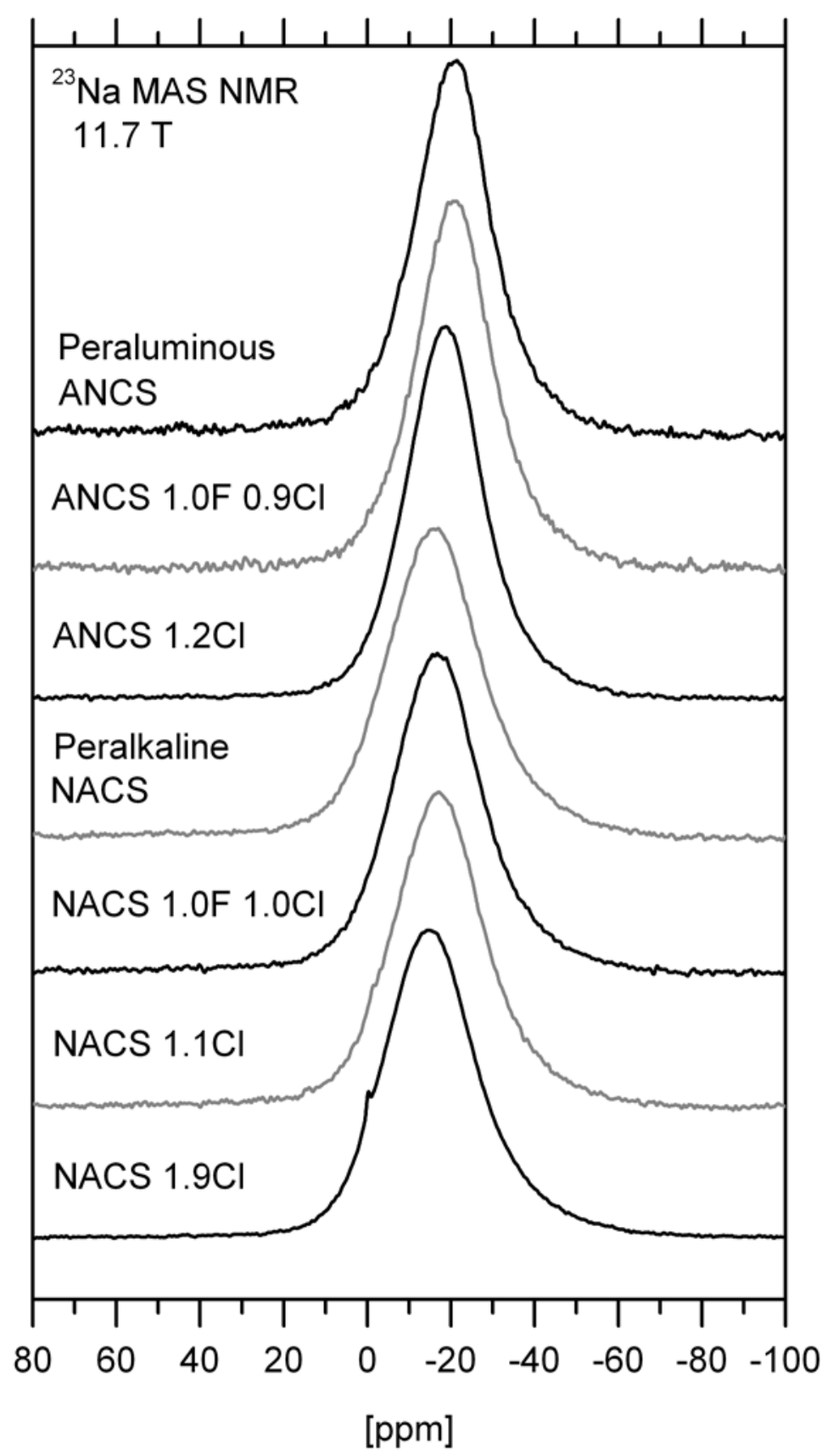

Fig. $8 .{ }^{23} \mathrm{Na}$ MAS NMR spectra of halogen-free and halogen-bearing peraluminous and peralkaline glasses at $11.7 \mathrm{~T}$. The spectra are normalised to the same peak area. The small peak in the high frequency flank of the peak of $\mathrm{NACS} 1.9 \mathrm{Cl}$ is a contamination with the reference material $\mathrm{NaCl}$. 


\subsection{3. ${ }^{27}$ Al MAS NMR}

The peak maxima, centres of gravity and the FWHM of the ${ }^{27}$ Al MAS NMR spectra are given in Table 6. The peak parameters and the spectra of the halogen-free sample NACS and ANCS were taken from Baasner et al. (2014) including the calculation of $\delta_{\text {iso }}$ and $C_{q}$ after Schmidt et al. (2000a).

Figure 9 shows ${ }^{27} \mathrm{Al}$ MAS NMR spectra at $11.7 \mathrm{~T}$ of the halogen-free peralkaline sample NACS and the Cl-bearing glass NACS $1.9 \mathrm{Cl}$. The peaks have an obvious quadrupole tail on the right hand. All $\mathrm{Al}$ is four-coordinated ( $\mathrm{Al}^{\mathrm{IV}}$ ) with a peak maximum at $\sim 55 \mathrm{ppm}$, no higher-coordinated $\mathrm{Al}\left(\mathrm{Al}^{\mathrm{V}}\right.$ or $\left.\mathrm{Al}^{\mathrm{Vl}}\right)$ is observed and the spectrum of Cl-bearing glass NACS $1.9 \mathrm{Cl}$ is virtually identical to that of the halogen-free glass NACS.

Figure 10 shows ${ }^{27} \mathrm{Al}$ MAS NMR spectra at $20 \mathrm{~T}$ of the halogen-free peraluminous sample ANCS and the Cl-bearing glass ANCS $1.2 \mathrm{Cl}$. Despite the high field a quadrupole tail on the right hand of the peaks is still visible. As found earlier for the halogen-free glass (Baasner et al. 2014) most $\mathrm{Al}$ is $\mathrm{Al}^{\mathrm{IV}}$ with a peak maximum at $\sim 57 \mathrm{ppm}$ and a small (5 - 6\% of the total Al) fraction of $\mathrm{Al}^{\vee}$ around $30 \mathrm{ppm}$ in both spectra. A subtraction of the spectrum of ANCS from ANCS $1.2 \mathrm{Cl}$ shows that the spectra are very similar although the amount of $\mathrm{Al}^{\vee}$ might be slightly higher $(<1 \%)$ in the $\mathrm{Cl}$-bearing glass than in the $\mathrm{Cl}$-free glass. 


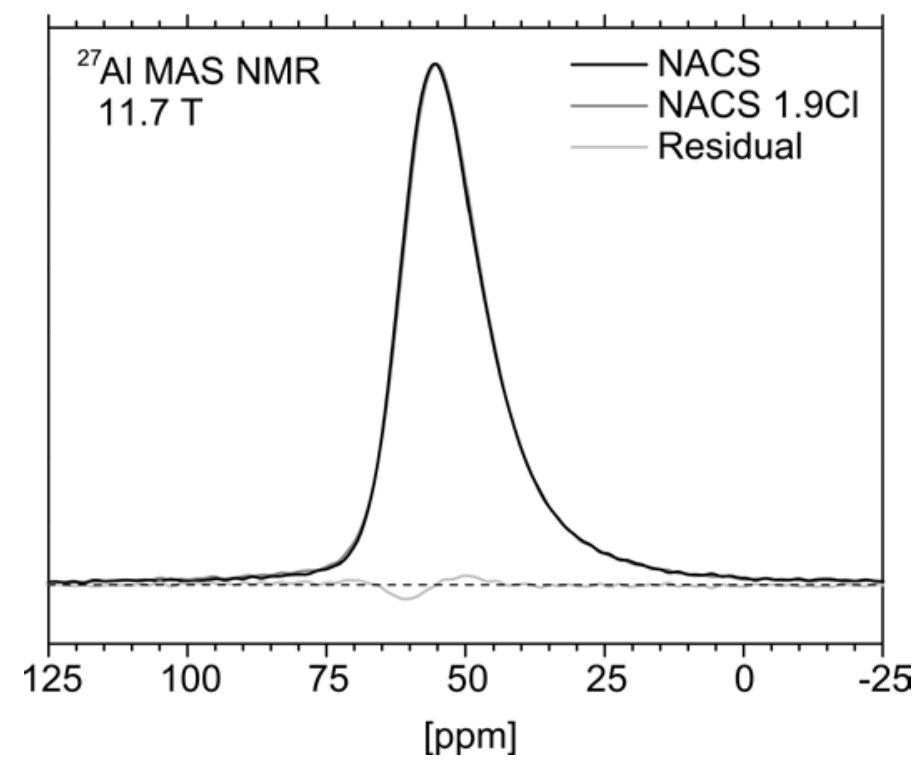

Fig. 9. ${ }^{27} \mathrm{Al}$ MAS NMR spectra of the Cl-free and Cl-bearing peralkaline (NACS) glasses at 11.7 T. The spectra are normalised to the same peak height. The residual results from subtracting the spectrum of NACS from that of NACS $1.9 \mathrm{Cl}$.

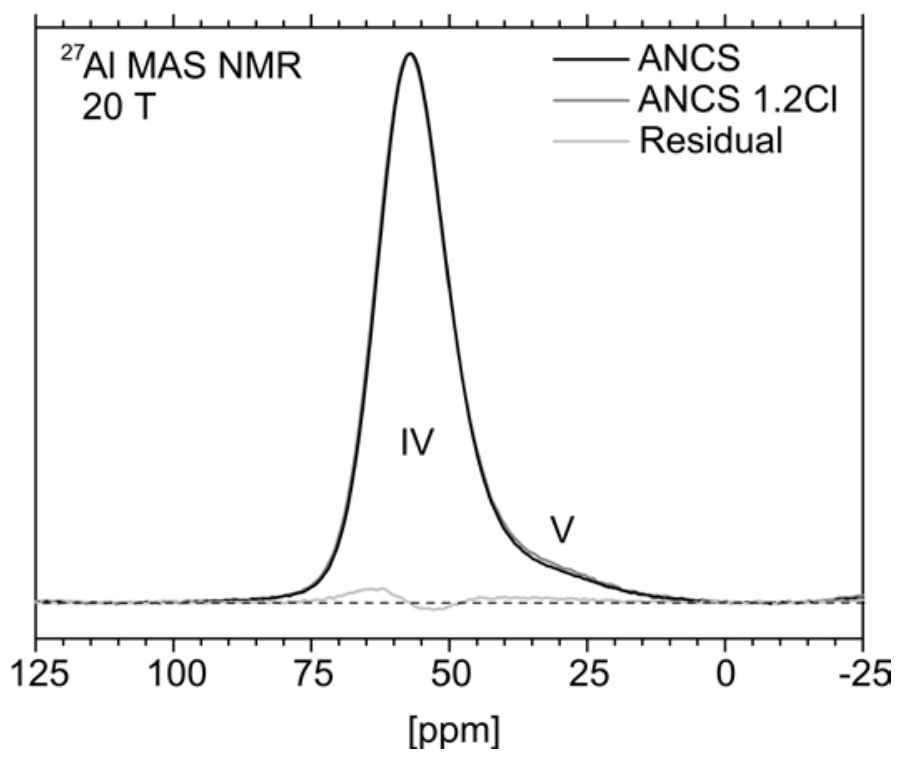

Fig. 10. ${ }^{27} \mathrm{Al}$ MAS NMR spectra of the $\mathrm{Cl}$-free and Cl-bearing peraluminous (ANCS) glasses at $11.7 \mathrm{~T}$. The spectra are normalised to the same peak height. The residual results from subtracting the spectrum of ANCS from that of ANCS 1.2Cl. 
Table $6 .{ }^{27} \mathrm{Al}$ peak maximum, centre of gravity and full width half maximum FWHM of the ${ }^{27} \mathrm{Al}$ MAS NMR spectra at different magnetic fields ${ }^{\text {a }}$.

\begin{tabular}{lcccc}
\hline & $\begin{array}{c}\text { Magnetic field } \\
{[\mathrm{T}]}\end{array}$ & $\begin{array}{c}\text { Peak maximum } \\
{[\mathrm{ppm}]}\end{array}$ & $\begin{array}{c}\text { Centre of gravity } \\
{[\mathrm{ppm}]}\end{array}$ & $\begin{array}{c}F W H M \\
{[\mathrm{ppm}]}\end{array}$ \\
\hline NACS $^{\text {b }}$ & 11.7 & 55.54 & 51.18 & 16.90 \\
NACS $1.1 \mathrm{Cl}$ & 11.7 & 55.36 & 52.54 & 16.96 \\
NACS $1.9 \mathrm{Cl}$ & 11.7 & 55.28 & 51.71 & 16.81 \\
ANCS $^{\text {b }}$ & 11.7 & 52.55 & 43.91 & 23.21 \\
ANCS1.2Cl $^{\text {ANCS }}$ & 11.7 & 52.82 & 41.57 & 23.89 \\
ANCS $1.2 \mathrm{Cl}^{\text {b }}$ & 20.0 & 57.03 & 54.30 & 15.04 \\
\hline
\end{tabular}

a - The errors of peak maximum, centre of gravity and FWHM are $\pm 0.25 \mathrm{ppm}$ for the 11.7 and $20 \mathrm{~T}$ spectra.

b - from Baasner et al. (2014)

\subsection{4. ${ }^{29}$ Si MAS NMR}

Figure 11 shows ${ }^{29} \mathrm{Si}$ MAS NMR spectra at $7 \mathrm{~T}$ of the halogen-free and Cl-bearing peralkaline and peraluminous glasses. The peaks have a Gaussian line shape. The peak maxima, centres of gravity and FWHM are given in Table 7. The peak parameters and the spectra of the halogen-free samples NACS and ANCS were taken from Baasner et al. (2014). The halogen-free peraluminous sample ANCS has a lower chemical shift, $-100.4 \mathrm{ppm}$, than the halogen-free peralkaline sample NACS, $-96.3 \mathrm{ppm}$. The ${ }^{29} \mathrm{Si}$ peak in the peraluminous glasses is unaffected by the presence of $\mathrm{Cl}$ (and $\mathrm{F}$ ), while in the peralkaline glasses $\mathrm{Cl}$ causes a shift in the peak maximum of $-0.9 \mathrm{ppm}$ and a shift in the centre of gravity of $-1.7 \mathrm{ppm}$. The ${ }^{29} \mathrm{Si}$ peaks in the spectra of NACS $1.1 \mathrm{Cl}$ and NACS $1.0 \mathrm{~F} 0.9 \mathrm{Cl}$ are within error the same.

Table $7 .{ }^{29} \mathrm{Si}$ isotropic chemical shift $\delta_{\text {iso }}$, centre of gravity and full width half maximum (FWHM) of the ${ }^{29}$ Si MAS NMR spectra at $7 \mathrm{~T}^{\mathrm{a}}$.

\begin{tabular}{lccc}
\hline & $\begin{array}{c}\delta_{\text {iso }} \\
{[\mathrm{ppm}]}\end{array}$ & $\begin{array}{c}\text { Centre of gravity } \\
{[\mathrm{ppm}]}\end{array}$ & $\begin{array}{c}F W H M \\
{[\mathrm{ppm}]}\end{array}$ \\
\hline NACS $^{\mathrm{b}}$ & -96.3 & -96.2 & 17.1 \\
NACS 1.0Cl 1.0F & -97.2 & -97.9 & 17.1 \\
NACS 1.1Cl & -97.2 & -97.9 & 17.5 \\
ANCS $^{\text {b }}$ & -100.4 & -100.4 & 17.9 \\
ANCS 0.9Cl 1.0F $^{\text {and }}$ & -100.8 & -101.1 & 18.0 \\
\hline
\end{tabular}

a - The errors of $\delta_{\text {iso }}$, centre of gravity and FWHM are $\sim \pm 0.4 \mathrm{ppm}$.

b - from Baasner et al. (2014) 


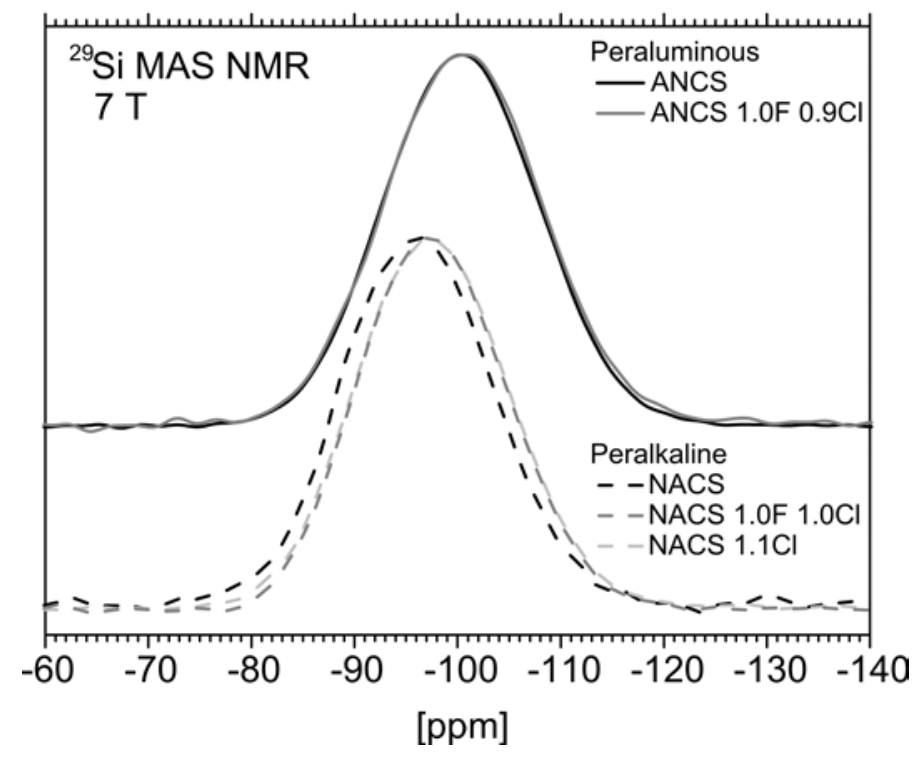

Fig. $11 .{ }^{29} \mathrm{Si}$ MAS NMR spectra of the halogen-free and halogen-bearing peraluminous and peralkaline glasses at $7 \mathrm{~T}$. The spectra are normalised to the same peak height.

\subsection{Discussion}

Although the values for mean isotropic chemical shift and quadrupole parameters derived using the methods of Schmidt et al. $(2000 a, b)$ and by fitting the spectra with Quadfit (QF) are somewhat different they show similar trends. The methods used to determine $\delta_{\text {iso, }} C_{q}, W_{c s d}$ and $W_{q}$ for the ${ }^{35} \mathrm{Cl}$ spectra (Schmidt et al., 2000a, b) (Fig. 6) are intended for peaks that were produced by a single environment without a large dispersion in $C_{q}$, although the ${ }^{35} \mathrm{Cl}$ line shape for the peralkaline and peraluminous glasses indicates that this is not the case. Sandland et al. (2004) suggested that in mixed $\mathrm{Na}_{2} \mathrm{O}-\mathrm{CaO}$ silicate glasses $\mathrm{Cl}$ exists in environments surrounded by either $\mathrm{Ca}$ or $\mathrm{Na}$ cations as well as in mixed cation environments. However the spectra of the peralkaline and peraluminous glasses are not well enough constrained to allow a meaningful fit to multiple lines even though there is some evidence that a one site simulation with Quadfit is insufficient (see e.g. Fig. 7). Stebbins and Du (2002) and Sandland et al. (2004) found that calcium (alumino)silicate glasses have a 150 ppm higher ${ }^{35} \mathrm{Cl}$ isotropic chemical shift (52 to $102 \mathrm{ppm}$ ) than sodium (alumino)silicate glasses (-65 to $-89 \mathrm{ppm}$ ) and that mixed $\mathrm{Na}_{2} \mathrm{O}-\mathrm{CaO}$ silicate glasses have an intermediate shift. No data are available for mixed $\mathrm{Na}_{2} \mathrm{O}-\mathrm{CaO}$ aluminosilicate glasses. The present peralkaline mixed $\mathrm{Na}_{2} \mathrm{O}-\mathrm{CaO}$ aluminosilicate glasses have a similar ${ }^{35} \mathrm{Cl}$ chemical shift to sodium silicate glass, -100 ppm ( -76 ppm, QF) (Figs. 1,2 and 4), 
suggesting that the ${ }^{35} \mathrm{Cl}$ sites are dominated by $\mathrm{Na}$ and that the $\mathrm{Cl}$ environments are very similar in both glass types, but with more disorder in the peralkaline glass. This was expected as in the peralkaline $\mathrm{Na}_{2} \mathrm{O}-\mathrm{CaO}$ aluminosilicate glasses with a $\mathrm{Ca} /[\mathrm{Ca}+\mathrm{Na}]$ ratio of 0.18 the $\mathrm{Na}$ concentration is much higher than the $\mathrm{Ca}$ concentration. The FWHM and $W_{c s d}$ of the ${ }^{35} \mathrm{Cl}$ MAS NMR signal is significantly broader in the peralkaline $\mathrm{Na}_{2} \mathrm{O}-\mathrm{CaO}$ aluminosilicate glasses than in the sodium silicate glass indicating a significantly larger chemical shift distribution, which could be either related to the incorporation of $\mathrm{Ca}$ cations in the $\mathrm{Cl}$ environment or due to the presence of Al. The latter is unlikely as the comparison of Al-bearing and Al-free glasses in previous studies showed that $\mathrm{Al}$ has no strong influence on the ${ }^{35} \mathrm{Cl}$ environment (Stebbins and Du, 2002; Sandland et al., 2004). Sandland et al. (2004) observed no preference of $\mathrm{Cl}$ for $\mathrm{Ca}$ or $\mathrm{Na}$ cations in mixed $\mathrm{Na}_{2} \mathrm{O}-\mathrm{CaO}$ silicate glasses. However, the ${ }^{35} \mathrm{Cl}$ MAS NMR resonance of the peraluminous mixed $\mathrm{Na}_{2} \mathrm{O}-\mathrm{CaO}$ aluminosilicate glasses is shifted by $\sim+25$ ppm ( +40 ppm QF) (Figs. 1, 2, 3 and 5) and the chemical shift distribution is $\sim 50 \%$ larger than for the peralkaline glasses. In analogy to the data of Stebbins and Du (2002) and Sandland et al. (2004) this shift may indicate that more $\mathrm{Ca}$ cations relative to $\mathrm{Na}$ cations are incorporated in the $\mathrm{Cl}$ sites even though the samples have the same $\mathrm{Ca} /[\mathrm{Ca}+\mathrm{Na}]$ ratio. This suggests that $\mathrm{Cl}$ has a slight preference for $\mathrm{Na}$ cations compared to $\mathrm{Ca}$ cations in peralkaline samples. In the peraluminous glasses, where most $\mathrm{Na}$ and $\mathrm{Ca}$ cations are assumed to charge-balance Al-tetrahedra, the $\mathrm{Na}$ and $\mathrm{Ca}$ cations cannot arrange as freely as in the peralkaline glasses and presumably therefore, more $\mathrm{Ca}$ is incorporated in the Cl environment.

The comparatively small ${ }^{35} \mathrm{Cl} C_{q}$ values of $2-4 \mathrm{MHz}$ (Tables 3 and 4 ) for the peralkaline, peraluminous and sodium silicate glasses are consistent with previous studies and indicate that the $\mathrm{Na}-\mathrm{Ca}-\mathrm{Cl}$ environments are relatively symmetric and similar to those in halides like $\mathrm{NaCl}$ (Stebbins and Du, 2002; Sandland et al., 2004). The $2 \mathrm{ppm}$ positive shift in the ${ }^{23} \mathrm{Na}$ spectra due to the presence of $\mathrm{Cl}$ in the peralkaline as well as in the peraluminous glasses (Fig. 8) is consistent with the formation of salt-like structural units similar to that in $\mathrm{NaCl}$ (Stebbins and $\mathrm{Du}, 2002$ ), which would lie with a shift of $0 \mathrm{ppm}$ in the high frequency flank of the ${ }^{23} \mathrm{Na}$ resonance of the glasses. Overall, except for the higher amount of $\mathrm{Ca}$ that is incorporated in the $\mathrm{Na}-\mathrm{Ca}-\mathrm{Cl}$ environments in the peraluminous glasses compared to the peralkaline glasses, the environments seem to be similar. A similarity was quite 
unexpected as it was proposed that $\mathrm{Cl}$ bonds to network-modifying cations (Stebbins and Du, 2002; Sandland et al., 2004), which do not exist in significant quantities in peraluminous glasses (Stebbins and Xu, 1997; Thompson and Stebbins, 2011). However, the ${ }^{35} \mathrm{Cl}$ signal shows that a significant fraction of $\mathrm{Cl}$ atoms in the peraluminous glasses are in relatively symmetric $\mathrm{Na}-\mathrm{Ca}-\mathrm{Cl}$ environments. There are two possible explanations for this: first, $\mathrm{Cl}$ in peraluminous glasses could occupy interstitial positions in the glass network between charge-balancing cations at Al-tetrahedra. If one assumes that the charge-balancing $\mathrm{Na}$ and $\mathrm{Ca}$ cations are randomly distributed, this incorporation mechanism would explain the higher amount of $\mathrm{Ca}$ cations in the $\mathrm{Cl}$ environment although it might have a preference for $\mathrm{Na}$ cations like in the peralkaline glasses. Second, as recently shown by Thompson and Stebbins (2011) with ${ }^{17} \mathrm{O}$ NMR, peraluminous glasses are not necessarily completely free of non-bridging oxygens, which would allow a small quantity of network-modifying cations to exist and to build $\mathrm{Na}-\mathrm{Ca}-\mathrm{Cl}$ environments. However, a quantification of the non-bridging oxygens is not possible since no ${ }^{17} \mathrm{O} N M R$ data is available for our composition.

In the peralkaline glasses the ${ }^{29} \mathrm{Si}$ peak of the $\mathrm{Cl}$-bearing glasses $\mathrm{NACS} 1.1 \mathrm{Cl}$ and NACS $1.0 \mathrm{~F} 1.0 \mathrm{Cl}$ are shifted to lower frequencies compared to the halogen-free glass NACS (Fig. 11), which shows that $\mathrm{Cl}$ causes further polymerisation of the glass-network (Engelhardt and Michel, 1987). Si-Cl environments could not be responsible for the shift, because the isotropic chemical shift for ${ }^{29} \mathrm{Si}$ in $\mathrm{SiCl}_{4}$ is -18.5 ppm (Marsmann et al., 1983), which would shift the signal to higher frequencies. This suggests that in peralkaline glasses the formation of $\mathrm{Na}-\mathrm{Ca}-\mathrm{Cl}$ environments reduces the number of network-modifying $\mathrm{Na}$ and $\mathrm{Ca}$ cations and, therefore, reduces the number of non-bridging oxygens, which leads to further polymerisation of the glass network. In contrast, the ${ }^{29} \mathrm{Si}$ spectrum of the peraluminous glass ANCS 1.0F 0.9Cl shows no difference due to the presence of $F$ and $\mathrm{Cl}$ compared to the spectrum of the halogen-free glass ANCS (Fig. 11). Fluorine was found to cause a negative chemical shift of the ${ }^{29} \mathrm{Si}$ peak in peraluminous glasses of -1 ppm for a concentration of 9.7 mol\% F (Baasner et al., 2014), which is ten times as much $\mathrm{F}$ as in ANCS $1.0 \mathrm{~F} 0.9 \mathrm{Cl}$. Thus, if $\mathrm{Cl}$ would have caused a shift in the spectrum of ANCS 1.0F 0.9Cl compared to ANCS, it would not be masked by an effect of $\mathrm{F}$. In the fully polymerised peraluminous glasses all $\mathrm{Na}$ and $\mathrm{Ca}$ cations are charge-balancing Al and nearly all Si-tetrahedra are fully connected with bridging 
oxygens to other Si- or Al-tetrahedra (e.g. Lee, 2004; Lee and Stebbins, 2009; Thompson and Stebbins, 2011). Therefore, $\mathrm{Cl}$ in peraluminous glasses should not have an influence on the Si environment by bonding to $\mathrm{Na}$ or $\mathrm{Ca}$ as in the peralkaline glasses, since the Si-tetrahedra are already fully polymerised.

$\mathrm{Cl}$ as a monovalent anion could compensate one positive charge of a charge-balancing cation by bonding to $\mathrm{Na}$ and $\mathrm{Ca}$ and, therefore, could create $\mathrm{Al}^{\mathrm{V}}$ in peraluminous glasses (e.g. Thompson and Stebbins, 2011). We only observed a slight increase of, at most, $1 \%$ in $\mathrm{Al}^{\mathrm{V}}$ in the ${ }^{27} \mathrm{Al}$ spectrum of ANCS $1.2 \mathrm{Cl}$ compared to that of ANCS, although this increase could be within the error (Fig. 10). However, a strong increase in $\mathrm{Al}^{\vee}$ due to $\mathrm{Cl}$ in the peraluminous glasses was not expected as the $\mathrm{Cl}$ concentration is small, $1.2 \mathrm{~mol} \%$, and less than $50 \%$ of the $\mathrm{Cl}$ exist in $\mathrm{Na}-\mathrm{Ca}-\mathrm{Cl}$ environments. Even if one assumes that one $\mathrm{Cl}$ anion could create one $\mathrm{Al}^{\mathrm{V}}$, one would expect only an increase of $2 \%$ in $\mathrm{Al}^{\mathrm{V}}$. Furthermore a recent study by Thompson and Stebbins (2011) showed that an excess of 1 mol\% Al compared to charge-balancing cations in peraluminous glasses is likely to result in the formation of only $0.25 \mathrm{~mol} \% \mathrm{Al}^{\mathrm{V}}$.

Compared to the sodium silicate glass only $\sim 60 \%$ of the ${ }^{35} \mathrm{Cl}$ MAS NMR signal for the peralkaline glasses and $\sim 25 \%$ for the peraluminous glasses normalised to the same number of acquisitions and molar concentration of $\mathrm{Cl}$ (Fig. 3) is observed. The values for $C_{q}$ and the distribution in $C_{q}$ are large enough to explain a significant proportion of the missing signal in terms of not spinning fast enough (Massiot et al., 1990; Table 4). However even in the static NMR spectrum (Fig. 4), (taken with a much larger sample and which extends over $\sim 94 \mathrm{kHz}$ ) only $\sim 80 \%$ of the ${ }^{35} \mathrm{Cl}$ signal was observed for the peralkaline glass NACS $1.1 \mathrm{Cl}$ and $\sim 25 \%$ for the peraluminous glass compared to the sodium silicate glass NS $2.2 \mathrm{Cl}$. There are several possibilities that could produce an electric field gradient large enough to make the signal unobservable by NMR spectroscopy, e.g. a higher asymmetry and/or a higher diversity within the nearest neighbours of some of the $\mathrm{Cl}$ environments. Three structural configurations of $\mathrm{Cl}$ are conceivable that explain the missing signal: First, the $\mathrm{Cl}$ exists in asymmetric interstitial positions between $\mathrm{Na}$ and $\mathrm{Ca}$ cations, presumably charge-balancing cations that are not as free to arrange as the network-modifying cations. Second, Al or $\mathrm{Si}$ cations are involved in the $\mathrm{Cl}$ environment like in $\mathrm{AlCl}_{3}$ or $\mathrm{SiCl}_{4}$, which both have a high quadrupole coupling 
constant of more than $9 \mathrm{MHz}$ (Sandland et al., 2004; Johnson et al., 1969) and, therefore, would not be observed. Third, $\mathrm{Cl}$ could also replace single bridging oxygens between Al- and Si-tetrahedra and then be additionally surrounded by other cations like $\mathrm{Ca}$ or $\mathrm{Na}$, as was observed for $\mathrm{F}$ in aluminosilicate glasses (e.g. Schaller et al., 1992; Stebbins et al., 2000; Stebbins and Zeng, 2000; Kiczenski and Stebbins, 2002; Mysen et al., 2004; Stamboulis et al., 2005; Karpukhina et al., 2008; Baasner et al., 2014). We think that the first is the most likely, as we found with the Quadfit simulations (Table 4) that the quadrupole distribution of the $\mathrm{Na}-\mathrm{Ca}-\mathrm{Cl}$ environments is large, $2.1-3 \mathrm{MHz}$, in the aluminosilicate glasses. Since the simulation does not take spinning speed into account, it is likely that the quadrupole distribution is, in some cases, even larger than estimated. In this case the long quadrupole tail caused by the distribution, which is difficult to detect, would be underestimated. We observed no significant influence of $\mathrm{Cl}$ on the ${ }^{27} \mathrm{Al}$ or ${ }^{29} \mathrm{Si}$ environment in the peraluminous glasses (Fig. 10, 11), that could show evidence for the second and third possibility although the amount of $\mathrm{Cl}$ is too small compared to that of $\mathrm{Al}$ and Si to definitely exclude these. The observation of a missing ${ }^{35} \mathrm{Cl}$ signal in aluminosilicate glasses was not made in the previous studies of Stebbins and Du (2002) or of Sandland et al. (2004) who observed at least $90 \%$ of the ${ }^{35} \mathrm{Cl}$ signal in their aluminosilicate glasses compared to silicate glasses. They investigated pure subaluminous $\mathrm{Na}_{2} \mathrm{O}$ and peralkaline to subaluminous $\mathrm{CaO}$ aluminosilicate glasses. The present samples are peralkaline and peraluminous mixed $\mathrm{Na}_{2} \mathrm{O}-\mathrm{CaO}$ aluminosilicate glasses. Therefore, we can conclude that the decrease in signal intensity is related to higher disorder in the $\mathrm{Cl}$ environment and is a mixed cation effect that depends additionally on the aluminium content or on a deficit in network-modifying $\mathrm{Na}$ and $\mathrm{Ca}$ cations.

The size of the electric field gradient and the large distribution of chemical shift for ${ }^{35} \mathrm{Cl}$ combined with the low solubility of $\mathrm{Cl}$ in aluminosilicate melts (Caroll, 2005) mean that the information that can be obtained about the ${ }^{35} \mathrm{Cl}$ environment with MAS NMR is limited, even at the highest available magnetic fields. Despite this we were able to show that the incorporation mechanisms of $\mathrm{Cl}$ in peralkaline and peraluminous $\mathrm{Na}_{2} \mathrm{O}-\mathrm{CaO}-\mathrm{Al}_{2} \mathrm{O}_{3}-\mathrm{SiO}_{2}$ glasses are similar but not identical. 


\subsection{Implications}

Baasner et al. (2013a) found an increase in viscosity due to the addition of $\mathrm{Cl}$ in peralkaline $\mathrm{Na}_{2} \mathrm{O}-\mathrm{CaO}$ aluminosilicate melts with similar compositions to the present samples which is consistent with an increase in polymerisation of the glass network indicated by the decrease in chemical shift of the ${ }^{29} \mathrm{Si}$ peak when $\mathrm{Cl}$ is present. However, they also found that $\mathrm{Cl}$ decreases viscosity in peraluminous $\mathrm{Na}_{2} \mathrm{O}-\mathrm{CaO}$ aluminosilicate melts. Theoretically, the formation of $\mathrm{Na}-\mathrm{Ca}-\mathrm{Cl}$ sites can decrease viscosity in peraluminous melts due to reduction of charge-balancing cations and the resulting transformation of $\mathrm{Al}^{\mathrm{IV}}$ to $\mathrm{Al}^{\mathrm{V}}$. $\mathrm{Al}^{\mathrm{V}}$ could decrease viscosity because the $\mathrm{Al}-\mathrm{O}$ bond length is longer than in tetrahedral coordinated $\mathrm{Al}^{\mathrm{IV}}$ (Tossell, 1993) and, therefore, weaker. Indeed, several studies showed that in aluminosilicate melts, after the viscosity reached its maximum at the subaluminous join, it decreases with increasing peraluminousity (Riebling, 1966; Toplis et al., 1997; Webb et al., 2007). We calculated how the removal of network-modifying cations in peralkaline melts as well as the removal of charge-balancing cations in peraluminous melts due the formation of Na-Ca-Cl environments would influence the $R$ value $\left(\mathrm{Na}_{2} \mathrm{O}+\mathrm{CaO} /\left[\mathrm{Na}_{2} \mathrm{O}+\mathrm{CaO}+\mathrm{Al}_{2} \mathrm{O}_{3}\right]\right)$ and then calculated the theoretical change in viscosity for melts in the system $\mathrm{Na}_{2} \mathrm{O}-\mathrm{CaO}-\mathrm{Al}_{2} \mathrm{O}_{3}-\mathrm{SiO}_{2}$ from Webb et al. (2007). From this simple approach the expected change in viscosity compared to the halogen-free melts is $\sim-0.02$ log units for the peraluminous sample ANCS $0.6 \mathrm{Cl}$ and $\sim+0.20 \log$ units for the peralkaline sample NACS $1.1 \mathrm{Cl}(1 \log$ unit $=\mathrm{a}$ factor of 10 in viscosity in $\mathrm{Pas}$ ). In contrast the viscosity measurements of these samples by Baasner et al. (2013a) showed that compared to the halogen-free melts $\mathrm{Cl}$ decreases viscosity by 0.34 log units for ANCS $0.6 \mathrm{Cl}$ and increases viscosity by 0.96 log units for NACS $1.1 \mathrm{Cl}$. In both cases the comparison of such estimates with real viscosity data of the present samples from Baasner et al. (2013a) showed that the measured effect of $\mathrm{Cl}$ on viscosity is larger than expected from simple structural considerations. The decreasing effect of $\mathrm{Cl}$ on the viscosity of the peraluminous melts suggests at least the possibility that some of the $\mathrm{Cl}$ replaces bridging oxygens at Al-tetrahedra in the glass network and forms non-bridging $\mathrm{Cl}$ sites similar to that observed for $\mathrm{F}$ by Baasner et al. (2014). 


\section{Acknowledgements}

We thank the NMR team at Warwick University for their assistance in collecting the NMR spectra. ${ }^{35} \mathrm{Cl}$ MAS NMR spectra at $19.6 \mathrm{~T}$ were acquired at the National High Magnetic Field Laboratory, which is supported by the National Science Foundation (DMR-0084173) and the State of Florida. We also thank Klaus Simon at University of Göttingen, who kindly performed the LA-ICPMS measurements. This project was funded by the German Research Foundation, DFG grant WE 1810/9-1. 


\section{References}

Aiuppa, A., Baker, D.R., Webster, J.D., 2009. Halogens in volcanic systems. Chem. Geol. 263, 1-18.

Allwardt, J.R., Lee, S.K., Stebbins, J.F., 2003. Bonding preferences of non-bridging O atoms: Evidence from ${ }^{17} \mathrm{O}$ MAS and $3 Q$ MAS NMR on calcium aluminate and low-silica Ca-aluminosilicate glasses. Am. Mineral. 88, 949-954.

Anderko, A., Pitzer, K.S., 1993. Equation-of-state representation of phase equilibria and volumetric properties of the system $\mathrm{NaCl}-\mathrm{H}_{2} \mathrm{O}$ above $573 \mathrm{~K}$. Geochim. Cosmochim. Acta 57, 1657-1680.

Baasner, A., Schmidt, B.C., Webb, S.L., 2013a. Compositional dependence of the rheology of halogen $(\mathrm{F}, \mathrm{Cl})$ bearing aluminosilicate melts. Chem. Geol. 346, 172-183.

Baasner, A., Schmidt, B.C., Webb, S.L., 2013b. The effect of chlorine, fluorine and water on the viscosity of aluminosilicate melts. Chem. Geol. 357, 134-149.

Baasner, A., Schmidt, B.C., Dupree, R., Webb, S.L.,2014a. Fluorine speciation as a function of composition in peralkaline and peraluminous $\mathrm{Na}_{2} \mathrm{O}-\mathrm{CaO}-\mathrm{Al}_{2} \mathrm{O}_{3}-\mathrm{SiO}_{2}$ glasses: $\mathrm{A}$ multinuclear NMR study. Geochim. Cosmochim. Acta 132, 151-169.

Candela, P.A., 1997. A review of shallow, ore-related granites: Textures, volatiles, and ore metals. J. Petrol. 38, 1619-1633.

Carroll, M.R., 2005. Chlorine solubility in evolved alkaline magmas. Ann. Geophys. 48, 619-631.

Dingwell, D.B., Hess, K.-U., 1998. Melt viscosities in the system Na-Fe-Si-O-F-Cl: Contrasting effects of $\mathrm{F}$ and $\mathrm{Cl}$ in alkaline melts. Am. Mineral. 83, 1016-1021.

Engelhardt, G., Michel, D., 1987. High-resolution solid-state NMR of silicates and zeolites. John Wiley \& Sons, Chichester.

Evans, K.A., Mavrogenes, J.A., O`Neill, H.S., Keller, N.S., Jang, L.-Y., 2008. A preliminary investigation of chlorine XANES in silicate glasses. Geochem. Geophy. Geosyst. 9, No. 10, 1-15.

Freude, D., Haase, J., 1993. Quadrupole effects in solid state nuclear magnetic resonance, in: Diehl, P., Flunck, E., Günther, H., Kosfeld, R., Seelig, J. (Eds.), NMR basic principles and progress, Vol. 29. Springer, New York, pp. 1-90. 
Helgeson, H.C., 1969, Thermodynamics of hydrothermal systems at elevated temperatures and pressures. Am. J. Sci. 267, 729-804.

Johnson, K.J., Hunt, J.P., Dodgen, H.W., 1969. Chlorine-35 NMR study of the shifts and line shapes of some liquid inorganic chlorides. J. Chem. Phys. 51, 4493-4496.

Karpukhina, N., Law, R.V., Hill, R.G., 2008. Solid state NMR study of calcium fluoroaluminosilicate glasses. Adv. Mat. Res. 39-40, 25-30.

Kemp, T.F., Smith, M.E., 2009. QuadFit - A new cross-platform computer program for simulation of NMR line shapes from solids with distributions of interaction parameters. Solid State Nucl. Mag. 35, 243-252.

Kiczenski, T.J., Stebbins, J.F., 2002. Fluorine sites in calcium and barium oxyfluorides: F-19 NMR on crystalline model compounds and glasses. J. Non-Cryst. Solids 306, 160-168.

Kohn, S.C., Dupree, R., Mortuza, M.G., Henderson, C.M.B., 1991. NMR evidence for five- and six-coordinated aluminium fluoride complexes in F-bearing aluminosilicate glasses. Am. Mineral. 76, 309-312.

Lee, S.K., 2004. Structure of silicate glasses and melts at high pressure: Quantum chemical calculations and solid-state NMR. J. Phys. Chem. B 108, 5889-5900.

Lee, S.K., Stebbins, J.F., 2009. Effects of the degree of polymerization on the structure of sodium silicate and aluminosilicate glasses and melts: An ${ }^{17} \mathrm{O}$ NMR study. Geochim. Cosmochim. Acta $73,1109-1119$.

Marsmann, H.C., Meyer, E., Vongehr, M., Weber, E.F., 1983. ${ }^{29}$ Si NMR-Untersuchungen an Polykieselsäureestern. Makromol. Chem. 184, 1817-1822.

Massiot, D., Bessada, C., Coutures, J.P., Taulelle, F., 1990. A quantitative study of ${ }^{27} \mathrm{Al}$ MAS NMR in crystalline YAG. J. Mag. Res. 90, 231-242.

Mysen, B.O., Cody, G.D., Smith, A., 2004. Solubility mechanisms of fluorine in peralkaline and meta-aluminous silicate glasses and in melts to magmatic temperatures. Geochim. Cosmochim. Acta 68, 2745-2769.

Riebling, E.F., 1966. Structure of sodium aluminosilicate melts containing at least 50 mole $\% \mathrm{SiO}_{2}$ at $1500^{\circ} \mathrm{C}$. J. Chem. Phys. $44,2857-2865$.

Sandland, T.O., Du, L.-S., Stebbins, J.F., Webster, J.D., 2004. Structure of Cl-containing silicate and aluminosilicate glasses: A ${ }^{35} \mathrm{Cl}$ MAS-NMR study. Geochim. Cosmochim. Acta 68, 5059-5069.

Schaller, T., Dingwell, D.B., Keppler, H., Knöller, W., Merwin, L., Sebald, A., 1992. Fluorine in 
silicate glasses: A multinuclear magnetic resonance study. Geochim. Cosmochim. Acta 56, 701-707.

Signorelli, S., Carroll, M.R., 2000. Solubility and fluid-melt partitioning of $\mathrm{Cl}$ in hydrous phonolitic melts. Geochim. Cosmochim. Acta, 64, 2851-2862.

Schmidt, B.C., Riemer, T., Kohn, S.C., Behrens, H., Dupree, R., 2000a. Different water solubility mechanisms in hydrous glasses along the Qz-Ab join: Evidence from NMR spectroscopy. Geochim. Cosmochim. Acta 64, 513-526.

Schmidt, B.C., Riemer, T., Kohn, S.C., Behrens, H., Dupree, R., 2000b. Erratum to "Different water solubility mechanisms in hydrous glasses along the Qz-Ab join: Evidence from NMR spectroscopy". Geochim. Cosmochim. Acta 64, 2895-2896.

Schmücker, M., MacKenzie, K.J.D., Schneider, H., Meinhold, R., 1997. NMR studies on rapidly solidified $\mathrm{SiO}_{2}-\mathrm{Al}_{2} \mathrm{O}_{3}$ and $\mathrm{SiO}_{2}-\mathrm{Al}_{2} \mathrm{O}_{3}-\mathrm{Na}_{2} \mathrm{O}$-glasses. J. Non-Cryst. Solids 217, 99-105.

Sourirajan, S., Kennedy, G.C., 1962. The system $\mathrm{H}_{2} \mathrm{O}-\mathrm{NaCl}$ at elevated temperatures and pressures. Am. J. Sci. 260, 115-141.

Stamboulis, A., Hill, R.G., Law, R.V., 2005. Structural characterization of fluorine containing glasses by ${ }^{19} \mathrm{~F},{ }^{27} \mathrm{Al},{ }^{29} \mathrm{Si}$ and ${ }^{31} \mathrm{P}$ MAS-NMR spectroscopy. J. Non-Cryst. Solids 351 , 3289-3295.

Stebbins, J.F., Du, L.-S., 2002. Chloride ion sites in silicate and aluminosilicate glasses: A preliminary study by ${ }^{35} \mathrm{Cl}$ solid-state NMR. Am. Mineral. 87, 359-363.

Stebbins, J.F.; Xu, Z., 1997. NMR evidence for excess non-bridging oxygen in an aluminosilicate glass. Nature 390, 60-61.

Stebbins, J.F., Zeng, Q., 2000. Cation ordering at fluoride sites in silicate glasses: a high-resolution ${ }^{19} \mathrm{~F}$ NMR study. J. Non-Cryst. Solids 262, 1-5.

Tanimoto, S., Rehren, T., 2008. Interactions between silicate and salt melts in LBA glassmaking. J. Archaeol. Sci. 35, 2566-2573.

Thompson, L.M., Stebbins, J.F., 2011. Non-bridging oxygen and high-coordinated aluminum in metaluminous and peraluminous calcium and potassium aluminosilicate glasses: High-resolution ${ }^{17} \mathrm{O}$ and ${ }^{27} \mathrm{Al}$ MAS NMR results. Am. Mineral. 96, 841-853.

Toplis, M.J., Dingwell, D.B., Lenci, T., 1997. Peraluminous viscosity maxima in $\mathrm{Na}_{2} \mathrm{O}-\mathrm{Al}_{2} \mathrm{O}_{3}-\mathrm{SiO}_{2}$ liquids: The role of triclusters in tectosilicate melts. Geochim. Cosmochim. Acta 61, 2605-2612. 
Tossell, J.A., 1993. Theoretical studies of the speciation of Al in F-bearing aluminosilicate glasses. Am. Mineral. 78, 16-22.

Webb, S.L., Banaszak, M., Köhler, U., Rausch S., Raschke, G., 2007. The viscosity of $\mathrm{Na}_{2} \mathrm{O}-\mathrm{CaO}-\mathrm{Al}_{2} \mathrm{O}_{3}-\mathrm{SiO}_{2}$ melts. Eur. J. Mineral. 19, 681-692.

Webster, J.D., 1997a. Exsolution of magmatic volatile phases from Cl-enriched mineralizing granitic magmas and implications for ore metal transport. Geochim. Cosmochim. Acta 61, 1017-1029.

Webster, J.D., 1997b. Chloride solubility in felsic melts and the role of chloride in magmatic degassing. J. Petrol. 38, 1793-1807.

Zeng, Q., Stebbins, J.F., 2000. Fluoride sites in aluminosilicate glasses: High-resolution ${ }^{19}$ F NMR results. Am. Mineral. 85, 863-867.

Zimova, M., Webb, S.L., 2006. The effect of chlorine on the viscosity of $\mathrm{Na}_{2} \mathrm{O}-\mathrm{Fe}_{2} \mathrm{O}_{3}-\mathrm{Al}_{2} \mathrm{O}_{3}-\mathrm{SiO}_{2}$ melts. Am. Mineral. 91, 344-352. 


\section{Supplementary Data}

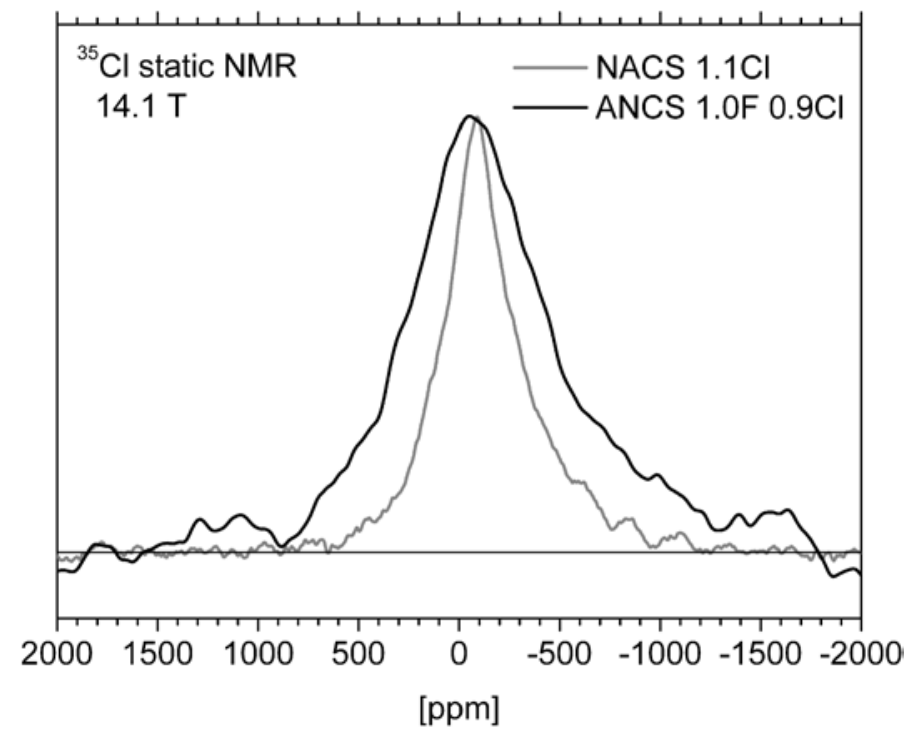

Fig. A. Static ${ }^{35} \mathrm{Cl}$ NMR spectra of the peralkaline glass NACS $1.1 \mathrm{Cl}$ and the peraluminous glass ANCS $1.0 \mathrm{~F} 0.9 \mathrm{Cl}$ at $14.1 \mathrm{~T}$. The peak maxima are at $\sim-90 \mathrm{ppm}$ for the peralkaline glass and $\sim-50$ ppm for the peraluminous glass. The spectra are normalised to the same peak height.

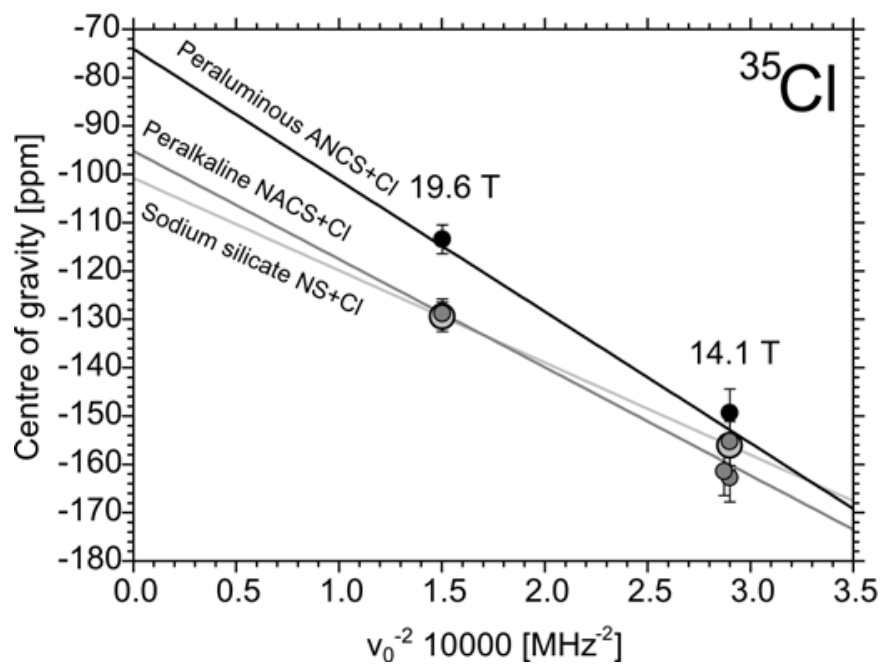

Fig. B. Centre of gravity of ${ }^{35} \mathrm{Cl}$ MAS NMR central bands of the $\mathrm{Cl}$-bearing peralkaline and sodium silicate glasses as a function of inverse squared Larmor frequency $v_{0}{ }^{-2}$. The ordinate of linear regressions gives the isotropic chemical shift $\delta_{\text {iso }}$ and the quadrupole coupling $C_{q}$ constant was calculated from the slope (see Table 3). The numbers on top of the data are the magnetic fields in Tesla. One linear equation was fitted to the combined data of NACS $1.1 \mathrm{Cl}$ at $14.1 \mathrm{~T}, 19.6 \mathrm{~T}$ and NACS $1.9 \mathrm{Cl}$ at $14.1 \mathrm{~T}$. 


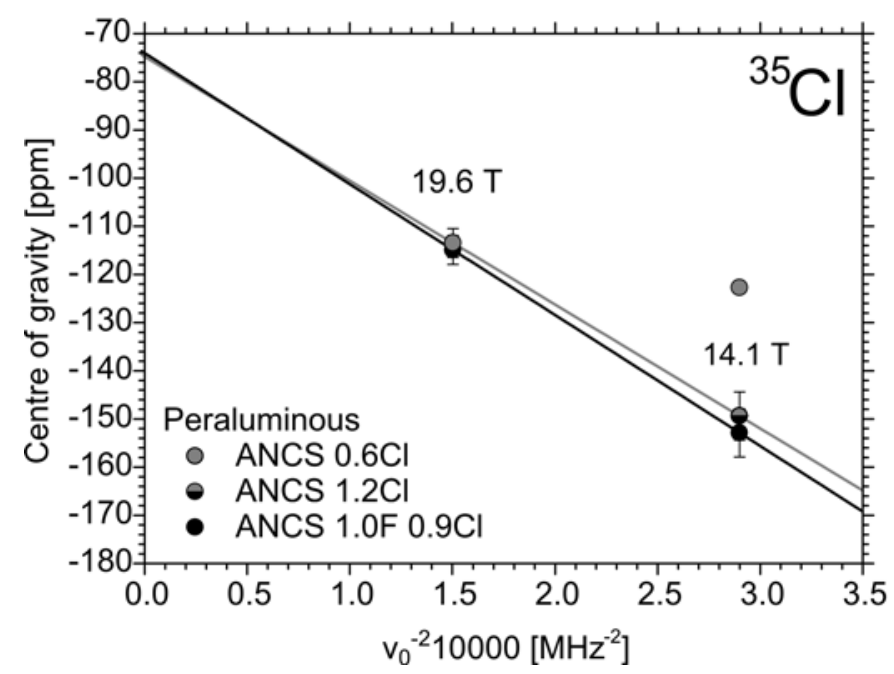

Fig. C. Centre of gravity of ${ }^{35} \mathrm{Cl}$ MAS NMR central bands of the $\mathrm{Cl}$-bearing peralkaline and sodium silicate glasses as a function of inverse squared Larmor frequency $v_{0}^{-2}$. The ordinate of the linear regressions gives the isotropic chemical shift $\delta_{i s o}$ and the quadrupole coupling $C_{q}$ constant was calculated from the slope (see Table 3). The numbers on top of the data are the magnetic fields in Tesla. The centre of gravity of ANCS $0.6 \mathrm{Cl}$ at $14.1 \mathrm{~T}$ was not used for further evaluation as the signal to noise ratio of the spectrum was too low and its usage in evaluation delivered an unusual low $C_{q}$ $\sim 1.5 \mathrm{MHz}$, which is not consistent with the general quadrupole line shape in the spectra in this study and previous studies (e.g. Sandland et al., 2004). Instead a linear equation was fitted to the centre of gravity of ANCS $1.2 \mathrm{Cl}$ at $14.1 \mathrm{~T}$ and the centre of gravity of ANCS $0.6 \mathrm{Cl}$ at $19.6 \mathrm{~T}$.

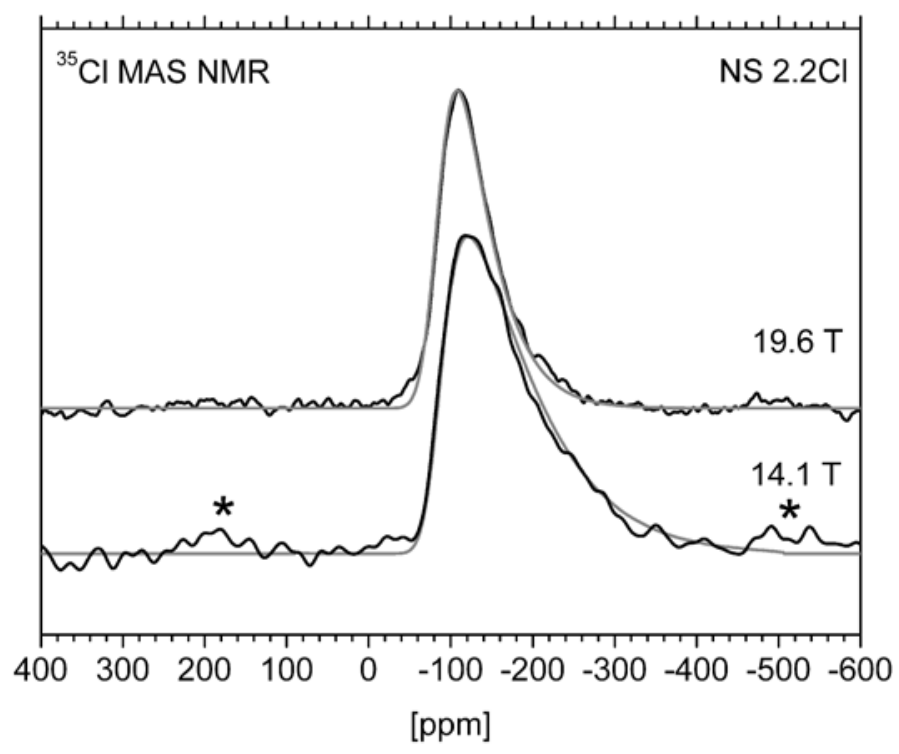

Fig. D. ${ }^{35} \mathrm{Cl}$ MAS NMR spectra of the sodium silicate glass NS 2.2Cl at $14.1 \mathrm{~T}$ and $19.6 \mathrm{~T}$ (black lines) fitted with the program Quadfit (grey lines). The fit is $\bar{C}_{q}=3.5 \mathrm{MHz}, \Delta \bar{C}_{q}=2.5 \mathrm{MHz}, \bar{\eta}=0.5$, $\Delta \bar{\eta}=0.3$. Spinning sidebands are marked with an asterisk. The spectra are normalised to the same peak height. 
Table A. Expected MAS relative intensities after Massiot et al. (1990) for a range of quadrupole coupling constants $C_{q}$ and an asymmetry parameter $\eta=0.8$ for different magnetic fields (values in $\mathrm{T}$ ) and spinning speeds (values in $\mathrm{kHz}$ ).

\begin{tabular}{ccc}
\hline $\mathrm{C}_{q}$ & Intensity & Intensity \\
{$[\mathrm{MHz}]$} & $14.1 \mathrm{~T} \mathrm{20} \mathrm{kHz}$ & $19.6 \mathrm{~T} \mathrm{30} \mathrm{kHz}$ \\
\hline 2.6 & 0.75 & 0.94 \\
3.5 & 0.38 & 0.80 \\
4.1 & 0.19 & 0.65 \\
4.3 & 0.16 & 0.58 \\
\hline
\end{tabular}




\section{Concluding remarks}

\subsection{Discussion}

Baasner et al. (2013a) proposed that fluorine (F) decreases viscosity more strongly in the peralkaline than in the peraluminous $\mathrm{Na}_{2} \mathrm{O}-\mathrm{CaO}-\mathrm{Al}_{2} \mathrm{O}_{3}-\mathrm{SiO}_{2}$ melts. Contrasting with this, the more detailed study by Baasner et al. (2013b) found that F decreases viscosity more strongly in the peraluminous than in the peralkaline melts and that in the peralkaline melts, although low $\mathrm{F}$ concentrations $(1.9 \mathrm{~mol} \%)$ decrease viscosity, higher F concentrations (6.2 mol\%) possibly increase viscosity.

The wrong conclusions from Baasner et al. (2013a) resulted from the limited amount of only two fluorine-bearing samples that had extremely different $F$ concentration with $1.9 \mathrm{~mol} \%$ in the peralkaline and $18.3 \mathrm{~mol} \%$ in the peraluminous melt. However, the decrease in viscosity due to $F$ becomes less with increasing concentration of $F$ in the peraluminous melts (Baasner et al., 2013b). Therefore, the linear interpolation done by Baasner et al. (2013a) to calculate the decrease in viscosity per mol\% F led to an underestimation of the effect of $F$ on viscosity of the peraluminous melt.

This is a good example of how careful one has to be with linear interpolation over a high compositional range. 


\subsection{Final conclusions}

(I) The influence of chlorine ( $\mathrm{Cl}$ ) and fluorine (F) on melt viscosity is disparate and depends on melt composition. The addition of $\mathrm{Cl}$ increases the viscosity in peralkaline (NACS) and decreases the viscosity in peraluminous (ANCS) $\mathrm{Na}_{2} \mathrm{O}-\mathrm{CaO}-\mathrm{Al}_{2} \mathrm{O}_{3}-\mathrm{SiO}_{2}$ melts. $\mathrm{F}$ decreases viscosity more strongly in peraluminous than in peralkaline melts. The decrease in viscosity due to the addition of $F$ is smaller in $\mathrm{Na}_{2} \mathrm{O}-\mathrm{CaO}-\mathrm{SiO}_{2}$ than in aluminosilicate melts and $\mathrm{Cl}$ has no significant effect on the viscosity of $\mathrm{Na}_{2} \mathrm{O}-\mathrm{CaO}-\mathrm{SiO}_{2}$ melts. The effects of $\mathrm{Cl}$ and $\mathrm{F}$ on viscosity appear to be independent of each other within the studied range of compositions (Baasner et al., 2013a) (Fig. 1).

In peralkaline melts $\mathrm{F}$ decreases viscosity up to a concentration of $1.9 \mathrm{~mol} \% \mathrm{~F}$, but for a concentration of $6.2 \mathrm{~mol} \% \mathrm{~F}$ no further decrease in viscosity is observed. Indeed a slight increase in viscosity can be seen for higher temperatures. In peraluminous melts up to a concentration of 18.3 mol\% $F$ further addition of $F$ leads to further decrease in viscosity. (Baasner et al., 2013b) (Fig. 2).

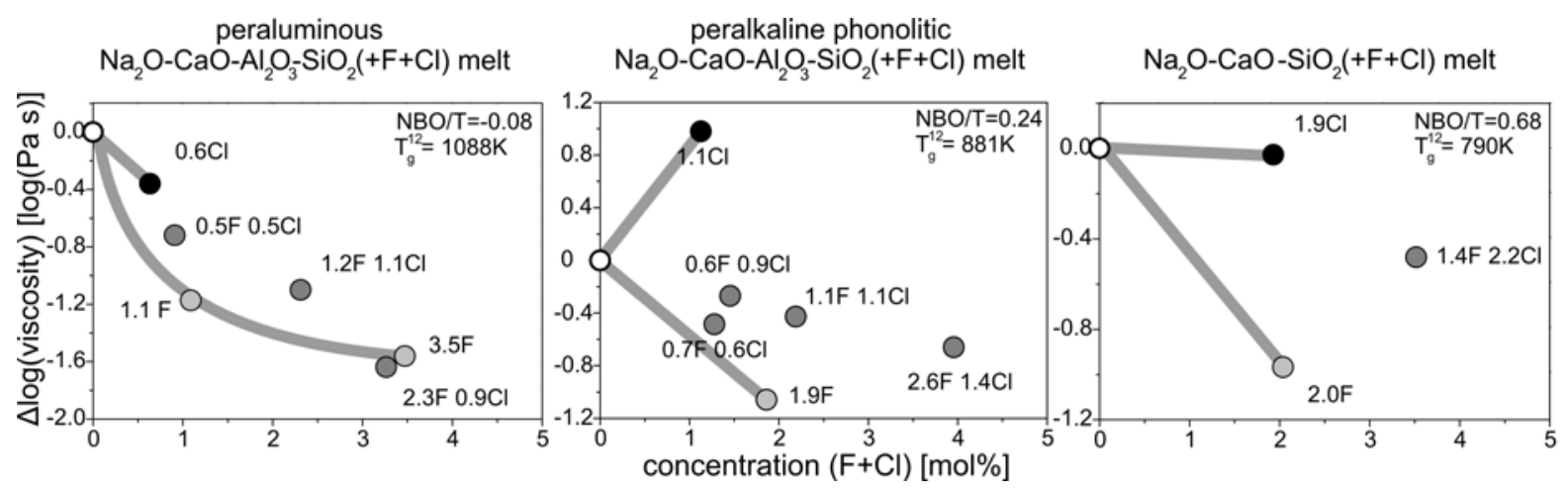

Fig. 1. The change in viscosity due to the addition of fluorine $(\mathrm{F})$ and chlorine $(\mathrm{Cl})$ to different silicate melts. The numbers near to the data points show the concentration of $\mathrm{F}$ and $\mathrm{Cl}$ in mol\%. The grey lines are a guide to the eye. The error of the viscosity is $0.08 \mathrm{log}$ units and that of the concentrations is $\sim 0.3$ mol\% (redrawn modified graphical abstract from Baasner et al., 2013a, extended with data from Baasner et al, 2013b). 


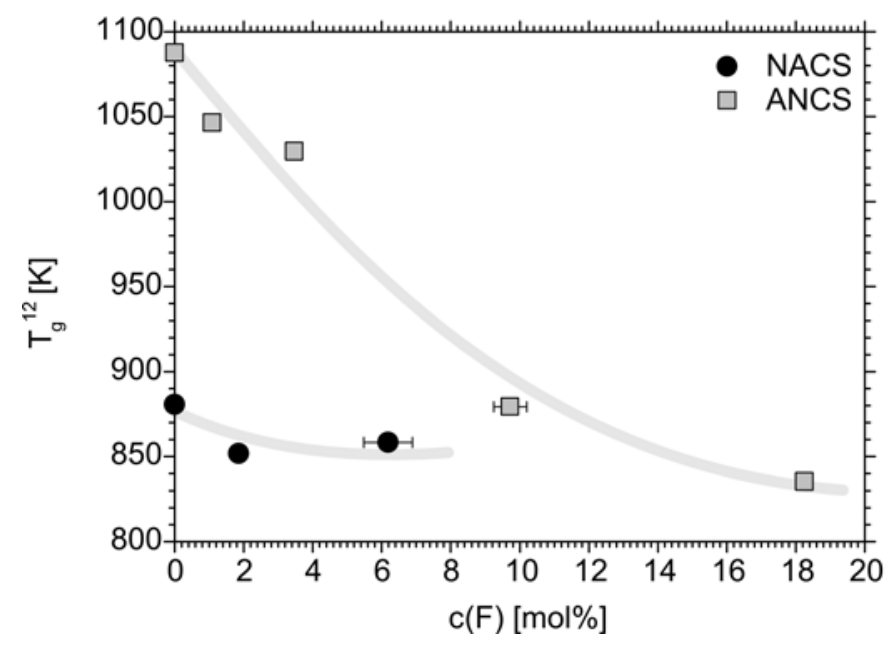

Fig. 2. $T_{g}{ }^{12}$ (temperature at $\eta=10^{12} \mathrm{Pas}$ ) as a function of fluorine concentration $c(\mathrm{~F})$ of the fluorine-free and fluorine-bearing peralkaline (NACS) and peraluminous (ANCS) melts. The grey lines were not fit, but only a guide to the eye. Y-errors are smaller than the symbols (Baasner et al., 2013b).

(II) Water decreases viscosity more strongly in the peraluminous than in the peralkaline melts (Fig. 2). The effect of water on viscosity is stronger than that of $\mathrm{Cl}$ and $\mathrm{F}$. In the peralkaline melts, the increase in viscosity due to $\mathrm{Cl}$ and the decrease in viscosity due to water add linearly, which shows that the effects are independent from each other. The combined effect of $F$ and water on viscosity in the peralkaline as well as in the peraluminous melts is less than would be expected from the addition of their single effects (Baasner et al., 2013b) (Fig . 3).

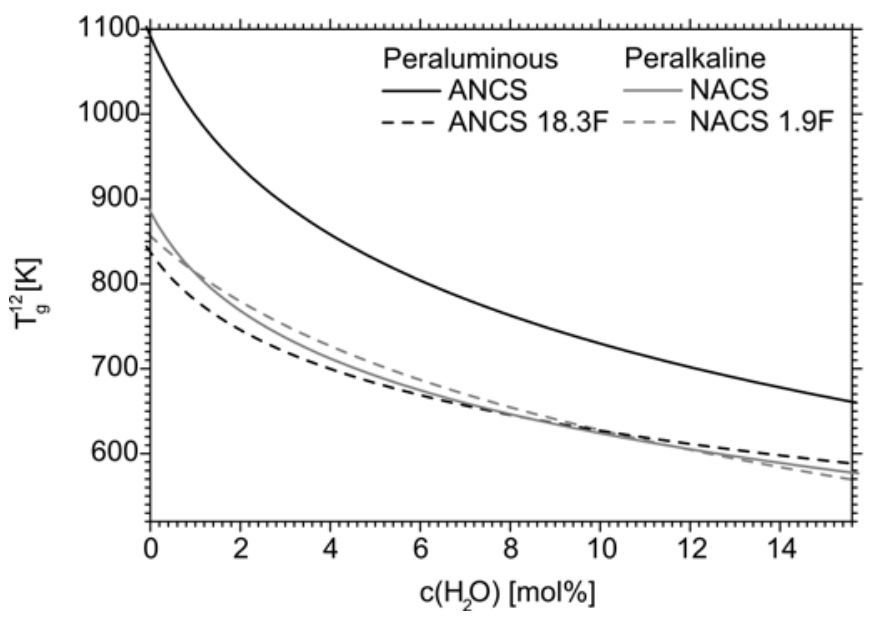

Fig. 3. $T_{g}{ }^{12}$ (temperature at $\eta=10^{12} \mathrm{Pas}$ ) as a function of water concentration $c\left(\mathrm{H}_{2} \mathrm{O}\right)$ of the halogen-free and halogen-bearing peralkaline (NACS) and peraluminous (ANCS) melts. Y-errors are smaller than the symbols (redrawn and modified after Baasner et al., 2013b). 
(III) ${ }^{19} \mathrm{~F}$ MAS NMR spectroscopy shows that the incorporation mechanism of $\mathrm{F}$ is different in peraluminous and peralkaline $\mathrm{Na}_{2} \mathrm{O}-\mathrm{CaO}-\mathrm{Al}_{2} \mathrm{O}_{3}-\mathrm{SiO}_{2}$ glasses (Fig. 4). In the peralkaline glasses $\mathrm{F}$ exists at least in five environments that could be divided in three groups:

o "Salt-like" F environments including network-modifiers F-Ca(n) and F-Na(n)

o Non-bridging F environments Si-F-Na(n)/Al-F-Ca(n) and Al-F-Na(n)

o Bridging F environments Al-F-Al.

Despite the low $\mathrm{Ca} / \mathrm{Na}$ ratio of $1 / 5$ in the glasses, $\mathrm{F}-\mathrm{Ca}(\mathrm{n})$ is the most abundant environment, indicating the strong preference of $\mathrm{F}$ for $\mathrm{Ca}^{2+}$ instead of $\mathrm{Na}^{+}$. In the peraluminous glasses, in the absence of network-modifying cations, $F$ only bonds to $\mathrm{Si}$ and $\mathrm{Al}$ by the formation of non-bridging and bridging $\mathrm{F}$ environments with $\mathrm{Al}-\mathrm{F}-\mathrm{Na}(\mathrm{n})$ being the most abundant environment, indicating a preference of $\mathrm{F}$ for $\mathrm{Al}^{3+}$ compared to $\mathrm{Si}^{4+}$ (Baasner et al., 2014a).
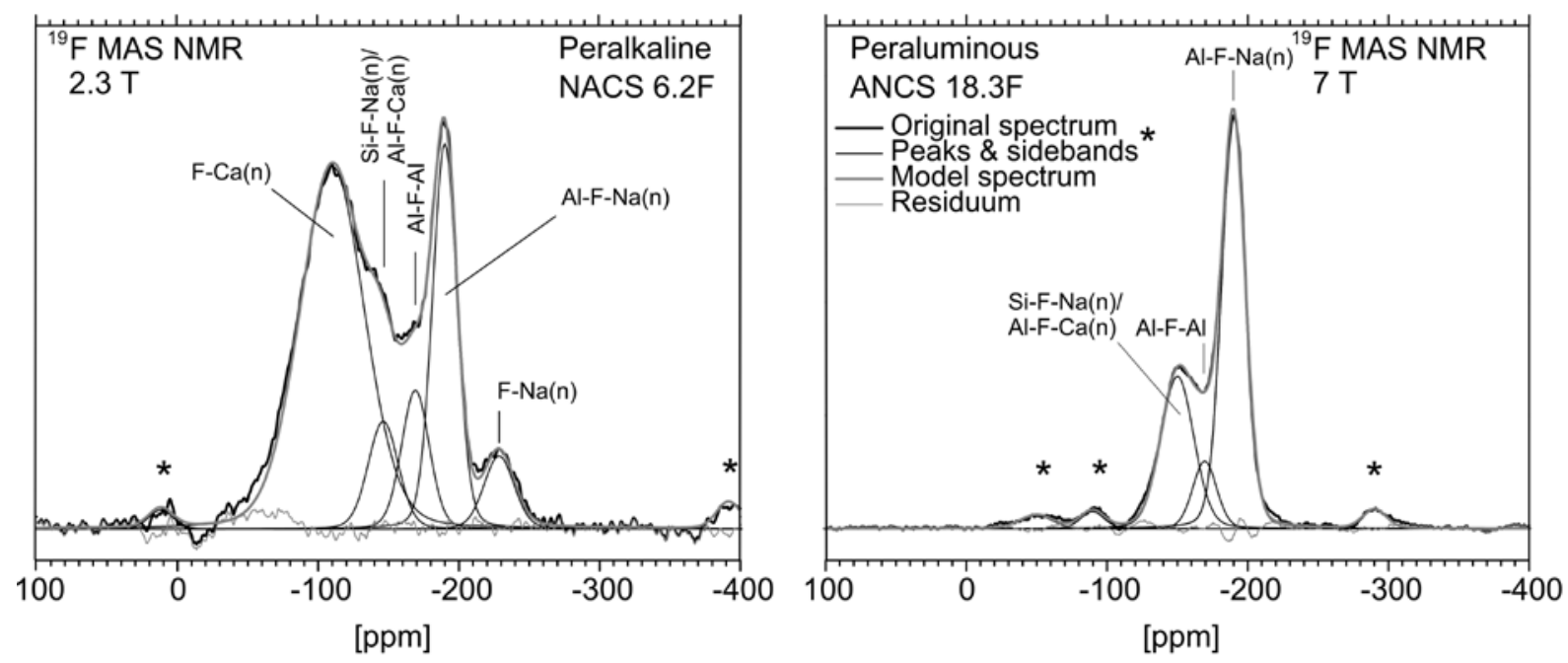

Fig. $4 .{ }^{19} \mathrm{~F}$ MAS NMR spectra of a dry fluorine-bearing peralkaline and a peraluminous glass at 2.3 and $7 \mathrm{~T}$. Spinning sidebands are marked with an asterisk. The spectra were normalised to the same peak height (redrawn after Baasner et al., 2014a). 
(IV) The "salt-like" F environments are expected to result in an increase in viscosity by decreasing the number of network-modifying cations. The non-bridging $F$ environments are expected to decrease viscosity by replacing bridging oxygens between Si- and Al-tetrahedra. The bridging $\mathrm{F}$ environments should decrease viscosity because the Al-F bond length should be longer and therefore weaker. In the peraluminous samples $\mathrm{F}$ exists only in environments that should decrease viscosity, while in the peralkaline samples $\mathrm{F}$ exists in environments that increase and decrease viscosity. Therefore, F decreases viscosity more strongly in the peraluminous than in peralkaline melts (Baasner et al., 2013b).

(V) ${ }^{19} F$ MAS NMR spectroscopy showed that $F$ speciation depends on the $F$ concentration. In the peralkaline glasses the relative fraction of the F-Ca(n) environments increases from 42 to $53 \%$ for an increase in F concentration from 1.2 to $6.2 \mathrm{~mol} \%$, while the relative fraction of the other environments stagnates or decreases. In the peraluminous melts a minor minimum of the relative fraction of the Al-F-Na(n) was found for $\mathrm{F}$ concentrations between 3.5 and $9.7 \mathrm{~mol} \%$, which corresponds to an maximum of the other environments (Baasner et al., 2014a).

The increase of the relative amount of the $\mathrm{F}-\mathrm{Ca}(\mathrm{n})$ environments with increasing $\mathrm{F}$ concentration in the peralkaline glasses can explain the increase in viscosity observed for higher $\mathrm{F}$ concentrations $(6.2 \mathrm{~mol} \% \mathrm{~F})$ in the peralkaline melts (Baasner et al, 2013b).

(VI) ${ }^{19} \mathrm{~F}$ MAS NMR spectroscopy showed that in the peralkaline glasses the relative fraction of $\mathrm{F}-\mathrm{Ca}(\mathrm{n})$ environments increases with increasing water content (Fig. 5), while the relative fraction of the environments where $\mathrm{F}$ bonds to $\mathrm{Al}$ decreases (Baasner et al., 2014a), which explains why in the peralkaline melts the decreasing effect of $F$ on viscosity becomes less with increasing water content (Baasner et al., 2013b).

For the peraluminous melts there are two conceivable processes that could results in the combined effect of $F$ and water on viscosity being less then the sum of their individual effects. Either the presence of water influences the $\mathrm{F}$ speciation or as suggested from IR spectroscopy the presence of $F$ changes the water speciation (Baasner et al., 2013b). 


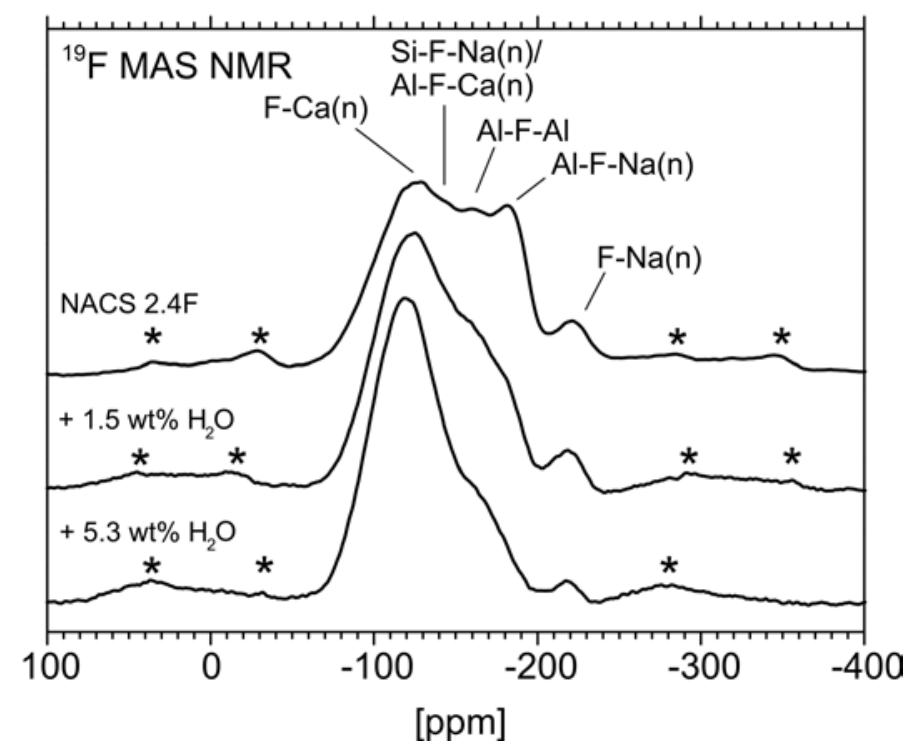

Fig. $5 .{ }^{19} \mathrm{~F}$ MAS NMR spectra at $2.3 \mathrm{~T}$ of the dry and hydrous samples of the peralkaline glass NACS 2.4F. Spinning sidebands are marked with an asterisk. The spectra were normalised to the same area (Baasner et al, 2014a).

(VII) ${ }^{35} \mathrm{Cl}$ MAS NMR spectroscopy showed that $\mathrm{Cl}$ exists in $\mathrm{Na}-\mathrm{Ca}-\mathrm{Cl}$ environments dominated by $\mathrm{Na}$, as expected from the $\mathrm{Ca} / \mathrm{Na}$ ratio of $1 / 5$ (Fig. 6). The $\mathrm{Cl}$ environment is similar in the peralkaline and peraluminous glasses, though there is more $\mathrm{Ca}$ incorporated in the $\mathrm{Cl}$ environment in the peraluminous glasses. The presence of the $\mathrm{Na}-\mathrm{Ca}-\mathrm{Cl}$ environments in both glass types suggests their existence does not solely depend on the presence of network-modifying cations. The increase in viscosity due to $\mathrm{Cl}$ in the peralkaline melts can be explained by $\mathrm{Cl}$ reducing the amount of network-modifiers, while there remain several possible processes, how $\mathrm{Cl}$ reduces viscosity in the peraluminous melts (Baasner et al., 2014b).

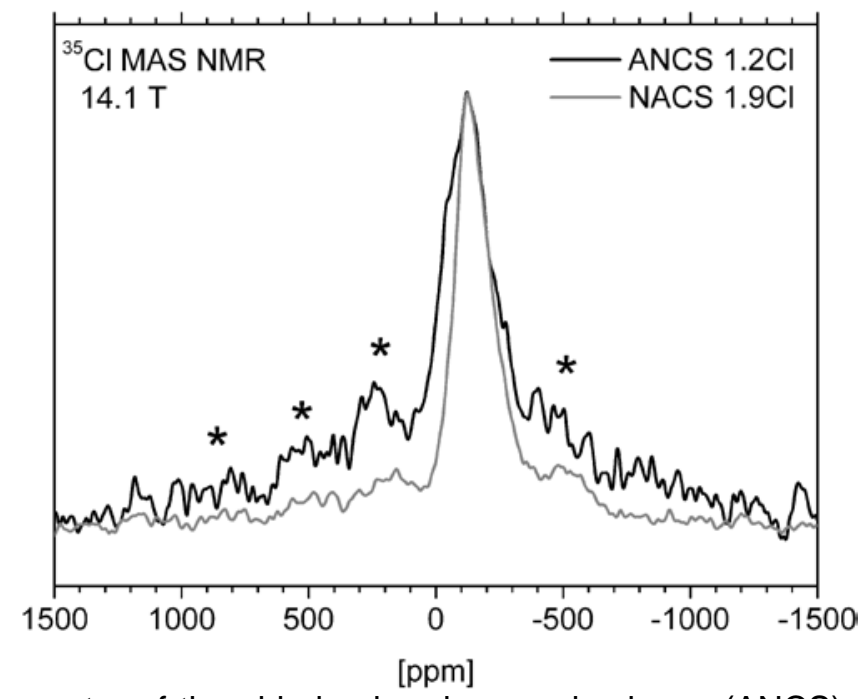

Fig. $6 .{ }^{35} \mathrm{CI}$ MAS NMR spectra of the chlorine-bearing peraluminous (ANCS) and peralkaline (NACS) glasses at 14.1 T. Spinning sidebands are marked with an asterisk. The spectra were normalised to the same peak height (redrawn and modified after Baasner et al, 2014b). 


\subsection{Implications}

The results and conclusions of this project hold implications for the interpretation of the compositional dependence of the diffusivity and solubility of $\mathrm{Cl}$ and $\mathrm{F}$ in silicate melts.

The salt-like $\mathrm{F}$ environments in the present peralkaline $\mathrm{Na}{ }_{2} \mathrm{O}-\mathrm{CaO}-\mathrm{Al}_{2} \mathrm{O}_{3}-\mathrm{SiO}_{2}$ peralkaline glasses, observed with ${ }^{19} \mathrm{~F}$ MAS NMR spectroscopy, support the idea of Böhm and Schmidt (2013) that the higher diffusivity of F compared to that of oxygen in phonolitic melts implies that the diffusion of $\mathrm{F}$ is decoupled from the aluminosilicate network and could be related to the formation of alkali- or alkaline-earth-halogen species.

The observed strong influence of the $\mathrm{Na}_{2} \mathrm{O}+\mathrm{CaO}$ to $\mathrm{Al}_{2} \mathrm{O}_{3}$ ratio, water and $\mathrm{F}$ concentrations on the $\mathrm{F}$ speciation in the $\mathrm{Na}_{2} \mathrm{O}-\mathrm{CaO}-\mathrm{Al}_{2} \mathrm{O}_{3}-\mathrm{SiO}_{2}$ melts provide useful information to understand different $F$ solubilities and the formation of calcium fluoride melt inclusions in silicate melts (e.g. Dolejs and Baker, 2006; Klemme, 2004; Peretyazhko et al., 2007)

The strong preference of $\mathrm{F}$ for $\mathrm{Ca}^{2+}$ in the present peralkaline glasses/melts suggests that one has to be careful to use synthetic melt or glass compositions without divalent cations in experiments to predict effects of $F$ on natural highly evolved magmatic melts. Most natural highly evolved magmatic melts contain $\mathrm{Ca}$ as a minor component. The present viscosity data suggest that the compositional dependent effect of $\mathrm{Cl}$ on the viscosity of silicate melts should be implemented in existing models for the prediction of the viscosity of natural melts (e.g. Hui and Zhang, 2007 and Giordano and Dingwell, 2008) even though it has usually a low abundance in natural melts. 


\subsection{Outlook}

This project gives a detailed view of the relation between the incorporation mechanisms of $\mathrm{F}$ and $\mathrm{Cl}$ and their influence on viscosity in dry and hydrous peralkaline and peraluminous $\mathrm{Na}_{2} \mathrm{O}-\mathrm{CaO}-\mathrm{Al}_{2} \mathrm{O}_{3}-\mathrm{SiO}_{2}$ melts, but it also raises new questions.

It remained unclear due to which process $\mathrm{Cl}$ decreases the viscosity in peraluminous melts. An answer could be found by investigating the influence of $\mathrm{Cl}$ on viscosity and structure of peraluminous melts with different Si/Al ratio. If there exists an alternative incorporation mechanism to the $\mathrm{Na}-\mathrm{Ca}-\mathrm{Cl}$ environments e.g. $\mathrm{Si}-\mathrm{Cl}$ or $\mathrm{Al}-\mathrm{Cl}$ environments, then one possibly could observe a change in the structural environment of $\mathrm{Cl}$ and its influence on viscosity as a function of the Si/Al ratio.

There are two possible F environments, Si-F-Na(n) and Al-F-Ca(n), that could be responsible for the peak at in the ${ }^{19} \mathrm{~F}$ MAS NMR spectra at $\sim-146 \mathrm{ppm}$. Which environment or approximately how much of both produces the peak could be investigated with NMR spectroscopy with cross polarisation experiments between ${ }^{19} \mathrm{~F}$ and ${ }^{29} \mathrm{Si}$ and HETCOR (hetero nuclear correlation) experiments between ${ }^{19} \mathrm{~F}$ and ${ }^{27} \mathrm{Al}$.

${ }^{19} \mathrm{~F} \quad$ NMR $\mathrm{MAS}$ spectra of hydrous fluorine-bearing peraluminous $\mathrm{Na}_{2} \mathrm{O}-\mathrm{CaO}-\mathrm{Al}_{2} \mathrm{O}_{3}-\mathrm{SiO}_{2}$ glasses could show, if water has an influence on $\mathrm{F}$ speciation like it was observed for the peralkaline glasses. These results then can be used to clarify why the combined effect of $\mathrm{F}$ and water on the viscosity of peraluminous melts is less than the sum of their individual effects.

The composition used in this project was intended as a simplified model for phonolitic melts. Now, a further aim should be to investigate how the conclusions from this study apply to natural melts. Most natural melts, even if highly evolved, contain at least small amounts of iron. While viscosity measurements on iron-bearing melts can relatively easy be used to get meaningful data to study the influence of $F$ on viscosity (see e.g. Zimova and Webb, 2007), NMR spectroscopy on glasses containing some mol\% of iron will be challenging. However, as ${ }^{19} \mathrm{~F}$ is a nucleus with a high NMR sensitivity and several mol\% of $F$ can be dissolved in silicate melts ${ }^{19} \mathrm{~F}$ MAS NMR spectroscopy on iron-bearing glasses might be worth trying. 


\section{References}

Baasner, A., Schmidt, B.C., Webb, S.L., 2013a. Compositional dependence of the rheology of halogen $(\mathrm{F}, \mathrm{Cl})$ bearing aluminosilicate melts. Chem. Geol. 346, 172-183.

Baasner, A., Schmidt, B.C., Webb, S.L., 2013b. The effect of chlorine, fluorine and water on the viscosity of aluminosilicate melts. Chem. Geol. 357, 134-149.

Baasner, A., Schmidt, B.C., Dupree, R., Webb, S.L.,2014a. Fluorine speciation as a function of composition in peralkaline and peraluminous $\mathrm{Na}_{2} \mathrm{O}-\mathrm{CaO}-\mathrm{Al}_{2} \mathrm{O}_{3}-\mathrm{SiO}_{2}$ glasses: $\mathrm{A}$ multinuclear NMR study. Geochim. Cosmochim. Acta 132, 151-169.

Baasner, A., Hung, I., Kemp, T.F., Dupree, R., Schmidt, B.C., Webb, S.L., 2014b. Constranints on the incorporation mechanism of chlorine in peralkaline and peraluminous $\mathrm{Na}_{2} \mathrm{O}-\mathrm{CaO}-\mathrm{Al}_{2} \mathrm{O}_{3}-\mathrm{SiO}_{2}$ glasses. Am. Mineral. http://dx.doi.org/10.2138/am.2014.4717.

Böhm, A., Schmidt, B.C., 2013. Fluorine and chlorine diffusion in phonolitic melt. Chem. Geol. 346, 162-171.

Dolejs, D., Baker, D.R., 2006. Fluorite solubility in hydrous haplogranitic melts at $100 \mathrm{MPa}$. Chem. Geol. 225, 40-60.

Giordano, D., Russell, J.K., Dingwell, D.B., 2008. Viscosity of magmatic liquids: A model. Earth Planet. Sci. Lett. 271, 123-134.

Hui, H., Zhang, Y., 2007. Toward a general viscosity equation for natural anhydrous and hydrous silicate melts. Geochim. Cosmochim. Acta 71, 403-416.

Klemme, S., 2004. Evidence for fluoride melts in Earth`s mantle formed by liquid immiscibility. Geology 32, 441-444.

Peretyazhko, I.S., Zagorsky, V.Y., Tsareva, E.A., Sapozhnikov, A.N., 2007. Immiscibility of calcium fluoride and aluminosilicate melts in ongonite from the Ary-Bulak intrusion, eastern transbaikal region. Dokl. Earth Sci. 413, 315-320.

Zimova, M., Webb, S.L., 2007. The combined effects of chlorine and fluorine on the viscosity of aluminosilicate melts. Geochim. Cosmochim. Acta 71, 1553-1562. 


\section{Acknowledgements}

This work would have been impossible without the patience and the wisdom of Sharon Webb, Burkhard Schmidt and Ray Dupree. They had always time for discussions and never got tired of correcting my English in our papers. I now feel well prepared to go out in the world and do science. I also like to thank Andreas Kronz, who encouraged me to improve my electron microprobe abilities, Enico Bali, who always had helpful suggestions how to improve my piston cylinder experiments, and my Hiwi Frederik Neumeier, who polished samples with courage and passion. The "Kaffeerunde" and Uschi Köhler supplied me with coffee and cake. Nina Pukallus removed a lot of typos in this thesis.

However, there is life beyond university and there are plenty of other people I have to thank for their support during these though times: My family, who always believed in me, as well as my friends and my entire fantasy roleplaying group, who helped me to escape the daily routine. I want to thank especially my boyfriend and my cats, who showed so much patience and always put a smile upon my face. 


\section{CURRICULUM VITAE}

PERSONAL DATA

Amrei Baasner

Born in Dortmund (Germany) 10/12/1985

\section{EDUCATION \& STUDIES}

\begin{tabular}{|c|c|}
\hline Since 06/2010 & $\begin{array}{l}\text { PhD student at the Department for Applied and Experimental } \\
\text { Petrology at Georg-August-University Göttingen (Germany) } \\
\text { Topic "The Influence of Fluorine, Chlorine and Water on the } \\
\text { Rheology and Structure of } \mathrm{Na}_{2} \mathrm{O}-\mathrm{CaO}-\mathrm{Al}_{2} \mathrm{O}_{3}-\mathrm{SiO}_{2} \text { Melts" }\end{array}$ \\
\hline 04/2009-06/2010 & $\begin{array}{l}\text { Master studies/Honors in geoscience at Georg-August-University } \\
\text { Göttingen with focus on mineralogy and isotope geology } \\
\text { (not finished after fast-track acceptance in PhD program after } 1 \\
\text { year of MSc program) }\end{array}$ \\
\hline $18 / 04 / 2009$ & $\begin{array}{l}\text { Bachelor degree (Grade A) } \\
\text { Bachelor thesis "Viscosities of water-bearing albitic melts" }\end{array}$ \\
\hline $04 / 2006-04 / 2009$ & Bachelor studies of geoscience at Georg-August-University \\
\hline $10 / 2005-03 / 2006$ & Studies of chemistry at Georg-August-University \\
\hline 24/06/2005 & $\begin{array}{l}\text { General university entrance qualification at } \\
\text { Theodor-Heuss-Gymnasium Göttingen }\end{array}$ \\
\hline
\end{tabular}

